
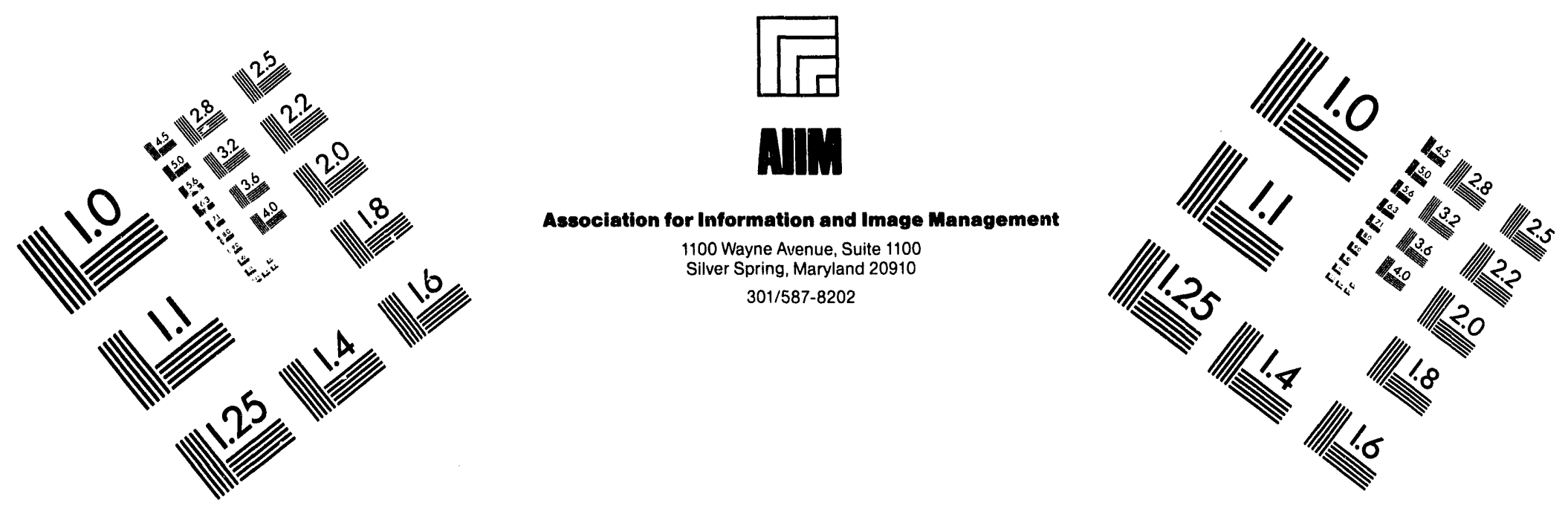

\title{
Centimeter
}

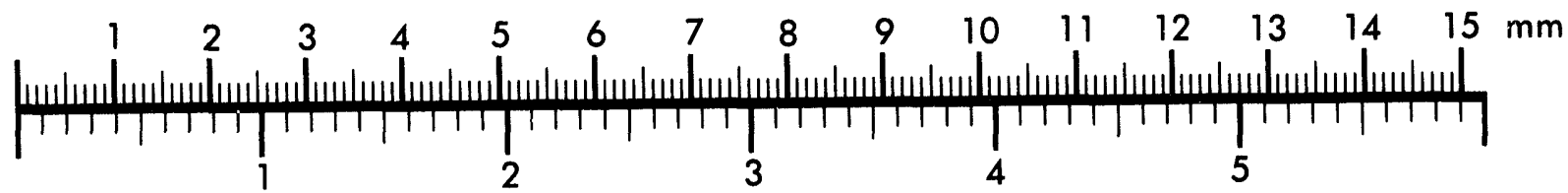
Inches
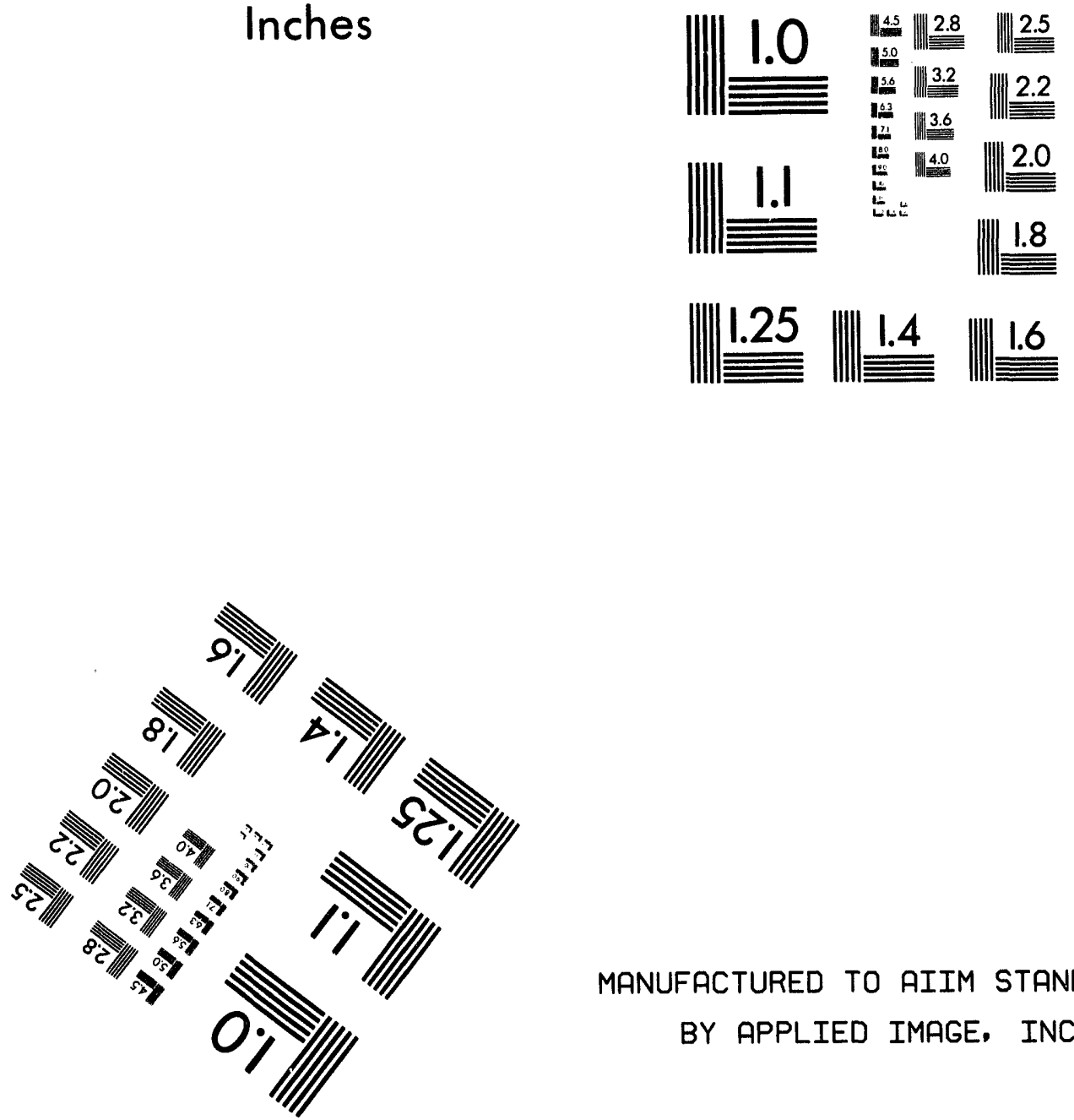

MANUFACTURED TO AIIM STANDARDS

BY APPLIED IMAGE. INC.

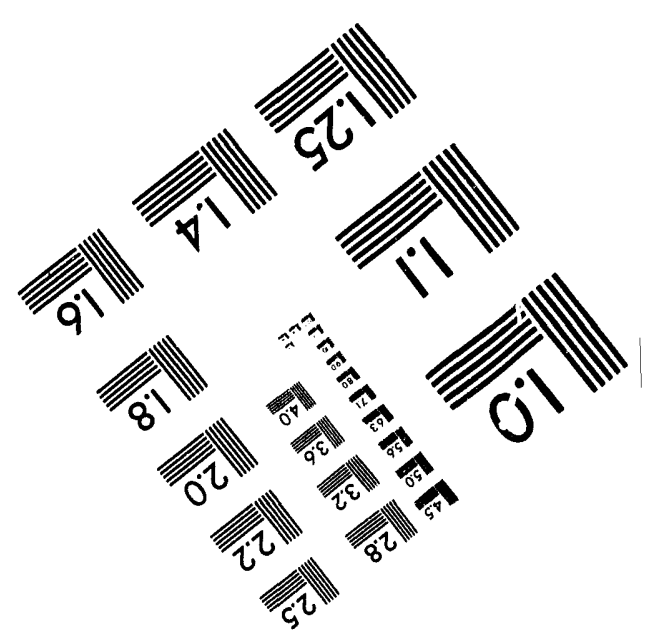



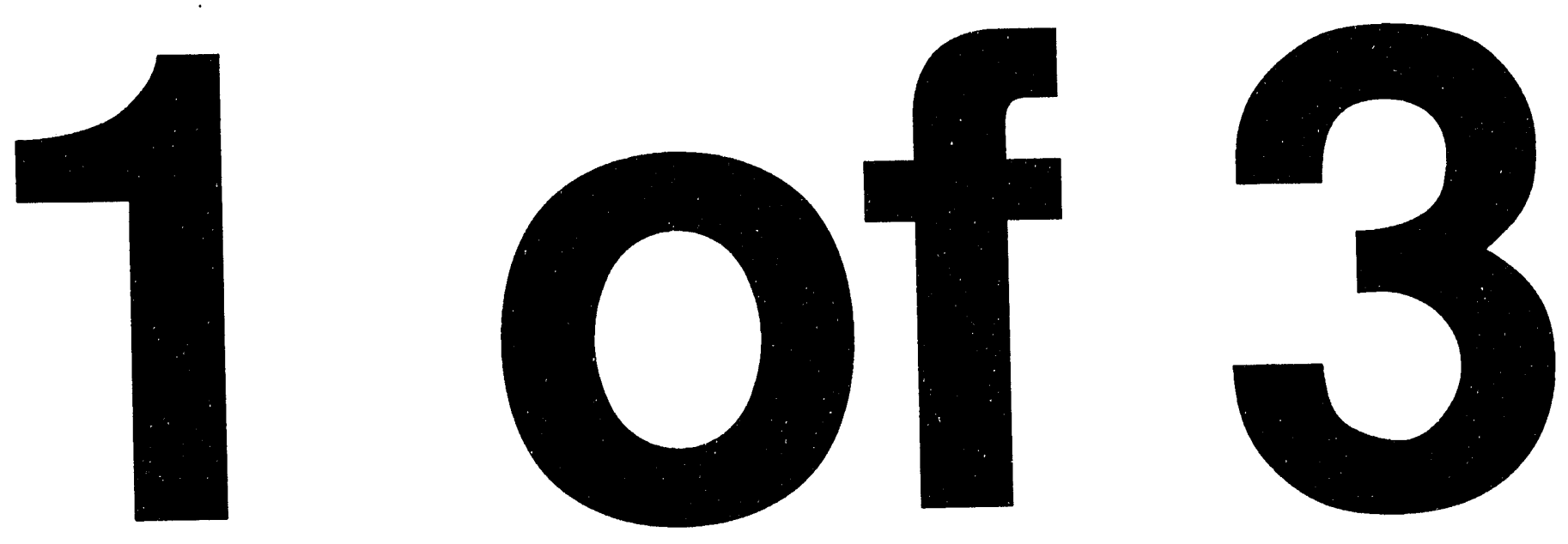
NUREG/CR-6178

CNWRA 93-013

\section{Laboratory Characterization of Rock Joints}

Manuscript Completed: March 1994

Date Published: May 1994

Prepared by

S. M. Hsiung, D. D. Kana, M. P. Ahola, A. H. Chowdhury, A. Ghosh

Center for Nuclear Waste Regulatory Analyses

6220 Culebra Road

San Antonio, TX 78238-5166

NRC Project Manager

Jacob Philip

\section{Prepared for}

Division of Regulatory Applications

Office of Nuclear Regulatory Research

U.S. Nuclear Regulatory Commission

Washington, DC 20555-0001

NRC FIN B6643

\section{MASTER}

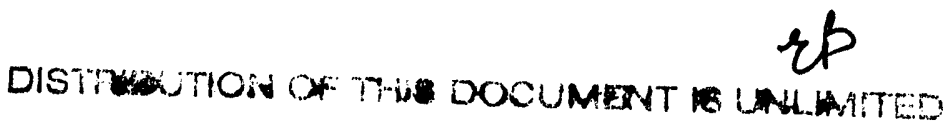




\section{PREVIOUS REPORTS IN SERIES}

Number

Name

Date Issued

CNWRA 90-004 Qualification Studies on the Distinct Element Code

January 1990

UDEC Against Some Benchmark Analytical Problems

CNWRA 90-005 Development of a Rock Joint Dynamic Shear Test

January 1990

Apparatus

CNWRA 90-006 Qualification Studies on the Finite Element Code HONDO II Against Some Benchmark Analytical

Problems

NUREG/CR-5440

Critical Assessment of Seismic and Geomechanics

June 1991

Literature Related to a High-Level Nuclear Waste

Underground Repository

CNWRA 92-005 Thermo-Hydro-Mechanical Coupled Modeling:

Multiple Fracture Model, BMT2

Coupled Stress - Flow Model, TC1

DECOVALEX - PHASE I

February 1990

CNWRA 92-012 Field Site Investigation: Effect of Mine Seismicity

December 1992 on a Jointed Rock Mass

April 1992

CNWRA 93-002

Thermo-Hydro-Mechanical Coupled Modeling:

August 1993

Near Field Repository Model, BMT3

DECOVALEX - PHASE II 


\begin{abstract}
A laboratory characterization of rock-joint behavior and mechanical properties of the Apache Leap tuff has been undertaken by the Center for Nuclear Waste Regulatory Analyses (CNWRA). The major concern driving this study is the ability of currently existing rock-joint models to adequately represent dynamic rock-joint behavior. These current rock-joint models were developed based on data taken under unidirectional pseudostatic loading conditions. Thus, the ability of the models to predict joint performance under cyclic pseudostatic and dynamic loading conditions has not been tested. Further, only limited cyclic pseudostatic and dynamic loading data are available to validate these rock-joint models. Consequently, joint behavior under cyclic pseudostatic and dynamic loading is not well understood. As part of this laboratory characterization of rock joints, rock joints were tested under cyclic pseudostatic and dynamic loads in order to obtain a better understanding of dynamic joint shear behavior and to generate a complete data set that can be used for validation of rock-joint models.
\end{abstract}

A number of methods are currently used in rock engineering practice to determine the joint roughness coefficient (JRC). However, these methods grossly underestimated the joint roughness of the Apache Leap tuff joints. Consequently, none of the methods evaluated in this report seem capable of providing a reasonable joint roughness coefficient value that can be readily used to estimate joint shear strength. The results of the direct shear tests on the Apache Leap tuff joints have indicated that both under cyclic pseudostatic and dynamic loadings the shear resistance upon reverse shearing is smaller than that of forward shearing and the joint dilation resulting from forward shearing recovers during reverse shearing. Within the range of variation of shearing velocity used in these tests, the shearing velocity effect on rock-joint behavior seems to be minor, and no noticeable effect on the peak joint shear strength and the joint shear strength for the reverse shearing is observed.

Both joint forward and reverse shearing are important phenomena of rock-joint behavior. Reverse shearing can result from earthquake, thermal loading, or both. Failure to consider this aspect of joint sehavior in an underground structural design and performance analysis could result in (i) an iverestimation of the stability of emplacement drifts and emplacement boreholes and (ii) prediction of an icorrect pattern of near-field flow (including preferential pathways for water and gas). 


\section{CONTENTS}

Section

Page

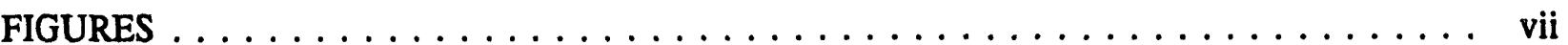

TABLES $\ldots \ldots \ldots \ldots \ldots \ldots \ldots \ldots \ldots \ldots \ldots \ldots \ldots \ldots \ldots \ldots \ldots \ldots$

ACKNOWLEDGMENTS $\ldots \ldots \ldots \ldots \ldots \ldots \ldots \ldots \ldots \ldots \ldots \ldots$ xiii

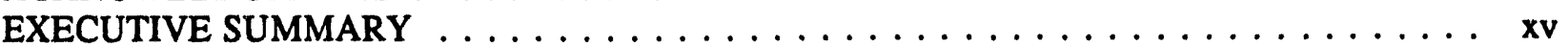

$1 \quad$ INTRODUCTION $\ldots \ldots \ldots \ldots \ldots \ldots \ldots \ldots \ldots \ldots \ldots \ldots \ldots \ldots \ldots \ldots \ldots, 1-1$

1.1 BACKGROUND $\ldots \ldots \ldots \ldots \ldots \ldots \ldots \ldots \ldots \ldots \ldots \ldots \ldots \ldots$

1.2 PURPOSE AND SCOPE OF LABORATORY CHARACTERIZATION

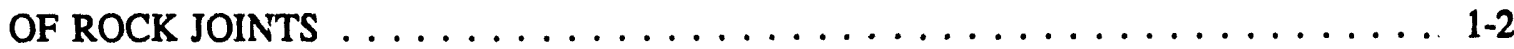

2 JOINTED ROCK CORF COLLECTION AND SAMPLE PREPARATION . . . . . . 2-1

2.1 SITE SELECTION FOR JOINTED ROCK CORE COLLECTION . . . . . . . . 2-1

2.2 IMPORTANT CONSIDERATIONS FOR ROCK CORE COLLECTION $\ldots \ldots \ldots . . .2$

2.3 TECHNIQUES FOR ROCK CORE COLLECTION $\ldots \ldots \ldots \ldots \ldots \ldots \ldots \ldots \ldots$

2.4 DISCUSSION FOR ROCK CORE COLLECTION $\ldots \ldots \ldots \ldots \ldots \ldots \ldots \ldots$

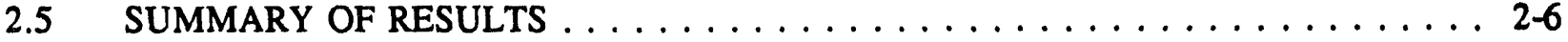

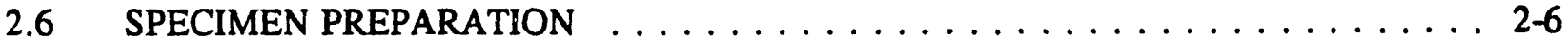

3 DEVELOPMENT OF JOINT PROFILE MEASUREMENT APPARATUS $\ldots \ldots \ldots$. .

4 DEVELOPMENT OF LABORATORY DIRECT SHEAR TEST APPARATUS $\ldots \ldots$. . 4-1

4.1 GENERAL $\ldots \ldots \ldots \ldots \ldots \ldots \ldots \ldots \ldots \ldots \ldots \ldots \ldots \ldots \ldots \ldots$

4.2 NORMAL LOAD SYSTEM $\ldots \ldots \ldots \ldots \ldots \ldots \ldots \ldots \ldots \ldots \ldots \ldots$

4.3 HORIZONTAL LOAD SYSTEM $\ldots \ldots \ldots \ldots \ldots \ldots \ldots \ldots \ldots \ldots \ldots$

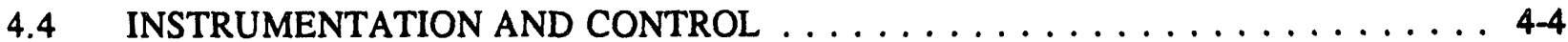

4.5 DATA ACQUISITION AND PROCESSING $\ldots \ldots \ldots \ldots \ldots \ldots \ldots \ldots \ldots$

$5 \quad$ ROCK AND JOINT STATIC PROPERTIES $\ldots \ldots \ldots \ldots \ldots \ldots \ldots \ldots \ldots$

5.1 BASIC MATERIAL PROPERTIES TESTS $\ldots \ldots \ldots \ldots \ldots \ldots \ldots \ldots \ldots \ldots$

5.1 .1 Uniaxial and Triaxial Compression Tests . . . . . . . . . . . . . . . . 5-1

5.1 .2 Brazilian Tests . . . . . . . . . . . . . . . . . . . . . . 5-1

5.2 JOINT INTERFACE CHARACTERIZATION TESTS . . . . . . . . . . . . 5-1

5.2 .1 Joint Profile Measurement Data $\ldots \ldots \ldots \ldots \ldots \ldots \ldots \ldots \ldots \ldots \ldots \ldots \ldots \ldots$

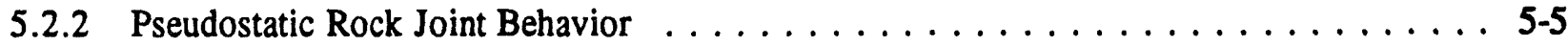

5.2.2.1 Normal Deformation Response . . . . . . . . . . . . . . . . . . 5 5

5.2.2.2 Shear Deformation Response . . . . . . . . . . . . . . . . . . 5-8

5.2.3 Parameter Determination for Mohr-Coulomb Joint Model . . . . . . . . . . . . . 5-15

5.2.4 Parameter Determination for Barton-Bandis Joint Model . . . . . . . . . . . . . . 5-25

5.2.4.1 Schmidt Hammer Test . . . . . . . . . . . . . . . . . . . . . 5-36

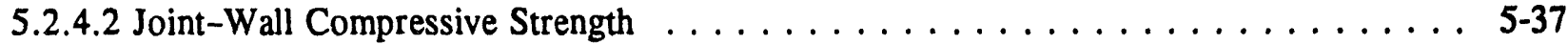

5.2.4.3 Residual Friction Angle Determination . . . . . . . . . . . . . . 5-38

5.2.4.4 Joint Roughness Coefficient Determination . . . . . . . . . . . . . . . . . 5-39

5.2.5 Parameter Determination for Continuously-Yielding Joint Model . . . . . . . . . . . 5-52 


\section{CONTENTS}

Section

6 DYNAMIC SHEAR BEHAVIOR OF ROCK JOINTS $\ldots \ldots \ldots \ldots \ldots \ldots$

6.1 ROCK JOINT SHEAR TEST UNDER HARMONIC LOADS $\ldots \ldots \ldots \ldots$. . . . . . . . 6-1

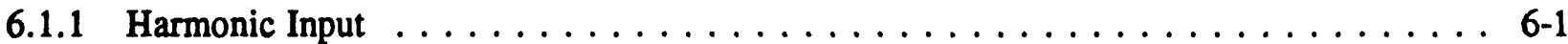

6.1 .2 Test Results . . . . . . . . . . . . . . . . . . . . . . . . . . . 6-2

6.2 ROCK JOINT SHEAR TESTS UNDER EARTHQUAKE LOADS $\ldots \ldots \ldots$

6.2 .1 Earthquake Input $\ldots \ldots \ldots \ldots \ldots \ldots \ldots \ldots \ldots \ldots \ldots$

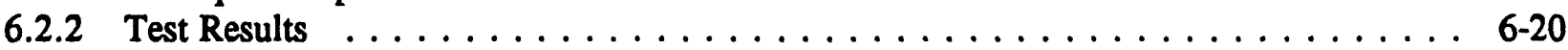

6.3 POTENTIAL DYNAMIC IMPACT ON ROCK JOINT BEHAVIOR $\ldots \ldots \ldots$. . . . . 6 -26

$7 \quad$ SUMMARY AND DISCUSSION $\ldots \ldots \ldots \ldots \ldots \ldots \ldots \ldots \ldots \ldots$

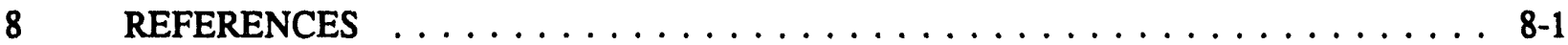

APPENDIX A Pseudostatic Direct Shear Test Results on Apache Leap Tuff Joints APPENDIX B Measured and Corrected Rebound Numbers on Intact Surfaces of Tuff Rock APPENDIX C Measured and Corrected Rebound Numbers on Tuff Joint Surfaces 


\section{FIGURES}

Figure

Page

2-1 Truck-mounted Joy 22 drill rig . . . . . . . . . . . . . . . . . . . . . 2-4

2-2 Location of drilled holes for sample collection at the Apache Leap tuff . . . . . . . . 2-5

2-3 Typical $457-\mathrm{mm}$ in diameter core with a smooth joint interface . . . . . . . . . . . 2-7

3-1 Profilometer for joint surface profile measurement $\ldots \ldots \ldots \ldots \ldots \ldots$. . . . . . .

4-1 Photograph of direct shear test apparatus . . . . . . . . . . . . . . . 4-2

4-2 Assembly and instrumentation diagram for direct shear test apparatus

(numbers in circles refer to instrumentation given in Table 4-1) $\ldots \ldots \ldots \ldots \ldots \ldots$. . . . . . . . . .

4-3 Excitation and control block diagram . . . . . . . . . . . . . . . . 4-6

4-4 Side view of vertical displacement instrumentation system . . . . . . . . . . . . 4-7

4-5 Close view of vertical displacement instrumentation system . . . . . . . . . . . . 4-7

4-6 Top view of vertical displacement instrumentation supports and targets . . . . . . . . 4-8

4-7 Side view of vertical displacement instrumentation supports and targets . . . . . . . . . 4-8

4-8 Location of relative displacement sensors on specimen lower block . . . . . . . . . . 4-9

5-1 Profile of the top block specimen for test no. 10 (SRM17.2.3/SRM17.2.4)

before pseudostatic direct shearing . . . . . . . . . . . . . . . . 5-11

5-2 Profile of the top block specimen for test no. 10 (SRM17.2.3/SRM17.2.4)

after pseudostatic direct shearing . . . . . . . . . . . . . . . . . 5-11

5-3 Normal stress versus closure relation for the welded tuff joint under repeated

normal load cycles (specimen for test no. 2) . . . . . . . . . . . . . . . 5 5-12

5-4 Shear stress versus shear displacement response as a function of applied

normal load for test nos. 7 through 11. Each curve represents the first

shear cycle on one particular sample. . . . . . . . . . . . . . . . 5-13

5-5 Normal displacement (dilation) response for test no. 7 under applied normal

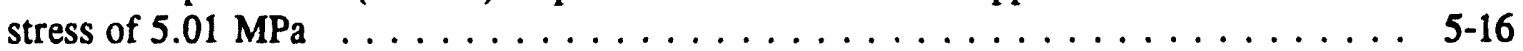

5-6 Shear stress versus shear displacement response for test no. 29 under applied

normal stress of $5.01 \mathrm{MPa}$ and saturated condition $\ldots \ldots \ldots \ldots$. . . . . . . . . .

5-7 Normal displacement (dilation) response for test no. 29 under applied normal

stress of $5.01 \mathrm{MPa}$ and saturated condition $\ldots \ldots \ldots \ldots \ldots \ldots$ 5-18

5-8 Schematic diagram of joint behavior in Mohr-Coulomb model of UDEC . . . . . . . . 5-20

5-9 Two types of shear stress versus shear displacement curve at constant confining

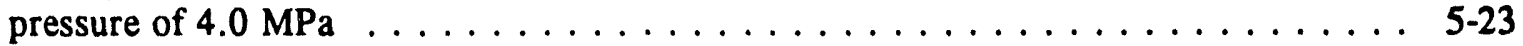

5-10 Normal displacement versus shear displacement curve with various parameters

used to describe it . . . . . . . . . . . . . . . . . . . . 5-28

5-11 Peak and residual behavior of shear stress versus shear displacement curve . . . . . . 5-28

5-12 Normal stress versus normal displacement curve with Barton-Bandis model . . . . . . 5-32

5-13 Basic friction angle, $\phi_{b}$, determination tilt test $\ldots \ldots \ldots \ldots \ldots \ldots \ldots \ldots$. $\ldots \ldots 2$

5-14 JRC distribution for top and bottom joint surfaces of specimen for test no. $19 \ldots \ldots$. . 5-50

5-15 JRC distribution for top and bottom joint surfaces of specimen for test no. $1 \ldots \ldots$. . . . 5-50

5-16 Plot of calculated and measured peak shear stress versus normal stress for

joint specimen used for test nos. 1 to $6 \ldots \ldots \ldots \ldots \ldots \ldots$ 


\section{FIGURES}

Figure

Page

6-1 Shear stress and shear displacement histories between 5th and 6th second of the first phase of test no. 14 with 1-MPa normal stress, 1.4-Hz input frequency,

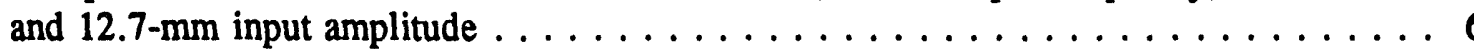

6-2 Shear stress and shear displacement histories between 5th and 6th second of the first phase of test no. 15 with 1-MPa normal stress, $1.4-\mathrm{Hz}$ input frequency, and $12.7-\mathrm{mm}$ input amplitude $\ldots \ldots \ldots \ldots \ldots \ldots \ldots \ldots \ldots \ldots$

6-3 Measured relative horizontal displacement between the horizontal load cell and the top rock block, and shear stress time history of the first phase of test no. $16 \ldots \ldots$

6-4 Shear displacement spectra for the first phase of test no. 14 with a harmonic input frequency of $1.4 \mathrm{~Hz} \ldots \ldots \ldots \ldots \ldots \ldots \ldots \ldots$. . . . . . . . . . . . . .

6-5 Shear displacement spectra for the first phase of test no. 15 with a harmonic

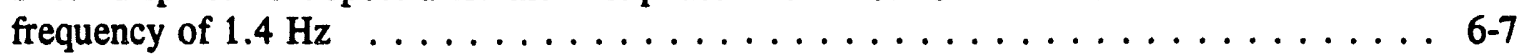

6-6 Semi-log plot of shear stress spectra for the first phase of test no. 14 with a harmonic input frequency of $1.4 \mathrm{~Hz} \ldots \ldots \ldots \ldots \ldots \ldots$

6-7 Normal stress and normal displacement (dilation) histories between 5 th and 6th second of the first phase of test no. 14 with 1-MPa normal stress, 1.4-Hz input frequency, and $12.7-\mathrm{mm}$ input amplitude $\ldots \ldots \ldots \ldots \ldots \ldots$

6-8 Normal stress and normal displacement (dilation) histories between 5 th and 6th second of the first phase of test no. 15 with $1-\mathrm{MPa}$ normal stress, $1.4-\mathrm{Hz}$ input frequency, and $12.7-\mathrm{mm}$ input amplitude $\ldots \ldots \ldots \ldots \ldots \ldots$

6-9 Normal stress spectra for the first phase of test no. 14 with a harmonic input

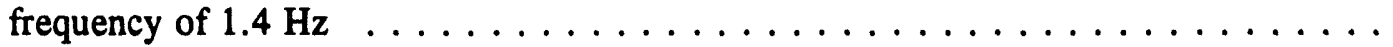

6-10 Acceleration time history of the top rock block between 5th and 6th second of the first phase of test no. 14 with 1-MPa normal stress, $1.4-\mathrm{Hz}$ input frequency, and $12.7-\mathrm{mm}$ input amplitude $\ldots \ldots \ldots \ldots \ldots \ldots \ldots$

6-11 Acceleration time history of the top rock block between 5th and 6th second of the first phase of test no. 15 with 1-MPa normal stress, 1.4- $\mathrm{Hz}$ input frequency, and $12.7-\mathrm{mm}$ input amplitude $\ldots \ldots \ldots \ldots \ldots \ldots \ldots \ldots$

6-12 Acceleration spectra of the top rock block for the first phase of test no. 15 with a harmonic input frequency of $1.4 \mathrm{~Hz} \ldots \ldots \ldots \ldots \ldots$. . . . . . . . . .

6-13 Semi-log plot of shear stress spectra for the first phase of test no. 15 with

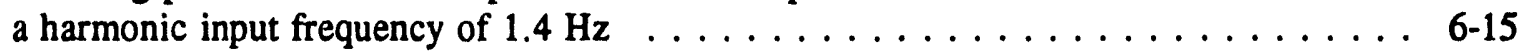

6-14 Acceleration history along the vertical direction of the 8.1 Richter scale earthquake, September 19, 1985 in Mexico . . . . . . . . . . . . . . . . . . . . 6-16

6-15 Acceleration history along the east direction of the 8.1 Richter scale earthquake, September 19, 1985 in Mexico . . . . . . . . . . . . . . . . . . . . 6-16

6-16 Acceleration history along the south direction of the 8.1 Richter scale earthquake, September 19, 1985 in Mexico . . . . . . . . . . . . . . . . 6-17

6-17 Displacement time history generated from the acceleration time history in Figure 6-16 .

6-18 Displacement spectra for the displacement time history in Figure 6-17 . . . . . . . .

6-19 Acceleration history calculated from the displacemert history in Figure 6-17 . . . . . 6-19 


\section{FIGURES}

Figure

Page

6-20 Shear stress and shear displacement history of the first phase of test no. 24 using a displacement input signal in Figure 6-17 with a maximum amplitude

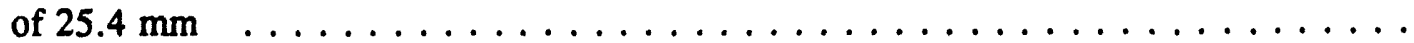

6-21 Shear stress and shear displacement history between 15th and 20th seconds of

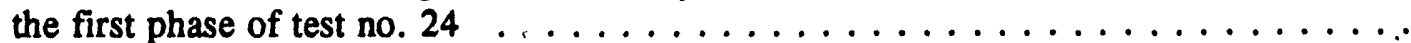

6-22 Shear stress and shear displacement history between 15th and 20th seconds of the first phase of test no. 25 using a displacement input signal in Figure 6-17 with a maximum displacement amplitude of $25.4 \mathrm{~mm} \ldots \ldots \ldots \ldots \ldots$

6-23 Normal stress and normal displacement (dilation) histories between 15th and 20th seconds of the first phase of test no. 25 using a displacement input signal in Figure 6-17 with a maximum displacement amplitude of $25.4 \mathrm{~mm} \ldots \ldots \ldots$

6-24 Normal stress and normal displacement (dilation) histories between 15th and 23rd seconds of the first phase of test no. 25 using a displacement input signal in Figure 6-17 with a maximum displacement amplitude of $25.4 \mathrm{~mm} \ldots \ldots$. . 6-25

6-25 Semi-log shear stress spectra plot of the first phase of test no. $24 \ldots \ldots$. . . . . . 6-27

6-26 Semi-log shear stress spectra plot of the first phase of test no. $26 \ldots \ldots \ldots$. . . . . . 6-27

6-27 Shear stress versus shear displacement curve for the first phase of test no. 14 under a harmonic load with 1.4- $\mathrm{Hz}$ input frequency and 12.7-mm input displacement amplitude (first three cycles and the 40 th cycle) $\ldots \ldots \ldots \ldots \ldots \ldots$

6-28 Shear stress versus shear displacement curve for the first phase of test no. 15 under a harmonic load with 1.4-Hz input frequency and $12.7-\mathrm{mm}$ input displacement amplitude (first three cycles and the 40 th cycle) $\ldots \ldots \ldots \ldots \ldots \ldots \ldots \ldots$. . . . . . . . . . .

6-29 Shear stress versus shear displacement curve for the first phase of test no. 24 under an earthquake load with a maximum input displacement amplitude of $25.4 \mathrm{~mm}$. . 6-29

6-30 Shear stress versus shear displacement curve for the first phase of test no. 25 under an earthquake load with a maximum input displacement amplitude of $25.4 \mathrm{~mm}$. . 6-29

6-31 Shear stress versus shear displacement curve for the first phase of test no. 26 under an earthquake load with a maximum input displacement amplitude of $25.4 \mathrm{~mm}$. . 6-30

6-32 Shear stress versus shear displacement curve for the first phase of test no. 30 under an earthquake load with a maximum input displacement amplitude of $25.4 \mathrm{~mm}$. . 6-30

6-33 Shear stress versus shear displacement curves for pseudostatic tests as a function of applied normal stress for test no. $1 . \ldots \ldots \ldots \ldots \ldots \ldots \ldots \ldots \ldots \ldots$ 6.32

6-34 Hypothesis of joint shear behavior during forward and reverse stages . . . . . . . . 6-33

6-35 Profile of the bottom rock block of the joint specimen used for test no. 14 before harmonic shearing . . . . . . . . . . . . . . . . . . . . . . 6-34

6-36 Profile of the bottom rock block of the joint specimen used for test no. 15 before harmonic shearing . . . . . . . . . . . . . . . . . . . . . 6-34

6-37 Effect of input frequency (shearing velocity) on peak joint shear strength . . . . . . . 6-37

6-38 Effect of input frequency (shearing velocity) on joint shear resistance on reverse

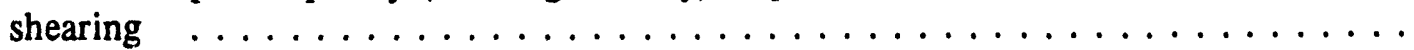

6-39 Joint normal displacement (dilation) versus shear displacement for the first phase of test no. 14 under a harmonic load with $1.4-\mathrm{Hz}$ input frequency and $12.7-\mathrm{mm}$ input displacement amplitude (first three cycles and the 40th cycle) $\ldots \ldots \ldots$ 


\section{FIGURES}

Figure

Page

6-40 Joint normal displacement (dilation) versus shear displacement for the first phase of test no. 15 under a harmonic load with 1.4-Hz input frequency and

12.7-mm displacement amplitude (first three cycles and the 40th cycle)

6-41 Joint normal displacement (dilation) versus shear displacement of the first phase of test no. 24 under an earthquake load with a maximum input displacement amplitude of $25.4 \mathrm{~mm}$

6-42 Joint normal displacement (dilation) versus shear displacement of the first phase of test no. 25 under an earthquake load with a maximum input displacement amplitude of $25.4 \mathrm{~mm}$

6-43 Joint normal displacement (dilation) versus shear displacement of the first phase of test no. 26 under an earthquake load with a maximum input displacement amplitude of

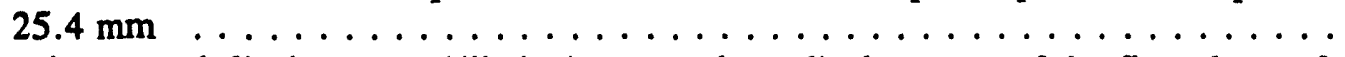

6-44 Joint normal displacement (dilation) versus shear displacement of the first phase of test no. 30 under an earthquake load with a maximum input displacement amplitude of

6-45 Joint normal displacement (dilation) versus shear displacement for pseudostatic tests as a function of applied normal stress for test no. 11 


\section{TABLES}

Table

Page

3-1 Tolerance limits for rock profilometer $\ldots \ldots \ldots \ldots \ldots \ldots$

4-1 Instrumentation channel identification for direct shear test apparatus $\ldots \ldots \ldots \ldots$. . . .

5-1 Uniaxial compressive strength, Young's modulus, and Poisson's ratio of

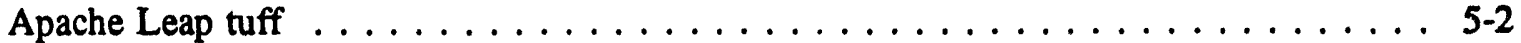

5-2 Triaxial compressive strength for Apache Leap tuff . . . . . . . . . . . . . . 5-6

5-3 Results of Brazilian disk tension test of Apache Leap tuff . . . . . . . . . . . . . 5-9

5-4 Peak shear data from first pseudostatic direct shear cycle for 16 samples . . . . . . . 5 5-14

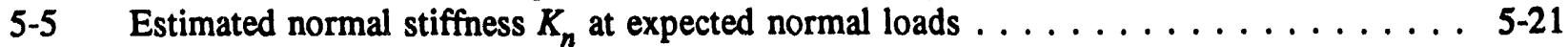

5-6 Estimated shear stiffness, $K_{s}$, at expected normal loads . . . . . . . . . . . . . 5-24

5-7 Estimated values of dilation angle, $\psi$, with other parameters to describe

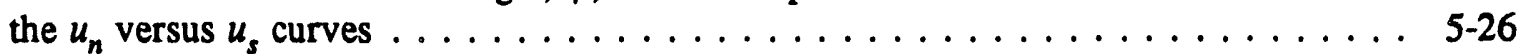

5-8 Estimated values of cohesion and friction angle . . . . . . . . . . . . . 5-29

5-9 Values of normal deformation parameters $a$ and $b$ of Barton-Bandis model . . . . . . 5-33

5-10 Values of initial joint normal stiffness, $K_{n i}$, and maximum possible closure, $V_{m} \ldots \ldots$ 5-35

5-11 Constants used for calculation of $V_{m}$ (Bandis et al., 1983) $\ldots \ldots \ldots \ldots \ldots \ldots$. . . . . .

5-12 Recommended correction for rebound number obtained through vertical downward impact . . . . . . . . . . . . . . . . . . . . 5 5-37

5-13 Measured and corrected rebound numbers on the unweathered surfaces of the

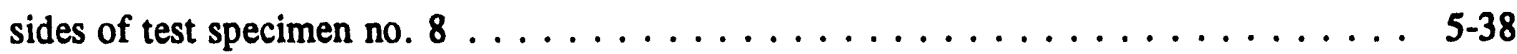

5-14 Measured and corrected rebound numbers on the two joint surfaces of the

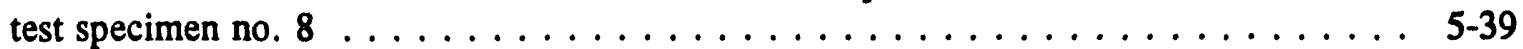

5-15 Representative rebound numbers for intact rock surface and joint surface of each test specimen . . . . . . . . . . . . . . . . . . . . . . 5-40

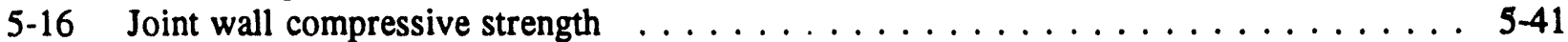

$5-17$ Estimated residual friction angles $\ldots \ldots \ldots \ldots \ldots \ldots \ldots \ldots \ldots$

5-18 Tilt angles, $\alpha$, along the direction of shear and the reversed direction . . . . . . . . . 5-44

5-19 Comparison of $\mathrm{JRC}_{o}$ determined by various methods $\ldots \ldots \ldots \ldots \ldots \ldots$. . . . . . . . . .

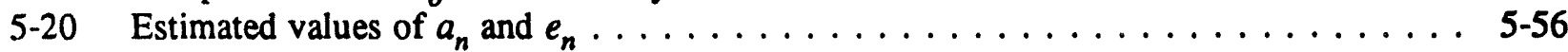

5-21 Estimation of $\phi_{\mathrm{mo}}, \phi, R$, and $K_{s} \ldots \ldots \ldots \ldots \ldots \ldots \ldots \ldots \ldots$

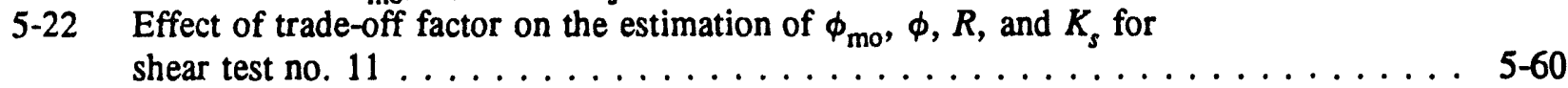

6-1 Test matrix for direct shear tests on jointed rock specimens under harmonic loads . . . . . . . . . . . . . . . . . . . . . . 6-2

6-2 Test matrix for direct shear tests on jointed rock specimen under earthquake load $\ldots \ldots \ldots \ldots \ldots \ldots \ldots \ldots \ldots \ldots$ 


\section{ACKNOWLEDGMENTS}

The authors thank Dr. Loren J. Lorig of Itasca Consulting Group, Inc. and Dr. Wesley C. Patrick of the Center for Nuclear Waste Regulatory Analyses (CNWRA) for their technical reviews of this document. The authors also express their appreciation to the Apache Leap Tuff Site Overview Committee (ALrSOC) and the Magma Copper Corporation (MCC) for providing access to the Apache Leap site for collecting jointed rock cores by the CNWRA. Special appreciation goes to Dr. Jaak J.K. Daemen, currently at the University of Nevada at Reno, Nevada, for facilitating ALTSOC/MCC permission and for conducting activities for the preparation of rock-joint shear specimens and laboratory determination of mechanical properties of the collected rock cores. The authors are greatly indebted to Mr. Allan M. Pickens of Southwest Research Institute (SwRI) for his diligence in performing various laboratory tests required in this study. The authors appreciate Dr. James F. Unruh's effort for developing the displacement input drive signal for earthquake tests on rock joints. Thanks also go to many others at the University of Arizona, Southwest Research Institute (SwRI), CNWRA, and the Boyles Brothers Drilling Company who have participated in various activities presented in this report. The authors are also thankful to Ms. Rebecca A. Sanchez for skillful typing and formatting of the report, and to Mr. James Pryor, who provided a full range of expert editorial services in the preparation of the final document.

This report was prepared to document work performed by the CNWRA for the U.S. Nuclear Regulatory Commission (NRC) under Contract No. NRC-02-88-005. The activities reported here were performed on behalf of the NRC Office of Nuclear Regulatory Research, Division of Regulatory Applications. This report is an independent product of the CNWRA and does not necessarily reflect the views or regulatory position of the NRC. 


\section{EXECUTIVE SUMMARY}

A state-of-the-art literature review revealed that repetitive ground motions due to seismic activities may impact both the short- and long-term performance of a repository. The fundamental failure mechanism for an excavation subjected to repetitive seismic loading is through accumulation of shear displacements along joints. Specific seismic implications to repository design and performance may include cumulative effects of repetitive seismic loads on (i) emplacement borehole/drift stability; (ii) underground opening stability; and (iii) creation of preferential water pathways to connect the emplacement area with perched water zones, neighboring steep hydraulic gradient zones, or the condensation area above the emplacement area. These cumulative effects cannot be analyzed by extrapolation of response data from a single earthquake or nuclear test. New techniques need to be established for simulation of rock mass subjected to repetitive seismic waves. The Seismic Rock Mechanics Research Project is studying repository response due to repetitive dynamic loadings. As part of this research project, a laboratory testing program on the characterization of rock joints has been undertaken at the Center for Nuclear Waste Regulatory Analyses (CNWRA). The goal of the program was to generate a reliable data set for the dynamic joint behavior for understanding the key seismic parameters that will affect repository design and performance and for evaluating the ability of existing rock-joint models to represent dynamic joint behavior.

Activities performed for this study included collecting jointed rock cores and preparing specimens for direct joint shear tests; developing a direct joint shear test apparatus and a rock-joint profilometer; conducting cyclic pseudostatic joint shear tests and dynamic joint shear tests under harmonic and earthquake loads; and characterizing mechanical properties of intact rock associated with the rock joints.

The Apache Leap site near Superior, Arizona, was selected for the jointed rock core collection. The rock type at the site is a densely welded tuff. The cores were collected using a core-drilling device with a 457-mm diameter, thin-wall core barrel. In this program, 29 boreholes were drilled to collect a sufficient number of cores to prepare 50 potentially usable joint specimens. The rock-joint specimens for the direct shear tests were prepared from these collected cores. The top half of the shear specimen measured $203 \times 203 \times 102 \mathrm{~mm}$ and the bottom half measured $305 \times 203 \times 102 \mathrm{~mm}$. Also, 50.8-mm diameter cylindrical specimens associated with these rock joints were prepared for uniaxial and triaxial compression and Brazilian tests.

The intact rock characterization results indicated that the average uniaxial compressive strength was $161 \pm 26 \mathrm{MPa}$, where $26 \mathrm{MPa}$ is the standard deviation. The mean indirect uniaxial tensile strength (from the Brazilian test results) was $10.3 \pm 2.2 \mathrm{MPa}$. The mean triaxial compressive strengths were $202 \pm 27$ $\mathrm{MPa}$ for a $3.4-\mathrm{MF}$ a confining pressure, $248 \pm 22 \mathrm{MPa}$ for a $6.9-\mathrm{MPa}$ confining pressure, and $271 \pm 18$ $\mathrm{MPa}$ for a 10.3-MPa confining pressure. Average values for the Young's modulus and Poisson's ratio were $38.6 \pm 3.4 \mathrm{GPa}$ and $0.2 \pm 0.0287$, respectively.

To characterize joint roughness, several methods are available, some of which require measurement of joint profiles. A profilometer was developed for joint profile measurement. This profilometer was a noncontact, surface-height-gauging type and consisted of an $\mathrm{X}-\mathrm{Y}-\mathrm{Z}$ positioner and a laser displacement meter.

Also developed for this program was a dynamic direct shear test apparatus, which included a 0.399 meganewtons $(\mathrm{MN})$ vertical and $0.222-\mathrm{MN}$ horizontal loading capability. The apparatus was designed to house rock-joint specimens with maximum sizes of $305 \times 203 \times 102 \mathrm{~mm}$ for the lower rock block and 
$203 \times 203 \times 102 \mathrm{~mm}$ for the top rock block. This apparatus has demonstrated its ability to perform the pseudostatic and dynamic shear tests required in this study. However, the servocontrolled valves for the vertical actuators could not respond adequately to the rapid vertical force variations to maintain a constant normal stress throughout the dynamic shear tests. The maximum normal stress variation was about $0.3 \mathrm{MPa}$ irrespective of the magnitude of applied normal stress, but this variation did not prevent the collection of useful dynamic data on joint behavior.

For this program, 19 fresh joint specimens were tested under cyclic pseudostatic shear loading conditions. Of the specimens, three were wetted with water prior to the tests and the other 16 were dry. In addition to these cyclic pseudostatic shear tests, two "fresh" joint specimens were tested under harmonic loading conditions, while four others were tested under earthquake loading conditions. Before each direct shear test was initiated, the rock joint specimens were subjected to five normal loading/unloading cycles. Five cycles were chosen because it was found that this number was sufficient to eliminate any additional hysteresis between the loading and unloading curves and to properly seat the joint prior to direct shear testing. The fifth-cycle data were used to determine the normal stress versus normal displacement response of the rock joints.

A fresh Apache Leap tuff joint exhibited a distinct peak shear strength that gradually declined to a residual value as shearing progressed for pseudostatic tests on dry and wet rock joints, and for dynamic tests. For the pseudostatic tests on wet rock joints, the joint specimens were immersed in water for more than a week before testing. The stick-slip behavior of a joint at the residual stage was evident during both forward and reverse shearing for both pseudostatic and dynamic tests on dry rock joints. This behavior, which became more pronounced at the higher normal loadings, was due to the momentary reduction in shear stress as individual asperities were sheared. However, the stick-slip behavior for the wet rock joints under pseudostatic test conditions was not as obvious. No appreciable difference was noted between the peak shear strengths for the dry and wet rock joints under cyclic pseudostatic testing conditions.

Six different equations were evaluated for the determination of rock-joint roughness coefficient (JRC), which is a generally accepted parameter in rock engineering practice for the characterization of joint roughness. Among the six equations, one is associated with the tilt test on rock joints, and one involves the use of the first derivative of the root mean square of a joint profile. The remaining four equations were developed using the theory of fractal geometry. The equations all predicted average JRC values that were smaller than the JRC back-calculated from the shear test results. In general, the degree of underestimation is quite substantial. Thus, it would seem that none of the methods evaluated can provide a reasonable JRC value that can be readily used to estimate joint shear strength, which is essential in understanding joint shear behavior.

An underestimation of the joint roughness values results in an underestimation of the joint shear strength and initial mechanical (hydraulic) joint aperture as well as subsequent aperture changes in joint shearing. The joint aperture increases with JRC. Underestimation of joint shear strength may prove to be conservative in both mechanical analysis and design of underground excavations. However, underestimating the joint aperture and its changes during shearing may be nonconservative from the standpoint of their impacts on fluid and gas flow through fractures.

The joint responses for all the dynamic tests performed in this study included high-frequency vibration. This vibration is excited by the breaking of rock pieces (asperities) from joint surfaces or the crushing and grinding of these pieces during shearing, and may include the mechanical mode response of the loading apparatus. 
The results of the direct shear tests on the Apache Leap tuff joints have indicated that, under both cyclic pseudostatic and dynamic loadings, the shear resistance upon reverse shearing is smaller than that of forward shearing and the joint dilation resulting from forward shearing recovers during reverse shearing. Both forward and reverse joint shearing are important phenomena for a rock joint when subjected to earthquake and thermal loads, unlike under static load in which only the forward shearing is of concern. Failure to consider the effect of reverse shearing on joint behavior when designing an underground structure or when analyzing its performance levels could result in overestimating the stability of emplacement drifts and boreholes. Furthermore, incorrect determination of joint dilation could result in predicting an erroneous pattern of near-field flow, including preferential water or gas pathways.

Within the range of variation of shearing velocity used in these tests, the shearing velocity effect on rock-joint behavior seems to be minor and no noticeable effect on the peak joint shear strength and the joint shear resistance for the reverse shearing is observed. Unlike the pseudostatic and earthquake shear tests, the dilation curves resulting from the harmonic tests showed numerous high-frequency, stick-slip (chatter) oscillations. The dynamic input also affected the size of hysteresis between the normal displacements during forward and reverse shearing at least for the first cycle. The hysteresis for the harmonic and earthquake tests was smaller than that for the pseudostatic tests. 


\section{INTRODUCTION}

\subsection{BACKGROUND}

In 1987, the United States Congress designated Yucca Mountain, in southern Nevada, as the only site to be characterized to determine its suitability for building a repository for high-level nuclear waste (HLW). The , roposed repository horizon is about $300 \mathrm{~m}$ beneath Yucca Mountain, in a densely welded prominently vertically and subvertically jointed tuff. The unit was chosen as the proposed repository horizon because of its thickness, lateral continuity, dense welding, and its location in the unsaturated zone about 200 to $400 \mathrm{~m}$ above the water table.

An important phenomenon that could affect the preclosure and postclosure performance of a repository is repeated ground motion due to seismic activities [Kana et al., 1991a; Nuclear Waste Technical Review Board, 1992]. The fundamental failure mechanism for an excavation in a jointed rock mass subjected to repetitive seismic loading is the accumulation of shear displacements at joints. Specific seismic implications for repository design and performance may include cumulative effects of repetitive seismic loads on (i) emplacement borehole/drift stability; (ii) underground opening stability; and (iii) creation of preferential water pathways to connect the emplacement area with perched water zones, neighboring steep hydraulic gradient zones, or the condensation area above the emplacement area.

The cumulative effects of these repetitive seismic loadings cannot be analyzed by extrapolation of response data from a single earthquake or nuclear test. New techniques need to be established to simulate rock mass that has been subjected to repetitive seismic waves. The technique should (i) determine the significance of the geomechanical responses due to repetitive seismic events, (ii) establish reliable data sets that permit a better understanding of important parameters controlling the joint dynamic behavior and that reflect the relation between geomechanical responses and repetitive seismic events in a properly characterized rock mass, and (iii) determine if currently available rock-joint models adequately describe the dynamic behavior of rock joints.

The exploratory Seismic Rock Mechanics Research Project, conducted by the Center for Nuclear Waste Regulatory Analyses (CNWRA), is studying repository response due to repetitive dynamic loadings. This research project has the dual focus of (i) understanding the key parameters affecting repository performance under repeated seismic loadings, and (ii) evaluating current capabilities for calculating such effects. A primary goal of this research project is to develop methodologies to evaluate, validate, and reduce uncertainties in the prediction models. These models eventually will be used to assess the effects of possible earthquake as well as ground shock events on the short- and long-term performances of a proposed underground repository at Yucca Mountain. The U.S. Nuclear Regulatory Commission (NRC) staff and its contractors anticipate using the results of this study during the process of License Application to determine the adequacy of the U.S. Department of Energy (DOE) repository design relevant to seismic activities.

As part of this research project, CNWRA has undertaken a laboratory characterization program on rock joints. Its aim is to generate a reliable data set for the dynamic joint behavior for understanding the key seismic parameters that will affect repository design and performance and for evaluating the ability of existing rock-joint models to represent dynamic joint behavior. The major concern driving this study is the ability of currently existing rock-joint models to adequately represent dynamic rock-joint behavior. These current rock-joint models were developed based primarily on data taken under 
unidirectional pseudostatic loading conditions. Thus, the ability of the models to predict joint performance under cyclic pseudostatic and dynamic loading conditions has not been tested. Furthermore, only limited cyclic pseudostatic and dynamic loading data are available to validate these rock-joint models. Consequently, joint behavior under cyclic pseudostatic and dynamic loading is not well understood. The rock-joint laboratory characterization activities reported herein will address this concern.

\subsection{PURPOSE AND SCOPE OF LABORATORY CHARACTERIZATION OF ROCK JOINTS}

The purposes of the laboratory program for the characterization of rock-joint behavior were to obtain a better understanding of joint behavior subjected to dynamic loads and to develop experimental data on dynamic behavior of rock joints to evaluate the ability of the existing rock-joint models that have been included in various numerical computer codes for dynamic analysis of rock masses.

The activities associated with this laboratory program included: (i) selecting a site for the collection of jointed rock cores; (ii) collecting jointed rock cores; (iii) preparing joint specimens for direct joint shear tests; (iv) determining mechanical properties of intact rock associated with the rock joints for the shear tests, including uniaxial and triaxial compressive strengths, uniaxial tensile strength, Young's modulus, and Poisson's ratio; (v) characterizing joint interfaces including joint profile measurements and joint roughness coefficient (JRC) determination through joint tilt test and rebound test on rock-joint interfaces; (vi) performing cyclic pseudostatic direct shear tests on rock joints to determine joint property parameters needed for the various rock-joint models to be evaluated; and (vii) performing direct shear tests on joints under harmonic and earthquake loads.

The evaluation and selection of a site for collection of jointed rock cores included the consideration of two sites: one site is located in southern Texas, and the other at Apache Leap near Superior, Arizona. The site at southern Texas was not selected because, unlike the rock at the proposed repository horizon at Yucca Mountain, the tuff at the site was nonwelded. Also the southern Texas tuff was considerably weaker compared to the welded tuff at the proposed repository horizon. The 457-mm diameter jointed rock cores were collected from the selected site at Apache Leap using thin-wall core barrels. The single joint shear specimens and the associated cylinders were prepared at the University of Arizona, Tıcson. These cylinders were subjected to uniaxial and triaxial compression and Brazilian tests for determination of mechanical properties of the intact rock. The cyclinder tests were performed following ASTM standards at the University of Arizona.

Rock joint profiles were measured using a profilometer that was designed and developed as a part of this laboratory work. Joint tilt tests and rebound tests were also conducted on the rock joints. The cyclic pseudostatic and dynamic tests were conducted using a dynamic shear testing apparatus that was designed and constructed under this experimental program (Kana et al., 1990; 1991b). 


\section{JOINTED ROCK CORE COLLECTION AND SAMPLE PREPARATION}

The laboratory characterization program on rock joints included a variety of testing activities whose goals were to determine the basic material properties of tuff, tuff-joint interface properties, and rock-joint responses under cyclic pseudostatic and various dynamic loading conditions, particularly under repeated dynamic loadings that arise from earthquakes. To perform these tests, a considerable number of specimens with naturally occurring joints were required. The following subsections discuss how these specimens were obtained.

\subsection{SITE SELECTION FOR JOINTED ROCK CORE COLLECTION}

Ideally, the rock specimens to be tested in the laboratory would come directly from the site to be evaluated or studied, that is, from the proposed Yucca Mountain repository site. However, collection of tuff rock-joint specimens from the Yucca Mountain site was not feasible because the sitecharacterization program proposed by the DOE had not been started when the laboratory characterization program was underway. Thus, an alternative site for specimen collection was required.

Three criteria were established to facilitate the process of site selection. The first requirement was that the rock type be similar (e.g., welded and jointed) to the tuff material at the proposed repository horizon at the Yucca Mountain site. The second criterion was that the site contain sufficient favorable locations to permit the collection of at least 50 rock-joint specimens. This criterion is important because of the relatively large dimensions of the rock-joint specimens required to perform the experiments for rock-joint characterization. The required dimensions are $305 \times 203 \times 102 \mathrm{~mm}$ for the bottom section and $203 \times 203 \times 102 \mathrm{~mm}$ for the top section of a prepared rock-joint specimen, with a natural joint interface between these two sections. The third criterion was that the site be easily accessible since heavy equipment must be used to collect and transport the specimens from the site.

Based on the three criteria, two alternative sites were evaluated. One site was located in southern Texas, and the other at Apache Leap near Superior, Arizona. Field observation showed that the rock at the southern Texas site was a nonwelded tuff, which is different from the rock at the proposed repository horizon at Yucca Mountain. Since the southern Texas tuff also was considerably weaker, it was felt that the tuff at the southern Texas site failed to satisfy the first siting criterion. As a result, the Texas site was not considered further.

On the other hand, the Apache Leap, Arizona, site was considered suitable for specimen collection. The rock at this site was a vitrified and densely welded tuff, similar to the tuff at the proposed repository horizon. Field observation indicated that Apache Leap tuff was moderately to heavily jointed. The tuff at the proposed repository horizon was also deemed to be heavily jointed. While physical properties between the tuffs at these two sites are somewhat different, these differences may be quantified so that validation of corresponding rock-joint models may still be achieved, provided the differences in corresponding parameters are considered.

The Apache Leap welded tuff has two predominant vertical joint sets, one minor subvertical joint set, and one horizontal joint set. The joint spacing for these joint sets ranged from $50 \mathrm{~mm}$ to meters. The spacing of the joints was crucial to the successful collection of the samples. For this study, the joint spacing had to be at least $102 \mathrm{~mm}$ to be collectable. However, field experience shows that it is much 
easier to collect specimens at areas with larger joint spacing. This joint spacing constraint limited the usable areas for sample collection at the Apache Leap site. Other constraints are discussed in a later subsection of this report. The area of interest for sample collection at the Apache Leap site was on an abandoned highway in a tunnel. This site had several advantages in that it was easily accessible and potential interference with sample collection was minimized.

The Apache Leap site was on property belonging to the Magma Copper Corporation (MCC). The Apache Leap Tuff Site Overview Committee (ALTSOC) reviewed the CNWRA application to access the Apache Leap site and gave a recommendation to the MCC. The CNWRA request was approved by MCC in November 1989.

\subsection{IMPORTANT ZONSIDERATIONS FOR ROCK CORE COL.LECTION}

Several important factors were considered in determining if a local area at the site would be suitable for rock core collection and if the rock joints collected would be acceptable for the direct shear experiments. Since the tuff at the proposed repository horizon at Yucca Mountain is about $244 \mathrm{~m}$ below the surface, the weathering condition on the tuff joints should be relatively minor. Therefore, collecting and testing specimen tuff joints that were highly weathered were avoided. Since almost all vertical joints on the surface at the site were believed to be highly weathered, they were deemed unsuitable for our needs. As a result, rock cores were collected on the horizontal and vertical joints from inside the abandoned highway tunnel, which was approximately 15 to $18 \mathrm{~m}$ below the surface. This procedure considerably reduced the potential area usable for rock core collection.

As discussed in Section 4, the rock-joint, dynamic shear-test apparatus was designed and fabricated to have a 25.4-mm gap between the top and bottom shear box edges of the assembled specimen unit. To prevent potential interference of the top box edge with the specimen joint interface of the bottom specimen, not only must the specimen joint interface fall within the 25.4-mm gap, but its apparent relief had to be smaller than $12.7 \mathrm{~mm}$. These requirements were applied in the field to determine the acceptability of a collected joint interface.

\subsection{TECHNIQUES FOR ROCK CORE COLLECTION}

Several techniques are available for core collection of rock joints. Some of these methods include chain saw or wire saw cutting; high-pressure water-jet cutting; hydraulic fracturing; and large-diameter core drilling.

In considering the first three techniques, several factors were noted. Chain sawing has been used successfully in nonwelded tuff, but not as successfully in welded tuff because of frequent equipment breakdown ${ }^{1}$. The high-pressure water-jet technique has been demonstrated to be effective in cutting welded tuff, but this technique is still state-of-the-art. Also, the high-pressure water jet is expensive. In addition, large quantities of water would be required for the process of cutting, and the ability to maintain a constant water supply in the field is questionable and expensive. The third technique, hydraulic fracturing, requires extensive small-diameter drilling around the boundary of a rock block to be collected.

\footnotetext{
${ }^{1}$ Personal communication with Dr. W.C. Patrick, CNWRA, 1989.
} 
However, because a considerable number of holes need to be drilled for each sample, the process is slow.

Perhaps the most important concern for all three techniques (chain saw, hydraulic fracturing, and high-pressure water jet) is that they can be used effectively only for shallow cutting. Difficulty arises as the cutting goes deeper. Given the large number of specimens needed for testing and the relatively small area usable for sample collection, it would be difficult to obtain an adequate number of specimens using these techniqu. ..

Large-diameter core drilling, on the other hand, is relatively favorable in that it is reasonably fasi, is less expensive, and has less machine maintenance problems. Considerable experience has been accumulated over the years in core drilling in the welded tuff $2^{t}$ the Apache Leap site ${ }^{2}$. To take advantage of this experience and the other favorable factors about large-diameter core drilling, this method was selected for the sample collection.

\subsection{DISCUSSION FOR ROCK CORE COLLECTION}

Because of the sample's large dimensions, it was determined that 457-mm diameter cores would be collected and that 457-mm diameter, thin-wall core barrels would be used for the drilling.

When performing large-diameter core drilling, two basic methods for obtaining a rock-joint feature were used. One method was drilling to intersect a joint feature, and the other was drilling parallel to the joint feature with the joint surface (interface) coinciding with the central plane of the core. Since the first method usually allows sufficient dimension for joint specimen preparation, it was the preferred method. However, this method often takes longer to obtain a rock joint than the second method, especially when the joint spacing is several meters. Although the second method has its advantages, it also has two problems in that it is extremely difficult (i) to align the axis of drilling with the strike/dip of a joint interface and (ii) to coincide the joint interface with the central plane of the core. Very often, undersized core pieces unsuitable for rock-joint specimen preparation were obtained. The first method, therefore, was used for most of the drilling except for three holes, one of which was vertical and two were angled. Only one potentially useful joint specimen was obtained from these three drillings.

Drilling for rock core collection was performed by a drilling company that had extensive drilling experience directly related to the Apache Leap site. During sample collection, a CNWRA staff member was on-site to provide technical decisions concerning location, direction (angle), and depth of drilling and to be responsible for technical aspects regarding packing and transporting core pieces. The entire activity for collecting tuff specimens was conducted following the CNWRA Technical Operating Procedure TOP-006, Procedure for Obtaining Seismic Rock Mechanics Test Specimens From the Field. The drilling phase was initiated on December 10, 1989, and completed on February 9, 1990.

A Joy 22 drill rig (Figure 2-1) was used. A borehole was usually started using a 0.46 - or 0.76- $\mathrm{m}$ long core barrel ( $457 \mathrm{~mm}$ in diameter). If a joint interface was not intersected after a depth equal to the barrel length was drilled, this core barrel was replaced with a $1.22-\mathrm{m}$ long barrel, and drilling was continued. A core breaker was used to break the core if no joint was intersected after $1.22 \mathrm{~m}$ of drilling. Drilling in the same hole continued after the core was removed from the hole.

\footnotetext{
${ }^{2}$ Personal communication with Dr. J.J.K. Daemen, University of Nevada at Reno, Nevada, 1989.
} 


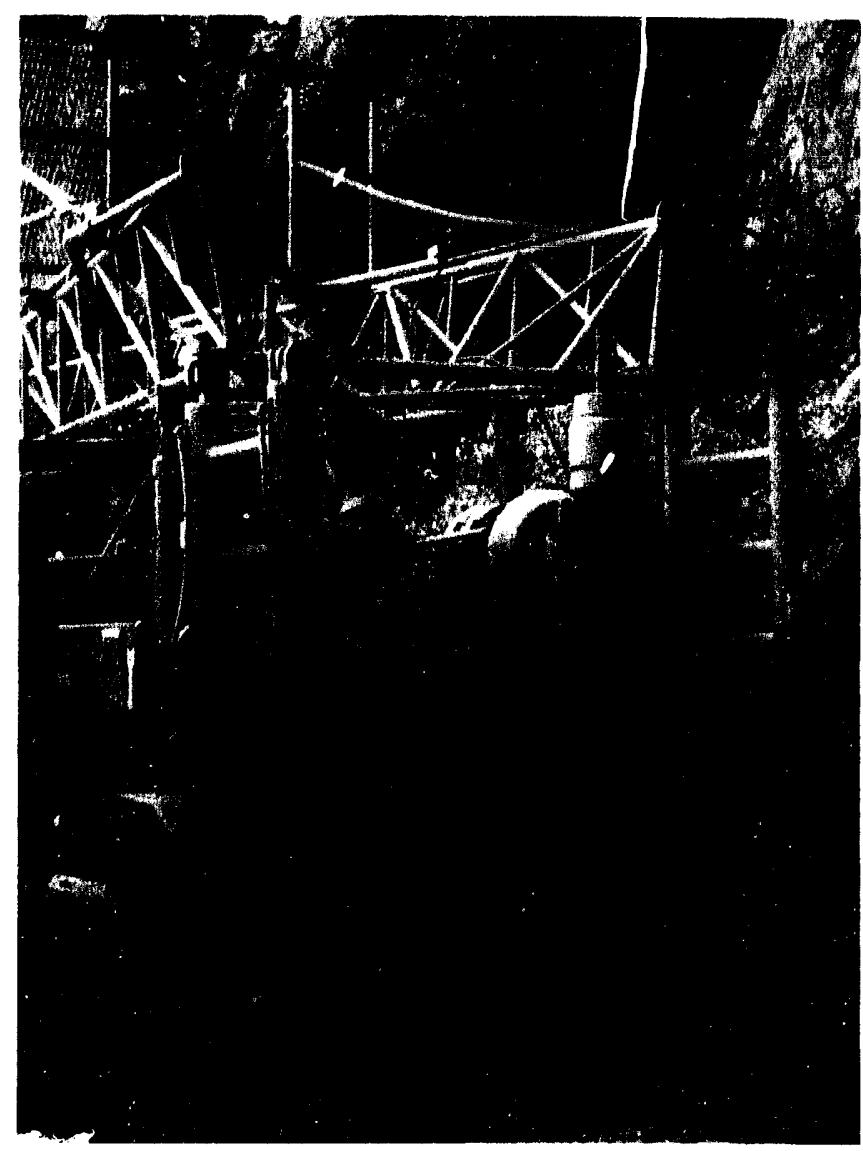

Figure 2-1. Truck-mounted Joy 22 drill rig

During this effort, 29 boreholes were drilled. Figure 2-2 presents a schematic showing the locations of the boreholes. Of these boreholes, 8 were vertical and 21 were angled or near-horizontal. Except for hole No. 14, all the angled holes were inside the highway tunnel, and most were on the north wall. The depth of drilling for the holes ranged from 1.52 to $3.35 \mathrm{~m}$. The hole numbers not indicated in the figure are those with drilled depths of less than $0.61 \mathrm{~m}$, and from which no potentially usable joint specimens were obtained.

The vertical drilling produced only three potentially usable joint specimens. Most of the intersected horizontal joint interfaces were too rough, and their apparent relief exceeded the maximum 25.4-mm gap value set by the design of the test apparatus, as well as the 12.7-mm value for avoiding test interference. Even for those three joint specimens considered potentially usable, their joint interfaces barely satisfied the $12.7-\mathrm{mm}$ requirement. These results required a major shift of drilling from the originally planned vertical direction to angle drilling. Although this change substantially slowed the drilling program, it was nevertheless necessary.

The program was also considerably affected by two other factors. The first one was due to the abrasiveness of the Apache Leap welded tuff. The so-called diamond bits installed at the bottom end of a core barrel for cutting purposes consist of industrial diamond particles in an alloy matrix. During cutting, the alloy matrix is designed to erode and to expose fresh diamond particles, which, in turn, cut 


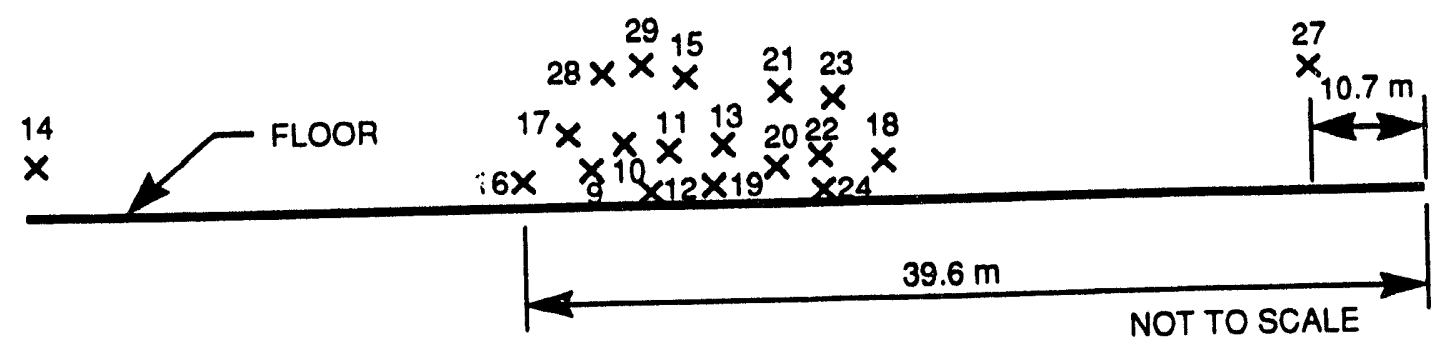

NORTH WALL OF ROAD TUNNEL

WEST END

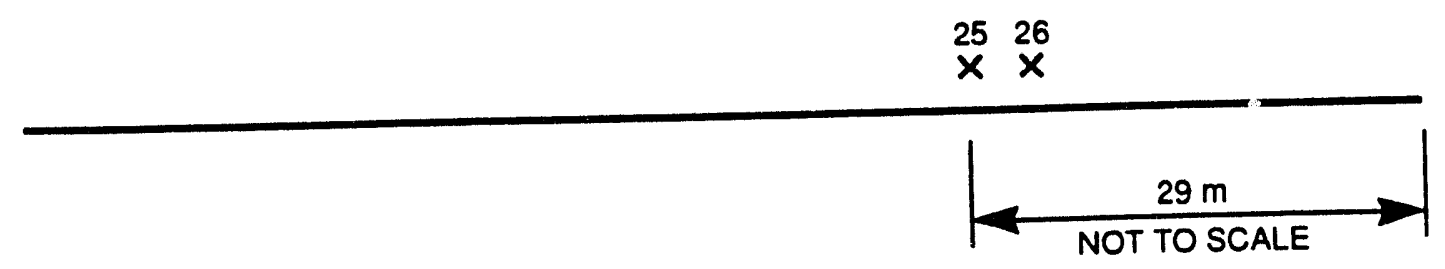

SOUTH WALL OF ROAD TUNNEL

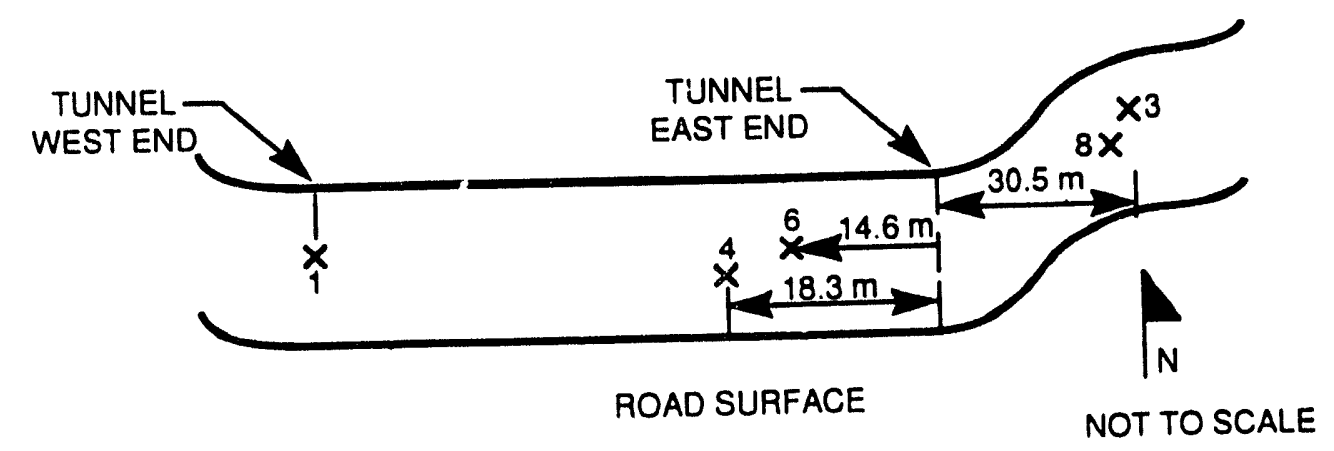

Figure 2-2. Location of drilled holes for sample collection at the Apache Leap site 
the rock. If the rock is relatively soft, the diamonds last a long time. Since the Apache Leap welded tuff is a hard rock, the diamonds wear out quickly. However, cutting could still proceed smoothly if fresh diamonds are exposed fairly quickly through erosion of the alloy matrix. The bits first selected for this rock core collection program had a very hard matrix material that was difficult to erode. As a result, drilling was slowed substantially. This situation was mitigated by replacing the bits with diamond bits composed of relatively soft matrix material.

The second factor was associated with core breaking. The longest core barrel used for the rock core collection was $1.22 \mathrm{~m}$. If a joint interface was not intersec $: d$ after $1.22 \mathrm{~m}$ of drilling, it was necessary to break the core and take it from the hole for subsequent drilling. However, breaking a 457-mm diameter hard rock core was difficult. A pair of wedges was used at shallow depths and a steel bar with a wedge on one end was used at greater depths. The force was applied by striking the end of the wedge with a 2.72- or 4.54-kg hammer. Approximately 20 to 30 min were needed to break a shallow core loose; at relatively greater depths, even longer times and greater efforts were required. This breaking process would sometimes severely damage an otherwise perfect joint interface.

At the completion of this collection activity, 50 potentially usable joint specimens were obtained: of these $\mathbf{5 0}$ specimens, 44 were from the central north wall of the tunnel and had relatively smooth joint interfaces. Figure 2-3 shows a typical $457-\mathrm{mm}$ diameter core with a smooth joint interface. Several unsuccessful attempts were made to locate other favorable areas for drilling in light of potential safety concerns of a large number of boreholes in one small area.

\subsection{SUMMARY OF RESULTS}

The difficulties notwithstanding, the rock core collection was a success. During the process, 50 potentially usable joint specimens were obtained, 10 percent more than required by the current experimental plan. The extra specimens were necessary to ensure that an adequate number of joint specimens could survive the preparation procedure.

Drilling in welded tuff was a slow process. However, the rate of drilling may be improved by careful selection of matrix material used for diamond bits. Experience indicates that a relatively soft matrix material facilitates drilling in the tuff rock.

Breaking a large-diameter core (e.g., $457 \mathrm{~mm}$ in diameter) from a borehole is a difficult task. It was a constant problem during sample collection, and some potential specimens were lost because of it. A new design for a core breaker is required if a similar drilling activity is to be carried out. It was also found that drilling to intersect the joint has a better chance for obtaining usable jointed specimens than drilling parallel to the joint.

\subsection{SPECIMEN PREPARATION}

The types of tests performed for jointed rock characterization included: (i) basic material properties tests, (ii) jointed-tuff interface-characterization tests, (iii) joint response for cyclic pseudostatic direct shear tests, (iv) joint response for harmonic load tests, and (v) joint response for earthquake load tests. The first three types of tests were used to determine basic tuff matrix and joint properties, while the last two were performed to analyze dynamic behavior of joints. 


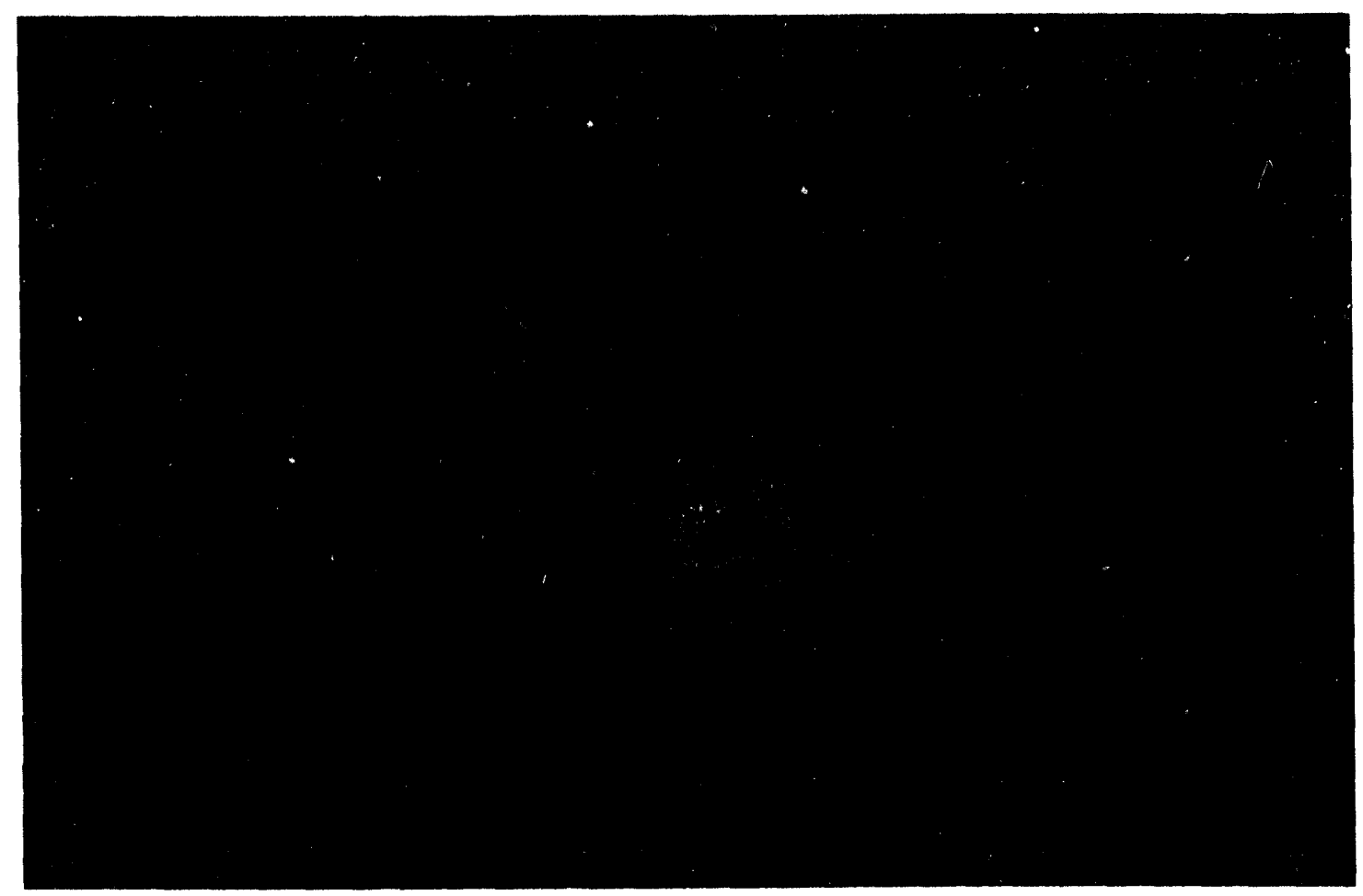

Figure 2-3. Typical $457-\mathrm{mm}$ in diameter core with a smooth joint interface

Forty-five usable rock-joint specimens for direct shear tests were prepared. Several issues were noted in the preparation of rock-joint specimens. One arose from using water as a cutting fluid to avoid altering fracture surface mechanical characteristics. However, the use of water as the cutting fluid subjected unpainted metal parts of the saw mechanism to rapid rusting and increased blade wear, as well as reducing the cutting effectiveness and cooling capability.

Also, some difficulty was encountered in clamping the large core pieces in the saw when the clamped rock surfaces were not flat. This difficulty in clamping resulted in the saw blade jamming in the sawcut. Because it was often necessary to back the blade off and reset the specimen, rougher or more uneven cuts resulted, which were smoothed out by surface grinding.

To determine basic tuff matrix properties, tests including uniaxial and triaxial compression and Brazilian tests were conducted on cylindrical specimens collected from the same tuff rock cores from which the rock-joint specimens were prepared. The cores received from the field were also cored in the laboratory to produce $50-\mathrm{mm}$ diameter cylindrical specimens. For uniaxial and triaxial compression testing, these specimens were cut to a length of $127 \mathrm{~mm}$, and surface ground. For Brazilian testing, a $50-\mathrm{mm}$ diameter core was cut to a thickness of $12 \mathrm{~mm}$. Procedures for specimen preparation (both shear 
and mechanical characterization test specimens) are documented in the Quality Assurance Program for Mechanical Characterization of Tuff, CNWRA, by Daemen (1990) ${ }^{3}$.

${ }^{3}$ Daemen, J.J.K. 1990. Quality Assurance Program for Mechanical Characterization of Tuff. Tucson, AZ: University of Arizona - Department of Mining and Geological Engineering. 


\section{DEVELOPMENT OF JOINT PROFILE MEASUREMENT APPARATUS}

The parameters required for joint interface characterization for various analytical joint models are different, and the methodologies for acquiring them also vary. One important parameter used in the Barton-Bandis joint model is JRC. The determination of this parameter requires profile measurements of a rock-joint surface.

The "rock profiler" (Figure 3-1) is a noncontact, surface-height-gauging profilometer assembled primarily from off-the-shelf equipment. This equipment includes an Asymtek A-102B benchtop gantry-type X-Y-Z positioner and a Keyence LC-2100/2320 laser displacement meter. An LC-2320 red-visible laser head, with specified displacement measurement resolution of about 0.5 micrometer, is attached to the $Z$ axis of the A-102B X-Y-Z gantry positioner.

A rock positioned beneath the A-102B gantry positioner is profiled by scanning the LC-2320 laser head across the rock surface in the X-and Y-axis directions in a raster scan pattern. The LC-2320 laser head has a measurement window of about $\pm 8 \mathrm{~mm}$ from a standoff position of about $50 \mathrm{~mm}$. The LC$2100 / 2320$ combination forms the laser displacement meter that operates on the principle of triangulation; that is, the apparent shift in the position of a laser light spot, as the laser head is raised or lowered, indicates displacement. The laser spot is quite small, about 140 micrometers at mid-range.

The rock profiler movements were controlled by PC/AT computer commands to the A-102B X-Y-Z Table via a serial communications port. The A-102B Table had a built-in computer for interpreting high-level commands from the PC/AT and then executing the moves. A custom computer program written in Borland's Turbo C, Version 2.0, was used to issue movement commands to the A-102B, to read the displacement measurement $\mathrm{Z}$-axis movement from the LC-2100, and to format and store pertinent scanning and rock-profile displacement information to a PC/AT floppy-or hard-disk data file. Additional software modifications were also made to further extend the rock-profiler measurement range from $\pm 8 \mathrm{~mm}$ to about $\pm 25 \mathrm{~mm}$, as the rock surface variations exceeded the originally assumed range of $\pm 8 \mathrm{~mm}$. The $Z$ axis of the A-102B was used to accomplish this greater range. The typical performance of the integrated rock profiler is characterized in Table 3-1. 


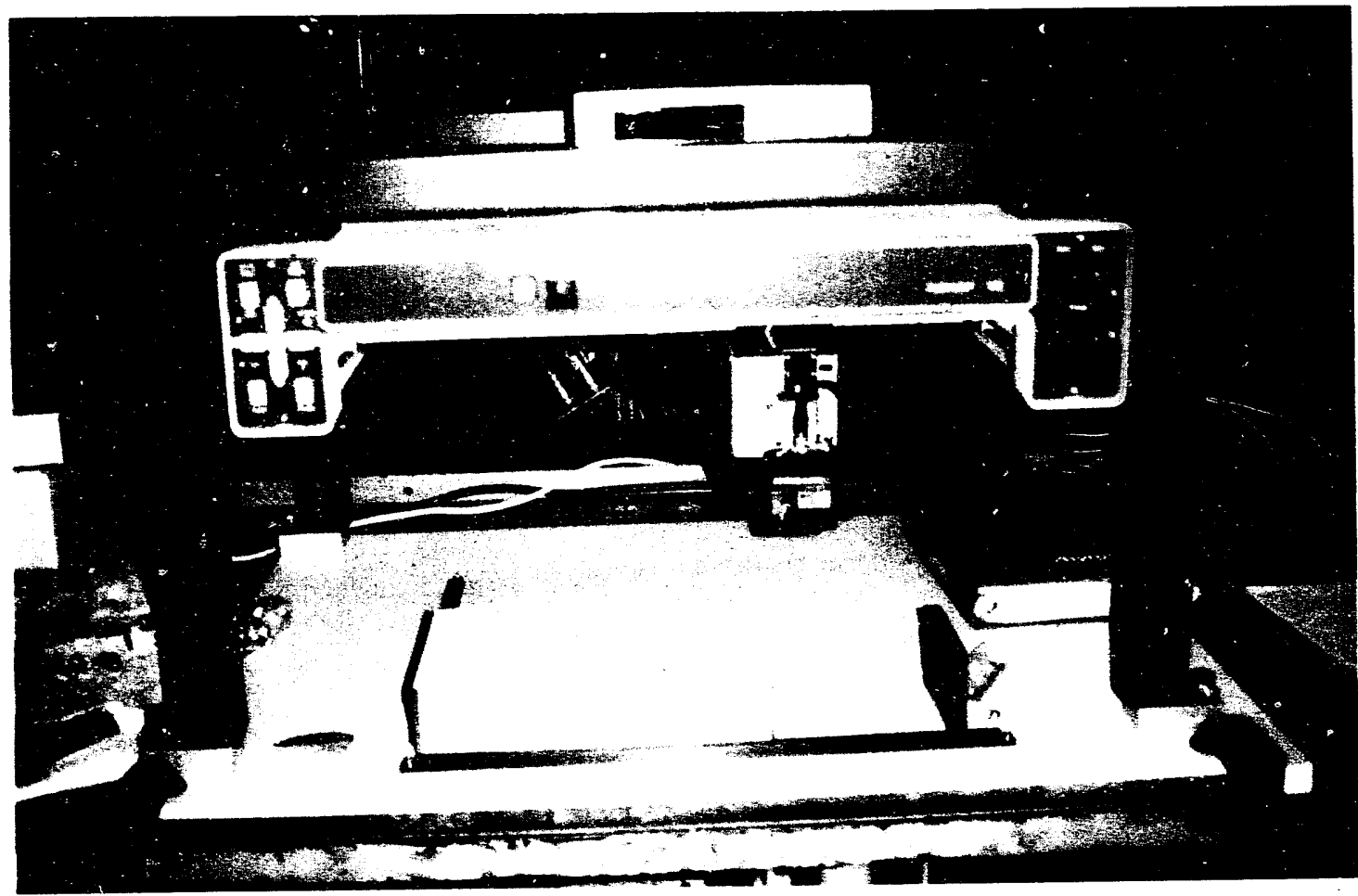

Figure 3-1. Profilometer for joint surface profile measurement 
Table 3-1. Tolerance limits for rock profilometer

\begin{tabular}{|c|c|}
\hline Maximum scan area & $45.7 \times 45.7 \mathrm{~cm}$ \\
\hline Nominal $X-Y$ scanning increment & $1.27 \mathrm{~mm}$ (can be modified in software) \\
\hline $\mathrm{Z}$-axis range & $50.8 \mathrm{~mm}$ \\
\hline Nominal $\mathrm{X}-\mathrm{Y}$ axis step & $0.025 \mathrm{~mm}$ \\
\hline Nominal $\mathrm{Z}$ axis step & $0.051 \mathrm{~mm}$ \\
\hline Maximum $X-Y$ axis move error & $\begin{array}{l}0.76 \mathrm{~mm} \text { (obtained by course calibration } \\
\text { verification grid over } 30.5 \times 30.5 \mathrm{~cm} \text { area) }\end{array}$ \\
\hline $\mathrm{Z}$-axis move error & $0.635 \mathrm{~mm} / 50.8 \mathrm{~mm}$ (before scale correction) \\
\hline Maximum LC-2100/2320 displacement error & $\begin{array}{l}0.033 \mathrm{~mm} \text { (for a } \pm 5 \mathrm{~mm} \text { range from then } \\
\text { LC- } 2320 \text { center point, ranging off the smooth } \\
\text { surface of stacked gauge blocks) }\end{array}$ \\
\hline Maximum observed Z-axis repeatability error & $0.0076 \mathrm{~mm}$ (due to homing error) \\
\hline Combined $\mathrm{Z}$-axis and LC-2100 linearity error & $0.01245 \mathrm{~mm}$ standard error \\
\hline Scan time & roughly 2 points per second \\
\hline
\end{tabular}




\section{DEVELOPMENT OF LABORATORY DIRECT SHEAR TEST APPARATUS}

\subsection{GENERAL}

In order to perform direct dynamic shear tests for joints in tuff materials in the laboratory, a servocontrolled test apparatus with combined normal and direct shear capability was designed, fabricated, and assembled at Southwest Research Institute (SwRI). A preliminary description of this apparatus was given by Kana et al. (1990). However, the preliminary design was modified as testing began. A description of the final design is given herein. Figure 4-1 is a photograph of the overall loading apparatus.

The apparatus consists of vertical and horizontal servocontrolled loading actuators, reaction frames, shear box fixtures, and finally, an instrumented jointed tuff specimen. The loading capacity for each of the three vertical actuators is $0.133 \mathrm{MN}$, while the horizontal actuator has a capacity of $0.222 \mathrm{MN}$. The horizontal actuator can be operated in either load or displacement control mode. Several loading patterns such as pseudostatic ramps, harmonic, and earthquake displacement time histories can be generated through the use of a function generator. Each vertical actuator is equipped with a 0.111-MN capacity load cell for monitoring the applied forces. The instrumentation for monitoring the applied normal load is arranged to provide an analog output for the sum of the three load cells, as well as for the individual signals. The bottom shear box was designed to house a specimen with maximum dimensions of $305 \times 203 \times 102 \mathrm{~mm}$. The top shear box houses a specimen with maximum dimensions of $203 \times 203 \times 102 \mathrm{~mm}$. Both specimens are grouted in their respective specimen boxes. The bottom shear box and other fixed devices are bolted to a $1.22 \times 2.13 \times 0.15-\mathrm{m}$ thick steel base plate for rigidity. The horizontal translation of the top shear box along the direction of shearing is guided through three rollers between the top shear box and normal load frame. It is also guided through side rollers as shown in later figures. Thus, the normal load frame and the side rollers prevent rotation of the vertical actuators (and, therefore, also the top specimen block) about a vertical axis perpendicular to the direction of shearing.

\subsection{NORMAL LOAD SYSTEM}

Normal compression is applied to the specimen by three vertical actuators set at $120^{\circ}$ about the specimen's vertical centerline. These actuators act through individual load cells whose output is summed and used as the control signal. Thus, the total normal load is controlled at a preselected static or slowly ramped value. This total resultant load is ultimately applied to the specimen via the normal load frame that acts on the three normal load rollers (see top view of Figure 4-2) and thereby on the upper specimen box. The line of action for this normal load is through the null position of the upper specimen box. Thus, the normal load frame is constrained to three degrees of freedom:

(i) vertical translation

(ii) rotation about the horizontal axis in line with the shear

(iii) rotation about the horizontal axis transverse to the shear

These constraints are assured by two double flexures that connect the normal load frame to a fixed reaction brace, and by the two side roller assemblies, which act on the upper specimen box. Thus, the upper specimen block is constrained to these same degrees of freedom, plus a fourth, which is translation in the direction of shear. 


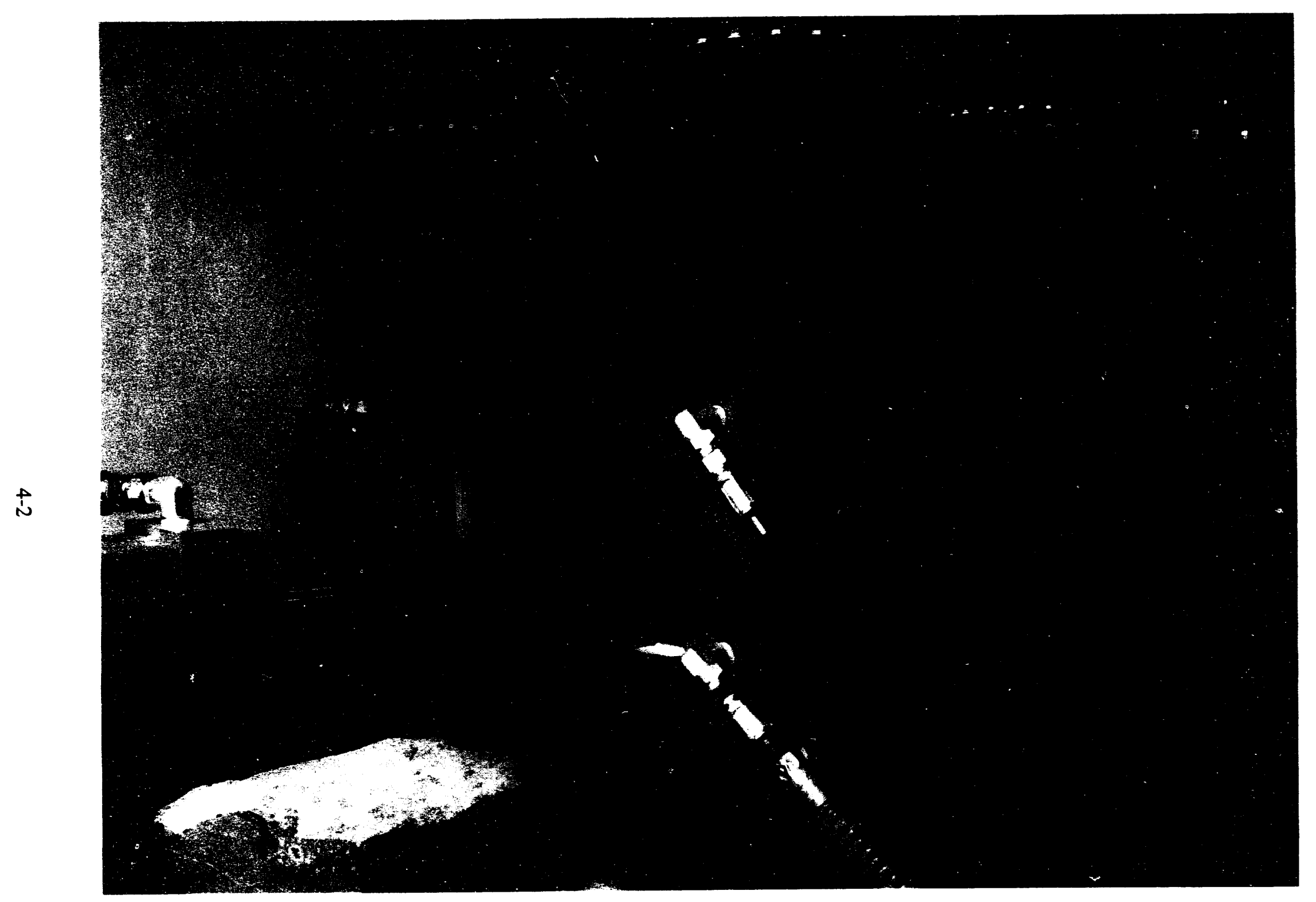

Figure 4-1. Photograph of direct shear test apparatus 

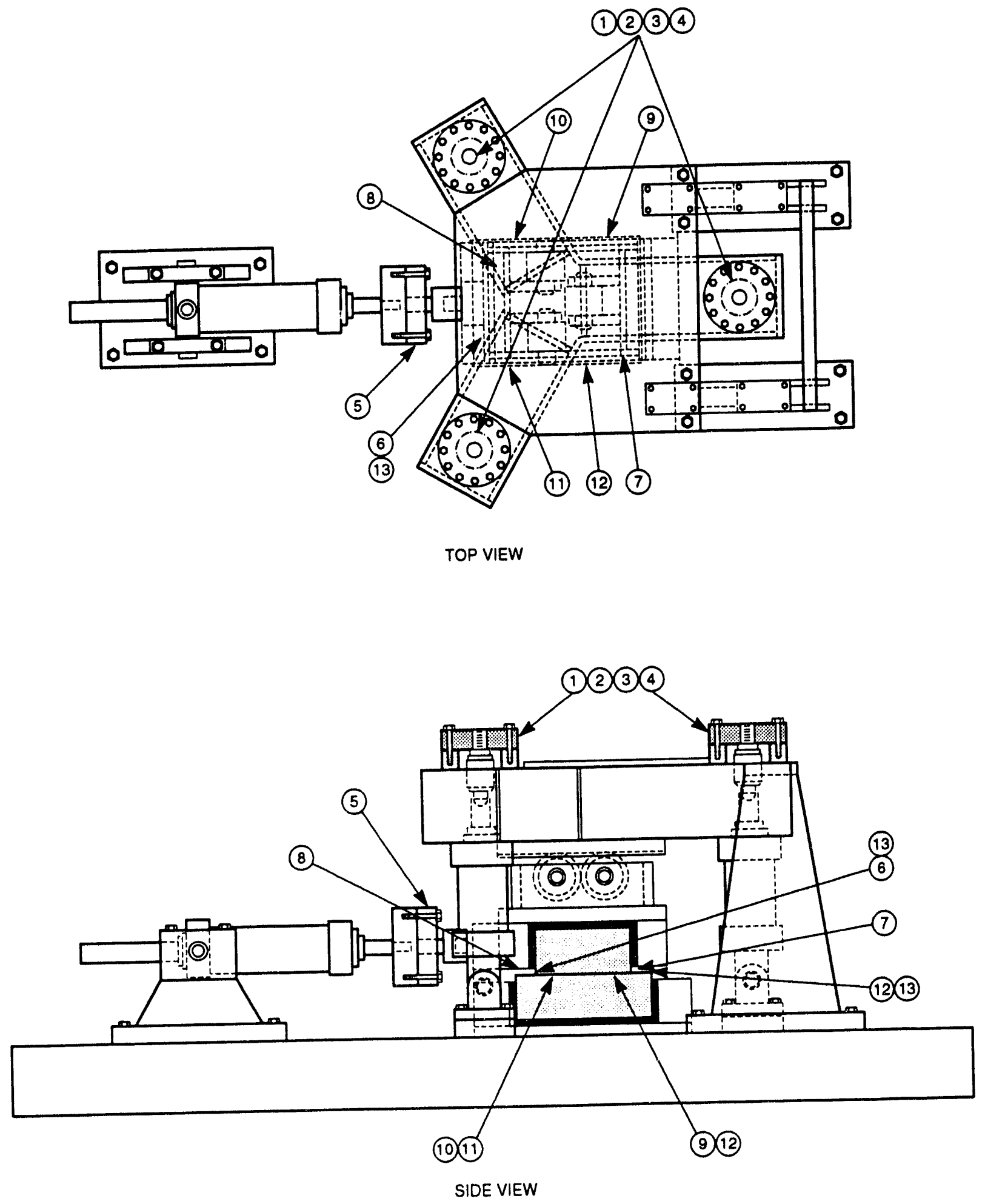

Figure 4-2. Assembly and instrumentation diagram for direct shear test apparatus (numbers in circles refer to instrumentation given in Table 4-1) 
As indicated in Figure 4-2, each of the three vertical actuators is pinned at the bottom to a clevis bolted to the base plate. At the top, each is connected to its associated load cell through a spherical coupling. This arrangement is consistent with the three degrees of freedom identified above. Furthermore, for quick disassembly, the three actuator pins are removed, the two double flexures are detached, and the entire normal load frame, with actuators attached, can be hoisted up away from the specimen/roller box assembly.

\subsection{HORIZONTAL LOAD SYSTEM}

The horizontal actuator produces direct shear to the upper specimen box via the horizontal load cell, which acts through a spherical coupling. This couping allows for slight misalignment in the horizontal shearing motion. It also allows for elevation changes of the upper specimen due to vertical load, joint surface roughness, and progressive wear. Control of the horizontal actuator load for all tests described herein was based on the horizontal shear displacement, as described in the next section.

\subsection{INSTRUMENTATION AND CONTROL}

Instrumentation channels are identified in Figure 4-2 and Table 4-1, and the associated excitation and control block diagram is shown in Figure 4-3. The locations of various relative displacement sensors on the specimen are shown in later figures.

All load cells are typical commercial strain gage units with dominant sensitivity to tension/compression along one axis. Reaction to the applied static normal load is measured in terms of relative vertical displacements of the two blocks at four locations near the interface. Measurements near the interface are desirable to reduce the effects of slack or lack of strength in the grout. The transducers are of proximity (noncontacting) eddy-current sensing type, since horizontal movement of the two surfaces must be allowed, but only vertical displacement changes must be sensed. Hence, the four vertical measurement points can be used to resolve the rigid body displacement of the upper block relative to the lower specimen block, according to the first three degrees of freedom identified above.

Vertical proximity transducers were mounted two on each side near the joint interface as shown in Figures 4-4 through 4-8. As indicated in Figure 4-7, the specimen is grouted into the upper and lower boxes so that a $25.4-\mathrm{mm}$ gap is left between the box faces. The interface, which varies from one specimen to another, is nominally enclosed within this gap. The sideplates of each half of the specimen box are slotted, so that vertical proximeter supports and target plates can be mounted directly onto the sides of respective halves of the specimen near the interface. Two prongs that support each plate component are cemented into lateral holes drilled into the specimen sides. The mean elevation of these $6.35-\mathrm{mm}$ thick steel components is set by gage blocks during the cementing process, so that their positions relative to the box faces are known, as indicated in Figure 4-7. Although some movement of the specimen within the grout occurs during loading, the side slots are large enough so that no interference occurs between the support prongs and the box side plates. Thus, as the upper box and associated target plates move horizontally relative to the lower specimen, change in vertical relative position is also sensed continuously. Furthermore, as shown in Figure 4-5, the heavy mounting frame for the upper box side rollers is slotted so that there is no interference between the frame and the target plates as the upper box displaces both horizontally due to shear and vertically due to unevenness and wear of the interface. 
Table 4-1. Instrumentation channel identification for direct shear test apparatus

\begin{tabular}{|c|l||}
\hline 1 & Vertical Load Cell No. 1 \\
\hline 2 & Vertical Load Cell No. 2 \\
\hline 3 & Vertical Load Cell No. 3 \\
\hline 4 & Analog Summation of Total Vertical Normal Load \\
\hline 5 & Horizontal Load Cell \\
\hline$* 6$ & $\begin{array}{l}\text { Horizontal Displacement of Top Block Relative to Bottom Block Near Actuator - } \\
\text { LVDT1 }\end{array}$ \\
\hline$* 7$ & $\begin{array}{l}\text { Horizontal Displacement of Top Block Relative to Bottom Block Opposite Actuator - } \\
\text { LVDT2 }\end{array}$ \\
\hline 8 & Horizontal Displacement of Top Block Relative to Horizontal Load Cell - LVDT3 \\
\hline$* 9$ & Specimen Vertical Relative Displacement Proximeter No. 4 \\
\hline$* 10$ & Specimen Vertical Relative Displacement Proximeter No. 5 \\
\hline$* 11$ & Specimen Vertical Relative Displacement Proximeter No. 6 \\
\hline$* 12$ & Specimen Vertical Relative Displacement Proximeter No. 7 \\
\hline 13 & Horizontal Acceleration at Near Left of Upper Specimen Block \\
\hline$*$ Note: See Figure 4-8 for exact locations \\
\hline
\end{tabular}

A horizontal accelerometer is mounted directly by bonding onto the upper specimen block. Thus, the accelerometer provides a measure of upper block absolute motion near the actuator attachment. Specimen block relative displacements are measured by three Linear Variable Differential Transformers (LVDT) as indicated in the various figures. LVDT1 is located at the near end of the specimen and measures displacement of the upper block relative to the lower block. Each half of the transducer is cemented directly into a hole drilled into the respective specimen block. LVDT2 is similarly mounted on the far side of the specimen pair, as shown in Figure 4-8. The outputs of these two transducers provide the direct shear movement of the joint interface. LVDT3 is mounted to sense displacement of the upper block relative to the horizontal load cell. Thus, it measures any compliance that may exist in the horizontal coupling and the grout for the upper block. The position of LVDT3 is $57.2 \mathrm{~mm}$ in from the outside surface of the upper specimen box, on the same side as proximeters P4 and P5. This position is not shown in Figure 4-8, since only the lower specimen box is depicted.

Control in all cases was imposed on a prescribed horizontal displacement signal whose character was determined by the following options:

Pseudostatic - A slow (20 min) ramp is applied to the relative displacement, while the force required is simultaneously recorded. 


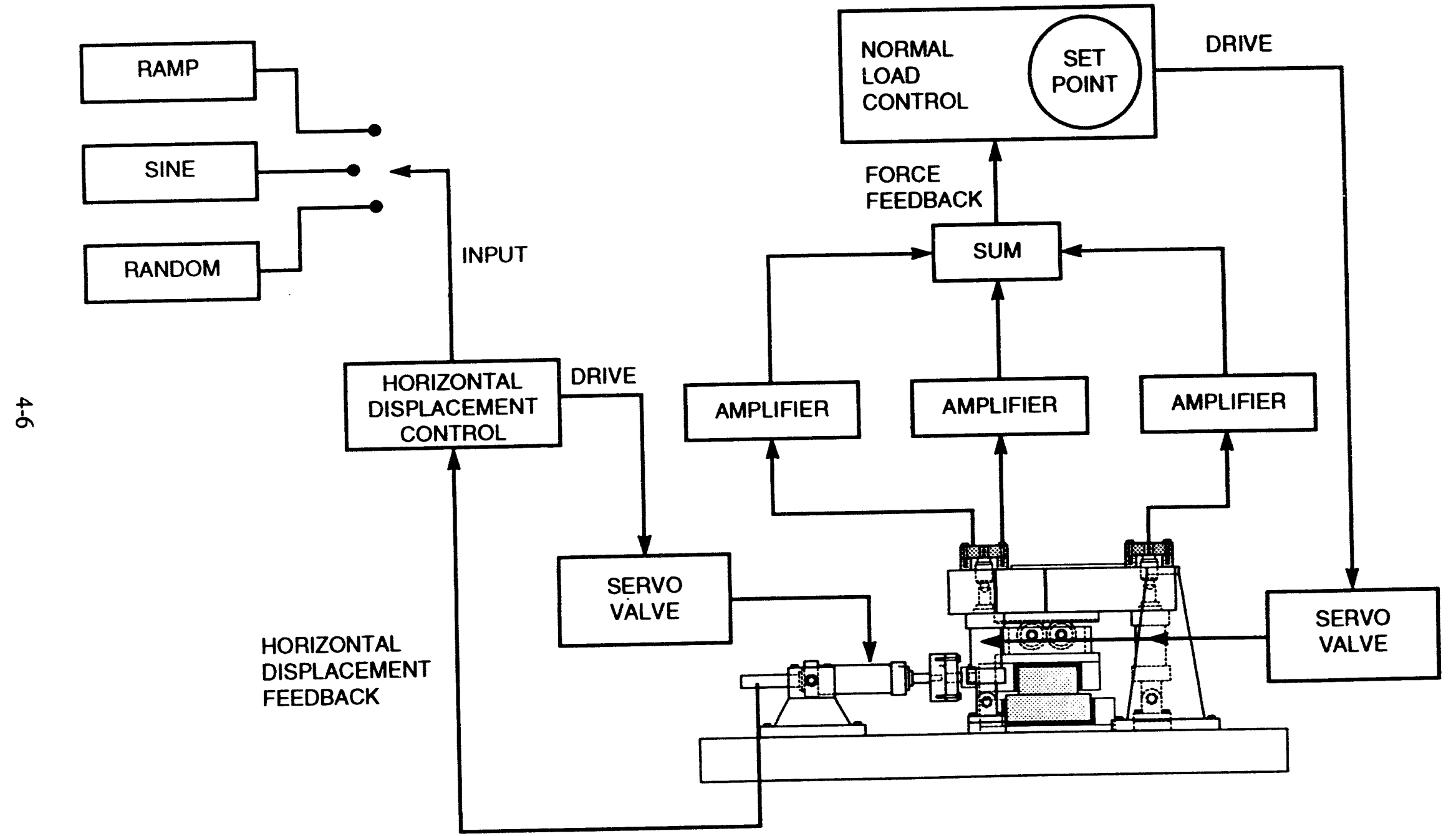

Figure 4-3. Excitation and control block diagram 


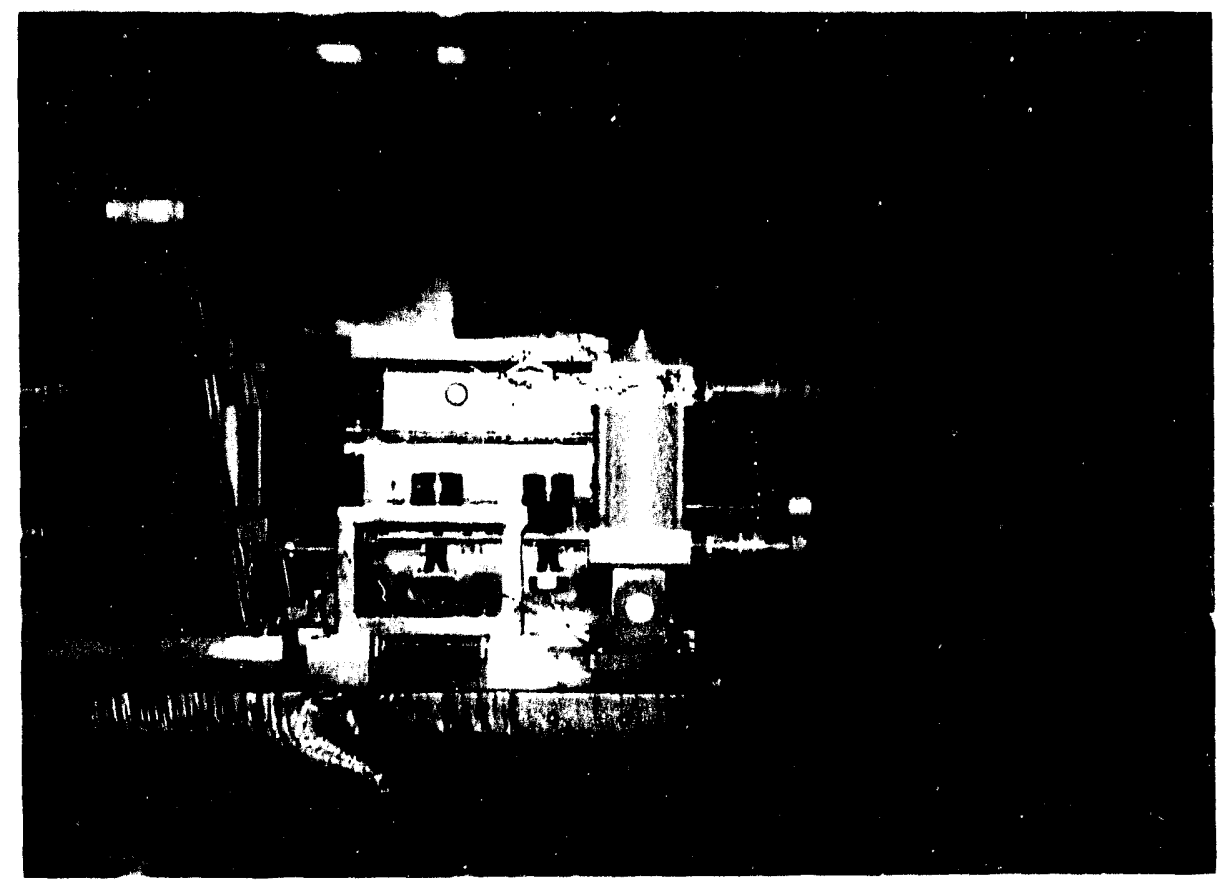

Figure 4-4. Side view of vertical displacement instrumentation system

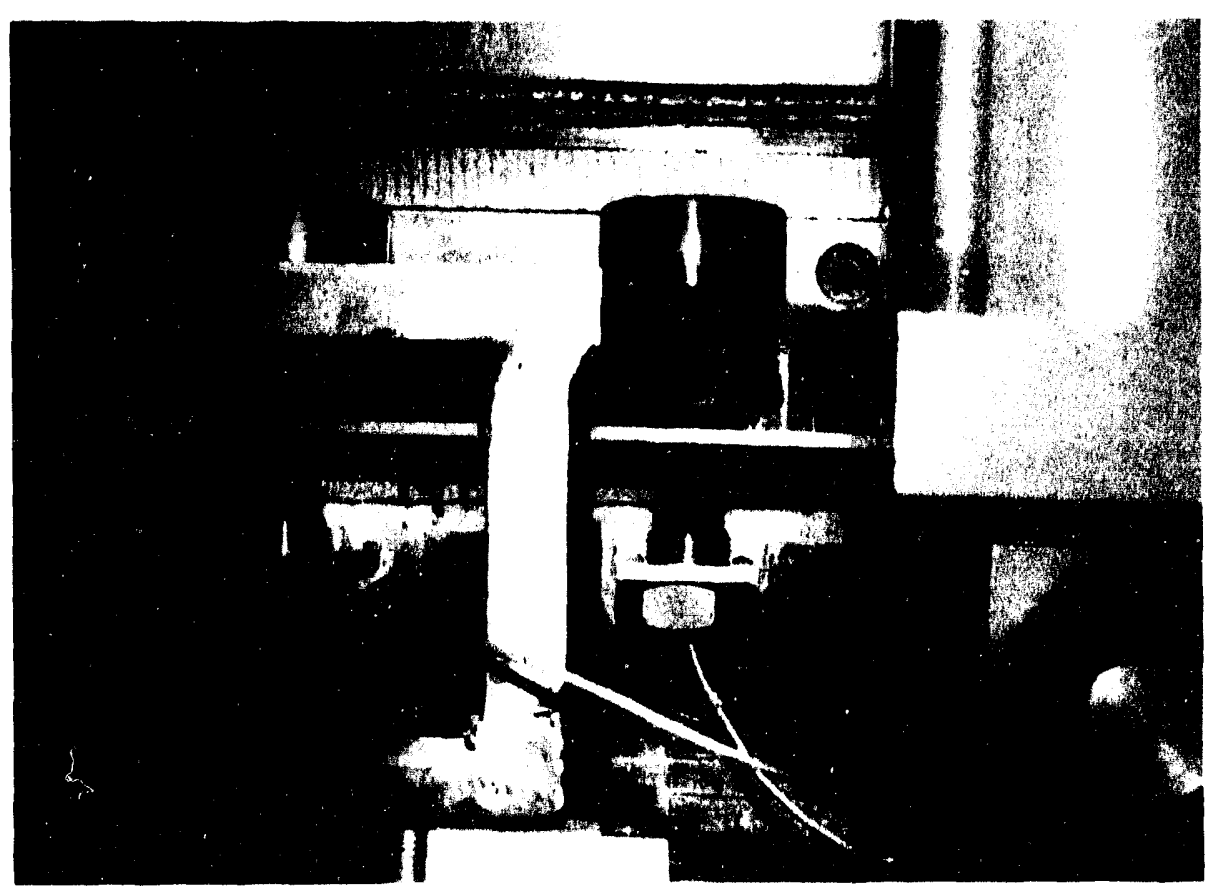

Figure 4-5. Close view of vertical displacement instrumentation system 


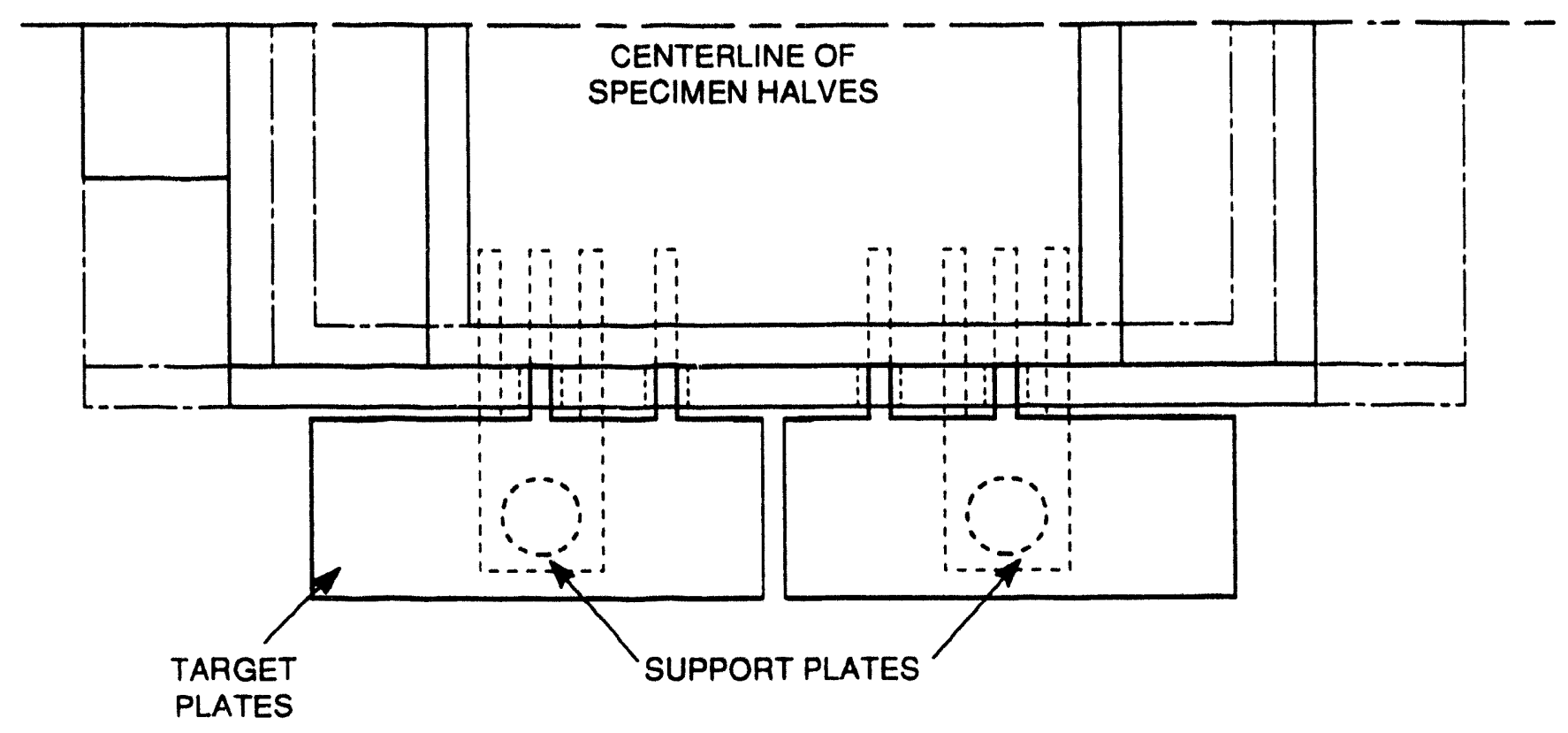

Figure 4-6. Top view of vertical displacement instrumentation supports and targets

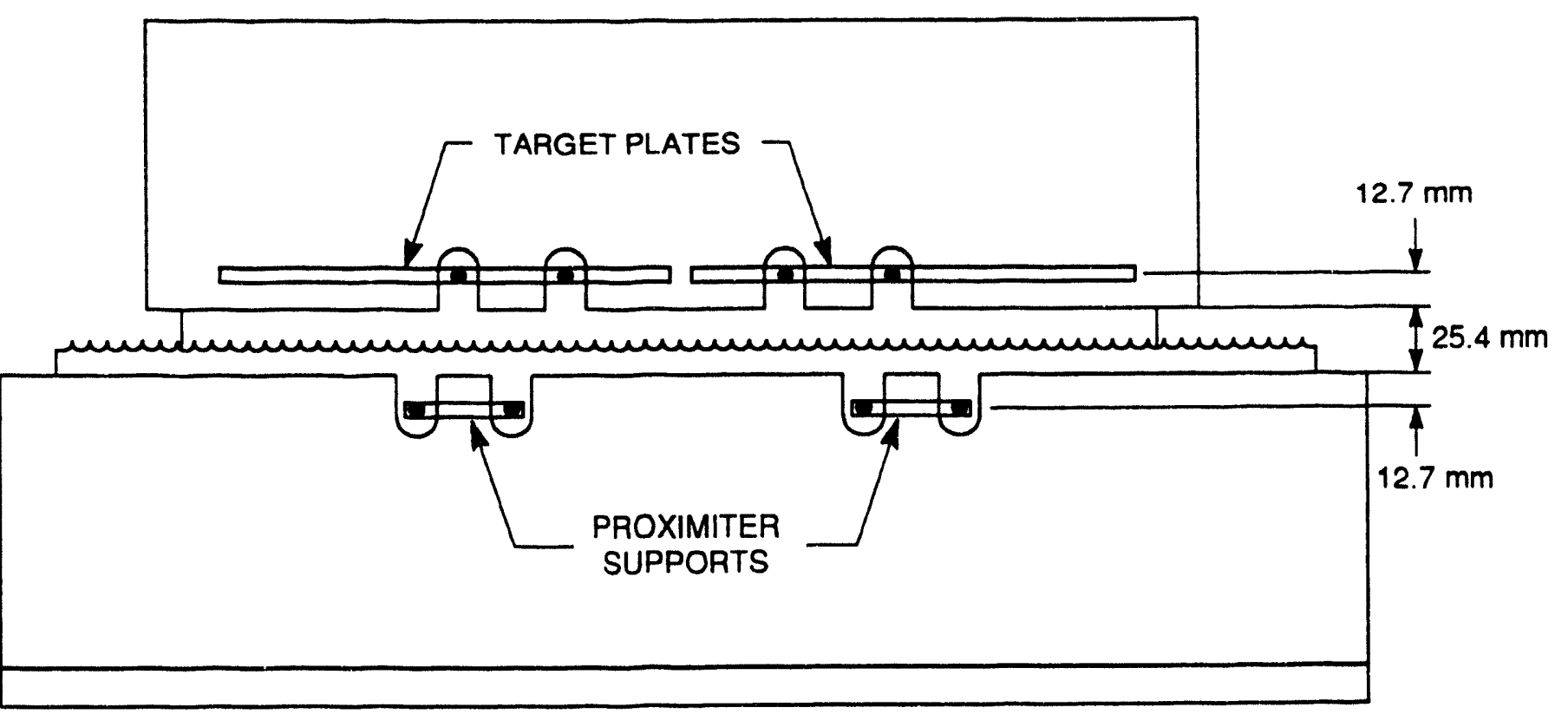

Figure 4-7. Side view of vertical displacement instrumentation supports and targets 


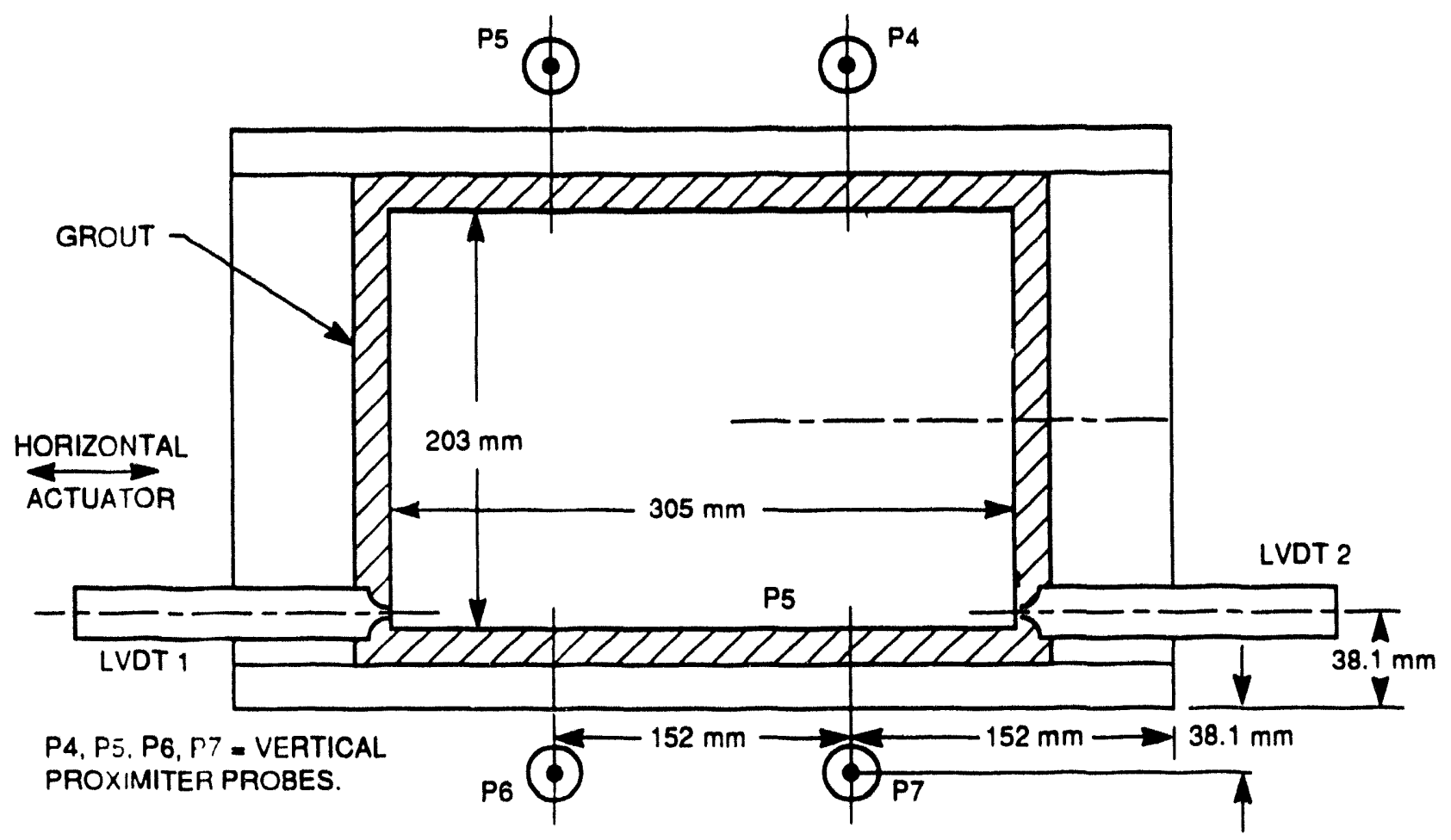

Figure 4-8. Location of relative displacement sensors on specimen lower block

Steady-State Cyclic - A sine wave drive signal is applied. Frequency, amplitude, and duration are based on the anticipated performance of the surface.

Earthquake Simulation - A drive signal is generated such that a specified acceleration time history is nominally matched for a given time duration.

Calibration of load cells was performed in a commercial hydraulic apparatus with digital voltage readout. A.ccuracy is within \pm 1.0 percent. The vertical proximity eddy-current transducers were calibrated by placing the sensors in an adjustable displacement device with micrometer head, and reading the displacement increments and associated voltages. Generally, all proximeters and LVDT provided essentially linear calibration performance in the required measurement ranges. Horizontal accelerometers were calibrated by comparison of their output with a National Institute of Standards and Technology (NIST) standard accelerometer, while being excited on an electrodynamic shaker.

\subsection{DATA ACQUISITION AND PROCESSING}

The 13 channels of data identified in Table 4-1 are sampled and recorded directly on the hard disk of a $640 \mathrm{~K}$ memory personal computer with a $40-\mathrm{MB}$ hard disk and diskette option. This system also contained a special math coprocessor and high-speed card option. Software has been implemented that 
allows sampling of data at preselected rates and times, which are required by the various types of dynamic tests described above. Data are ultimately transferred to a diskette for further processing and plotting on other digital computers. The design and functional capability of the apparatus have been assessed using cast concrete specimens. The results from pseudostatic and dynamic tests are given by Kana et al. (1990). 


\section{ROCK AND JOINT STATIC PROPERTIES}

\subsection{BASIC MATERIAL PROPERTIES 'IESTS}

\subsubsection{Uniaxial and Triaxial Compression Tests}

For this program, 113 uniaxial specimens and 72 triaxial specimens were tested according to the testing procedures specified in the Quality Assurance Program for Mechanical Characterization of Tuff. CNWRA, by Daemen (1990). The test results for the uniaxial and triaxial compressive tests are listed in Table 5-1 and 5-2, respectively.

Statistical analysis indicates a mean uniaxial compressive strength of $161 \mathrm{MPa}$ (with a standard deviation of $26 \mathrm{MPa}$ ). The mean triaxial compressive strength is $202 \mathrm{MPa}$ (with a standard deviation of $27 \mathrm{MPa}$ ) with $3.4 \mathrm{MPa}$ confining pressure, $248 \mathrm{MPa}$ (with a standard deviation of $22 \mathrm{MPa}$ ) with $6.9 \mathrm{MPa}$ confining pressure, and $271 \mathrm{MPa}$ (with a standard deviation of $18 \mathrm{MPa}$ ) with $10.3 \mathrm{MPa}$ confining pressure. Average values for Young's modulus and Poisson's ratio of the Apache Leap tuff are 38.6 GPa (with a standard deviation of $3.4 \mathrm{GPa}$ ) and 0.2 (with a standard deviation of 0.0287 ), respectively.

\subsubsection{Brazilian Tests}

One to three disk specimens for each group of uniaxial and triaxial compression test specimens were cut to length from the 50-mm diameter cores. A total of 123 Brazilian disk specimens have been tested according to the testing procedures specified in the Quality Assurance Program for Mechanical Characterization of Tuff, CNWRA, by Daemen (1990), and the results are given in Table 5-3. The mean uniaxial tensile strength is $10.3 \mathrm{MPa}$ (with a standard deviation of $2.2 \mathrm{MPa}$ ).

\subsection{JOINT INTERFACE CHARACTERIZATION TESTS}

\subsubsection{Joint Profile Measurement Data}

Prior to cyclic pseudostatic or dynamic direct shear testing of the single-jointed Apache Leap tuff specimens, profile measurements were taken of both the top and bottom joint surfaces for determination of the pretesting (initial) JRC. The profile measurements were performed after the top and bottom block specimens were grouted in their respective steel boxes. After the steel box with the specimen was aligned under the rock profilometer, the computer program was initiated. The operator manually positioned the laser to define the $\mathrm{X}$ and $\mathrm{Y}$ offset for the start of the profile measurement (i.e., lower left corner of the rock specimen). The operator also manually defined the scanning window by moving the laser to the four edges of the rock specimen. After the four edges were identified, these parameters were stored in a configuration file, and the program then automatically scanned the entire joint surface. The scanning interval in both the $X$ and $Y$ directions was nominally set at $1.27 \mathrm{~mm}$, and the scan time was roughly 2 points $/ \mathrm{sec}$. The total scanning time for the bottom block $(305 \times 203 \mathrm{~mm})$ and top block $(203 \times 203 \mathrm{~mm})$ took approximately $4 \mathrm{hr}$ and $3 \mathrm{hr}$, respectively. After the normal loading and direct shear tests were conducted, joint profile measurements were again taken to determine the after-testing JRC for additional use in interpreting the direct shear test results. For these final profile measurements, 
Table 5-1. Uniaxial compressive strength, Young's modulus, and Poisson's ratio of Apache Leap tuff

\begin{tabular}{||l|c|c|c||}
\hline Specimen No. & $\begin{array}{c}\text { Failure Stress } \\
\text { (MPa) }\end{array}$ & $\begin{array}{c}\text { Young's Modulus } \\
\text { (GPa) }\end{array}$ & Poisson's Ratio \\
\hline SRM1.1.1-U-1 & 172.97 & 35.17 & .19 \\
SRM1.1.1-U-2 & 163.17 & 33.79 & .19 \\
SRM1.2.2-U-1 & 168.00 & 42.07 & .23 \\
SRM1.3.3-U-1 & 153.38 & 42.76 & .23 \\
SRM1.3.3-U-2 & 168.90 & 39.31 & .17 \\
SRM9.1.1-U-1 & 207.38 & 46.21 & .19 \\
SRM9.1.1-U-2 & 177.10 & 40.00 & $* .11$ \\
SRM9.3.4-U-2 & 75.86 & - &.. \\
SRM10.1.1-U-1 & 166.20 & 37.93 & .18 \\
SRM10.1.1-U-2 & 152.97 & 37.93 & .17 \\
SRM10.2.2-3-U-1 & 186.21 & 40.00 & .23 \\
SRM10.2.2-3-U-2 & 179.31 & 40.00 & .24 \\
SRM10.2.2-3-U-3 & 175.17 & 36.55 & .16 \\
SRM10.3.4-U-2 & 162.76 & 44.14 & .28 \\
SRM10.4.5-U-1 & 186.90 & 39.31 & .21 \\
SRM13.2.3-U-1 & 157.10 & 40.69 & .19 \\
SRM13.3.4-U-1 & 187.17 & 38.62 & .23 \\
SRM13.3.4-U-2 & 187.86 & 39.31 & .25 \\
SRM13.5.7-U-1 & 139.31 & 42.07 & .11 \\
SRM13.5.7-U-2 & 187.59 & 41.38 & $* .12$ \\
SRM15.1.1-U-1 & 168.97 & 40.69 & .20 \\
SRM15.2.2-U-1 & 177.31 & 33.10 & .18 \\
SRM15.2.2-U-2 & 148.07 & 35.17 & .23 \\
SRM15.2.3-U-1 & 164.14 & 35.86 & .19 \\
SRM15.3.4-U-1 & 173.52 & 38.62 & .29 \\
SRM15.3.4-U-2 & 173.10 & 44.14 & .17 \\
SRM16.1.1-U-1 & 185.10 & 44.83 & .19 \\
SRM16.1.1-U-2 & 208.34 & 44.83 & .18 \\
SRM16.2.2-U-1 & 133.10 & 38.62 & .21 \\
SRM17.2.3-U-1 & 120.48 & $* 133.10$ & \\
\hline \hline *Further check required & & & \\
\hline
\end{tabular}


Table 5-1. Uniaxial compressive strength, Young's modulus, and Poisson's ratio of Apache Leap tuff (cont'd)

\begin{tabular}{|c|c|c|c|}
\hline Specimen No. & Failure Stress (MPa) & $\begin{array}{c}\text { Young's Modulus } \\
\text { (GPa) }\end{array}$ & Poisson's Ratio \\
\hline SRM9.2.3-U-1 & 159.31 & 35.86 & .20 \\
\hline SRM9.2.3-U-2 & 167.59 & 35.17 & - \\
\hline SRM9.3.4-U-1 & 113.10 & 44.14 & - \\
\hline SRM9.4.5-U-1 & 175.17 & 38.62 & .22 \\
\hline SRM9.4.5-U-2 & 157.24 & 33.79 & .28 \\
\hline SRM10-2.2-1-U-1 & 146.90 & 39.31 & .20 \\
\hline SRM10-2.2-3-U-4 & 172.41 & 37.93 & .17 \\
\hline SRM10.3.4-U-1 & 146.90 & 42.07 & .18 \\
\hline SRM11.1.1-U-1 & 114.48 & 31.03 & .21 \\
\hline SRM11.1.1-U-2 & 144.83 & 35.86 & .17 \\
\hline SRM11.1.2-U-1 & 165.52 & 37.24 & .19 \\
\hline SRM11.2.3-U-1 & 132.41 & 32.41 & .23 \\
\hline SRM11.2.3-U-2 & 175.17 & 35.86 & .17 \\
\hline SRM11.2.3-U-3 & 162.76 & 43.45 & .19 \\
\hline SRM11.3.4-U-1 & 173.79 & 39.31 & .19 \\
\hline SRM11.3.4-U-2 & 149.66 & 35.17 & .17 \\
\hline SRM12.1.1-1-U-1 & 171.72 & 35.86 & .18 \\
\hline SRM12.1.1-2-U-1 & 170.34 & 35.17 & .17 \\
\hline SRM12.1.1-2-U-2 & 155.86 & 35.17 & .17 \\
\hline SRM12.3.3-U-1 & 170.34 & 42.76 & .20 \\
\hline SRM12.3.3-U-2 & 151.03 & 36.55 & .24 \\
\hline SRM12.3.3-U-3 & 172.41 & 39.31 & .20 \\
\hline SRM13.1.2-U-1 & 167.59 & 38.62 & .17 \\
\hline SRM13.2.3-U-2 & 192.41 & 35.17 & .20 \\
\hline SRM13.3.4-U-3 & 186.90 & 36.55 & .18 \\
\hline SRM13.4.5-U-1 & 179.31 & 42.07 & .20 \\
\hline SRM13.4.5-U-2 & 175.17 & 39.31 & .17 \\
\hline SRM13.4.6-1-U-1 & 137.93 & 33.10 & .25 \\
\hline SRM15.3.5-U-1 & 173.10 & 37.24 & .18 \\
\hline SRM15.4.6-U-1 & 191.03 & 40.69 & .17 \\
\hline SRM15.4.6-U-2 & 165.52 & 45.52 & .19 \\
\hline SRM15.5.7-U-1 & 164.83 & 38.62 & .18 \\
\hline SRM15.5.7-U-2 & 182.07 & 37.24 & .20 \\
\hline SRM15.5.7-U-3 & 155.86 & 40.69 & .19 \\
\hline SRM16.3.3-U-1 & 182.07 & 39.31 & .17 \\
\hline SRM16.3.3-U-2 & 168.97 & 46.21 & .23 \\
\hline SRM17.3.4-U-1 & 142.07 & 36.55 & .20 \\
\hline
\end{tabular}


Table 5-1. Uniaxial compressive strength, Young's modulus, and Poisson's ratio of Apache Leap tuff (cont'd)

\begin{tabular}{|c|c|c|c|}
\hline Specimen No. & Failure Stress (MPa) & $\begin{array}{c}\text { Young's Modulus } \\
\text { (GPa) }\end{array}$ & Poisson's Ratio \\
\hline SRM17.3.4-U-2 & 162.07 & 42.07 & .20 \\
\hline SRM19.1.1-U-1 & 169.86 & 36.55 & .18 \\
\hline SRM19.1.1-U-2 & 177.93 & 31.03 & .18 \\
\hline SRM20.1.1-U-1 & 200.69 & 35.17 & .22 \\
\hline SRM20.1.1-U-2 & 185.86 & 38.62 & .17 \\
\hline SRM20.2.2-U-1 & 182.07 & 33.10 & .19 \\
\hline SRM20.3.3-U-1 & 166.55 & 35.86 & .17 \\
\hline SRM20.3.3-U-2 & 171.03 & 35.86 & .17 \\
\hline SRM20.3.3-U-3 & 173.10 & 35.17 & .19 \\
\hline SRM20.4.5-U-1 & 149.24 & 33.79 & .20 \\
\hline SRM22.1.1-U-1 & 173.86 & 42.07 & .20 \\
\hline SRM22.1.1-U-2 & 144.07 & - & -- \\
\hline SRM22.4.4-U-1 & 158.55 & 37.93 & $* .11$ \\
\hline SRM22.5.5-U-1 & 188.97 & 47.59 & .20 \\
\hline SRM22.5.5-U-2 & 218.34 & 42.76 & .16 \\
\hline SRM23.1.2-U-1 & 158.97 & 40.00 & .20 \\
\hline SRM23.3.4-U-1 & 174.21 & 40.69 & $* .46$ \\
\hline SRM23.3.4-U-2 & 139.17 & 40.69 & .20 \\
\hline SRM25.1.1-U-1 & 112.28 & $* 133.10$ & .17 \\
\hline SRM25.1.1-U-2 & 114.34 & 37.93 & .25 \\
\hline SRM25.1.1-U-3 & 130.55 & 42.76 & .22 \\
\hline SRM26.2.2-U-1 & 184.34 & 44.14 & .17 \\
\hline SRM26.2.2-U-2 & 169.45 & 41.38 & .24 \\
\hline SRM26.2.3-U-1 & 164.28 & 40.69 & .21 \\
\hline SRM27.3.4-U-1 & 150.14 & 43.45 & .20 \\
\hline SRM27.3.4-U-2 & 184.97 & 42.76 & .20 \\
\hline SRM27.3.4-U-3 & 190.76 & 44.83 & .21 \\
\hline SRM28.1.1-U-1 & 121.93 & 37.93 & .17 \\
\hline SRM28.1.1-U-2 & 134.14 & 33.79 & .17 \\
\hline SRM28.1.2-1-U-1 & 122.48 & *113.79 & .18 \\
\hline SRM28.2.3-U-1 & 177.24 & 44.83 & .24 \\
\hline SRM28.2.3-U-2 & 164.07 & 45.52 & .24 \\
\hline SRM28.3.4-U-1 & 113.31 & *148.97 & .17 \\
\hline SRM28.3.4-U-2 & 104.83 & 37.93 & .25 \\
\hline SRM29.2.4-U-1 & 154.00 & 37.24 & .20 \\
\hline SRM29.2.4-U-2 & 176.00 & 38.62 & .18 \\
\hline
\end{tabular}


Table 5-1. Uniaxial compressive strength, Young's modulus, and Poisson's ratio of Apache leap tuff (cont'd)

\begin{tabular}{||l|c|c|c|}
\hline Specimen No. & Failure Stress (MPa) & $\begin{array}{c}\text { Young's Modulus } \\
\text { (GPa) }\end{array}$ & Poisson's Ratio \\
\hline SRM29.2.4-U-3 & 169.03 & 40.69 & .17 \\
SRM10.3.3-U-1 & 53.78 & - & - \\
SRM17.1.2-U-1 & 88.94 & 19.99 & .17 \\
SRM17.2.3-U-2 & 154.44 & 32.41 & .27 \\
SRM22.2.2-U-1 & 157.89 & 43.44 & .22 \\
SRM22.2.2-U-2 & 172.37 & 39.30 & .18 \\
SRM22.3.3-U-1 & 170.99 & 39.99 & .18 \\
SRM22.3.3-U-2 & 162.72 & 40.68 & .18 \\
SRM23.2.3-U-1 & 176.51 & 37.23 & .22 \\
SRM23.2.3-U-2 & 161.34 & 36.54 & .22 \\
\hline
\end{tabular}

the X-Y offset and scanning window lengths were used from the initial profile so that the location of each individual scanning point was the same for both the before- and after-testing joint profiles.

Figures 5-1 and 5-2 show plots of the profile measurements taken for one of the top blocks before and after pseudostatic direct shear testing (test no. 10). Only every other data point was used in plotting these profile measurement results. For this particular test, pseudostatic direct shear tests in the forward and reverse directions (i.e., along the $X$ axis) were conducted under normal stresses of 2, 3, 4, and $5 \mathrm{MPa}$. A careful examination of the two figures shows the changes in the joint profiles, since some of the asperities are sheared and rock breakage occurs along the block edges during shear testing. Accurate measurements of these changes were made from profilometer results.

\subsubsection{Pseudostatic Rock Joint Behavior}

\subsubsection{Normal Deformation Response}

In order to establish the relation between the normal stress and joint closure for the Apache Leap welded tuff joints, a series of five repeated normal load cycles was applied to each sample. Five cycles were chosen, because it was found that this number was sufficient to eliminate any additional hysteresis between the loading and unloading curves, and to properly seat the joint prior to direct shear testing. A maximum normal stress of $8.0 \mathrm{MPa}$ could be applied across the joint based on the capacity of the normal load cell transducers and the surface area of the joint $\left(413 \mathrm{~cm}^{2}\right)$. The time required to complete both a loading and unloading cycle was approximately $10 \mathrm{~min}$. Normal joint displacement was measured using noncontacting displacement transducers as discussed earlier. Normal joint loading was performed on 30 specimens, prior to either cyclic pseudostatic or dynamic direct shearing.

A typical plot for the response of the natural joint to a series of cyclical normal loadings is shown in Figure 5-3. In this figure, the average joint closure measured by the four proximeters is plotted against the average applied normal stress. Each of the cycles has been adjusted by subtracting the initial 
Table 5-2. Triaxial compressive strength for Apache Leap tuff

\begin{tabular}{|c|c|c|c|}
\hline Specimen No. & $\begin{array}{c}\text { Confining Pressure } \\
(\mathbf{M P a}) \\
\end{array}$ & $\begin{array}{l}\text { Failure Struss } \\
\text { (MPRj) }\end{array}$ & $\begin{array}{c}\text { Density } \\
\left(10^{3} \mathrm{~kg} / \mathrm{m}^{3}\right) \\
\end{array}$ \\
\hline SRM25.1.1-T-2 & 3.4 & 208.21 & - \\
\hline SRM17.2.3-T-1 & 3.4 & 170.90 & 2.42 \\
\hline SRM16.1.1-T-1 & 3.4 & 205.52 & 2.42 \\
\hline SRM23.3.4-T-1 & 3.4 & 217.93 & - \\
\hline SRM1.3.3-T-1 & 3.4 & 186.21 & 2.42 \\
\hline SRM1.1.1-T-1 & 3.4 & 199.31 & 2.39 \\
\hline SRM1.2.2-T-1 & 6.9 & 262.07 & 2.40 \\
\hline SRM9.1.1-T-1 & 10.3 & 277.24 & 2.40 \\
\hline SRM9.2.3-T-1 & 3.4 & 232.41 & 2.42 \\
\hline SRM9.3.4-T-1 & 6.9 & 205.52 & 2.42 \\
\hline SRM9.4.5-T-1 & 3.4 & 206.90 & 2.42 \\
\hline SRM9.4.5-T-2 & 10.3 & 280.69 & 2.42 \\
\hline SRM10.1.1-T-1 & 3.4 & 201.38 & 2.40 \\
\hline SRM10.1.1-T-2 & 6.9 & 211.72 & 2.40 \\
\hline SRM10.2.2-3-T-1 & 10.3 & 285.52 & 2.44 \\
\hline SRM10.2.2-3-T-2 & 6.9 & 247.59 & 2.40 \\
\hline SRM10.3.3-T-2 & 3.4 & 166.21 & 2.42 \\
\hline SRM10.3.4-T-1 & 3.4 & 222.07 & 2.42 \\
\hline SRM10.4.5-T-1 & 6.9 & 263.45 & 2.49 \\
\hline SRM10.4.5-T-2 & 10.3 & 273.10 & 2.42 \\
\hline SRM13.2.3-T-1 & 6.9 & 255.17 & 2.42 \\
\hline SRM13.3.4-T-1 & 10.3 & 287.59 & 2.42 \\
\hline SRM15.1.1-T-1 & 6.9 & 255.17 & 2.49 \\
\hline SRM15.2.2-T-1 & 6.9 & 241.38 & 2.42 \\
\hline SRM15.3.4-T-1 & 6.9 & 226.90 & 2.42 \\
\hline
\end{tabular}


Table 5-2. Triaxial compressive strength for Apache Leap tuff (cont'd)

\begin{tabular}{||l|c|c|c||}
\hline Specimen No. & $\begin{array}{c}\text { Confining Pressure } \\
\text { (MPa) }\end{array}$ & $\begin{array}{c}\text { Failure Stress } \\
(\mathbf{M P a})\end{array}$ & $\begin{array}{c}\text { Density } \\
\left(\mathbf{1 0}^{\mathbf{3}} \mathbf{~ k g} \mathbf{m}^{\mathbf{3}}\right)\end{array}$ \\
\hline \hline SRM11.2.3-T-1 & 6.9 & 251.72 & 2.42 \\
SRM12.1.1-1-T-1 & 3.4 & 215.17 & 2.47 \\
SRM12.1.1-2-T-1 & 10.3 & 248.28 & 2.44 \\
SRM12.3.3-T-1 & 3.4 & 196.55 & 2.42 \\
SRM12.3.3-T-2 & 10.3 & 258.62 & 2.42 \\
SRM13.1.2-T-1 & 3.4 & 117.24 & 2.42 \\
SRM13.1.2-T-2 & 6.9 & 264.83 & 2.44 \\
SRM13.4.5-T-1 & 10.3 & 284.14 & 242 \\
SRM13.4.6-1-T-1 & 3.4 & 210.34 & 2.42 \\
SRM15.2.3-T-1 & 3.4 & 209.66 & 2.42 \\
SRM15.3.5-T-1 & 10.3 & 293.10 & 2.42 \\
SRM15.4.6-T-1 & 10.3 & 247.59 & 2.40 \\
SRM15.4.6-T-2 & 3.4 & 234.48 & 2.42 \\
SRM15.5.7-T-1 & 3.4 & 229.66 & 2.42 \\
SRM15.5.7-T-2 & 3.4 & 194.48 & 2.40 \\
SRM16.2.2-T-1 & 10.3 & 237.93 & 2.42 \\
SRM17.3.4.-T-1 & 3.4 & 182.07 & 2.42 \\
SRM19.1.1-T-1 & 3.4 & 182.07 & 2.40 \\
SRM19.1.1-T-2 & 10.3 & 262.07 & 2.42 \\
SRM11.1.1-T-1 & 10.3 & 290.27 & 2.42 \\
SRM11.1.2-T-1 & 3.4 & 205.46 & 2.40 \\
SRM11.2.3-T-2 & 10.3 & 225.46 & 2.40 \\
SRM11.3.4-T-1 & 3.4 & 204.08 & 2.42 \\
SRM16.3.3-T-1 & 3.4 & 214.43 & 2.42 \\
SRM17.1.2-T-1 & 3.4 & 239.94 & 2.40 \\
SRM20.1.1-T-1 & 10.3 & 286.82 & 2.42 \\
SRM20.2.2-T-2 & 3.4 & 134.45 & 2.40 \\
SRM20.3.3-T-1 & 6.9 & 262.00 & 2.42 \\
SRM20.3.3-T-2 & 10.3 & 282.69 & 2.40 \\
SRM20.4.5-T-1 & 3.4 & 184.09 & 2.40 \\
SRM22.1.1-T-1 & 0.7 & 170.99 & 2.40 \\
SRM22.2.2-T-1 & 10.3 & 266.14 & 2.40 \\
SRM22.3.3-T-1 & 3.4 & 231.66 & 2.42 \\
\hline \hline
\end{tabular}


Table 5-2. Triaxial compressive strength for Apache Leap tuff (cont'd)

\begin{tabular}{||c|c|c|c||}
\hline Specimen No. & $\begin{array}{c}\text { Confining Pressure } \\
\text { (MPa) }\end{array}$ & $\begin{array}{c}\text { Failure Stress } \\
\text { (MPa) }\end{array}$ & $\begin{array}{c}\text { Density } \\
\left(\mathbf{1 0}^{\mathbf{3}} \mathbf{~ k g} / \mathbf{m}^{\mathbf{3}}\right)\end{array}$ \\
\hline \hline SRM22.4.4-T-1 & 10.3 & 290.96 & 2.42 \\
SRM22.5.5-T-1 & 3.4 & 226.15 & 2.42 \\
SRM23.2.3-T-1 & 3.4 & 175.82 & 2.40 \\
SRM23.2.3-T-2 & 10.3 & 281.31 & 2.42 \\
SRM25.1.1-T-1 & 6.9 & 282.69 & 2.40 \\
SRM26.2.2-T-1 & 3.4 & 199.95 & 2.42 \\
SRM26.2.3-T-1 & 10.3 & 273.72 & 2.42 \\
SRM27.3.4-T-1 & 3.4 & 235.80 & 2.44 \\
SRM27.3.4-T-2 & 10.3 & 264.07 & 2.42 \\
SRM28.1.1-T-1 & 3.4 & 197.19 & 2.40 \\
SRM28.1.2-1-T-1 & 10.3 & 244.07 & 2.39 \\
SRM28.2.3-T-1 & 3.4 & 218.56 & 2.42 \\
SRM28.3.4-T-1 & 10.3 & 275.79 & 2.42 \\
SRM29.2.4-T-1 & 3.4 & 225.46 & 2.42 \\
SRM29.2.4-T-2 & 10.3 & 218.56 & 2.42 \\
\hline
\end{tabular}

reading at the start of each load cycle. The third and fourth cycles are not shown for clarity. An important aspect of the normal closure behavior is the hysteresis and large permanent set seen in the first cycle. Subsequent cycles show much less hysteresis and permanent set, with the normal stiffness (slope) increasing much more rapidly with increasing stress. By the fourth or fifth cycle, very iittle hysteresis remains, and the joint behaves more or less elastically. This type of normal deformation pattern was common for all 30 specimens tested. However, the magnitude of maximum joint closure varied somewhat between samples, possibly due to the degree of joint roughness or weathering from specimen to specimen. These variations are evident in Sections 5.2.4 and 5.2.5, where coefficients are determined for the Barton-Bandis and Continuously-Yielding joint models to describe joint normal deformation behavior.

\subsubsection{Shear Deformation Response}

For the joint interface characterization tests, direct shear tests were performed on a total of 16 dry and 3 saturated, naturally jointed Apache Leap tuff samples. The first 16 jointed tuff specimens were dried in an oven at $105{ }^{\circ} \mathrm{C}$ for approximately $24 \mathrm{hr}$ after being grouted in the steel boxes, and subsequently allowed to cool before testing was conducted. The last three specimens were submerged in a tank of water for approximately 7 days and allowed to saturate before direct shear testing was conducted. The first shear cycle on the initially undamaged joint surface was conducted under different values of normal load, ranging from 0.5 to $6.0 \mathrm{MPa}$, to obtain a good representation of the "fresh" joint response under various applied normal loads. The normal load cycling conducted prior to the direct shear tests aided in seating the welded tuff joint (i.e., returning the joint to its original state in the field). 
Table 5-3. Results of Brazilian disk tension test of Apache Leap tuff

\begin{tabular}{|c|c|c|c|}
\hline Specimen No. & $\begin{array}{c}\text { Failure Stress } \\
(\mathbf{M P a})\end{array}$ & Specimen No. & $\begin{array}{l}\text { Failure Stress } \\
\text { (MPa) }\end{array}$ \\
\hline SRM9.2.3-B-1 & 13.10 & SRM23.3.4-B-1 & 12.90 \\
\hline SRM9.2.3-B-2 & 13.17 & SRM10.1.1-B-1 & 12.14 \\
\hline SRM9.3.4-B-1 & 6.83 & SRM10.1.1-B-2 & 13.72 \\
\hline SRM9.4.5-B-1 & 11.10 & SRM10.1.1-B-3 & 11.66 \\
\hline SRM9.4.5-B-2 & 13.31 & SRM23.1.2-B-1 & 12.00 \\
\hline SRM10.2.2-1-B-1 & 10.76 & SRM23.1.2-B-2 & 11.79 \\
\hline SRM10.2.2-2-B-1 & 8.28 & SRM23.3.4-B-2 & 12.69 \\
\hline SRM10.2.2-2-B-2 & 7.45 & SRM28.2.3-B-1 & 11.59 \\
\hline SRM10.2.2-2-B-3 & 7.93 & SRM28.2.3-B-2 & 9.10 \\
\hline SRM10.3.3-B-1 & 7.59 & SRM28.2.3-B-3 & 10.69 \\
\hline SRM10.3.4-B-1 & 10.21 & SRM28.1.2-1-B-1 & 8.34 \\
\hline SRM10.4.5-B-1 & 9.45 & SRM28.1.2-1-B-2 & 10.00 \\
\hline SRM10.4.5-B-2 & 10.34 & SRM15.3.4-B-3 & 8.34 \\
\hline SRM13.2.3-B-1 & 6.34 & SRM15.3.4-B-1 & 10.83 \\
\hline SRM13.2.3-B-2 & 7.17 & SRM1.3.3-B-3 & 6.07 \\
\hline SRM13.3.4-B-1 & 10.34 & SRM1.3.3-B-2 & 5.45 \\
\hline SRM13.3.4-B-2 & 10.41 & SRM1.3.3-B-1 & 5.69 \\
\hline SRM13.3.4-B-3 & 8.34 & SRM17.2.3-B-1 & 11.93 \\
\hline SRM15.1.1-B-1 & 7.17 & SRM17.2.3-B-2 & 10.14 \\
\hline SRM15.1.1-B-2 & 10.07 & SRM17.2.3-B-3 & 9.93 \\
\hline SRM15.2.2-B-2 & 8.41 & SRM13.5.7-B-3 & 16.00 \\
\hline SRM15.2.3-B-1 & 7.45 & SRM13.5.7-B-1 & 10.07 \\
\hline SRM16.2.2-B-1 & 11.72 & SRM13.5.7-B-2 & 10.90 \\
\hline SRM16.2.2-B-2 & 8.07 & SRM21.1.2-B-1 & 12.48 \\
\hline SRM22.5.5-B-1 & 11.03 & SRM21.1.2-B-2 & 10.41 \\
\hline SRM22.5.5-B-2 & 14.97 & SRM16.1.1-B-1 & 16.24 \\
\hline SRM25.1.1-B-2 & 7.66 & SRM16.1.1-B-2 & 10.03 \\
\hline SRM25.1.1-B-3 & 11.59 & SRM15.3.4-B-2 & 9.93 \\
\hline SRM26.2.3-B-1 & 6.34 & SRM16.1.1-B-3 & 10.83 \\
\hline SRM27.3.4-B-1 & 9.52 & SRM16.1.1-B-4 & 8.21 \\
\hline SRM27.3.4-B-2 & 9.10 & SRM1.1.1-B-1 & 9.59 \\
\hline SRM28.3.4-B-1 & 5.86 & SRM1.1.1-B-2 & 14.69 \\
\hline SRM29.2.4-B-1 & 9.52 & SRM9.1.1-B-1 & 8.90 \\
\hline SRM29.2.4-B-2 & 9.86 & SRM9.1.1-B-2 & 12.97 \\
\hline
\end{tabular}


Table 5-3. Results of Brazilian disk tension test of Apache Leap tuff (cont'd)

\begin{tabular}{||l|c||c|c||}
\hline Specimen No. & $\begin{array}{c}\text { Failure Stress } \\
(\text { MPa })\end{array}$ & Specimen No. & $\begin{array}{c}\text { Failure Stress } \\
\text { (MPa) }\end{array}$ \\
\hline SRM11.1.1-B-1 & 15.17 & SRM17.3.4-B-1 & 13.45 \\
SRM11.1.1-B-2 & 8.69 & SRM19.1.1-B-1 & 10.76 \\
SRM11.1.2-B-1 & 9.72 & SRM19.1.1-B-2 & 9.10 \\
SRM11.1.2-B-2 & 10.76 & SRM19.1.1-B-3 & 8.97 \\
SRM11.2.3-B-1 & 11.72 & SRM20.1.1-B-1 & 13.52 \\
SRM11.2.3-B-2 & 9.03 & SRM20.1.1-B-2 & 11.03 \\
SRM11.3.4-B-1 & 14.76 & SRM20.1.1-B-3 & 7.86 \\
SRM11.3.4-B-2 & 10.34 & SRM20.2.2-B-1 & 13.52 \\
SRM12.1.1-1-B-1 & 10.28 & SRM20.2.2-B-2 & 11.59 \\
SRM12.1.1-1-B-2 & 12.00 & SRM20.3.3-B-1 & 9.79 \\
SRM12.1.1-2-B-1 & 10.55 & SRM20.4.5-B-1 & 10.21 \\
SRM12.3.3-B-1 & 10.97 & SRM22.1.1-B-1 & 12.96 \\
SRM12.3.3-B-2 & 8.97 & SRM22.1.1-B-2 & 9.72 \\
SRM12.3.3-B-3 & 6.30 & SRM22.2.2-B-1 & 10.34 \\
SRM13.1.2-B-1 & 9.10 & SRM22.2.2-B-2 & 8.48 \\
SRM13.1.2-B-2 & 10.21 & SRM22.3.3-B-1 & 9.72 \\
SRM13.4.5-B-1 & 9.48 & SRM22.3.3-B-2 & 11.24 \\
SRM13.4.5-B-2 & 10.10 & SRM22.4.4-B-1 & 11.59 \\
SRM13.4.6-1-B-1 & 6.65 & SRM22.4.4-B-2 & 15.86 \\
SRM15.3.5-B-1 & 10.99 & SRM23.1.2-B-2 & 11.79 \\
SRM15.3.5-B-2 & 9.66 & SRM23.2.3-B-1 & 9.45 \\
SRM15.4.6-B-1 & 11.93 & SRM25.1.1-B-1 & 11.86 \\
SRM15.4.6-B-2 & 8.76 & SRM26.2.2-B-1 & 10.00 \\
SRM15.5.7-B-1 & 9.95 & SRM26.2.2-B-2 & 12.14 \\
SRM15.5.7-B-2 & 13.03 & SRM26.2.3-B-2 & 8.97 \\
SRM16.3.3-B-1 & 7.79 & SRM28.1.1-B-1 & 10.34 \\
SRM17.1.2-B-1 & 9.45 & SRM28.1.1-B-2 & 11.86 \\
SRM17.1.2-B-2 & 11.03 & SRM29.3.5-B-2 & 8.50 \\
\hline
\end{tabular}



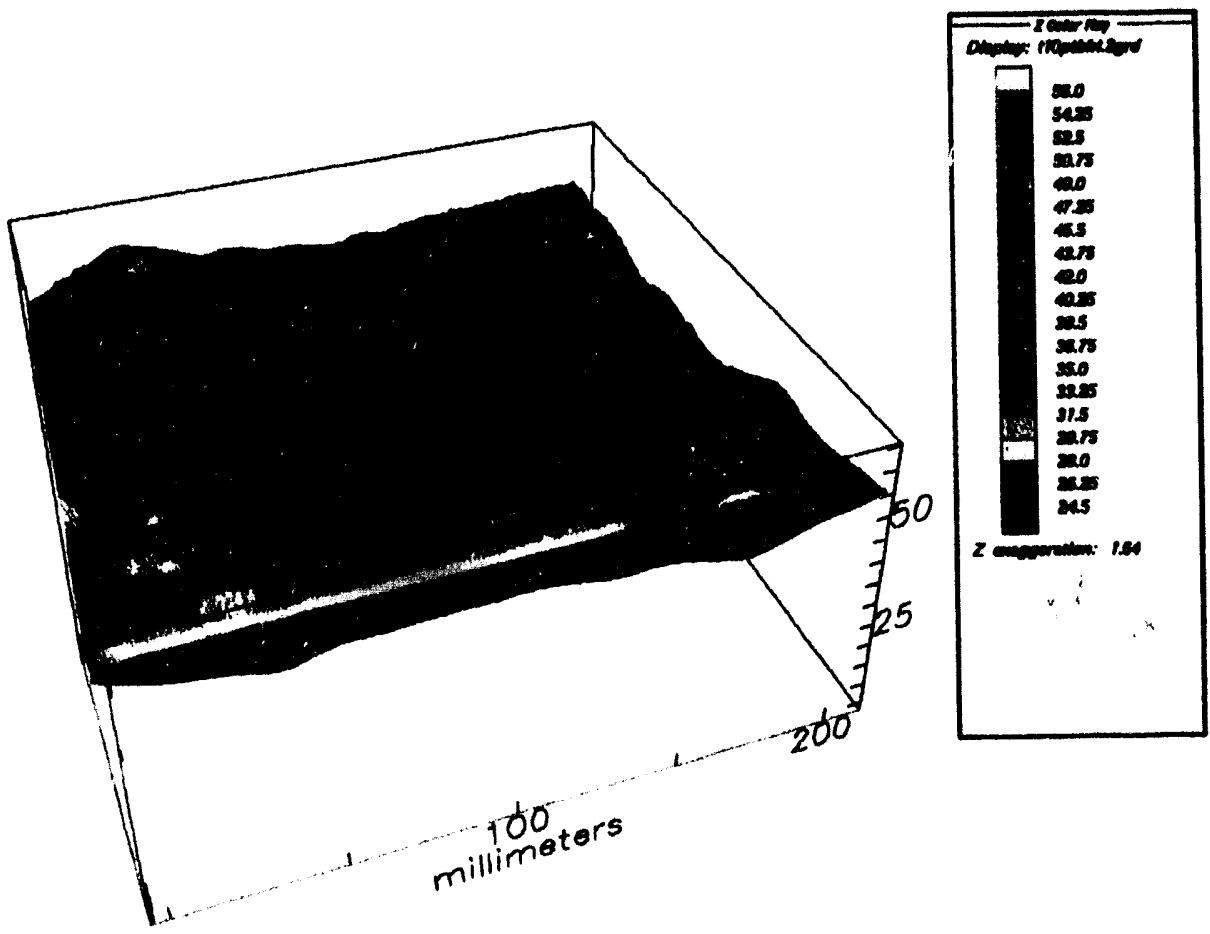

Figure 5-1. Profile of the top block of specimen for test no. 10 (SRM17.2.3/SRM17.2.4) before pseudostatic direct shearing
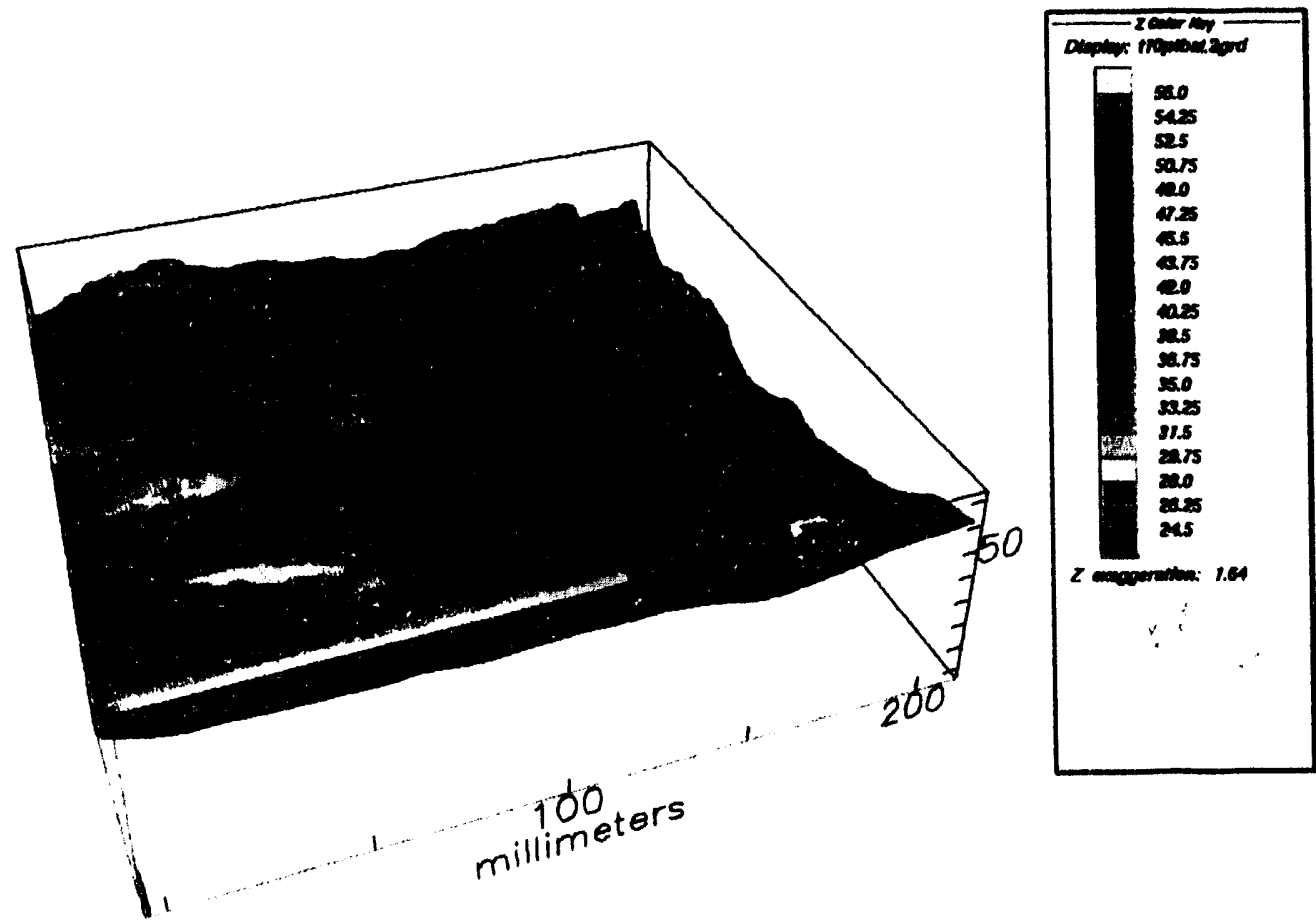

Figure 5-2. Profile of the top block of specimen for test no. 10 (SRM 17.2.3/SRM 17.3.4) after pseudostatic direct shear testing 


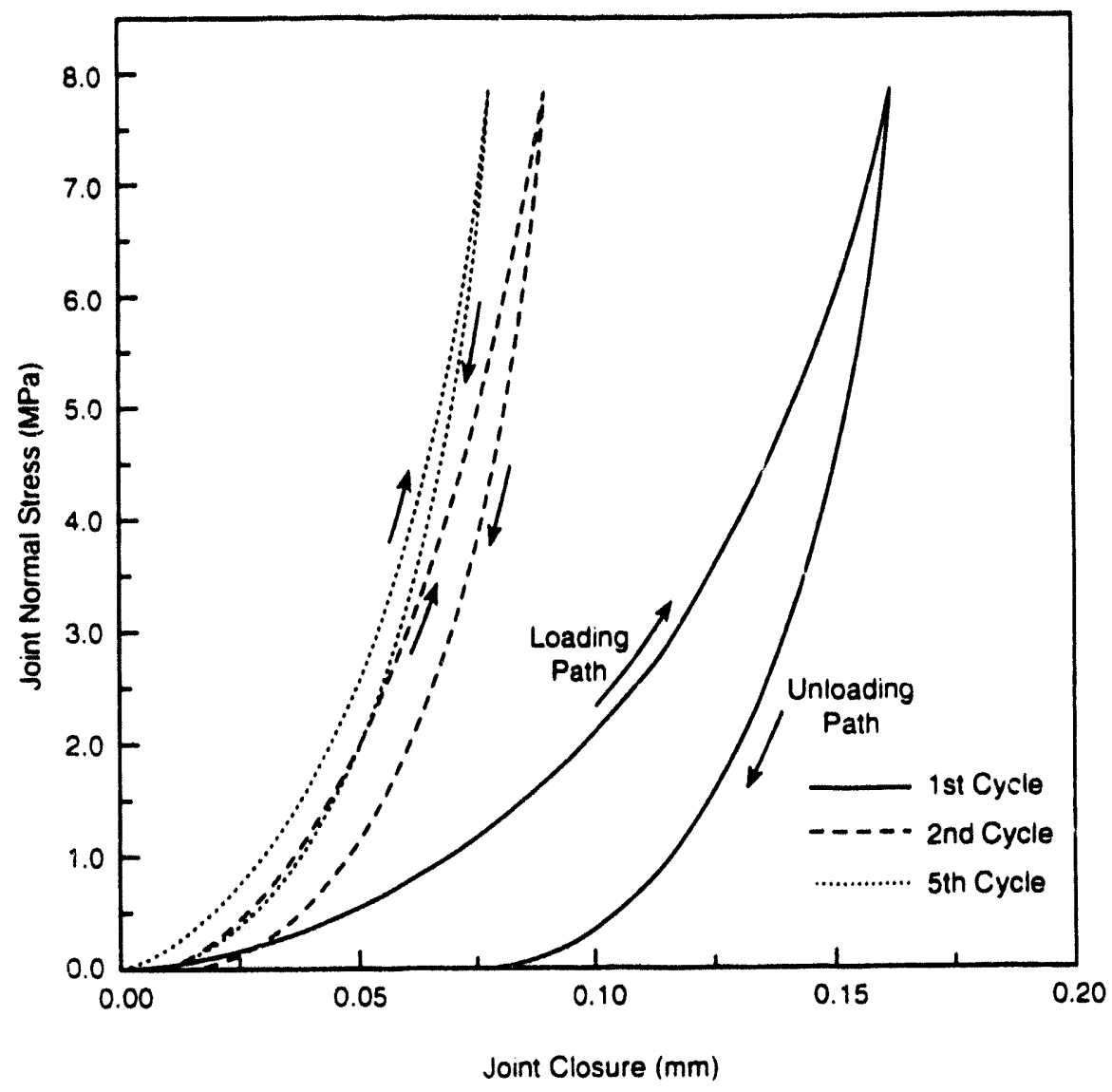

Figure 5-3. Normal stress versus closure relation for the welded tuff joint under repeated normal load cycles (specimen for test no. 2)

Each sample was sheared a distance of $50.8 \mathrm{~mm}$ in one direction over a period of $20 \mathrm{~min}$ followed by a reversal of shearing back to the original starting position over the next $20 \mathrm{~min}$. The next higher normal load was then applied, and the direct shear cycle was repeated. The applied normal loading was held constant during each shear cycle through the use of servocontrolled hydraulic actuators. Relative shear displacements across the joint were measured using an LVDT attached to the rock directly above and below the joint surface.

Figure 5-4 shows the shear deformation response for specimens 7 through 11. Each curve corresponds to the first shear cycle for each of the five specimens, under different applied normal loadings. The five curves show, in general, a distinct peak shear strength, which gradually reduces to a residual value at greater shear displacements. The curves in Figure 5-4 show the stick-slip behavior that occurs during shearing, especially at the higher normal loadings. This stick-slip behavior is due to the momentary reduction in shear stress as individual asperities are sheared. It should be noted that the stick-slip behavior may also be influenced by machine stiffness (Lorig and Hobbs, 1990). Table 5-4 gives the peak shear stress values as well as the shear displacement and applied normal load corresponding to this peak for the first 16 specimens. 


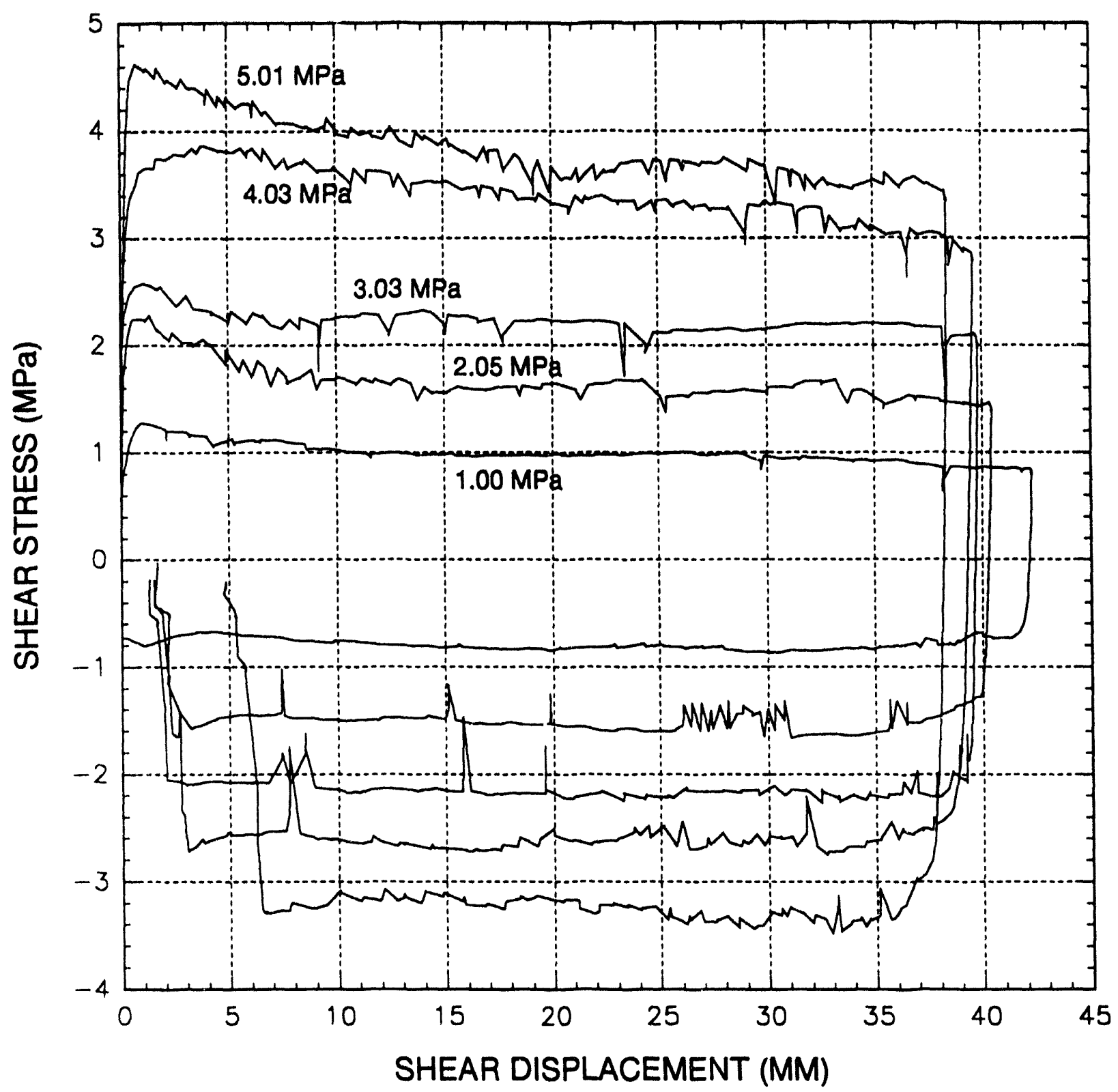

Figure 5-4. Shear stress versus shear displacement response as a function of applied normal stress for test nos. 7 through 11. Each curve represents the first shear cycle on one particular sample. 
Table 5-4. Peak shear data from nrst pseudostatic direct shear cycle for 16 samples

\begin{tabular}{|c|c|c|c|c|}
\hline Test No. & $\begin{array}{l}\text { Specimen } \\
\text { Identification }\end{array}$ & $\begin{array}{l}\text { Peak Shear } \\
\text { Stress (MPa) }\end{array}$ & $\begin{array}{c}\text { Peak Shear } \\
\text { Displacement }(\mathrm{mm})\end{array}$ & $\begin{array}{l}\text { Applied Normal } \\
\text { Stress (MPa) }\end{array}$ \\
\hline 1 & $\begin{array}{l}\text { SRM 25.1.1 } \\
\text { SRM 25.1.2 } \\
\end{array}$ & 0.794 & 1.702 & 0.573 \\
\hline 2 & $\begin{array}{l}\text { SRM } 29.2 .3 \\
\text { SRM 29.2.4 }\end{array}$ & 1.435 & 0.203 & 1.046 \\
\hline 3 & $\begin{array}{l}\text { SRM 28.3.4 } \\
\text { SRM 28.2.3.A } \\
\end{array}$ & 2.008 & 1.308 & 1.971 \\
\hline 4 & $\begin{array}{l}\text { SRM 11.2.3.A } \\
\text { SRM 11.3.4 }\end{array}$ & 2.738 & 7.289 & 3.054 \\
\hline 5 & $\begin{array}{l}\text { SRM 15.5.7 } \\
\text { SRM 15.4.6.(2) }\end{array}$ & 3.795 & 3.962 & 4.037 \\
\hline 6 & $\begin{array}{l}\text { SRM 9.1.1 } \\
\text { SRM } 9.2 .2\end{array}$ & 4.956 & 3.721 & 5.371 \\
\hline 7 & $\begin{array}{l}\text { SRM 16.3.3 } \\
\text { SRM 16.2.2-A }\end{array}$ & 4.625 & 0.737 & 5.014 \\
\hline 8 & $\begin{array}{l}\text { SRM } 12.4 .4 \\
\text { SRM } 12.3 .3 \\
\end{array}$ & 3.863 & 3.937 & 4.031 \\
\hline 9 & $\begin{array}{l}\text { SRM 20.1.1 } \\
\text { SRM 20.2.2 }\end{array}$ & 2.581 & 1.079 & 3.033 \\
\hline 10 & $\begin{array}{l}\text { SRM 17.2.3 } \\
\text { SRM 17.3.4 } \\
\end{array}$ & 2.249 & 0.610 & 2.055 \\
\hline 11 & $\begin{array}{l}\text { SRM 11.2.3 } \\
\text { SRM 11.1.2.A }\end{array}$ & 1.272 & 0.965 & 1.077 \\
\hline 17 & $\begin{array}{l}\text { SRM } 12.4 .5 \\
\text { SRM } 12.4 .4-A \\
\end{array}$ & 1.174 & 0.267 & 1.009 \\
\hline 18 & $\begin{array}{l}\text { SRM 15.3.5-A } \\
\text { SRM 15.4.6-1 } \\
\end{array}$ & 1.976 & 0.254 & 1.965 \\
\hline 19 & $\begin{array}{l}\text { SRM 19.1.3-1 } \\
\text { SRM 19.1.3-2 }\end{array}$ & 2.778 & 2.388 & 2.985 \\
\hline 20 & $\begin{array}{l}\text { SRM } 15.3 .4 \\
\text { SRM } 15.3 .5\end{array}$ & 4.858 & 2.591 & 3.988 \\
\hline 21 & $\begin{array}{l}\text { SRM 11.1.1 } \\
\text { SRM 11.1.2 } \\
\end{array}$ & 5.681 & 1.094 & 5.013 \\
\hline 27 & $\begin{array}{l}\text { SRM 23.1.2 } \\
\text { SRM 23.2.3-A } \\
\end{array}$ & 1.482 & 2.972 & 0.990 \\
\hline 28 & $\begin{array}{l}\text { SRM } 15.3 .4 \\
\text { SRM } 15.3 .5\end{array}$ & N/A & N/A & N/A \\
\hline 29 & $\begin{array}{l}\text { SRM 10.2.2-2 } \\
\text { SRM } 10.2 .2-3\end{array}$ & 4.896 & 2.756 & 4.951 \\
\hline
\end{tabular}


An example of the typical relation between normal displacement (dilation) and shear displacement is given in Figure 5-5 for test no. 7 under an applied normal stress condition of 5.01 MPa. The corresponding shear stress versus shear displacement curve is given in Figure 5-4. The shear stress versus shear displacement curves and normal displacement versus shear displacement curves are given in Appendix A. The joint dilation is seen to increase rapidly during the initial stage of shearing, and begins to level off only after approximately $40 \mathrm{~mm}$ of shear displacement. Upon reversal of shear displacement, there is some degree of hysteresis with the normal displacement returning towards zero from below the forward direction curve. The pseudostatic tests on other jointed tuff specimens exhibited similar behavior. In general, for repeated shear cycles conducted on the same sample, the amount of joint dilation decreased with increasing normal load. However, the amount of joint dilation for any two particular samples tested under the same normal load conditions sometimes varied substantially, depending on the difference in joint roughness between the specimens. The maximum dilation measured for all the specimens was less than $3 \mathrm{~mm}$.

In this study, three specimens were tested under wet conditions. These direct shear tests were conducted to determine if wetting the welded tuff samples had any effect on the ultimate shear strength compared to the dry specimens, due to possible lubricating effects of the moisture on the joint surface. Figure 5-6 shows the test results for the first shear cycle on specimen 29 (SRM10.2.2-2/SRM10.2.2-3) under an applied normal stress of approximately $5 \mathrm{MPa}$. Comparing this curve with that given in Figure 5-4 for specimen 7, which was conducted under dry conditions and the same normal stress, shows that the magnitude of peak shear strength is approximately the same for both conditions. However, the curve for the wet specimen shows a more rounded peak shear strength and less stick-slip behavior throughout the shear cycle. Figure 5-7 shows the corresponding normal displacement versus shear displacement response. This plot shows the normal displacement peak after approximately $25 \mathrm{~mm}$ of shear displacement and subsequent decrease during further forward shear displacement. On the contrary, as shown in Figure 5-5 for the specimen tested under the same normal load and dry conditions, the normal displacement continually increases during the entire forward shear cycle. The reason for this particular behavior is not entirely clear. Further analyses of the joint profiles are necessary to determine if this is a property of the wet versus dry sample condition or the nature of the joint profile itself.

\subsubsection{Parameter Determination for Mohr-Coulomb Joint Model}

The Mohr-Coulomb joint model, as implemented in UDEC (Itasca Consulting Group, Inc., 1992) is a modified version of the Coulomb model (Goodman, 1976). The Coulomb model includes a shear failure criterion for a rock joint and is given by:

$$
\tau=C+\sigma_{n} \tan \phi
$$

where $\tau$ is shear stress along the joint, $\sigma_{n}$ is normal stress across the joint, $C$ is cohesion, and $\phi$ is friction angle. The Mohr-Coulomb joint model available in UDEC also accounts for the normal and shear deformation responses of the joint. The stress displacement relation in the normal direction is approximated by a linear relation:

$$
\Delta \sigma_{n}=K_{n} \Delta u_{n}
$$

where $\Delta \sigma_{n}$ is effective normal stress increment, $\Delta u_{n}$ is increment of normal displacement, and $K_{n}$ is normal stiffness. There is also a limiting tensile strength of the joint. If the tensile stress across the joint 


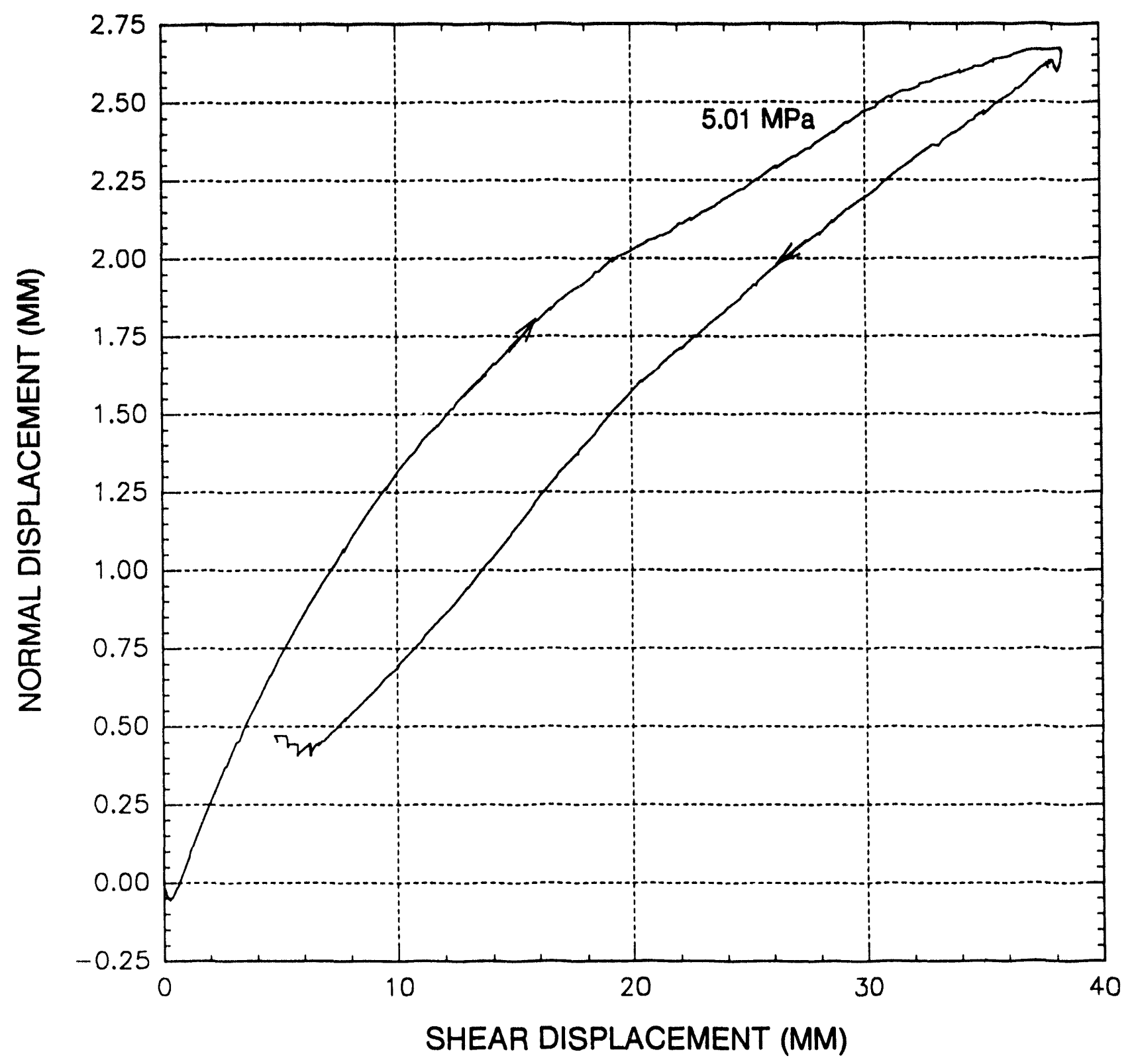

Figure 5-5. Normal displacement (dilation) response for test no. 7 under applied normal stress of $5.01 \mathrm{MPa}$ 


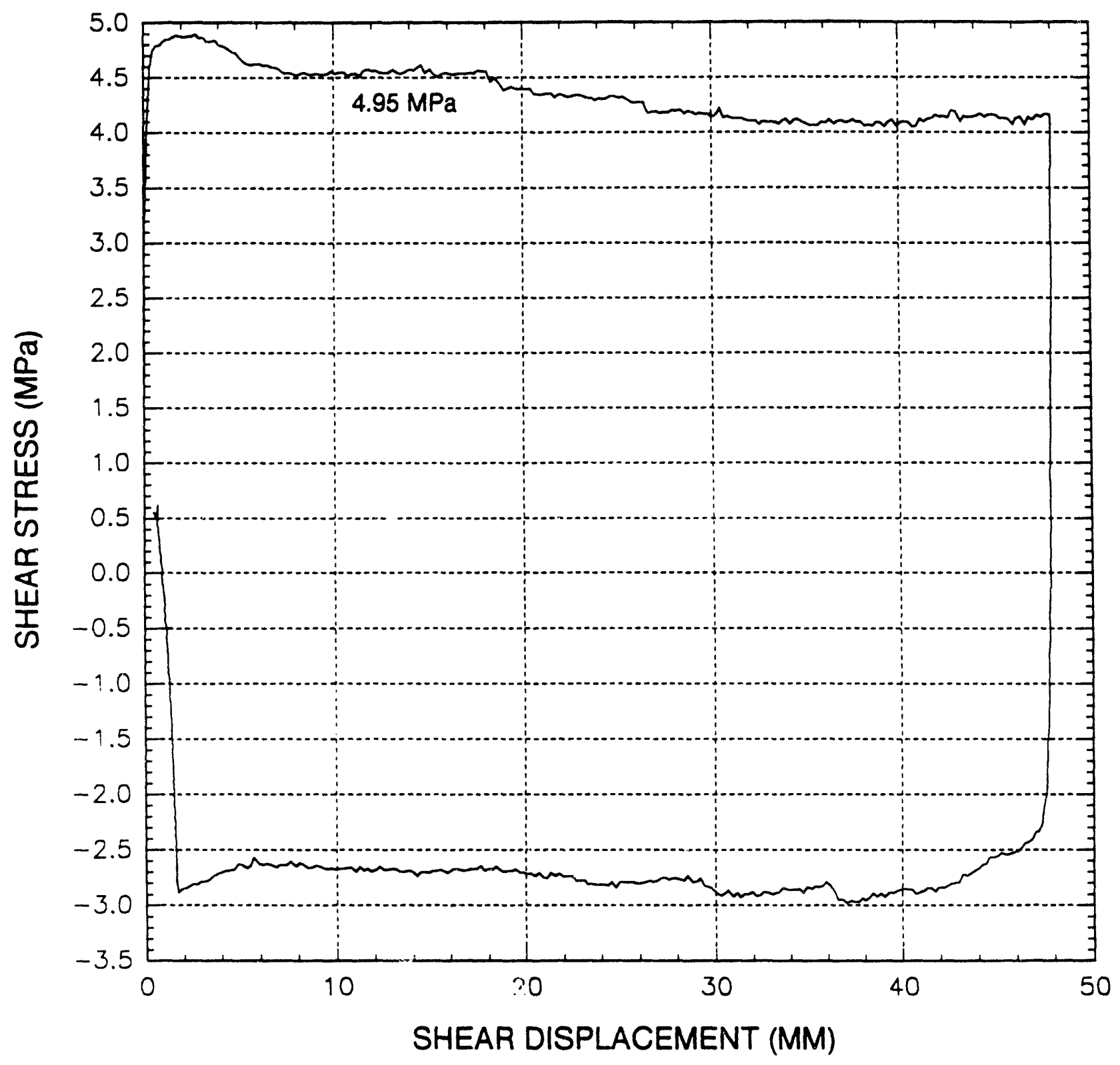

Figure 5-6. Shear stress versus shear displacement response for test no. 29 under applied normal stress of 5.01 MPa and saturated condition 


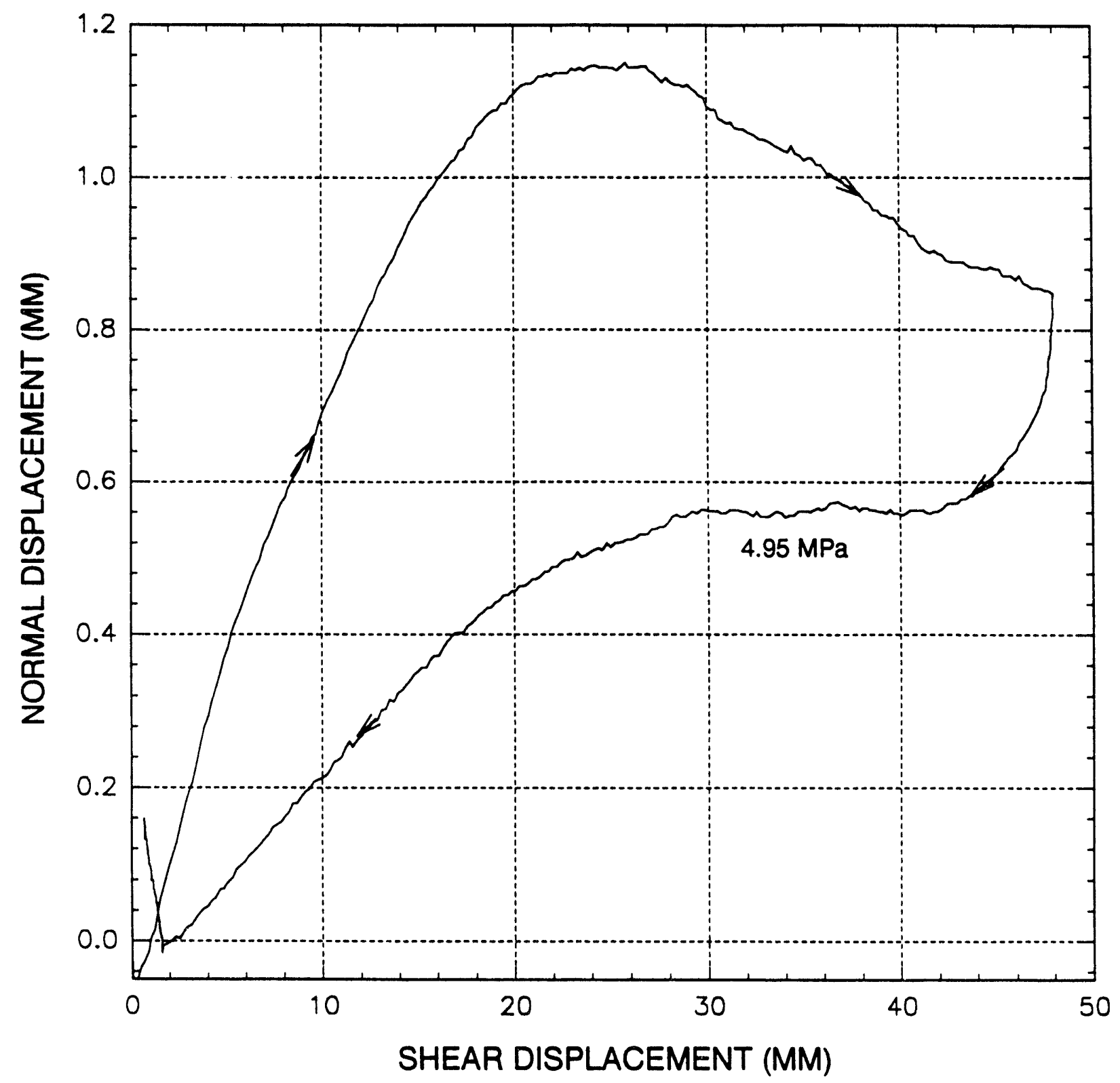

Figure 5-7. Normal displacement (dilation) response for test no. 29 under applied normal stress of 5.01 MPa and saturated condition 
exceeds this value, the joint fails in tension and $\sigma_{n}$ becomes equal to zero. Similarly, the shear response is governed by a constant shear stiffness $K_{s}$ :

$$
\Delta \sigma_{s}=K_{s} \Delta u_{s}^{e}
$$

where $\Delta u_{s}^{e}$ is an elastic component of the incremental shear displacement, and $\Delta \sigma_{s}$ is incremental shear stress.

In UDEC, the dilation is added to the Mohr-Coulomb model and is restricted such that the dilation angle $\psi$ is zero until shear stress has reached the peak (Figure 5-8). Mathematically, the relation is (ITASCA Consulting Group, Inc., 1992):

$$
\text { if }\left|\tau_{s}\right|<\tau_{\max } \text {, then } \psi=0
$$

and

$$
\text { if }\left|\tau_{s}\right|=\tau_{\max } \text { and }\left|u_{s}\right| \geq u_{c s} \text {, then } \Psi=0
$$

where $u_{c s}$ is the critical displacement. The parameters for the Mohr-Coulomb model in UDEC are joint normal stiffness, $K_{n}$, joint shear stiffness, $K_{s}$, joint friction angle, $\phi$, cohesion, $C$, and dilation angle, $\psi$. Although $K_{n}$ and $K_{s}$ are not part of the Coulomb failure criterion, they are necessary to run the UDEC model. Other parameters are set to the default value of zero if no value is specified.

The normal stiffness of the joint surface has been calculated from the experimental data obtained in normal deformation tests in the laboratory. Although the normal stress $\sigma_{n}$ versus normal displacement (closure) $u_{n}$ curve is highly nonlinear, a linear relation has been assumed [Eq. (5-2)]. This linear relation gives a constant normal stiffness $K_{n}$. From the experimental results, two stiffness values have been calculated at the expected normal load:

(i) a global slope of $\sigma_{n}$ versus $u_{n}$ curve (equivalent to secant stiffness)

(ii) a local slope of $\sigma_{n}$ versus $u_{n}$ curve (equivalent to tangent stiffness)

The values are reported in Table 5-5. The normal loading and unloading cycle have been repeated at least five times for each specimen. As mentioned before, there is hysteresis between the loading and unloading portion of the curve. The hysteresis decreases with the number of loading-unloading cycles. Around the fifth cycle, the hysteresis becomes insignificant and the joint can be taken as close to the in situ condition. The stiffness values were determined from the fifth cycle data.

The shear stiffness, $K_{s}$, is the slope of the shear stress $\sigma_{s}$ versus shear displacement, $u_{s}$, curve in the elastic region. The shear stiffness is "highly variable and extremely difficult to predict" (Brady and Brown, 1985). It depends on the disturbance of the discontinuity, testing technique, specimen size, and normal stress (Brady and Brown, 1985). Most numerical models assume a piecewise linear curve with constant, $K_{s}$, in the prepeak region. The curves obtained in the experiments reported here can be classified into two distinct types. Schematic diagrams of these curves are shown in Figure 5-9. Curve A shows a rapid rise in shear stress up to a peak value, followed by an irregular post-peak region. The load-carrying capacity decreases in the post-peak region. Goodman (1976) characterized this type of curve as representative of rough unfilled joints. The shear stress rises gradually in Curve B and the slope is 


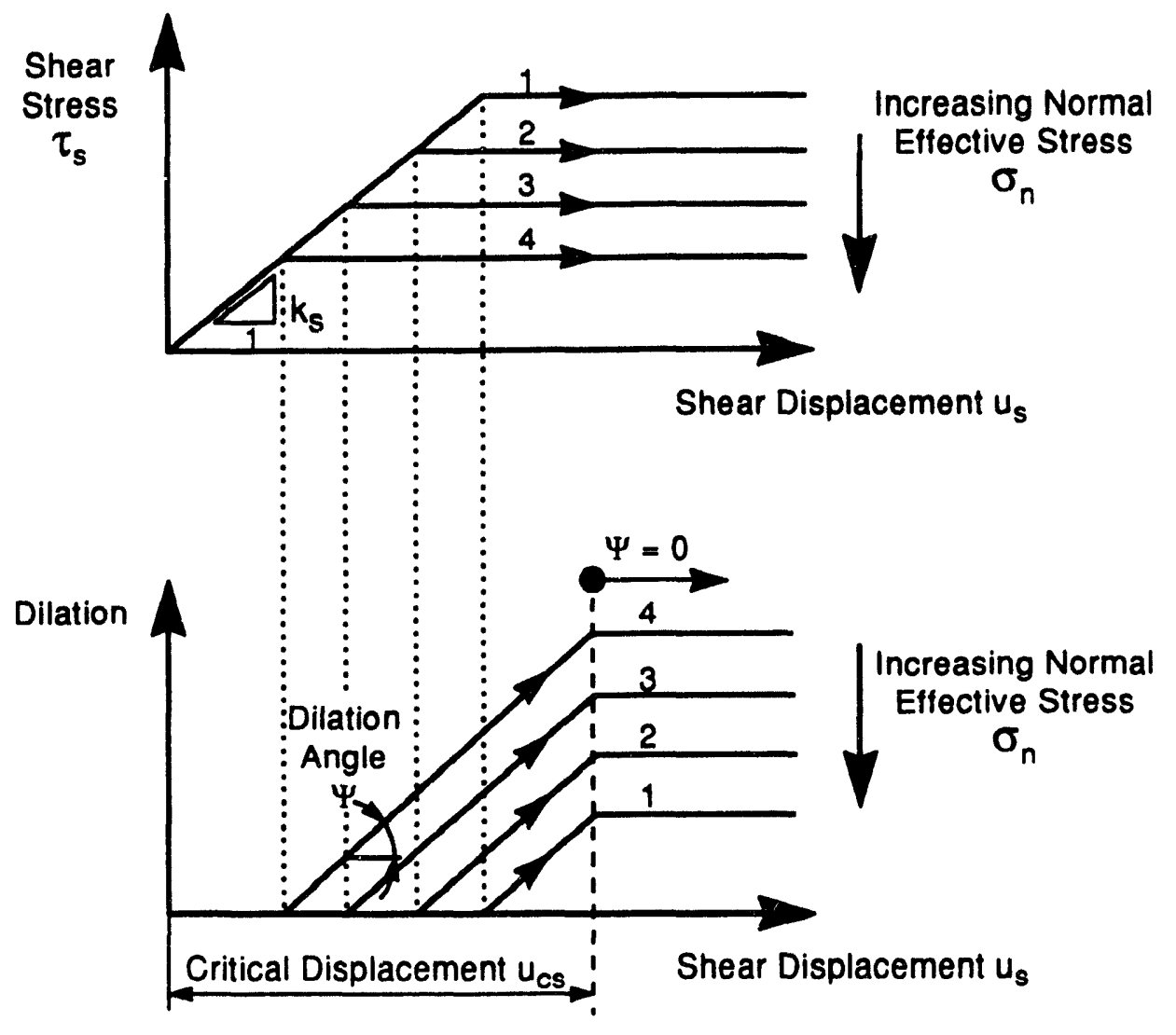

Figure 5-8. Schematic diagram of joint behavior in Mohr-Coulomb model of UDEC (Itasca Consulting Group, Inc., 1992)

convex downward with poorly defined peak stress and continuously changing slope. Goodman (1976) described this type of curve as representative of filled joints. Many of the curves belonging to types A and $B$ show sudden loss of shear stress followed by rapid rise. This sudden change in the curves probably indicates failure of the dominant locked asperities. The surfaces become locked again with further shear displacement.

The shear stiffness, $K_{s}$, is estimated from the experimental, $\sigma_{s}$, versus $u_{s}$ curve obtained in the laboratory for each specimen with each normal stress applied on the specimen. The estimated values are reported in Table 5-6. The estimated values are the global slope of the curve in the elastic region; that is, they are the secant stiffnesses of the joint at the given normal stress.

A typical normal displacement, $u_{n}$, versus shear displacement, $u_{s}$, is shown in Figure 5-5. At first, normal displacements are negative (i.e., the joint closes) as shear displacement increases. Normal displacement reaches a minimum and then returns to zero as shear displacement and joint dilation increase. Thereafter, dilation normal to the joint continues until the direction of shear reverses. Dilation angle, $\psi$, has been calculated as the global slope (secant slope) of the curve between zero dilation and maximum dilation. Table 5-7 lists the dilation angle and the values of all parameters to describe the $u_{n}$ versus $u_{s}$ curves for each shear test at different normal loads. Five parameters were used to represent each curve: 


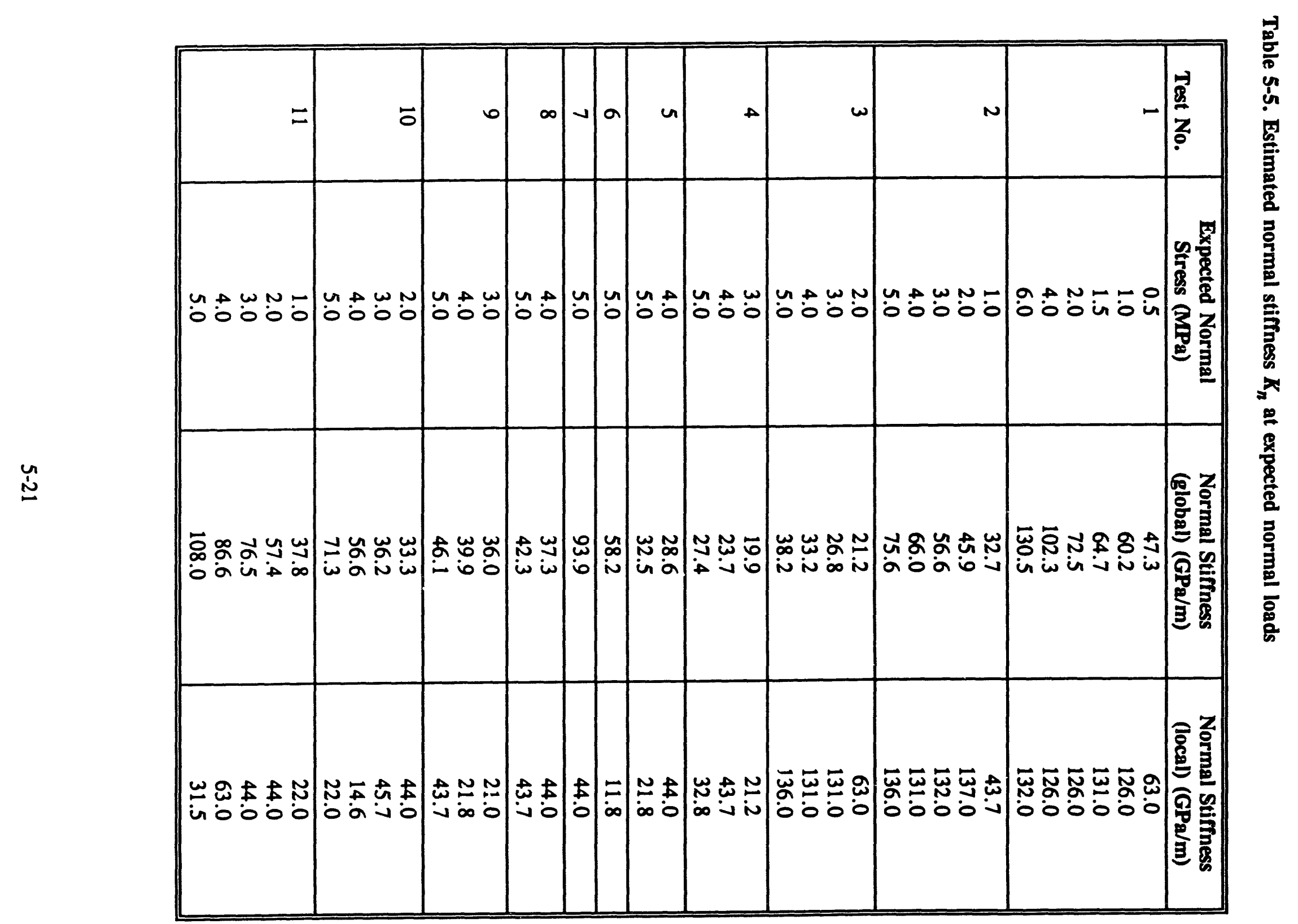


Table 5-5. Estimated normal stiffness $\boldsymbol{K}_{\boldsymbol{n}}$ at expected normal loads (cont'd)

\begin{tabular}{|c|c|c|c|}
\hline \multirow{2}{*}{ Test No. } & $\begin{array}{c}\text { Expected Normal } \\
\text { Stress (MPa) }\end{array}$ & $\begin{array}{c}\text { Normal Stiffness } \\
\text { (global) (GPa/m) }\end{array}$ & $\begin{array}{c}\text { Normal Stiffness } \\
\text { (local) (GPa/m) }\end{array}$ \\
\hline 17 & 1.0 & 21.9 & 44.0 \\
& 2.0 & 36.0 & 44.0 \\
& 3.0 & 51.9 & 44.0 \\
& 4.0 & 81.1 & 44.3 \\
& 5.0 & 68.4 & 44.0 \\
\hline 18 & 2.0 & 18.7 & 66.0 \\
& 3.0 & 23.8 & 63.5 \\
& 4.0 & 28.0 & 44.0 \\
& 5.0 & 32.8 & 63.0 \\
\hline 19 & 3.0 & 40.8 & 44.0 \\
& 4.0 & 49.3 & 44.0 \\
& 5.0 & 54.4 & 44.0 \\
\hline 20 & 4.0 & 25.1 & 46.0 \\
& 5.0 & 29.2 & 44.0 \\
\hline 21 & 5.0 & 27.0 & 44.0 \\
\hline 27 & 1.0 & 11.9 & 10.5 \\
& 2.0 & 16.4 & 25.4 \\
& 3.0 & 21.6 & 14.7 \\
& 4.0 & 24.9 & 42.0 \\
\hline 28 & 5.0 & 28.7 & 44.0 \\
\hline 29 & 3.0 & 17.5 & 18.9 \\
& 4.0 & 19.8 & 14.7 \\
& 5.0 & 22.5 & 21.8 \\
\hline & 5.0 & 24.9 & 63.0 \\
\hline
\end{tabular}

$\begin{array}{ll}u_{\mathrm{ncmax}} & =\text { maximum joint closure } \\ u_{\mathrm{sc}} & =\text { shear displacement at which maximum joint closure occurs } \\ u_{\mathrm{sd}} & =\text { shear displacement at which dilation starts } \\ u_{\mathrm{nmax}} & =\text { peak dilation } \\ u_{\mathrm{sdmax}} & =\text { shear displacement at peak dilation }\end{array}$

These parameters are also shown in Figure 5-10.

Cohesion, $C$, and friction angle, $\phi$, represent the strength of the rock joint. Hoek and Bray (1981) have defined the shear strength of a rock joint as peak and residual corresponding to the peak and residual regions of the shear stress versus shear displacement curve (Figure 5-11). The Coulomb law for peak shear strength is represented by a straight line in peak shear stress, $\tau_{p}$, versus normal stress, $\sigma_{n}$, space. The slope of the straight line is $\tan \phi_{p}$ and the intercept is the peak cohesion, $C_{p}$. Here $\phi_{p}$ is the peak friction angle. Plotting the residual shear strength, $\tau_{r}$, against the normal stress, $\sigma_{n}$, also gives a straight line. The slope of the line is $\tan \phi_{r}$, where $\phi_{r}$ is the residual friction angle. Hoek and Bray (1981) 


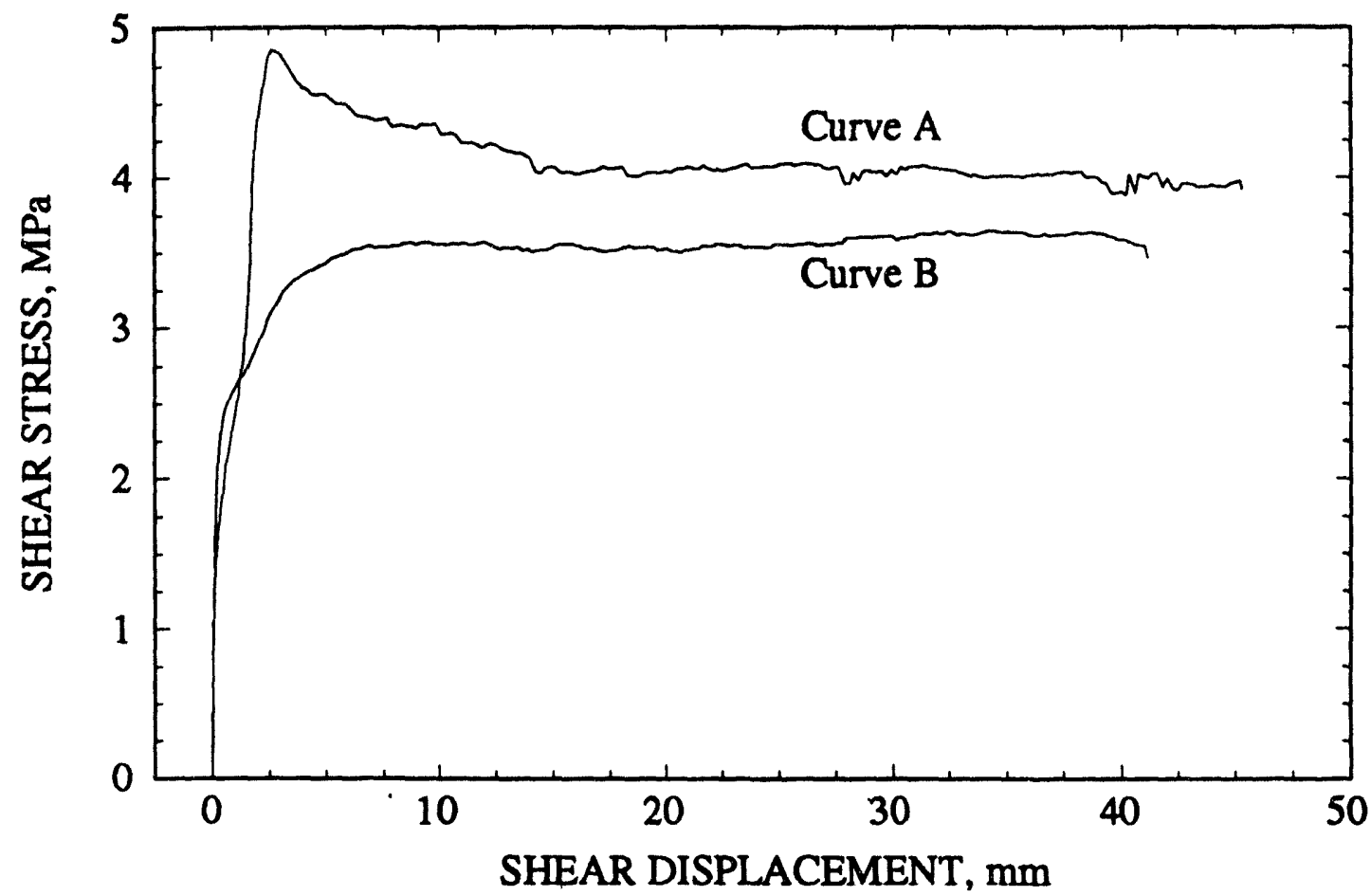

Figure 5-9. Two types of shear stress versus shear displacement curve at constant confining pressure of $4.0 \mathrm{MPa}$

have reported that the intercept of the line becomes extremely small, indicating that all cohesive strength of the cementing material $C_{r}$ has been lost.

As discussed before, the peak behavior (in a type A curve shown in Figure 5-9) is seen only when the joint is fresh. Therefore, only one measurement result is available from each specimen and is shown in Table 5-8. These results were combined to estimate the average peak shear strength of the rock joints:

$$
\tau_{p}=(0.34 \pm 0.34)+(0.88 \pm 0.11) \sigma_{n}
$$

with coefficient of determination $R^{2}$ equal to 0.95 . The estimated value of $\phi_{p}$ is $41.3^{\circ}$ and the 95 -percent confidence intervals are $37.6^{\circ}$ and $44.7^{\circ}$. In many shear stress experiments, several different normal stresses were applied on the specimens. As a result, $C_{r}$ and $\phi_{r}$ can be estimated for each specimen if more than one normal stress has been used. The 95-percent confidence levels for the estimated parameters are also calculated. The 95-percent confidence interval is the standard error of estimate multiplied by Student's $t$ value with $(N-2)$ degrees of freedom where $N$ is the number of data points. As a result, it requires more than two data points to calculate the 95-percent confidence interval. The interval is reported only if more than two data points were available for curve fitting. It should be recognized that the number of data points available for each specimen is extremely small. The maximum number of data points available is six. This small number does not give a good constraint on fixing the failure envelope in $\tau_{r}$ versus $\sigma_{n}$ space. Large Student's $t$ values are the result of lack of sufficient number of data points. A small number of data points can produce a negative value of cohesion while fitting a straight line, which is physically impossible. Therefore, the line has been forced through the origin, indicating zero cohesion. 
Table 5-6. Estimated shear stiffness, $\boldsymbol{K}_{s}$, at expected normal loads

\begin{tabular}{|c|c|c|}
\hline Test No. & $\begin{array}{l}\text { Normal Stress } \\
(\mathrm{MPa})\end{array}$ & $\begin{array}{c}K_{s} \text { at Expected Normal Stress } \\
(\mathbf{G P a} / \mathrm{m})\end{array}$ \\
\hline 1 & $\begin{array}{l}0.5 \\
1.0 \\
1.5 \\
2.0 \\
4.0 \\
6.0\end{array}$ & $\begin{array}{l}0.47 \\
0.63 \\
3.17 \\
3.14 \\
4.82 \\
7.75\end{array}$ \\
\hline 2 & $\begin{array}{l}1.0 \\
2.0 \\
3.0 \\
4.0 \\
5.0 \\
\end{array}$ & $\begin{array}{l}7.29 \\
2.70 \\
5.33 \\
7.15 \\
8.61 \\
\end{array}$ \\
\hline 3 & $\begin{array}{l}2.0 \\
3.0 \\
4.0 \\
5.0\end{array}$ & $\begin{array}{r}1.81 \\
7.55 \\
9.25 \\
10.93\end{array}$ \\
\hline 4 & $\begin{array}{l}3.0 \\
4.0 \\
5.0 \\
\end{array}$ & $\begin{array}{l}1.25 \\
5.33 \\
9.92 \\
\end{array}$ \\
\hline 5 & $\begin{array}{l}4.0 \\
5.0\end{array}$ & $\begin{array}{l}1.81 \\
6.14\end{array}$ \\
\hline 6 & 5.0 & 7.17 \\
\hline 7 & 5.0 & 16.98 \\
\hline 8 & $\begin{array}{l}4.0 \\
5.0\end{array}$ & $\begin{array}{l}11.75 \\
11.60\end{array}$ \\
\hline 9 & $\begin{array}{l}3.0 \\
4.0 \\
5.0 \\
\end{array}$ & $\begin{array}{l}16.93 \\
13.88 \\
13.28 \\
\end{array}$ \\
\hline 10 & $\begin{array}{l}2.0 \\
3.0 \\
4.0 \\
5.0 \\
\end{array}$ & $\begin{array}{l}8.64 \\
9.48 \\
9.50 \\
9.51 \\
\end{array}$ \\
\hline 11 & $\begin{array}{l}1.0 \\
2.0 \\
3.0 \\
4.0 \\
5.0 \\
\end{array}$ & $\begin{array}{r}5.46 \\
2.30 \\
10.39 \\
25.53 \\
12.43\end{array}$ \\
\hline
\end{tabular}


Table 5-6. Estimated shear stiffness, $\boldsymbol{K}_{s}$, at expected normal loads (cont'd)

\begin{tabular}{|c|c|c|}
\hline \multirow{2}{*}{ Test No. } & $\begin{array}{c}\text { Normal Stress } \\
(\mathbf{M P a})\end{array}$ & $\begin{array}{c}\boldsymbol{K}_{s} \text { at Expected Normal Stress } \\
(\mathbf{G P a} / \mathbf{m})\end{array}$ \\
\hline 17 & 1.0 & 16.65 \\
& 2.0 & 5.86 \\
& 3.0 & 9.18 \\
& 4.0 & 25.53 \\
& 5.0 & 10.14 \\
\hline 18 & 2.0 & 15.49 \\
& 3.0 & 6.0 \\
& 4.0 & 10.94 \\
& 5.0 & 13.87 \\
\hline 19 & 3.0 & 10.5 \\
& 4.0 & 9.03 \\
& 5.0 & 10.14 \\
\hline 20 & 4.0 & 2.05 \\
& 5.0 & 16.19 \\
\hline 21 & 5.0 & 23.32 \\
\hline 27 & 1.0 & 1.31 \\
& 2.0 & 5.79 \\
& 3.0 & 7.49 \\
& 4.0 & 10.04 \\
& 5.0 & 12.37 \\
\hline 28 & 3.0 & 2.91 \\
& 4.0 & 11.85 \\
& 5.0 & 8.09 \\
\hline 29 & 5.0 & 23.14 \\
\hline & & \\
\hline
\end{tabular}

Again, combining data from all shear tests, the average residual shear strength envelope of the rock joints is:

$$
\tau_{r}=(0.20 \pm 0.25)+(0.80 \pm 0.06) \sigma_{n}
$$

with an $\mathrm{R}^{2}$ value of 0.90 . The estimated value of $\phi_{r}$ is $38.7^{\circ}$ and the 95 -percent confidence intervals are $36.5^{\circ}$ and $40.7^{\circ}$. Results given in Table 5-8 show that the residual cohesions for Apache Leap tuff joints are almost insignificant. These results are consistent with the observation of Hoek and Bray (1981).

\subsubsection{Parameter Determination for Barton-Bandis Joint Model}

The joint behavior model proposed by Barton and Bandis (1982) encompasses two major parts: the description of joint normal closure behavior and the joint shear behavior. The joint normal stress-displacement path is provided in Eq. (5-8). The initial normal stiffness $\left(K_{n i}\right)$ and maximum 
Table 5-7. Estimated values of dilation angle, $\psi$, with other parameters to describe the $u_{n}$ versus $u_{s}$ curves

\begin{tabular}{|c|c|c|c|c|c|c|c|}
\hline $\begin{array}{c}\text { Shear } \\
\text { Test }\end{array}$ & $\begin{array}{c}\text { Normal } \\
\text { Stress } \\
\text { (MPa) } \\
\end{array}$ & $\begin{array}{c}u_{\text {ncmax }} \\
(\mathbf{m m})\end{array}$ & $\begin{array}{r}u_{s c} \\
(\mathrm{~mm})\end{array}$ & $\begin{array}{c}u_{\mathrm{sd}} \\
(\mathrm{mm})\end{array}$ & $\begin{array}{c}\text { Peak } \\
\text { Dilation } \\
u_{\text {nmax }}(\mathbf{m m}) \\
\end{array}$ & $\begin{array}{l}\text { Shear Disp. } \\
\text { at Peak } \\
\text { Dilation } \\
u_{\text {sdmax }}(\mathrm{mm})\end{array}$ & $\begin{array}{l}\text { Dilation } \\
\text { Angle, } \psi \\
\text { (degree) } \\
\end{array}$ \\
\hline 1 & $\begin{array}{l}0.5 \\
1.0 \\
1.5 \\
2.0 \\
4.0 \\
6.0\end{array}$ & $\begin{array}{l}0.029 \\
0.226 \\
0.174 \\
0.111 \\
0.125 \\
0.056\end{array}$ & $\begin{array}{l}0.241 \\
3.759 \\
2.629 \\
0.800 \\
1.105 \\
1.346\end{array}$ & $\begin{array}{r}0.490 \\
11.892 \\
7.917 \\
6.393 \\
8.865 \\
7.099\end{array}$ & $\begin{array}{l}1.257 \\
0.147 \\
0.335 \\
0.259 \\
0.203 \\
0.195\end{array}$ & $\begin{array}{r}0.641 \\
19.406 \\
31.572 \\
22.644 \\
19.075 \\
28.321\end{array}$ & $\begin{array}{l}8.7 \\
1.1 \\
0.8 \\
0.9 \\
1.1 \\
0.5\end{array}$ \\
\hline 2 & $\begin{array}{l}1.0 \\
2.0 \\
3.0 \\
4.0 \\
5.0\end{array}$ & $\begin{array}{l}0.009 \\
0.107 \\
0.067 \\
0.041 \\
0.054 \\
\end{array}$ & $\begin{array}{l}0.051 \\
1.372 \\
1.359 \\
1.562 \\
1.588 \\
\end{array}$ & $\begin{array}{l}0.144 \\
3.167 \\
3.632 \\
3.856 \\
5.237 \\
\end{array}$ & $\begin{array}{l}1.449 \\
1.495 \\
1.497 \\
1.507 \\
1.481 \\
\end{array}$ & $\begin{array}{r}8.420 \\
23.139 \\
33.401 \\
41.084 \\
39.497 \\
\end{array}$ & $\begin{array}{l}9.9 \\
4.3 \\
2.9 \\
2.3 \\
2.5\end{array}$ \\
\hline 3 & $\begin{array}{l}2.0 \\
3.0 \\
4.0 \\
5.0\end{array}$ & $\begin{array}{l}0.043 \\
0.000 \\
0.181 \\
0.048 \\
\end{array}$ & $\begin{array}{l}0.559 \\
0.000 \\
2.756 \\
2.705 \\
\end{array}$ & $\begin{array}{l}0.926 \\
0.000 \\
7.160 \\
5.768\end{array}$ & $\begin{array}{l}2.332 \\
1.549 \\
0.884 \\
2.004 \\
\end{array}$ & $\begin{array}{l}38.722 \\
29.096 \\
34.620 \\
39.294 \\
\end{array}$ & $\begin{array}{l}3.5 \\
3.0 \\
1.8 \\
3.4\end{array}$ \\
\hline 4 & $\begin{array}{l}3.0 \\
4.0 \\
5.0 \\
\end{array}$ & $\begin{array}{l}0.190 \\
0.173 \\
0.141 \\
\end{array}$ & $\begin{array}{l}1.842 \\
2.464 \\
3.023 \\
\end{array}$ & $\begin{array}{l}4.417 \\
8.148 \\
9.037 \\
\end{array}$ & $\begin{array}{l}2.215 \\
1.633 \\
0.224\end{array}$ & $\begin{array}{l}42.354 \\
39.573 \\
14.834 \\
\end{array}$ & $\begin{array}{l}3.0 \\
3.0 \\
2.2\end{array}$ \\
\hline 5 & $\begin{array}{l}4.0 \\
5.0 \\
\end{array}$ & $\begin{array}{l}0.251 \\
0.143 \\
\end{array}$ & $\begin{array}{l}2.134 \\
1.740 \\
\end{array}$ & $\begin{array}{l}4.750 \\
6.676 \\
\end{array}$ & $\begin{array}{l}1.263 \\
0.824 \\
\end{array}$ & $\begin{array}{l}35.141 \\
38.430 \\
\end{array}$ & $\begin{array}{l}2.4 \\
1.5 \\
\end{array}$ \\
\hline 6 & 5.0 & 0.064 & 1.283 & 2.591 & 2.634 & 40.284 & 4.0 \\
\hline 7 & 5.0 & 0.057 & 0.267 & 0.686 & 2.669 & 37.249 & 4.1 \\
\hline 8 & $\begin{array}{l}4.0 \\
5.0 \\
\end{array}$ & $\begin{array}{l}0.000 \\
0.017 \\
\end{array}$ & $\begin{array}{l}0.000 \\
0.330 \\
\end{array}$ & $\begin{array}{l}0.000 \\
1.143 \\
\end{array}$ & $\begin{array}{l}2.771 \\
1.938 \\
\end{array}$ & $\begin{array}{l}37.986 \\
36.627 \\
\end{array}$ & $\begin{array}{l}4.2 \\
3.0 \\
\end{array}$ \\
\hline 9 & $\begin{array}{l}3.0 \\
4.0 \\
5.0 \\
\end{array}$ & $\begin{array}{l}0.000 \\
0.038 \\
0.084 \\
\end{array}$ & $\begin{array}{l}0.000 \\
0.444 \\
1.105 \\
\end{array}$ & $\begin{array}{l}0.000 \\
1.913 \\
5.773 \\
\end{array}$ & $\begin{array}{l}1.611 \\
1.006 \\
0.744 \\
\end{array}$ & $\begin{array}{l}38.151 \\
37.846 \\
37.490 \\
\end{array}$ & $\begin{array}{l}2.4 \\
1.6 \\
1.3 \\
\end{array}$ \\
\hline 10 & $\begin{array}{l}2.0 \\
3.0 \\
4.0 \\
5.0\end{array}$ & $\begin{array}{l}0.022 \\
0.077 \\
0.130 \\
0.312\end{array}$ & $\begin{array}{l}0.102 \\
1.168 \\
4.089 \\
5.410\end{array}$ & $\begin{array}{r}0.202 \\
3.920 \\
11.151 \\
29.379\end{array}$ & $\begin{array}{l}1.918 \\
1.030 \\
0.574 \\
0.141\end{array}$ & $\begin{array}{l}40.322 \\
38.113 \\
36.982 \\
36.957\end{array}$ & $\begin{array}{l}2.7 \\
1.7 \\
1.3 \\
1.1\end{array}$ \\
\hline
\end{tabular}


Table 5-7. Estimated values of dilation angle, $\psi$, with other parameters to describe the $u_{n}$ versus $u_{s}$ curves (cont'd)

\begin{tabular}{|c|c|c|c|c|c|c|c|}
\hline $\begin{array}{c}\text { Shear } \\
\text { Test }\end{array}$ & $\begin{array}{c}\text { Normal } \\
\text { Stress } \\
\text { (MPa) } \\
\end{array}$ & $\begin{array}{c}u_{\text {ncmax }} \\
(\mathbf{m m})\end{array}$ & $\begin{array}{c}u_{s c} \\
(\mathrm{~mm})\end{array}$ & $\begin{array}{c}u_{\mathrm{sd}} \\
(\mathrm{mm})\end{array}$ & $\begin{array}{c}\text { Peak } \\
\text { Dilation } \\
\boldsymbol{u}_{\operatorname{mmax}}(\mathbf{m m}) \\
\end{array}$ & $\begin{array}{l}\text { Shear Disp. } \\
\text { at Peak } \\
\text { Dllation } \\
u_{\text {sdmax }}(\mathbf{m m})\end{array}$ & $\begin{array}{c}\text { Dilation } \\
\text { Angle, } \psi \\
\text { (degree) } \\
\end{array}$ \\
\hline 11 & $\begin{array}{l}1.0 \\
2.0 \\
3.0 \\
4.0 \\
5.0\end{array}$ & $\begin{array}{l}0.000 \\
0.116 \\
0.046 \\
0.047 \\
0.213 \\
\end{array}$ & $\begin{array}{l}0.000 \\
1.753 \\
1.638 \\
1.753 \\
4.750 \\
\end{array}$ & $\begin{array}{r}0.000 \\
4.127 \\
2.957 \\
4.152 \\
21.311 \\
\end{array}$ & $\begin{array}{l}1.846 \\
0.966 \\
0.732 \\
0.484 \\
0.212 \\
\end{array}$ & $\begin{array}{l}37.008 \\
42.837 \\
39.903 \\
34.798 \\
38.062 \\
\end{array}$ & $\begin{array}{l}2.9 \\
1.4 \\
1.1 \\
0.9 \\
0.7\end{array}$ \\
\hline 17 & $\begin{array}{l}1.0 \\
2.0 \\
3.0 \\
4.0 \\
5.0\end{array}$ & $\begin{array}{l}0.000 \\
0.028 \\
0.065 \\
0.105 \\
0.125\end{array}$ & $\begin{array}{l}0.000 \\
0.127 \\
0.737 \\
2.134 \\
2.235\end{array}$ & $\begin{array}{r}0.000 \\
1.047 \\
3.002 \\
7.509 \\
10.389 \\
\end{array}$ & $\begin{array}{l}2.793 \\
2.176 \\
1.803 \\
1.450 \\
1.167 \\
\end{array}$ & $\begin{array}{l}44.641 \\
43.840 \\
42.418 \\
40.919 \\
39.535 \\
\end{array}$ & $\begin{array}{l}3.6 \\
2.9 \\
2.6 \\
2.5 \\
2.3 \\
\end{array}$ \\
\hline 18 & $\begin{array}{l}2.0 \\
3.0 \\
4.0 \\
5.0 \\
\end{array}$ & $\begin{array}{l}0.000 \\
0.076 \\
0.071 \\
0.088 \\
\end{array}$ & $\begin{array}{l}0.000 \\
0.635 \\
0.686 \\
1.600 \\
\end{array}$ & $\begin{array}{l}0.000 \\
2.846 \\
3.490 \\
5.169 \\
\end{array}$ & $\begin{array}{l}2.872 \\
2.115 \\
1.714 \\
1.414 \\
\end{array}$ & $\begin{array}{l}38.468 \\
42.240 \\
39.903 \\
38.710 \\
\end{array}$ & $\begin{array}{l}4.3 \\
3.1 \\
2.7 \\
2.4\end{array}$ \\
\hline 19 & $\begin{array}{l}3.0 \\
4.0 \\
5.0 \\
\end{array}$ & $\begin{array}{l}0.011 \\
0.067 \\
0.093 \\
\end{array}$ & $\begin{array}{l}0.114 \\
1.143 \\
3.010 \\
\end{array}$ & $\begin{array}{r}0.444 \\
4.115 \\
11.655 \\
\end{array}$ & $\begin{array}{l}1.743 \\
1.059 \\
0.501 \\
\end{array}$ & $\begin{array}{l}25.794 \\
42.735 \\
43.218 \\
\end{array}$ & $\begin{array}{l}3.9 \\
1.6 \\
0.9 \\
\end{array}$ \\
\hline 20 & $\begin{array}{l}4.0 \\
5.0 \\
\end{array}$ & $\begin{array}{l}0.345 \\
0.038 \\
\end{array}$ & $\begin{array}{l}1.714 \\
0.241 \\
\end{array}$ & $\begin{array}{l}3.849 \\
1.909 \\
\end{array}$ & $\begin{array}{l}3.117 \\
2.185 \\
\end{array}$ & $\begin{array}{r}45.187 \\
46.418 \\
\end{array}$ & $\begin{array}{l}4.3 \\
2.8 \\
\end{array}$ \\
\hline 21 & 5.0 & 0.787 & 0.089 & 3.653 & 2.415 & 47.307 & 3.2 \\
\hline 27 & $\begin{array}{l}1.0 \\
2.0 \\
3.0 \\
4.0 \\
5.0 \\
\end{array}$ & $\begin{array}{l}0.154 \\
0.269 \\
0.282 \\
0.417 \\
0.521 \\
\end{array}$ & $\begin{array}{r}0.787 \\
2.946 \\
4.966 \\
19.228 \\
21.514 \\
\end{array}$ & $\begin{array}{c}1.996 \\
11.621 \\
29.801 \\
-- \\
-- \\
\end{array}$ & $\begin{array}{c}2.670 \\
0.617 \\
0.170 \\
\text { No dilation } \\
\text { No dilation } \\
\end{array}$ & $\begin{array}{c}25.298 \\
30.594 \\
48.044 \\
-- \\
-- \\
\end{array}$ & $\begin{array}{c}6.5 \\
1.9 \\
0.5 \\
-- \\
-- \\
\end{array}$ \\
\hline 28 & $\begin{array}{l}3.0 \\
4.0 \\
5.0 \\
\end{array}$ & $\begin{array}{l}0.000 \\
0.116 \\
0.379 \\
\end{array}$ & $\begin{array}{r}0.000 \\
1.930 \\
10.338 \\
\end{array}$ & $\begin{array}{r}0.000 \\
17.847 \\
42.253 \\
\end{array}$ & $\begin{array}{l}0.828 \\
0.414 \\
0.036 \\
\end{array}$ & $\begin{array}{l}30.963 \\
46.088 \\
46.698 \\
\end{array}$ & $\begin{array}{l}1.5 \\
0.8 \\
0.5 \\
\end{array}$ \\
\hline 29 & 5.0 & 0.053 & 0.267 & 0.966 & 1.151 & 25.806 & 2.7 \\
\hline
\end{tabular}




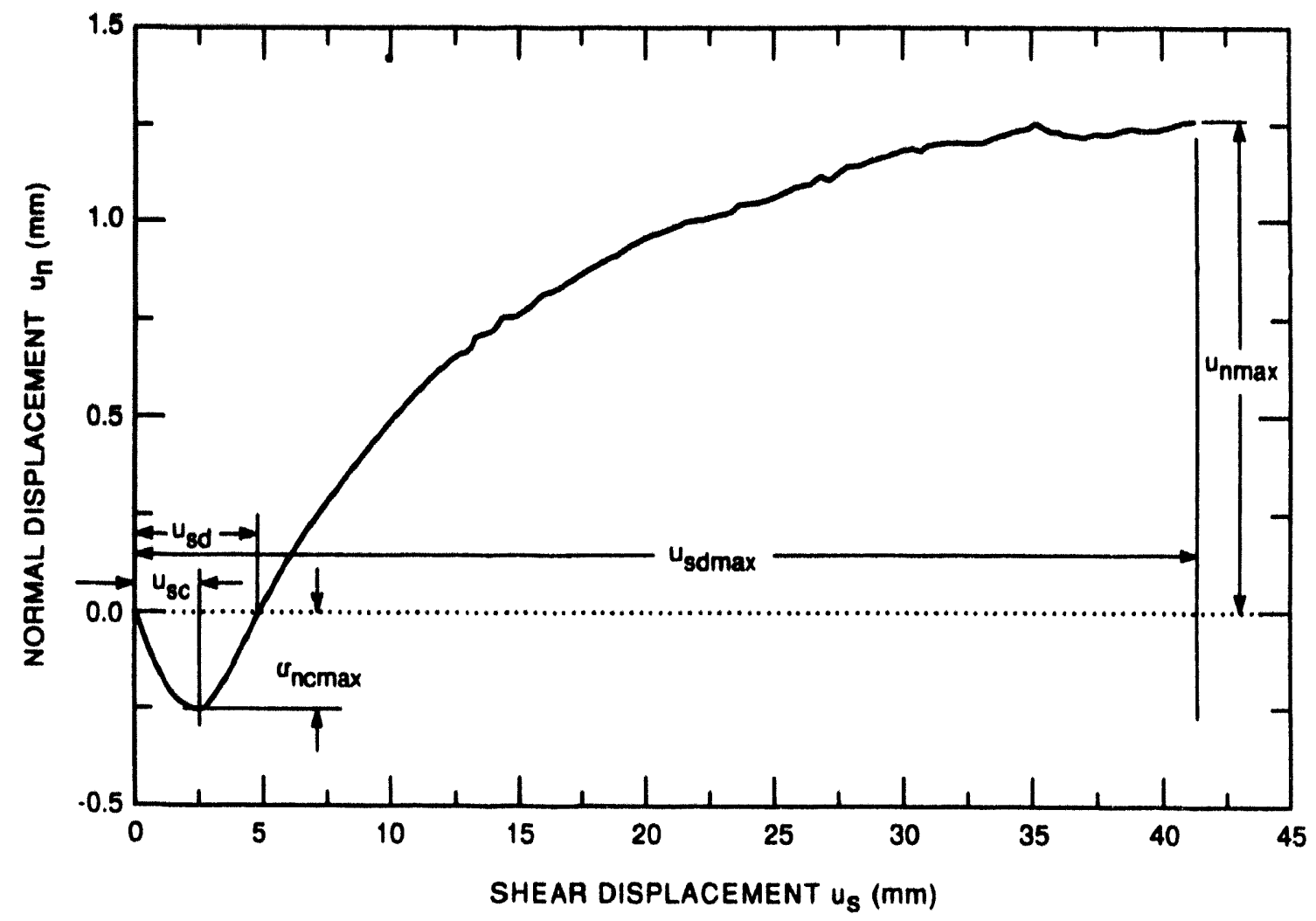

Figure 5-10. Normal displacement versus shear displacement curve with various parameters used to describe it

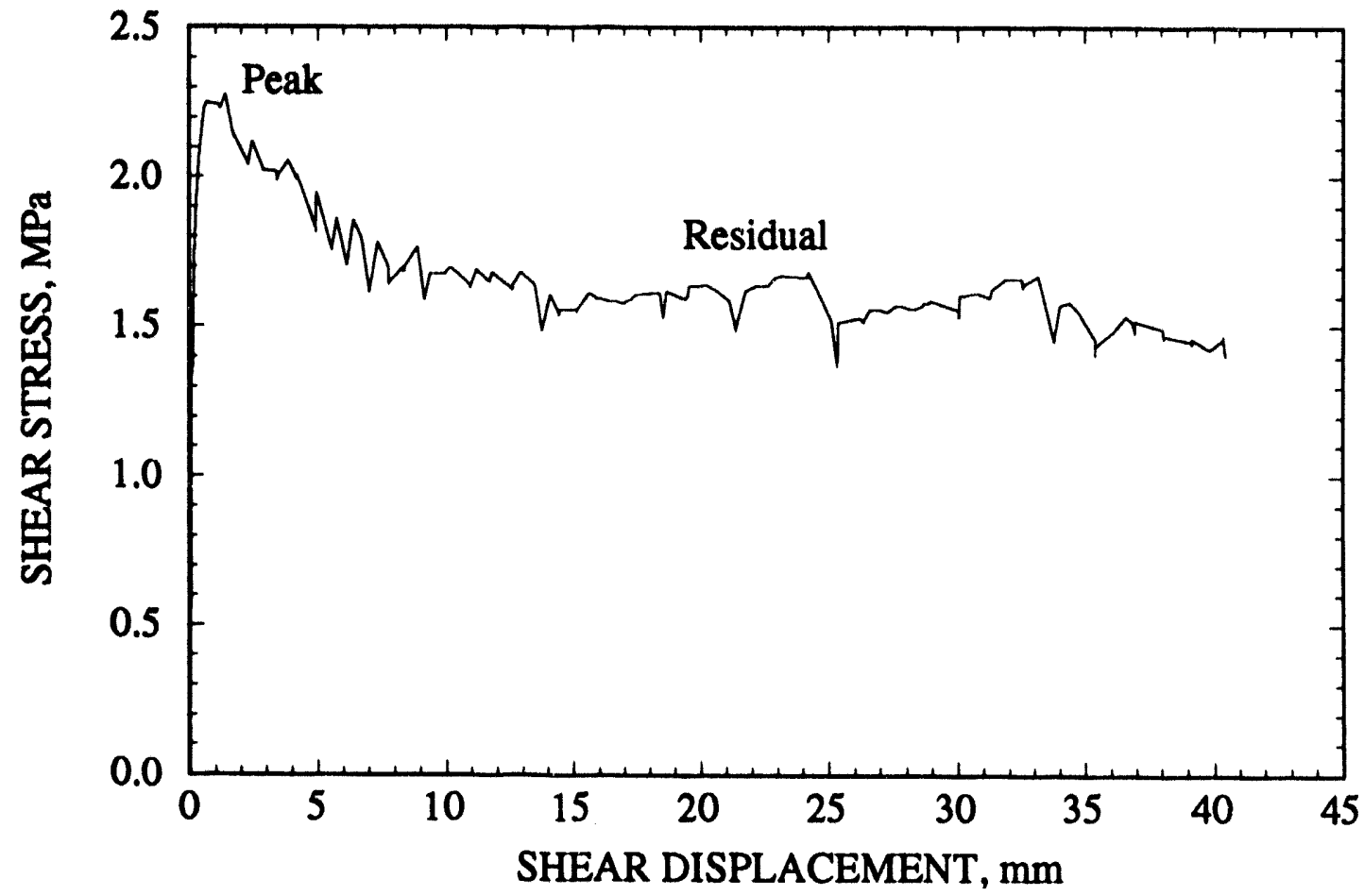

Figure 5-11. Peak and residual behavior of shear stress versus shear displacement curve 
Table 5-8. Estimated values of cohesion and friction angle

\begin{tabular}{|c|c|c|c|c|c|c|}
\hline $\begin{array}{c}\text { Shear } \\
\text { Test }\end{array}$ & $\begin{array}{c}\text { Residual } \\
\text { Shear Stress } \\
\text { (mm) }\end{array}$ & $\begin{array}{l}\text { Shear Disp. } \\
\text { at Residual } \\
\text { Shear Stress } \\
\text { (mm) }\end{array}$ & $\begin{array}{c}\text { Normal Stress } \\
(\mathrm{MPa})\end{array}$ & $\begin{array}{l}\text { Residual } \\
\text { Cohesion } \\
C_{r}(\mathrm{MPa})\end{array}$ & $\tan \phi_{\text {res }}$ & $\begin{array}{c}\text { Residual Friction } \\
\text { Angle } \\
\phi_{r}^{\min }, \phi_{r} \phi_{r}^{\max } \\
\text { (degrees) }\end{array}$ \\
\hline 1 & $\begin{array}{l}0.678 \\
0.888 \\
1.261 \\
1.803 \\
3.364 \\
4.898\end{array}$ & $\begin{array}{l}20.117 \\
20.041 \\
20.053 \\
20.206 \\
20.117 \\
20.180\end{array}$ & $\begin{array}{l}0.652 \\
0.925 \\
1.487 \\
1.976 \\
3.937 \\
5.913\end{array}$ & $0.14 \pm 0.11$ & $0.81 \pm 0.03$ & $38.0,39.0,40.0$ \\
\hline 2 & $\begin{array}{l}0.962 \\
1.897 \\
3.033 \\
3.842 \\
4.762 \\
\end{array}$ & $\begin{array}{l}20.053 \\
20.028 \\
20.168 \\
20.218 \\
20.015\end{array}$ & $\begin{array}{l}1.056 \\
2.002 \\
2.980 \\
4.000 \\
4.998\end{array}$ & $0.0 \pm 0.35$ & $0.97 \pm 0.10$ & $41.0,44.1,46.9$ \\
\hline 3 & $\begin{array}{l}1.508 \\
2.554 \\
3.558 \\
4.320\end{array}$ & $\begin{array}{l}25.133 \\
25.108 \\
25.006 \\
25.057\end{array}$ & $\begin{array}{l}1.966 \\
2.996 \\
3.947 \\
4.967 \\
\end{array}$ & $0.0 \pm 0.0$ & $0.87 \pm 0.09$ & $38.0,41.0,43.8$ \\
\hline 4 & $\begin{array}{l}2.423 \\
3.290 \\
4.199 \\
\end{array}$ & $\begin{array}{l}25.286 \\
25.019 \\
14.707 \\
\end{array}$ & $\begin{array}{l}3.048 \\
4.047 \\
5.046 \\
\end{array}$ & $0.0 \pm 0.0$ & $|0.82 \pm 0.13|$ & $34.6,39.4,43.5$ \\
\hline 5 & $\begin{array}{l}2.996 \\
3.658 \\
\end{array}$ & $\begin{array}{l}25.337 \\
25.324 \\
\end{array}$ & $\begin{array}{l}4.042 \\
5.030 \\
\end{array}$ & 0.29 & 0.67 & 33.8 \\
\hline 6 & 4.404 & 25.184 & 5.366 & $\cdots$ & - & - \\
\hline 7 & 3.721 & 25.171 & 5.019 & - & - & - \\
\hline 8 & $\begin{array}{l}3.358 \\
4.131 \\
\end{array}$ & $\begin{array}{l}25.451 \\
25.590 \\
\end{array}$ & $\begin{array}{l}4.031 \\
5.009 \\
\end{array}$ & 0.27 & 0.77 & 37.6 \\
\hline 9 & $\begin{array}{l}2.228 \\
3.127 \\
3.958 \\
\end{array}$ & $\begin{array}{l}20.015 \\
20.091 \\
20.257 \\
\end{array}$ & $\begin{array}{l}3.027 \\
4.010 \\
5.004 \\
\end{array}$ & $0.0 \pm 0.0$ & $0.78 \pm 0.13$ & $33 \cdot 0,38 \cdot 0,42.3$ \\
\hline 10 & $\begin{array}{l}1.640 \\
2.570 \\
3.306 \\
3.942\end{array}$ & $\begin{array}{l}20.193 \\
20.206 \\
20.079 \\
20.003\end{array}$ & $\begin{array}{l}2.050 \\
3.033 \\
4.021 \\
5.004\end{array}$ & $0.19 \pm 0.73$ & $0.76 \pm 0.22$ & $28.4,37.2,44.4$ \\
\hline
\end{tabular}


Table 5-8. Estimated values of cohesion and friction angle (cont'd)

\begin{tabular}{|c|c|c|c|c|c|c|}
\hline $\begin{array}{c}\text { Shear } \\
\text { Test }\end{array}$ & $\begin{array}{c}\text { Residual } \\
\text { Shear Stress } \\
\text { (mm) }\end{array}$ & $\begin{array}{c}\text { Shear Disp. } \\
\text { at Residual } \\
\text { Shear Stress } \\
\text { (mm) }\end{array}$ & $\begin{array}{c}\text { Normal Stress } \\
(\mathrm{MPa})\end{array}$ & $\begin{array}{l}\text { Residual } \\
\text { Cohesion } \\
C_{r}(\mathrm{MPa})\end{array}$ & $\tan \phi_{\text {res }}$ & $\begin{array}{l}\text { Residual Friction } \\
\text { Angle } \\
\phi_{r}^{\text {min }}, \phi_{r} \phi_{r}^{\text {max }} \\
\text { (degrees) }\end{array}$ \\
\hline 11 & $\begin{array}{l}0.983 \\
1.734 \\
2.539 \\
4.184 \\
3.858\end{array}$ & $\begin{array}{l}25.044 \\
25.070 \\
25.032 \\
25.121 \\
25.362\end{array}$ & $\begin{array}{l}1.077 \\
2.066 \\
3.054 \\
3.737 \\
4.735\end{array}$ & $0.02 \pm 1.94$ & $0.90 \pm 0.60$ & $17.0,43.0,56.3$ \\
\hline 17 & $\begin{array}{l}0.807 \\
1.724 \\
2.631 \\
3.480 \\
4.214\end{array}$ & $\begin{array}{l}20.155 \\
20.066 \\
20.041 \\
20.155 \\
20.079\end{array}$ & $\begin{array}{l}1.004 \\
1.997 \\
2.995 \\
3.988 \\
4.987\end{array}$ & 0.0 & $0.86 \pm 0.03$ & $39.7,40.7,41.7$ \\
\hline 18 & $\begin{array}{l}1.488 \\
2.809 \\
3.700 \\
4.591\end{array}$ & $\begin{array}{l}30.226 \\
30.150 \\
30.175 \\
30.188\end{array}$ & $\begin{array}{l}1.970 \\
2.964 \\
3.957 \\
4.955\end{array}$ & 0.0 & $0.92 \pm 0.13$ & $38.3,42.6,46.4$ \\
\hline 19 & $\begin{array}{l}2.217 \\
2.846 \\
3.522\end{array}$ & $\begin{array}{l}30.086 \\
30.048 \\
30.023\end{array}$ & $\begin{array}{l}2.979 \\
3.973 \\
4.971\end{array}$ & $0.26 \pm 0.64$ & $0.66 \pm 0.13$ & $27.9,33.4,38.3$ \\
\hline 20 & $\begin{array}{l}4.020 \\
4.015\end{array}$ & $\begin{array}{l}30.150 \\
30.074\end{array}$ & $\begin{array}{l}3.983 \\
4.981\end{array}$ & * & * & * \\
\hline 27 & $\begin{array}{l}0.979 \\
1.991 \\
3.036 \\
3.955 \\
5.011\end{array}$ & $\begin{array}{l}30.124 \\
30.162 \\
30.112 \\
30.023 \\
30.035\end{array}$ & $\begin{array}{l}0.996 \\
1.975 \\
2.960 \\
3.945 \\
4.941\end{array}$ & $0.0 \pm 0.0$ & $1.01 \pm 0.0$ & $45 \cdot 3,45 \cdot 3,45 \cdot 3$ \\
\hline 28 & $\begin{array}{l}2.913 \\
3.627 \\
4.584\end{array}$ & $\begin{array}{l}35.166 \\
25.095 \\
25.006\end{array}$ & $\begin{array}{l}2.073 \\
3.898 \\
4.893\end{array}$ & $1.65 \pm 7.12$ & $0.57 \pm 1.91$ & $0.0^{* *}, 29.7,68.0$ \\
\hline 29 & 4.311 & 25.146 & 4.951 & - & - & - \\
\hline
\end{tabular}

allowable closure $\left(V_{m}\right)$ for each loading/unloading cycle can be determined through laboratory cyclic normal loading/unloading tests and calculating $1 / a$ for $K_{n i}$ and $a / b$ for $V_{m}$. The joint closure under normal load can be modeled empirically using hyperbolic loading and unloading curves relating the effective normal stress, $\sigma_{n}$, and joint closure, $u_{n}$ : 


$$
\sigma_{n}=\frac{u_{n}}{a-b u_{n}}
$$

where $a$ and $b$ are empirical constants. Figure 5-12 shows the typical results of fitting Eq. (5-8) to the normal stress curves. For many values of normal displacement, Figure 5-12 shows multiple normal stress values. The reason for these multiple values is not clear. The results show that the Barton-Bandis model fits the experimental results reasonably well for high normal stresses. For lower normal stresses, the Barton-Bandis model appears to underestimate the joint closure. The values of the empirical constants $a$ and $b$ for all the tests are given in Table 5-9.

Bandis et al. (1983) show that the initial normal stiffness, $K_{n i}$, of the joint in normal stress, $\sigma_{n}$, versus normal displacement, $u_{n}$, curve is equal to the inverse of the constant $a$ in Eq. (5-8) and the maximum possible closure, $V_{m}$, is defined by $a / b$. Table 5-10 lists the initial normal stiffness and the maximum closures for the fifth cycle predicted using the Barton-Bandis model and calculated based on the experimental data for all the tests.

Bandis et al. (1983) also proposed a general empirical approach for $V_{m}$ and $K_{n i}$ determination through the following two equations, which have been adopted in the UDEC code for Barton-Bandis joint model:

$$
V_{m}=A+B\left(\mathrm{JRC}_{o}\right)+C\left(\frac{\mathrm{JCS}}{a_{j}}\right)^{D}
$$

and

$$
K_{n i}=E\left(\frac{\mathrm{JCS}}{a_{j}}\right)+F\left(\mathrm{JRC}_{0}\right)+G
$$

where $\mathrm{JRC}_{o}$ is joint roughness coefficient, JCS is joint wall compressive strength, $a_{j}$ is joint mechanical aperture for a loading or unloading path, and $A, B, C, D, E, F$, and $G$ are constants. All the constants can be determined from laboratory results. However, some general values for constants $A, B, C$, and $D$ are available (Table 5-11) (Bandis et al., 1983) for the first three loading/unloading cycles. Constants for the subsequent cycles may be assumed essentially to be the same as those of the third cycle as listed in Table 5-11. The values for the constants listed in Table 5-11 are usable, provided that $\mathrm{JRC}_{o}$ is between 5 and 15, JCS ranges from 22 to $182 \mathrm{MPa}$, and $a_{j}$ is not smaller than $0.1 \mathrm{~mm}$ nor greater than $0.6 \mathrm{~mm}$. In order to calculate the $K_{n i}$ using Eq. (5-10), Bandis (1980) suggested that constant $E$ is equal to 0.02, $F$ is equal to 1.75 , and constant $G$ is equal to -7.15 . With the existence of Eqs. $(5-9)$ and $(5-10)$, preliminary joint normal stress displacement (closure) can be evaluated without laboratory test results. Equations (5-9) and (5-10) also provide a link between joint normal behavior and joint mechanical aperture, which makes the study of coupled hydromechanical effects possible. (Note that an empirical equation for calculating joint hydraulic aperture from joint mechanical aperture is available.) 


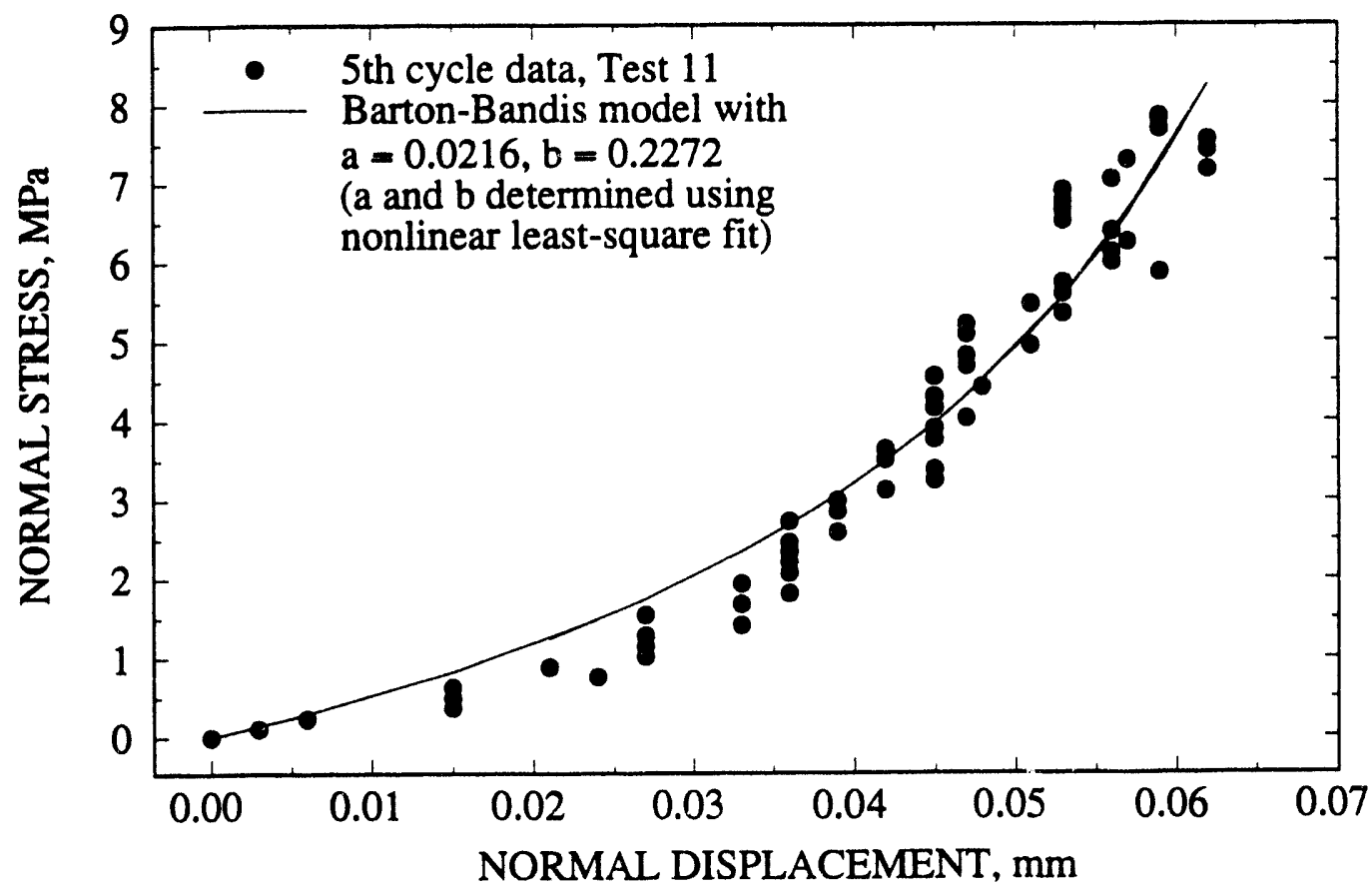

Figure 5-12. Normal stress versus normal displacement curve with Barton-Bandis model

The joint mechanical aperture for the first cycle, $a_{j i}$, can be determined by the following equation:

$$
a_{j i}=\mathrm{JRC}_{\circ}\left(\frac{0.04 \sigma_{c}}{\mathrm{JCS}}-0.02\right)
$$

where $\sigma_{c}$ is the uniaxial compressive strength. Joint mechanical aperture for the subsequent loading/unloading cycles can be obtained by subtracting the irrecoverable closure, $V_{i r}$ from the $a_{j i}$.

$$
V_{t r r}=\left[C 1-C 2\left(\frac{\mathrm{JCS}}{a_{j}}\right)\right] \frac{V_{m} \sigma_{n c}}{100\left(\sigma_{n c}-K_{n i} V_{m}\right)}
$$

where $\sigma_{n c}$ is the normal stress when unloading starts, and $C 1$ and $C 2$ are constants.

The joint shear behavior for the Barton-Bandis joint model (Barton et al., 1985) is governed by:

$$
\sigma_{s}=\sigma_{n} \tan \left[\mathrm{JRC}_{m} \log \left(\frac{\mathrm{JCS}}{\sigma_{n}}\right)+\phi_{r}\right]
$$

where $\sigma_{s}$ is shear stress, $\sigma_{n}$ is normal stress, $\mathrm{JRC}_{m}$ is mobilized joint roughness coefficient, and $\phi_{r}$ is residual joint friction angle. 
Table 5-9. Values of normal deformation parameters $a$ and $b$ of Barton-Bandis model

\begin{tabular}{|c|c|c|c|c|c|}
\hline Test No. & Cycle 1 & Cycle 2 & Cycle 3 & Cycle 4 & Cycle 5 \\
\hline 1 & $\begin{array}{l}a=0.0200 \\
b=0.1994\end{array}$ & $\begin{array}{l}a=0.0288 \\
b=0.3512\end{array}$ & $\begin{array}{l}a=0.0414 \\
b=0.2357\end{array}$ & $\begin{array}{l}a=0.0130 \\
b=0.2211\end{array}$ & $\begin{array}{l}a=0.0197 \\
b=0.2547\end{array}$ \\
\hline 2 & $\begin{array}{l}a=0.0649 \\
b=0.4113\end{array}$ & $\begin{array}{l}a=0.0271 \\
b=0.2811 \\
\end{array}$ & $\begin{array}{l}a=0.0302 \\
b=0.3513\end{array}$ & $\begin{array}{l}a=0.0277 \\
b=0.3378 \\
\end{array}$ & $\begin{array}{l}a=0.0362 \\
b=0.2+12\end{array}$ \\
\hline 3 & $\begin{array}{l}a=0.0591 \\
b=0.5096\end{array}$ & $\begin{array}{l}a=0.0774 \\
b=0.5433\end{array}$ & $\begin{array}{l}a=0.0587 \\
b=0.3642\end{array}$ & $\begin{array}{l}a=0.0658 \\
b=0.4545\end{array}$ & $\begin{array}{l}a=0.0558 \\
b=0.4302\end{array}$ \\
\hline 4 & $\begin{array}{l}a=0.0696 \\
b=0.1895\end{array}$ & $\begin{array}{l}a=0.0495 \\
b=0.2482\end{array}$ & $\begin{array}{l}a=0.0400 \\
b=0.2496\end{array}$ & $\begin{array}{l}a=0.0390 \\
b=0.2333\end{array}$ & $\begin{array}{l}a=0.0343 \\
b=0.2227\end{array}$ \\
\hline 5 & $\begin{array}{l}a=0.0772 \\
b=0.1409\end{array}$ & $\begin{array}{l}a=0.0573 \\
b=0.1550\end{array}$ & $\begin{array}{l}a=0.0538 \\
b=0.1669\end{array}$ & $\begin{array}{l}a=0.0552 \\
b=0.1883\end{array}$ & $\begin{array}{l}a=0.0687 \\
b=0.2296\end{array}$ \\
\hline 6 & $\begin{array}{l}a=0.0585 \\
b=0.1401\end{array}$ & $\begin{array}{l}a=0.0461 \\
b=0.1688\end{array}$ & $\begin{array}{l}a=0.0427 \\
b=0.1959\end{array}$ & $\begin{array}{l}a=0.0391 \\
b=0.1929\end{array}$ & $\begin{array}{l}a=0.0358 \\
b=0.1652 \\
\end{array}$ \\
\hline 7 & $\begin{array}{l}a=0.0723 \\
b=0.3557 \\
\end{array}$ & $\begin{array}{l}a=0.0231 \\
b=0.2112\end{array}$ & $\begin{array}{l}a=0.0242 \\
b=0.2128\end{array}$ & $\begin{array}{l}a=0.0228 \\
b=0.2111 \\
\end{array}$ & $\begin{array}{l}a=0.0238 \\
b=0.2457 \\
\end{array}$ \\
\hline 8 & $\begin{array}{l}a=0.0745 \\
b=0.2670\end{array}$ & $\begin{array}{l}a=0.0485 \\
b=0.2212\end{array}$ & $\begin{array}{l}a=0.0505 \\
b=0.2226\end{array}$ & $\begin{array}{l}a=0.0576 \\
b=0.2587\end{array}$ & $\begin{array}{l}a=0.0538 \\
b=0.2483\end{array}$ \\
\hline 9 & $\begin{array}{l}a=0.0995 \\
b=0.3157\end{array}$ & $\begin{array}{l}a=0.0584 \\
b=0.2590\end{array}$ & $\begin{array}{l}a=0.0554 \\
b=0.2656\end{array}$ & $\begin{array}{l}a=0.0569 \\
b=0.2724\end{array}$ & $\begin{array}{l}a=0.0489 \\
b=0.2424\end{array}$ \\
\hline 10 & $\begin{array}{l}a=0.0376 \\
b=0.1521 \\
\end{array}$ & $\begin{array}{l}a=0.0369 \\
b=0.2019 \\
\end{array}$ & $\begin{array}{l}a=0.0283 \\
b=0.1459\end{array}$ & $\begin{array}{l}a=0.0346 \\
b=0.1851\end{array}$ & $\begin{array}{l}a=0.0252 \\
b=0.1275 \\
\end{array}$ \\
\hline 11 & $\begin{array}{l}a=0.0479 \\
b=0.2905\end{array}$ & $\begin{array}{l}a=0.0374 \\
b=0.3110\end{array}$ & $\begin{array}{l}a=0.0255 \\
b=0.1968\end{array}$ & $\begin{array}{l}a=0.0249 \\
b=0.2368\end{array}$ & $\begin{array}{l}a=0.0261 \\
b=0.2272\end{array}$ \\
\hline 12 & $\begin{array}{l}a=0.0296 \\
b=0.2145\end{array}$ & $\begin{array}{l}a=0.0171 \\
b=0.1706\end{array}$ & $\begin{array}{l}a=0.0258 \\
b=0.2830\end{array}$ & $\begin{array}{l}a=0.0222 \\
b=0.2322\end{array}$ & $\begin{array}{l}a=0.0243 \\
b=0.2709\end{array}$ \\
\hline 13 & $\begin{array}{l}a=0.0277 \\
b=0.1508\end{array}$ & $\begin{array}{l}a=0.0234 \\
b=0.1320 \\
\end{array}$ & $\begin{array}{l}a=0.0240 \\
b=0.1410\end{array}$ & $\begin{array}{l}a=0.0262 \\
b=0.1656\end{array}$ & $\begin{array}{l}a=0.0232 \\
b=0.1436\end{array}$ \\
\hline 14 & $\begin{array}{l}a=0.1052 \\
b=0.3436\end{array}$ & $\begin{array}{l}a=0.0252 \\
b=0.1523\end{array}$ & $\begin{array}{l}a=0.0279 \\
b=0.2036\end{array}$ & $\begin{array}{l}a=0.0364 \\
b=0.2728\end{array}$ & $\begin{array}{l}a=0.0311 \\
b=0.2309 \\
\end{array}$ \\
\hline 15 & $\begin{array}{l}a=0.0311 \\
b=0.1430 \\
\end{array}$ & $\begin{array}{l}a=0.0427 \\
b=0.2562 \\
\end{array}$ & $\begin{array}{l}a=0.0384 \\
b=0.2298\end{array}$ & $\begin{array}{l}a=0.0397 \\
b=0.2375\end{array}$ & $\begin{array}{l}a=0.0353 \\
b=0.2034 \\
\end{array}$ \\
\hline 16 & $\begin{array}{l}a=0.0608 \\
b=0.2883\end{array}$ & $\begin{array}{l}a=0.0429 \\
b=0.2377\end{array}$ & $\begin{array}{l}a=0.0444 \\
b=0.2461\end{array}$ & $\begin{array}{l}a=0.0419 \\
b=0.2316\end{array}$ & $\begin{array}{l}a=0.0453 \\
b=0.2593\end{array}$ \\
\hline
\end{tabular}


Table 5-9. Values of normal deformation parameters $a$ and $b$ of Barton-Bandis model (cont'd)

\begin{tabular}{|c|c|c|c|c|c|}
\hline Test No. & Cycle 1 & Cycle 2 & Cycle 3 & Cycle 4 & Cycle 5 \\
\hline 17 & $\begin{array}{l}a=0.0398 \\
b=0.3300\end{array}$ & $\begin{array}{l}a=0.0498 \\
b=0.4587\end{array}$ & $\begin{array}{l}a=0.0377 \\
b=0.3162\end{array}$ & $\begin{array}{l}a=0.0461 \\
b=0.3932\end{array}$ & $\begin{array}{l}a=0.0440 \\
b=0.3976\end{array}$ \\
\hline 18 & $\begin{array}{l}a=0.0799 \\
b=0.4949\end{array}$ & $\begin{array}{l}a=0.0556 \\
b=0.3540\end{array}$ & $\begin{array}{l}a=0.2031 \\
b=0.5376\end{array}$ & $\begin{array}{l}a=0.1061 \\
b=0.4384\end{array}$ & $\begin{array}{l}a=0.0950 \\
b=0.4152\end{array}$ \\
\hline 19 & $\begin{array}{l}a=0.0473 \\
b=0.2327\end{array}$ & $\begin{array}{l}a=0.0401 \\
b=0.2217\end{array}$ & $\begin{array}{l}a=0.0444 \\
b=0.2586\end{array}$ & $\begin{array}{l}a=0.0409 \\
b=0.2449\end{array}$ & $\begin{array}{l}a=0.0423 \\
b=0.2541\end{array}$ \\
\hline 20 & $\begin{array}{l}a=0.2205 \\
b=0.4297\end{array}$ & $\begin{array}{l}a=0.1155 \\
b=0.4066\end{array}$ & $\begin{array}{l}a=0.1153 \\
b=0.4335\end{array}$ & $\begin{array}{l}a=0.1221 \\
b=0.4852\end{array}$ & $\begin{array}{l}a=0.1202 \\
b=0.4878\end{array}$ \\
\hline 21 & $\begin{array}{l}a=0.3597 \\
b=0.4833\end{array}$ & $\begin{array}{l}a=0.1663 \\
b=0.4934\end{array}$ & $\begin{array}{l}a=0.1489 \\
b=0.5158\end{array}$ & $\begin{array}{l}a=0.1155 \\
b=0.4454\end{array}$ & $\begin{array}{l}a=0.1417 \\
b=0.5459\end{array}$ \\
\hline 24 & $\begin{array}{l}a=0.1388 \\
b=0.6970\end{array}$ & $\begin{array}{l}a=0.1263 \\
b=0.6134\end{array}$ & $\begin{array}{l}a=0.0267 \\
b=0.1440\end{array}$ & $\begin{array}{l}a=0.0298 \\
b=0.1712\end{array}$ & $\begin{array}{l}a=0.0248 \\
b=0.1364\end{array}$ \\
\hline 26 & $\begin{array}{l}a=0.0785 \\
b=0.2015\end{array}$ & $\begin{array}{l}a=0.0642 \\
b=0.2248\end{array}$ & $\begin{array}{l}a=0.0724 \\
b=0.2610\end{array}$ & $\begin{array}{l}a=0.0767 \\
b=0.2874\end{array}$ & $\begin{array}{l}a=0.0693 \\
b=0.2568\end{array}$ \\
\hline 27 & $\begin{array}{l}a=0.1652 \\
b=0.4077\end{array}$ & $\begin{array}{l}a=0.0895 \\
b=0.3040\end{array}$ & $\begin{array}{l}a=0.0902 \\
b=0.3079\end{array}$ & $\begin{array}{l}a=0.0951 \\
b=0.3338\end{array}$ & $\begin{array}{l}a=0.0994 \\
b=0.3606\end{array}$ \\
\hline 28 & $\begin{array}{l}a=0.1255 \\
b=0.2299\end{array}$ & $\begin{array}{l}a=0.1028 \\
b=0.2315\end{array}$ & $\begin{array}{l}a=0.0984 \\
b=0.2423\end{array}$ & $\begin{array}{l}a=0.1031 \\
b=0.2648\end{array}$ & $\begin{array}{l}a=0.0994 \\
b=0.2445\end{array}$ \\
\hline 29 & $\begin{array}{l}a=0.1164 \\
b=0.2448\end{array}$ & $\begin{array}{l}a=0.1280 \\
b=0.3728\end{array}$ & $\begin{array}{l}a=0.1243 \\
b=0.3938\end{array}$ & $\begin{array}{l}a=0.1202 \\
b=0.3908\end{array}$ & $\begin{array}{l}a=0.1245 \\
b=0.4122\end{array}$ \\
\hline 30 & $\begin{array}{l}a=0.1118 \\
b=0.2441\end{array}$ & $\begin{array}{l}a=0.0442 \\
b=0.2041\end{array}$ & $\begin{array}{l}a=0.0594 \\
b=0.3502\end{array}$ & $\begin{array}{l}a=0.0594 \\
b=0.3503\end{array}$ & $\begin{array}{l}a=0.0552 \\
b=0.3034\end{array}$ \\
\hline
\end{tabular}
1985):

The mobilized dilation angle, $d_{m}$, is also calculated from the mobilized roughness (Barton et al.,

$$
d_{m}=0.5 \mathrm{JRC}_{m} \log \left(\frac{\mathrm{JCS}}{\sigma_{n}}\right)
$$

The Barton-Bandis model in UDEC (ITASCA Consulting Group, Inc., 1992) has the following parameters:

- initial aperture of the joint, which will be calculated if not supplied (mm)

- laboratory-scale joint wall compressive strength JCS (MPa)

- joint normal stiffness, $K_{n}$, at expected normal load 
Table 5-10. Values of initial joint normal stiffness, $K_{n l}$, and maximum possible closure, $V_{m}$

\begin{tabular}{|c|c|c|}
\hline Test No. & $K_{n l}=1 / a(\mathrm{GPa} / \mathrm{m})$ & $V_{m}=a / b(\mathrm{~mm})$ \\
\hline 1 & 50.76 & 0.08 \\
\hline 2 & 27.62 & 0.11 \\
\hline 3 & 17.92 & 0.13 \\
\hline 4 & 29.16 & 0.15 \\
\hline 5 & 14.56 & 0.30 \\
\hline 6 & 27.93 & 0.22 \\
\hline 7 & 42.02 & 0.10 \\
\hline 8 & 18.59 & 0.22 \\
\hline 9 & 20.45 & 0.20 \\
\hline 10 & 39.68 & 0.20 \\
\hline 11 & 38.31 & 0.11 \\
\hline 12 & 41.15 & 0.09 \\
\hline 13 & 43.10 & 0.16 \\
\hline 14 & 32.15 & 0.13 \\
\hline 15 & 28.33 & 0.17 \\
\hline 16 & 22.08 & 0.17 \\
\hline 17 & 22.73 & 0.11 \\
\hline 18 & 10.53 & 0.23 \\
\hline 19 & 23.64 & 0.17 \\
\hline 20 & 8.32 & 0.25 \\
\hline 21 & 7.06 & 0.26 \\
\hline 24 & 40.32 & 0.18 \\
\hline 26 & 14.43 & 0.27 \\
\hline 27 & 10.06 & 0.28 \\
\hline 28 & 10.06 & 0.41 \\
\hline 29 & 8.03 & 0.30 \\
\hline 30 & 18.12 & 0.18 \\
\hline
\end{tabular}


Table 5-11. Constants used for calculation of $V_{m}$ (Bandis et al., 1983)

\begin{tabular}{|c|c|c|c|}
\hline Constant & Cycle 1 & Cycle 2 & Cycle 3 \\
\hline$A$ & -0.2960 & -0.1005 & -0.1032 \\
\hline$B$ & -0.0056 & -0.0073 & -0.0074 \\
\hline$C$ & 2.2410 & 1.0082 & 1.1350 \\
\hline$D$ & -0.2450 & -0.2301 & -0.2510 \\
\hline
\end{tabular}

- joint initial shear stiffness, $K_{s i}$, at expected normal load

- laboratory-scale JRC

- field-scale joint length, $\ln (\mathrm{m})$

- laboratory-scale joint length, $l o(\mathrm{~m})$

- residual angle of friction, $\phi_{r}$ (degree)

- intact rock uniaxial compressive strength $(\mathrm{MPa})$

In the laboratory experiments, both $\ln$ and $l o$ are equal to $0.2032 \mathrm{~m}$. In the following sections, discussions focus on the determination of $\mathrm{JRC}_{o}, \mathrm{JCS}$, and $\phi_{r}$, and comparison of shear stress displacement predicted from the Barton-Bandis model and that of the experimental result.

In order to be able to predict joint shear stress using Eq. (5-13) without performing direct joint shear tests, Barton and Choubey (1977) have proposed a number of methods for the determination of parameters such as $\mathrm{JRC}_{o}, \mathrm{JCS}$, and $\phi_{r}$. These methods are discussed in the following subsections.

\subsubsection{Schmidt Hammer Test}

Rebound numbers for the unweathered rock surface $(R)$ and joint surfaces $(r)$ measured using Schmidt Hammer are the key factors for the determination of JCS and $\phi_{r}$. In this study, except for the four specimens for Tests Nos. 1 through 4, Schmidt Hammer tests to determine rebound numbers $R$ and $r$ were performed on each of the single-joint tuff specimens used for both pseudostatic and dynamic tests. Please note that $R$ is the rebound number on the unweathered rock surface and $r$ is the rebound number on a joint surface. The L-type hammer was used. During the tests, the hammer was used on horizontal surfaces, and the rebound value obtained was corrected according to operating instructions for nonhorizontal impacts. Table 5-12 lists the recommended adjustments for the vertical impact approach that were adopted in this study.

For the $R$ determination, four numbers were obtained across the rock surface on each side of a specimen block. As a result, a total of 16 rebound numbers for each specimen block were obtained. These numbers were then corrected based on Table 5-12. A linear interpolation approach for compensation of rebound number between the numbers shown in Table 5-12 was adopted. For rebound values greater than 60 , the value used for the rebound number adjustment is +1.7 , the same as the value used for rebound number 60 . An average value calculated from the corrected numbers of both top and bottom specimen blocks is assumed to be the $R$ of that single-joint specimen. Table 5-13 lists the measured rebound numbers and adjusted rebound numbers for the intact portion of the specimen for Test No. 8. Also included in the table are average rebound values of the specimen and the standard deviation 
Table 5-12. Recommended correction for rebound number obtained through vertical downward impact

\begin{tabular}{|c|c||c|c|}
\hline Rebound Number & $\begin{array}{c}\text { Correction for 90 } \\
\text { Downward Impact }\end{array}$ & Rebound Number & $\begin{array}{c}\text { Correction for } 90^{\circ} \\
\text { Downward Impact }\end{array}$ \\
\hline \hline 10 & +3.2 & 40 & +2.7 \\
\hline 20 & +3.4 & 50 & +2.2 \\
\hline 30 & +3.1 & 60 & +1.7 \\
\hline
\end{tabular}

of the mean. As observed from the table, the rebound readings from the intact portion of the rock are not very scattered. Similar information for other test specimens is provided in Appendix B.

The $r$ value on the joint of a single-joint specimen was determined by obtaining ten initial rebound numbers across the joint surfaces of both specimen blocks, and the mean rebound value was calculated. Individual rebound values that deviated from the mean by more than five units were discarded and replaced by the rebound numbers obtained through further impact tests. The mean value for the new set of data was again calculated and compared with the individual data. This process continued until the difference between the mean and each individual rebound value was smaller than five units. These final rebound number data were then corrected based on Table 5-12 using the same approach as described earlier. An average value calculated from the corrected values from both top and bottom joint surfaces is the $r$ of that single-joint specimen. Table 5-14 lists the measured rebound numbers and adjusted rebound numbers for the joint of the specimen for Test No. 8. Also included in the table is the average rebound number of the joint and the standard deviation of the mean. As can be observed from the table, the rebound readings from the joint surfaces of the specimen are quite scattered. Similar information for other test specimens is provided in Appendix C.

The rebound values of intact rock surfaces $(R)$ and joint surfaces $(r)$ for the 26 tests are listed in Table 5-15.

\subsubsection{Joint-Wall Compressive Strength}

For the determination of joint-wall compressive strength, Barton and Choubey (1977) have proposed an equation developed by Miller (1965) for the calculation of uniaxial compressive strength of rock using the Schmidt Hammer rebound tests. This equation is presented as follows:

$$
\log \left(\sigma_{c}\right)=0.00088 \gamma R+1.01
$$

where $\sigma_{c}$ is the uniaxial compressive strength in $\mathrm{MPa}, \gamma$ is rock unit weight in $\mathrm{kN} / \mathrm{m}^{3}$, and $R$ is rebound value on the unweathered rock surface. If $\sigma_{c}$ and $R$ are replaced by JCS and rebound value on joint surface, $r$, respectively, then joint-wall compressive strength can be determined. This substitution suggests that when the joint surface is completely unweathered, its strength should be the same as the uniaxial compressive strength. In other words, the extent of weathering of a joint may be estimated using the $r$ to $R$ ratio. The smaller the ratio, the more severe the joint has been weathered. Judging from the difference between $R$ and $r$ of each test specimen, the extent of joint weathering the specimens seems to 
Table 5-13. Measured and corrected rebound numbers on the unweathered surfaces of the sides of test specimen no. 8

\begin{tabular}{|c|c|c|c|c|}
\hline $\begin{array}{l}\text { No. of } \\
\text { Readings }\end{array}$ & $\begin{array}{l}\text { Measured } \\
\text { Rebound } \\
\text { Number for } \\
\text { Top Block }\end{array}$ & $\begin{array}{l}\text { Corrected } \\
\text { Rebound } \\
\text { Number for } \\
\text { Top Block }\end{array}$ & $\begin{array}{l}\text { Measured } \\
\text { Rebound } \\
\text { Number for } \\
\text { Bottom Block }\end{array}$ & $\begin{array}{c}\text { Corrected } \\
\text { Rebound } \\
\text { Number for } \\
\text { Bottom Block }\end{array}$ \\
\hline 1 & 62 & 63.7 & 58 & 59.8 \\
\hline 2 & 62 & 63.7 & 62 & 63.7 \\
\hline 3 & 63 & 64.7 & 62 & 63.7 \\
\hline 4 & 61 & 62.7 & 61 & 62.7 \\
\hline 5 & 63 & 64.7 & 63 & 64.7 \\
\hline 6 & 61 & 62.7 & 60 & 61.7 \\
\hline 7 & 61 & 62.7 & 60 & 61.7 \\
\hline 8 & 63 & 64.7 & 58 & 59.8 \\
\hline 9 & 63 & 64.7 & 64 & 65.7 \\
\hline 10 & 63 & 64.7 & 61 & 62.7 \\
\hline 11 & 59 & 60.75 & 64 & 65.7 \\
\hline 12 & 63 & 64.7 & 63 & 64.7 \\
\hline 13 & 62 & 63.7 & 62 & 63.7 \\
\hline 14 & 60 & 61.7 & 60 & 61.7 \\
\hline 15 & 63 & 64.7 & 61 & 62.7 \\
\hline 16 & 62 & 63.7 & 63 & 64.7 \\
\hline
\end{tabular}

be at the same level. In this study, Eq. (5-15) was adopted for joint-wall compressive strength calculation. Table 5-16 lists the JCS values for the single joint specimens.

\subsubsection{Residual Friction Angle Determination}

Residual friction angle $\phi_{r}$ in Eq. (5-13) can be determined from tilt tests and Schmidt Hammer tests. The proposed equations for their determination (Barton and Choubey, 1977) are given as follows:

$$
\phi_{r}=\left(\phi_{b}-20^{\circ}\right)+20\left(\frac{r^{\prime}}{R}\right)
$$

where $\phi_{b}$ is the basic friction angle and $r^{\prime}$ is the rebound value on the saturated joint surface. In this study, the rebound value for the dry joint surface was used to calculate $\phi_{r}$. This approach results in a slight overestimation on $\phi_{r}$. 
Table 5-14. Measured and corrected rebound numbers on the two joint surfaces of the test specimen no. 8

\begin{tabular}{|c|c|c|c|c|}
\hline $\begin{array}{c}\text { No. of } \\
\text { Readings }\end{array}$ & $\begin{array}{c}\text { Measured } \\
\text { Rebound Number } \\
\text { for Joint on } \\
\text { Top Block }\end{array}$ & $\begin{array}{c}\text { Corrected } \\
\text { Rebound Number } \\
\text { for Joint on } \\
\text { Top Block }\end{array}$ & $\begin{array}{c}\text { Measured } \\
\text { Rebound Number } \\
\text { for Joint on } \\
\text { Bottom Block }\end{array}$ & $\begin{array}{c}\text { Corrected } \\
\text { Rebound Number } \\
\text { for Joint On } \\
\text { Bottom Block }\end{array}$ \\
\hline 1 & 51 & 53.15 & 52 & 54.1 \\
\hline 2 & 57 & 58.85 & 56 & 57.9 \\
\hline 3 & 57 & 58.85 & 53 & 55.05 \\
\hline 4 & 54 & 56.0 & 53 & 55.05 \\
\hline 5 & 52 & 54.1 & 49 & 51.25 \\
\hline 6 & 57 & 58.85 & 48 & 50.3 \\
\hline 7 & 52 & 54.1 & 56 & 57.9 \\
\hline 8 & 52 & 54.1 & 50 & 52.2 \\
\hline 9 & 55 & 56.95 & 48 & 50.3 \\
\hline 10 & 54 & 56.0 & 46 & 48.4 \\
\hline \hline Mean and standard deviation of data in columns 3 and $5: 54.7$ and 3.1 & \\
\hline
\end{tabular}

Parameter $\phi_{b}$ can be estimated by performing a tilt test on dry core cylinders (Barton et al., 1985). In performing the tilt test, one cylindrical core specimen is put on top of another cylindrical specimen, which sits on a flat plate as shown in Figure 5-13. By raising one end of the plate, as shown in Figure 5-13, until sliding of the top cylinder along the direction of core axis is initiated, the angle between the flat plate and the horizontal surface is the basic friction angle, $\phi_{b}$.

Six tilt tests on a combination of four cylindrical core specimens were performed for the Apache Leap tuff. The six basic friction angles, $\phi_{b}$, obtained from the tests are $28^{\circ}, 29^{\circ}, 29.5^{\circ}, 30^{\circ}, 30^{\circ}$, and $31^{\circ}$. The average $\phi_{b}$ is $29.583^{\circ}$ with a standard deviation of $1.02^{\circ}$. With the $\phi_{b}, r$, and $R$ known, the residual friction angles, $\phi_{r}$, of the single joint specimens can be calculated using Eq. (5-16) and are listed in Table 5-17.

\subsubsection{Joint Roughness Coefficient Determination}

A numerical description of rock joint roughness is necessary to describe pseudostatic and dynamic rock-joint behavior. The most commonly used measure of joint roughness in rock engineering practice is the joint roughness coefficient (JRC ${ }_{o}$ ), proposed by Barton (1973) and adopted by the International Society for Rock Mechanics (1978). Barton and Choubey (1977) proposed an approximation of the $\mathrm{JRC}_{o}$ by visually matching joint surface profiles with their ten "standard" profiles that range from 0 to 20. This approach is highly subjective (Miller et al., 1989; Wakabayashi and Fukushige, 1992) and may introduce large estimation errors for the shear strength of rock joints, especially when the normal stress is low. 
Table 5-15. Representative rebound numbers for intact rock surface and joint surface of each test specimen

\begin{tabular}{|c|c|c||c|c|c||}
\hline Test No. & $\begin{array}{c}\text { Rebound No. } \\
\text { Intact Rock } \\
\text { Surface }\end{array}$ & $\begin{array}{c}\text { Rebound } \\
\text { No. Joint } \\
\text { Surface }\end{array}$ & Test No. & $\begin{array}{c}\text { Rebound No. } \\
\text { Intact Rock } \\
\text { Surface }\end{array}$ & $\begin{array}{c}\text { Rebound No. } \\
\text { Joint Surface }\end{array}$ \\
\hline 1 & N/A* & N/A & 16 & 61.5 & 49.0 \\
\hline 2 & N/A & N/A & 17 & 61.5 & 49.1 \\
\hline 3 & N/A & N/A & 18 & 61.9 & 49.7 \\
\hline 4 & N/A & N/A & 19 & 62.1 & 48.2 \\
\hline 5 & 62.3 & 51.7 & 20 & 61.6 & 46.4 \\
\hline 6 & 62.6 & 54.77 & 21 & 61.4 & 45.8 \\
\hline 7 & 62.1 & 51.6 & 22 & 61.5 & 52.9 \\
\hline 8 & 63.7 & 55.5 & 23 & 62.7 & 53.2 \\
\hline 9 & 62.74 & 58.9 & 24 & 60.7 & 52.2 \\
\hline 10 & 60.3 & 50.2 & 25 & 61.4 & 51.2 \\
\hline 11 & 62.6 & 56.4 & 26 & 58.2 & 55.0 \\
\hline $12^{* *}$ & 61.1 & 55.0 & 27 & 58.0 & 52.6 \\
\hline $13^{* *}$ & 61.1 & 55.0 & 28 & 57.9 & 52.6 \\
\hline 14 & 65.0 & 49.0 & 29 & 58.5 & 53.0 \\
\hline 15 & 60.6 & 56.2 & 30 & 60.8 & 51.0 \\
\hline \hline Not available & & & & \\
\hline Same specimen & & & & \\
\hline
\end{tabular}

To overcome or minimize this subjectivity, a number of methods for the determination of $\mathrm{JRC}_{0}$ have been proposed. These methods may be categorized into three groups. Two methods require the measurement of rock joint profiles, that is, a detailed description of joint surfaces; one method involves using an average deviation from the centerline about which roughness is measured (Tse and Cruden, 1979; Yu and Vayssade, 1991); and the other uses the theory of fractal geometry. The third group does not require a profile measurement; it requires only a tilt test on rock joints as proposed by Barton and Choubey (1977).

In this report, several methods were evaluated to determine their appropriateness for use in the assessment of rock-joint behavior of Apache Leap tuff joints by comparing the $\mathrm{JRC}_{o}$ values estimated using these methods to the $\mathrm{JRC}_{o}$ values back-calculated from the laboratory cirect shear test results.

\section{Estimation of JRC From Tilt Tests}

The tilt test method has been proposed by Barton and Choubey (1977) to calculate $\mathrm{JRC}_{0}$ objectively. This test involves a determination of the tilt angle at which the top block of a mated joint specimen begins to slide downward along the proposed direction of shear. Different tilt angles will normally be obtained for the top block to slide along different directions of shear. The maximum 
Table 5-16. Joint wall compressive strength

\begin{tabular}{|c|c|c|c|}
\hline Test No. & $\begin{array}{c}\text { Joint Wall Compressive } \\
\text { Strength (MPa) }\end{array}$ & Test No. & $\begin{array}{c}\text { Joint Wall Compressive } \\
\text { Strength (MPa) }\end{array}$ \\
\hline 1 & N/A* & 16 & 106.3 \\
\hline 2 & N/A & 17 & 106.8 \\
\hline 3 & N/A & 18 & 109.9 \\
\hline 4 & N/A & 19 & 102.3 \\
\hline 5 & 120.9 & 20 & 93.8 \\
\hline 6 & 140.0 & 21 & 91.2 \\
\hline 7 & 120.3 & 22 & 128.0 \\
\hline 8 & 144.9 & 23 & 129.9 \\
\hline 9 & 170.5 & 24 & 123.4 \\
\hline 10 & 112.5 & 25 & 118.0 \\
\hline 11 & 115.3 & 26 & 141.5 \\
\hline 12 & 141.5 & 27 & 126.2 \\
\hline 13 & 141.5 & 28 & 126.2 \\
\hline 14 & 106.3 & 29 & 128.6 \\
\hline 15 & 149.9 & 30 & 118.6 \\
\hline \hline Not available & & & \\
\hline
\end{tabular}

observed difference in tilt angles of an Apache Leap tuff joint, which were measured along the direction of shear and in the reverse direction, was about $7.5^{\circ}$. This difference results in different JRC values and gives a clear indication of the directionality of rock joint behavior. None of the other methods discussed in this report provide such information. Table 5-18 lists the results of the tilt tests for the single-joint specimens of Apache Leap tuff.

Once a tilt angle is obtained, the $\mathrm{JRC}_{o}$ can be calculated using the following equation (Barton and Choubey, 1977):

$$
\mathrm{JRC}_{0}=\frac{\alpha-\phi_{r}}{\log \left(\frac{\mathrm{JCS}}{\sigma_{n o}}\right)}
$$

where $\alpha$ is the tilt angle, $\phi_{r}$ is the joint residual angle of friction, JCS is the joint wall compressive strength, and $\sigma_{n o}$ is the corresponding effective normal stress calculated from the weight of the top block of the joint specimen when sliding occurs. In Eq. (5-17), $\alpha$ and $\sigma_{n o}$ are related to each other. With a heavier top block, one would expect a smaller tilt angle, providing that the rest of the conditions are the same. Two variables in Eq. (5-17), $\phi_{r}$ and JCS, need to be calculated separately and, consequently, may introduce some uncertainties into the determination of JRC. However, the effect is expected to be small because the ratio of JCS to $\sigma_{\text {no }}$ in Eq. (5-17) is under logarithm. This effect is further reduced given that 


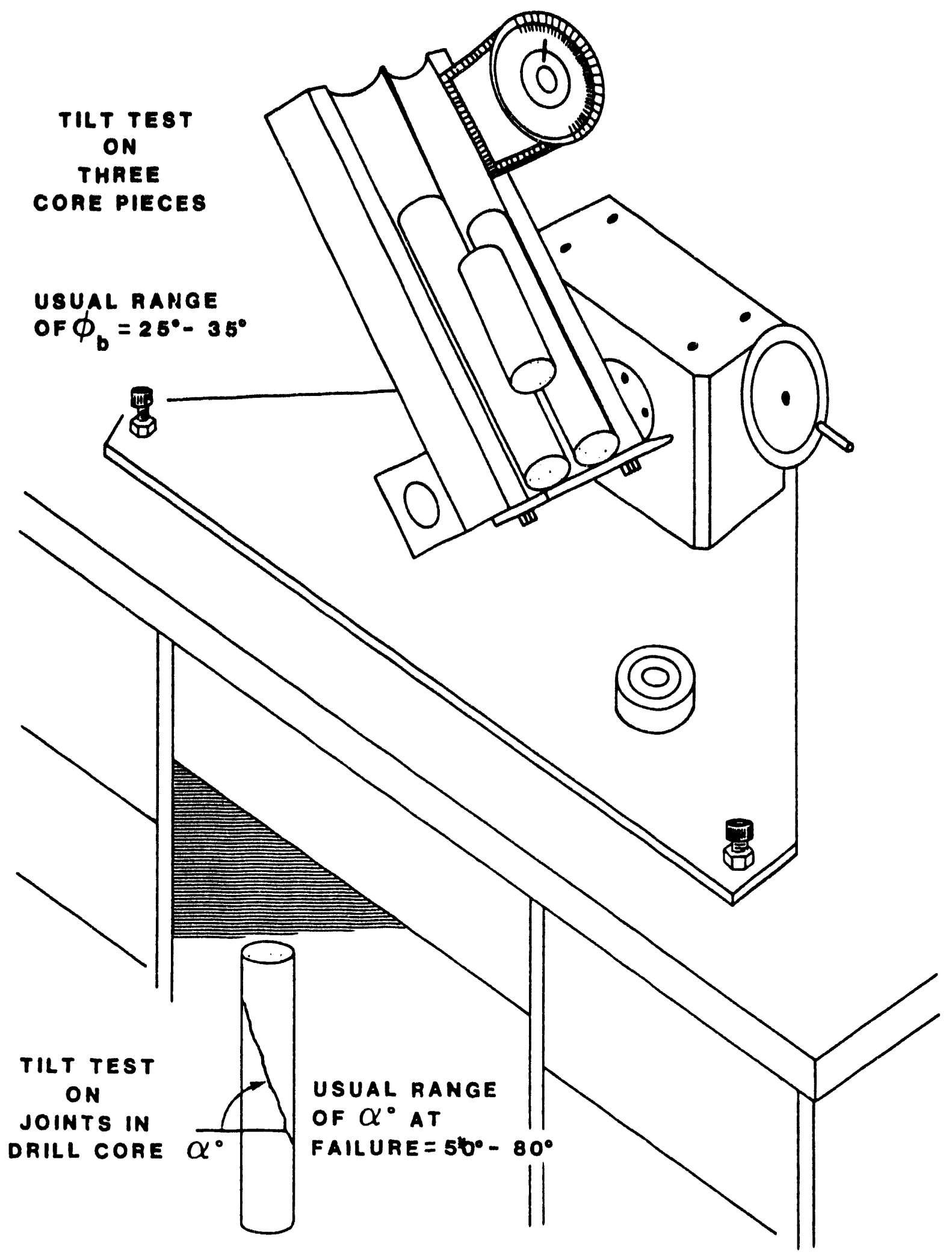

Figure 5-13. Basic friction angle, $\phi_{b}$, determination tilt test 


$$
\frac{z}{l}\left[\operatorname{xp}_{z} \kappa_{7=x}^{0=x} \int^{\frac{T}{I}}\right]=\text { SWY }
$$

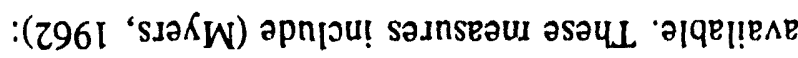

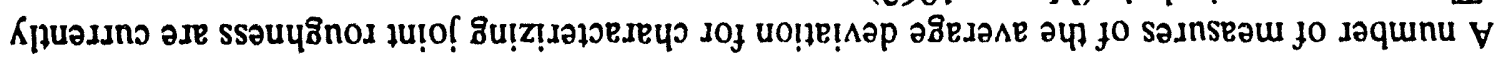

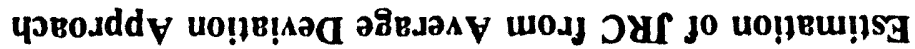

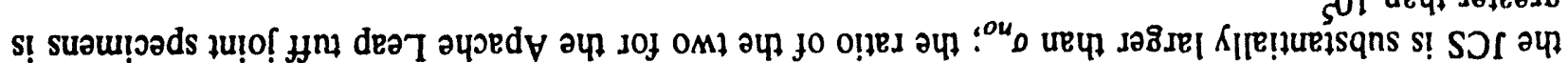

\begin{tabular}{|c|c|c|c|}
\hline & & & गІQв!IEAR ION \\
\hline s'92 & $0 \varepsilon$ & 1.82 & SI \\
\hline$L^{\prime} L Z$ & 62 & $L^{\prime}+2$ & $t I$ \\
\hline $8 . \angle 2$ & 82 & $9<2$ & દI \\
\hline$L^{\prime} L Z$ & $L Z$ & $9^{\circ} \angle 2$ & $2 I$ \\
\hline 5.82 & 92 & $9 \cdot \angle 2$ & II \\
\hline$\varepsilon^{\prime} 92$ & $\$ 2$ & 2.92 & OI \\
\hline 8.92 & $t z$ & 7.82 & 6 \\
\hline $9^{\circ} 92$ & $\varepsilon 2$ & $0 . \angle 2$ & 8 \\
\hline $8^{\prime} 92$ & 22 & 2.92 & $L$ \\
\hline$s^{\prime}+z$ & 12 & $I^{\prime} \angle Z$ & 9 \\
\hline $9 \cdot+2$ & 02 & $\tau^{\prime} 92$ & $s$ \\
\hline 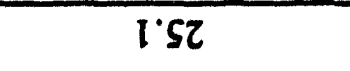 & 61 & $\forall / N$ & $b$ \\
\hline $9 ' S z$ & 81 & $\nabla / N$ & $\bar{\varepsilon}$ \\
\hline 9.52 & LI & $V / N$ & 2 \\
\hline$s ' s z$ & 91 & $* \forall / N$ & $I$ \\
\hline 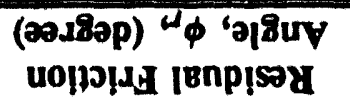 & ON $150 \mathrm{~L}$ & 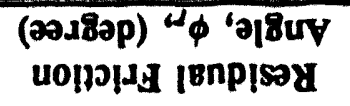 & ON $100 \mathrm{I}$ \\
\hline
\end{tabular}


Table 5-18. Tilt angles, $\alpha$, along the direction of shear and the reversed direction

\begin{tabular}{|c|c|c|c|c|c|}
\hline Test No. & $\begin{array}{c}\text { Tilt Angle } \\
\text { Direction of } \\
\text { Shear } \\
\text { (degrees) }\end{array}$ & $\begin{array}{c}\text { Tilt Angle } \\
\text { Reversed } \\
\text { Direction } \\
\text { (degrees) }\end{array}$ & Test No. & $\begin{array}{c}\text { Tilt Angle } \\
\text { Direction of } \\
\text { Shear } \\
\text { (degrees) }\end{array}$ & $\begin{array}{c}\text { Tilt Angle } \\
\text { Reversed } \\
\text { Direction } \\
\text { (degrees) }\end{array}$ \\
\hline 1 & N/A & N/A & $16^{* *}$ & N/A & N/A \\
\hline 2 & N/A & N/A & 17 & 57 & 58 \\
\hline 3 & N/A & N/A & 18 & 54.5 & 56 \\
\hline 4 & N/A & N/A & 19 & 57 & 56 \\
\hline 5 & 54 & 56 & 20 & 59.5 & 62 \\
\hline 6 & 48 & 49 & 21 & 66 & 66 \\
\hline 7 & 57 & 54 & 22 & 35 & 34 \\
\hline 8 & 57.5 & 50 & 23 & 58 & 55 \\
\hline 9 & 56 & 50 & 24 & 54.5 & 59 \\
\hline 10 & 57 & 54 & $25^{* *}$ & N/A & N/A \\
\hline 11 & 46.5 & 44.5 & 26 & 62 & 67 \\
\hline $12^{*}$ & 48 & 53 & 27 & 58 & 57 \\
\hline $13^{*}$ & N/A & N/A & 28 & 48 & 56 \\
\hline 14 & 63.5 & 63.5 & 29 & 44 & 54 \\
\hline 15 & 51.5 & 52.5 & 30 & 62 & 67 \\
\hline \hline$*$ Same specimen & & & & \\
\hline No tilt angle could be obtained & & & & \\
\hline
\end{tabular}

$$
\begin{aligned}
& Z_{2}=\left[\frac{1}{L} \int_{x=0}^{x=L}\left(\frac{d y}{d x}\right)^{2} d x\right]^{\frac{1}{2}} \\
& Z_{3}=\left[\frac{1}{L} \int_{x=0}^{x=L}\left(\frac{d^{2} y}{d x^{2}}\right)^{2} d x\right]^{\frac{1}{2}}
\end{aligned}
$$

where RMS is the root mean square of the profile, $Z_{2}$ is the root mean square of the first derivative of the profile; $Z_{3}$ is the root mean square of the second derivative of the profile; $L$ is the length of the profile along abscissa; $d y$ is the difference in amplitude, $y$, of two points along the profile; and $d x$ is the distance of the two points used for calculating $d y$.

Tse and Cruden (1979) have established, through regression analysis, the relation between $\mathrm{JRC}_{o}$ and $Z_{2}$, which is determined by numerical characterization of the ten standard profiles proposed by Barton 
and Choubey (1977). The digitizing interval for the numerical characterization was $1.27 \mathrm{~mm}(0.05 \mathrm{in}$.) The relation can be expressed as follows:

$$
\mathrm{JRC}_{0}=32.2+32.47 \log \left(Z_{2}\right)
$$

Other similar equations are also available. However, these equations were developed using different digitizing intervals. It has been demonstrated that the parameter $Z_{2}$ is sensitive to digitizing interval of a profile (Yu and Vayssade, 1991). Since the measuring interval used for profile measurement of the Apache Leap tuff joints is $1.27 \mathrm{~mm}$, which is consistent with the digitizing interval used by Tse and Cruden (1979), the applicability of Eq. (5-21) to the profile measurement for tuff joints is assured, while the application of the other equations is questionable. Consequently, they are not included in this study.

\section{Estimation of JRC Using the Theory of Fractal Geometry}

The theory of fractal geometry (Mandelbrot, 1982; Feder, 1988) can be used to quantitatively characterize the roughness of joint profiles. According to Mandelbrot (1982), a fractal is a shape made of parts similar to the whole in some way. Shapes in Euclidian space, for example, a straight line, a plane surface, or a sphere, are smooth. Real objects are far from these ideal ones. They exhibit some roughness or intricate details over a wide range of scales. For example, a coastline is rough from global scale to atomic scale. Its intricacy is visible in photographs taken from a satellite. It remains jagged when observed from an airplane or while walking along the shore. The theory of fractal geometry takes into account this roughness, which is independent of the scale (Mandelbrot, 1982). The fractal dimension is a quantitative measure of this roughness (Mandelbrot, 1982; Feder, 1988). A fractal object can have a fractal dimension that is different from the topological dimension in Euclidian space (e.g., a line has a topological dimension 1 , a surface has a dimension 2, etc.).

If an object is divided into $N$ numbers of smaller objects each with a size $R$, then the dimension $D$ of the object is defined as (Mandelbrot, 1982):

$$
D=\frac{\log N}{\log \left(\frac{1}{R}\right)}
$$

This equation can be written as

$$
N=R^{-D}
$$

This equation means that the object is composed of several copies of itself with possible rotation and translation. Each of these copies is scaled down from the original by a constant ratio $r(r<1)$ in all spatial directions. Formally, points $X=\left(x_{1}, \ldots, x_{E}\right)$ in $E$-dimensional space transform into new points $X^{\prime}=$ $\left(r x_{1}, \ldots, r x_{E}\right)$ with the same scaling ratio. Therefore, a part of the object, when enlarged appropriately, is identical to the object (Mandelbrot, 1982). These are called self-similar fractals (Mandelbrot, 1982; Feder, 1988; Voss, 1985). The coastline of Great Britain is a famous example of self-similar fractals (Mandelbrot, 1967).

There are several fractal objects that require different scaling factors in different directions. Formally, the points $X=\left(x_{1}, \ldots, x_{E}\right)$ transform into new points $X^{\prime}=\left(r_{1} x_{1}, \ldots, r_{E} x_{E}\right)$. The scaling 
ratios $r_{1}, \ldots, r_{E}$ are not equal. These objects are called self-affine fractals (Mandelbrot, 1982; Feder, 1988). In two dimensions, if the scaling ratios in horizontal and vertical directions are $r_{x}$ and $r_{y}$, respectively, then $r_{x}=r_{y}{ }^{H}$ (Mandelbrot, 1982; Feder, 1988; Voss, 1985; Wong and Lin, 1988) where $H$ has a value between 0 and 1 . One dimensional random walk of a particle is an example of self-affine fractal (Mandelbrot, 1982; Feder, 1988; Voss, 1985).

The fractal dimension of a self-affine fractal is not uniquely defined (Mandelbrot, 1982; Feder, 1988). If the divider length, $R$, is too large compared to the roughness of the fractal object, then the fractal dimension is equal to the topological dimension, which means, in a global sense, that the object is not fractal. But in a local sense, that is, using a small divider length compared to the fluctuation, the fractal dimension can be defined as (Feder, 1988):

$$
D=\frac{1}{H}
$$

This behavior of the self-affine fractal involves a crossover value of the sample interval in which the local value of the fractal dimension passes to a global one. The self-affine property can be viewed as a generalization of the self-similar property.

Assuming the rock surface profiles are self-similar fractals, researchers such as Carr and Warriner (1989), Lee et al. (1990), and Wakabayashi and Fukushige (1992) have developed relations between the fractal dimension $D$ and the $\mathrm{JRC}_{o}$. The relations are as follows:

Carr and Warriner (1989):

$$
\mathrm{JRC}_{0}=-1022.55+1223.92 D
$$

Lee et al., (1990):

$$
\mathrm{JRC}_{0}=-0.8780+37.7844\left(\frac{D-1}{0.015}\right)-16.9304\left(\frac{D-1}{0.015}\right)^{2}
$$

Wakabayashi and Fukushige (1992):

$$
\mathrm{JRC}_{0}=\sqrt{\frac{D-1}{0.00004413}}
$$

Equation (5-25) of Carr and Warriner (1989) was developed using the data collected from a joint face of size $150 \times 15 \mathrm{~m}$ in Libby Dam, Montana. The spacing between two consecutive points of measurement is $15.2 \mathrm{~cm}$. JRC values were estimated by matching with the standard profiles. Lee et al. (1990) and Wakabayashi and Fukushige (1992) developed their relations by directly digitizing the ten standard profiles (Barton and Choubey, 1977), assuming self-similar fractals. Although not mentioned specifically in their paper, the interval used by Lee et al. (1990) for digitizing the ten standard profiles was about $0.5 \mathrm{~mm}$ and the divider lengths used for the determination of fractal dimension of each profile were $1,2,3$, and $5 \mathrm{~mm}$. The divider lengths, which range from 0.05 to $5 \mathrm{~mm}$, were used by Wakabayashi and Fukushige (1992) to determine fractal dimensions for the standard profiles. 
Fractal dimensions of the ten standard profiles (Barton and Choubey, 1977), assuming selfsimilar fractals, have also been calculated by Turk et al. (1987) using divider lengths of 2, 6, 20, and $60 \mathrm{~mm}$. The authors of this report performed a linear regression using the data of Turk et al. (1987) to develop a relation between the $\mathrm{JRC}_{o}$ and the fractal dimension, $D$. The resulting equation is:

$$
\mathrm{JRC}_{0}=-1138.6+1141.6 D
$$

with the coefficient of determination equal to 0.84 .

In order to properly evaluate the abovementioned four fractal-based empirical equations, fractal dimensions for the Apache Leap tuff joints were calculated using the self-similar approach as used for the development of the four equations. The data used for the determination of fractal dimensions were the measurements taken from the profilometer. A computer program, DIVIDER, has been written in FORTRAN 77 to calculate the fractal dimension of a profile using the divider method. For each profile, 12 divider lengths were used: $1.27,1.59,1.91,2.22,2.54,2.86,3.18,3.49,3.81,4.14,4.45$, and $4.76 \mathrm{~mm}$. While traversing the profile, a segment of the profile, $\varepsilon$, smaller than the divider length, almost always remains. This length has been added to the calculated length to estimate the length of the profile more accurately. Therefore, the length of the profile is:

$$
L \approx N \times R+\varepsilon \propto R^{1-D}
$$

where $N$ is the number of arc lengths traversed along the profile with an arc or divider length of $R$. The slope of the best fit line through the data points in a $\log (L)$ versus $\log (R)$ plot is equal to $(1-D)$.

The self-similar approach adopted above for fractal dimension determination is for the purpose of assessing the four fractal-based equations for JRC calculation. It should be noted, however, that, unlike the trace of a coastline, a profile of a rock joint needs different scaling ratios in horizontal and vertical directions to keep the shape of the profile the same. As discussed before, this is the nature of self-affine fractals. The fractal dimensions estimated for all the profiles in this and other studies dealing with rock-joint profiles (Wakabayashi and Fukushige, 1992; Carr and Warriner, 1989; Lee et al., 1990; Turk et al., 1987) are very close to 1.0, which is the topological dimension of the profile. At a much larger scale, Aviles et al. (1987) have observed similar fractal dimensions for segments of the San Andreas fault. The fractal dimension of a joint surface close to 1.0 implies that this surface is smooth, which is contrary to the physical observation of the joint surface. This phenomenon occurs because the divider lengths used in all the studies mentioned above are too large to capture the fluctuation of the profiles. In order to better characterize the roughness of the profiles by the divider method, the divider length has to be quite small. There is a transition point in the scale (crossover length) below which the estimated fractal dimension beccmes significantly larger than the topological dimension and adequately characterizes the self-affine character of the profile (Wong and Lin, 1988). The issue of crossover length is discussed in a later section.

\section{Calculation of $\mathrm{JRC}_{o}$ using Laboratory Joint Shear Test Results}

As discussed earlier, $\mathrm{JRC}_{o}$ is one of several key parameters used by Barton and Choubey (1977) in the development of an empirical equation to predict joint shear behavior, including joint shear strength as shown in Eq. (5-13). With a little manipulation of the equation, the $\mathrm{JRC}_{o}$ can be calculated from the test results through the following equation: 


$$
\mathrm{RC}_{0}=\frac{\tan ^{-1}\left(\frac{\tau}{\sigma_{n}}\right)-\phi_{r}}{\log \left(\frac{J C S}{\sigma_{n}}\right)}
$$

It should be noted that Eq. (5-30) was derived only for back-calculating the $\mathrm{JRC}_{o}$ so that various methods discussed in this section can be compared and, to a certain extent, evaluated. Using this equation to obtain the $\mathrm{JRC}_{o}$ value defeats the purpose of Eq. (5-13), which should be used to predict joint shear strength without performing laboratory joint shear tests.

\section{Comparison of Joint Roughness Coefficient from Various Methods}

Table 5-19 lists the JRC ${ }_{o}$ values calculated from the tilt test [Eq. (5-17)], Tse and Cruden's (1979) equation [Eq. (5-21)], and the four fractal-based equations [Eqs. (5-25), (5-26), (5-27), and (5-28)] for 16 Apache Leap tuff joints that were used for pseudostatic direct shear tests under the dry condition. Not listed in this table are those $\mathrm{JRC}_{o}$ values for the specimens that were used for harmonic, seismic, and wet pseudostatic tests. These tests were conducted under conditions different from those of dry pseudostatic shear tests. As a result, the calculated $\mathrm{JRC}_{o}$ values from the results of the different types of shear tests are not comparable. Consequently, they are excluded from this discussion. Tilt tests were not performed for the first four rock-joint specimens. Consequently, no JRC ${ }_{o}$ values are available for these four specimens. Although the tilt angle and the $\mathrm{JRC}_{o}$ of an Apache Leap tuff joint are shear direction dependent, the difference in $\mathrm{JRC}_{o}$ in the direction of shear and in the reverse direction is less than one. Only those $\mathrm{JRC}_{o}$ values in the direction of shear are presented in the table.

As discussed earlier, for a given joint surface, profiles along more than 140 longitudinal sections were taken. Each profile can be used to obtain a $\mathrm{JRC}_{o}$ value. Each $\mathrm{JRC}_{o}$ value listed in columns 3 through 8 in Table 5-19 represents an arithmetic average of at least $280 \mathrm{JRC}_{o}$ values obtained from both top and bottom joint blocks of a single rock-joint specimen.

Examining more than $280 \mathrm{JRC}_{o}$ values of each joint specimen indicates that, for most of the sixteen specimens, the variation of the majority of the $\mathrm{JRC}_{o}$ values falls within a narrow range of less than five. Consequently, using the average value to represent the roughness of a rock joint should be reasonable. However, as one would expect, there were cases in which the variation among the JRCo values along different cross sections of a joint surface was quite large. Figure 5-14 shows an example of the distribution and frequency of occurrence of $\mathrm{JRC}_{o}$ values calculated using Tse and Cruden's equation [Eq. (5-21)] for the joint surfaces of specimen for test no. 19. As indicated in the figure, the $\mathrm{JRC}_{o}$ values of this specimen ranged from 3 to 16 , with a majority of the values between 5 to 11 and an average value of 8.2. Whether this average $\mathrm{JRC}_{o}$ value is representative of the joint roughness is arguable.

It is even more complicated for a case, as shown in Figure 5-15, in which two distinct JRC groups were observed. Should the representative $\mathrm{JRC}_{o}$ be calculated by averaging all $\mathrm{JRC}_{o}$ values or perhaps just the values in the group that contains larger $\mathrm{JRC}_{o}$ ? The key issue is how the joint behaves under such a complicated condition. To the authors' knowledge, little relevant discussion exists in the literature. 
Table 5-19. Comparison of $\mathrm{JRC}_{0}$ determined by various methods

\begin{tabular}{|c|c|c|c|c|c|c|c|}
\hline 1 & 2 & 3 & 4 & 5 & 6 & 7 & 8 \\
\hline $\begin{array}{l}\text { Test } \\
\text { No. }\end{array}$ & $\begin{array}{l}\text { Tilt } \\
\text { Test }\end{array}$ & $\begin{array}{l}\text { Tse and } \\
\text { Cruden } \\
\text { (1979) }\end{array}$ & $\begin{array}{c}\text { Carr \& } \\
\text { Warriner } \\
\text { (1989) }\end{array}$ & $\begin{array}{c}\text { Turk et al. } \\
\text { (1987) }\end{array}$ & $\begin{array}{c}\text { Lee et al. } \\
\text { (1990) }\end{array}$ & $\begin{array}{c}\text { Wakabayashi } \\
\text { \& Fukushige } \\
\text { (1992) }\end{array}$ & $\begin{array}{l}\text { Shear } \\
\text { Test* }\end{array}$ \\
\hline 1 & N/A** & 8.0 & 4.6 & 6.6 & 6.2 & 8.3 & 12.0 \\
\hline 2 & N/A & 7.3 & 5.5 & 7.6 & 8.0 & 9.5 & 13.4 \\
\hline 3 & N/A & 8.5 & 5.5 & 7.6 & 8.1 & 9.6 & 10.8 \\
\hline 4 & N/A & 6.9 & 4.6 & 6.7 & 6.4 & 8.5 & 9.8 \\
\hline 5 & 5.6 & 5.2 & 4.4 & 6.4 & 5.9 & 8.2 & 11.6 \\
\hline 6 & 4.1 & 5.7 & 4.4 & 6.4 & 6.0 & 8.2 & 10.5 \\
\hline 7 & 6.2 & 6.8 & 4.5 & 6.5 & 6.2 & 8.4 & 12.1 \\
\hline 8 & 6.0 & 6.3 & 4.5 & 6.5 & 6.1 & 8.3 & 11.0 \\
\hline 9 & 5.4 & 2.0 & 3.0 & 4.8 & 3.0 & 6.0 & 7.1 \\
\hline 10 & 6.1 & 8.1 & 5.2 & 7.2 & 7.4 & 9.2 & 11.8 \\
\hline 11 & 3.8 & 1.9 & 3.0 & 4.8 & 3.0 & 6.0 & 10.4 \\
\hline 17 & 6.4 & 7.2 & 5.5 & 7.6 & 8.0 & 9.5 & 11.9 \\
\hline 18 & 5.8 & 7.0 & 5.2 & 7.2 & 7.4 & 9.2 & 11.2 \\
\hline 19 & 6.3 & 8.2 & 5.2 & 7.2 & 7.4 & 9.1 & 11.1 \\
\hline 20 & 7.3 & 7.3 & 5.0 & 7.0 & 7.0 & 8.9 & 19.8 \\
\hline 21 & 8.1 & 10.5 & 8.0 & 10.4 & 12.3 & 12.4 & 18.8 \\
\hline
\end{tabular}

Column 3 in Table 5-19 lists the average $\mathrm{JRC}_{o}$ values calculated from Tse and Crudeis's equation [Eq. (5-21)] for the 16 test specimens. For each joint, the $\mathrm{JRC}_{o}$ values of the longitudinal profiles obtained from Eq. (5-21) smaller than 0 or greater than 20 were excluded in the calculation of the average $\mathrm{JRC}_{o}$ value of the joint, since the 10 standard profiles (Barton and Choubey, 1977) include only JRC values within the range of 0 to 20 and Eq. (5-21) was developed based on these profiles. Based on Eq. $(5-21), \mathrm{JRC}_{0}$ will be greater than 20 when $Z_{2}$ is greater than 0.42 and smaller than 0 when $Z_{2}$ is smaller than 0.1 .

Columns 4 through 7 of Table 5-19 represent the $\mathrm{JRC}_{o}$ values calculated using the four fractalbased equations [Eq. (5-25) through (5-28)]. The $\mathrm{JRC}_{o}$ values predicted by these four equations appear to be quite different. The Carr and Warriner equation [Eq. (5-25)] predicts the lowest $\mathrm{JRC}_{o}$ value, while the equation developed by Wakabayashi and Fukushige [Eq. (5-27)] gives the highest prediction. The 


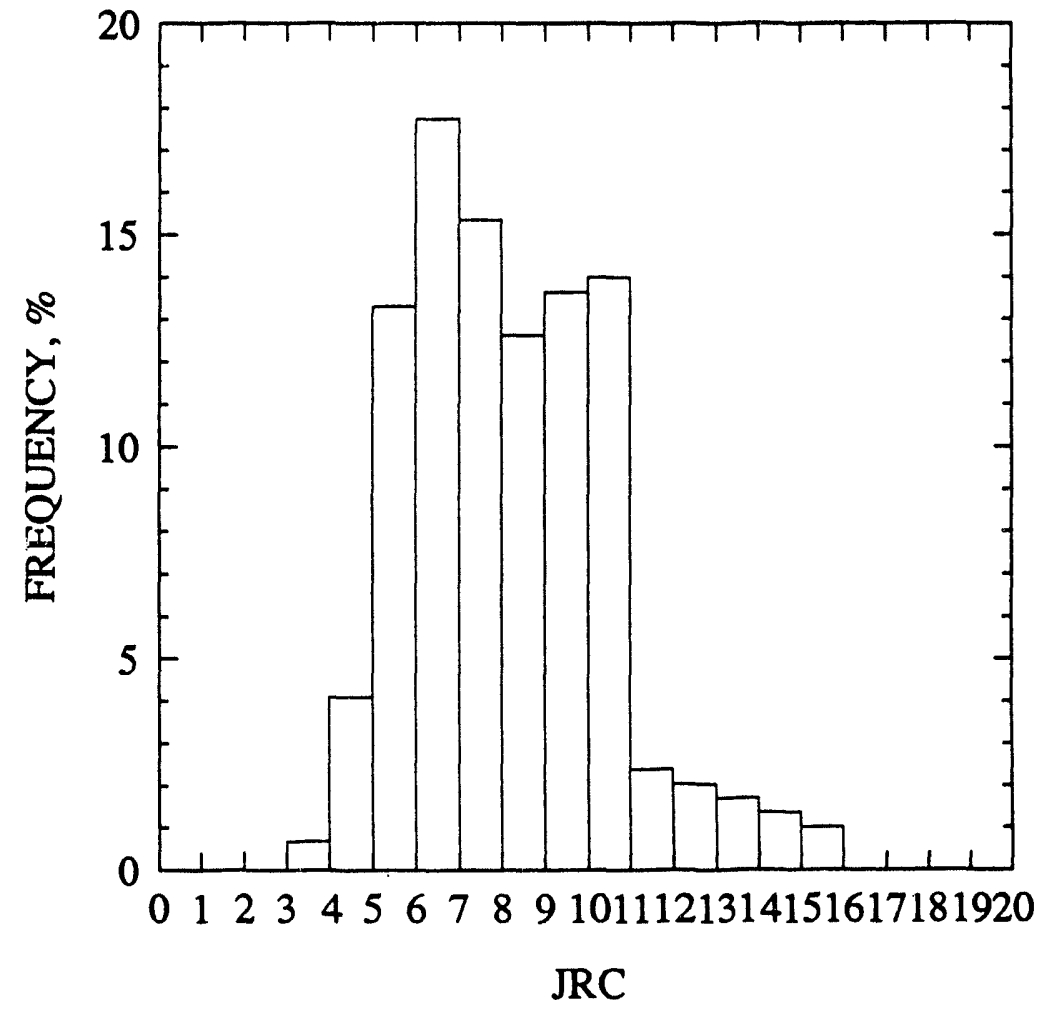

Figure 5-14. JRC distribution for top and bottom joint surfaces of specimen used for test no. 19

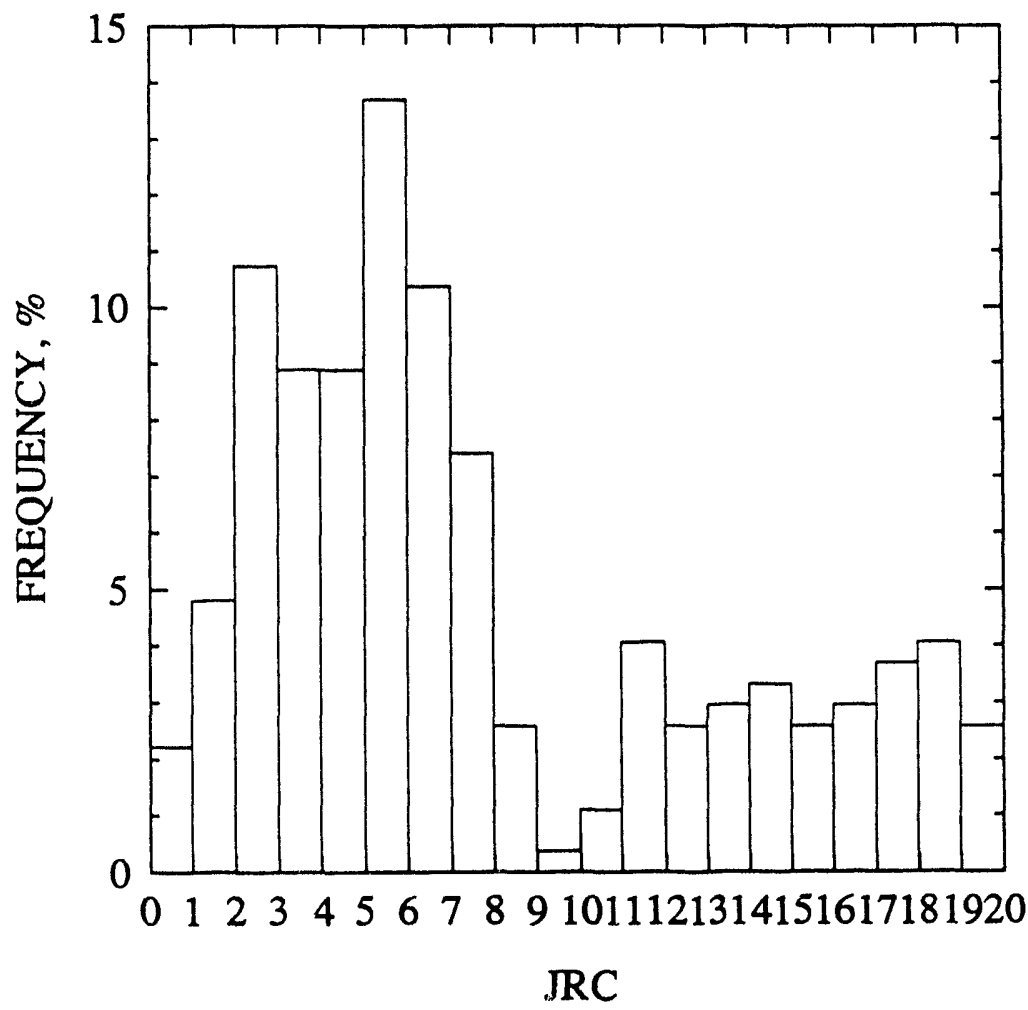

Figure 5-15. JRC distribution for top and bottom joint surfaces of specimen used for test no. 1 
equations from Lee et al. [Eq. (5-26)] and Turk et al. [Eq. (5-28)] generate similar results. As much as 100-percent difference in predicted values has been realized using these four equations.

Column 8 lists the $\mathrm{JRC}_{o}$ values back-calculated from Eq. (5-30) using the direct joint shear test results. As indicated in Eq. (5-30), $\mathrm{JRC}_{o}$ is a function of four variables, namely, $\sigma_{s}, \sigma_{n}, \mathrm{JCS}$, and $\phi_{r}$. $\sigma_{s}$ and $\sigma_{n}$ are obtained directly from the joint shear test results, while JCS and $\phi_{r}$ have to be determined using separate tests, as discussed in the previous section. For a constant $\sigma_{s}$ and $\sigma_{n}, \mathrm{JRC}_{o}$ decreases with an increase in JCS or $\phi_{r}$. A comparison of the $\mathrm{JRC}_{o}$ values calculated using JCS with those $\mathrm{JRC}_{o}$ values calculated using the uniaxial compressive strength of the intact rock surrounding the joint shows that the effect of the JCS on $\mathrm{JRC}_{o}$ for the Apache Leap tuff joint is small. However, variation of $\phi_{r}$ has a large effect on $\mathrm{JRC}_{o}$. The calculation of $\phi_{r}$ in this study was based on the approach recommended by Barton and Choubey (1977). The conclusion drawn in the next few paragraphs of this report includes the assumption that the recommended approach will generate reasonable and reliable value for $\phi_{r}$. The conclusion may need to be modified if the approach for the determination of $\phi_{r}$ is found to be inappropriate in the future. In any event, the values of $\mathrm{JRC}_{o}$ predicted by the methods listed in Table 5-19 are so different that some work is needed to reconcile the differences.

Table 5-19 illustrates that all the methods listed underestimate the $\mathrm{JRC}_{o}$ (back-calculated from the shear tests) of Apache Leap tuff joints. In general, the extent of the underestimation is quite substantial. In many cases, the difference is more than a factor of two, except for the predictions (column 7) produced by the fractal-based empirical equation [Eq. (5-27)] developed by Wakabayashi and Fukushige (1992). Even with this equation, the underestimation of Eq. (5-18) could be as large as 40

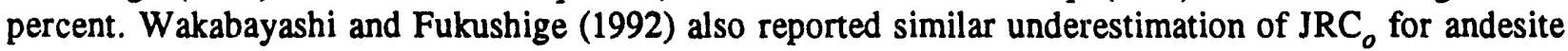
and grani ${ }^{4}$ joints. The back-calculated $\mathrm{JRC}_{o}$ for the andesite joint is about 1.6 times the $\mathrm{JRC}_{o}$ value calculated from Eq. (5-27), and it is about 1.4 times for the granite joint.

A statistical analysis was performed in order to try to establish a relation between $\mathrm{JRC}_{o}$ values determined from the various methods and $\mathrm{JRC}_{o}$ values determined from the direct shear test results. The Wilcoxon signed-rank test on the matched-pairs consisting of the $\mathrm{JRC}_{o}$ values from each method in Table 5-19 and those from joint shear tests has led to a rejection of the null hypothesis, $H_{o}$, that the two data sets are equivalent, at a level of significance $\alpha=0.05$. This value indicates that none of the methods can predict a $\mathrm{JRC}_{o}$ value for an Apache Leap tuff joint that is not significantly different from the value obtained directly from the joint shear test result. Among the various test methods, the Wilcoxon test results reveal that there is no statistically significant difference in the results generated by the equations proposed by Turk et al. [Eq. (5-28)] and Lee et al. [Eq. (5-26)]. Also no difference was found between the results from Eq. (5-21) and Eq. (5-28).

The positive correlation was evaluated for the data generated by the various methods with respect to those from the joint shear test results using the Spearman's rank correlation coefficient test. This test provides a measure of correlation between the trends of two sample sets; that is, whether an increase in the first sample set corresponds to an increase in the second sample set. For a "perfect positive agreement," the correlation coefficient, $r_{s}$, is equal to 1.0. The $r_{s}$ value for the various methods with the shear test results in this study ranges from 0.51 to 0.55 , with the exception of the tilt test, which has a $r_{s}$ value of about 0.85 . The hypothesis testing of the significance of the $r_{s}$ values was carried out at $\alpha=0.05$. The results indicate that the $\mathrm{JRC}_{o}$ value calculated from the various methods tends to increase with the $\mathrm{JRC}_{o}$ value from the shear test result. This trend is, however, quite weak given that the corresponding $r_{s}$ is relatively small. 
Currently, it seems that none of the methods discussed here can provide a reasonable $\mathrm{JRC}_{o}$ value to be used for the estimation of joint shear strength, which is essential to understanding joint shear behavior. The idea of using these methods for $\mathrm{JRC}_{0}$ calculation to reduce the need for pseudostatic joint shear tests in the laboratory may not be sound at present. Additional study is needed to further define and modify these methods before they can be used with confidence.

The observed underestimation of the $\mathrm{JRC}_{o}$ value for the Apache Leap tuff joints will result in an underestimation of their joint shear strength (Figure 5-16) and initial mechanical (hydraulic) joint aperture, and subsequent aperture changes in joint shearing. Barton et al. (1985) has proposed an empirical equation that links the joint aperture and $\mathrm{JRC}_{o}$. Based on the proposed equation, joint aperture increases with $\mathrm{JRC}_{0}$. Underestimation of joint shear strength may prove to be conservative in mechanical analysis as well as for design of underground excavations. However, an underestimation of joint aperture and its changes during shearing may not be conservative from the standpoint of their impact on fluid and gas flow through fractures in the context of long-term repository performance.

\subsubsection{Parameter Determination for Continuously-Yielding Joint Model}

The Continuously-Yielding model for rock joint deformation under normal and shear loads has been developed by Itasca Consulting Group, Inc. (Itasca Consulting Group, Inc. 1992; Cundall and Lemos, 1988). The model can simulate, in a simple way, the progressive damage of the joint surface under shear displacement. The model also provides continuous hysteretic damping under dynamic load by using the "bounding surface" concept. UDEC (Version 1.8) employs a modified version of the Continuously-Yielding model as one of the options for rock joint model.

The response of the joint to normal compressive loading is described incrementally as:

$$
\Delta \sigma_{n}=K_{n} \Delta u_{n}
$$

where the normal stiffness of the joint $K_{n}$ is:

$$
K_{n}=a_{n} \sigma_{n}^{e_{n}}
$$

Therefore,

$$
\Delta \sigma_{n}=a_{n} \sigma_{n}^{e_{n}} \Delta u_{n}
$$

Parameters $a_{n}$ and $e_{n}$ in Eq. (5-32) are constants. Equation (5-32) models the increase in normal stiffness with an increase in normal stress. The Continuously-Yielding model displays irreversible nonlinear behavior from the onset of shear loading. The shear stress increment is described as:

$$
\Delta \sigma_{s}=F K_{s} \Delta u_{s}
$$

where the shear stiffness $K_{s}$ is:

$$
K_{s}=a_{s} \sigma_{n}^{e_{s}}
$$

Therefore, the change in shear stress due to change in shear displacement is: 


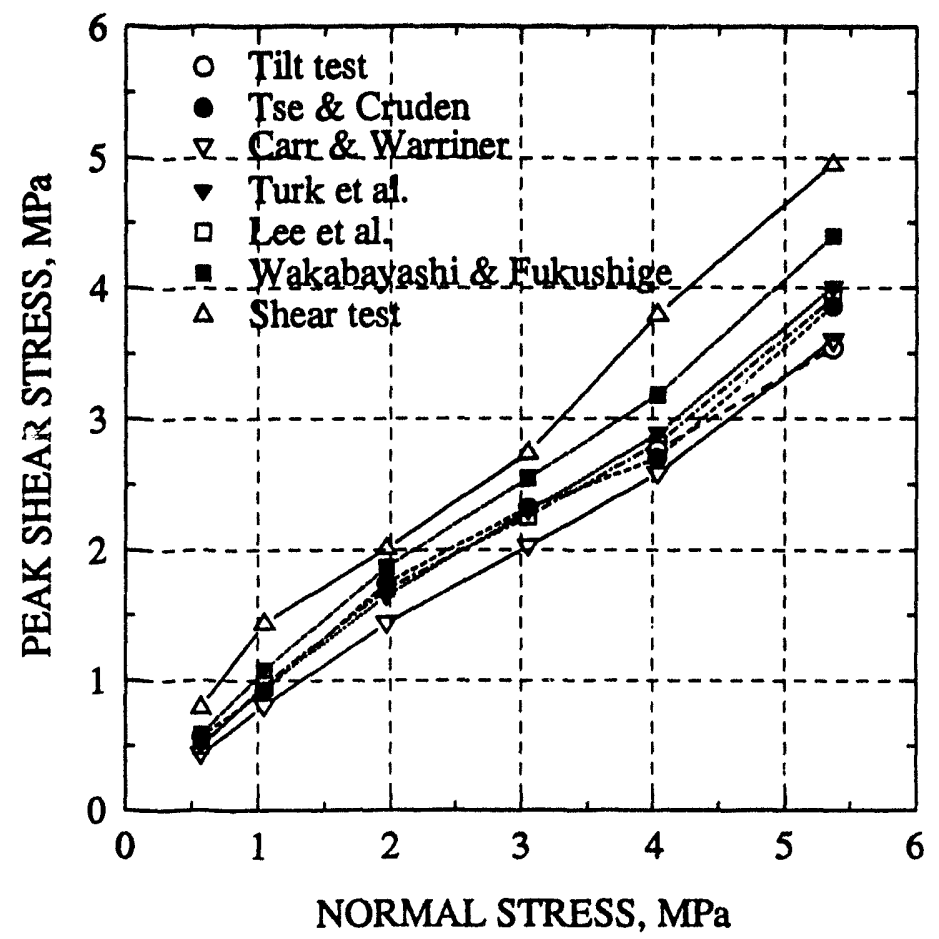

Figure 5-16. Plot of calculated and measured peak shear stress versus normal stress for joint specimen used for test nos. 1 to 6

$$
\Delta \sigma_{s}=F a_{s} \sigma_{n}^{e s} \Delta u_{s}
$$

where $F$ is a factor that governs the shear stiffness, and parameters $a_{s}$ and $e^{s}$ in Eq. (5-35) are constants. $F$ depends on the difference between the actual stress curve and the bounding strength curve $\tau_{m}$ and is given as:

$$
F=\frac{\left(1-\sigma / \tau_{m}\right)}{(1-r)}
$$

Therefore, $\Delta \sigma_{s}$ is:

$$
\Delta \sigma_{s}=\frac{\left(1-\sigma_{g} / \tau_{m}\right)}{(1-r)} a_{s} \sigma_{n}^{e s} \Delta u_{s}
$$

The factor $r$ is initially 0 . It restores the elastic stiffness immediately after load reversal. That means $r$ is set to $\sigma_{s} / \tau_{m}$ (F becomes 1) whenever the sign of $\left(\Delta u_{s}\right)$ is not the same as the sign of $\left(\Delta u_{s}\right.$ old $)$. In practice, $r$ is restricted to a maximum value of 0.75 to avoid numerical noise when the shear stress is approximately equal to the bounding strength, $\tau_{m}$. The bounding strength, $\tau_{m}$, is

$$
\tau_{m}=\sigma_{n} \tan \phi_{m} \operatorname{sign}\left(\Delta u_{s}\right)
$$

$\phi_{m}$ is the friction angle that would apply if the joint is to dilate at the maximum dilation angle and is initially equal to the joint initial friction angle, $\phi_{m o}$. As damage accumulates, $\phi_{m}$ is continuously reduced according to 


$$
\Delta \phi_{m}=-\frac{1}{R}\left(\phi_{m}-\phi\right) \Delta u_{s}^{p}
$$

where $\Delta u_{s}^{p}$ is the plastic displacement increment and is given by

$$
\Delta u_{s}^{p}=(1-F)\left|\Delta u_{s}\right|
$$

and $\phi$ is the basic friction angle of the rock surface. $R$ is a material parameter with a dimension of length that expresses the joint roughness. A large value of $R$ produces slower reduction of $\phi_{m}$ and a higher peak. The pe.sk is reached when the bounding strength equals the shear stress. After the peak, the joint is in the softening region and the value of $F$ becomes negative.

The Continuously-Yielding joint model in UDEC requires the following parameters as input:

- jen: exponent of joint elastic normal stiffness [ $e_{n}$ in Eq. (5-32)]

- jes: exponent of joint elastic sinear stiffness $\left[e_{s}\right.$ in Eq. (5-35)]

- jif: joint initial friction angle $\left(\phi_{m o}\right)$

- jr: joint roughness parameter $[R$ in Eq. (5-40)]

- jkn: joint normal stiffness $\left[a_{n}\right.$ in Eq. (5-32)]

- jks: joint shear stiffness $\left[a_{s}\right.$ in Eq. (5-35)]

- jfric: joint residual friction angle [ $\phi$ in Eq. (5-40)]

Hakala et al. (1993) have developed a methodology to estimate the input parameters for the ContinuouslyYielding joint model that best "fit" a set of laboratory data. A set of initial values for the parameter $P_{i}$ $(i=1, \ldots, n p$, where $n p$ is the total number of parameters in the model) is given by the user as input. The fit of the parameters to the data is evaluated. Initially, the fit is calculated based on the least-square method. The "fit" is improved by independently changing each parameter, in turn, by a small amount $\Delta P$. The change in fit is calculated as the sums of square error $\operatorname{SSE}(P)$. For each parameter $P_{i}$,

$$
\frac{\delta S S E}{\delta P_{i}}=\frac{\operatorname{SSE}(P)-\operatorname{SSE}(P+\Delta P)}{\Delta P}
$$

is evaluated. A modified Levenherg-Marquardt algorithm is used to determine how each parameter should be changed for the next evaluation.

Two fitting programs were used (Hakala et al., 1993) to determine the input parameters for joint normal deformation (NORMFIT.EXE) and shear deformation (SHEARFIT.EXE). NORMFIT.EXE estimates $a_{n}$ and $e_{n}$ from normal load versus joint closure data for each test. It uses only the loading portion of the data. SHEARFIT.EXE estimates $\phi_{m o}, \phi, R, a_{s}$, and $e_{s}$ from shear stress versus joint shear displacement data under constant normal load. Both programs can simultaneously incorporate several test data files for estimating the parameters or may be run with only one data file. However, SHEARFIT.EXE cannot estimate $a_{s}$ and $e_{s}$ from only one test. In such cases, $K_{s}$ is estimated instead (that is, it is assumed that $e_{s}$ is equal to 0.0 or shear stiffness of the joint is independent of normal stress applied across it). 
Both fitting programs use a modified least-square objective function. In NORMFIT.EXE, the objective function is:

$$
\text { Minimize SSE }=\sum_{j=1}^{M} \sum_{i=1}^{N_{j}}\left[U_{n}^{\prime}(i, j)-U_{n}(i, j)\right]^{2}
$$

where $M$ is the number of data sets, $N_{j}$ is the number of data records in the $j$-th set, $U_{n}(i, j)$ is the $i$-th measured joint closure in the $j$-th set, and $U_{n}{ }^{\prime}(i j)$ is the $i$-th predicted joint closure in the $j$-th set.

In SHEARFIT.EXE, the objective function is:

$$
\begin{aligned}
\text { Minimize SSE } & =\sum_{j=1}^{M} \sum_{i=1}^{N_{j}} W_{n}\left[U_{n}^{\prime}(i, j)-U_{n}(i, j)\right]^{2} \\
& +\sum_{j=1}^{M} \sum_{i=1}^{N_{j}} W_{s}\left[S_{s}^{\prime}(i, j)-S_{s}(i, j)\right]^{2}
\end{aligned}
$$

where $M$ is the number of data sets, $N_{j}$ is the number of data records in the $j$-th set, $W_{n}$ is a weight placed on the joint displacement lack-of-fit, $W_{s}$ is a weight placed on the shear stress lack-of-fit, $U_{n}(i, j)$ is the $i$-th measured joint displacement in the $j$-th set, $U_{n}{ }^{\prime}(i, j)$ is the $i$-th predicted joint displacement in the $j$-th set, $S_{s}(i, j)$ is the $i$-th measured shear stress in the $j$-th set, and $S_{s}{ }^{\prime}(i, j)$ is the $i$-th predicted shear stress in the $j$-th set. The sum of $\mathrm{W}_{n}$ and $\mathrm{W}_{s}$ is equal to 1 . The weights are calculated in such a way that the lack-of-fit of joint displacement and lack-of-fit of shear stress have a user-specified relative importance (trade-off factor). The weights are necessary as a significant difference in units between the two lack-of-fit components exists.

Both NORMFIT.EXE and SHEARFIT.EXE were used to estimate the normal and shear deformation parameters for all the pseudostatic shear tests. The normal deformation parameters were calculated for each cycle. Results are given in Table 5-20. Shear deformation parameters are estimated for each test from the data for first normal load (fresh joint). These results are reported in Table 5-21. The 68-percent confidence intervals for each parameter are also given in Table 5-21. Effect of userspecified relative importance parameters, which varies from 0.0 to 1.0, has been studied for the data set from shear test no. 11. The results, shown in Table 5-22, are quite insensitive to the trade-off factor except near the two extreme regions. 
Table 5-20. Estimated values of $a_{n}$ and $e_{n}$

\begin{tabular}{|c|c|c|c|c|c|c|}
\hline $\begin{array}{l}\text { Test } \\
\text { No. }\end{array}$ & Cycle 1 & Cycle 2 & Cycle 3 & Cycle 4 & Cycle 5 & Combined \\
\hline 1 & $\begin{array}{l}a_{n}=30827 \\
e_{n}=0.9826\end{array}$ & $\begin{array}{l}a_{n}=90553 \\
e_{n}=0.6882\end{array}$ & $\begin{array}{l}a_{n}=119931 \\
e_{n}=0.6293\end{array}$ & $\begin{array}{l}a_{n}=118722 \\
e_{n}=0.6683\end{array}$ & $\begin{array}{l}a_{n}=86129 \\
e_{n}=0.6813\end{array}$ & $\begin{array}{l}a_{n}=74785 \\
e_{n}=0.7837\end{array}$ \\
\hline 2 & $\begin{array}{l}a_{n}=35560 \\
e_{n}=0.8384\end{array}$ & $\begin{array}{l}a_{n}=70377 \\
e_{n}=0.6628\end{array}$ & $\begin{array}{l}a_{n}=73926 \\
e_{n}=0.7278\end{array}$ & $\begin{array}{l}a_{n}=77273 \\
e_{n}=0.7226\end{array}$ & $\begin{array}{l}a_{n}=58640 \\
e_{n}=0.7240\end{array}$ & $\begin{array}{l}a_{n}=58312 \\
e_{n}=0.7467\end{array}$ \\
\hline 3 & $\begin{array}{l}a_{n}=31238 \\
e_{n}=0.5787\end{array}$ & $\begin{array}{l}a_{n}=40849 \\
e_{n}=0.7213\end{array}$ & $\begin{array}{l}a_{n}=42086 \\
e_{n}=0.7803\end{array}$ & $\begin{array}{l}a_{n}=38945 \\
e_{n}=0.8793\end{array}$ & $\begin{array}{l}a_{n}=32857 \\
e_{n}=0.8643\end{array}$ & $\begin{array}{l}a_{n}=38902 \\
e_{n}=0.7888\end{array}$ \\
\hline 4 & $\begin{array}{l}a_{n}=21733 \\
e_{n}=0.5616\end{array}$ & $\begin{array}{l}a_{n}=22443 \\
e_{n}=0.6389\end{array}$ & $\begin{array}{l}a_{n}=23535 \\
e_{n}=0.6569\end{array}$ & $\begin{array}{l}a_{n}=22953 \\
e_{n}=0.7016\end{array}$ & $\begin{array}{l}a_{n}=22122 \\
e_{n}=0.6915\end{array}$ & $\begin{array}{l}a_{n}=22585 \\
e_{n}=0.6390\end{array}$ \\
\hline 5 & $\begin{array}{l}a_{n}=18731 \\
e_{n}=0.4250\end{array}$ & $\begin{array}{l}a_{n}=24362 \\
e_{n}=0.5123\end{array}$ & $\begin{array}{l}a_{n}=25368 \\
e_{n}=0.5823\end{array}$ & $\begin{array}{l}a_{n}=28197 \\
e_{n}=0.5672\end{array}$ & $\begin{array}{l}a_{n}=24708 \\
e_{n}=0.6231\end{array}$ & $\begin{array}{l}a_{n}=23852 \\
e_{n}=0.5253\end{array}$ \\
\hline 6 & $\begin{array}{l}a_{n}=23142 \\
e_{n}=0.4700\end{array}$ & $\begin{array}{l}a_{n}=32070 \\
e_{n}=0.5100\end{array}$ & $\begin{array}{l}a_{n}=39452 \\
e_{n}=0.5400\end{array}$ & $\begin{array}{l}a_{n}=42329 \\
e_{n}=0.5233\end{array}$ & $\begin{array}{l}a_{n}=42830 \\
e_{n}=0.4811\end{array}$ & $\begin{array}{l}a_{n}=34201 \\
e_{n}=0.4948\end{array}$ \\
\hline 7 & $\begin{array}{l}a_{n}=32871 \\
e_{n}=0.7546\end{array}$ & $\begin{array}{l}a_{n}=68108 \\
e_{n}=0.7317\end{array}$ & $\begin{array}{l}a_{n}=69859 \\
e_{n}=0.6324\end{array}$ & $\begin{array}{l}a_{n}=74002 \\
e_{n}=0.6710\end{array}$ & $\begin{array}{l}a_{n}=74848 \\
e_{n}=0.6860\end{array}$ & $\begin{array}{l}a_{n}=57857 \\
e_{n}=0.7086\end{array}$ \\
\hline 8 & $\begin{array}{l}a_{n}=26840 \\
e_{n}=0.6231\end{array}$ & $\begin{array}{l}a_{n}=36069 \\
e_{n}=0.5797\end{array}$ & $\begin{array}{l}a_{n}=36731 \\
e_{n}=0.5732\end{array}$ & $\begin{array}{l}a_{n}=36964 \\
e_{n}=0.5941\end{array}$ & $\begin{array}{l}a_{n}=36080 \\
e_{n}=0.6086\end{array}$ & $\begin{array}{l}a_{n}=34045 \\
e_{n}=0.5965\end{array}$ \\
\hline 9 & $\begin{array}{l}a_{n}=19661 \\
e_{n}=0.7356\end{array}$ & $\begin{array}{l}a_{n}=31865 \\
e_{n}=0.6417\end{array}$ & $\begin{array}{l}a_{n}=34349 \\
e_{n}=0.6307\end{array}$ & $\begin{array}{l}a_{n}=33069 \\
e_{n}=0.6913\end{array}$ & $\begin{array}{l}a_{n}=35020 \\
e_{n}=0.6541\end{array}$ & $\begin{array}{l}a_{n}=29361 \\
e_{n}=0.6783\end{array}$ \\
\hline 10 & $\begin{array}{l}a_{n}=43635 \\
e_{n}=0.4263\end{array}$ & $\begin{array}{l}a_{n}=46622 \\
e_{n}=0.5600\end{array}$ & $\begin{array}{l}a_{n}=51167 \\
e_{n}=0.5029\end{array}$ & $\begin{array}{l}a_{n}=47425 \\
e_{n}=0.5740\end{array}$ & $\begin{array}{l}a_{n}=51644 \\
e_{n}=0.5344\end{array}$ & $\begin{array}{l}a_{n}=47801 \\
e_{n}=0.5199\end{array}$ \\
\hline
\end{tabular}


Table 5-20. Estimated values of $a_{n}$ and $e_{n}$ (cont'd)

\begin{tabular}{|c|c|c|c|c|c|c|}
\hline $\begin{array}{l}\text { Test } \\
\text { No. }\end{array}$ & Cycle 1 & Cycle 2 & Cycle 3 & Cycle 4 & Cycle 5 & Combined \\
\hline 11 & $\begin{array}{l}a_{n}=37082 \\
e_{n}=0.7836\end{array}$ & $\begin{array}{l}a_{n}=54625 \\
e_{n}=0.7731\end{array}$ & $\begin{array}{l}a_{n}=66944 \\
e_{n}=0.5795\end{array}$ & $\begin{array}{l}a_{n}=68578 \\
e_{n}=0.7508\end{array}$ & $\begin{array}{l}a_{n}=77733 \\
e_{n}=0.7344\end{array}$ & $\begin{array}{l}a_{n}=56953 \\
e_{n}=0.7304\end{array}$ \\
\hline 12 & $\begin{array}{l}a_{n}=59122 \\
e_{n}=0.5789\end{array}$ & $\begin{array}{l}a_{n}=91723 \\
e_{n}=0.5472\end{array}$ & $\begin{array}{l}a_{n}=78910 \\
e_{n}=0.7695\end{array}$ & $\begin{array}{l}a_{n}=96453 \\
e_{n}=0.5504\end{array}$ & $\begin{array}{l}a_{n}=83712 \\
e_{n}=0.7099\end{array}$ & $\begin{array}{l}a_{n}=79849 \\
e_{n}=0.6244\end{array}$ \\
\hline 13 & $\begin{array}{l}a_{n}=50201 \\
e_{n}=0.4928\end{array}$ & $\begin{array}{l}a_{n}=53527 \\
e_{n}=0.4965\end{array}$ & $\begin{array}{l}a_{n}=54517 \\
e_{n}=0.4862\end{array}$ & $\begin{array}{l}a_{n}=52843 \\
e_{n}=0.5364\end{array}$ & $\begin{array}{l}a_{n}=53685 \\
e_{n}=0.5309\end{array}$ & $\begin{array}{l}a_{n}=52931 \\
e_{n}=0.5072\end{array}$ \\
\hline 14 & $\begin{array}{l}a_{n}=18944 \\
e_{n}=0.8037\end{array}$ & $\begin{array}{l}a_{n}=53514 \\
e_{n}=0.5499\end{array}$ & $\begin{array}{l}a_{n}=54428 \\
e_{n}=0.6137\end{array}$ & $\begin{array}{l}a_{n}=54772 \\
e_{n}=0.6300\end{array}$ & $\begin{array}{l}a_{n}=52993 \\
e_{n}=0.66\end{array}$ & $\begin{array}{l}a_{n}=39141 \\
e_{n}=0.6885\end{array}$ \\
\hline 15 & $\begin{array}{l}a_{n}=52419 \\
e_{n}=0.3921\end{array}$ & $\begin{array}{l}a_{n}=46343 \\
e_{n}=0.5835\end{array}$ & $\begin{array}{l}a_{n}=45291 \\
e_{n}=0.6052\end{array}$ & $\begin{array}{l}a_{n}=47923 \\
e_{n}=0.5509\end{array}$ & $\begin{array}{l}a_{n}=46329 \\
e_{n}=0.56\end{array}$ & $\begin{array}{l}a_{n}=47224 \\
e_{n}=0.5474\end{array}$ \\
\hline 16 & $\begin{array}{l}a_{n}=32267 \\
e_{n}=0.7243\end{array}$ & $\begin{array}{l}a_{n}=40455 \\
e_{n}=0.6627\end{array}$ & $\begin{array}{l}a_{n}=39581 \\
e_{n}=0.6937\end{array}$ & $\begin{array}{l}a_{n}=40836 \\
e_{n}=0.6573\end{array}$ & $\begin{array}{l}a_{n}=43709 \\
e_{n}=0.61\end{array}$ & $\begin{array}{l}a_{n}=38938 \\
e_{n}=0.6726\end{array}$ \\
\hline 17 & $\begin{array}{l}a_{n}=65054 \\
e_{n}=0.7301\end{array}$ & $\begin{array}{l}a_{n}=68737 \\
e_{n}=0.7198\end{array}$ & $\begin{array}{l}a_{n}=61546 \\
e_{n}=0.8206\end{array}$ & $\begin{array}{l}a_{n}=6588 \\
e_{n}=0.7370\end{array}$ & $\begin{array}{l}a_{n}=65240 \\
e_{n}=0.78\end{array}$ & $\begin{array}{l}a_{n}=65256 \\
e_{n}=0.7570\end{array}$ \\
\hline 18 & $\begin{array}{l}a_{n}=48950 \\
e_{n}=0.7036\end{array}$ & $\begin{array}{l}a_{n}=49250 \\
e_{n}=0.7482\end{array}$ & $\begin{array}{l}a_{n}=16248 \\
e_{n}=0.8742\end{array}$ & $\begin{array}{l}a_{n}=28505 \\
e_{n}=0.7643\end{array}$ & $\begin{array}{l}a_{n}=31988 \\
e_{n}=0.73\end{array}$ & $\begin{array}{l}a_{n}=28639 \\
e_{n}=0.8245\end{array}$ \\
\hline 19 & $\begin{array}{l}a_{n}=41215 \\
e_{n}=0.5789\end{array}$ & $\begin{array}{l}a_{n}=46380 \\
e_{n}=0.5811\end{array}$ & $\begin{array}{l}a_{n}=48320 \\
e_{n}=0.6039\end{array}$ & $\begin{array}{l}a_{n}=49551 \\
e_{n}=0.6208\end{array}$ & $\begin{array}{l}a_{n}=50712 \\
e_{n}=0.58\end{array}$ & $\begin{array}{l}a_{n}=47058 \\
e_{n}=0.5904\end{array}$ \\
\hline 20 & $\begin{array}{l}a_{n}=10599 \\
e_{n}=0.8724\end{array}$ & $\begin{array}{l}a_{n}=22484 \\
e_{n}=0.7827\end{array}$ & $\begin{array}{l}a_{n}=23548 \\
e_{n}=0.8330\end{array}$ & $\begin{array}{l}a_{n}=25487 \\
e_{n}=0.8053\end{array}$ & $\begin{array}{l}a_{n}=25570 \\
e_{n}=0.83\end{array}$ & $\begin{array}{l}a_{n}=19349 \\
e_{n}=0.8161\end{array}$ \\
\hline 21 & $\begin{array}{l}a_{n}=7069 \\
e_{n}=0.9114\end{array}$ & $\begin{array}{l}a_{n}=20200 \\
e_{n}=0.8272\end{array}$ & $\begin{array}{l}a_{n}=23874 \\
e_{n}=0.7908\end{array}$ & $\begin{array}{l}a_{n}=26959 \\
e_{n}=0.7579 \\
\end{array}$ & $\begin{array}{l}a_{n}=28025 \\
e_{n}=0.75\end{array}$ & $\begin{array}{l}a_{n}=16479 \\
e_{n}=0.8425\end{array}$ \\
\hline
\end{tabular}


Table 5-20. Estimated values of $a_{n}$ and $e_{n}$ (cont'd)

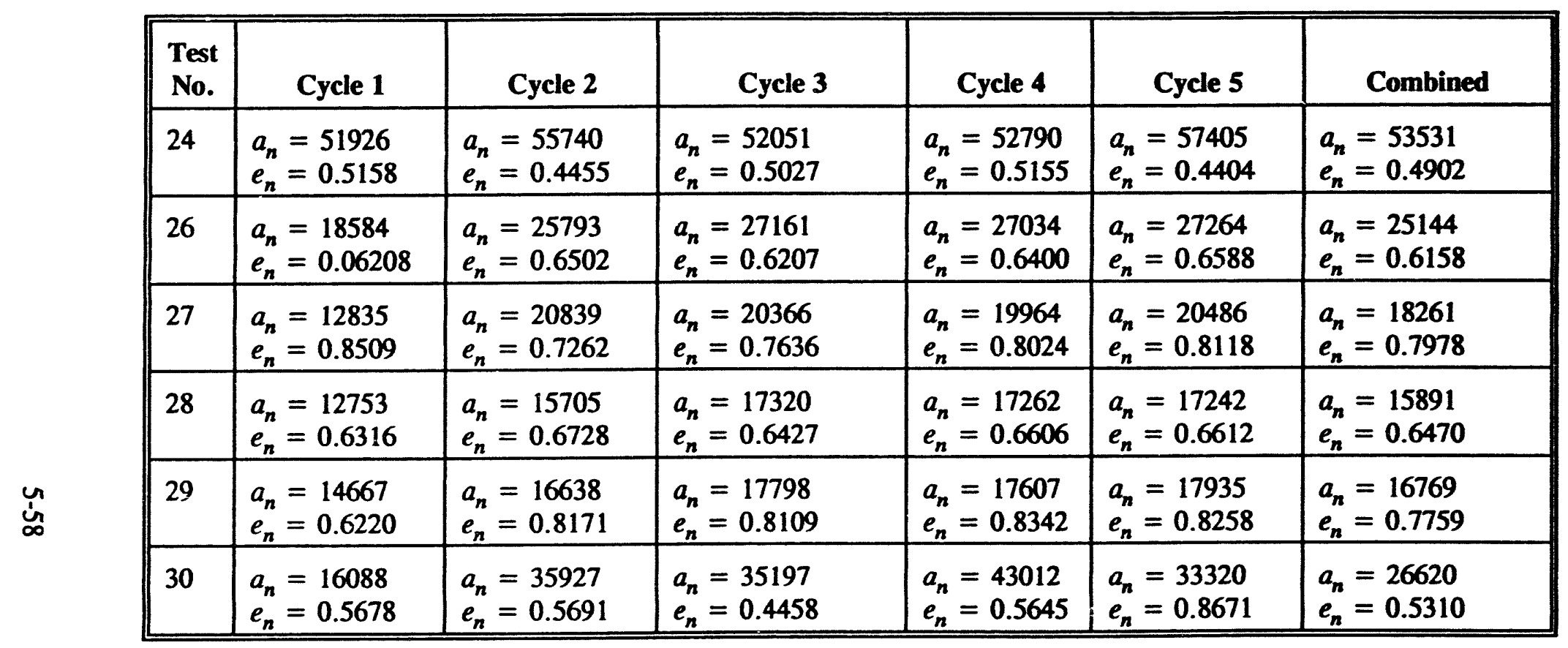



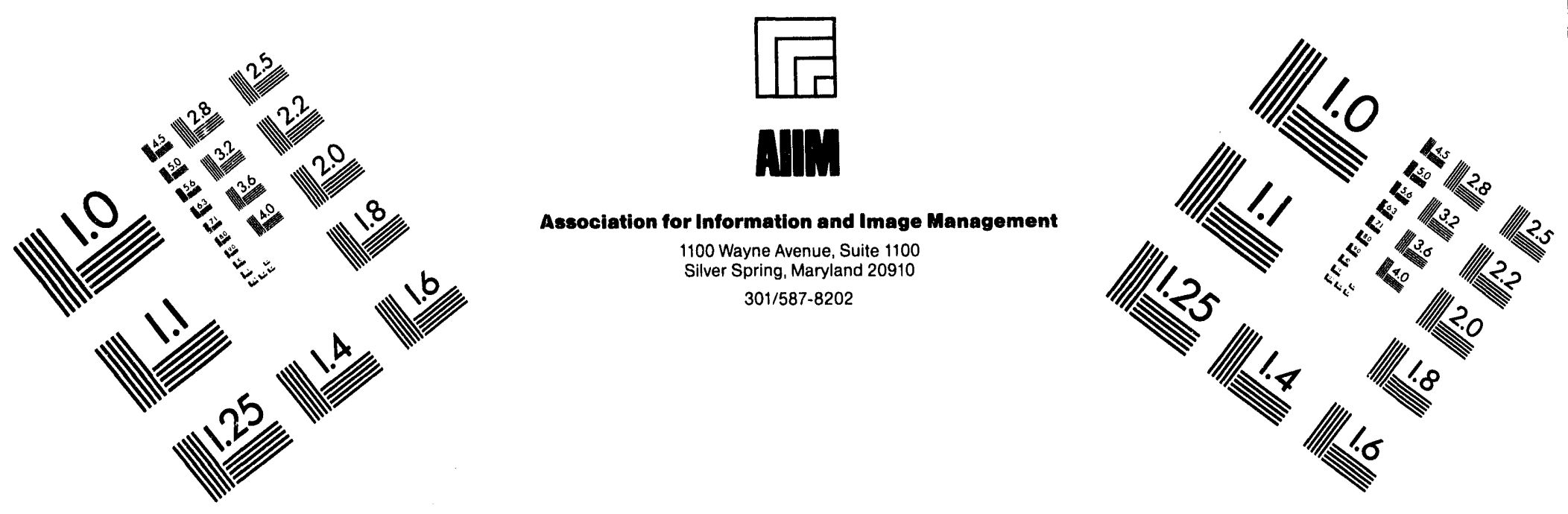

Centimeter

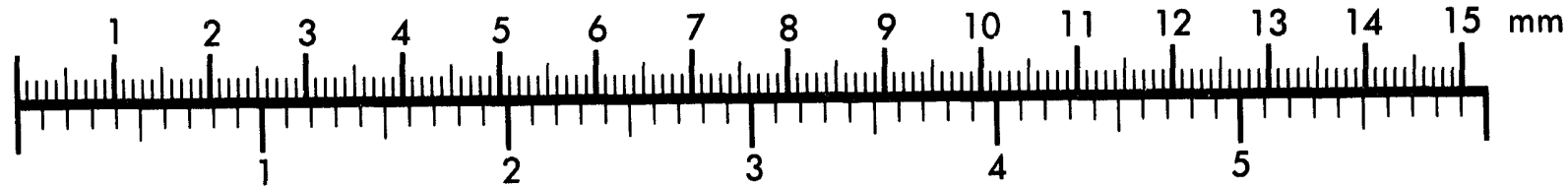
Inches
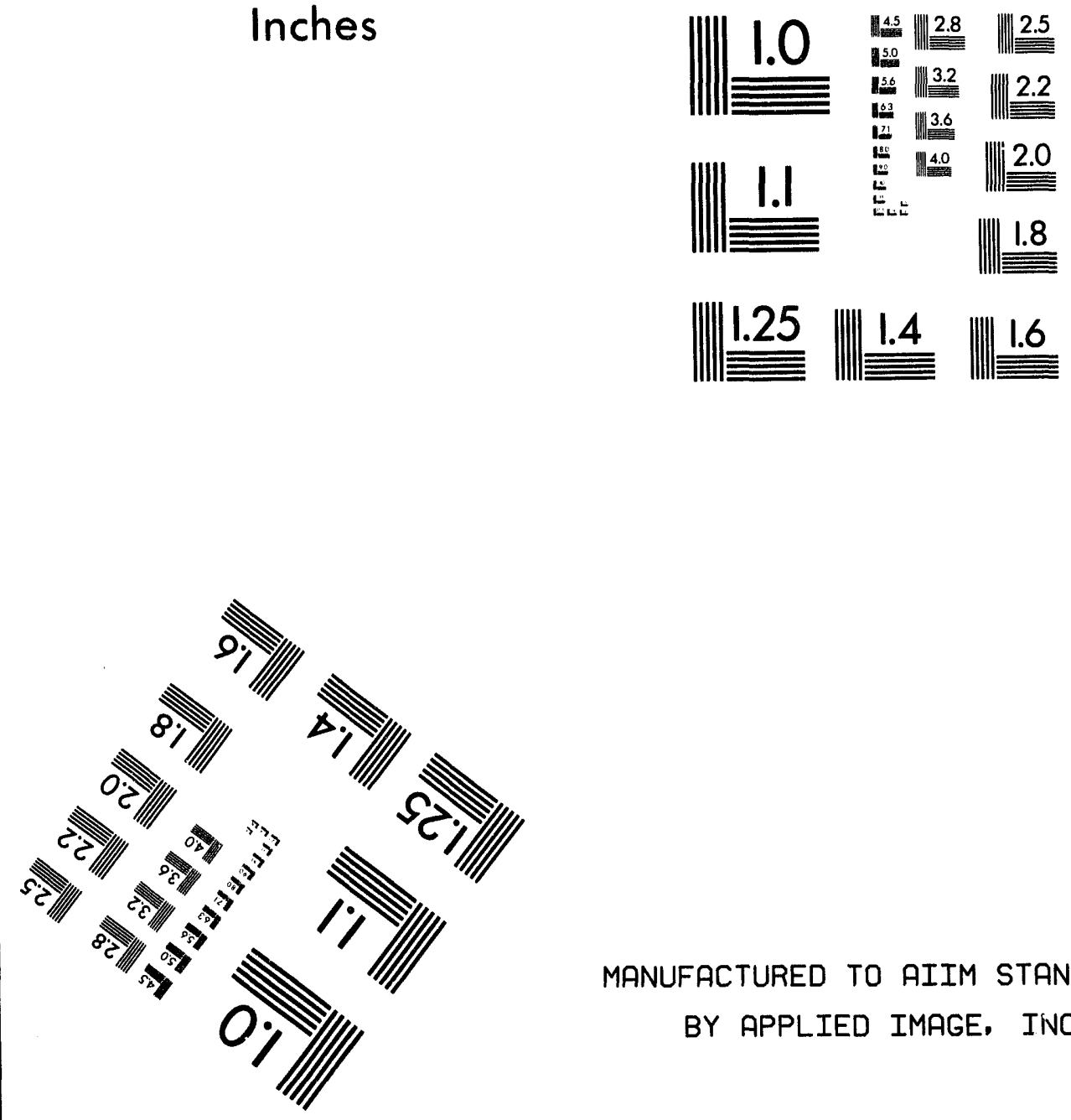

MANUFACTURED TO AIIM STANDARDS

BY APPLIED IMAGE, INC.

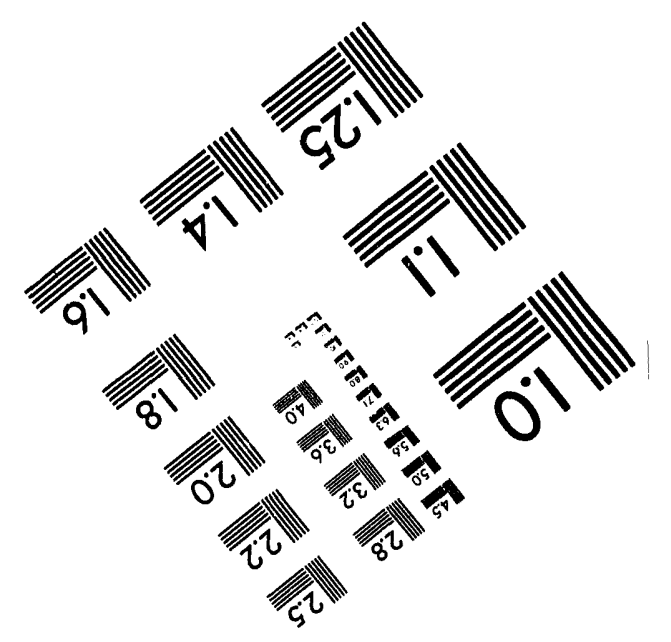



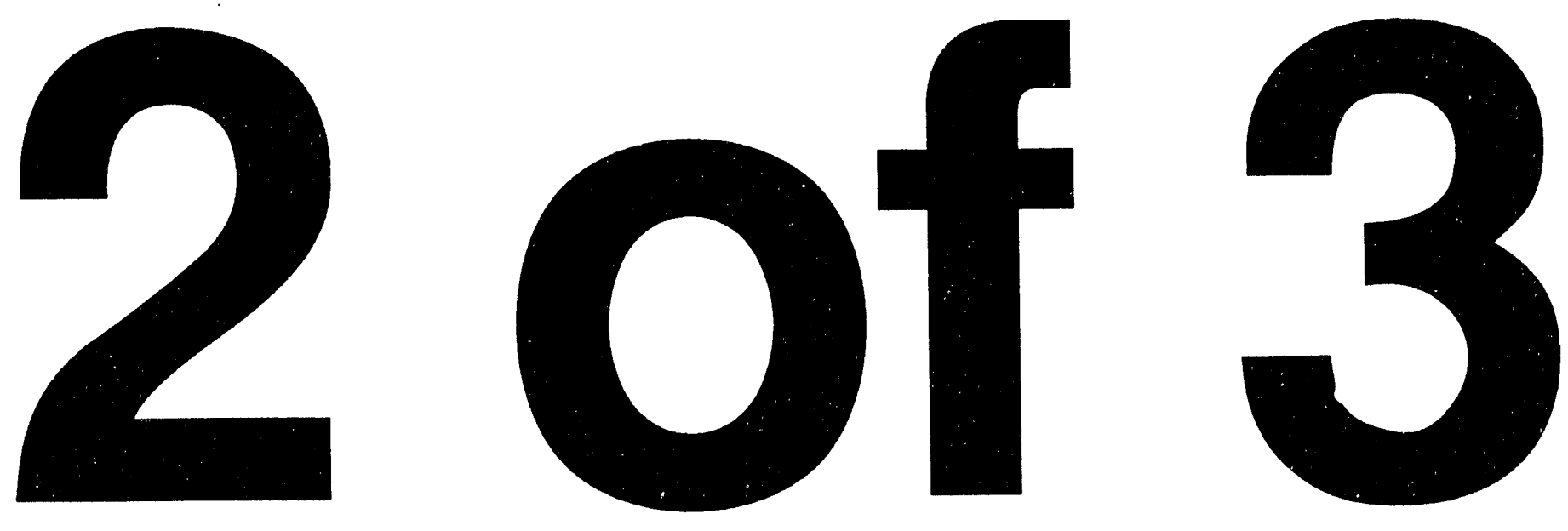
Table 5-21. Estimation of $\phi_{\mathrm{mo}}, \phi, R$, and $K_{s}$

\begin{tabular}{|c|c|c|c|c|}
\hline Test Number & $\phi_{\text {mo }}$ (degree) & $\phi$ (degree) & $R(\mathbf{m})$ & $\mathrm{K}_{s}(\mathrm{GPa} / \mathrm{m})$ \\
\hline 1 & $56.7 \pm 0.6$ & $43.4 \pm 0.2$ & $0.0053 \pm 0.0003$ & $2.46 \pm 0.12$ \\
\hline 2 & $*$ & * & * & * \\
\hline 3 & $45.0 \pm 0.1$ & $36.2 \pm 0.1$ & $0.0163 \pm 0.0002$ & $4.16 \pm 0.12$ \\
\hline 4 & $40.0 \pm 0.3$ & $34.8 \pm 0.2$ & $0.0380 \pm 0.0019$ & $2.19 \pm 0.09$ \\
\hline 5 & $40.9 \pm 0.3$ & $36.2 \pm 0.2$ & $0.0191 \pm 0.0011$ & $4.83 \pm .028$ \\
\hline 6 & $42.5 \pm 0.2$ & $36.4 \pm 0.2$ & $0.0403 \pm 0.0011$ & $6.54 \pm 0.26$ \\
\hline 7 & $43.0 \pm 0.1$ & $33.2 \pm 0.1$ & $0.0176 \pm 0.0001$ & $25.03 \pm 0.38$ \\
\hline 8 & $44.7 \pm 0.2$ & $35.8 \pm 0.2$ & $0.0210 \pm 0.0002$ & $27.22 \pm 1.36$ \\
\hline 9 & $39.3 \pm 0.1$ & $33.5 \pm 0.1$ & $0.0175 \pm 0.0001$ & $29.31 \pm 1.04$ \\
\hline 10 & $44.0 \pm 0.1$ & $35.9 \pm 0.1$ & $0.0139 \pm 0.0002$ & $26.75 \pm 1.04$ \\
\hline 11 & $47.4 \pm 0.2$ & $39.3 \pm 0.1$ & $0.0132 \pm 0.0002$ & $13.88 \pm 0.82$ \\
\hline 17 & $48.9 \pm 0.2$ & $36.0 \pm 0.1$ & $0.0105 \pm 0.0001$ & $19.68 \pm 0.1$ \\
\hline 18 & $44.4 \pm 0.1$ & $35.1 \pm 0.1$ & $0.0216 \pm 0.0003$ & $38.18 \pm 0.13$ \\
\hline 19 & $43.6 \pm 0.1$ & $36.0 \pm 0.1$ & $0.0159 \pm 0.0002$ & $16.97 \pm 0.4$ \\
\hline 20 & $47.2 \pm 0.2$ & $42.0 \pm 0.1$ & $0.0934 \pm 0.0092$ & $4.75 \pm 0.18$ \\
\hline 27 & $57.5 \pm 0.4$ & $44.4 \pm 0.1$ & $0.0113 \pm 0.0004$ & $2.34 \pm 0.12$ \\
\hline 28 & $0.2 \pm 0.3$ & $0.0 \pm 3.1$ & $0.0348 \pm 0.0232$ & $56.67 \pm 0.64$ \\
\hline 29 & $46.2 \pm 0.2$ & $39.9 \pm 0.1$ & $0.0098 \pm 0.0004$ & $57.85 \pm 1.91$ \\
\hline
\end{tabular}


Table 5-22. Effect of trade-off factor on the estimation of $\phi_{\text {mo }}, \phi, R$, and $K_{s}$ for shear test no. 11

\begin{tabular}{||c|c|c|c|c||}
\hline $\begin{array}{c}\text { Trade-0ff } \\
\text { Factor }\end{array}$ & $\begin{array}{c}\phi_{\mathrm{mo}} \\
\text { (degree) }\end{array}$ & $\phi$ (degree) & $\boldsymbol{R}(\mathbf{m})$ & $\boldsymbol{K}_{s}(\mathrm{GPa} / \mathrm{m})$ \\
\hline 0.0 & $46.2 \pm 0.3$ & $0.0 \pm 52.4$ & $0.2072 \pm 0.2603$ & $14.17 \pm 0.53$ \\
\hline 0.1 & $47.2 \pm 0.2$ & $39.3 \pm 0.1$ & $0.0136 \pm 0.0004$ & $13.74 \pm 0.61$ \\
\hline 0.2 & $47.2 \pm 0.2$ & $39.3 \pm 0.1$ & $0.0135 \pm 0.0003$ & $13.76 \pm 0.65$ \\
\hline 0.3 & $47.3 \pm 0.2$ & $39.3 \pm 0.1$ & $0.0133 \pm 0.0003$ & $13.76 \pm 0.69$ \\
\hline 0.4 & $47.3 \pm 0.2$ & $39.3 \pm 0.1$ & $0.0133 \pm 0.0002$ & $13.81 \pm 0.74$ \\
\hline 0.5 & $47.4 \pm 0.2$ & $39.3 \pm 0.1$ & $0.0132 \pm 0.0002$ & $13.88 \pm 0.82$ \\
\hline 0.6 & $47.4 \pm 0.2$ & $39.3 \pm 0.2$ & $0.0132 \pm 0.0002$ & $13.98 \pm 0.91$ \\
\hline 0.7 & $47.4 \pm 0.2$ & $39.3 \pm 0.2$ & $0.0132 \pm 0.0002$ & $14.15 \pm 1.06$ \\
\hline 0.8 & $47.4 \pm 0.2$ & $39.3 \pm 0.2$ & $0.0132 \pm 0.0002$ & $14.42 \pm 1.31$ \\
\hline 0.9 & $47.4 \pm 0.3$ & $39.3 \pm 0.3$ & $0.0132 \pm 0.0001$ & $15.05 \pm 1.9$ \\
\hline 1.0 & $48.7 \pm 4166.1$ & $39.3 \pm 4166.0$ & $0.0145 \pm 0.0003$ & $3.43 \pm 3429.11$ \\
\hline
\end{tabular}




\section{DYNAMIC SHEAR BEHAVIOR OF ROCK JOINTS}

The conditions for joint behavior to be considered explicitly in assessing the performance of jointed rock mass around a repository include:

- joints under pseudostatic conditions

- joints under dynamic loading conditions

- joints under repetitive episodes of dynamic loading arising from a series of earthquakes or a series of underground nuclear explosions

Current empirical representations of jointed rock behavior reside in the Mohr-Coulomb Friction, BartonBandis, and Continuously-Yielding models. These models were developed based on the data obtained under unidirectional pseudostatic loading conditions. Their ability to predict joint performance under the cyclic pseudostatic and the second and third conditions listed above is not known. Furthermore, only limited data for cyclic pseudostatic and dynamic loading are currently available for the purpose of validation of these rock-joint models. Consequently, joint behavior under cyclic pseudostatic and dynamic loading is not well understood. As part of this study of laboratory characterization of rock joints, rock joints were tested under cyclic pseudostatic and dynamic loads in order to obtain a better understanding of dynamic joint shear behavior and generate a complete data set that can be used for validation of rockjoint models.

Dynamic direct shear tests on single-joint Apache Leap tuff specimens performed in this study include harmonic load tests and earthquake load tests. The results of these tests are presented in the following subsections.

\subsection{ROCK JOINT SHEAR TEST UNDER HARMONIC LOADS}

\subsubsection{Harmonic Input}

As discussed in Section 4.3, the horizontal load that produces direct shear to the upper specimen box was provided by a horizontal actuator. Control of the horizontal actuator load was based on the prescribed horizontal shear displacement inputs. For the harmonic direct shear tests, the prescribed horizontal shear displacement inputs were sine wave drive signals. The total duration for all the harmonic tests was $30 \mathrm{sec}$, and the sampling rate was 800 points/sec. The high sampling rate was intended to capture high-frequency responses of joints during harmonic tests. Frequency and amplitude of the input displacement sine wave signal varied for different tests, with the frequency ranging from 1.4 to $3.5 \mathrm{~Hz}$ and amplitude from 6.35 to $25.4 \mathrm{~mm}$. This frequency range was considered to be commensurate with typical earthquake displacement histories. Table 6-1 shows the matrix of the harmonic tests performed under various conditions. For each test specimen, eight tests were conducted under different combinations of input frequency and amplitude, except for test Specimen No. 14. The numbers in the columns for each test specimen denote the test sequence. The first test for each specimen was always started with a sine wave shear displacement input of $12.7 \mathrm{~mm}$ in amplitude and $1.4 \mathrm{~Hz}$ in frequency. As can be observed in the table, the test sequence for each test specimen is essentially the same. The normal stress applied for all the tests was fixed at $1.0 \mathrm{MPa}$ such that the effect of joint roughness could be estimated. No tests were performed for test Specimen No. 14 under frequencies 2.1 and $3.5 \mathrm{~Hz}$. The test specimen for test no. 16 was the same one used for test no. 15. A certain extent of wear on the joint had been realized before this test. 
Table 6-1. Test matrix for direct shear tests on jointed rock specimens under harmonic loads

\begin{tabular}{||c|c|c|c|c||}
\hline \multicolumn{2}{|c|}{ Sine Wave Input } & \multicolumn{3}{c|}{ Test Specimen Number } \\
\hline \hline $\begin{array}{c}\text { Frequency } \\
(\mathbf{H z})\end{array}$ & Amplitude (mm) & Test No. 14 & Test No. 15 & Test No.16 \\
\hline \multirow{2}{*}{1.4} & 12.7 & 1st & 1st & 1st \\
\cline { 2 - 5 } & 25.4 & 2nd & 2nd & 2nd \\
\hline \multirow{2}{*}{2.1} & 12.7 & No Test & 5th & 5th \\
\hline \multirow{2}{*}{2.8} & 25.4 & No Test & 6th & 6th \\
\cline { 2 - 6 } & 6.35 & 3rd & 3rd & 3rd \\
\cline { 2 - 6 } & 12.7 & 4th & 4th & 4th \\
\hline \multirow{2}{*}{3.5} & 6.35 & No Test & 7th & 7th \\
\cline { 2 - 6 } & 12.7 & No Test & 8th & 8th \\
\hline
\end{tabular}

\subsubsection{Test Results}

The measurements of the harmonic tests, as discussed in Section 4, include normal and shear loads, joint normal and shear displacements, acceleration responses of the top rock block, and displacement response between the horizontal load cell and the top shear box. Figures 6-1 and 6-2 show a typical measured shear displacement time history of the first phase and the corresponding response of shear stress time history for test nos. 14 and 15. The test duration for each test was $30 \mathrm{sec}$. However, only the test results between the 5th and 6th second are presented in the figure for clarity. This $1 \mathrm{sec}$ contains more than one cycle of response data. Displacement measurements at both ends of the top rock block along the direction of shear were taken simultaneously. It was found that measured displacement time histories at both instrumentation locations are essentially the same, and no phase difference between the two was observed. This observation suggests that the top rock block may undergo only rigid body motion along the interface (joint). Therefore, the effect of deformation or displacement within the top rock block on the joint shear stress, as calculated using the shear force from the horizontal actuator, should be negligible.

Figures 6-1 and 6-2 also indicate that there is a phase difference between the shear displacement and shear stress time histories, with the shear displacement lagging behind. This phenomenon has been observed for all harmonic tests. The observed delayed response of the joint shear displacement may be real in terms of joint behavior or it may be due to some other phenomena, for example, compression and dilation of the cement grouts used to fill the gaps between the steel box and the rock specimen. Note that the joint shear displacement histories in both figures were the horizontal displacement of the top rock block relative to the bottom one measured with the LVDTs mounted directly on the rock specimen pair. The shear force history used to calculate the joint shear stress was measured from the load cell of the 


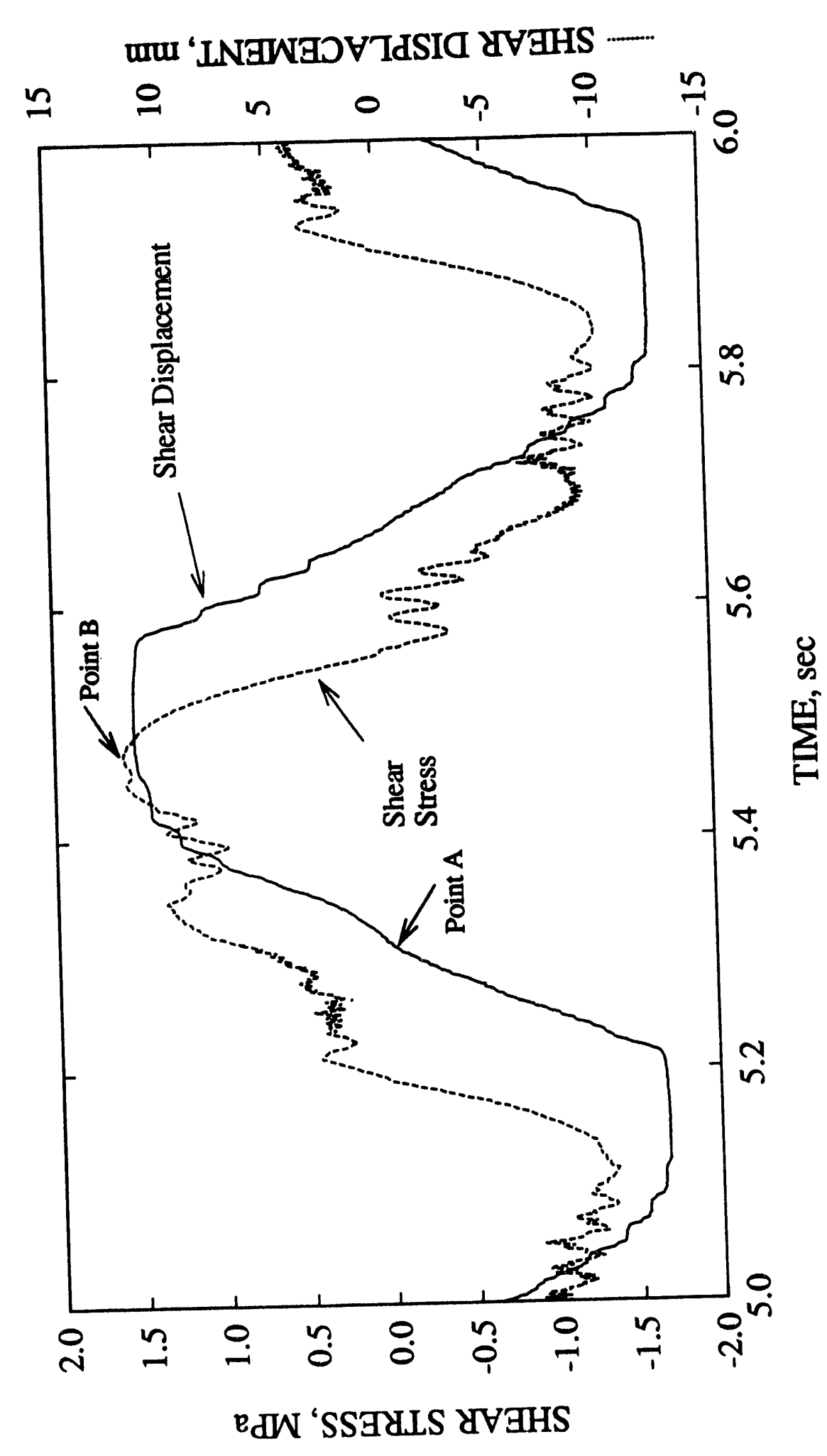

$\sum_{1}^{a}$

重

$\circ$

है

5

ช

点

폴

\%

행

5

뭍

हี

象

홀

벼ㅇㅝㅗ

듬

냉

究

믈 플

8.

본

कै

कै

ป

总氞 


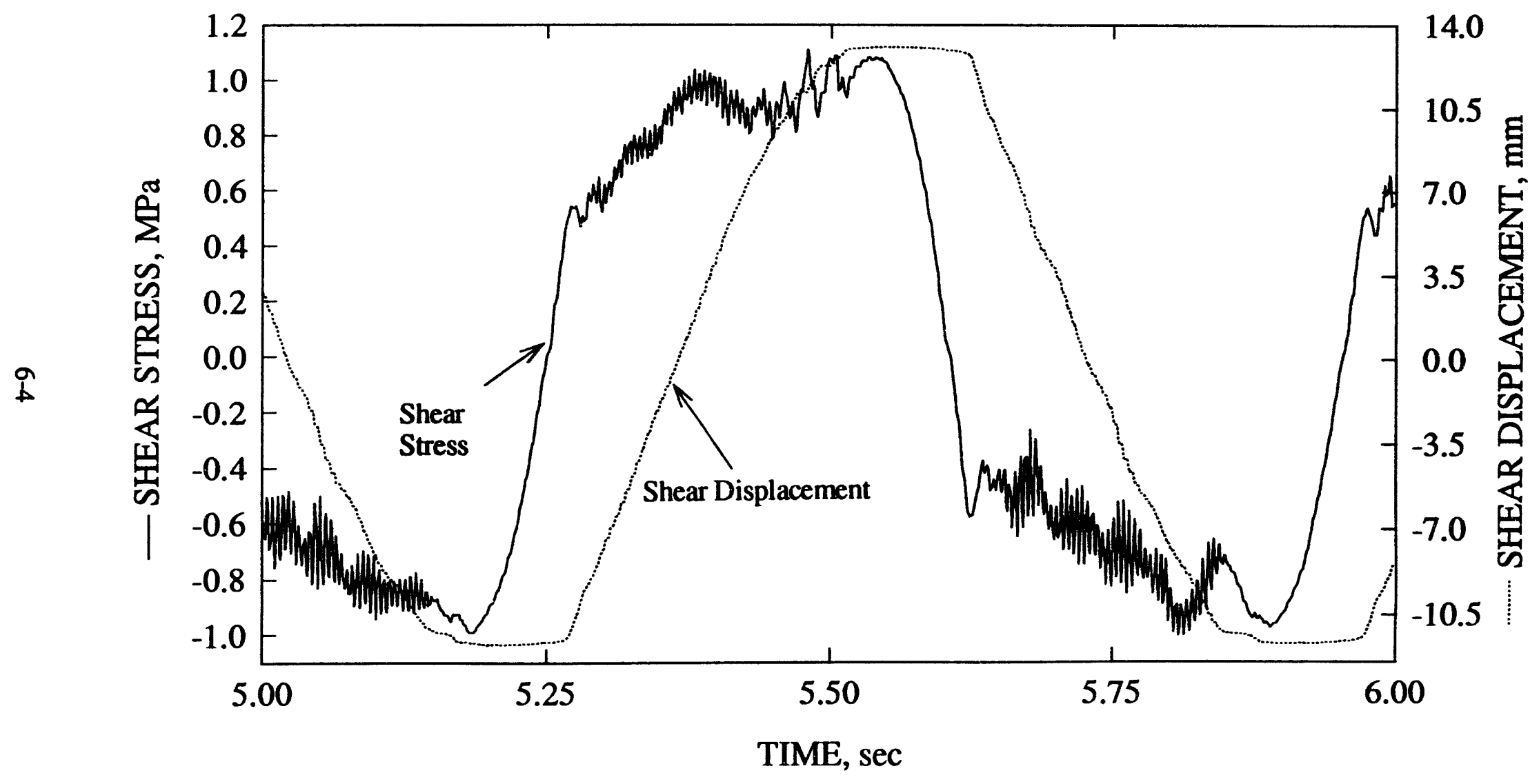

Figure 6-2. Shear stress and shear displacement histories between 5th and 6th second of the first phase of test no. 15 with 1-MPa normal stress, $1.4-\mathrm{Hz}$ input frequency, and $12.7-\mathrm{mm}$ input amplitude 
horizontal actuator that was connected to the top shear box. As a result, the deformation associated with the compression and dilation of the grouts was not reflected in the measured shear displacements as shown in Figures 6-1 and 6-2. It was decided that this effect should be evaluated. Consequently, one additional LVDT was added to quantify the total deformation between the horizontal load cell and the top rock block (on the side of the horizontal actuator) during test no. 16.

Figure 6-3 shows the results of the measured horizontal displacement for the first phase of the test from this additional LVDT. Again, the data between the 5th and 6th second are presented for clarity. It can be seen in the figure that this displacement history contains high-frequency noise. The source of this noise is not certain. The general trend indicates that the total horizontal displacement between the load cell and the top rock block is small (less than $2 \mathrm{~mm}$ ) as compared to the joint shear displacement, which was from -12.7 to $12.7 \mathrm{~mm}$. It is also noticed that the horizontal displacement does not vary with changing joint shear displacement. Furthermore, the horizontal displacement shown in Figure 6-3 exhibits no phase difference with the shear stress time history (Figure 6-3). This observation implies that the ball joint between the horizontal load cell and the top shear box and the grout between the shear box and the joint specimen contributes little, if any, to the phase shift between the joint shear stress and joint shear displacement. Therefore, it may be concluded that the phase shift simply results from shear stress buildup to a level required to initiate joint shearing. This conclusion is important in that the horizontal compliance in the experimental apparatus does not affect the experimental results, and direct modeling of the rock behavior from the results is valid.

As discussed earlier, the excitation signal is sinusoidal and displacement controlled. As a result, the measured shear stress is cyclic. As expected, the fundamental frequency for the shear stress time history (Figures 6-4 and 6-5) is $1.4 \mathrm{~Hz}$, which is the input frequency. The shear stress time histories also include some higher frequency components as shown in both figures. The amplitudes of these higher frequencies are relatively small as compared to the amplitude at $1.4 \mathrm{~Hz}$ frequency. A semi-log plot in the frequency domain for the shear stress time history of the first phase of test no. 14 reveals that it also contains two other components in the higher frequency range-one in the area of $50 \mathrm{~Hz}$ and one in the area of $250 \mathrm{~Hz}$ (Figure 6-6). Similar observation can also be made for the first phase of test no. 15 in terms of frequency components, only that one is located in the area of 225 instead of $250 \mathrm{~Hz}$. The fact that shearing of joint surfaces with different roughness generates similar frequency response indicates the presence of some form of natural mode response in the apparatus.

The magnitude of the shear stress depends upon the conditions of the joint (e.g., waviness of the joint surface, residual joint friction angle, etc.). Figure 6-1 contains a cycle of shear displacement history. The cycle starts a little after $5.3 \mathrm{sec}$ (as indicated by point $\mathrm{A}$ in the figure where the shear displacement is zero) and ends after the 6th second when the top rock block comes back to its original position before the test. When the top block moves away from the original position, it has been defined in this report as forward shearing, while it is reverse shearing when the top rock block moves toward its original position. The corresponding shear stress magnitude increases during forward shearing. Peak shear stress is reached after a certain amount of shear displacement, and the shear stress decreases afterwards. However, it can be observed that the shear stress seems to experience a higher frequency component subsequently, which correlates well with stepwise shear displacements observed in the displacement time history. This higher frequency component appears to be associated with rapid stick-slip (i.e. chatter) of the interface surface, and may be enhanced by the presence of apparatus natural vibrational modes as well. The same behavior is also observed during reverse shearing. 


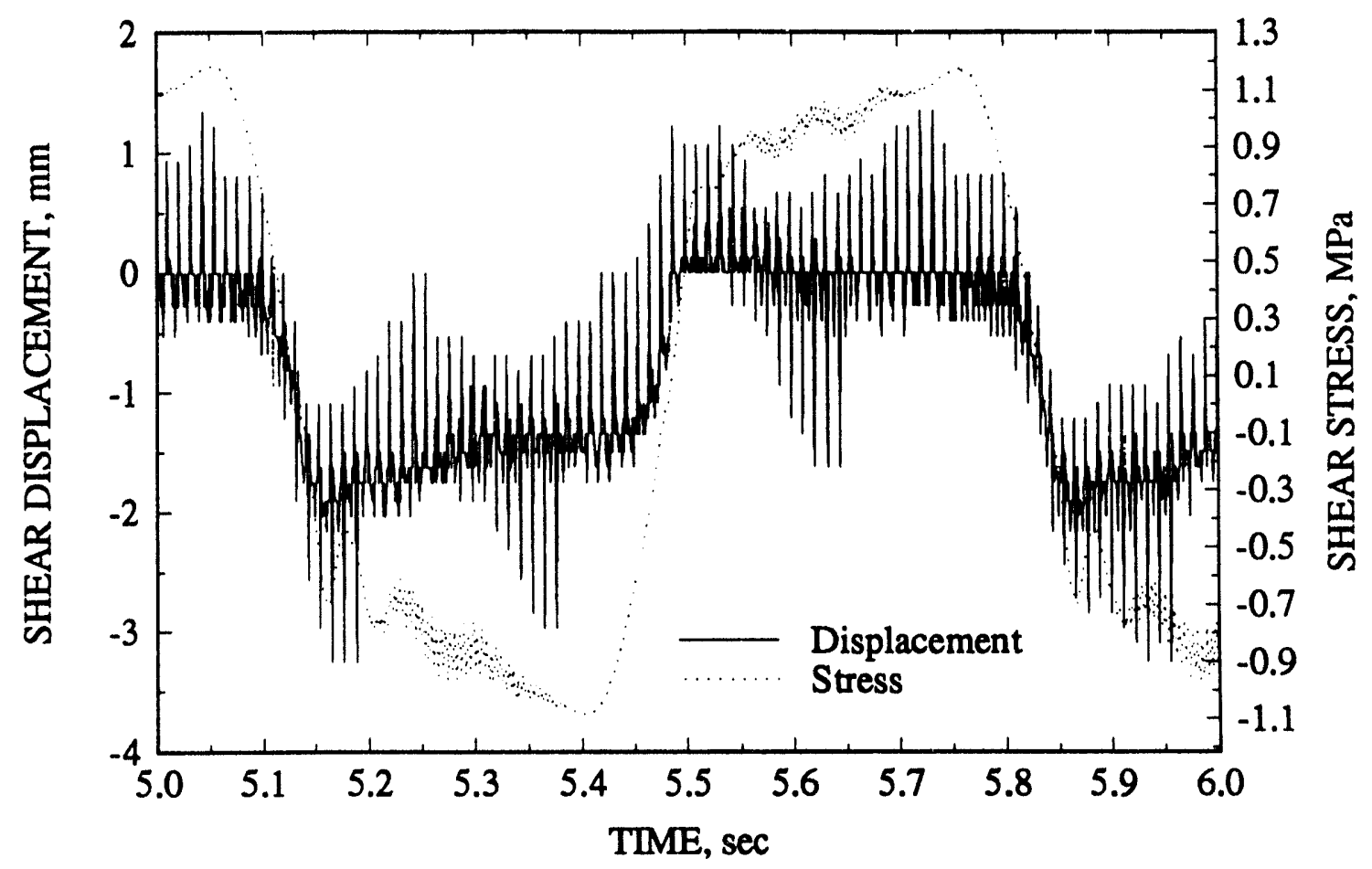

Figure 6-3. Measured relative horizontal displacement between the horizontal load cell and the top rock block, and shear stress time history of the first phase of test no. 16

The above-described chatter behavior is believed to be excited by the waviness of the joint surface as well as pieces of rock fragments broken from the joint surface. Visual inspection at the conclusion of each test revealed many rock fragments. When the movement of the top rock block is restrained by asperities on the joint surface, it tends to stop until the shear stress is built up sufficiently to overcome this additional resistance by either breaking or riding over the asperity. Depending upon the size and strength of these asperities, the high-frequency responses will vary in amplitude as shown in Figures 6-1, 6-2, and 6-6. Once the obstacles are overcome, the shear stress experiences a sharp drop. There is a period as indicated above, starting perhaps from point B to the right of Figure 6-1, that the shear stress decreases due to cycling. During this period, the shear stress is actually smaller than the shear resistance. Consequently, the top rock block is stopped until reverse shearing starts when the negative shear stress begins to increase. This behavior is evident by the flattening of the relative shear displacement near its peak values. Similar observations can also be made from Figure 6-2. Note that the negative sign for the shear stress indicates its direction, not magnitude.

Figures 6-7 and 6-8 show the measured normal stress and normal displacement (dilation) histories between the 5th and 6th second of the first phase for test nos. 14 and 15, respectively. The time history of the normal displacement in both figures indicates that the joint dilated (increasing in normal displacement) during forward shearing along either side of the original position, and the dilation gradually returned during reverse shearing. When the top rock block was not moving due to the two conditions described in the previous paragraph, joint dilation remained constant. However, small high-frequency variations around nominal values continued.

The normal displacement time history in Figure 6-7 of test no. 14 contains a fundamental frequency of $2.8 \mathrm{~Hz}$ (Figure 6-9), which is twice the input frequency or the frequency for the shear 


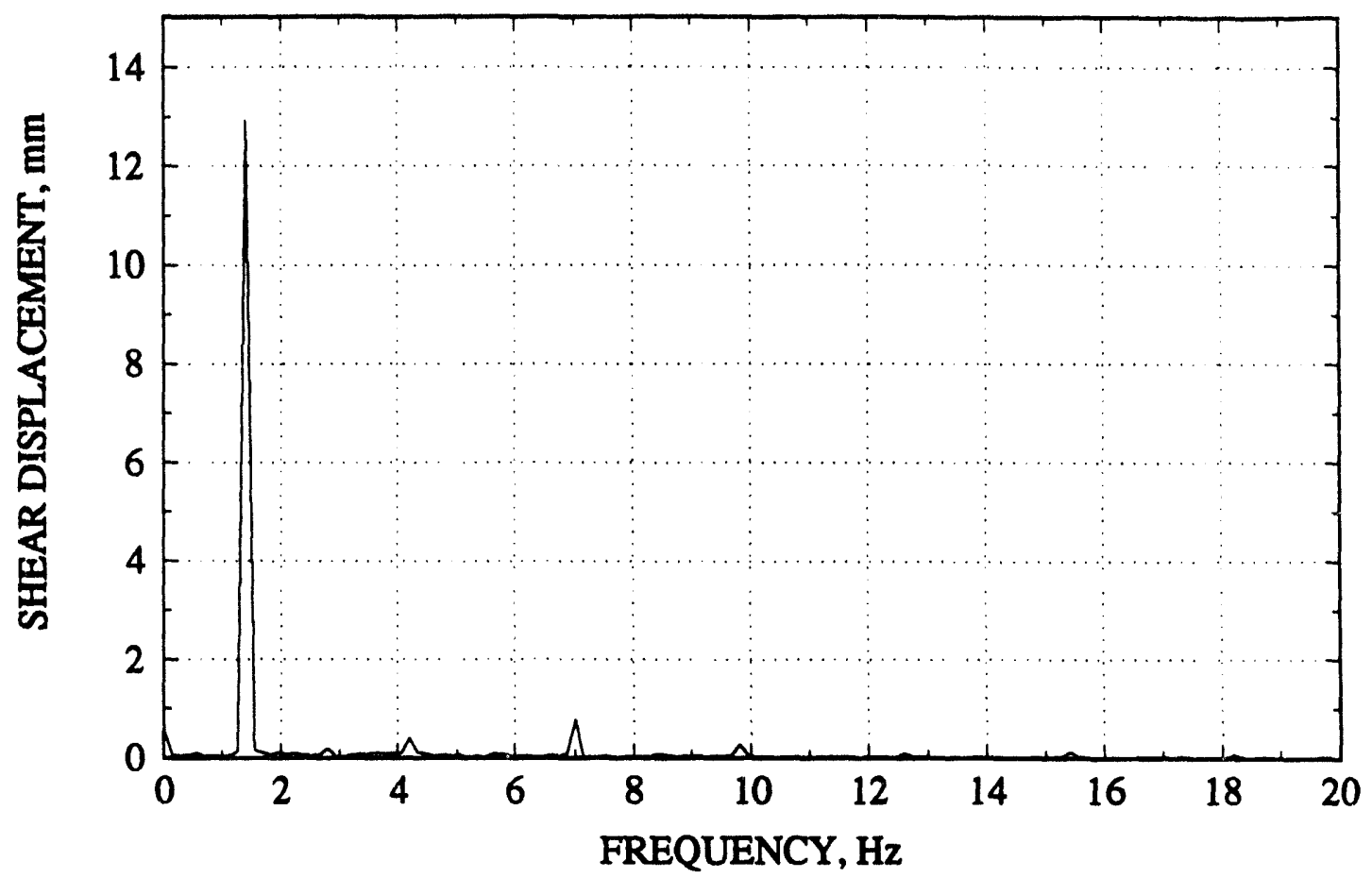

Figure 6-4. Shear displacement spectra for the first phase of test no. 14 with a harmonic input frequency of $1.4 \mathrm{~Hz}$

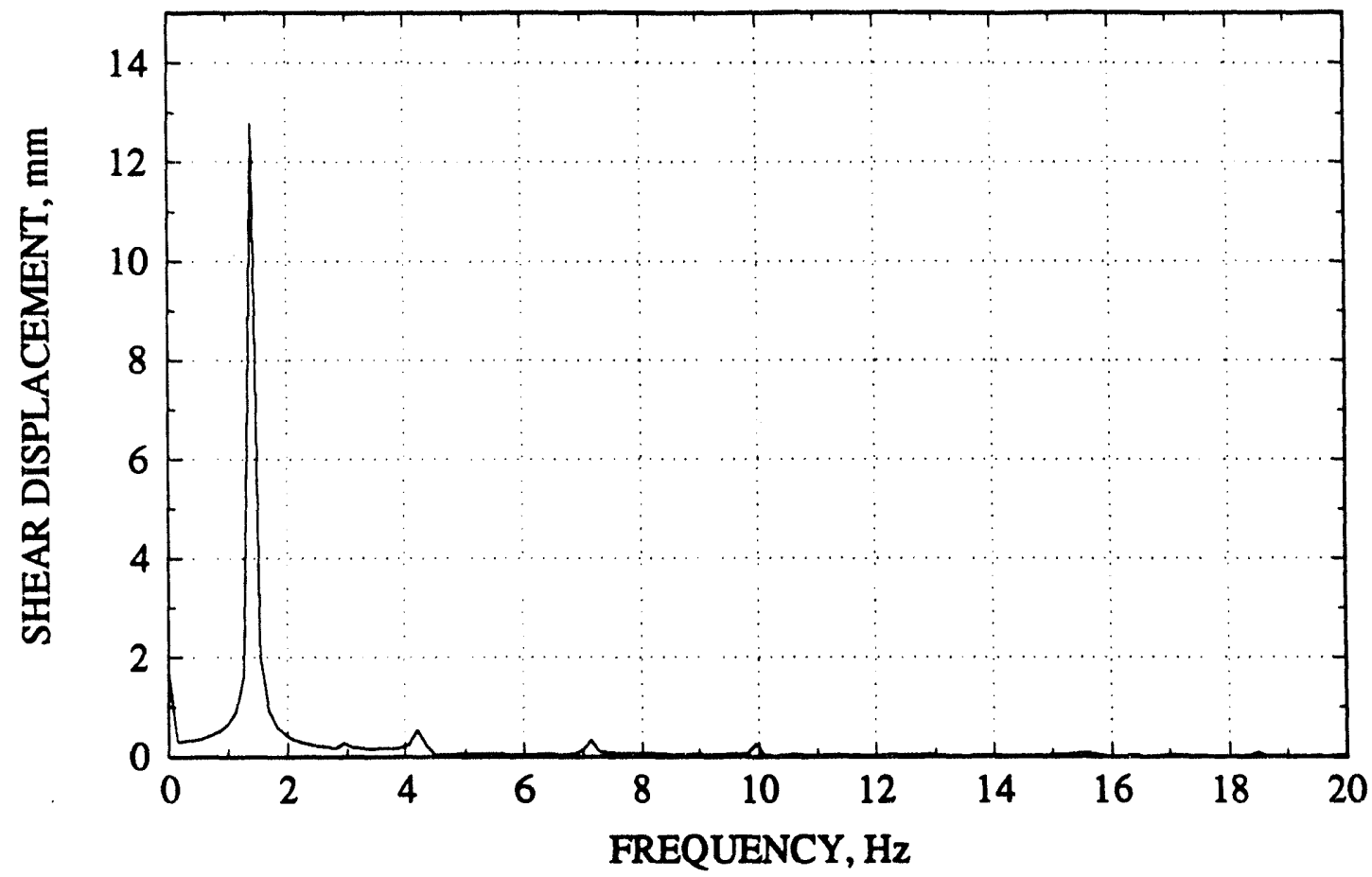

Figure 6-5. Shear displacement spectra for the first phase of test no. 15 with a harmonic frequency of $1.4 \mathrm{~Hz}$ 


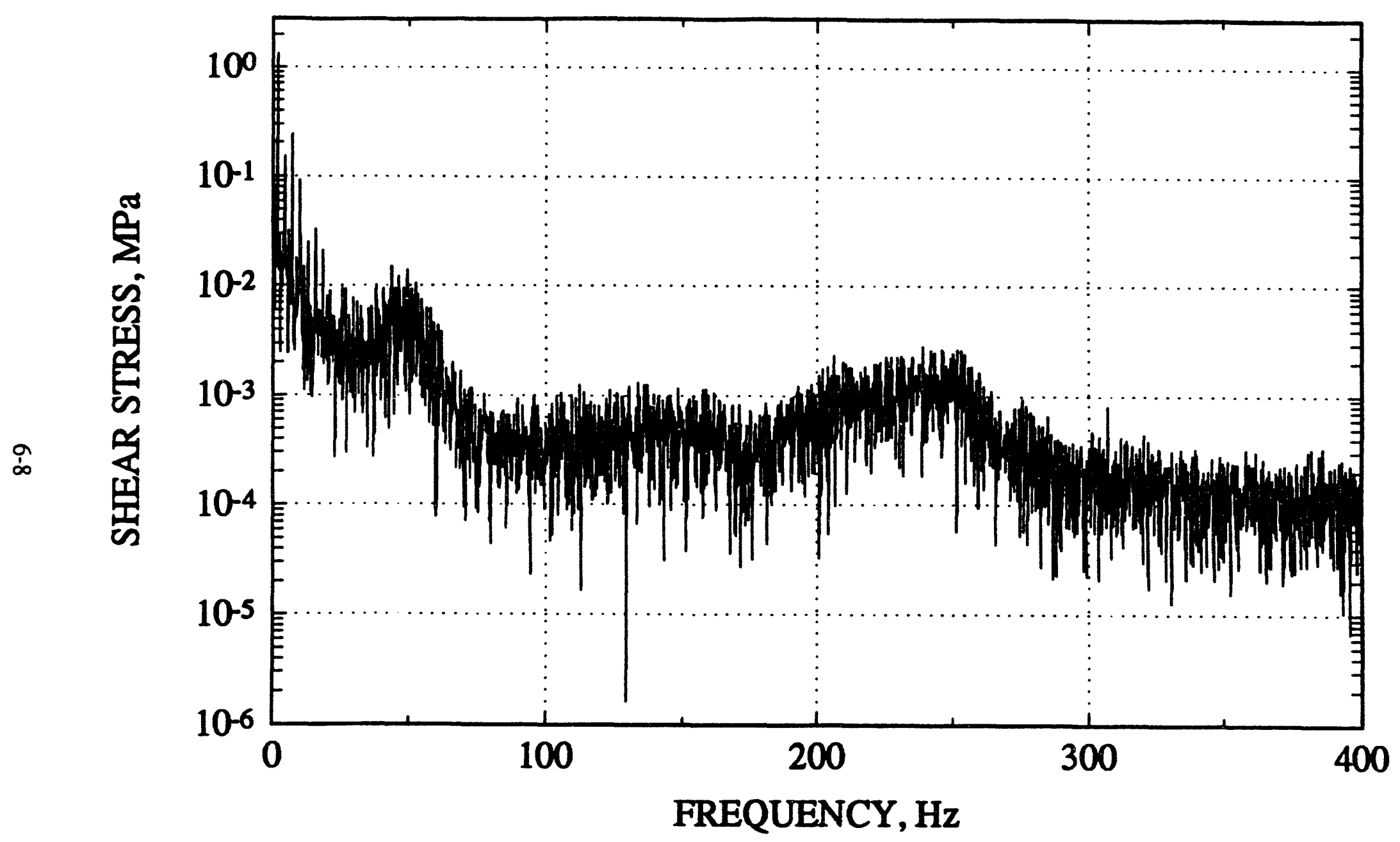

Figure 6-6. Semi-log plot of shear stress spectra for the first phase of test no. 14 with a harmonic input frequency of $1.4 \mathrm{~Hz}$ 


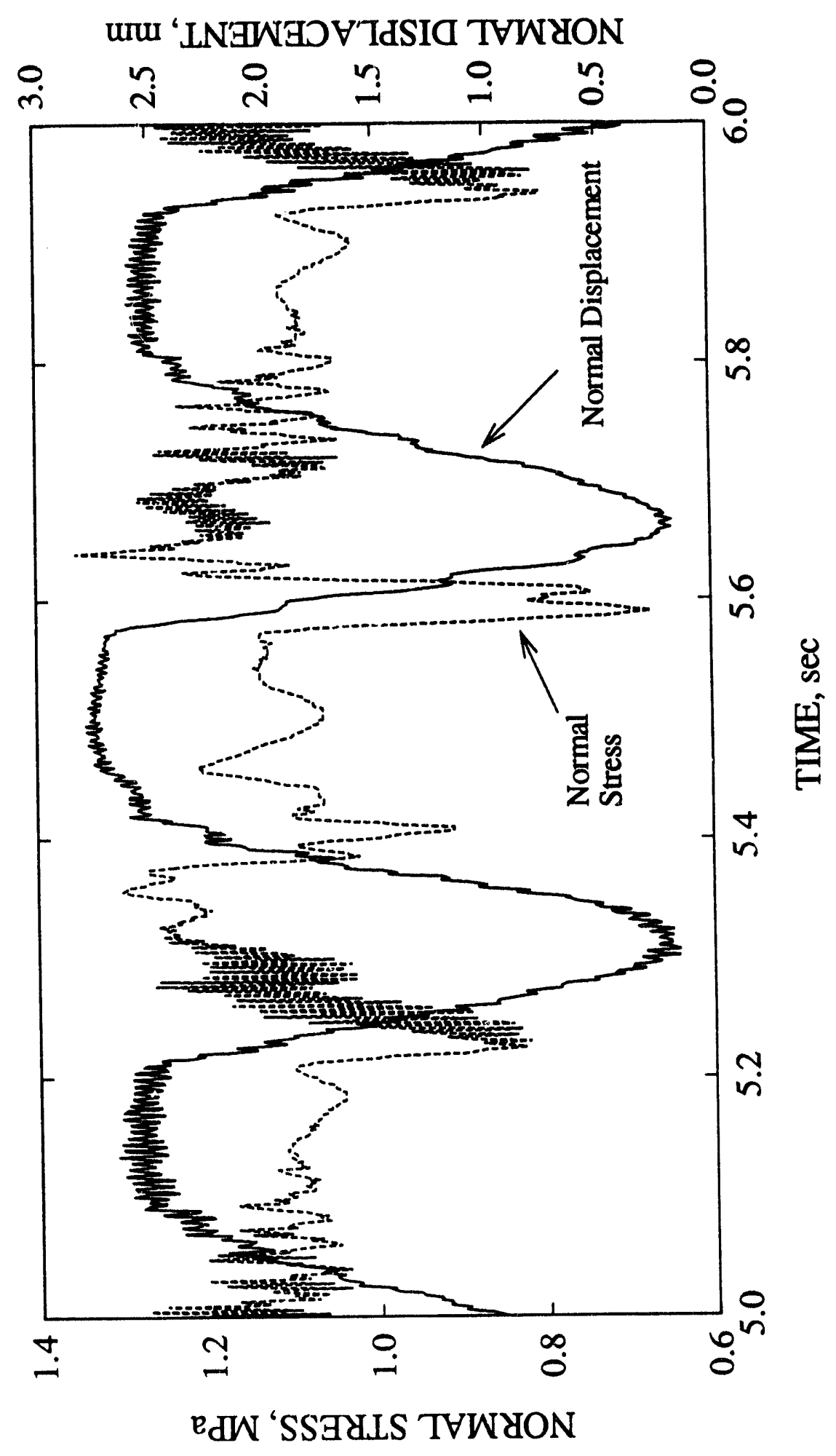

$\pm$

$\dot{8}$

8

6

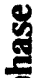

点

I

뚱

8

5

뭉

흔

.

\&

를

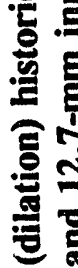

붕

岁

过

믐

을

్ㅗㄹ

을

굴

के

总新

플 즐

乙 할 \&

물 


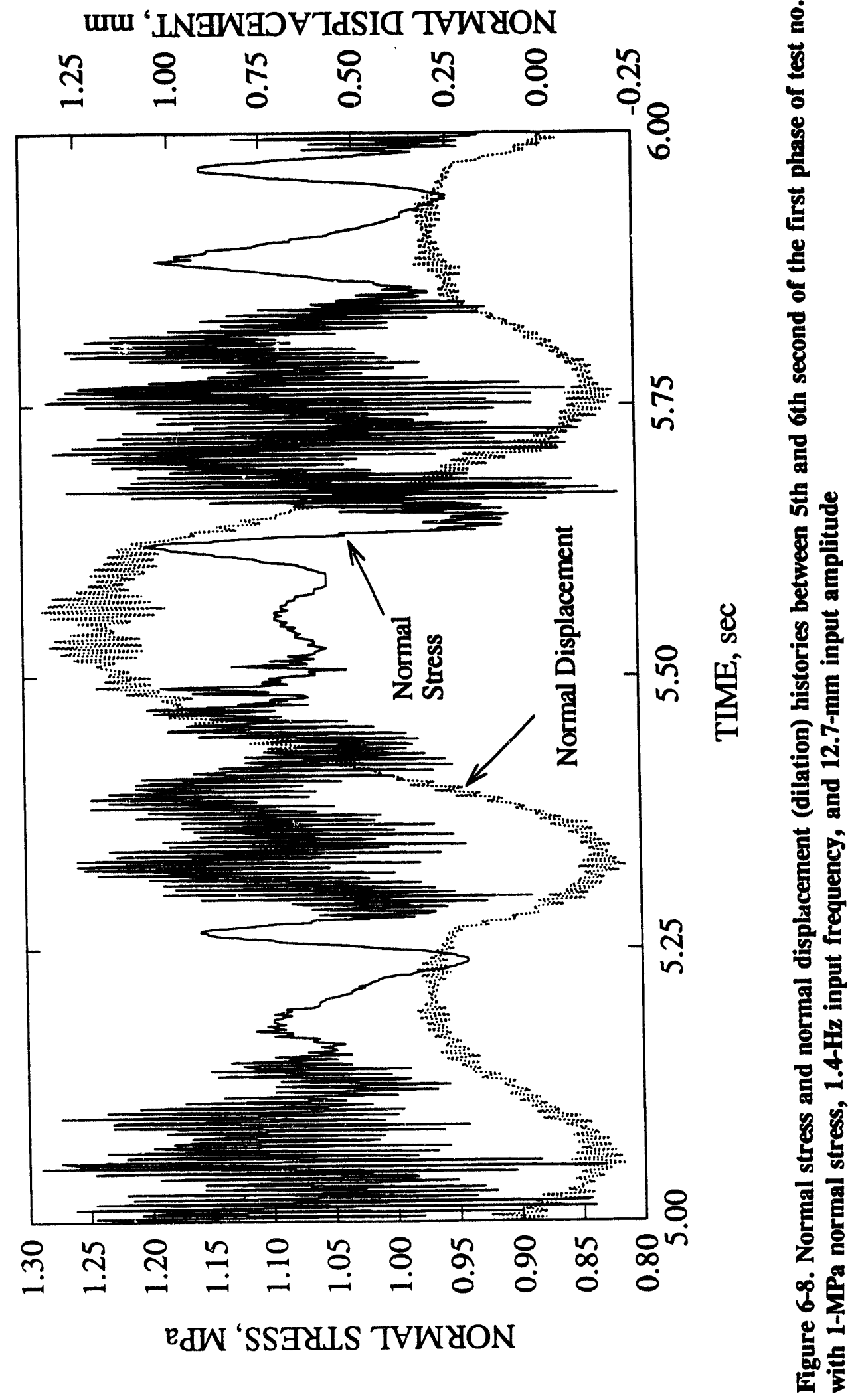




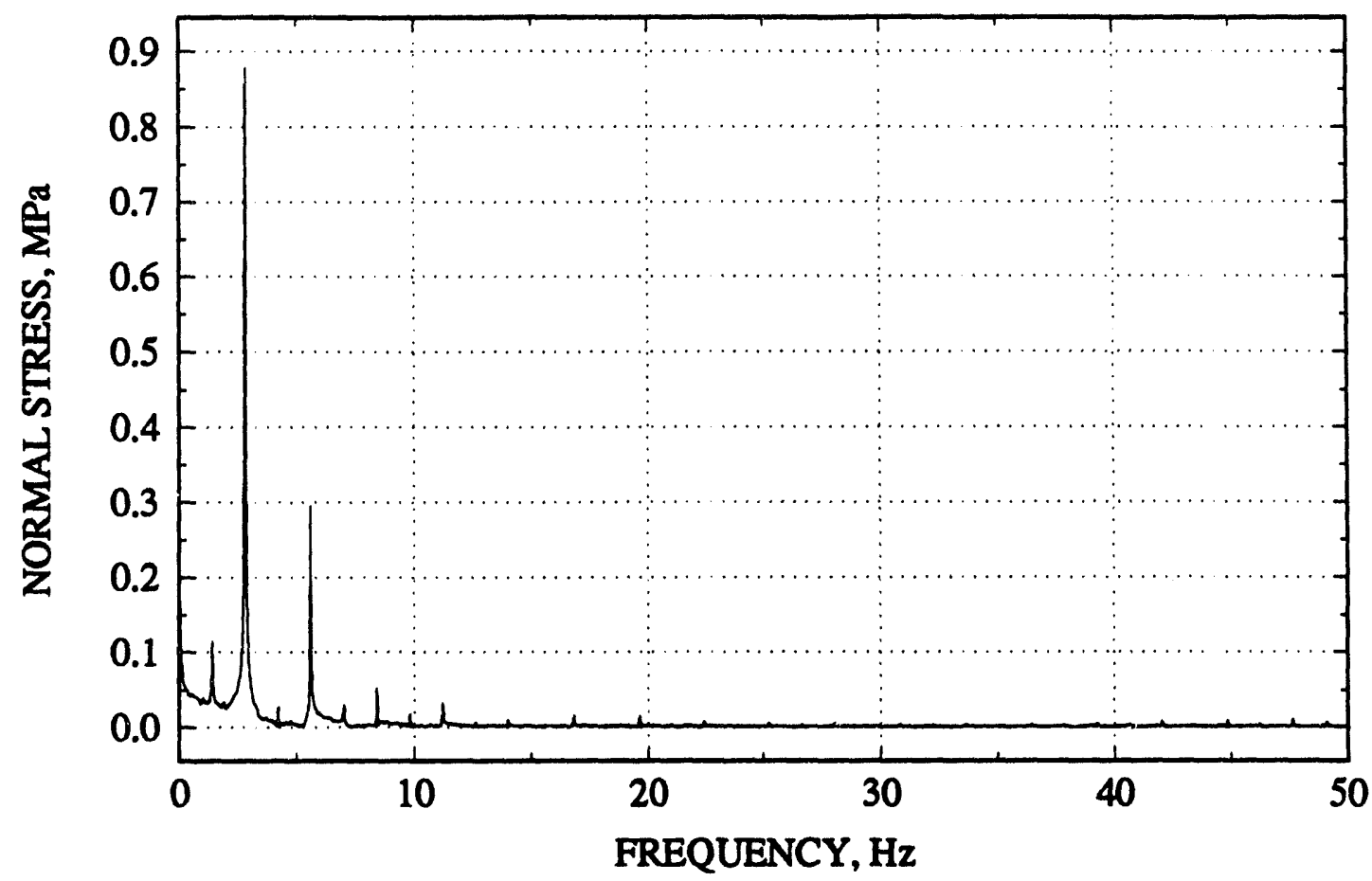

Figure 6-9. Normal stress spectra for the first phase of test no. 14 with a harmonic input frequency of $1.4 \mathrm{~Hz}$

displacement measurement. This fundamental frequency is because the magnitudes of joint dilation for forward shearing along both sides of the original position are essentially the same. If they are substantially different as is the case in test no. 15 (Figure 6-8), the fundamental frequency will be the same as the input frequency, $1.4 \mathrm{~Hz}$. It is clear from Figures 6-7 and 6-8 that both normal displacement histories contain higher frequency response as do the shear stress and displacement histories. This phenomenon of high-frequency vibration is unique to the joint dynamic behavior.

Unlike the pseudostatic direct shear tests, the normal stress for dynamic tests cannot be maintained as a constant during the course of the tests (Figures 6-7 and 6-8). This inability is related to the capability of the test apparatus. The input for the dynamic tests in this study was cyclic and changed so rapidly that the control system could not respond quickly enough to the force changes in the vertical actuators to maintain a constant normal stress at the higher frequencies. These sudden changes are associated with the vibration of the shear stress and the normal displacement. The extent of the effect of normal stress variation on the joint behavior is not clear. However, it may not necessarily affect substantially the general pattern of the responses of shear stress, shear displacement, and joint normal displacement due to the transient nature of the variation. Further investigation of this behavior is currently in progress on an internal research and development project at SwRI.

The acceleration measurements of the top rock block for the first phase of test nos. 14 and 15 contained predominantly repeated bursts of higher frequency components, as shown in Figures 6-10 and 6-11. In comparing the acceleration measurements in these two figures with the corresponding shear stress time histories in Figures 6-1 and 6-2, it can be observed that these higher frequency signals were related to shearing in the residual state. The acceleration associated with the joint stick-slip behavior included relatively lower frequency content. The frequencies for the acceleration were even smaller in the time period when the top rock block was stationary. All the observations seem to indicate that the 

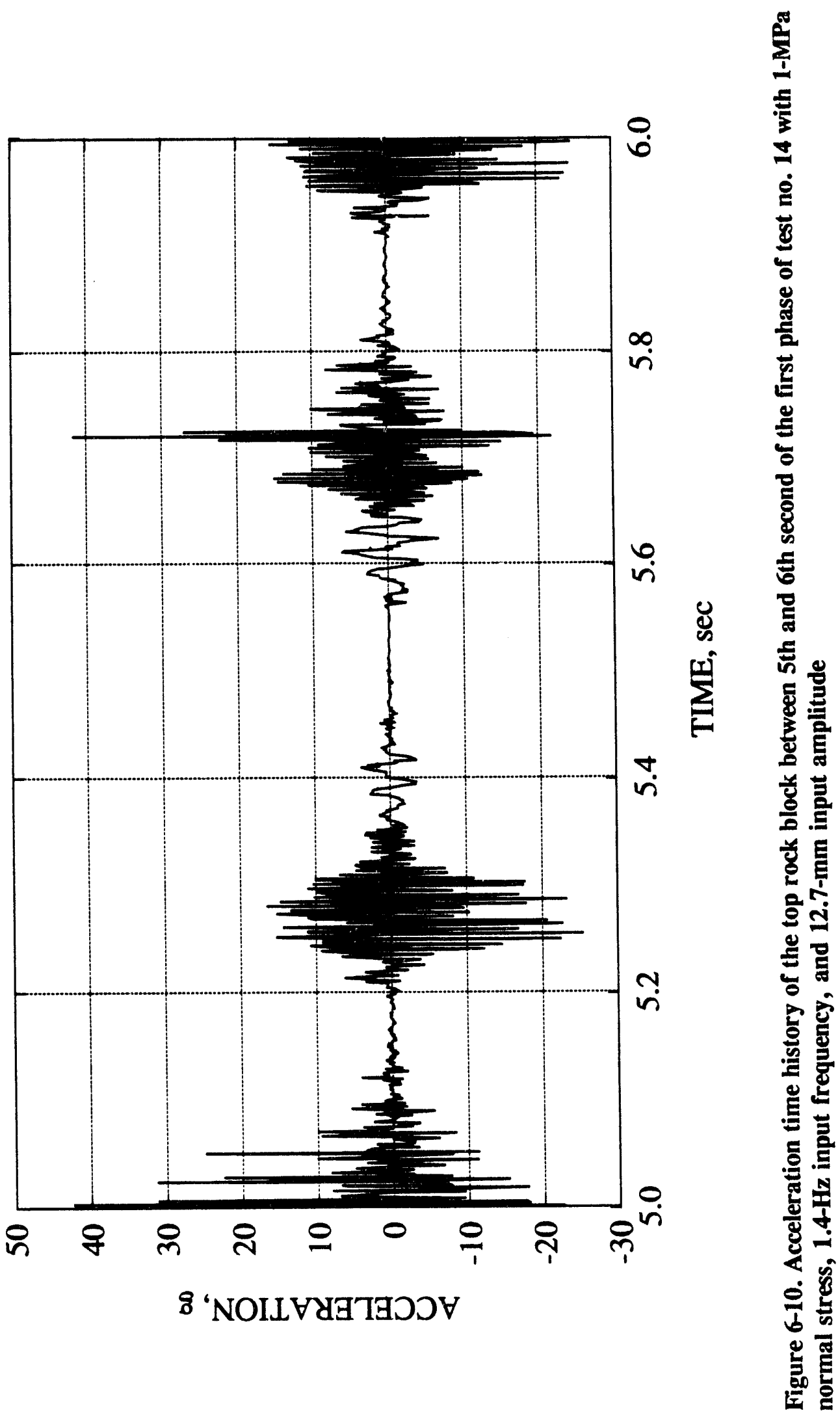


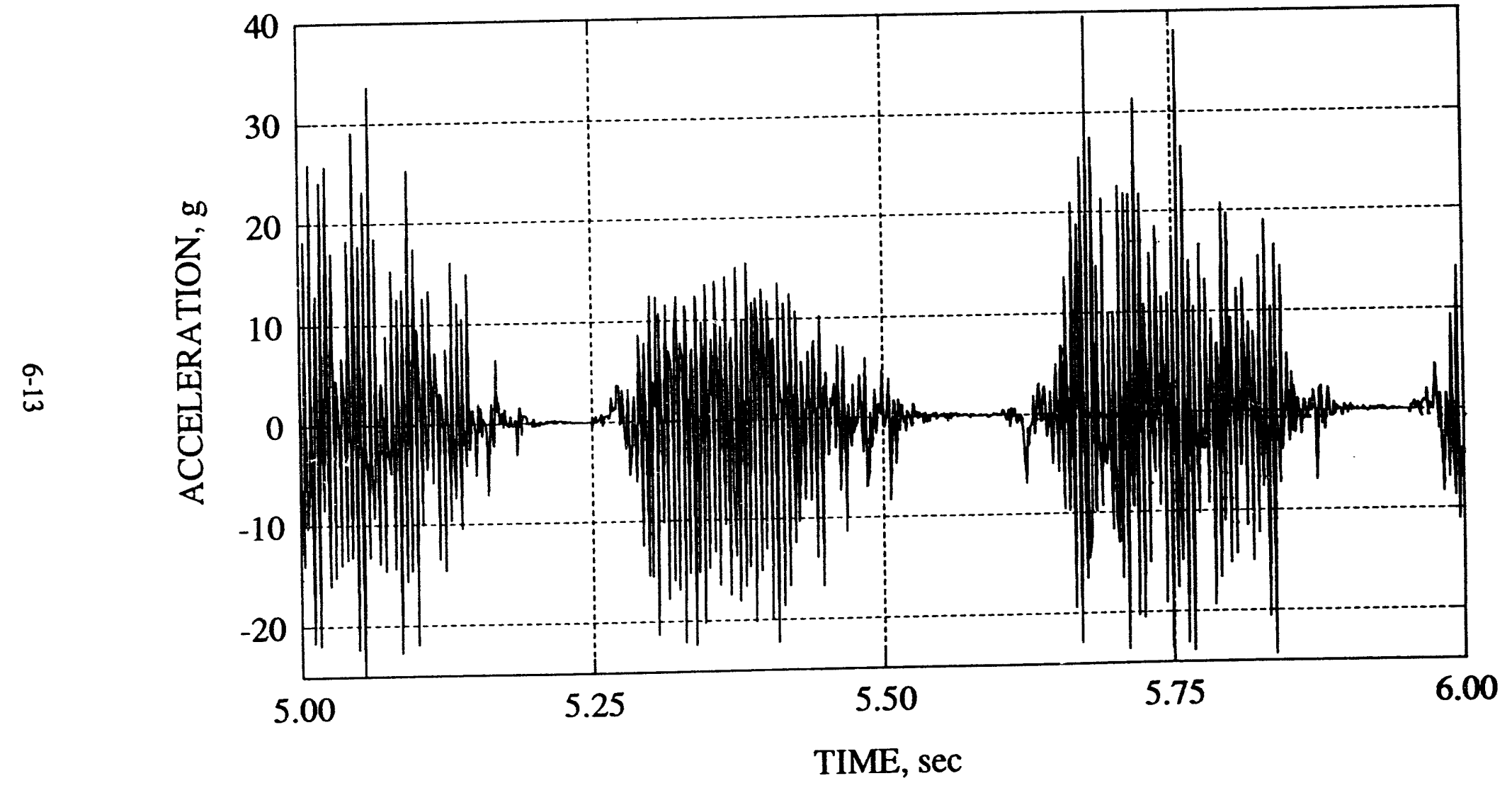

Figure 6-11. Acceleration time history of the top rock block between 5th and 6th second of the first phase of test no. 15 with 1-MPa normal stress, 1.4-Hz input frequency, and 12.7-mm input amplitude 


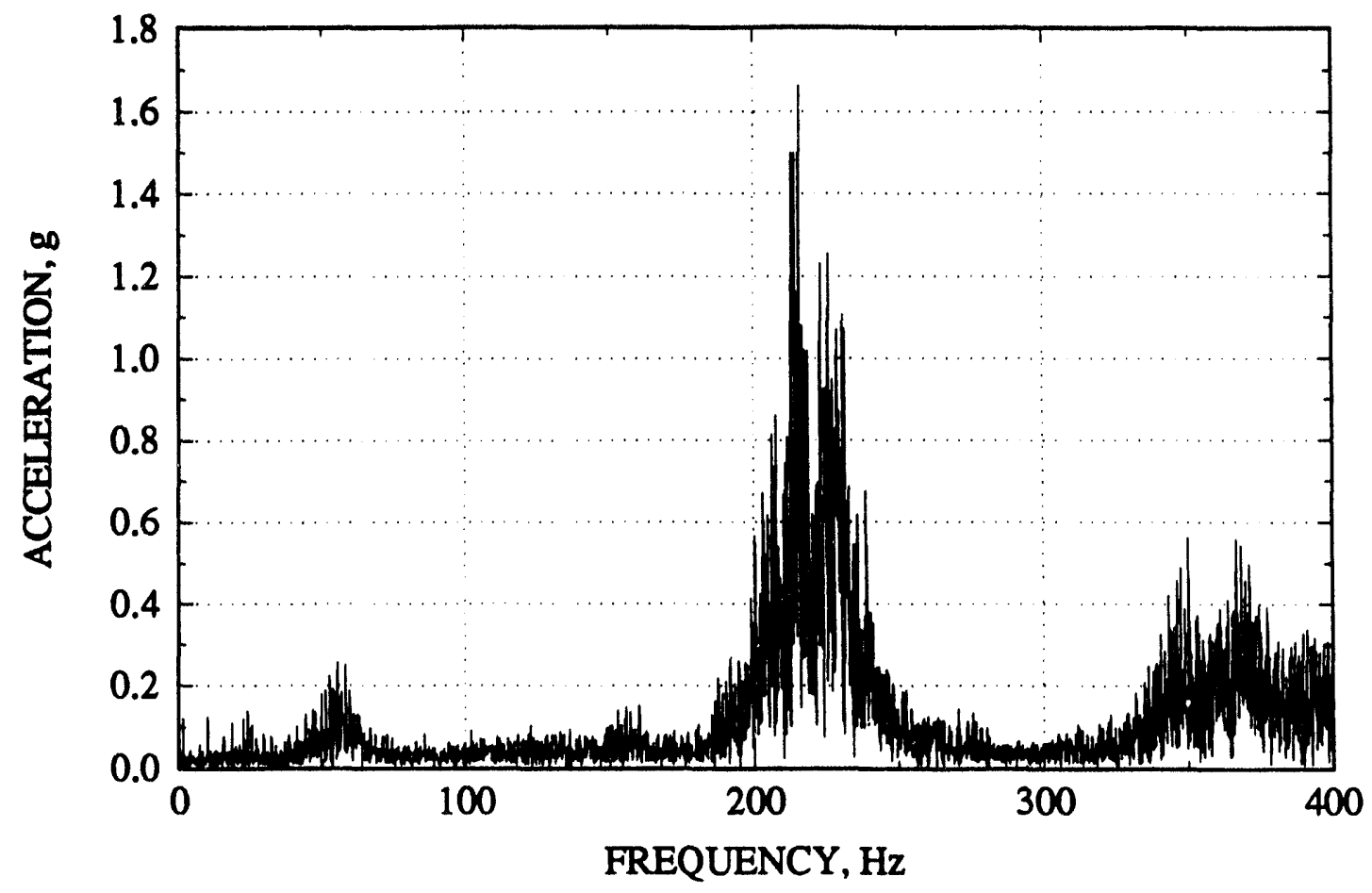

Figure 6-12. Acceleration spectra of the top rock block for the first phase of test no. 15 with a harmonic input frequency of $1.4 \mathrm{~Hz}$

high-frequency components were generated by the chatter mechanism previously described. Figure 6-12 plots the acceleration measurements for the first phase of test no. 15 in the frequency domain. The plot contains three major vibrational modes. One is near $60 \mathrm{~Hz}$, one between 200 and $240 \mathrm{~Hz}$, and one greater than $340 \mathrm{~Hz}$. The first two modes matched quite well with those observed in the shear stress frequency plot (Figure 6-13). Note that Figure 6-13 is a semi-log plot, which displays higher frequencies that would otherwise be too small in amplitude to show in a conventional amplitude-frequency plot.

\subsection{ROCK JOINT SHEAR TESTS UNDER EARTHQUAKE LOADS}

\subsubsection{Earthquake Input}

Several candidate earthquake accelerograms were considered for use as a drive signal for joint shear tests. The final displacement drive signal used for the joint shear tests under earthquake loads was derived from the acceleration response signal recorded from the Guerrero accelerograph array for the earthquake of September 19, 1985, in Mexico. This earthquake had a magnitude of 8.1 on the Richter scale. The acceleration data were recorded on digital data cassette-type magnetic tapes. The data were processed and converted into an ASCII format by Anderson of the University of Nevada at Reno, Nevada 


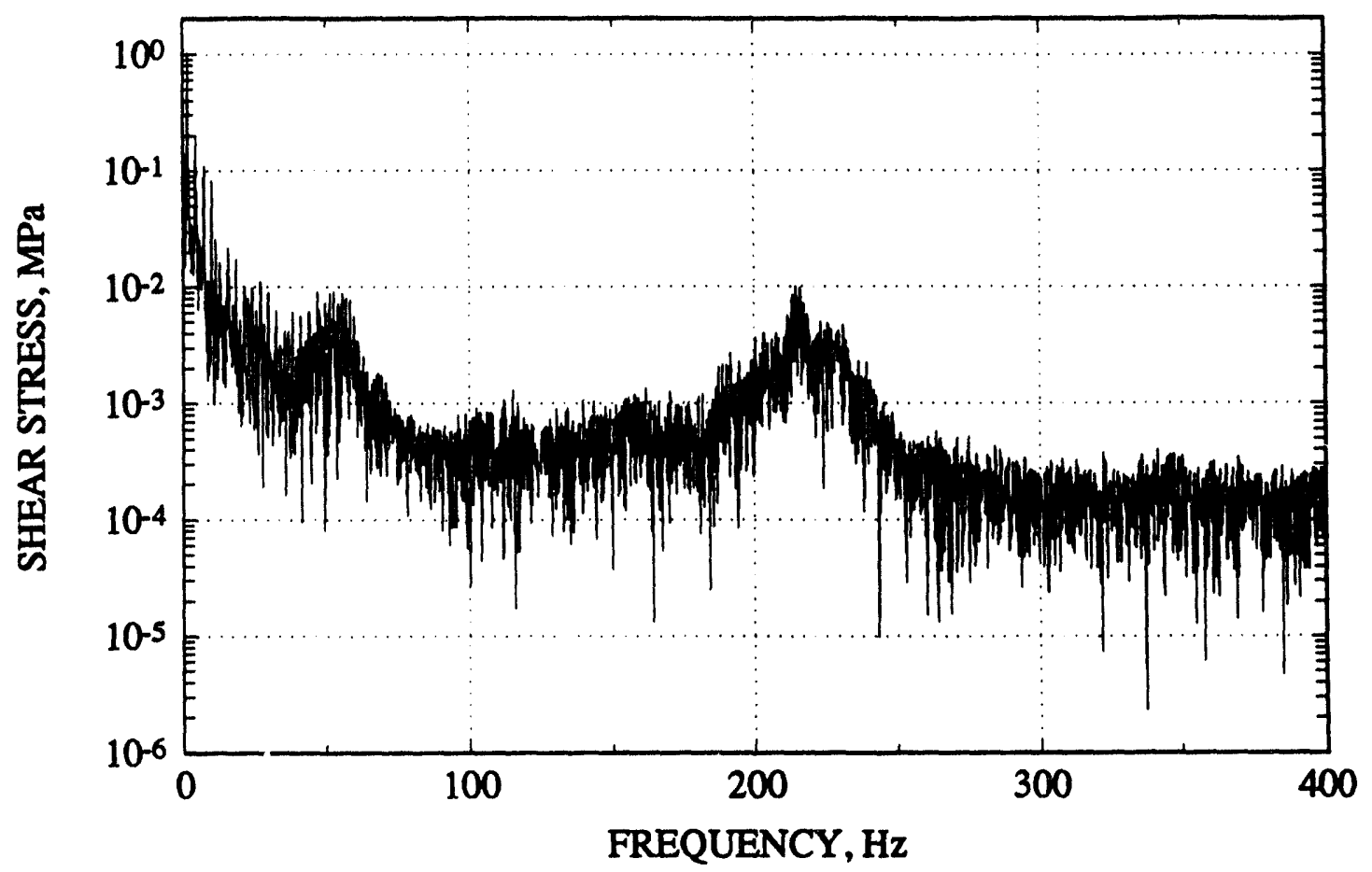

Figure 6-13. Semi-log plot of shear stress spectra for the first phase of test no. 15 with a harmonic input frequency of $1.4 \mathrm{~Hz}$

(Anderson and Quaas, 1992) ${ }^{4}$. The data file for the acceleration response signals contains three components with vibrations along each axis in the vertical, east, and south direction (Figures 6-14, 6-15, and 6-16). The data were organized to have a sampling rate of 50 data points/sec. Each component was about $50 \mathrm{sec}$ in duration with the strong motion portion lasting about $25 \mathrm{sec}$. The acceleration response signal measured along the south axis appeared complete and contained sufficient data to generate a displacement drive signal for the planned joint shear tests subjected to earthquake loads. Thus, it was selected for further processing to develop an input displacement drive signal.

For the earthquake shear tests, three additional channels were added to the 13 channels listed in Table 4-1 for data acquisition. These additional channels were planned for measuring the horizontal acceleration of the bottom rock block, horizontal acceleration of the top shear box, and horizontal displacement of horizontal actuator piston. The data sampling rate was set at 800 points $/ \mathrm{sec}$. For these parameters, the data capacity for the acquisition system described in Section 4.5 for the planned number of channels and sampling rate was about $40 \mathrm{sec}$. In order to ensure that this capacity was not exceeded, it was decided to reduce the 50-sec data in Figure 6-16 to $30 \mathrm{sec}$ duration. The remaining capacity of the system was used to provide the initial and trailing zero drive signals to allow manual start and stop of the data acquisition system. These allowances were important to ensure capturing all starting and stopping responses to the input signal. The reduced acceleration history consisted primarily of the strong motion portion of the data, which was of major interest. Another important aspect considercd in the data reduction process was to avoid small step functions in the input drive signal due to the limitation of the horizontal actuator to handle these step functions, and the high sensitivity of the shear stress to such small

${ }^{4}$ Anderson, J.G., and R. Quaas. 1992. Guerrero Accelerograph Network: Overview of Data From the First Seven Years of Operations 


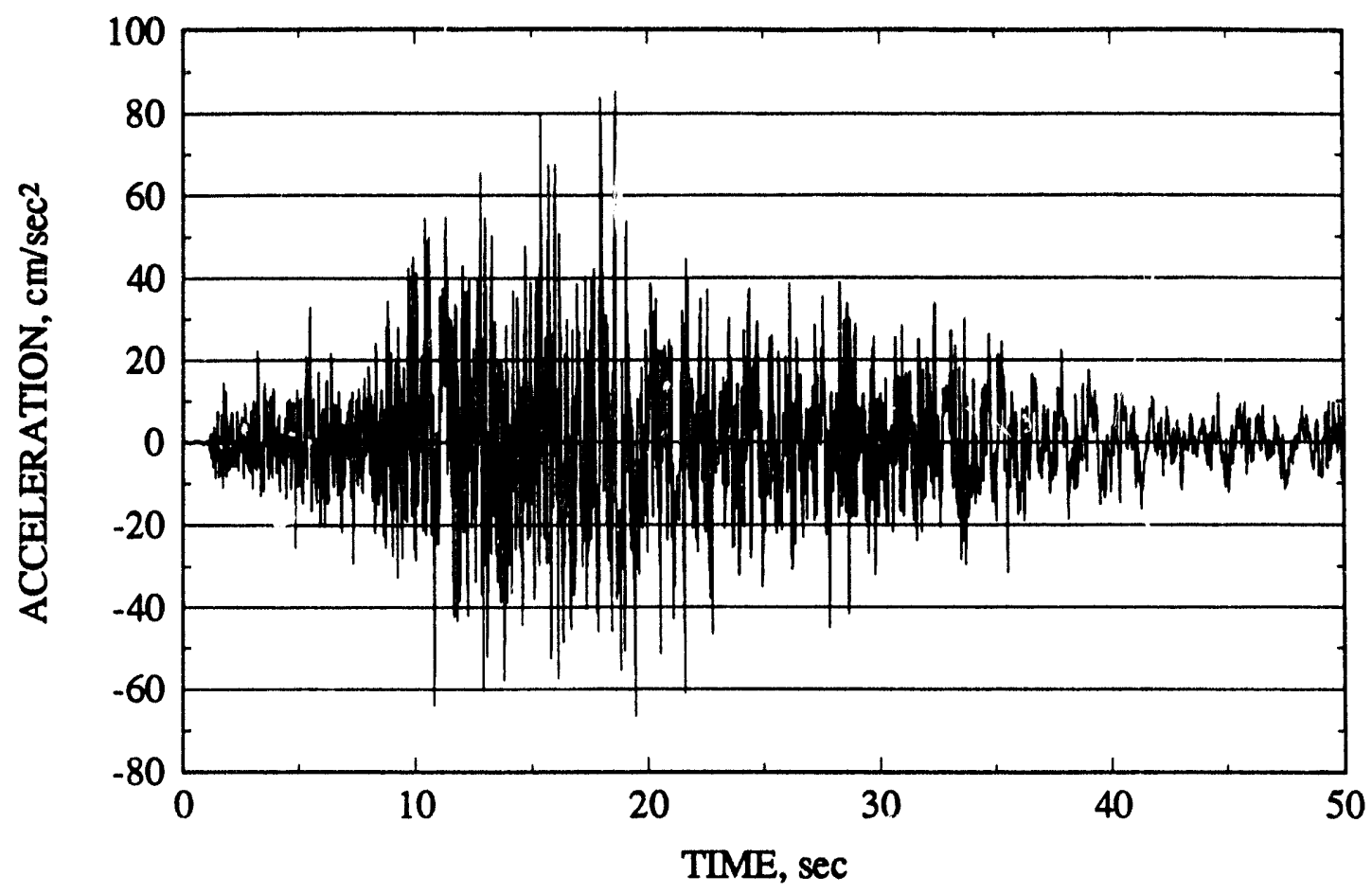

Figure 6-14. Acceleration history along the vertical direction of the 8.1 Richter scale earthquake, September 19, 1985 in Mexico

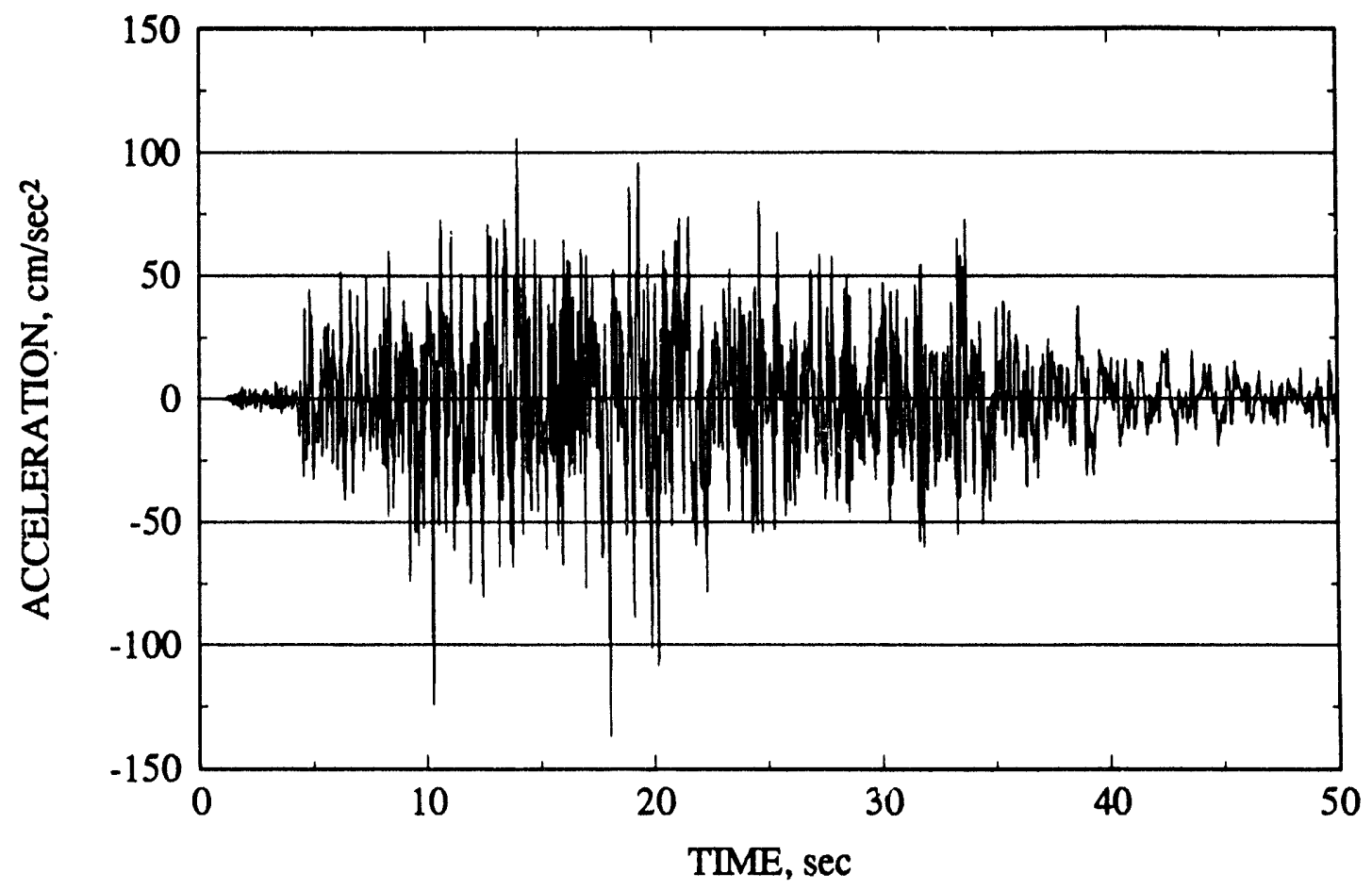

Figure 6-15. Acceleration history along the east direction of the 8.1 Richter scale earthquake, September 19, 1985 in Mexico 


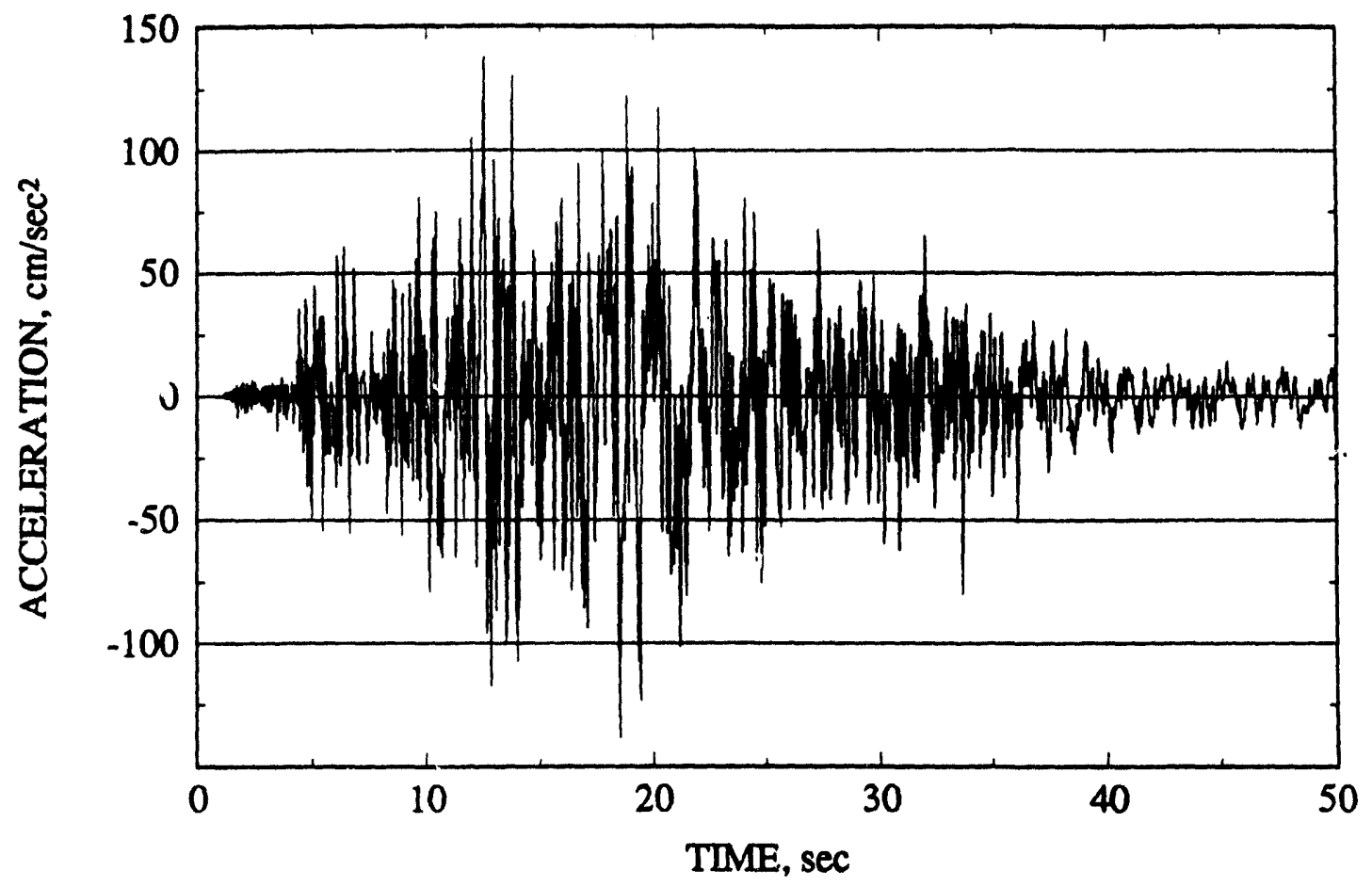

Figure 6-16. Acceleration history along the south direction of the 8.1 Richter scale earthquake, September 19, 1985 in Mexico

displacements. Thus, the input displacement time history should be developed with a ramp from 0 to start the excitation and a ramp to 0 to end the process to prevent these step inputs. To achieve this goal, an enveloping time window was applied to the acceleration time history (Figure 6-16).

An initial input displacement drive signal was obtained by double-integration of the windowed acceleration data in the frequency domain (Fourier spectra). Before the double-integration, a band-pass filter was applied to the acceleration Fourier spectra. This filter was defined by low- $(0.5 \mathrm{~Hz})$ and highfrequency, $(15 \mathrm{~Hz})$ values. The high pass filtering was intended to eliminate the possibility of developing extremely large-amplitude, low-frequency offset in the data during integration. Low pass filtering of the data was intended, however, to eliminate aliasing of the data due to its limited sampling rate of 50 points/sec (relative to the 800 points/sec specified for the data acquisition system). All spectral amplitudes outside the low- and high-frequency values of the filter were assigned to 0 . The filtered acceleration spectra were double-integrated to obtain a displacement spectra by dividing the spectral acceleration values by the negative of the square of the corresponding bin circular frequency. After the inverse Fourier transform was performed on the displacement spectra to obtain the displacement time history, the window was applied again to the displacement time history to ensure proper signal start and end. Figure 6-17 shows the resulting calculated displacement time history. This displacement time history contains a major frequency range from 0 to $2.0 \mathrm{~Hz}$, with a dominant frequency at $0.5 \mathrm{~Hz}$ (Figure 6-18). The vertical caption in Figure 6-18 denotes root mean square amplitude. The frequency range for harmonic tests was comparable, but both were greater than the input frequency for the pseudostatic tests, which was equivalent to $2.1 \times 10^{-4} \mathrm{~Hz}$. (The total time used to complete one-half cycle of the shear displacement, that is, for the top rock block to move away from its original position about $50.8 \mathrm{~mm}$ and then return to the original position, was about $40 \mathrm{~min}$.) 


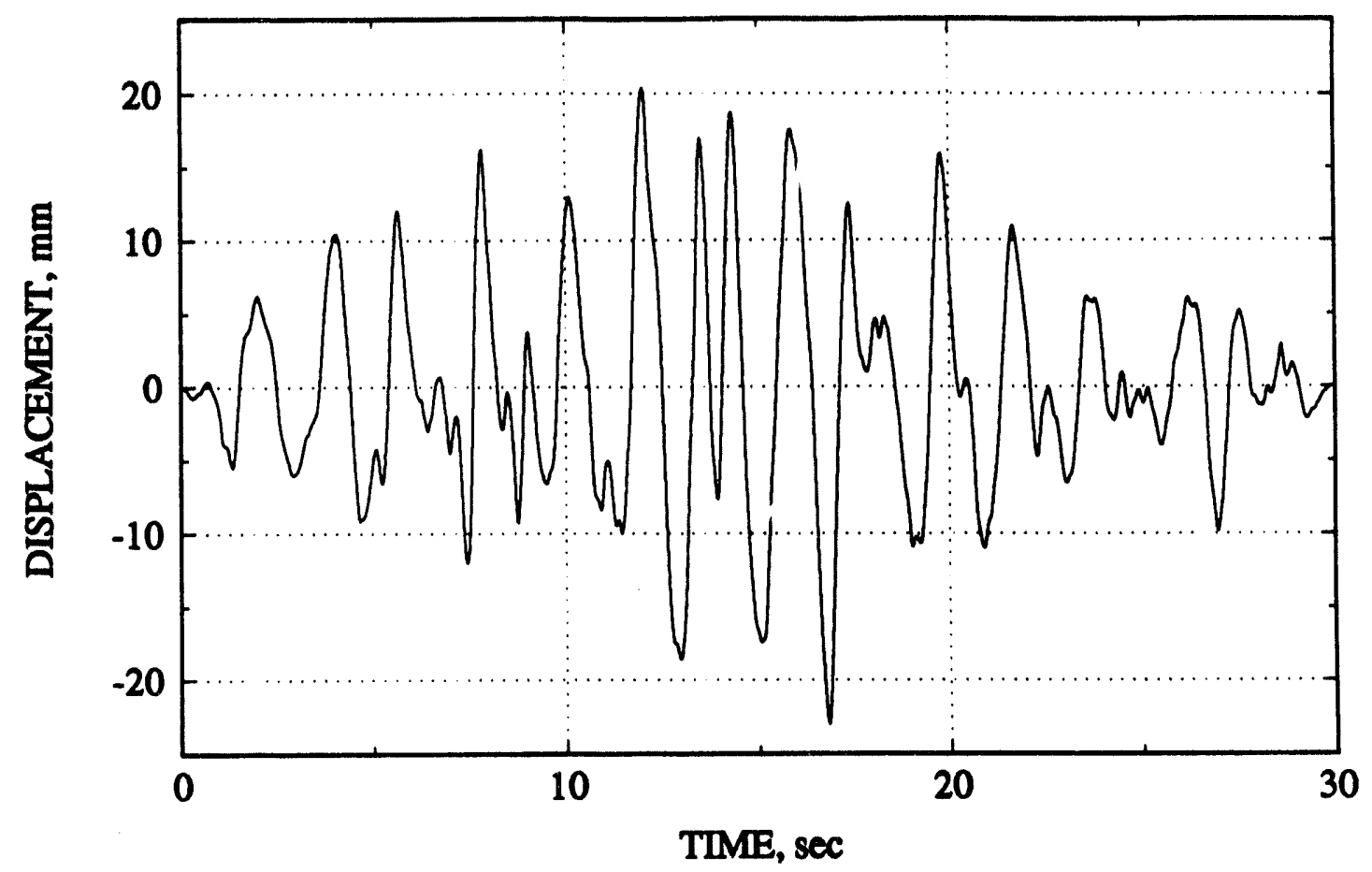

Figure 6-17. Displacement time history generated from the acceleration time history in Figure 6-16

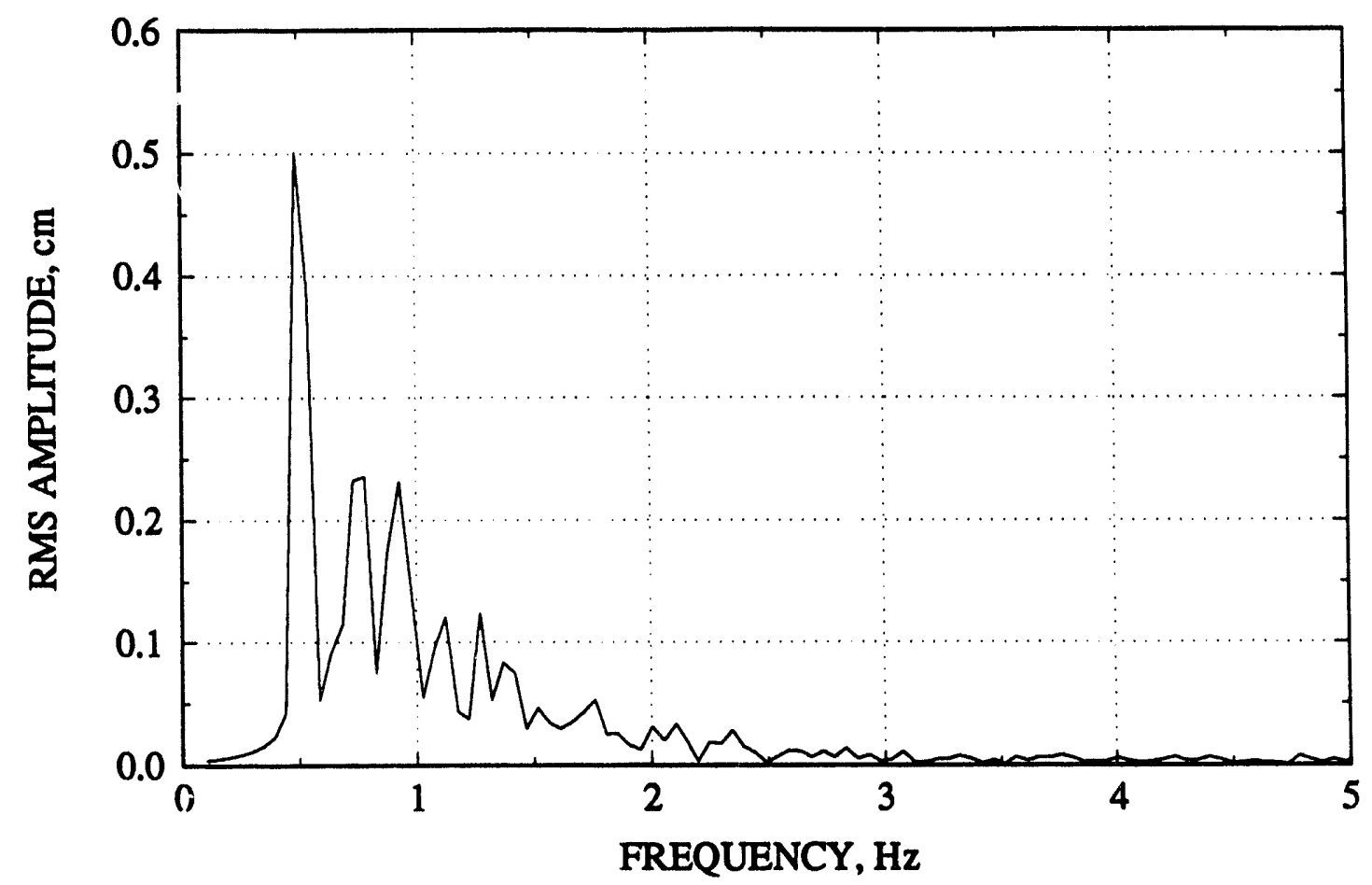

Figure 6-18. Displacement spectra for the displacement time history in Figure 6-17 
Figure 6-19 shows the acceleration time history regenerated from the displacement drive signal to show the effects of the time window and filtering applied to the displacement drive signal. It is observed that this acceleration time history can be directly compared to the strong motion portion of the original acceleration signal as shown in Figure 6-16. This observation means that the developed displacement signal captured all the essential characteristics of the original acceleration signal, an indication that the windowing and filtering had little effect on the original acceleration signal. For the various shear tests, two displacement drive signals were used, one with a peak drive signal of $25.4 \mathrm{~mm}$ and the other, $50.8 \mathrm{~mm}$. These two signals were obtained by scaling the displacement signal in Figure 6-17.

In order to ensure that full joint responses to the displacement signal as shown in Figure 6-17 would be captured during the tests, it was decided that a square wave approximately $4 \mathrm{sec}$ in duration followed by $5 \mathrm{sec}$ of 0 lead time (which contains 0 displacement amplitude) would be initiated before the displacement drive signal. The horizontal actuator switch would be turned on to actually start a test after the square wave had passed and before the start of the actual displacement input. Consequently, the square wave input did not have any effect on the shear test results, but could be used as a visual timing signal. The time available for such an action was about $5 \mathrm{sec}$, as discussed earlier.

Table 6-2 shows the matrix of the direct joint shear tests performed under various earthquake loading conditions. For each test specimen, six tests were conducted under different combinations of input amplitude and normal stress conditions. The numbers in the columns for each test specimen denote the test sequence. The input frequency for the first phase of test no. 26 was only half of the actual input frequency for the rest of the earthquake tests.

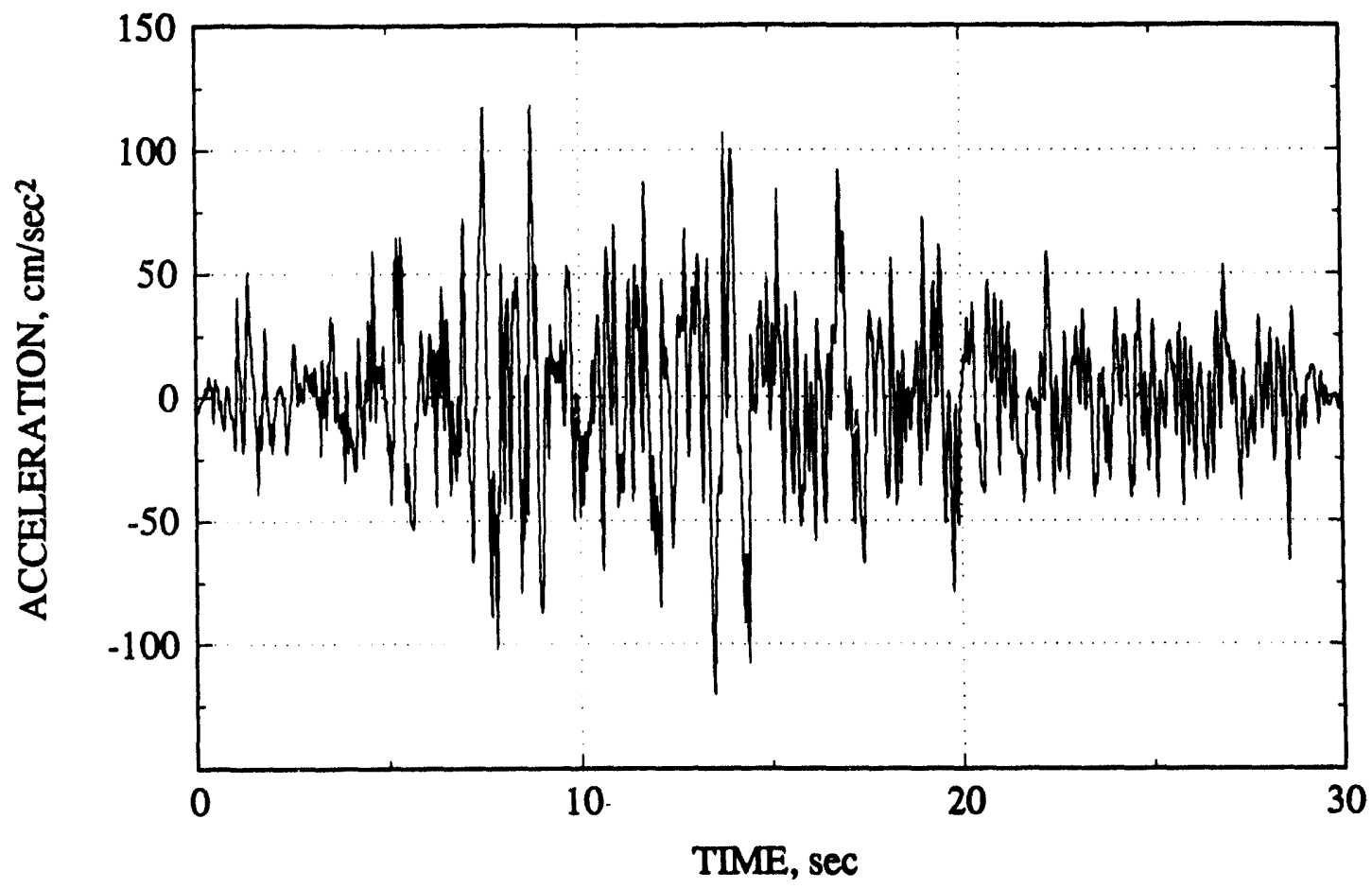

Figure 6-19. Acceleration history calculated from the displacement history in Figure 6-17 
Table 6-2. Test matrix for direct shear tests on jointed rock specimen under earthquake load

\begin{tabular}{||c|c|c|c|c|c||}
\hline \multicolumn{2}{|c|}{ Earthquake Input } & \multicolumn{4}{|c||}{ Test Specimen Number } \\
\hline $\begin{array}{c}\text { Normal } \\
\text { stress } \\
\text { applied } \\
\text { (MPa) }\end{array}$ & $\begin{array}{c}\text { Peak } \\
\text { amplitude } \\
\text { (mm) }\end{array}$ & Test No. 24 & Test No. 25 & Test No. 26 & Test No.30 \\
\hline \hline \multirow{2}{*}{1.0} & 25.4 & 1st & 1st & 1st & 1st \\
\cline { 2 - 6 } & 50.8 & 2nd & 2nd & 2nd & 2nd \\
\hline \multirow{2}{*}{3.0} & 25.4 & 3rd & 3rd & 3rd & 3rd \\
\cline { 2 - 7 } & 50.8 & 4th & 4th & 4th & 4th \\
\hline \multirow{2}{*}{5.0} & 25.4 & 5th & 5th & 5th & 5th \\
\cline { 2 - 7 } & 50.8 & 6th & 6th & 6th & 6th \\
\hline
\end{tabular}

\subsubsection{Test Results}

The types of measurements taken for the direct shear tests on rock joints subjected earthquake signal are essentially the same as those for the harmonic tests, which include normal and shear loads, joint normal and shear displacements, acceleration responses of the top and bottom rock blocks, and displacement response between the horizontal load cell and the top shear box. Both an analog tape recorder and a computer were used for data acquisition for these tests. Figure 6-20 shows the measured shear displacement time history and the corresponding response of shear stress time history of the first phase for test no. 24. It shows clearly a response of the shear stress to the input square wave which lasted about $4 \mathrm{sec}$ with an amplitude around $0.5 \mathrm{MPa}$. In the same time period, no shear displacement was observed, an indication that the actual test was not started. The actual test was started immediately at the end of the square wave response (point $A$ in Figure 6-20).

Similar to the harmonic tests, a phase difference between the shear stress and shear displacement with the shear displacement lagging behind was also observed for the earthquake tests performed in this study. An example is shown in Figure 6-20. One can also observe from the figure that the amount of shear displacement required for the shear stress to reach peak value is relatively small compared to the shear displacement input amplitude. Consequently, the shear stress levels for each displacement cycle are fairly constant irrespective of the amplitude of the cycles.

Figures 6-21 and 6-22 show the shear stress and shear displacement time histories from the 15th to 20th second for the first phase of test nos. 24 and 25. The measured shear displacement responses for both tests were essentially the same. The shear stress history for test no. 25 shows distinct transition, a sharp increase in shear stress magnitude when the top rock block moved past its original position, while such a difference was not as obvious for test no. 24. The same observation can also be made for test nos. 14 and 15 (Figures 6-1 and 6-2). This difference is related to the extent of the waviness of joint profiles. 


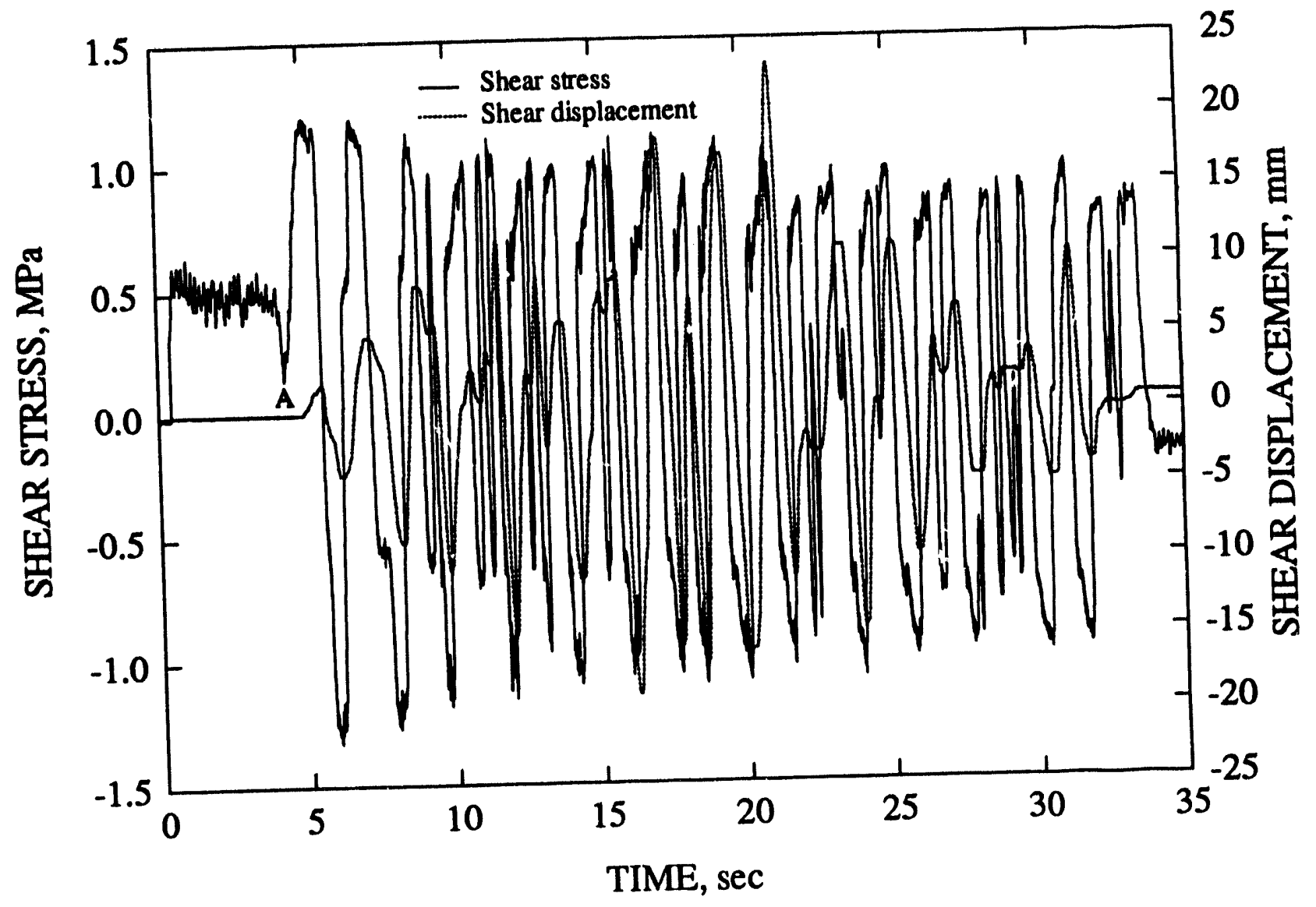

Figure 6-20. Shear stress and shear displacement history of the first test of test no. 24 using a displacement input signal in Figure 6-17 with a maximum amplitude of $25.4 \mathrm{~mm}$

Figures 6-23 and 6-24 show the normal stress and normal displacement responses between the 15 th and 20 th second of the first phase of test nos. 24 and 25, respectively. The normal stress responses to the earthquake displacement input in both figures included higher frequency components during the test as was observed for the harmonic tests. However, impact of this variation on the normal displacement appears to be small. A closer examination shows that variations of both measurements are not exactly synchronized. The same observation can be made regarding the results of the harmonic tests (Figures 6-7 and 6-8). This lack of synchronization, combined with the fact that the normal displacement vibrated even at times when there was no shear displacement (Figures 6-1 and 6-7), seems to indicate that the normal displacement variation may not be part of a joint behavior. Instead, it may be a result of interaction with some apparatus vibrational modes. Fortunately, the magnitude of the vibration is small for both types of tests and will not affect the ability of obtaining an understanding of joint-dilation behavior.

It should be noted that the normal displacement measurement in Figure 6-24 shows sharp variations at three locations. These sharp variations could not be the real response of the joint since one of the readings indicated a normal displacement of more than $-4 \mathrm{~mm}$. A positive normal displacement in the figure indicates dilation, that is, the two rock blocks at both side of the joint moving away from each other, while the negative value indicates the two compressing with each other or joint closure. Joint closure of such a magnitude, $4 \mathrm{~mm}$, cannot be achieved even with extremely high normal stresses. The joint normal stiffness is, in general, not a constant. Experimental results from the repeated normal 
$22-9$

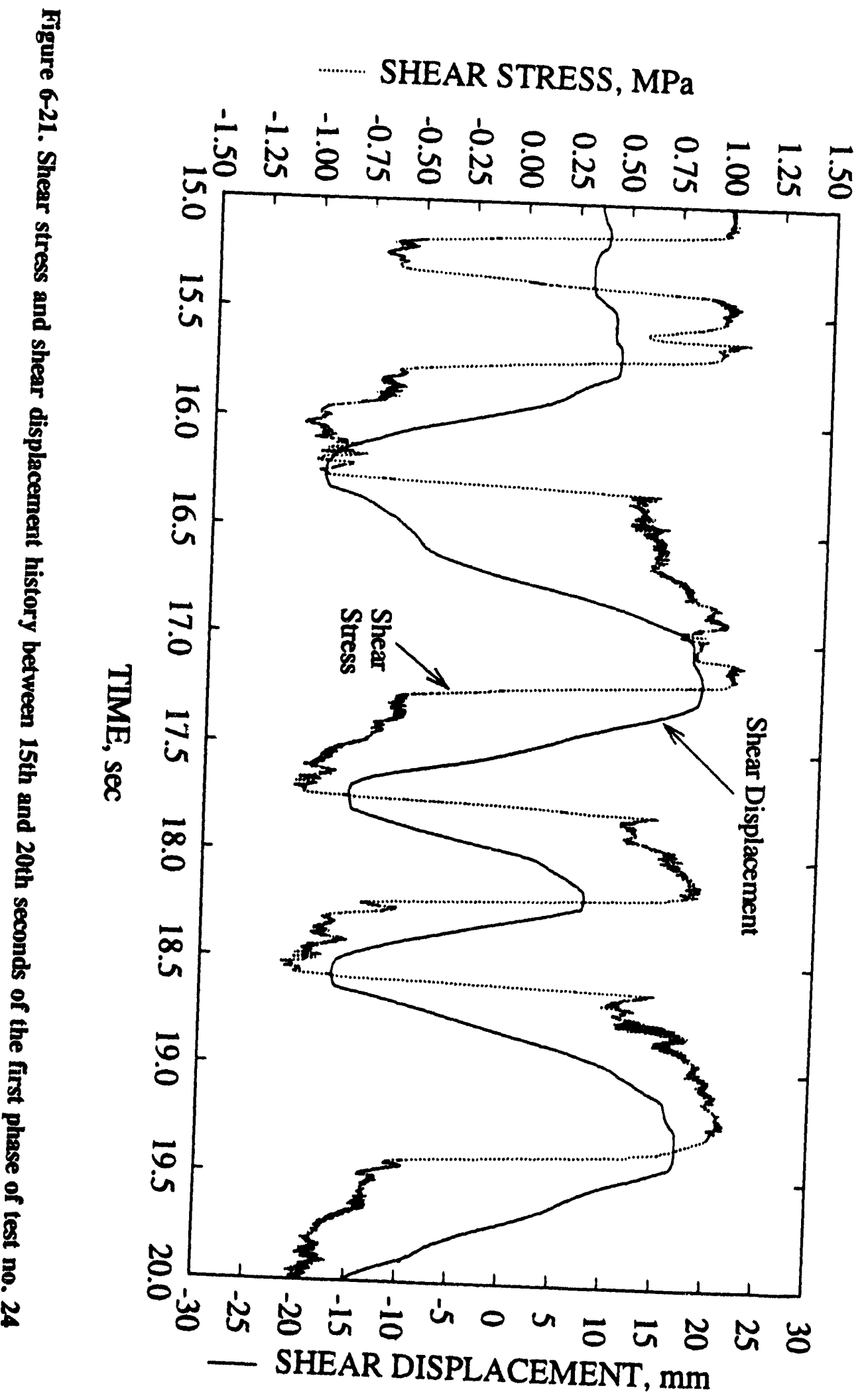




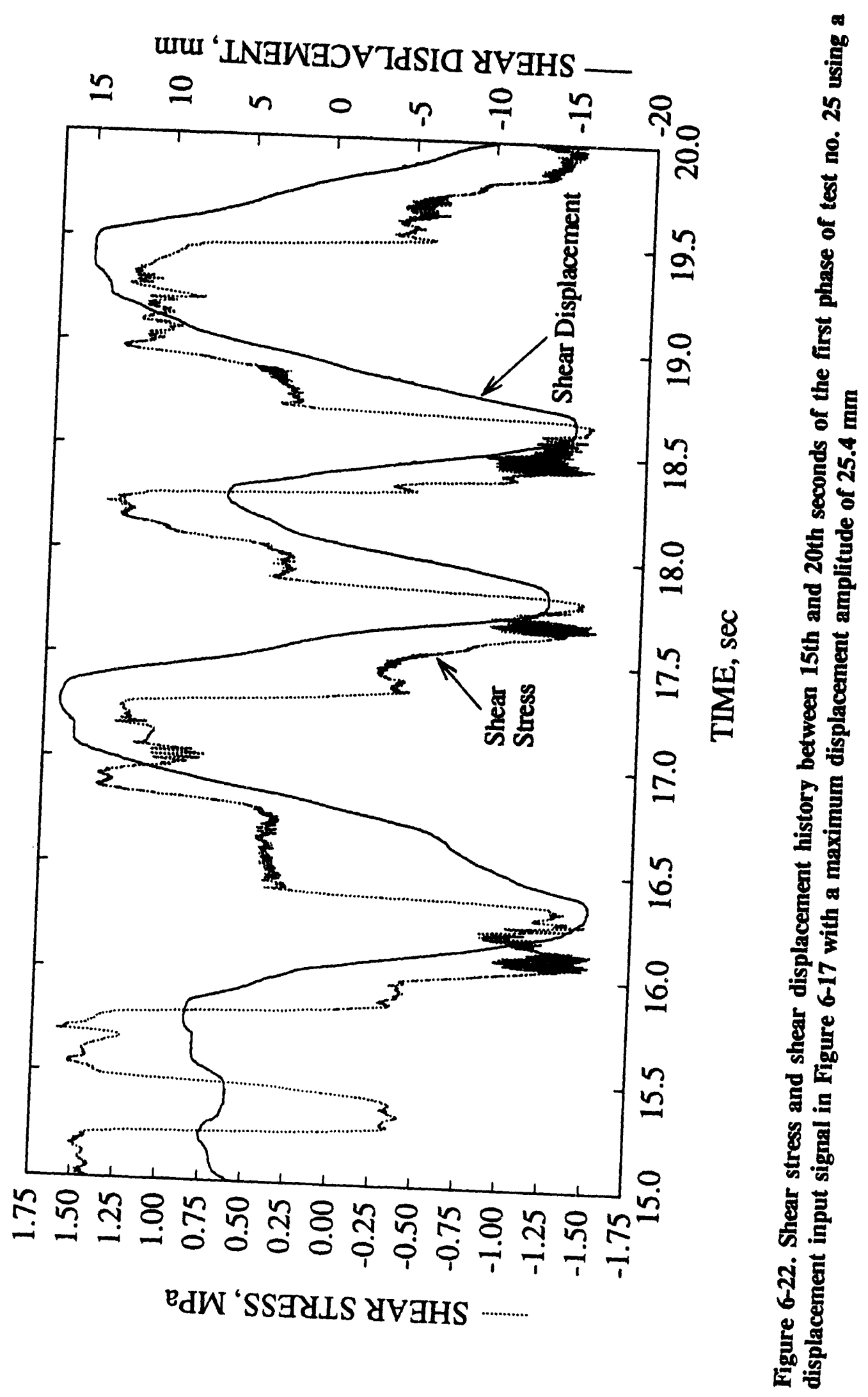




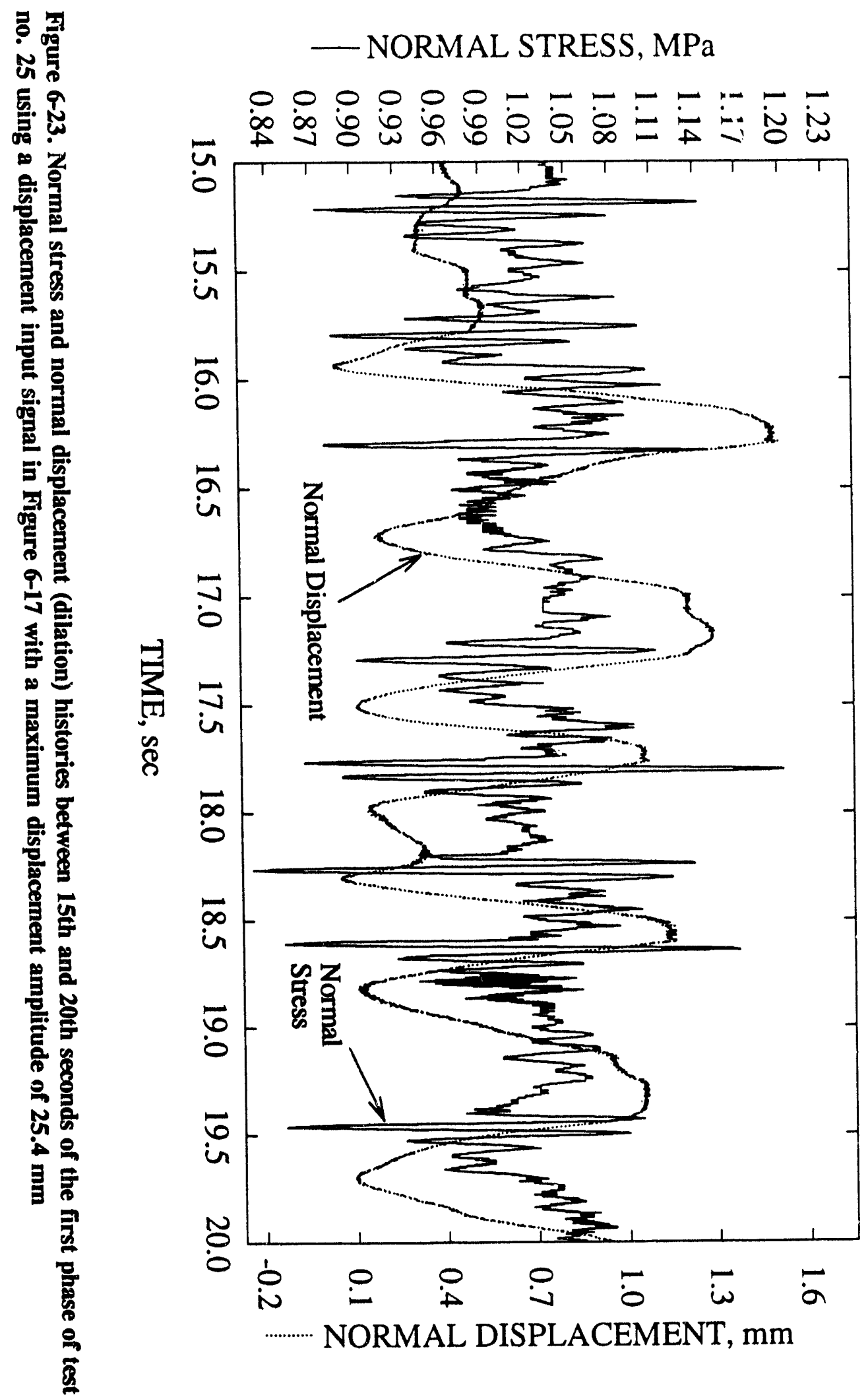




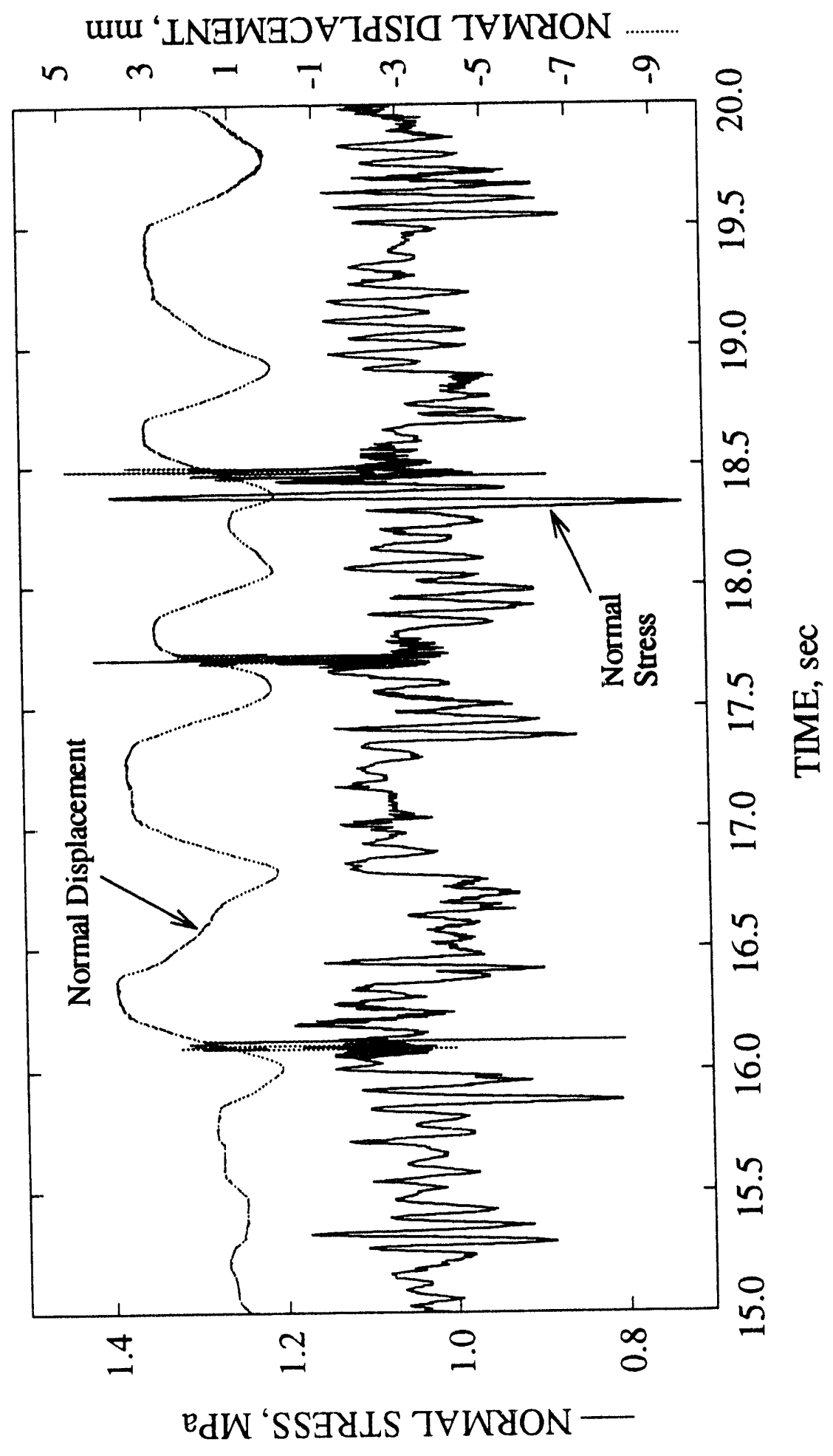

药

氜

है

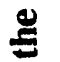

ํํำ

용

8

กั

를

를 릉

들

해욤

要

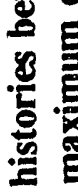

동

호ㅇㅗㅗ

픈

들

통 농

焉

ㄹ.

흘

를

볼

를

\&

홍

퐁

ㄹ.

2 o

خु่

는

象 
loading/unloading tests have shown that the joint normal stiffness increases as does the joint closure. The change in the joint normal stiffness is usually very large and, consequently, the joint normal stiffness becomes very high with a relative small amount of joint closure. In other words, after a small amount of joint closure, the joint becomes so stiff that it is almost no longer "compressible." This closure value, as observed, realized in the normal cyclic loading/unloading tests is at least one order of magnitude smaller than $4 \mathrm{~mm}$ (Figure 5-3). Therefore, the observed anomalies in Figure 6-24 have not yet been explained.

Figures 6-25 and 6-26 show the response frequency contents for the shear stress of the first phase of test nos. 24 and 25 in semi-log form. The spectrum values in these two figures were the averaged value of 5 data segments containing $5 \mathrm{sec}$ of data each. The low-frequency contents for both tests were essentially the same with the dominant frequency at about $0.5 \mathrm{~Hz}$, which coincides with the displacement input signal. Both figures also contain a vibrational mode at the high-frequency level. For test no. 24 (Figure 6-25), this vibrational mode is at $290 \mathrm{~Hz}$, and it is $270 \mathrm{~Hz}$ for test no. 25 (Figure 6-26). As discussed in the last paragraph of Section 6.1.2, this vibration mode may be a result of breaking rock asperities from joint surfaces or crushing these pieces during shearing and possible interaction with apparatus modes.

\subsection{POTENTIAL DYNAMIC IMPACT ON ROCK-JOINT BEHAVIOR}

As discussed earlier, the normal stress for dynamic tests could not be maintained as a constant value during the course of the tests (Figures 6-7, 6-8, 6-23, and 6-24) as planned, due to the inability of the servocontrolled valve for the vertical actuators to adjust quickly to the sudden changes in the normal stress in response to changes in asperities during shearing. The largest variation observed for the normal stress response was about $0.3 \mathrm{MPa}$. This variation was associated with a test under $1 \mathrm{MPa}$ of normal stress. It is reasonable to conclude that, as the normal stress increases, its normalized variation (presented as percentage of change) decreases, and so does the potential impact of normal stress variation for the dynamic tests. Also, as discussed earlier, the vibration mode of the normal stress is not exactly synchronized with that of the normal displacement, and the variation of the normal displacement at highfrequency is quite small. Therefore, it could be concluded that the effect of normal stress variation is likely to be small. The extent of the normal stress variation to the shear stress response at the low normal stress level is difficult to judge. However, given the transient nature of the variation, its impact should also be small.

Figures 6-27 to 6-32 show the characteristic hysteresis of the joint shear stress versus joint shear displacement for the first phase of test nos. 14, 15, 24, 25, 26, and 30, all of which were for 1-MPa normal stress. It should be noted again that test nos. 14 and 16 were conducted using a harmonic input motion with $1.4-\mathrm{Hz}$ in frequency and $12.7-\mathrm{mm}$ in amplitude. The same amplitude earthquake input motion was used for test nos. 24, 25, 26, and 30. All figures include the test results of the first three cycles, and Figures 6-27 and 6-28 also include the result of the 40th cycle. For all the tests, the experiment started with the shearing of the top rock block from its original position (represented as the 0 shear displacement in the figures) toward one end of the bottom rock block until a predetermined maximum value of shear displacement (based on the input displacement time history) was reached. The corresponding subsequent shear stress versus shear displacement characteristic curve with this portion of shearing is shown in the first quadrant of the figures (i.e., clockwise progression around the figure). After the maximum shear displacement in the first quadrant was reached, the top rock block began to move back toward and eventually past its original position. The corresponding shear stress versus shear displacement 


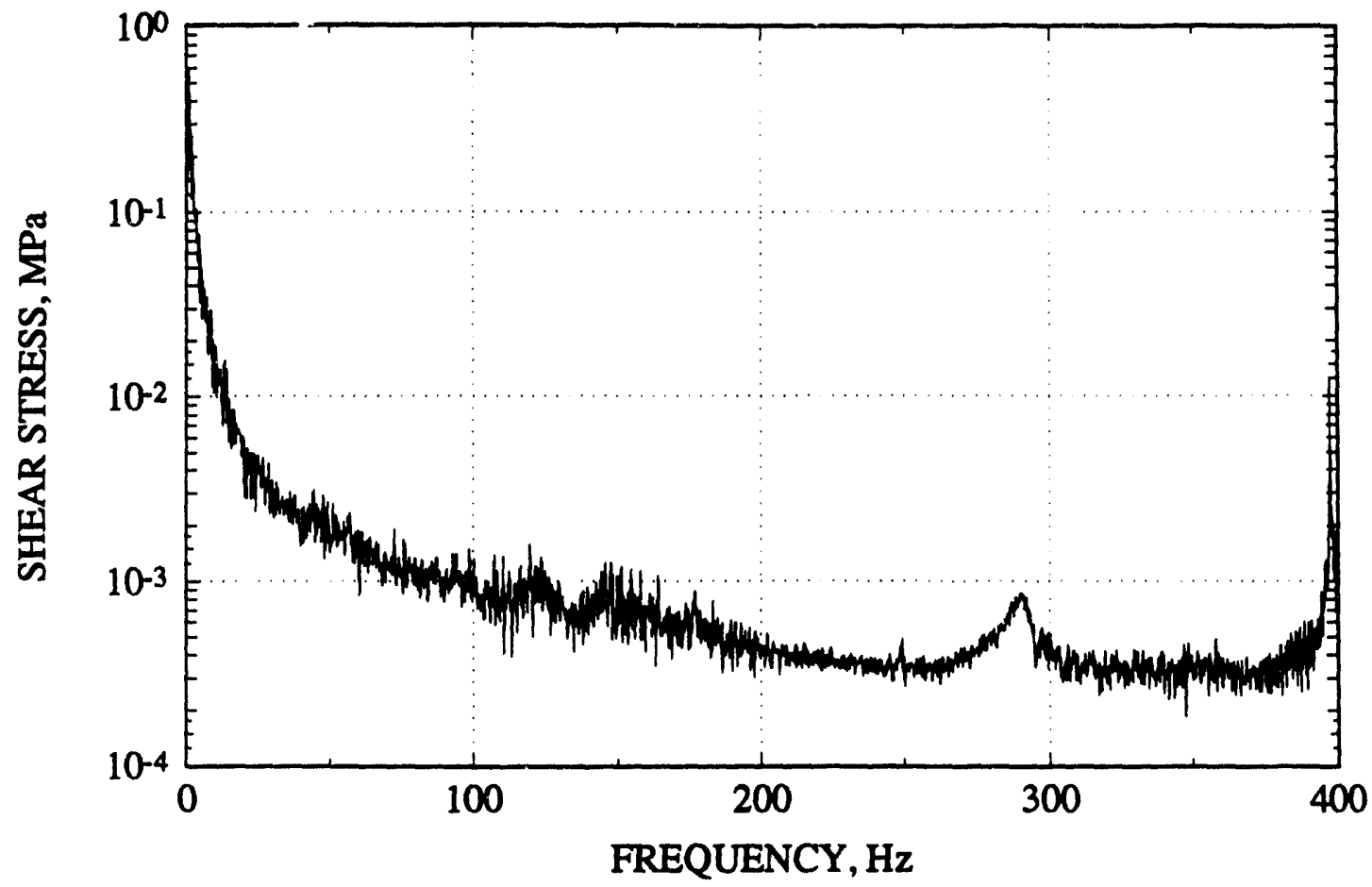

Figure 6-25. Semi-log shear stress spectra plot of the first phase of test no. 24

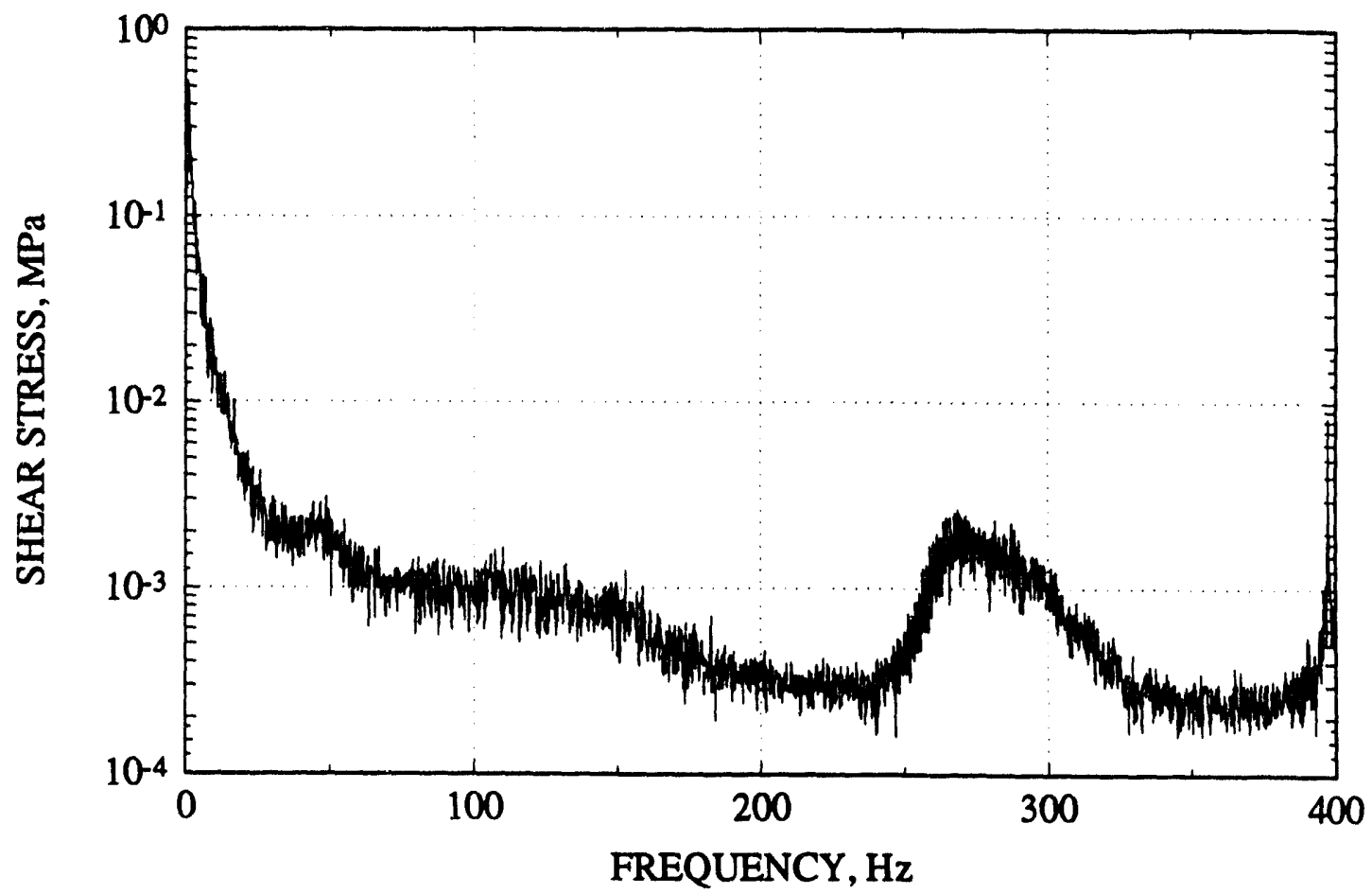

Figure 6-26. Semi-log shear stress spectra plot of the first phase of test no. 26 


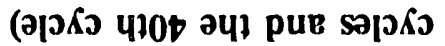

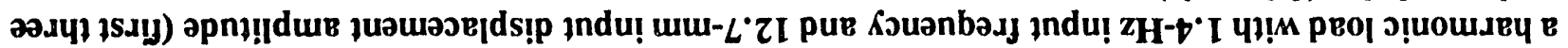

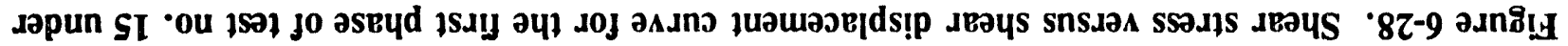

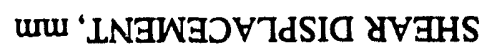

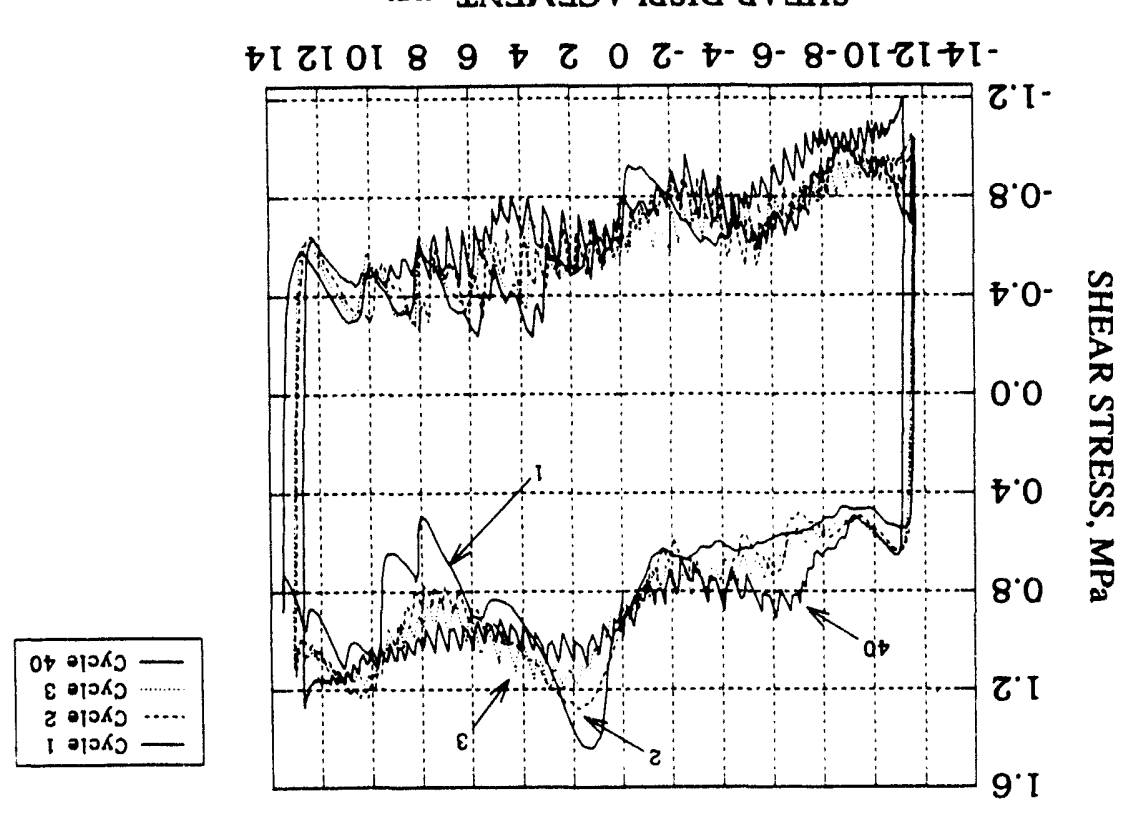

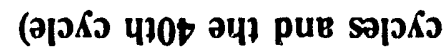

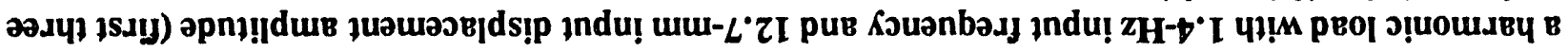

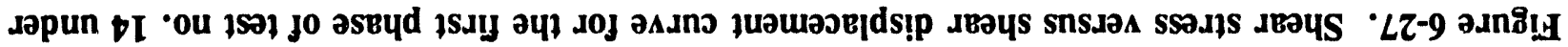

URU 'LNGWGOVTdSIC \&VIHS

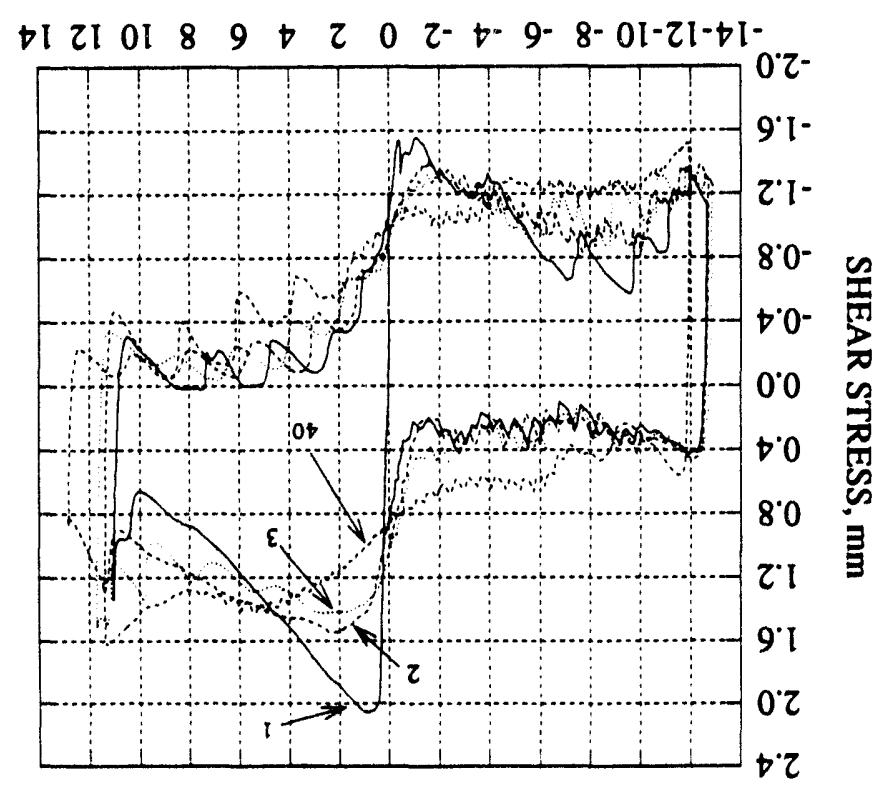




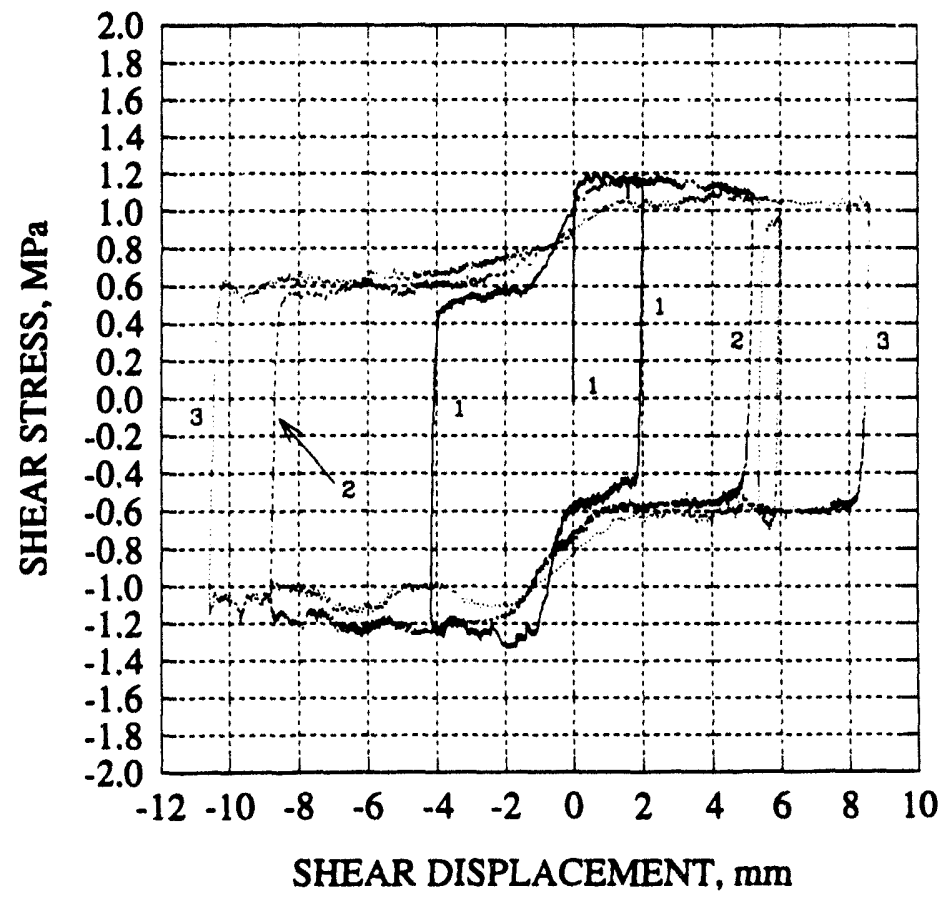

Figure 6-29. Shear stress versus shear displacement curve for the first phase of test no. 24 under an earthquake load with a maximum input displacement amplitude of $25.4 \mathrm{~mm}$

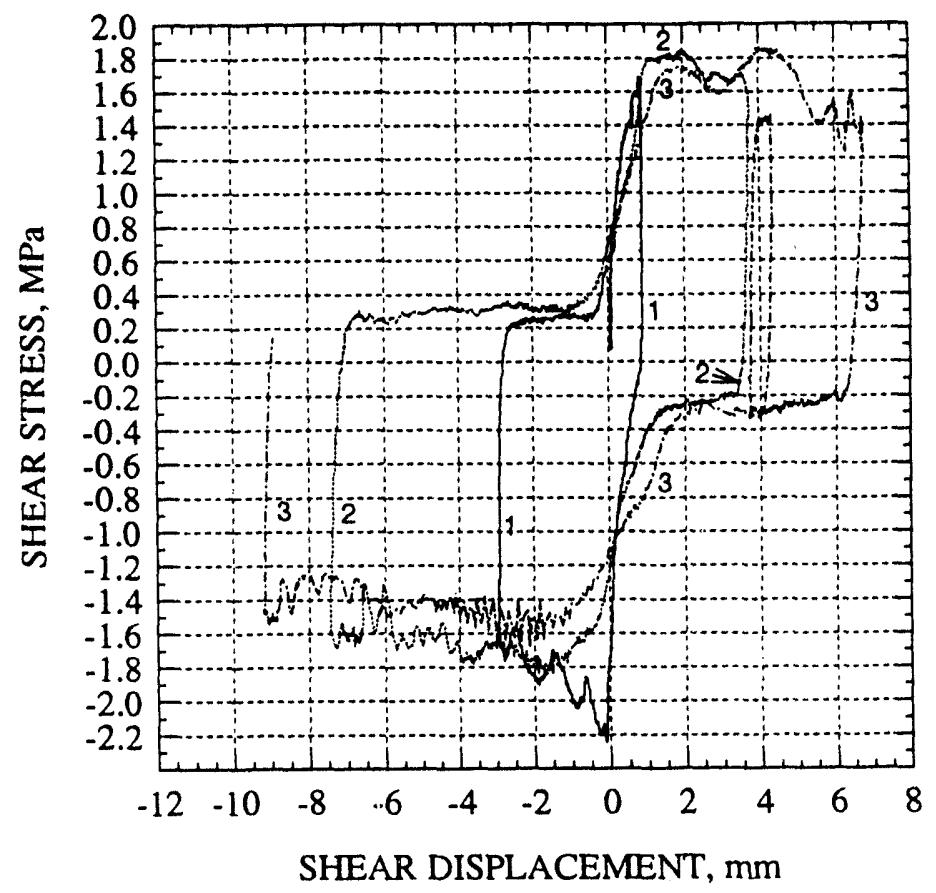

Figure 6-30. Shear stress versus shear displacement curve for the first phase of test no. 25 under an earthquake load with a maximum input displacement amplitude of $25.4 \mathrm{~mm}$ 


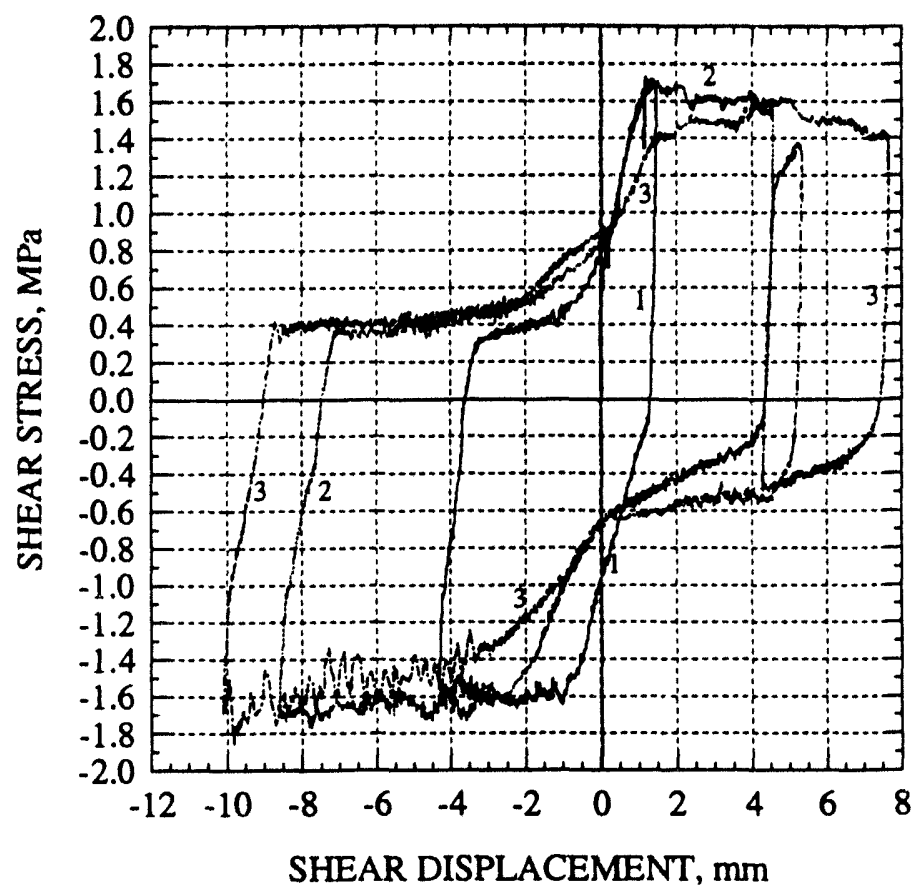

Figure 6-31. Shear stress versus shear displacement curve for the first phase of test no. 26 under an earthquake load with a maximum input displacement amplitude of $25.4 \mathrm{~mm}$

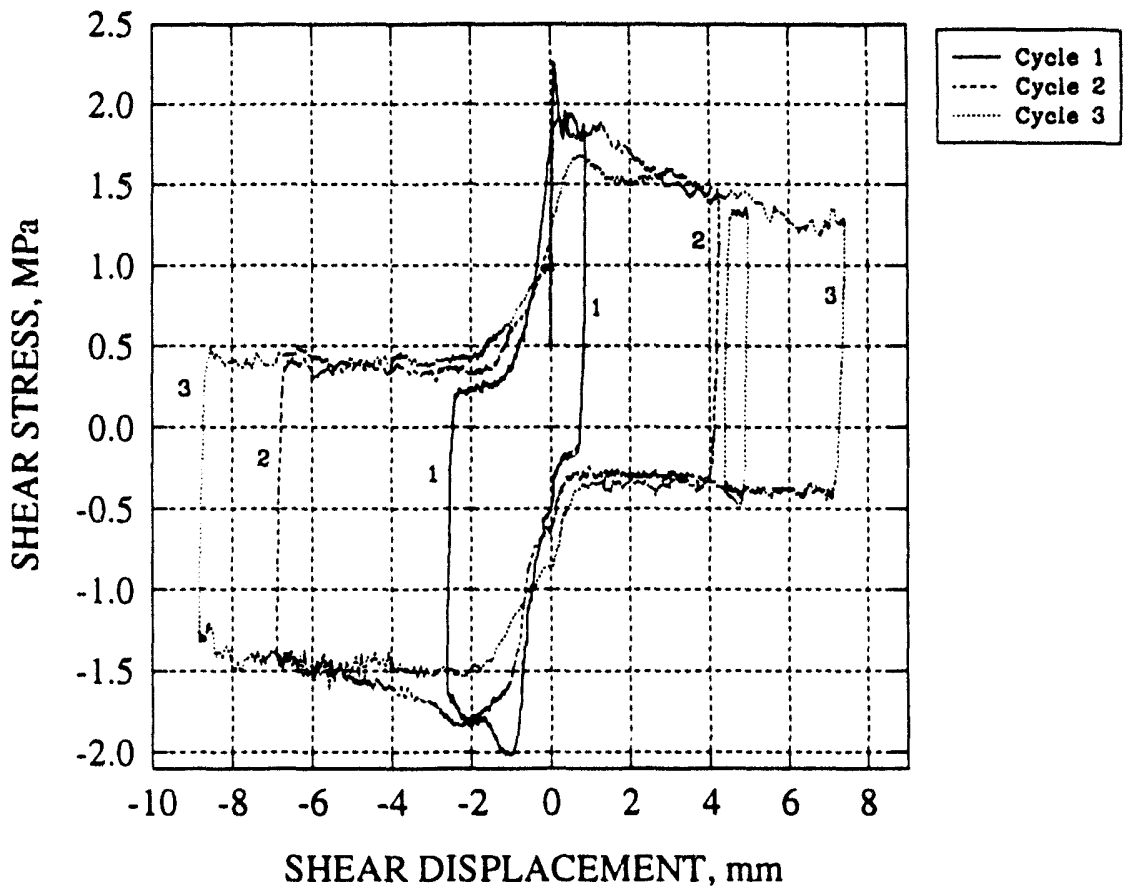

Figure 6-32. Shear stress versus shear displacement curve for the first phase of test no. 30 under an earthquake load with a maximum input displacement amplitude of $25.4 \mathrm{~mm}$ 
characteristic curves are presented in the fourth and third quadrants of the figures, respectively. After the maximum shear displacement in the third quadrant was reached, the top rock block moved again back to its original position to complete a cycle of shear motion. The associated shear stress versus shear displacement characteristic curve is presented in the second quadrant of the figures. This process was repeated for a number of cycles. Bear in mind that the tests were set up to have the top block set in the middle of the bottom block to allow the top block a maximum allowable travel about $50.8 \mathrm{~mm}$ on either side of the original position along the direction of shearing. As shown in the figures, the shear stress is assigned to be positive when the shearing is along one direction and becomes negative when the shearing follows the opposite direction. Consequently, the sign for the shear stress denotes the direction of the shear instead of the magnitude of the shear stress.

As was observed for the pseudostatic tests, a peak joint shear stress (peak joint shear resistance) was also observed for the first cycle for both harmonic and earthquake tests if the jointed specimens used for the tests were never shear tested before or showed signs of past shearing before sample collection. The phenomenon of wear of the joint is also clear, shown in the figures as the shear stress (joint shear resistance) decreases with the number of cycles. To aid the discussion, the term of forward shearing is used throughout this section to indicate that the top rock block moves away from its original position, while the term reverse shearing denotes the top rock block moving toward its original position.

One distinct feature of the shear stress versus shear displacement characteristic in Figures 6-27 to 6-32 is the nature of the smaller shear resistance upon reverse shearing as compared to that of forward shearing (the first quadrant versus the fourth quadrant, the third quadrant versus the second quadrant). The same behavior was also observed for the pseudostatic tests on the Apache Leap natural tuff joints (Figures 5-4 and 6-33) and reported by other researchers (Jing et al., 1992; Wibowo et al., 1992; Huang et al., 1993) for rock joint replicas under pseudostatic loads. The shear stress versus shear displacement curves in Figure 5-4 represent the test results on different fresh joints under five different normal loading conditions, while the curves in Figure 6-33 represent the test results on the same joint under various normal loading conditions.

It should be noted that both joint forward and reverse shearing are important phenomena for a rock joint when it is subjected to earthquake loads, unlike under static load where the forward shearing is the only concern. The low shear resistance associated with the reverse shearing process may play a key role in determining the stability of an underground opening if the condition is unfavorable. Therefore, a better understanding of the cause of the observation discussed in the previous paragraph is important to the design of a stable underground excavation.

Jing et al. (1992) suggested that the difference may be a result of different damage states of asperities on the joint surface. They implied that, on a larger scale, a rock-joint surface is normally not planar. Rather, it is curved and contains dominant wavelengths. These wavelengths could be either large or small. Portions of the joint surface stretched across these wavelengths are called "primary asperities" and there also exist, on the joint surface, "higher order asperities" that have much smaller sizes as compared to the primary asperities [Figure 6-34(a)]. These higher order asperities may be considered as noise on a waveform. Profiles taken from the Apache Leap tuff joints confirm the existence of the primary and higher order asperities as suggested (Jing et al., 1992; Huang et al., 1993). Figures 6-35 and 6-36 show the joint surfaces of the bottom rock blocks for the specimens for test nos. 14 and 15 . The $\mathrm{Z}$-axis in both figures is not according to scale. Both joint surfaces contain primary and higher order asperities. As shown in both figures, the joint surface can be considered to contain two orthogonal sets of primary waveforms; one along the $\mathrm{X}$-axis and the other along the $\mathrm{Y}$-axis. The direction of shear for 


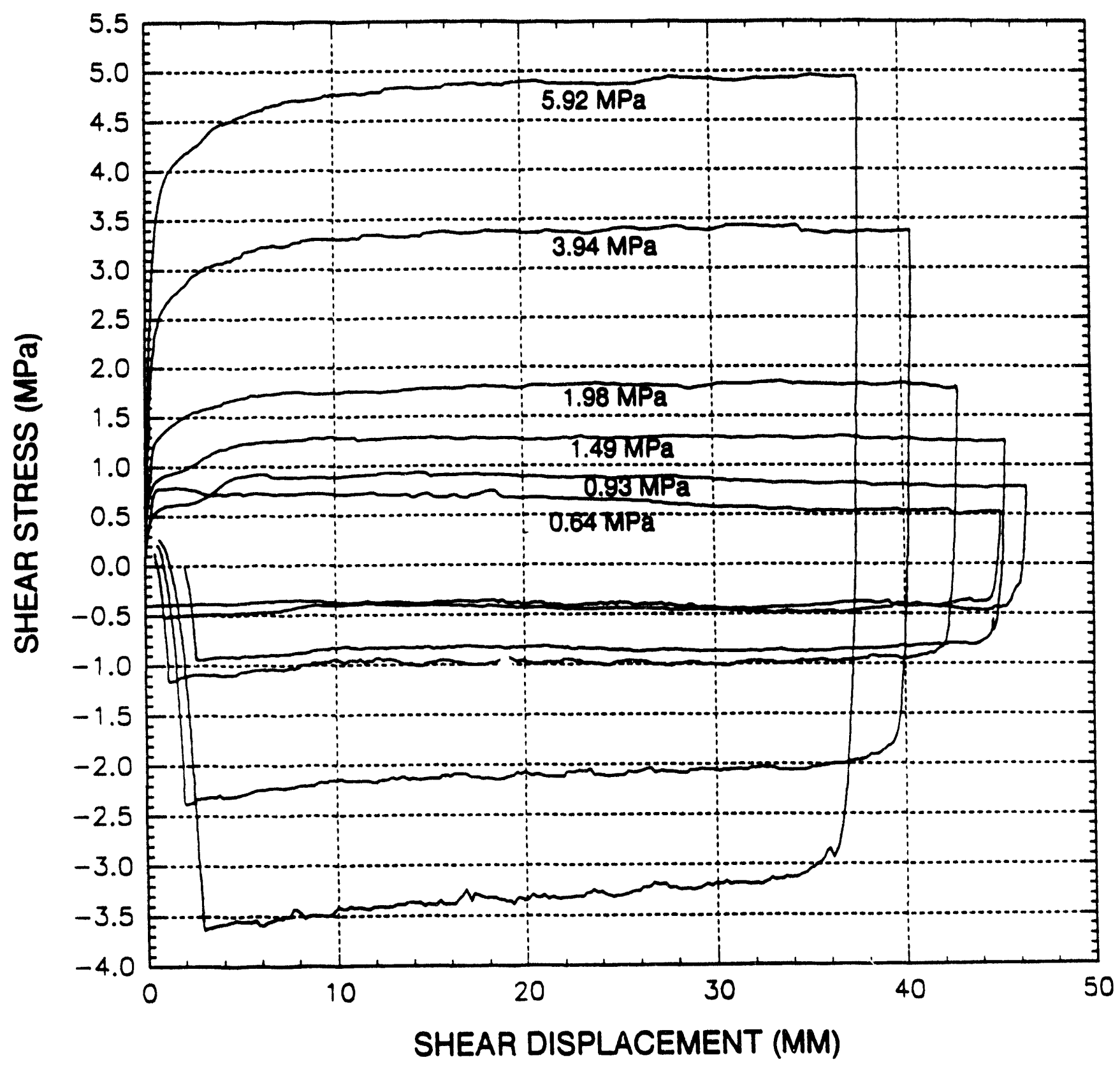

Figure 6-33. Shear stress versus shear displacement curves for pseudostatic tests as a function of applied normal stress for test no. 1 


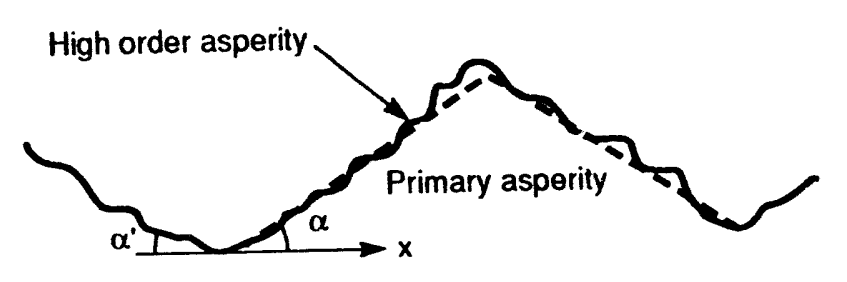

(a)

$\stackrel{a}{\omega}$

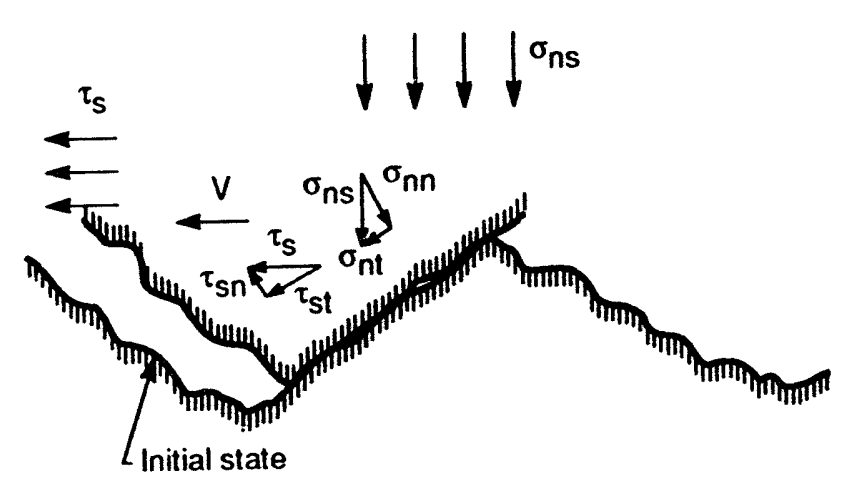

(c)

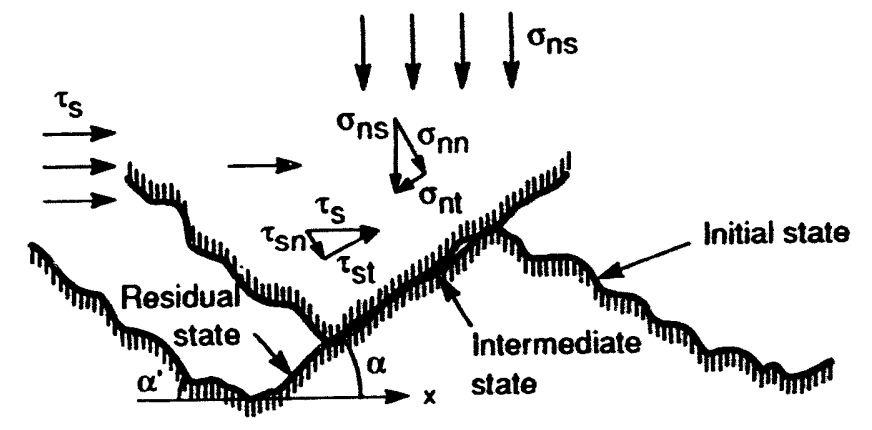

(b)

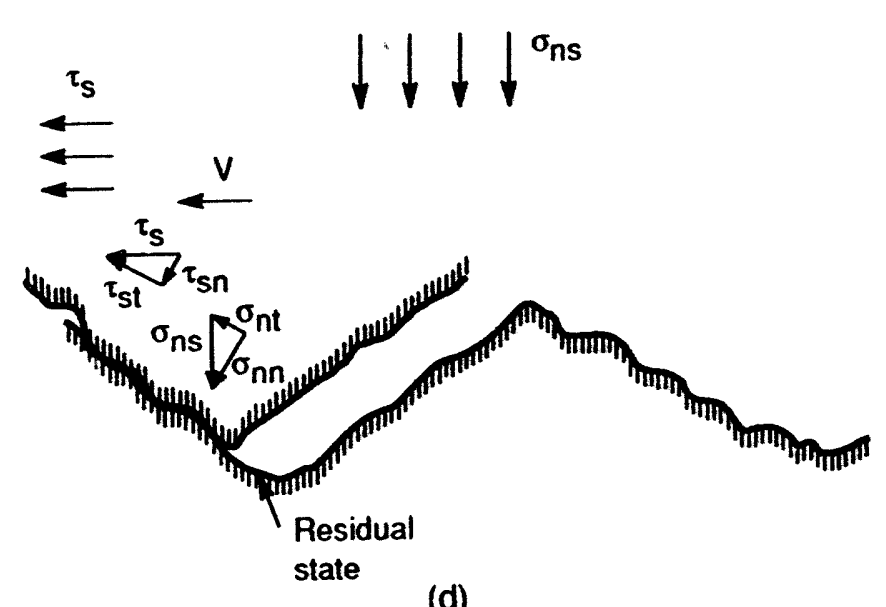

Figure 6-34. Hypothesis of joint shear behavior during forward and reverse stages 


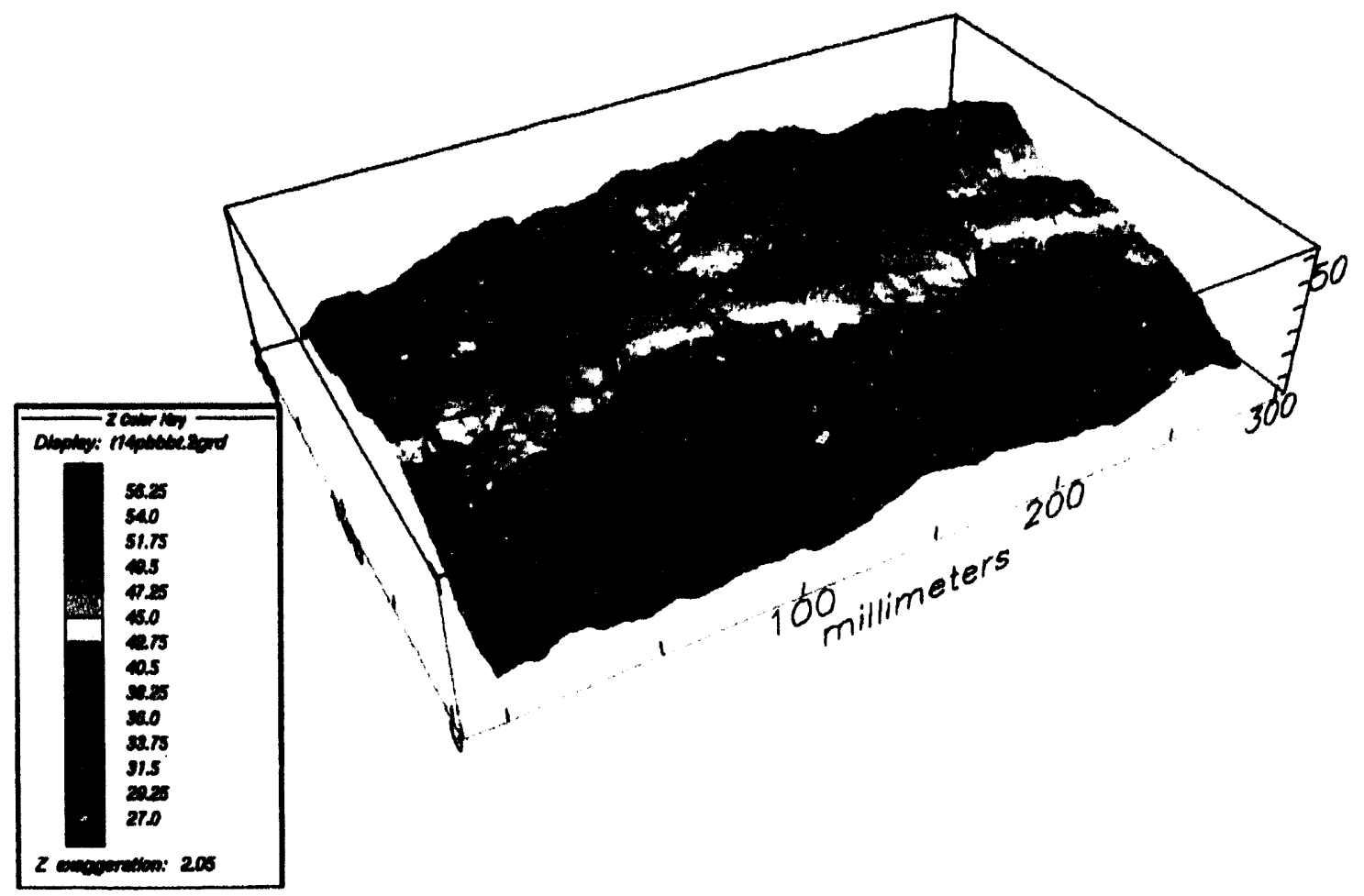

Figure 6-35. Profile of the bottom rock block of the joint specimen used for test no. 14 before harmonic shearing

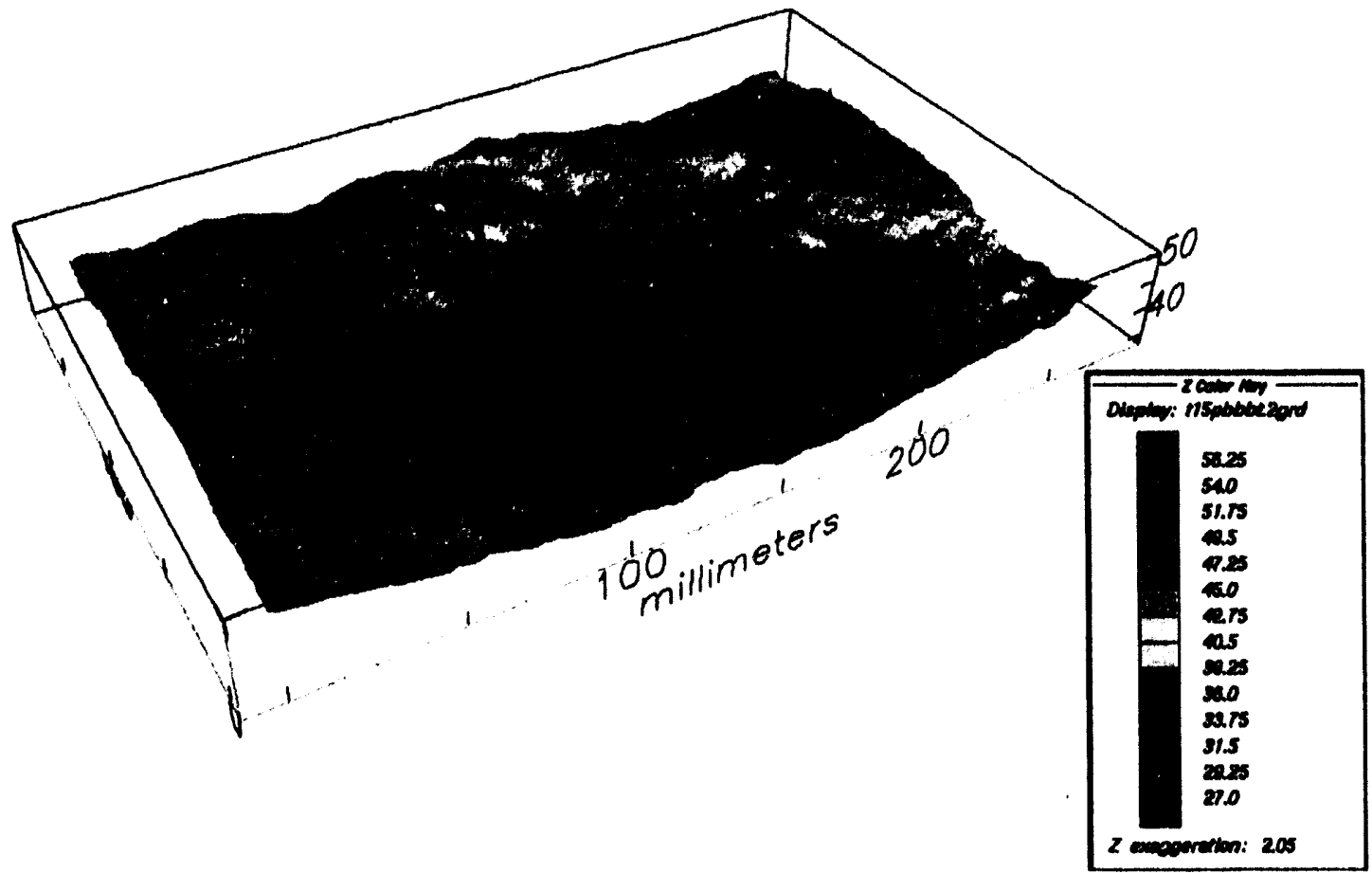

Figure 6-36. Profile of the bottom rock block of the joint specimen used for test no. 15 before harmonic shearing 
all the shear tests conducted in this study was along the $X$-axis. Since the test apparatus was designed to provide substantial constraints on the $Y$-direction during the test, it is reasonable to assume that the wave shape along the $\mathrm{Y}$-axis should not have a significant impact on the joint behavior along the $\mathrm{X}$-axis. As suggested in these two figures, the effective wavelength and amplitude could be different for different joint surfaces. The effective wavelength and amplitude are defined as the ones that control the overall behavior of a joint, given that they may be different for different cross sections along the $\mathrm{X}$-axis. It is also likely that the effective wavelength and amplitude controlling the joint shear behavior in one direction are different from those in the opposite direction. In this report, no attempt has been made to determine the effective wavelength and amplitude for rock joints.

Three factors have been suggested (Jing et al., 1992) to affect joint shear behavior. These factors include the higher order asperities, amplitude to wavelength ratio of the joint surface curvature, and the basic friction angle of material. The higher order asperities and the basic friction angle of material provide the fundamental joint resistance to shear while the amplitude to wavelength ratio determines the magnitude of the tangential component of the "system" normal stress, $\sigma_{n s}$, (vertical stress) along the curved surface. Depending upon the direction of shear, this tangential component could either increase or decrease joint shear resistance. As shown in Figure 6-34(b), when the top rock block is moving upslope, the "local" direction of shear is opposite to the direction of the tangential component. Consequently, more system shear stress is needed to overcome this tangential component. If the local direction of shear is the same as that of the tangential component of the system normal stress as indicated in Figure 6-34(c) where the top rock block moves downslope, relatively smaller system shear stress is required to mobilize the joint. This conceptual model explains quite well the phenomenon that the shear resistance is smaller upon joint reverse shearing than that of the forward shearing as shown in Figures 6-27 through 6-33.

Observation of the dynamic test results of the Apache Leap tuff joints suggests that the principal factor responsible for the above described phenomenon is the primary asperities. The amplitude to wavelength ratio will determine the magnitude of joint shear resistance. The role of the higher order asperities is expected to be relatively small, because the higher order asperities will be sheared off quickly after a few cycles of shearing.

There exists another important factor that was not included in the hypothesis proposed by Jing et al. (1992) and may also contribute to the difference in shear resistance between forward and reverse shearing; it is the normal component of the applied system shear stress to the curved surface. When the top block is climbing upward along a primary asperity, a portion of the applied shear stress (horizontal stress) becomes actually localized normal stress, $\tau_{s n}$, as shown in Figure 6-34(b), which tends to resist shear. As a result, the actual localized shear stress becomes smaller than the system shear stress, $\tau_{s}$. Consequently, more system shear stress is required to overcome this additional normal stress in order to mobilize the joint. On the other hand, if the top rock block is moving downslope, this normal component of the system shear stress tends to offset the applied local normal stress [Figure 6-34(c)]. As a result, smaller shear stress is required to mobilize the joint.

The magnitude of the shear resistance during reverse shearing may be related to a number of factors, such as the amplitude-to-wavelength ratio of the primary asperities. In some cases, the shear resistance can be very low, as shown in Figure 6-27. The difference between the shear resistances for the forward and reverse shearing may gradually becomes smaller as the primary asperities are gradually worn down. However, this wearing will require a substantial number of cycles of shearing, and very much depends on the amplitude-to-wavelength ratio of the joint surface curvature and the joint strength. 
It has been suggested by Jing et al. (1992) that the shear resistance during the reverse shearing period should be more or less constant due to the absence of higher order asperities, which have been theoretically worn out or sheared off during forward shearing. The results from cyclic pseudostatic and dynamic tests on the Apache Leap tuff joints have led to a contradictory observation in which the shear stress versus shear displacement curve may not be as smooth. Instead, in many cases, the shear stress experienced continuing increases and decreases during the course of forward and reverse shearing. These variations can be better characterized as chatter behavior. During a shear test, when the shear stress is equal to the joint shear strength, joint slip begins. This joint slip will continue until asperities are encountered, which tend to resist joint slip, that is, increase the joint shear resistance. In such a situation, the joint stops slipping. The termination of a joint slip is the "sticking" component of the phenomenon. The joint slip will not resume until the applied shear stress is increased to a level that overcomes this additional amount of joint shear resistance.

The chatter behavior may be related to joint roughness, state of normal stress, frequency of the loading cycles (velocity of shear displacement), perhaps the local strength of the asperities, and possibly enhanced by the presence of apparatus modes. As shown in Figure 5-4, which displays the relation between the shear stress and shear displacement of different joints under pseudostatic test condition, the joint chatter behavior was not as pronounced at relatively lower normal stress level; in this figure, it is $1 \mathrm{MPa}$. However, when the input frequency was increased from $2.1 \times 10^{-4} \mathrm{~Hz}$ for the pseudostatic tests to $0.5 \mathrm{~Hz}$ for the earthquake tests, or more than $1 \mathrm{~Hz}$ for the harmonic tests, the chatter behavior becomes increasingly pronounced, although the applied normal stress was $1 \mathrm{MPa}$ (Figures 6-27 to 6-32). It is also interesting to note that in some cases of the dynamic tests, as were shown, for example, in Figures 6-28, 6-30, and 6-31, the chatter behavior continues even after a number of cycles of shearing, which suggests that the "bumps" or "obstacles" mentioned earlier should include not only the higher order asperities as indicated by Jing et al. (1992), but also those rock fragments broken off from the joint surfaces in the shearing process. If these rock fragments are strong, more shear stress is needed in order for the top rock block to crush or ride over them. Small shear displacement may be allowed in the process of crushing or riding over the rock fragments since these rock fragments may not be fixed in place. Therefore, the stick component of the chatter behavior in this sense should be treated more broadly.

Considerable attention in this section has been given to the joint behavior during forward and reverse shearing and the associated potential effects of dynamic input, which, in the interest of discussion in this report, is the input frequency. The focus of this paragraph is to explore the potential impact of dynamic input on the peak joint shear resistance. Since natural rock joints were used for performing direct shear tests under pseudostatic, harmonic, and earthquake loading conditions, a different joint specimen would be needed for each test. As a result, the joint characteristic for each test was different. Therefore, it is impossible to evaluate directly the dynamic effect on the joint shear resistance, unless some means is developed to account for the effect of different joint roughness. Figure 6-37 provides an approximate means for such an evaluation. Admittedly, the conclusion that can be drawn from this figure is at best an approximation, due to a number of uncertainties involved. However, it does give an indication of the potential dynamic effect on the peak shear resistance. The horizontal axis of the figure represents the JRC value calculated from the tilt test, while the vertical axis represents the JRC value calculated from the direct shear test results [using Eq. (5-30)]. It has been determined in the early discussion that the tilt test method grossly underestimates the real JRC value, as do other methods discussed in Section 5. However, it has been shown that the JRC value from the tilt test has a strong positive correlation with the corresponding JRC values calculated from the shear test results with a correlation coefficient of about 0.85 . Therefore, it is possible to develop an empirical expression relating the JRC values from the two 


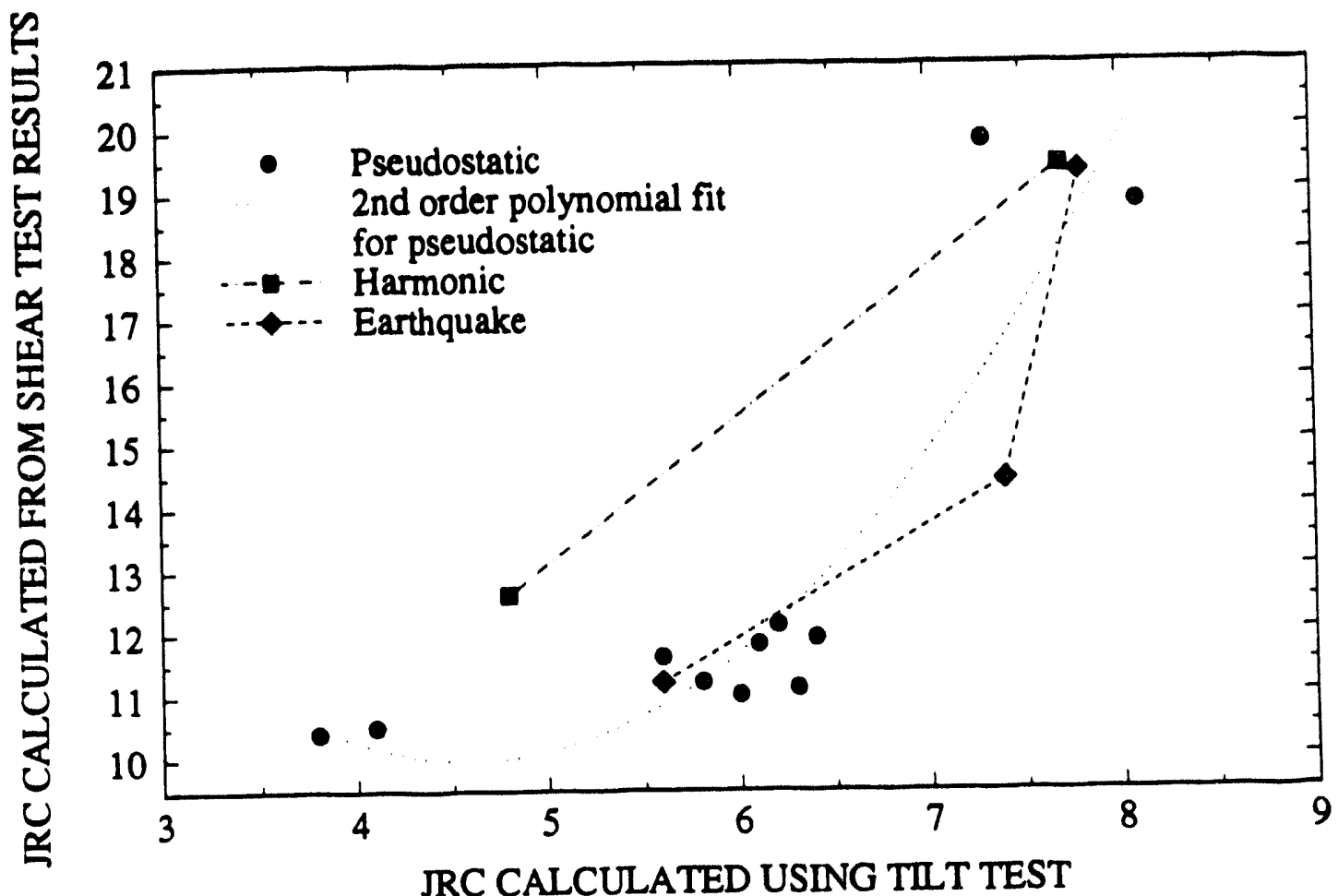

Figure 6-37. Effect of input frequency (shearing velocity) on peak joint shear strength

methods. The dotted line in Figure 6-37 shows a second order polynomial fit between JRC values from the "pseudostatic" test results and the corresponding JRC from the tilt test. This polynomial fit $\left(R^{2}=0.82\right)$ should provide sufficient confidence in estimating the JRC for the Apache Leap tuff joints using the tilt test. Subsequently, the estimated JRC can be used to estimate the "pseudostatic" peak joint shear resistance with reasonable confidence. Assuming that the peak joint shear resistance will be affected by dynamic loads (e.g., induce a higher peak shear resistance than the peak shear resistance if the same specimen were tested under pseudostatic condition), then the JRC value calculated from the "dynamic" joint shear resistance should be larger than the JRC value from the pseudostatic shear resistance. In other words, the dynamic JRC should fall above the second polynomial curve if plotted in Figure 6-37. Figure 6-37 includes the dynamic JRC from the harmonic and earthquake test results. Examination of the figure indicates that, in general, the dynamic JRC values do not significantly differ from the corresponding pseudostatic JRC values, except for one data point from a harmonic test result. This is an indication that the dynamic input may not have an appreciable influence on the peak joint shear resistance.

Figure 6-38 shows the effect of joint roughness on the joint shear stress reduction during reverse shearing for the dynamic tests. The horizontal axis represents the JRC values that were calculated using the dynamic peak shear resistance results. The vertical axis is the ratio of the approximate shear resistance during reverse shearing to the corresponding peak shear resistance for forward shearing. There are two curves for each type of dynamic tests in the figure. The legend Earthquake, 1 denotes that the data in the first and fourth quadrants of Figures 6-29, 6-30, 6-31, and 6-23 were used while the legend Earthquake, 2 denotes that the data in the third and second quadrants were used. The same approach was used for the harmonic tests from Figures 6-27 and 6-28. Figure 6-38 clearly shows that the difference between the joint shear resistance during reverse shearing and the peak shear resistance will be larger for joints with rougher surfaces. The dynamic effect is, on the other hand, not clearly shown in the figure. 


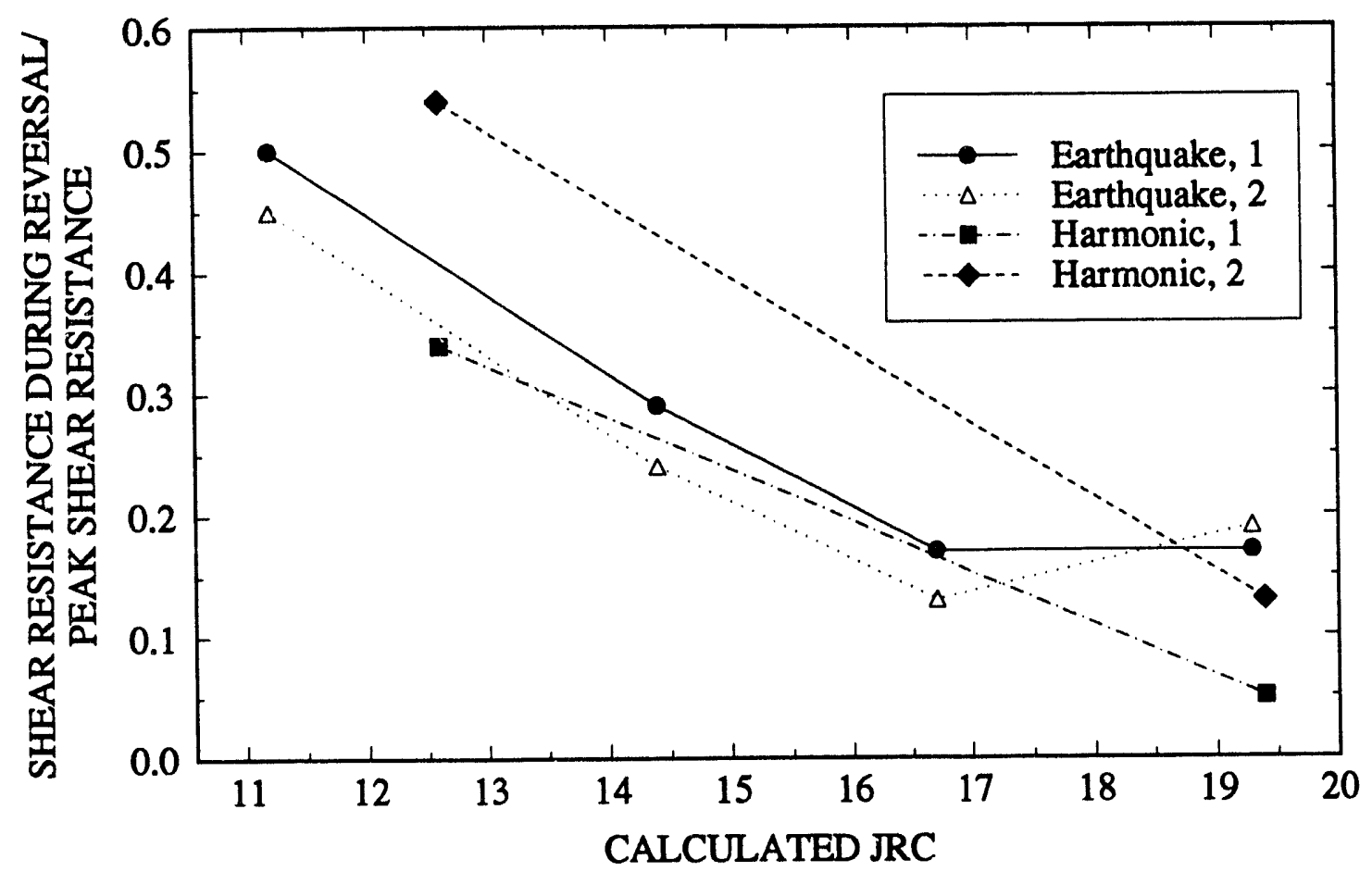

Figure 6-38. Effect of input frequency (shearing velocity) on joint shear resistance on reverse shearing

Figures 6-39 through 6-44 show the joint normal displacement versus shear displacement characteristic curves for the first tests of test nos. 14, 15, 24, 25, 26, and 30. Again, the wear of the joint surfaces is a continuing process as is evident in these figures in which the maximum joint normal displacement continues to decrease through the cycles of shearing. It is interesting to note that joint dilation (positive normal displacement) tends to decrease constantly during reverse shearing and may retain a small amcunt of dilation as the top rock block returns to its original position. This phenomenon can be explained quite well using the conceptual model shown in Figure 6-34. Dilation reduces when the top rock block goes downslope, which is always the case during reverse shearing if the top and bottom rock blocks are closely matched before test. The normal displacement curves are highly nonlinear and are quite smooth for at least the first three cycles of all the earthquake tests. The normal displacement versus shear displacement curves for the pseudostatic tests are also highly nonlinear but quite smooth (Figure 5-5), as are those for the earthquake tests. However, for the harmonic tests, many small-scale stick-slip oscillations that continued for many cycles were observed. This observation gives an indication of the potential impact of the input frequencies on joint dilation, which may be related to the existence of small-size rock fragments created in the process of shearing. Under pseudostatic conditions or smaller input frequency conditions, shear stress tends to crush these rock fragments instead of riding over them. However, under conditions of high input frequencies, or high velocity for that matter, the rock fragments are stronger and tend to resist crushing and thus result in a temporary increase in normal displacement (the top block riding over these fragments). It is commonly understood that rock strength depends on loading rate and generally increases with increased loading rate. Once the fragments are crushed, the normal displacement tends to return to the original path.

The hysteresis between the normal displacements during forward and reverse shearing of the first cycle for the harmonic and earthquake tests is smaller than that observed for the pseudostatic tests. A typical hysteresis from a pseudostatic test with an applied normal stress of $1 \mathrm{MPa}$ is shown in 


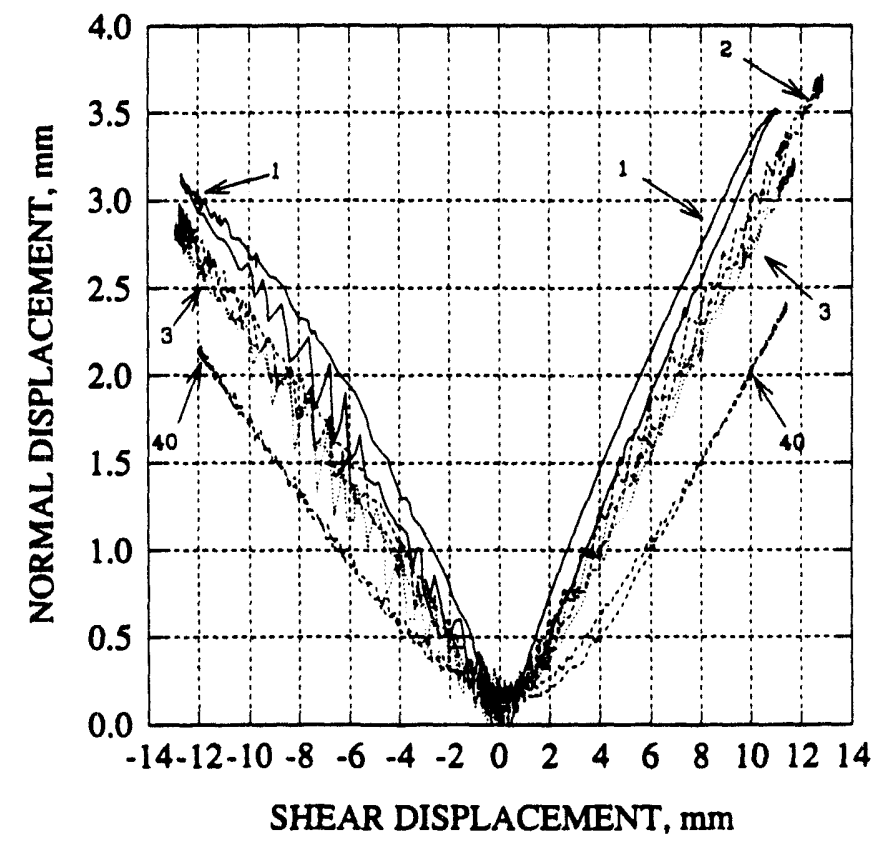

Figure 6-39. Joint normal displacement (dilation) versus shear displacement for the first phase of test no. 14 under a harmonic load with $1.4-\mathrm{Hz}$ input frequency and $12.7-\mathrm{mm}$ input displacement amplitude (first three cycles and the 40th cycle)

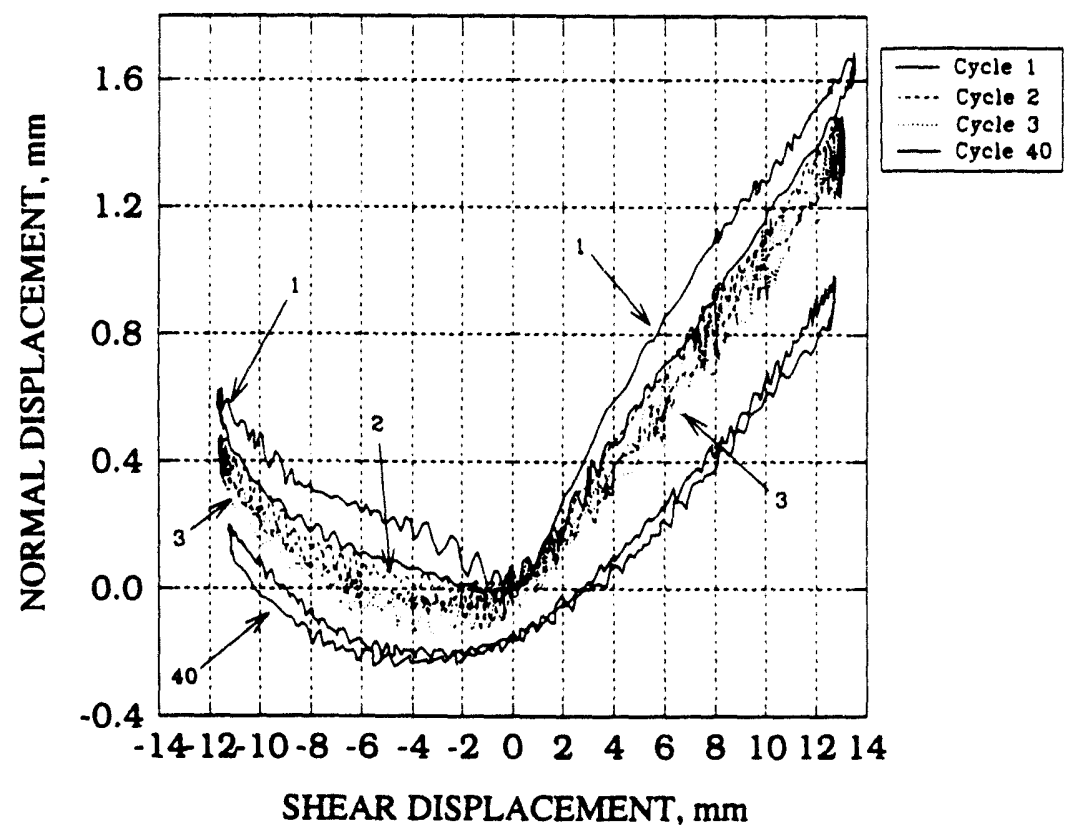

Figure 6-40. Joint normal displacement (dilation) versus shear displacement for the first phase of test no. 15 under a harmonic load with $1.4 \mathrm{~Hz}$-input frequency and 12.7- $\mathrm{mm}$ displacement amplitude (first three cycles and the 40th cycle) 


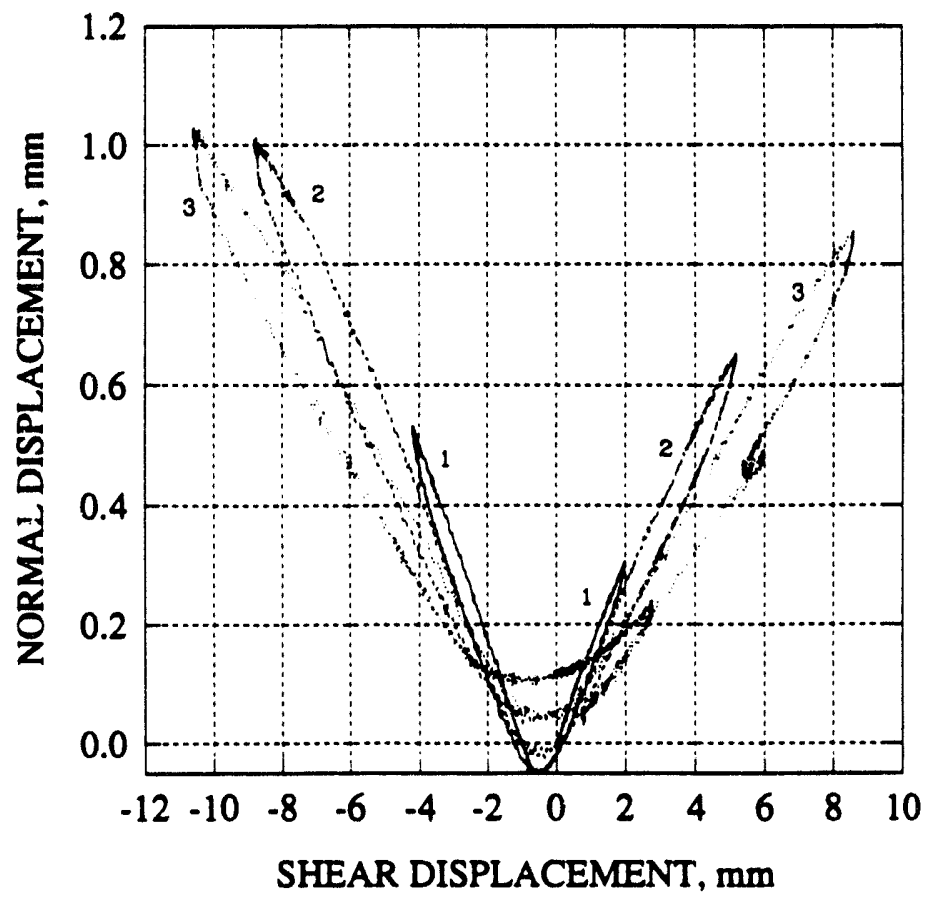

Figure 6-41. Joint normal displacement (dilation) versus shear displacement of the first phase of test no. 24 under an earthquake load with a maximum input displacement amplitude of $25.4 \mathrm{~mm}$

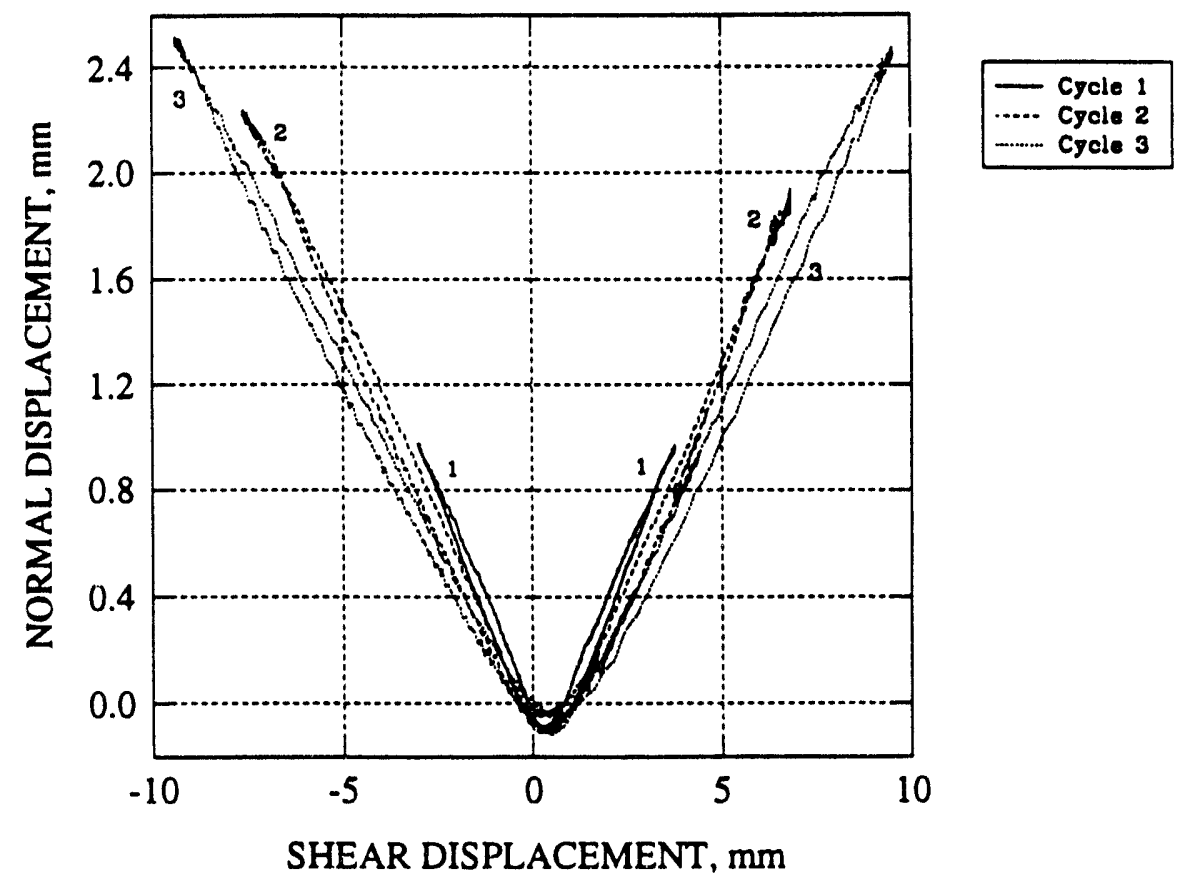

Figure 6-42. Joint normal displacement (dilation) versus shear displacement of the first phase of test no. 25 under an earthquake load with a maximum input displacement amplitude of $25.4 \mathrm{~mm}$ 


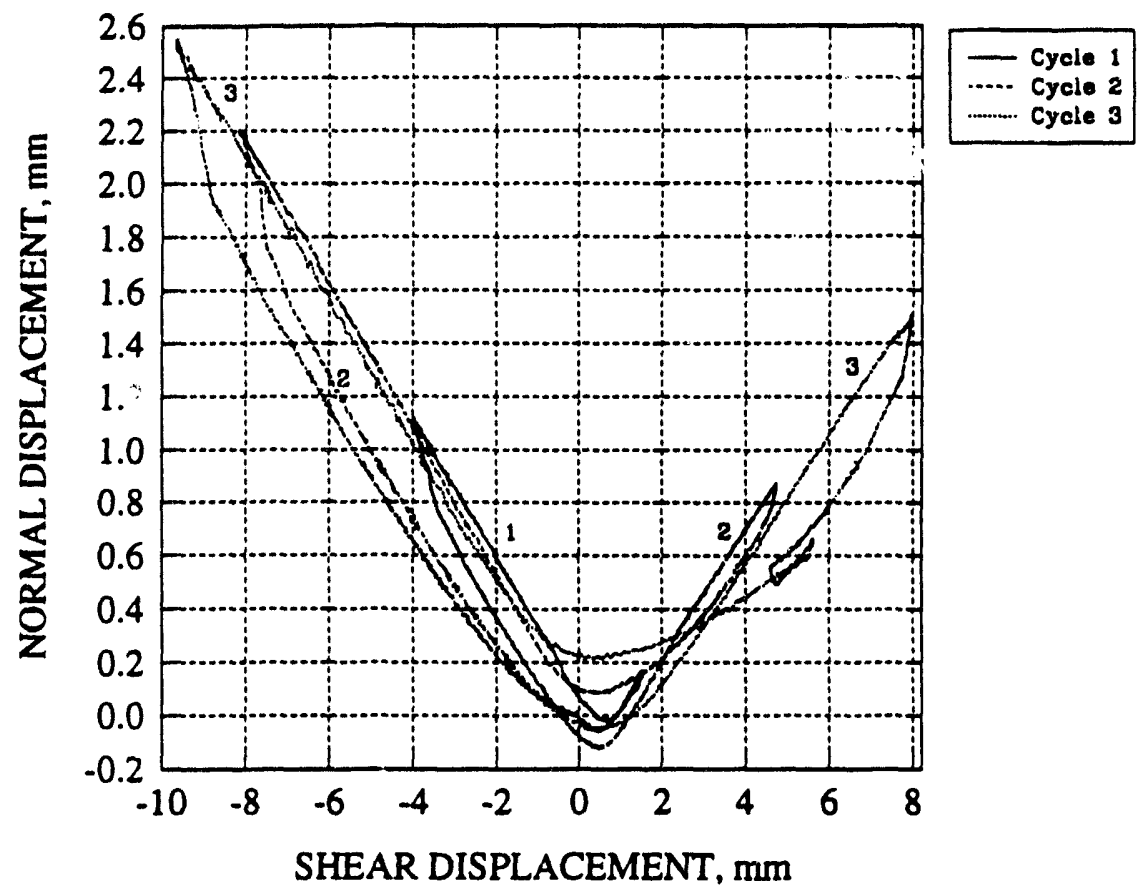

Figure 6-43. Joint normal displacement (dilation) versus shear displacement of the first phase of test no. 26 under an earthquake load with a maximum input displacement amplitude of $25.4 \mathrm{~mm}$

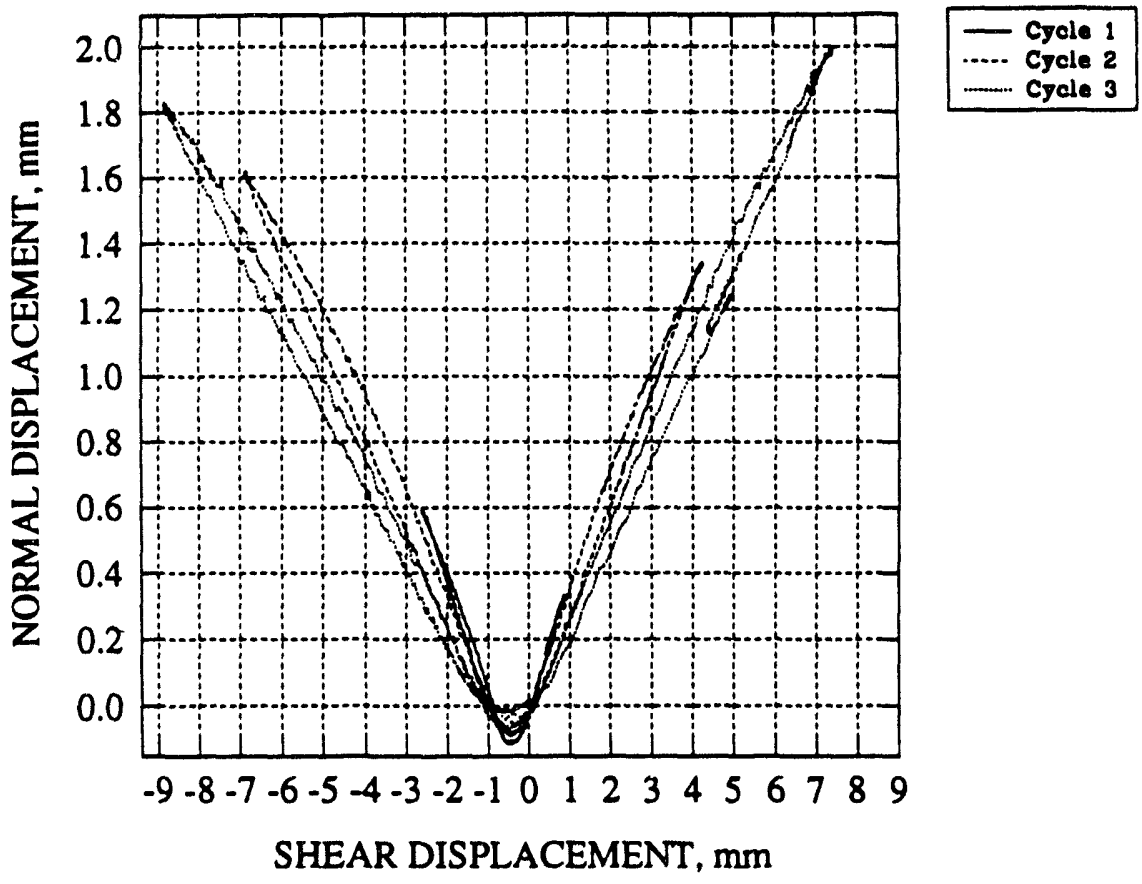

Figure 6-44. Joint normal displacement (dilation) versus shear displacement of the first phase of test no. 30 under an earthquake load with a maximum input displacement amplitude of $25.4 \mathrm{~mm}$ 
Figure 6-45. No good explanation can be offered for this difference other than as discussed in the previous paragraph that, unlike the dynamic tests, joint shear stress under a pseudostatic condition tends to crush these rock fragments instead riding over them.

In Figure 6-40, the dilation curve for the 40th cycle of the test is also shown. The shape of the dilation curve and relative dilation magnitude with respect to that at 0 displacement are generally correct. However, the absolute dilation is not correct. In theory, the joint dilation or joint normal displacement is the relative displacement of the two points on opposite sides of a joint. These two points should be located on the joint surfaces of the joint. In reality, however, this is impossible. One of the technical difficulties is instrumentation, given that the initial aperture between the two points on the opposite sides on a joint before a shear test is very small $(0.01$ to $0.1 \mathrm{~mm})$. Even if this difficulty is overcome, there is the problem of joint wear resulting from joint shearing. After a certain extent of wearing, depending upon the strength of the joint, these two points used for the normal displacement measurement will certainly be worn away. As a result, no further dilation or normal displacement can be obtained. Because of these problems, the joint dilation measurements in this study were taken between two horizontal planes on the opposite sides of a joint. The separation of these two planes was about $6 \mathrm{~mm}$. As the joint wear continues during the shearing, the distance between the two planes becomes smaller. The amount of the decrease in the distance will be treated as a form of dilation or normal displacement, since the noncontact probes used for the normal displacement measurement detect only the distance between the sensor and the target plate as discussed in Section 4. Consequently, it will not discriminate the actual joint normal displacement from the distance change between the two horizontal planes due to joint wear. This explains the considerable amount of closure observed for the 40th cycle in Figure 6-40. The extent of the closure between the two horizontal planes is believed to be a function of joint strength. 


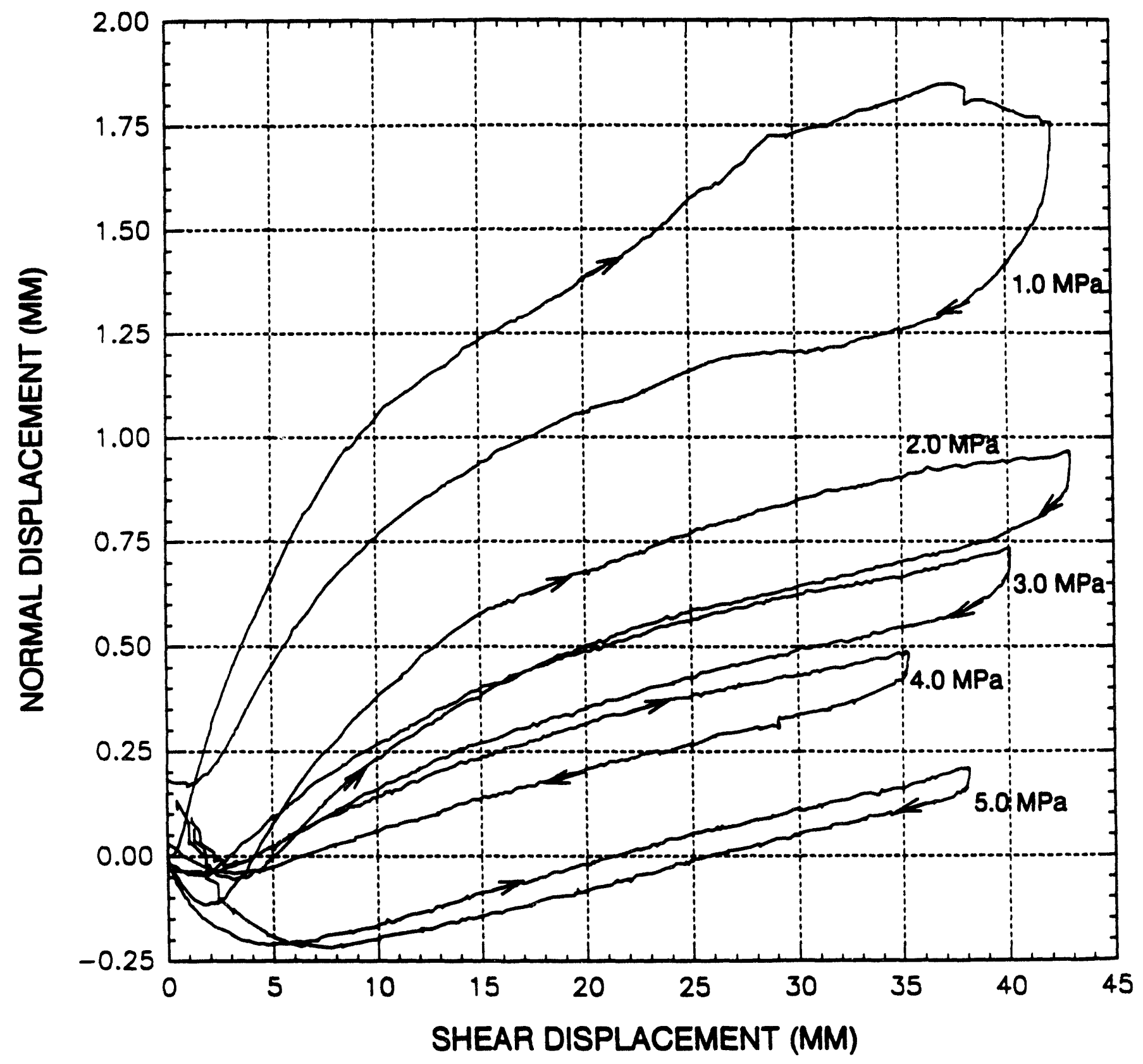

Figure 6-45. Joint normal displacement (dilation) versus shear displacement for pseudostatic tests as a function of applied normal stress for test no. 11 


\section{SUMMARY AND DISCUSSION}

As described earlier, the objectives of laboratory characterization of jointed rock are to obtain a better understanding of and to develop experimental data on dynamic behavior of rock joints so that the currently existing empirical rock joint models can be evaluated to assess their capability of representing dynamic joint behavior. To accomplish these goals, a number of activities were included in this study: rock core collection and preparation for direct joint shear tests, laboratory test apparatus development, rock joint profilometer development, cyclic pseudostatic and dynamic joint shear tests subjected to harmonic and earthquake loads, and mechanical properties characterization of intact rock associated with the rock joints for the shear tests.

The densely welded tuff rock specimens used in this study were collected from the Apache Leap site near Superior, Arizona. A total of 50 potentially usable joint specimens were obtained. The results of the intact rock characterization indicate that the average uniaxial compressive strength is $161 \pm 26 \mathrm{MPa}$, the mean indirect uniaxial tensile strength (from the Brazilian test results) is $10.3 \pm 2.2 \mathrm{MPa}$, and the mean triaxial compressive strength is $202 \pm 27 \mathrm{MPa}$ for a $3.4-\mathrm{MPa}$ confining pressure, $248 \pm 22 \mathrm{MPa}$ for a $6.9-\mathrm{MPa}$ confining pressure, and $271 \pm 18 \mathrm{MPa}$ for a $10.3-\mathrm{MPa}$ confining pressure. Average values for the Young's modulus and Poisson's ratio are $38.6 \pm 3.4 \mathrm{GPa}$ and $0.2 \pm 0.0287$, respectively.

A dynamic direct shear test apparatus was developed that includes a $0.339-\mathrm{MN}$ vertical and $0.222-\mathrm{MN}$ horizontal loading capability designed to house a specimen with a maximum size of $305 \times 203 \times 102 \mathrm{~mm}$ for the lower rock block and $203 \times 203 \times 102 \mathrm{~mm}$ for the top rock block. This apparatus has demonstrated its capability of performing the pseudostatic and dynamic shear tests required in this study. However, the servocontrolled valves for the vertical actuators could not respond quickly enough to the quick paced vertical force variation to maintain a constant normal stress throughout the dynamic shear tests. The maximum normal stress variation was about $0.3 \mathrm{MPa}$, irrespective of the magnitude of applied normal stress, but this variation did not prevent the collection of useful dynamic data on joint behavior.

As described earlier, the joint specimens were grouted in the shear boxes with cement filling the gap between the rock block and the shear box. The measured deformation associated with the compression and expansion of the grouts during the dynamic shear tests was small and did not have any noticeable effect on the study of joint dynamic behavior.

Before each direct shear test on a joint was started, the rock joint was put through several normal loading/unloading cycles to determine the normal stress versus normal displacement response, eliminate hysteresis as much as possible, and properly seat the joint prior to direct shear testing. It was found that by the fourth or fifth normal cycle, very little hysteresis and additional permanent set of the normal displacement remain, and the relation between the normal stress and normal displacement becomes repeatable.

As expected, a fresh Apache Leap tuff joint exhibited a distinct peak shear strength that gradually reduced to a residual value as shearing progressed for pseudostatic tests on dry and wet rock joints and for dynamic tests. The chatter behavior of a joint at the residual stage was evident both during forward and reverse shearing for both pseudostatic and dynamic tests on dry rock joints. This behavior became more pronounced at the higher normal loadings and is due to the momentary reduction in shear stress as individual asperities are sheared. The chatter behavior for the wet rock joints under pseudostatic test 
conditions is not as obvious. There is no appreciable difference, however, between the peak shear strengths for the dry and wet rock joints under cyclic pseudostatic testing condition.

Six different equations were evaluated for the determination of JRC, which is a generally accepted parameter for the characterization of joint roughness in rock engineering practice. Among the six equations, one is associated with the tilt test on rock joints, one involves the use of the first derivative of the root mean square of a joint profile, and the rest were developed using the theory of fractal geometry. The JRC calculated with all the equations evaluated was smaller than the JRC back-calculated from the shear test results of the Apache Leap tuff joints. In general, the extent of the underestimation is quite substantial. In many cases the difference is more than a factor of two, except for the predictions produced by the fractal-based empirical equation [Eq. (5-21)] developed by Wakabayashi and Fukushige (1992). Even with this equation, the underestimation of Eq. (5-27) could be as large as 40 percent. A similar type of underestimation was also reported elsewhere for andesite and granite joints (Wakabayashi and Fukushige, 1992) where Eq. (5-27) was used. At the current stage, none of the methods discussed here would seem to be capable of providing a reasonable JRC value that can be readily used for the estimation of joint shear strength, which is essential in obtaining an understanding of joint shear behavior.

The observed underestimation of the joint roughness values for the Apache Leap tuff joints will result in an underestimation of their joint shear strength (Figure 5-16) and initial mechanical (hydraulic) joint aperture, and subsequent aperture changes. The joint aperture can be linked to the JRC and, in general, increases with JRC. Underestimation of joint shear strength may prove to be conservative in mechanical analysis as well as for design of underground excavations. However, an underestimation of joint aperture and its changes during shearing may be nonconservative from the standpoint of their impact on fluid and gas flow through fractures in the context of long-term repository performance.

The largest variation observed for the normal stress response for the dynamic tests performed in this study under an applied normal stress up to $5 \mathrm{MPa}$ was about $0.3 \mathrm{MPa}$. This is to say that, as the confining normal stress increases, its normalized variation (percentage of change) decreases, and so does the impact of normal stress variation for the dynamic tests. Data analysis has shown that the vibrational mode of the normal stress was not in exact synchronization with that of the normal displacement. The magnitude of this variation is small and can be easily identified and separated. Therefore, this variation will not interfere with the interpretation of the data associated with the joint normal displacement (dilation). The effect of normal stress variation is expected to be small because of the nature of high joint normal stiffness. The extent of the normal stress variation to the shear stress response at low confining normal stresses is difficult to judge. However, given the transient nature of the variation, its impact should also be small.

A phase difference between the shear displacement and shear stress time histories with the shear displacement lagging behind is a common phenomenon for all the dynamic tests performed in this study. The observed delayed response of the joint shear displacement is due to the buildup of the shear stress to a level that is required to have joint shearing initiated. This finding effectively simplifies the effort of the numerical modeling of dynamic shear tests by not having to simulate the overall test apparatus in order to evaluate the test results.

The joint responses for all the dynamic tests performed in this study included high-frequency vibrations. These vibrations may be the result of breaking asperities from joint surfaces or crushing and grinding these pieces during shearing. The extent of joint roughness and strength determines the formation of rock pieces between the joint surfaces. 
Two important distinct features for a joint during shear have been identified during the direct shear tests on the Apache Leap tuff joints; one is that the shear resistance upon reverse shearing is smaller than that during forward shearing and the other is that the joint dilation resulting from forward shearing recovers during reverse shearing. These two aspects of the joint behavior are independent of the environmental conditions under which the joint is tested. Both forward and reverse shearing are important phenomena of rock joint behavior. Reverse shearing can result from earthquake, thermal loading, or both. Failure to consider this aspect of joint behavior in an underground structural design and performance analysis could result in (i) an overestimation of the stability of emplacement drifts and emplacement boreholes and (ii) prediction of an incorrect pattern of near-field flow (including preferential pathways for water and gas).

The cause of the distinct joint behavior during reverse shearing can be explained quite well using the concept that a joint surface is comprised of primary and higher order asperities. The primary asperities contain distinct wavelengths that are normally longer than the amount of the shear displacement, while the higher order asperities contain considerably shorter wavelengths than the shear displacement. The primary asperities of a joint, in general, control the fundamental joint shear behavior. The top rock blocks during the shear tests in this study are always traveling upslope during forward shearing and downslope during reverse shearing, because the top and bottom rock blocks were closely matched before shear tests through several cycles of normal loading/unloading process. The shear stress required to overcome the joint shear resistance to move the top rock block is larger for the upslope movement than the downslope movement. Also, the separation (dilation) between the top and bottom rock block should be smaller during the downslope (reverse) shearing than the upslope (forward) shearing. The magnitude of the shear strength or resistance depends primarily on the ratio of the amplitude to the wavelength of the primary asperities and, to a much lesser extent, the higher order asperities, of which the effect will last, perhaps, for only a few cycles of shearing. The higher order asperities contribute to the peak shear strength in the first cycle of joint shearing.

Within the range of variation of shearing velocity used in these tests, the shearing velocity effect on rock-joint behavior seems to be minor, and no noticeable effect on the peak joint shear strength and the joint shear resistance for the reverse shearing is observed. Contrary to the pseudostatic and dynamic shear tests, the dilation curves for the harmonic tests show many small-scale chatter oscillations that, apparently, can be attributed to the effect of input frequency. These oscillations continued for many cycles and were controlled by the production of small-size rock fragments created in the process of shearing. These rock pieces are stronger when subjected to higher shear loading rates than to lower shear loading rates. As a result, these rock fragments tend to resist crushing and thus result in a temporary increase in normal displacement (the top block riding over these fragments). The dynamic input also affects the size of hysteresis between the normal displacements during forward and reverse shearing of at least the first cycle. The hysteresis for the harmonic and earthquake tests is smaller than that for the pseudostatic tests. This phenomenon can again be related to the presence of rock fragments between the joint surfaces. 


\section{REFERENCES}

Aviles, C.A., C.H. Scholz, and J. Boatwright. 1987. Fractal analysis applied to characteristic segments of the San Andreas fault. Journal of Geophysical Research 92(B1): 331-344.

Bandis, S.C., A.C. Lumsden, and N.R. Barton. 1983. Fundamentals of rock joint deformation. International Journal of Rock Mechanics and Mining Sciences \& Geomechanics Abstract 20: 249. 268.

Bandis, S.C. 1980. Experimental Studies of Scale Effects on Shear Strength and Deformation of Rock Joints. Ph.D. Thesis. University of Leeds. 385.

Barton, N.R., 1973. Review of a new shear strength criterion for rock joints. Engineering Geology 7: 287-332.

Barton, N.R., S.C. Bandis, and K. Bakhtar. 1985. Strength, deformation and conductivity coupling of rock joints. International Journal of Rock Mechanics and Mining Sciences \& Geomechanics Abstracts 22(3): 121-140.

Barton, N.R., and S.C. Bandis. 1982. Effects of block size on the shear behavior of jointed rock. 23rd U.S. Symposium on Rock Mechanics. Berkeley, CA.

Barton, N.R., and V. Choubey. 1977. The shear strength of rock joints in theory and practice. Rock Mechanics 10: 1-54.

Brady, B.H.G., and E.T. Brown. 1985. Rock Mechanics for Underground Mining. London, UK: George Allen \& Unwin (Publishers) Ltd.

Carr, J.R., and J.B. Warriner. 1989. Relationship between the fractal dimension and joint roughness coefficient. Bulletin Association of Engineering Geologists. XXVI(2):253-263.

Cundall, P.A., and J.V. Lemos. 1988. Numerical simulation of fault instabilities with the continuously-yielding joint model. Proceedings of the 2nd International Symposium on Rockbursts and Seismicity in Mines. Minneapolis, MN: University of Minnesota.

Feder, J. 1988. Fractals. New York, NY: Plenum Press. 283.

Goodman, R.E. 1976. Methods of Geological Engineering in Discontinuous Rock. St. Paul, MN: West Publishing Company.

Hakala, M., E. Johansson, A. Simmen, and L.J. Lorig. 1993. Application of the Continuously-Yielding Joint Model for Studying Disposal of High-Level Nuclear Waste in Crystalline Rock. YJT-93-06. Helsinki: Nuclear Waste Commission of Finnish Power Companies.

Hoek, E., and J.W. Bray. 1981. Rock Slope Engineering. Third Edition. The Institute of Mining and Metallurgy, London, UK: 358. 
Huang, X., B.C. Haimson, M.E. Plesha, and X. Qiu. 1993. An investigation of the mechanics of rock joints-Part I. Laboratory investigation. International Journal of Rock Mechanics and Mining Sciences \& Geomechanics Abstracts 30(3): 257-269.

International Society for Rock Mechanics (ISRM). 1978. Suggested methods for the quantitative description of discontinuities in rock masses, International Journal of Rock Mechanics and Mining Sciences \& Geomechanics Abstracts 15: 319-368.

ITASCA Consulting Group, Inc. 1992. UDEC Universal Distinct Element Code Version 1.8 Volume I: User's Manual. Minneapolis, MN: ITASCA Consulting Group, Inc.

Jing, L., E. Nordlund, and O. Stephansson. 1992. An experimental study on the anisotropy and stress-dependency of the strength and deformability of rock joints. International Journal of Rock Mechanics and Mining Sciences \& Geomechanics Abstracts 29(6): 535-542.

Kana, D.D., D.C. Scheidt, B.H.G. Brady, A.H. Chowdhury, S.M. Hsiung, and B.W. Vanzant. 1990. Development of a Rock Joint Dynamic Shear Test Apparatus. Report CNWRA-90-005. San Antonio, TX: Center for Nuclear Waste Regulatory Analyses.

Kana, D.D., B.H.G. Brady, B.W. Vanzant, and P.K. Nair. 1991a. Critical Assessment of Seismic and Geomechanics Literature Related to a High-Level Nuclear Waste Underground Repository. NUREG/CR-5440. Washington, DC: U.S. Nuclear Regulatory Commission.

Kana, D.D., A.H. Chowdhury, S.M. Hsiung, M.P. Ahola, B.H.G. Brady, and J. Philip. 1991 b. Experimental techniques for dynamic shear testing of natural rock joints. Proceedings of International Congress on Rock Mechanics. W. Wittke, ed. Rotterdam: A.A. Balkema: 519-526.

Lee, Y.-H., J.R. Carr, D.J. Barr, and C.J. Haas. 1990. The fractal dimension as a measure of the roughness of rock discontinuity profiles. International Journal of Rock Mechanics and Mining Sciences \& Geomechanics Abstracts 27: 453-464.

Lorig, L.J., and B.E. Hobbs. 1990. Numerical modeling of slip instability using the distinct element method with state variable friction laws. International Journal of Rock Mechanics and Mining Sciences \& Geomechanics Abstracts 27(6): 525-534.

Mandelbrot, B.B. 1967. How long is the coast of Britain? Statistical self-similarity and fractal dimension. Science. 156: 636-638.

Mandelbrot, B.B. 1982. The Fractal Geometry of Nature. San Francisco, CA: Freeman: 468.

Miller, R.P. 1965. Engineering Classification and Index Properties for Intact Rock. Ph.D. Thesis. Champagne-Urbana. University of Illinois: 332.

Miller, S.M., P.C. McWilliams, and J.C. Kerkering. 1989. Evaluation of stereo digitizing rock fracture roughness. Rock Mechanics as a Guide for Efficient Utilization of Natural Resources. A.W. Khair, ed. Rotterdam: A.A. Balkema: 201-208.

Myers, N.O. 1962. Characterization of Surface Roughness. Wear 5: 182-189. 
Nuclear Waste Technical Review Board. 1992. Fifth Report to the U.S. Congress and the U.S. Secretary of Energy. Washington, DC: U.S. Government Printing Office.

Tse, R., and D.M. Cruden. 1979. Estimating joint roughness coefficients. International Journal of Rock Mechanics and Mining Sciences \& Geomechanics Abstracts 16: 202-207.

Turk N., M.J. Greig, W.R. Dearman, and F.F. Amin. 1987. Characterization of rock joint surfaces by fractal dimension. 28th U.S. Symposium on Rock Mechanics. Tucson, AZ: University of Arizona: 1223-1236.

Voss, R.F. 1985. Random Fractals: Characterization and measurement. Scaling Phenomena in Disordered Media. NATO ASI Series, Series B: Physics. R. Pynn and A. Skjeltrop, eds. Plenum Press. 133: 1-11.

Wakabayashi, N., and I. Fukushige. 1992. Experimental study on the relation between fractal dimension and shear strength. Conference of Fractured and Jointed Rock Masses. Preprints. June 3-5, 1992. Lake Tahoe, CA.

Wibowo, J.T., B. Amadei, S. Sture, and A.B. Robertson. 1992. Shear response of a rock joint under different boundary conditions: An experimental study. Conference of Fractured and Jointed Rock Masses. Preprints. June 3-5, 1992. Lake Tahoe, CA.

Wong, P., and J. Lin. 1988. Studying fractal geometry on submicron length scales by small-angle scattering. Mathematical Geology 20(6): 655-665.

Yu, X., and B. Vayssade. 1991. Joint profiles and their roughness parameters, technical note. International Journal of Rock Mechanics and Mining Sciences \& Geomechanics Abstracts 28: 333-336. 
APPENDIX A

PSEUDOSTATIC DIRECT SHEAR TEST RESULTS ON APACHE LEAP TUFF JOINTS 


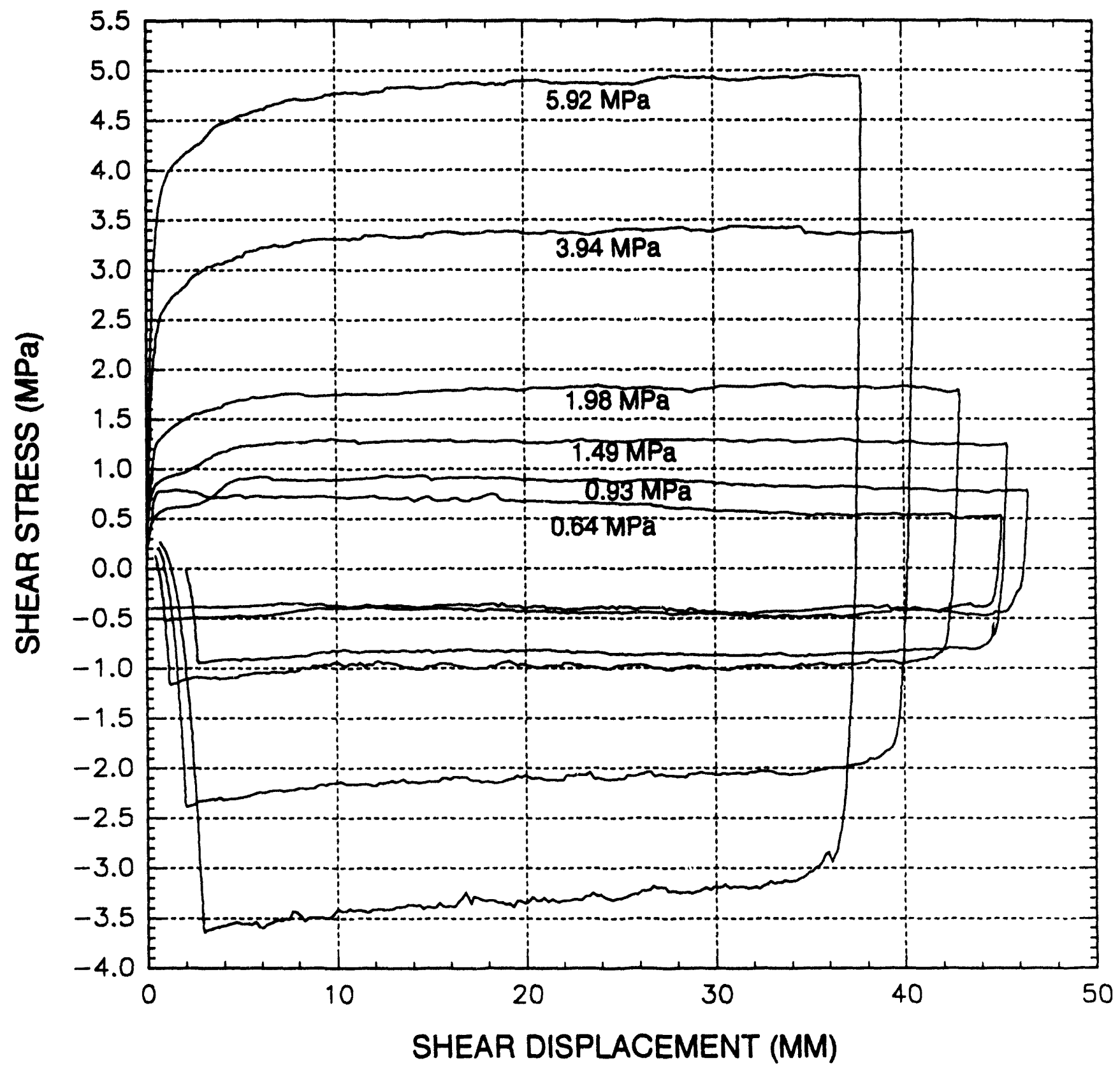

Figure A-1. Shear stress versus shear displacement response on the same joint specimen as a function of normal stress for test no. 1 


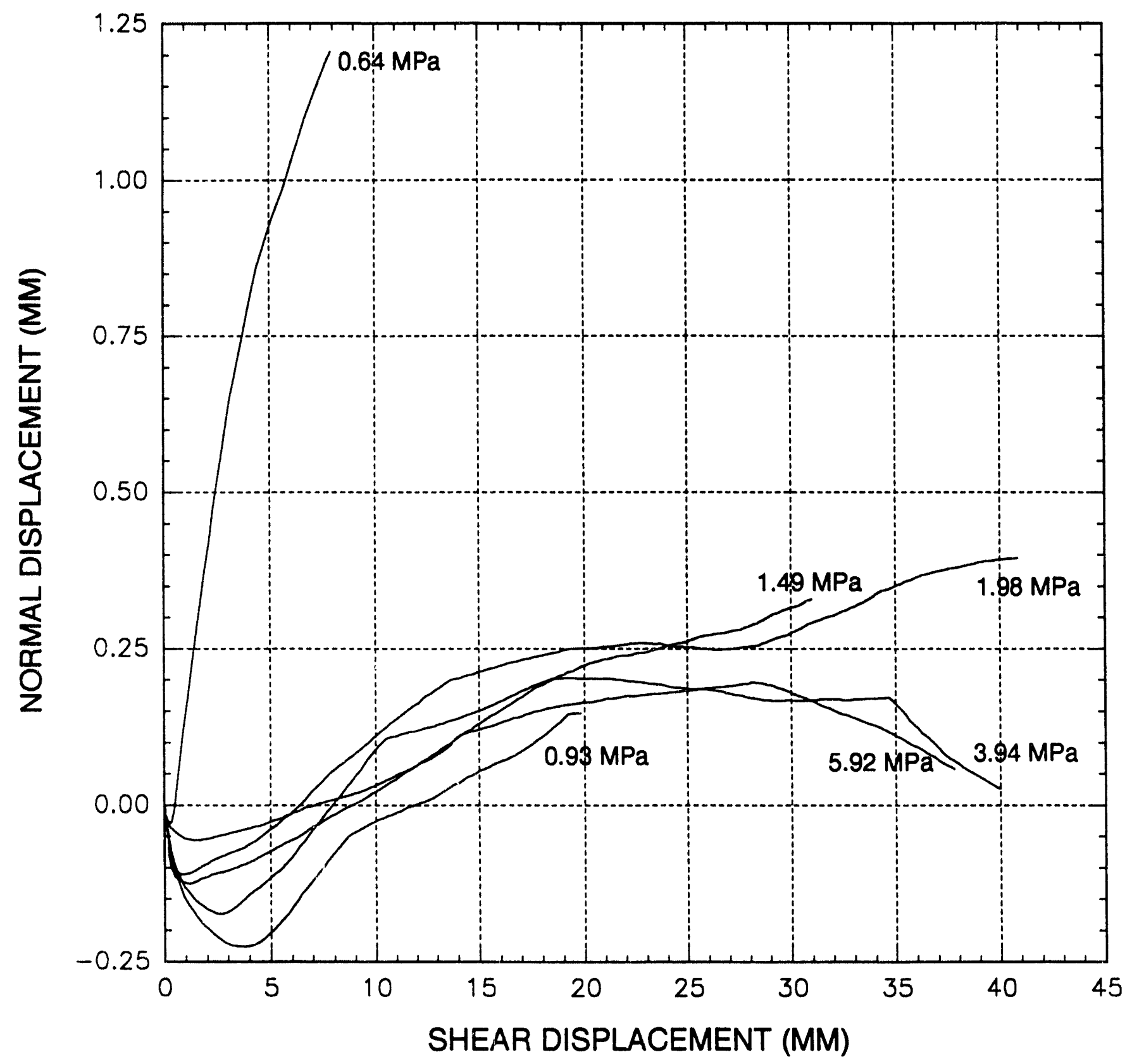

Figure A-2. Normal displacement (dilation) response on the same specimen as a function of normal stress for test no. 1 


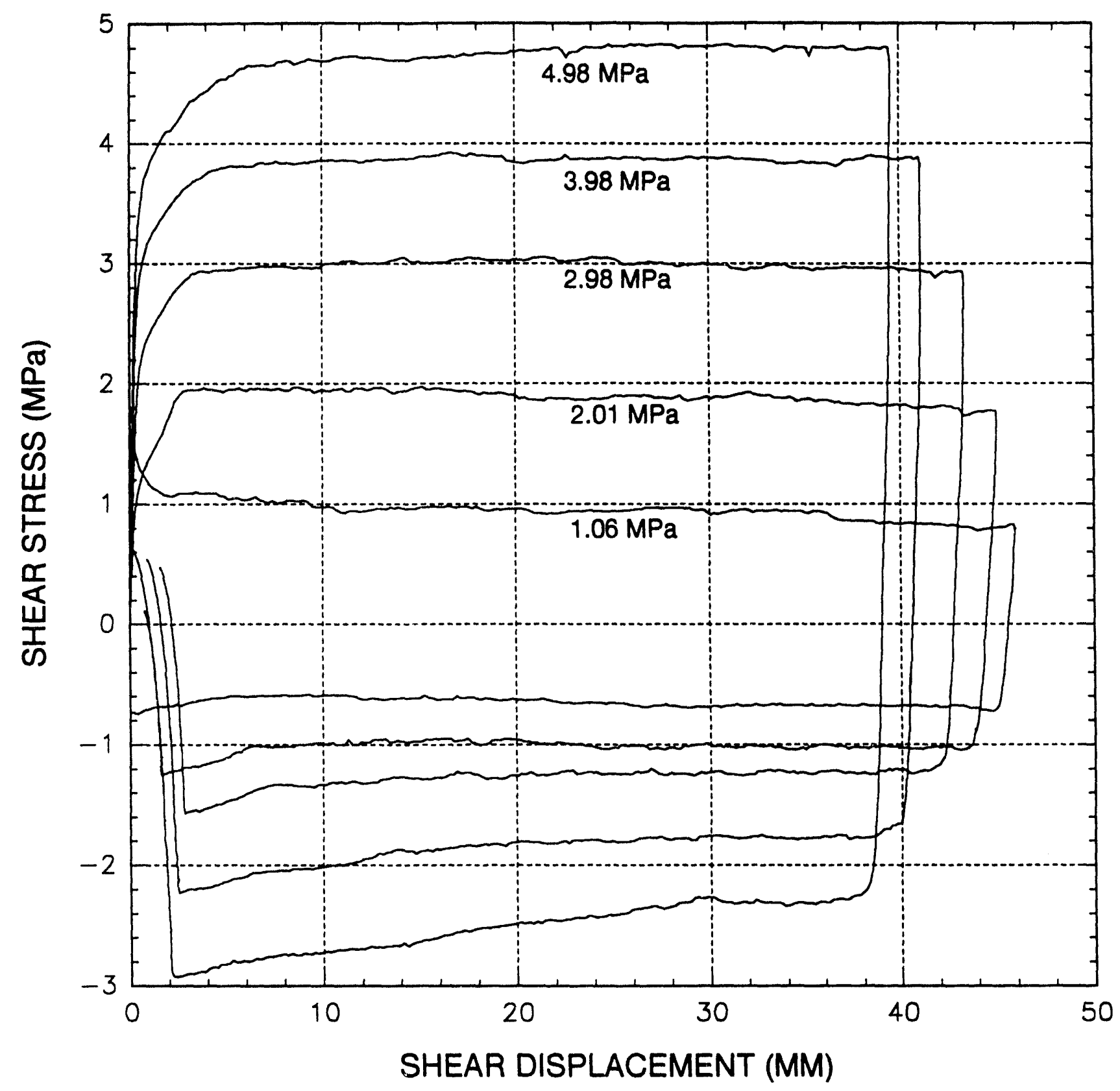

Figure A-3. Shear stress versus shear displacement response on the same joint specimen as a function of normal stress for test no. 2 


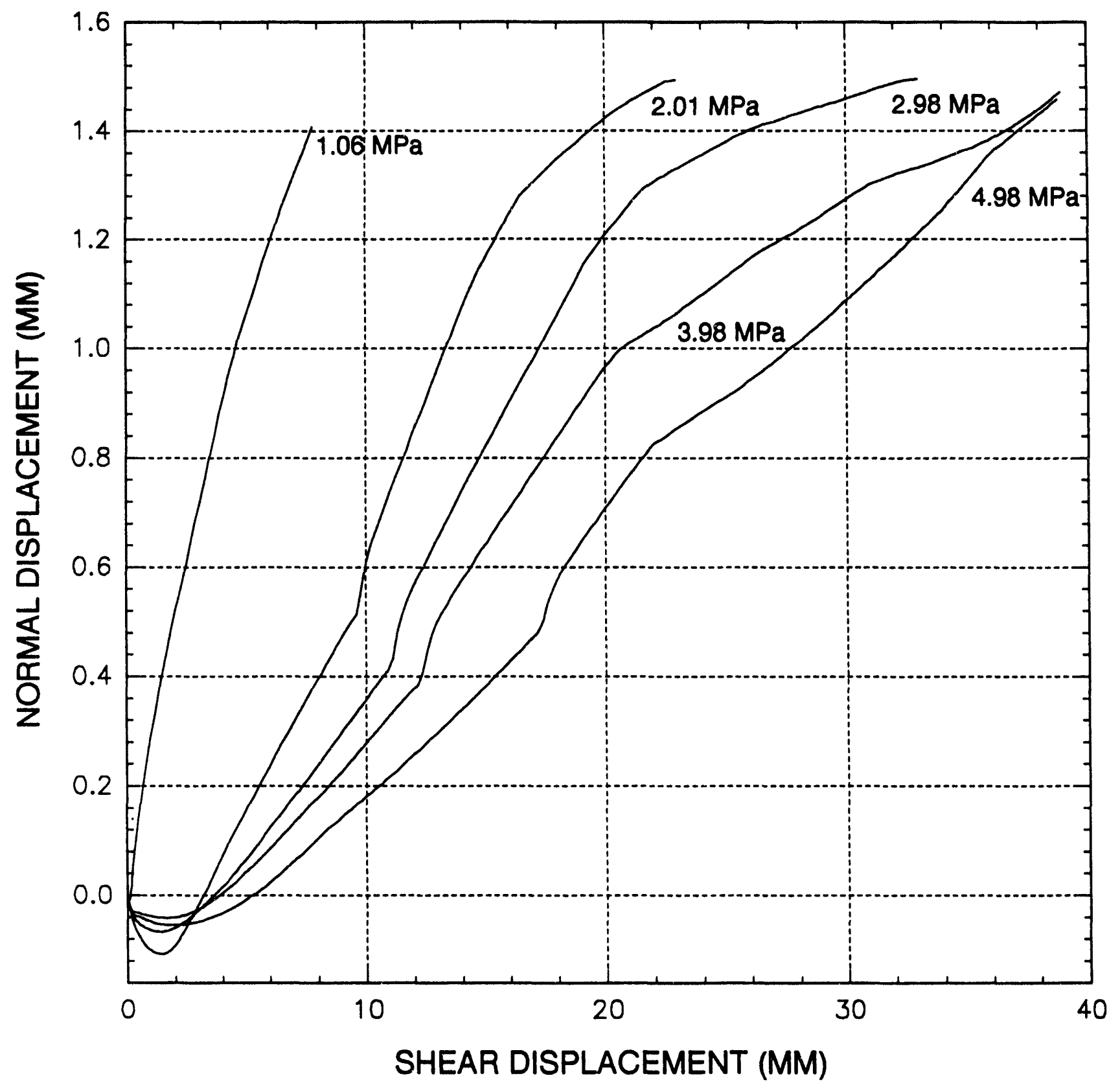

Figure A-4. Normal displacement (dilation) response on the same specimen as a function of normal stress for test no. 2 


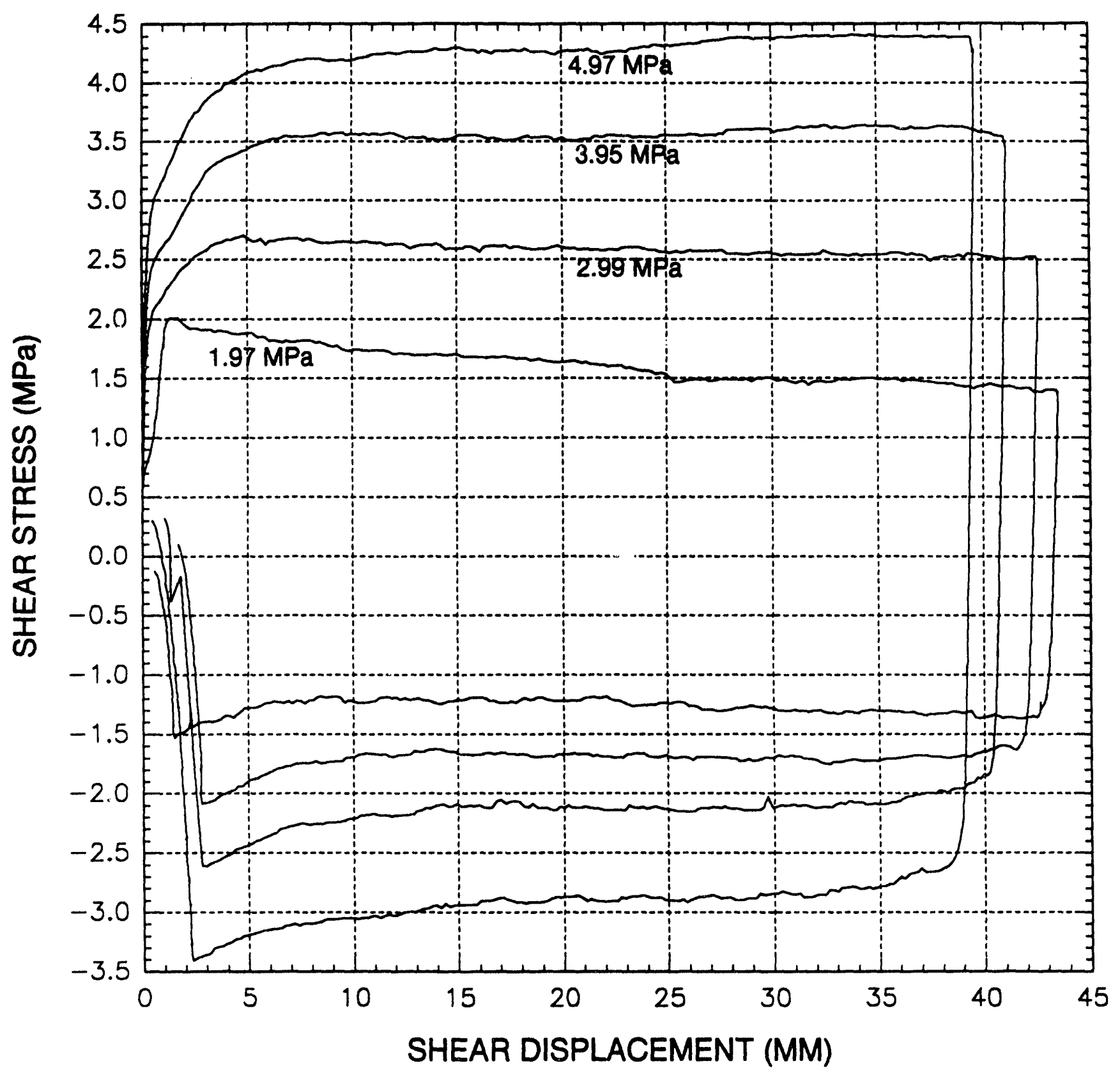

Figure A-5. Shear stress versus shear displacement response on the same joint specimen as a function of normal stress for test no. 3 


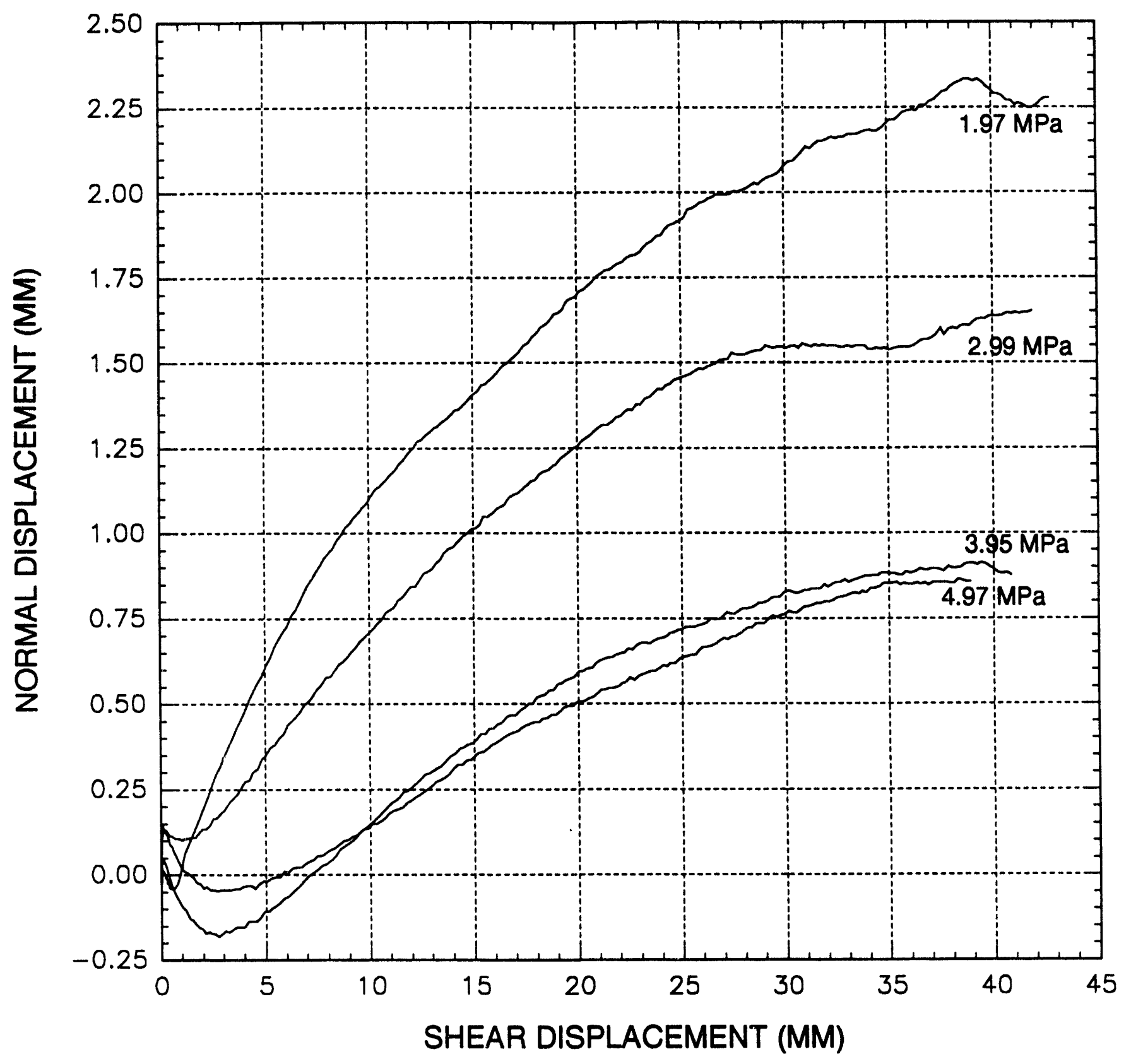

Figure A-6. Normal displacement (dilation) response on the same specimen as a function of normal stress for test no. 3 


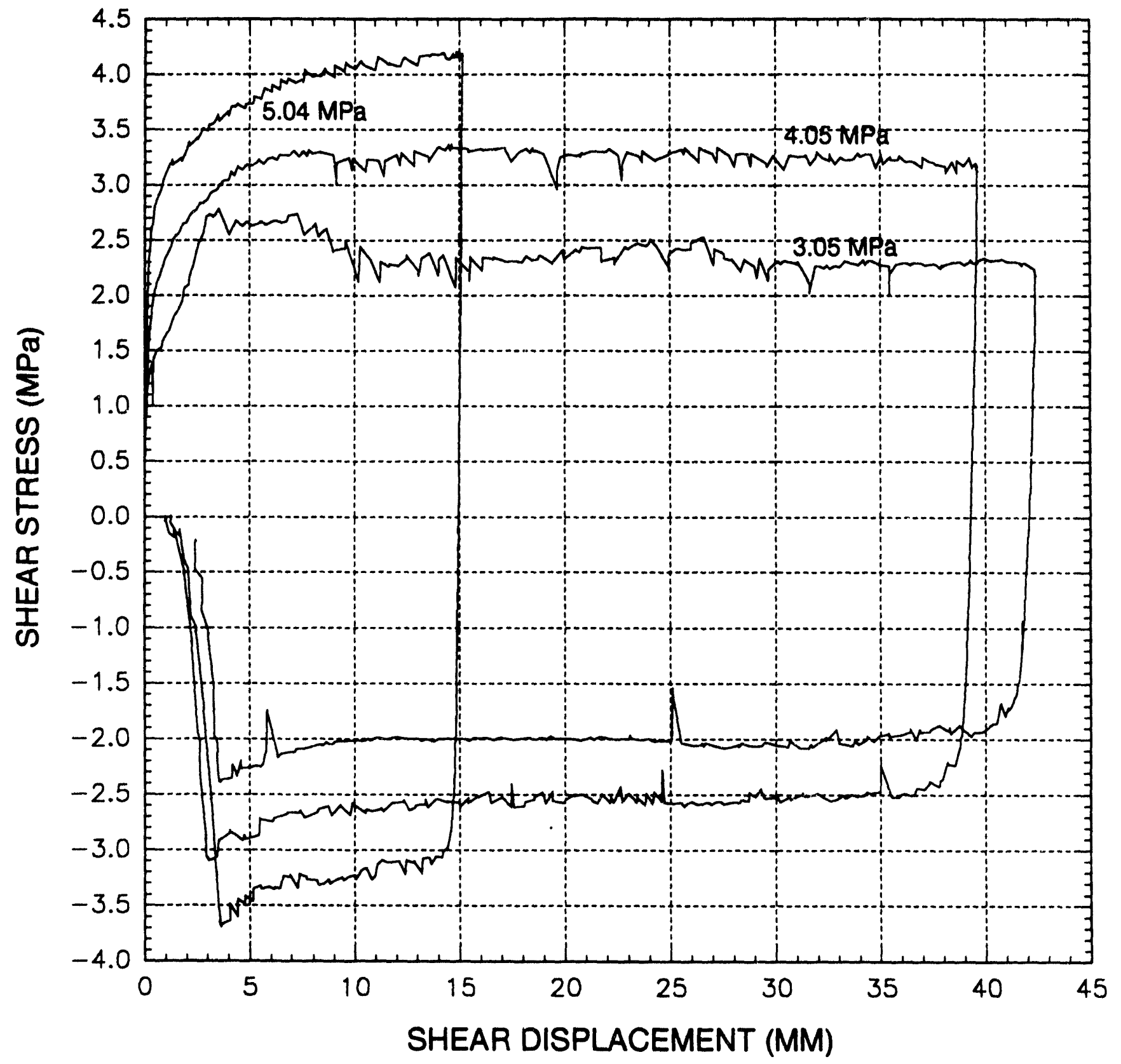

Figure A-7. Shear stress versus shear displacement response on the same joint specimen as a function of normal stress for test no. 4 


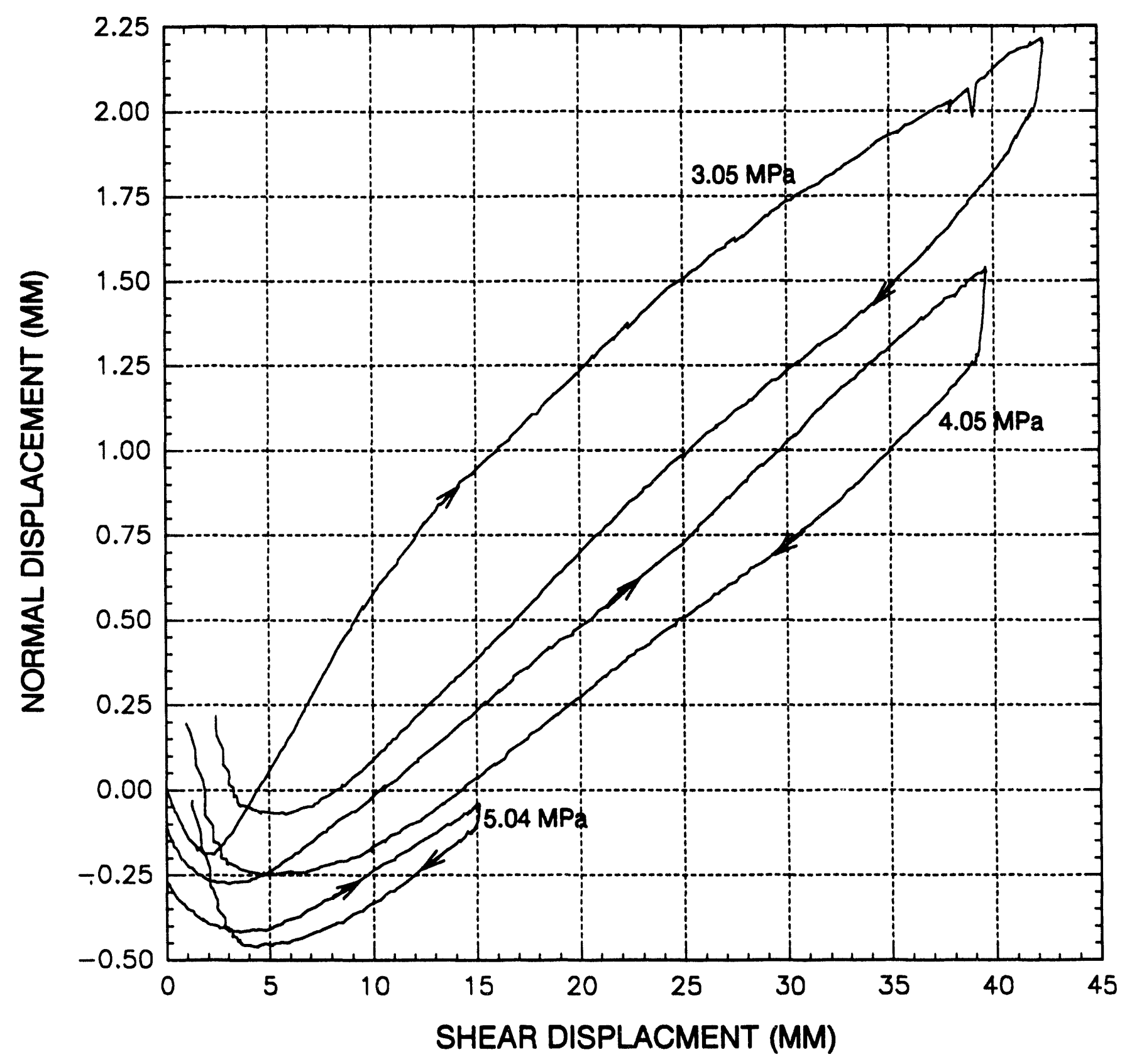

Figure A-8. Normal displacement (dilation) response on the same specimen as a function of normal stress for test no. 4 


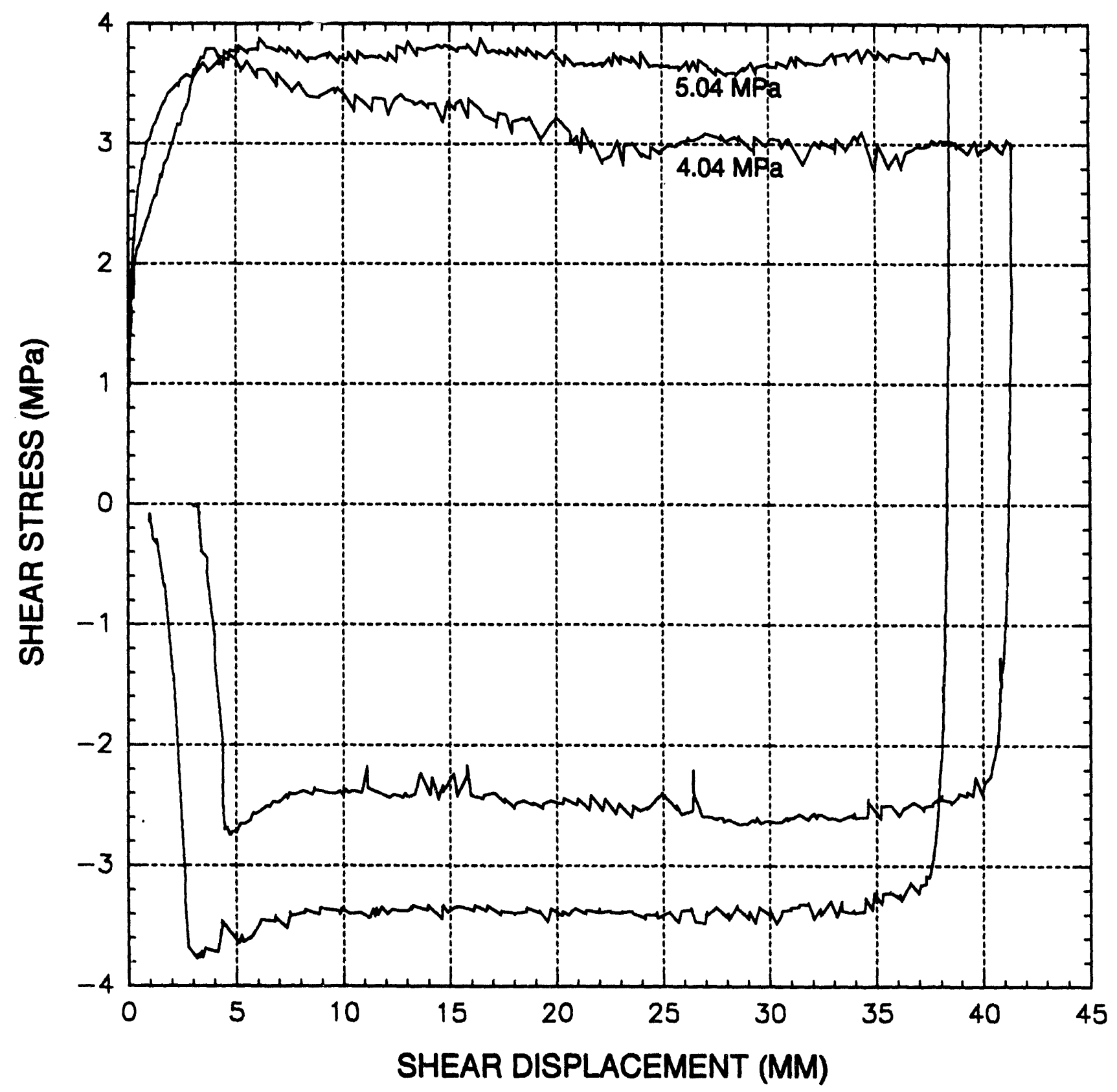

Figure A-9. Shear stress versus shear displacement response on the same joint specimen as a function of normal stress for test no. 5 


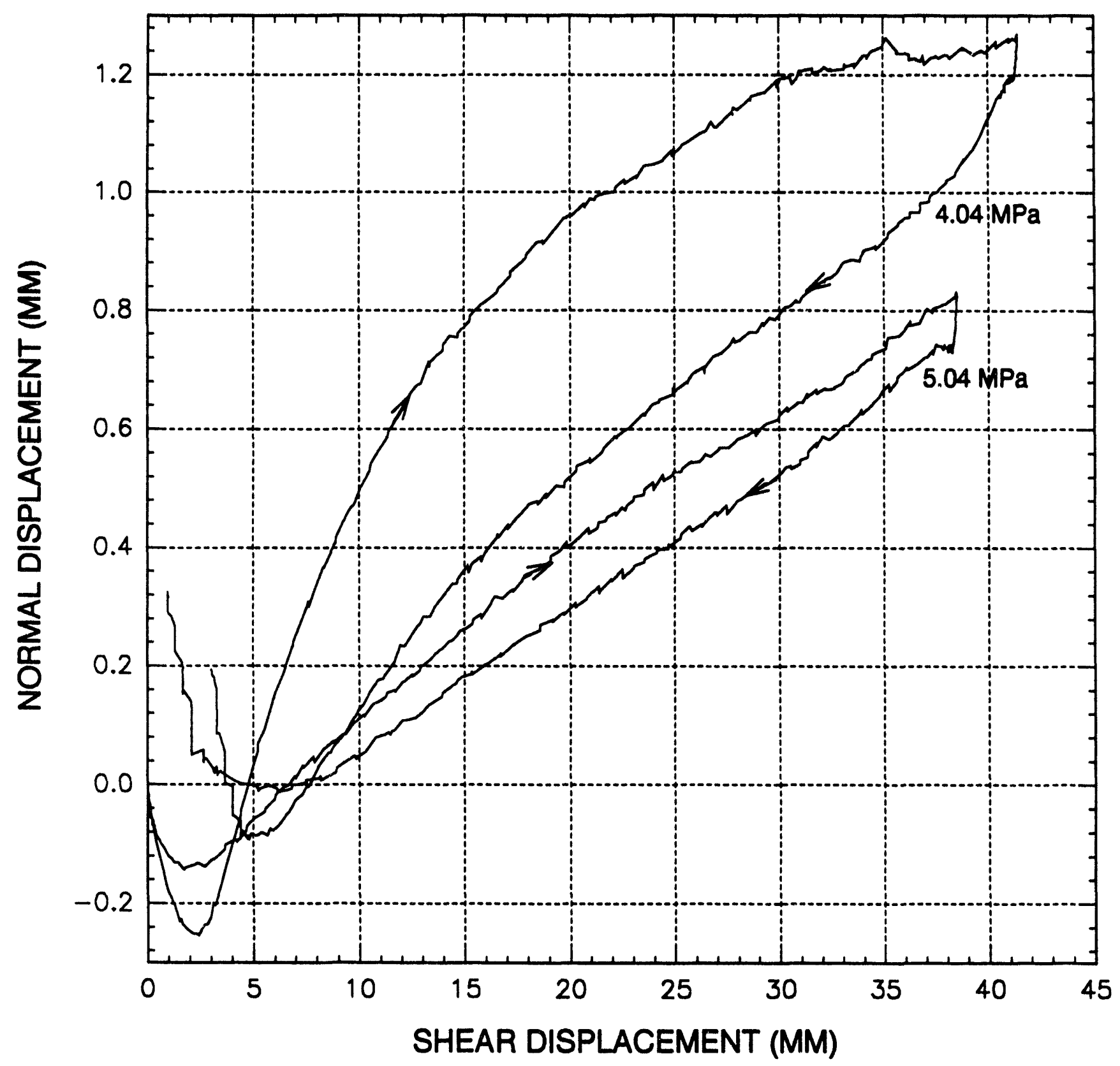

Figure A-10. Normal displacement (dilation) response on the same specimen as a function of normal stress for test no. 5 


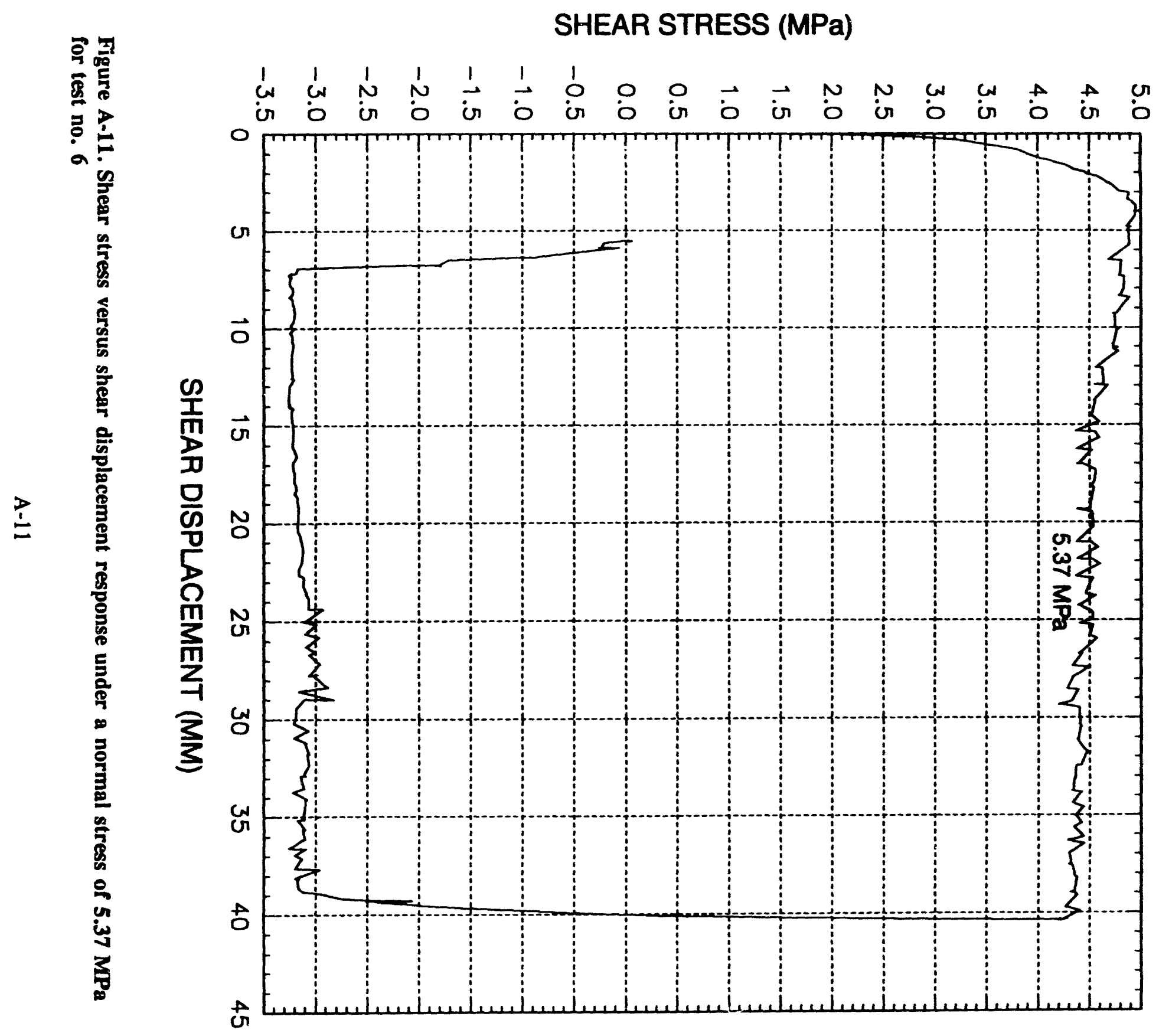




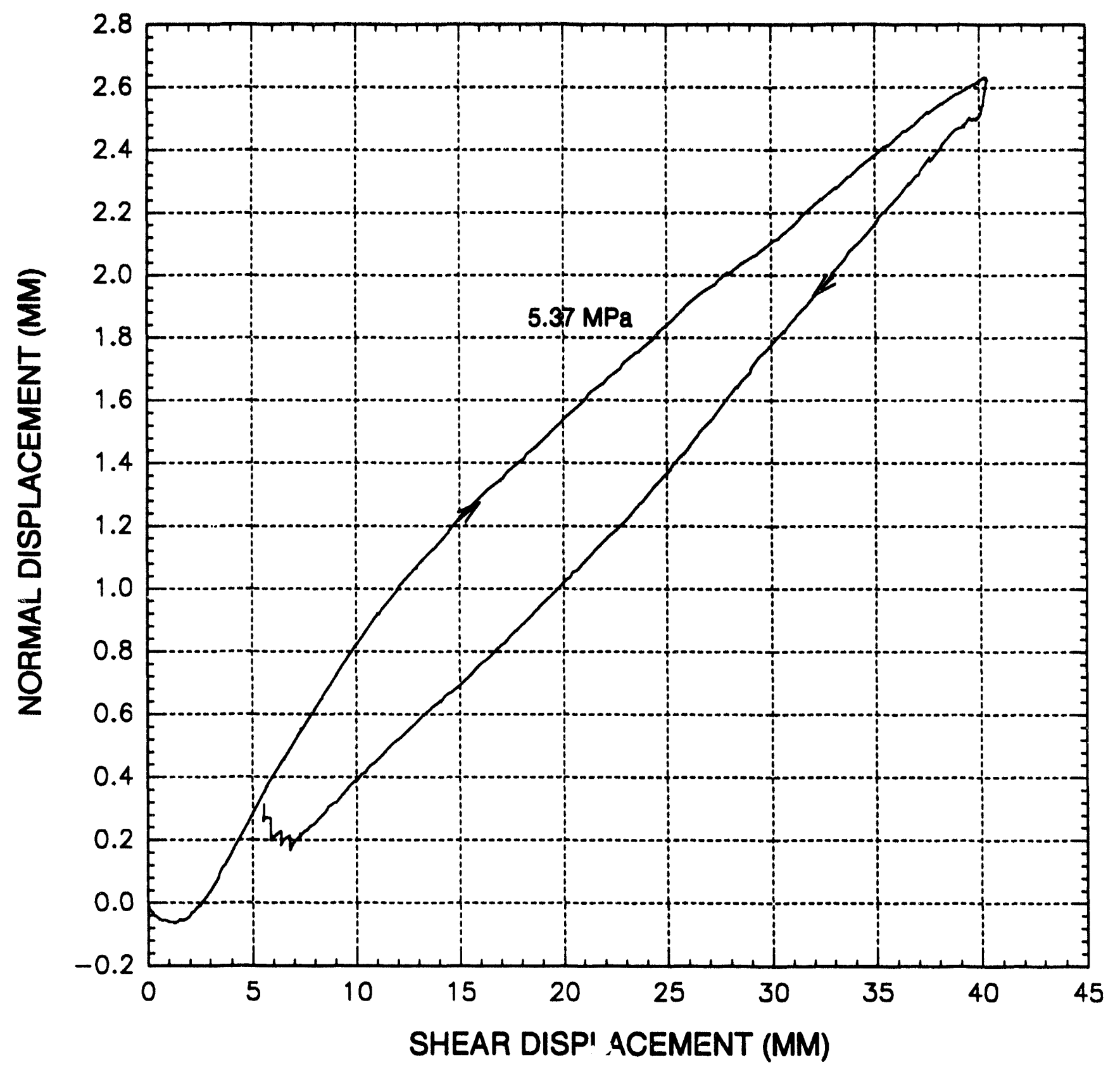

Figure A-12. Normal displacement (dilation) response under a normal stress of $5.37 \mathrm{MPa}$ for test no. 6 


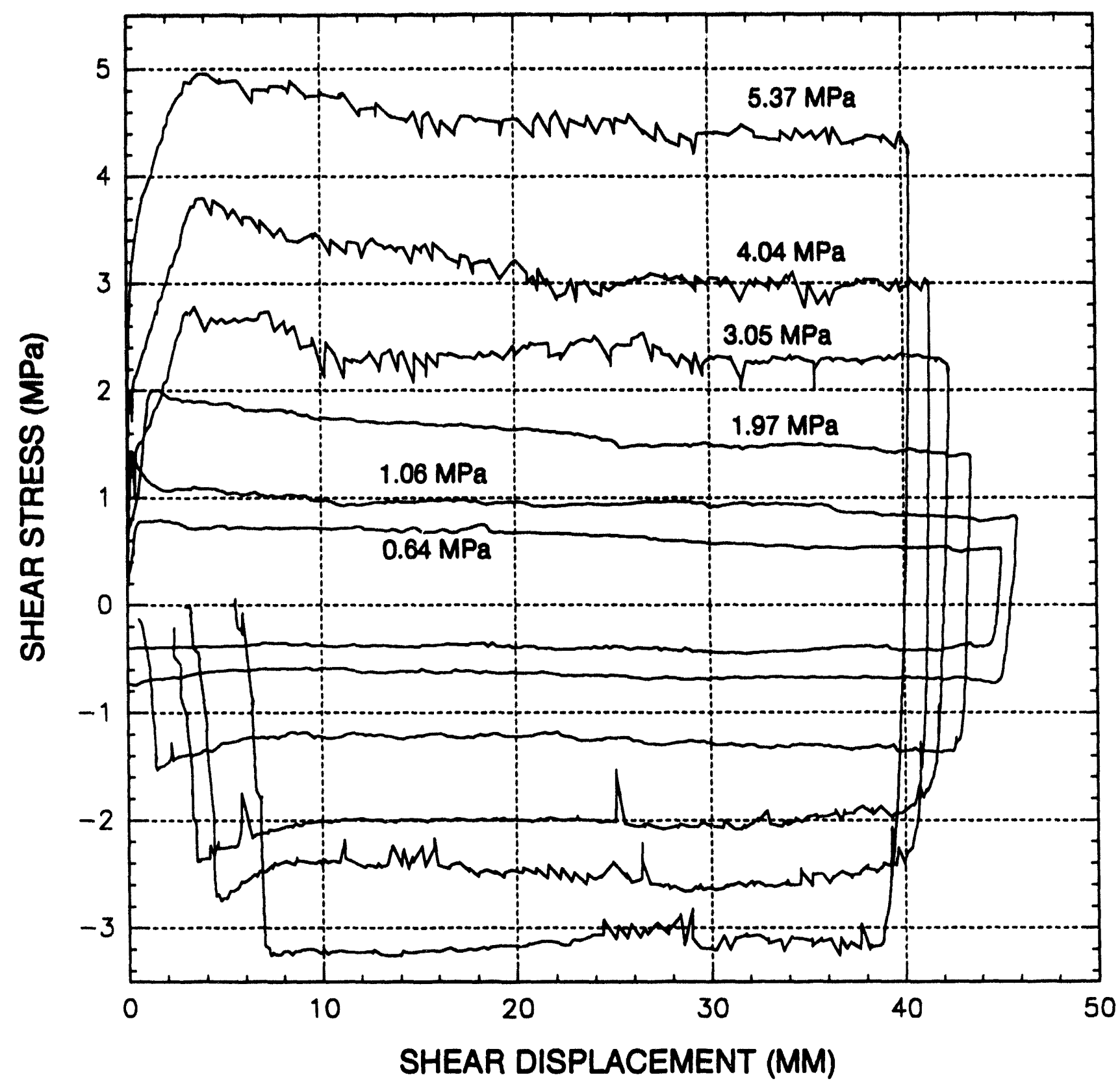

Figure A-13. Shear stress versus shear displacement response as a function of normal stress for test nos. 1 through 6. Each curve represents the first shear cycle on the particular sample. 


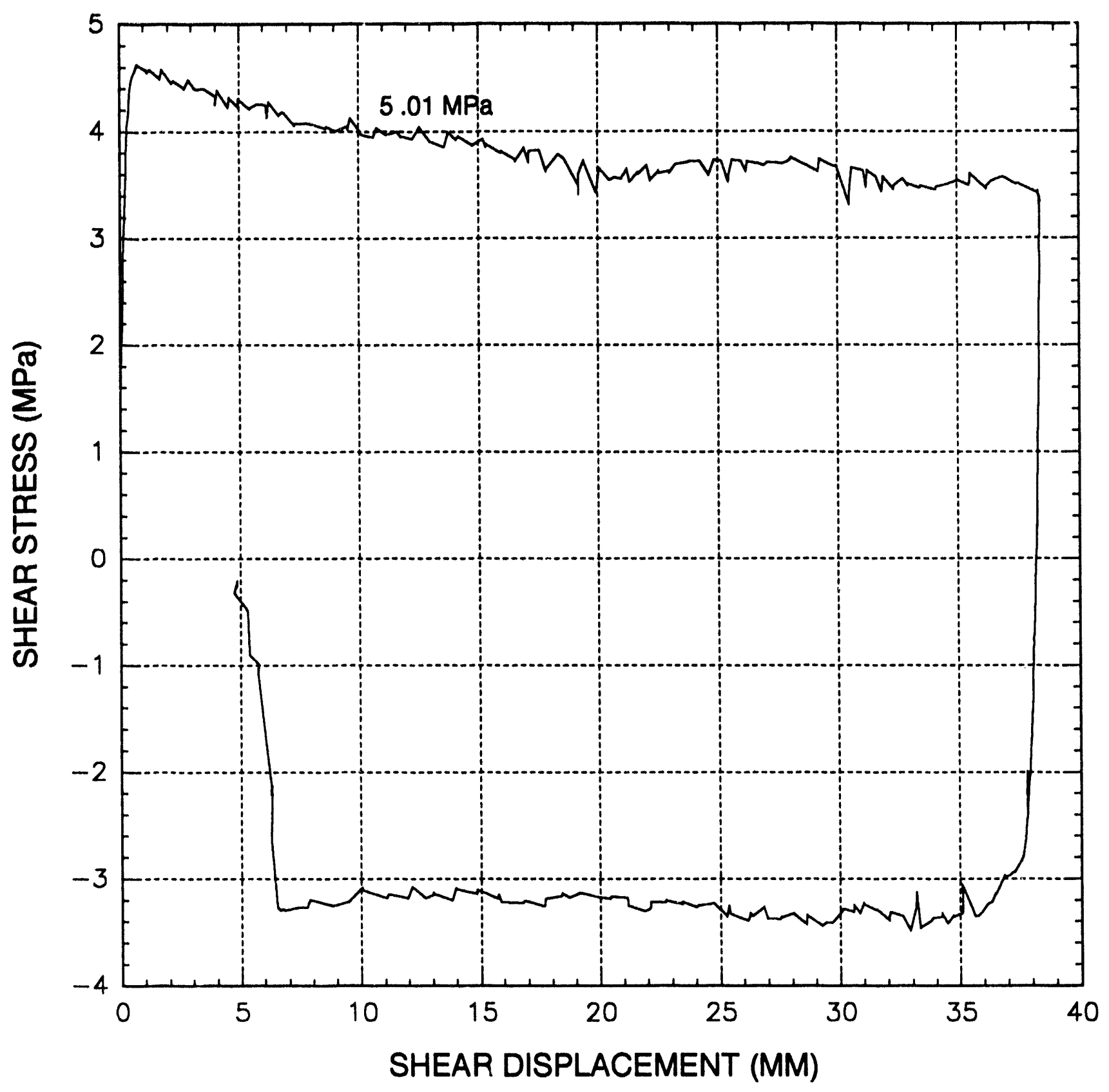

Figure A-14. Shear stress versus shear displacement response under a normal stress of $5.01 \mathrm{MPa}$ for test no. 7 


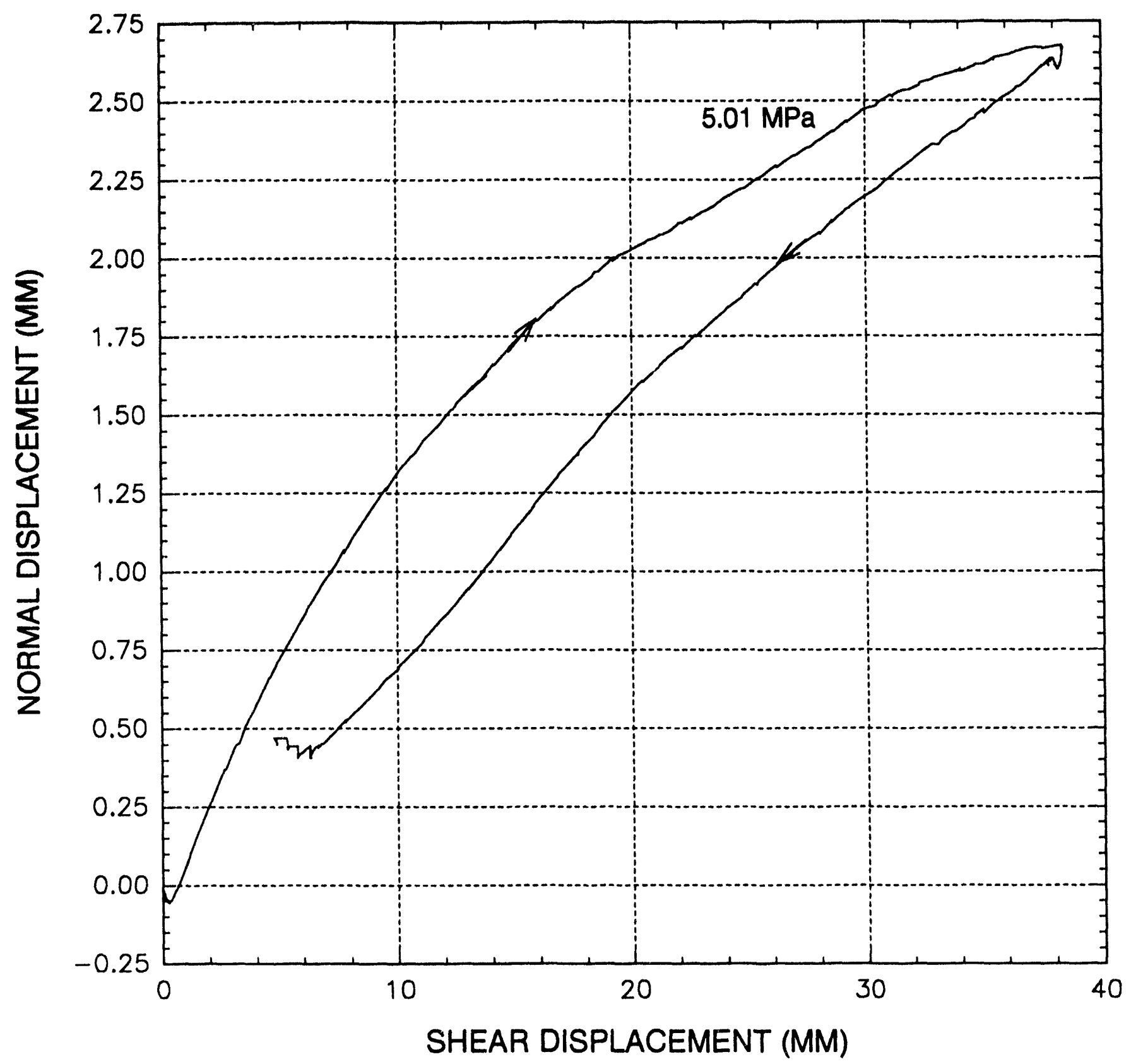

Figure A-15. Normal displacement (dilation) response under a normal stress of $5.01 \mathrm{MPa}$ for test no. 7 


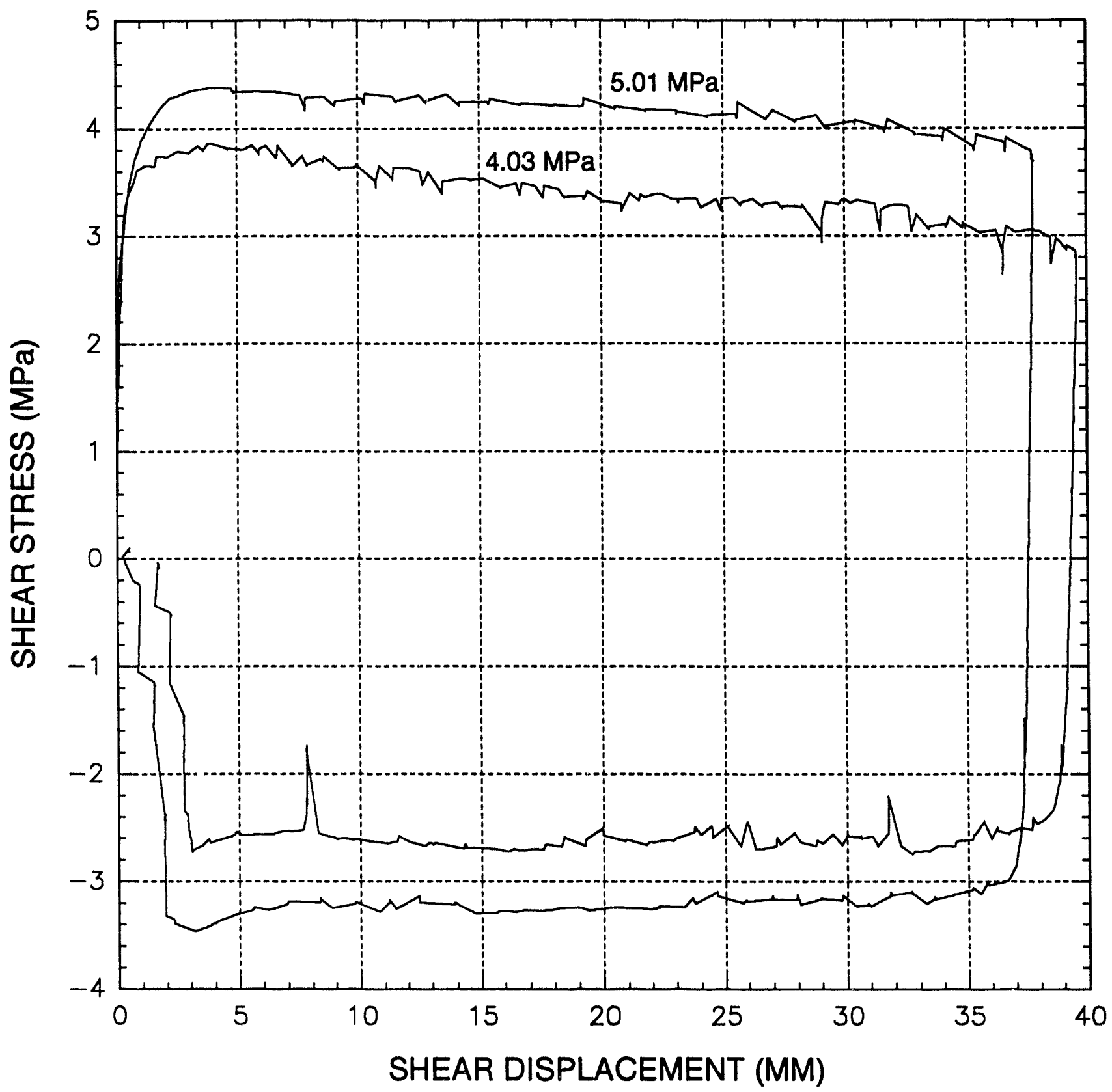

Figure A-16. Shear stress versus shear displacement response on the same joint specimen as a function of normal stress for test no. 8 


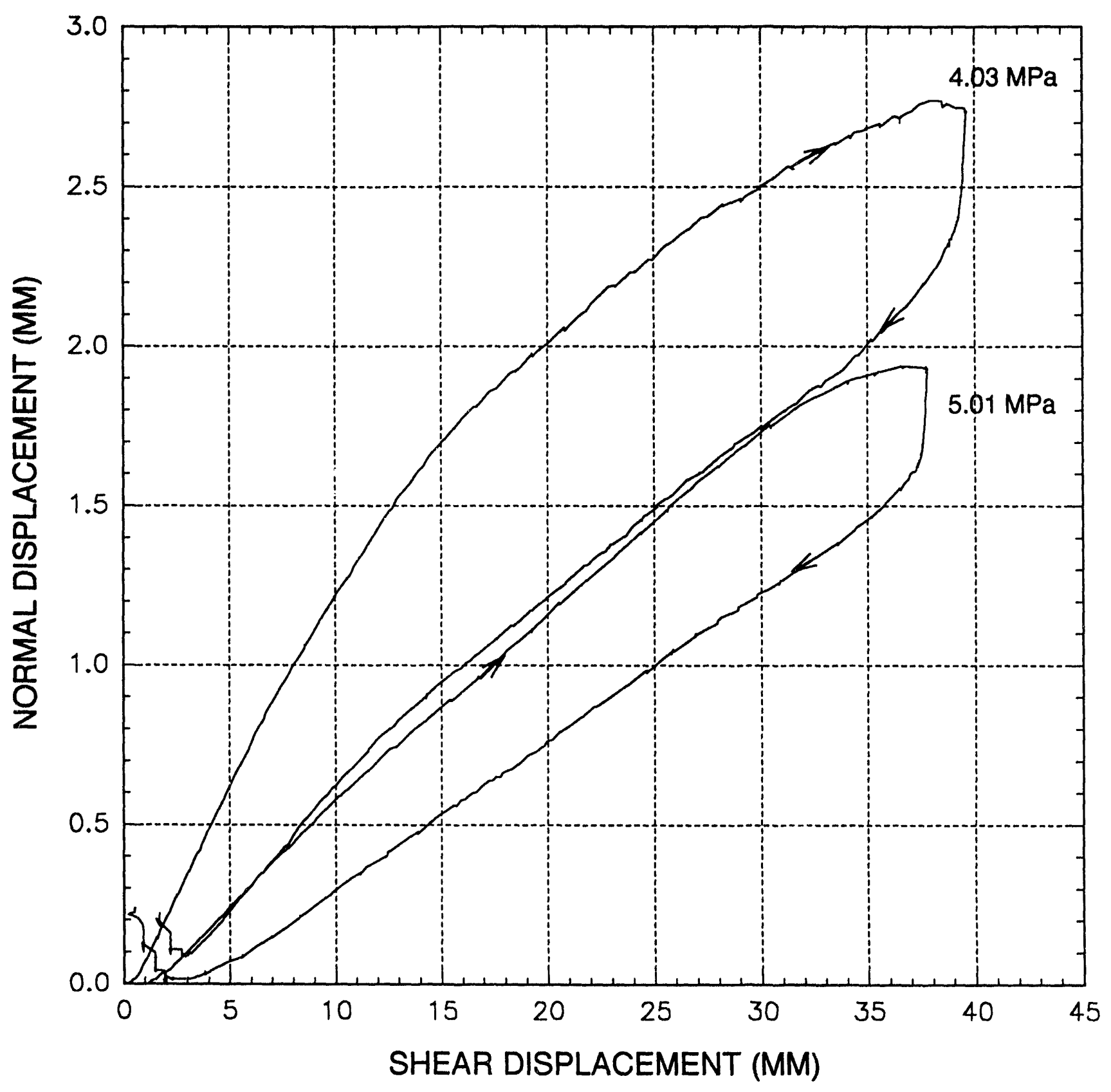

Figure A-17. Normal displacement (dilation) response on the same specimen as a function of normal stress for test no. 8 


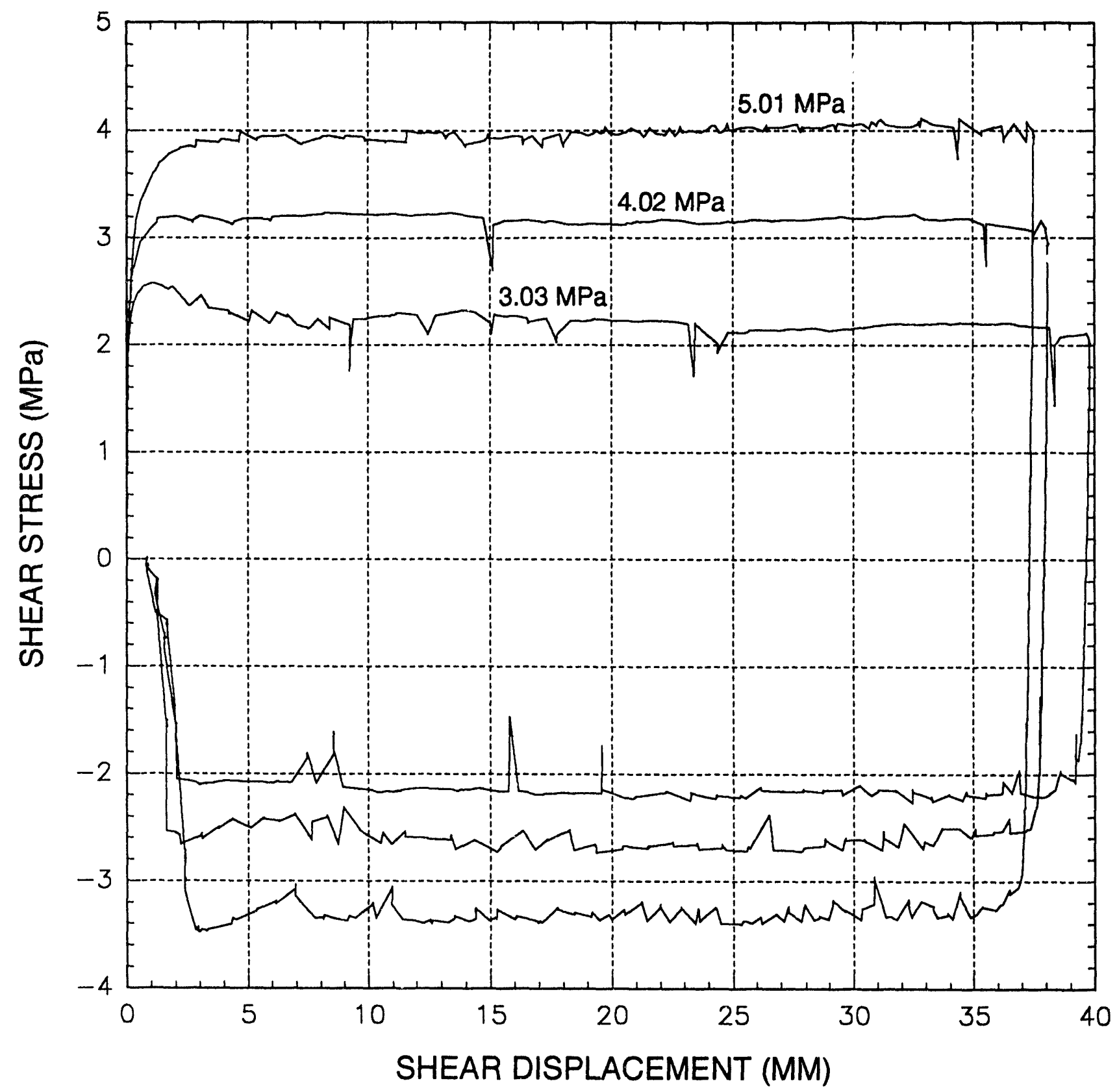

Figure A-18. Shear stress versus shear displacement response on the same joint specimen as a function of normal stress for test no. 9 


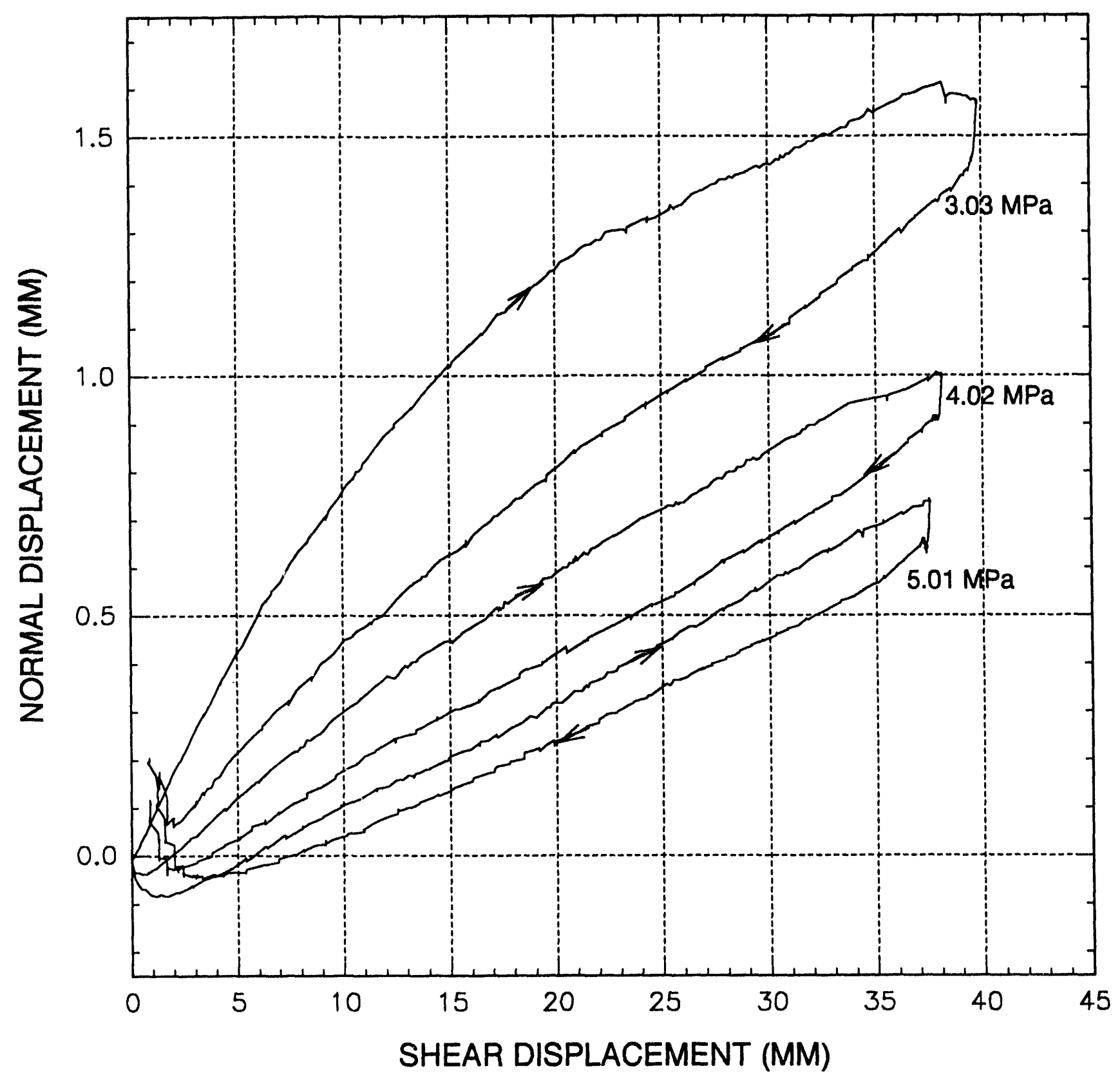

Figure A-19. Normal displacement (dilation) response on the same specimen as a function of normal stress for test no. 9 


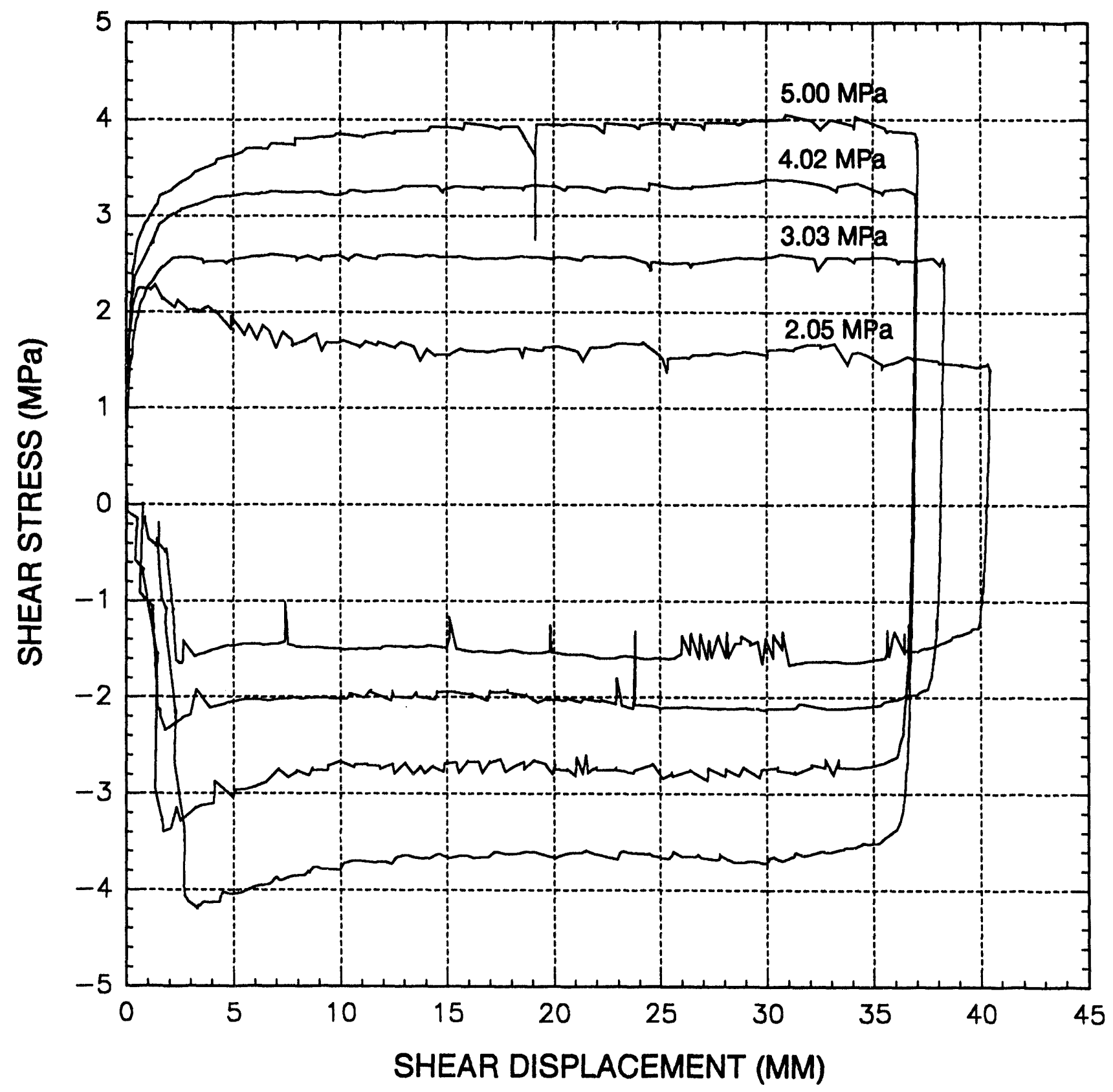

Figure A-20. Shear stress versus shear displacement response on the same joint specimen as a function of normal stress for test no. 10 


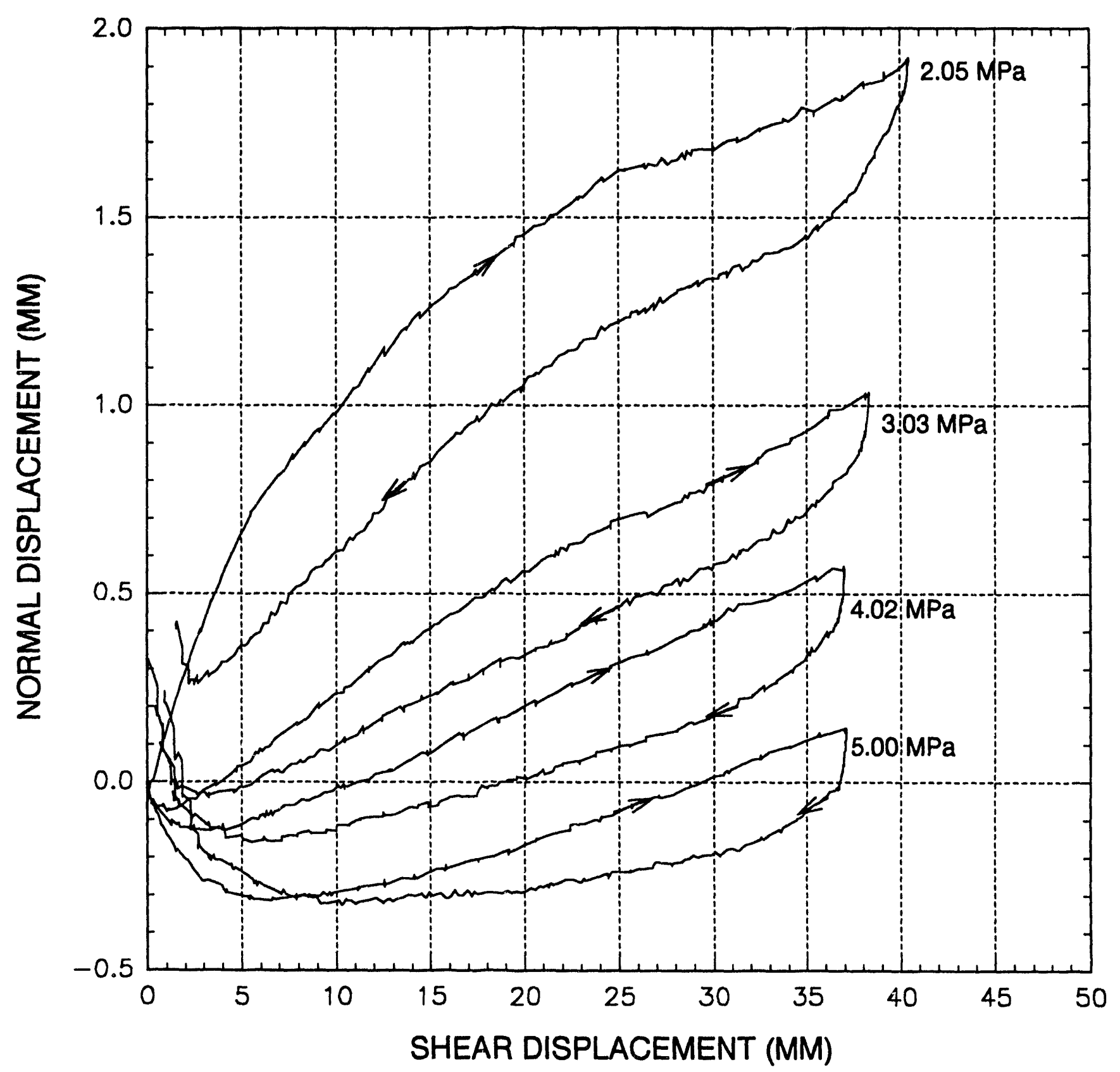

Figure A-21. Normal displacement (dilation) response on the same specimen as a function of normal stress for test no. 10 


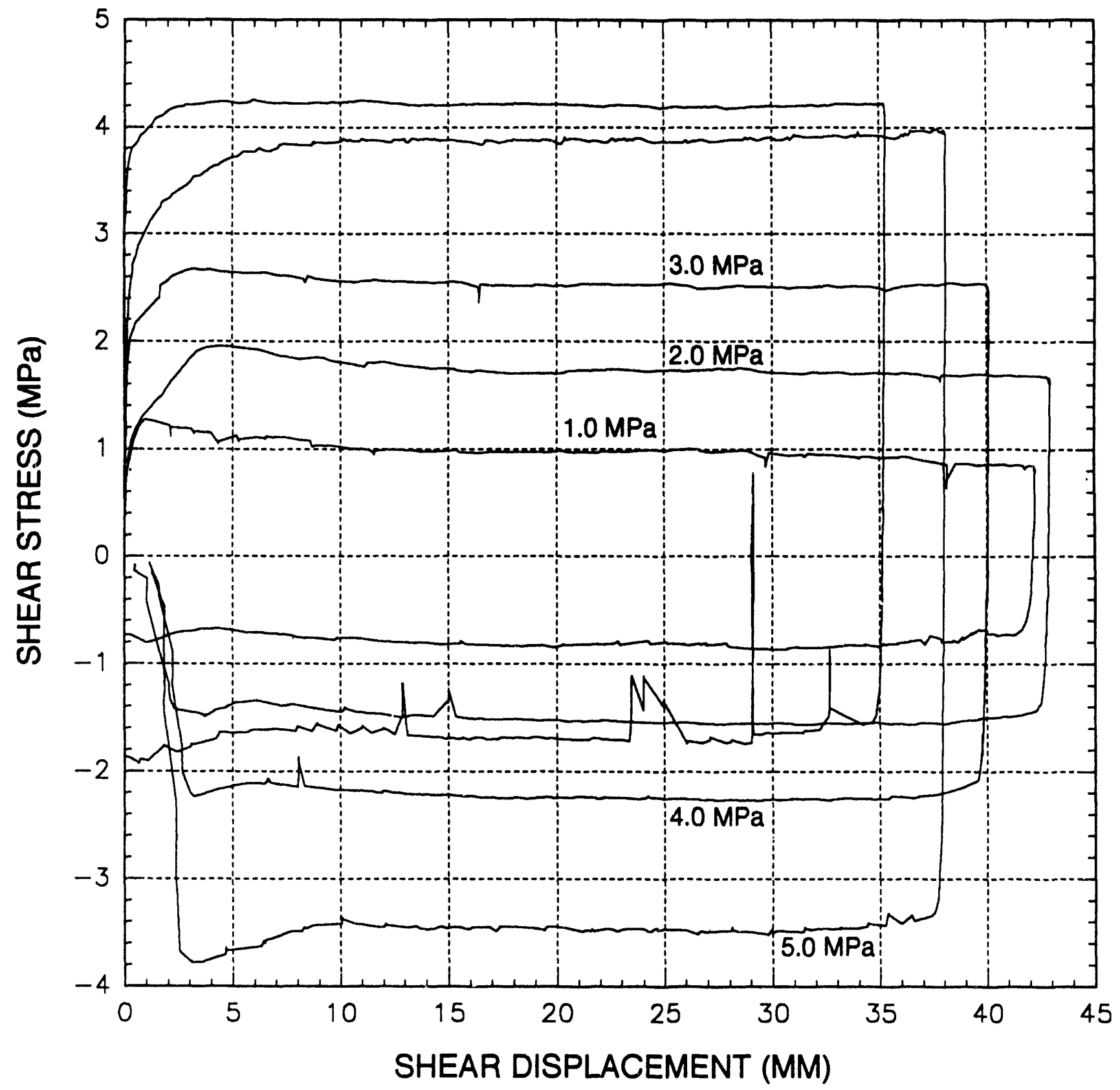

Figure A-22. Shear stress versus shear displacement response on the same joint specimen as a function of normal stress for test no. 11 


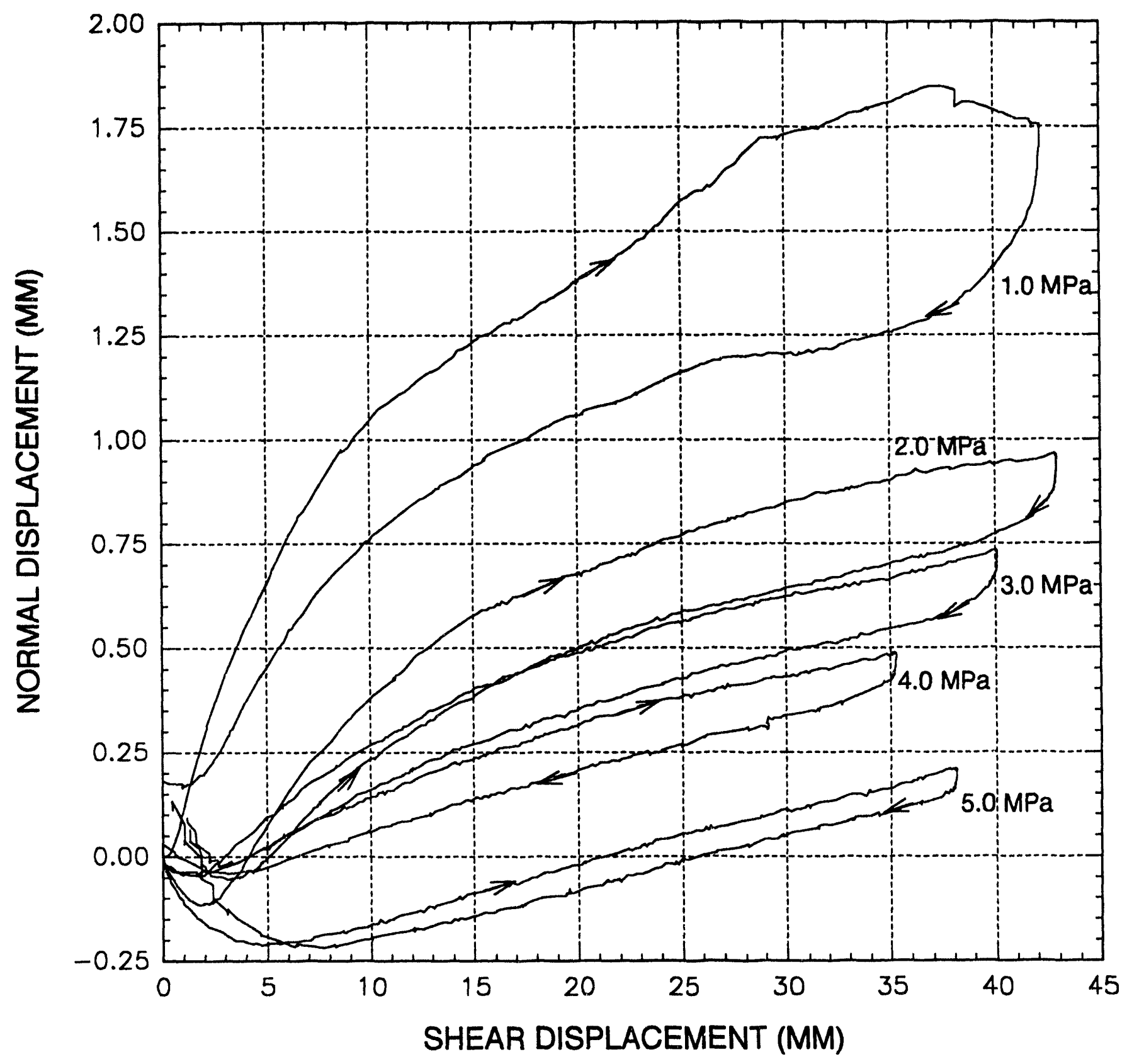

Figure A-23. Normal displacement (dilation) response on the same specimen as a function of normal stress for test no. 11 


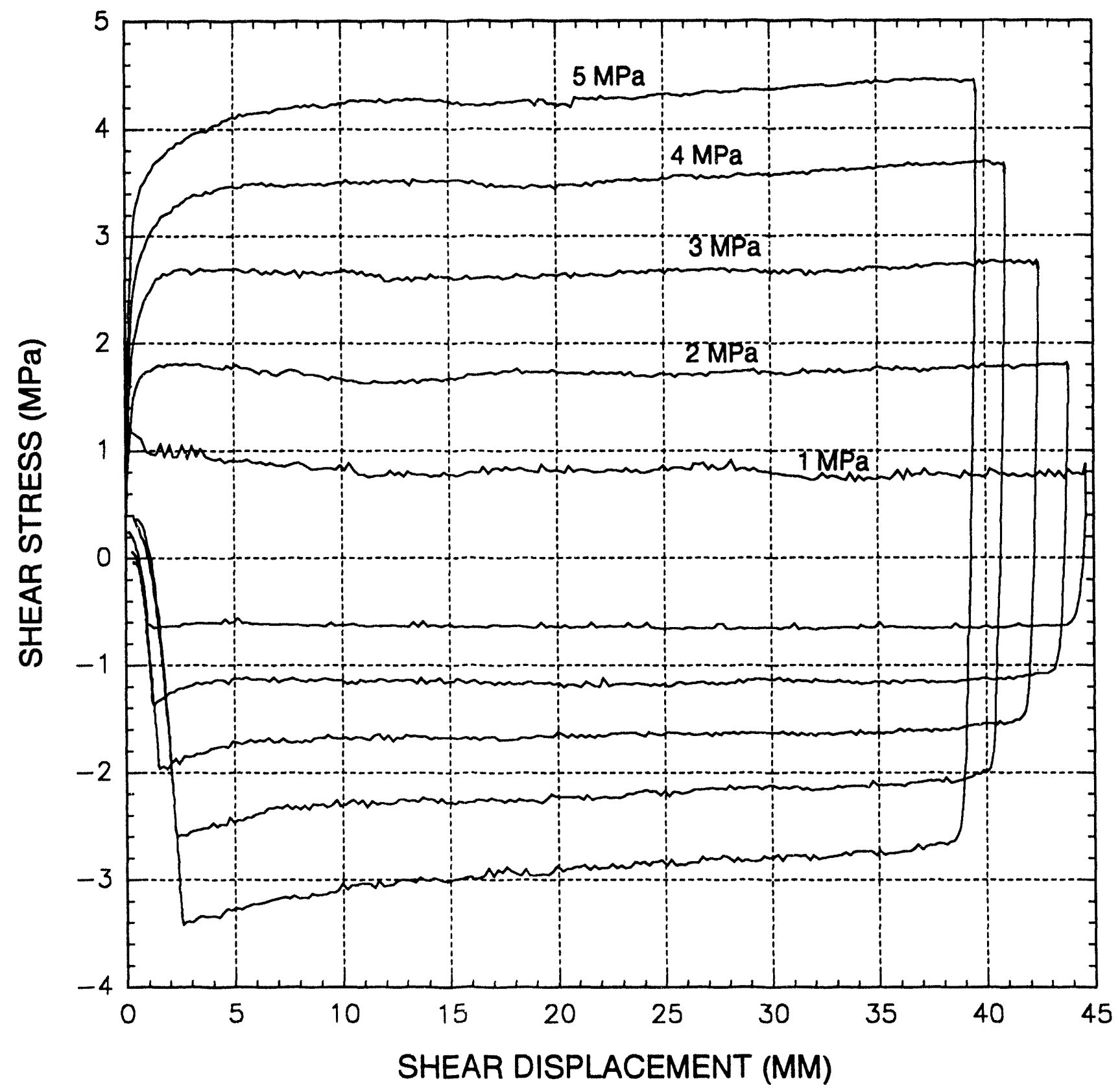

Figure A-24. Shear stress versus shear displacement response on the same joint specimen as a function of normal stress for test no. 17 


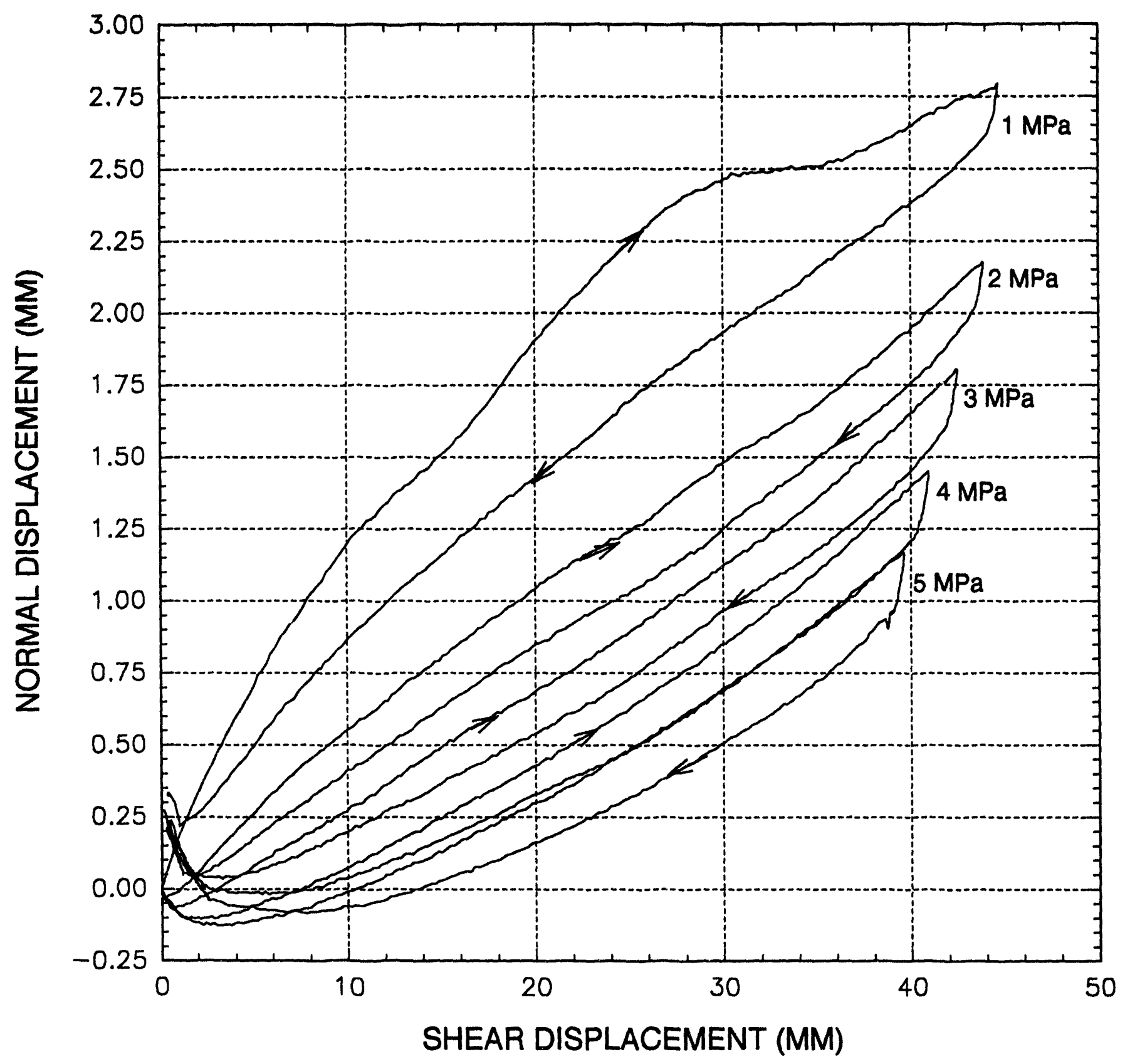

Figure A-25. Normal displacement (dilation) response on the same specimen as a function of normal stress for test no. 17 


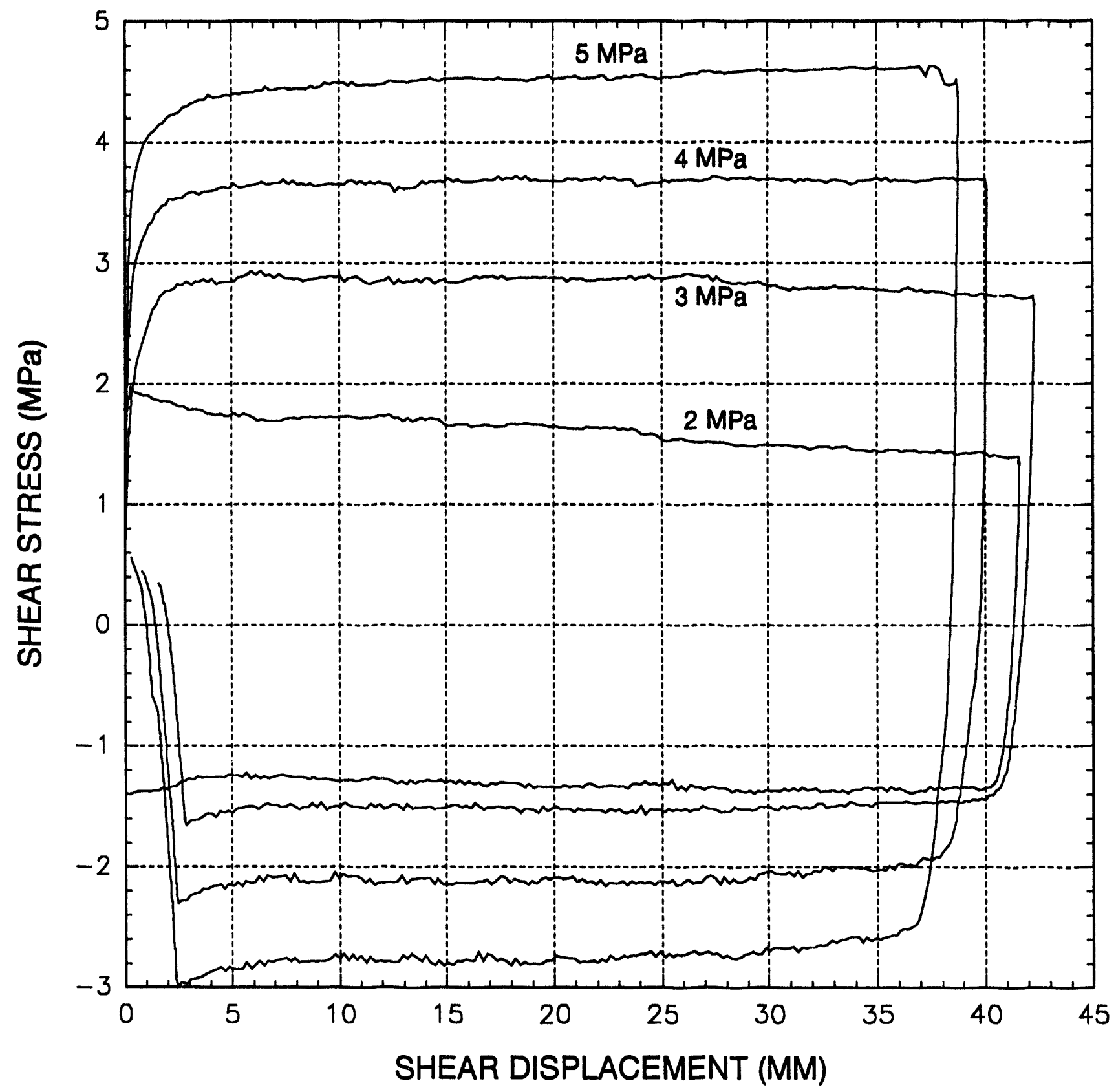

Figure A-26. Shear stress versus shear displacement response on the same joint specimen as a function of normal stress for test no. 18 


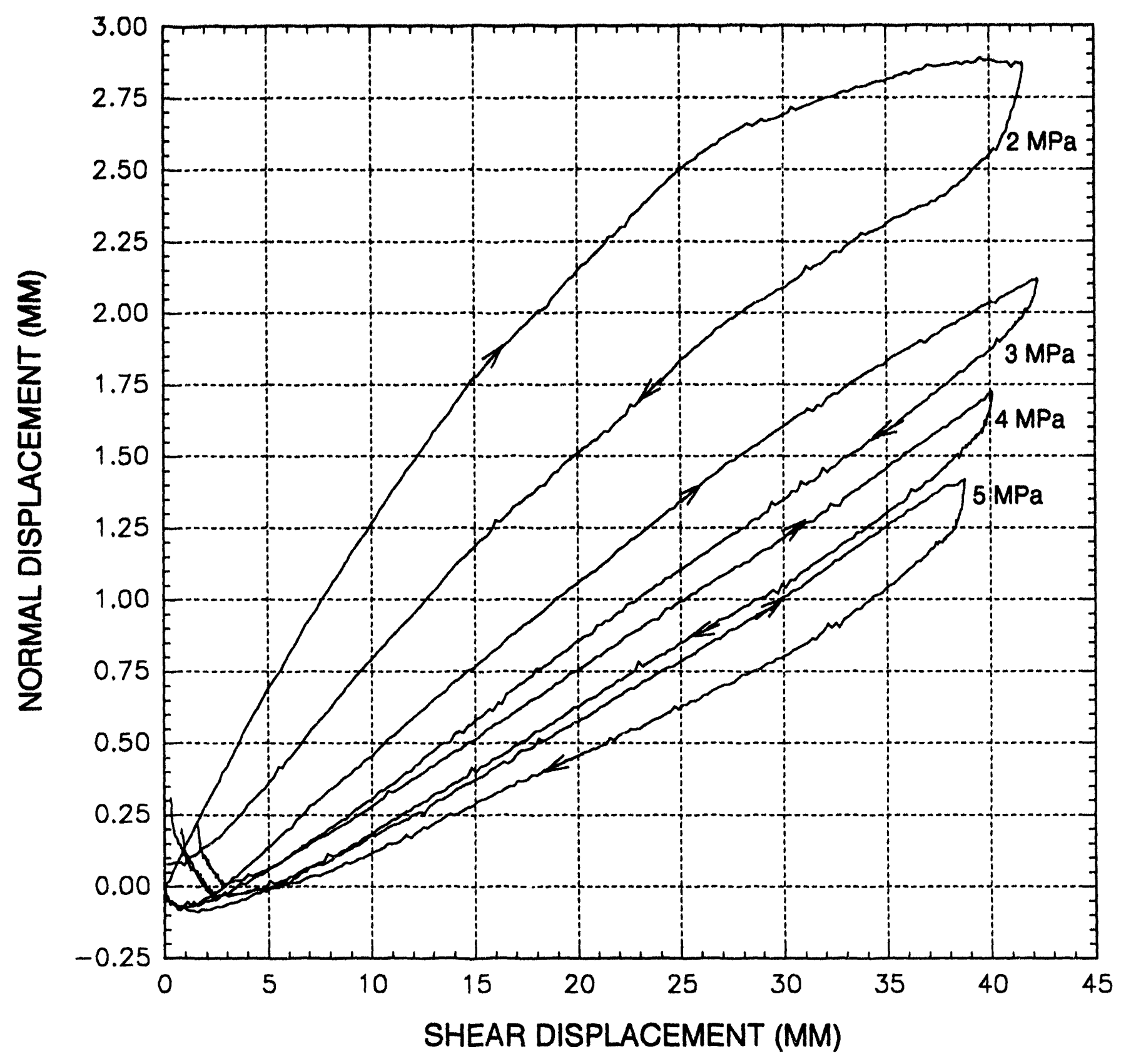

Figure A-27. Normal displacement (dilation) response on the same specimen as a function of normal stress for test no. 18 


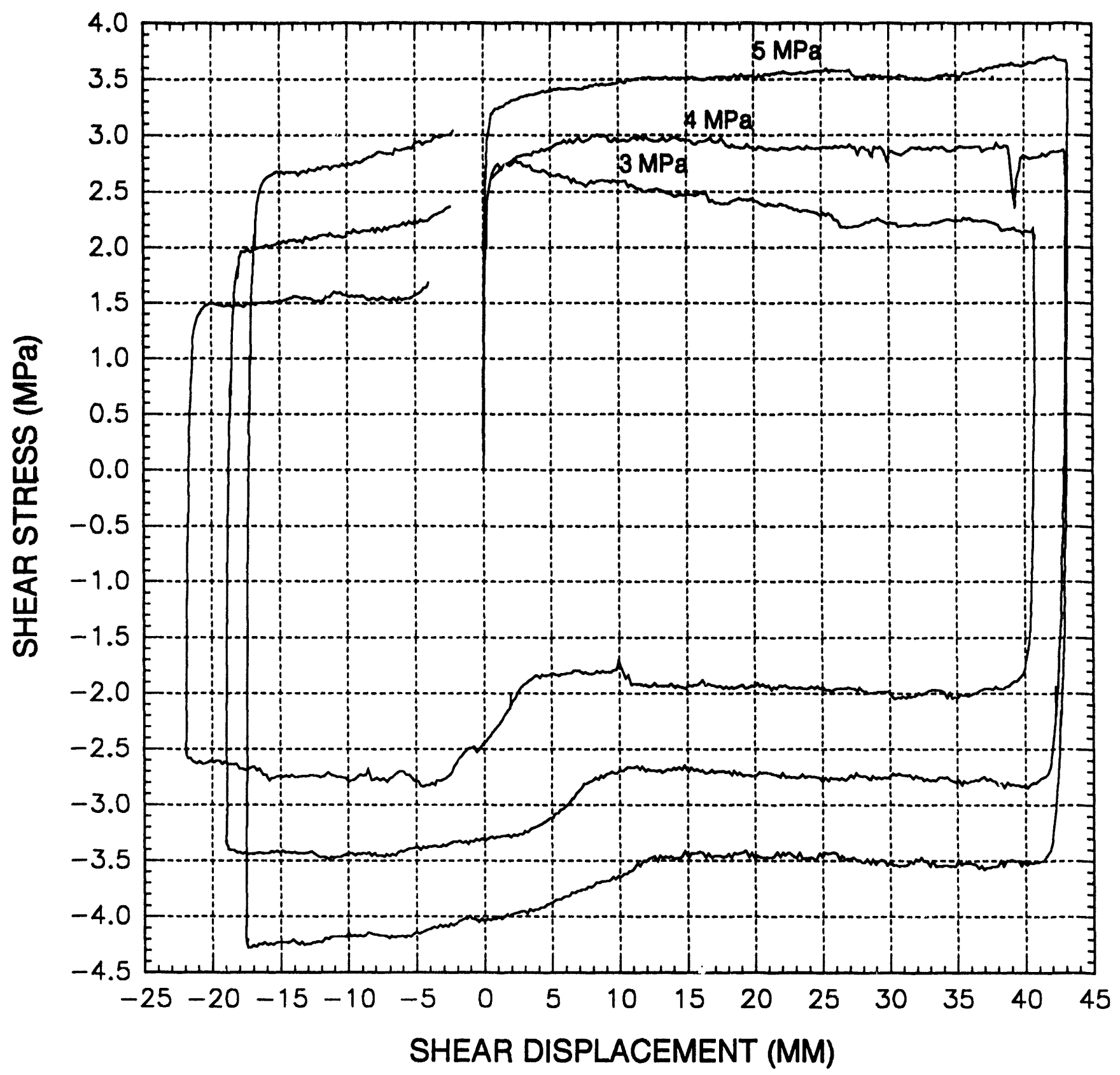

Figure A-28. Shear stress versus shear displacement response on the same joint specimen as a function of normal stress for test no. 19 


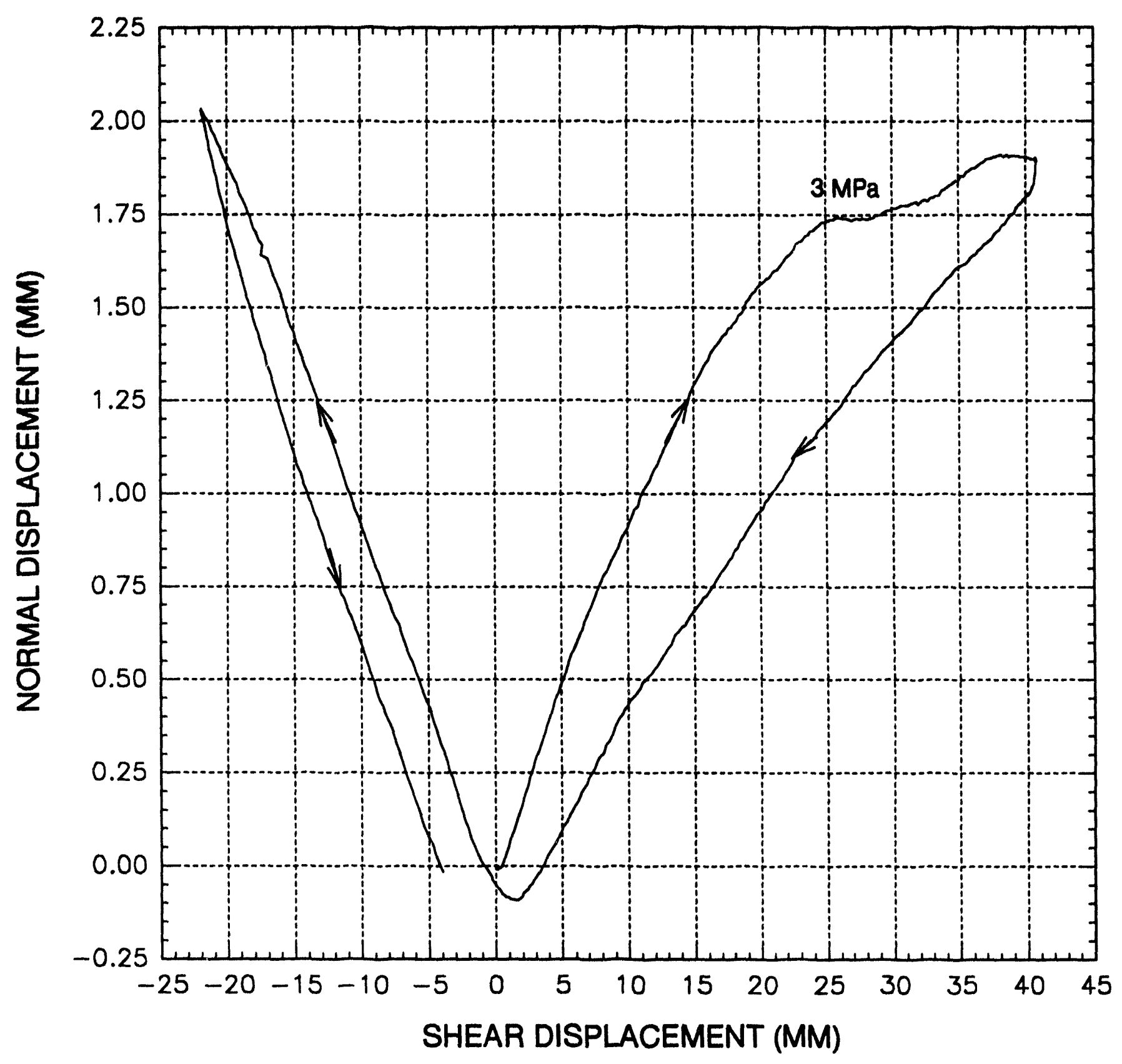

Figure A-29. Normal displacement (dilation) response under a normal stress of $3 \mathrm{MPa}$ for test no. 19 


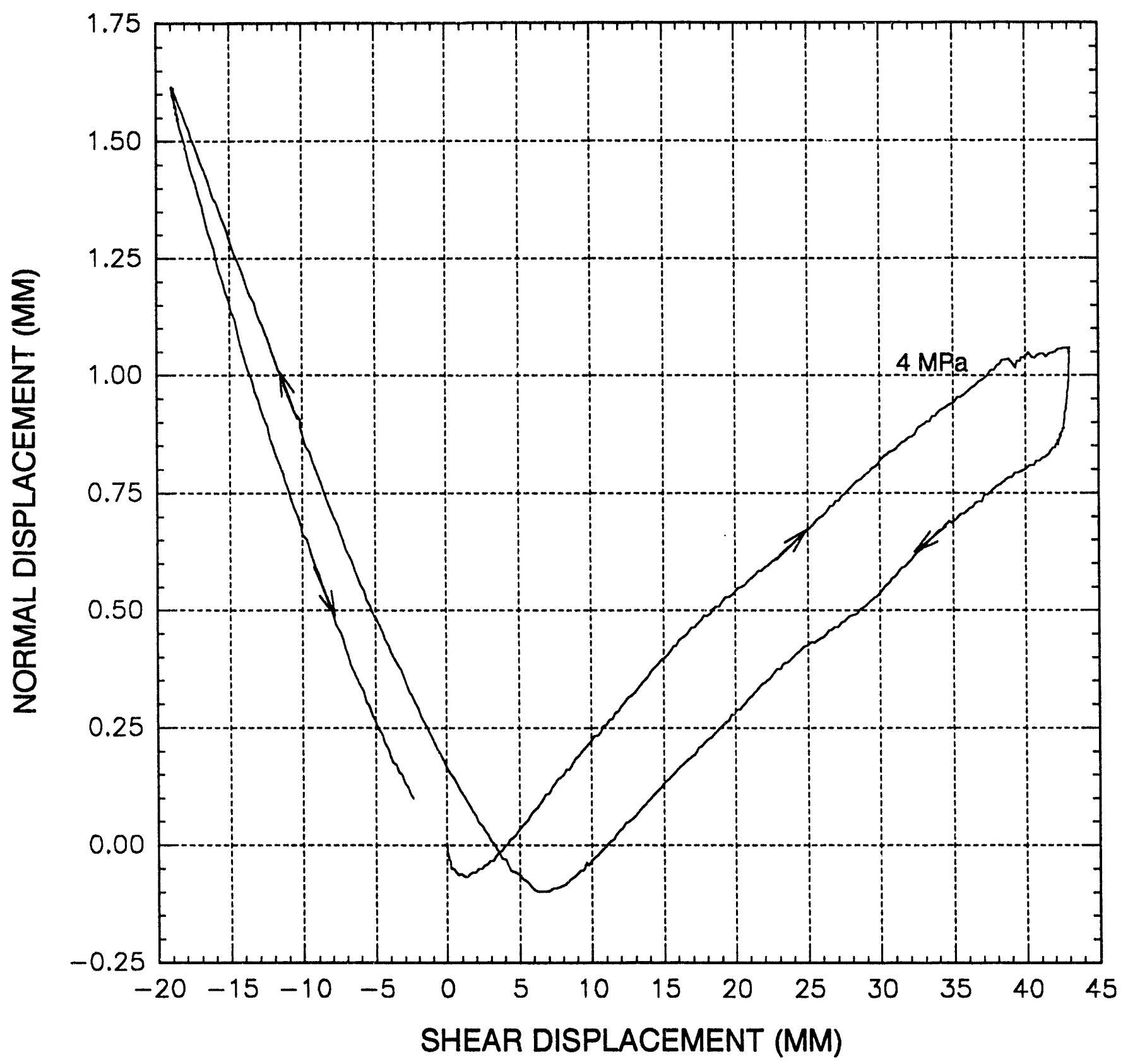

Figure A-30. Normal displacement (dilation) response under a normal stress of $4 \mathrm{MPa}$ for test no. 19 


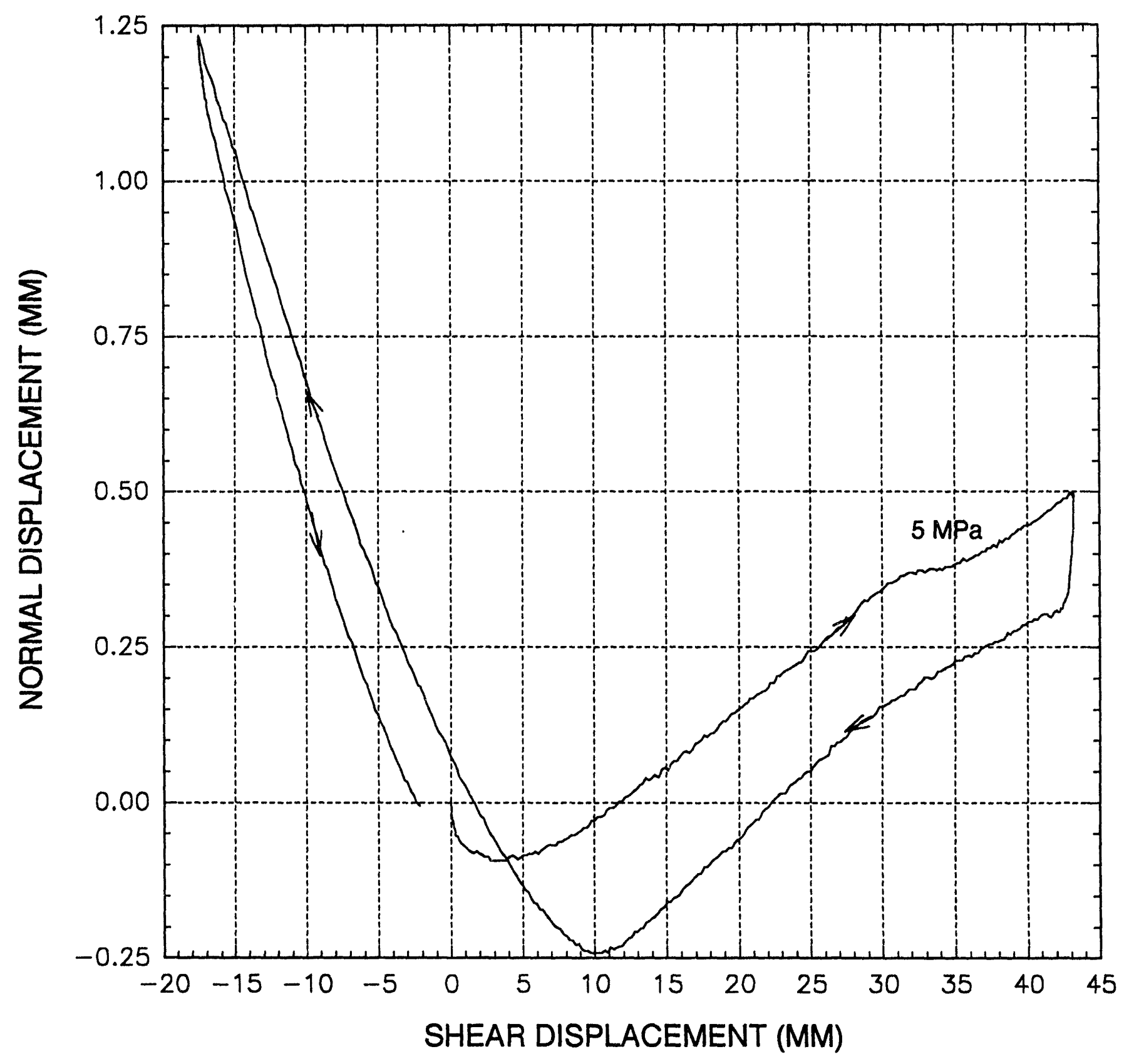

Figure A-31. Normal displacement (dilation) response under a normal stress of $5 \mathrm{MPa}$ for test no. 19 


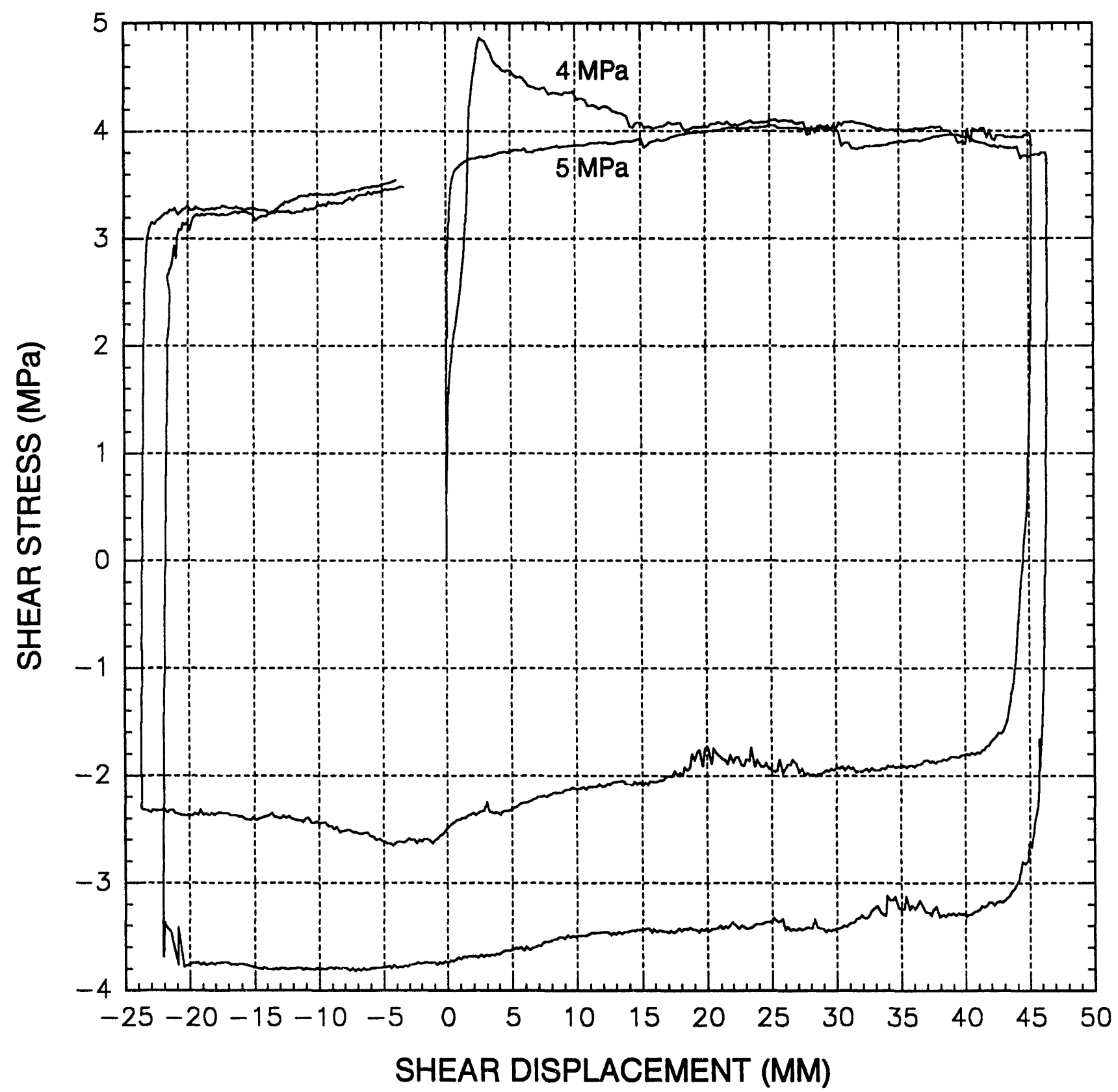

Figure A-32. Shear stress versus shear displacement response on the same joint specimen as a function of normal stress for test no. 20 


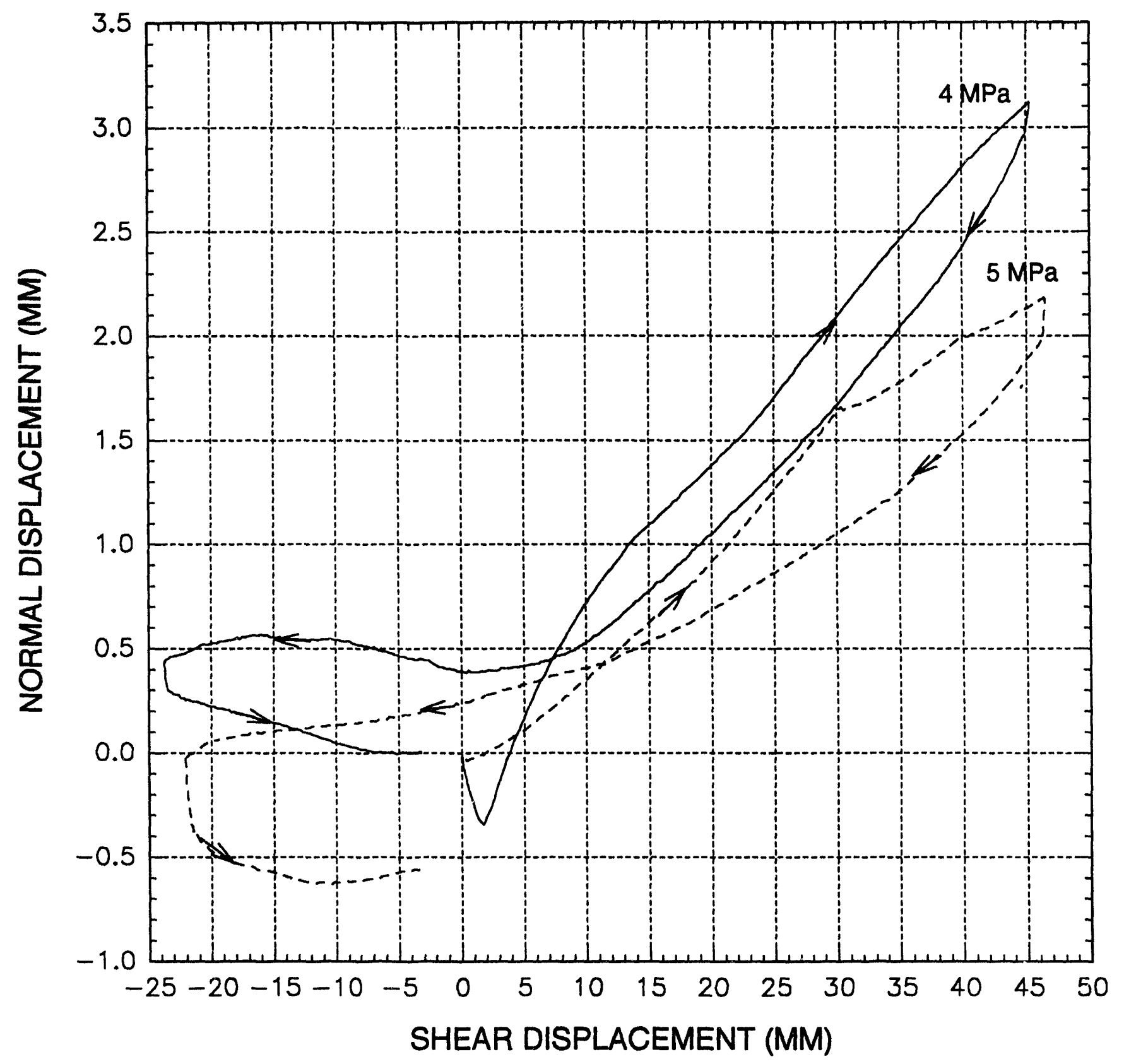

Figure A-33. Normal displacement (dilation) response on the same specimen as a function of normal stress for test no. 20 


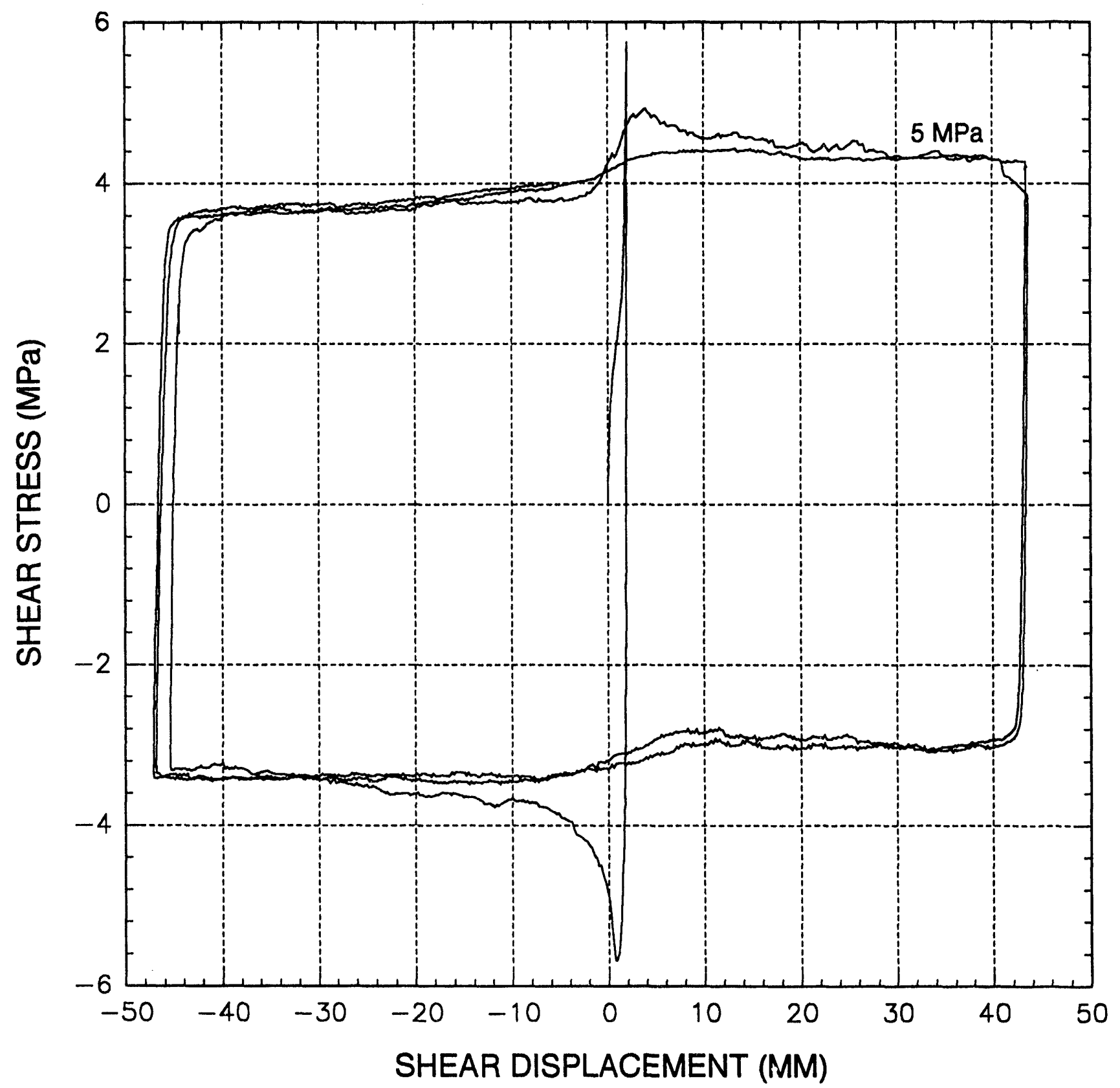

Figure A-34. Shear stress versus shear displacement response under a normal stress of $5 \mathrm{MPa}$ for test no. 21 


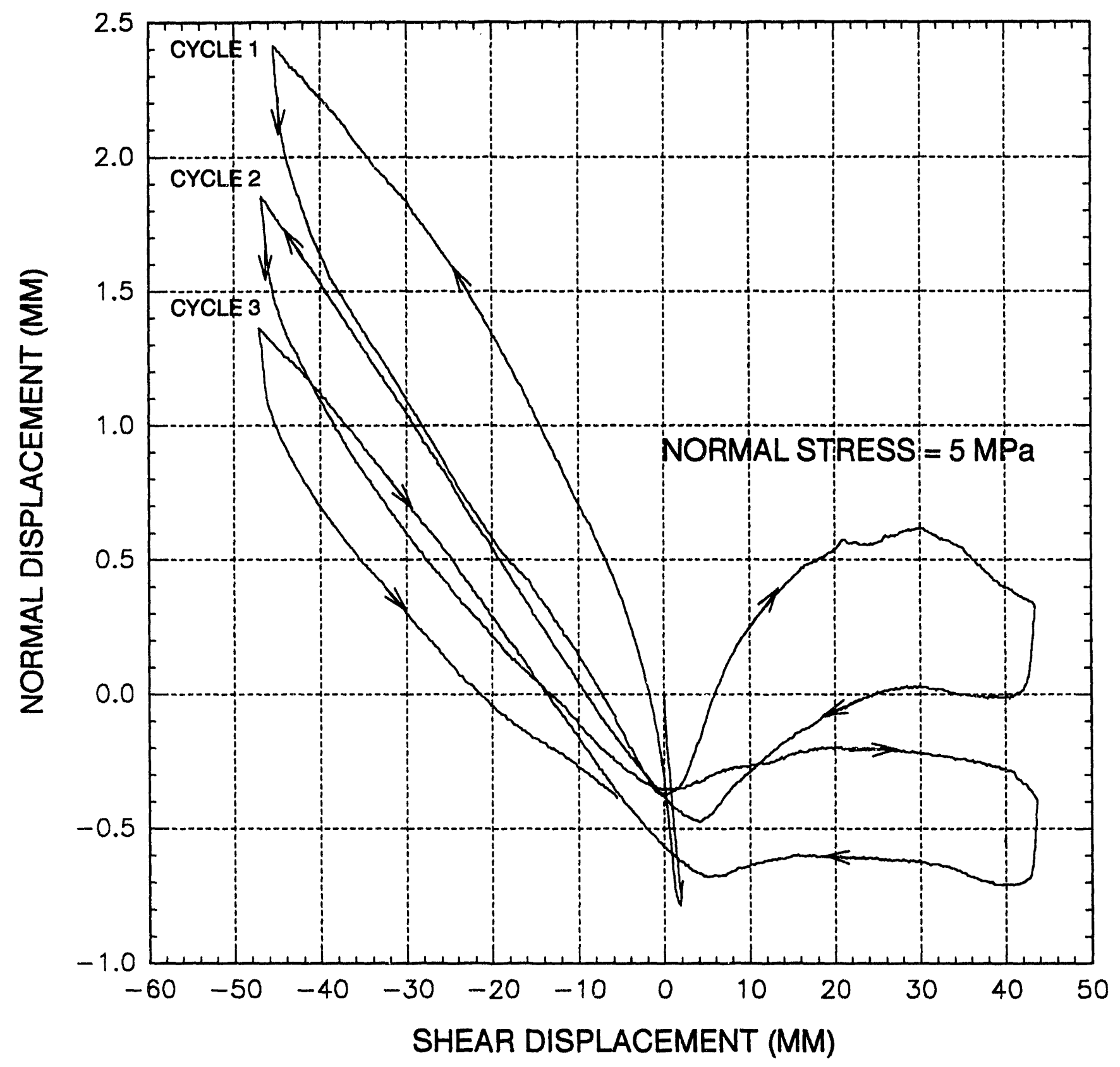

Figure A-35. Normal displacement (dilation) response under a normal stress of $5 \mathrm{MPa}$ for test no. 21 


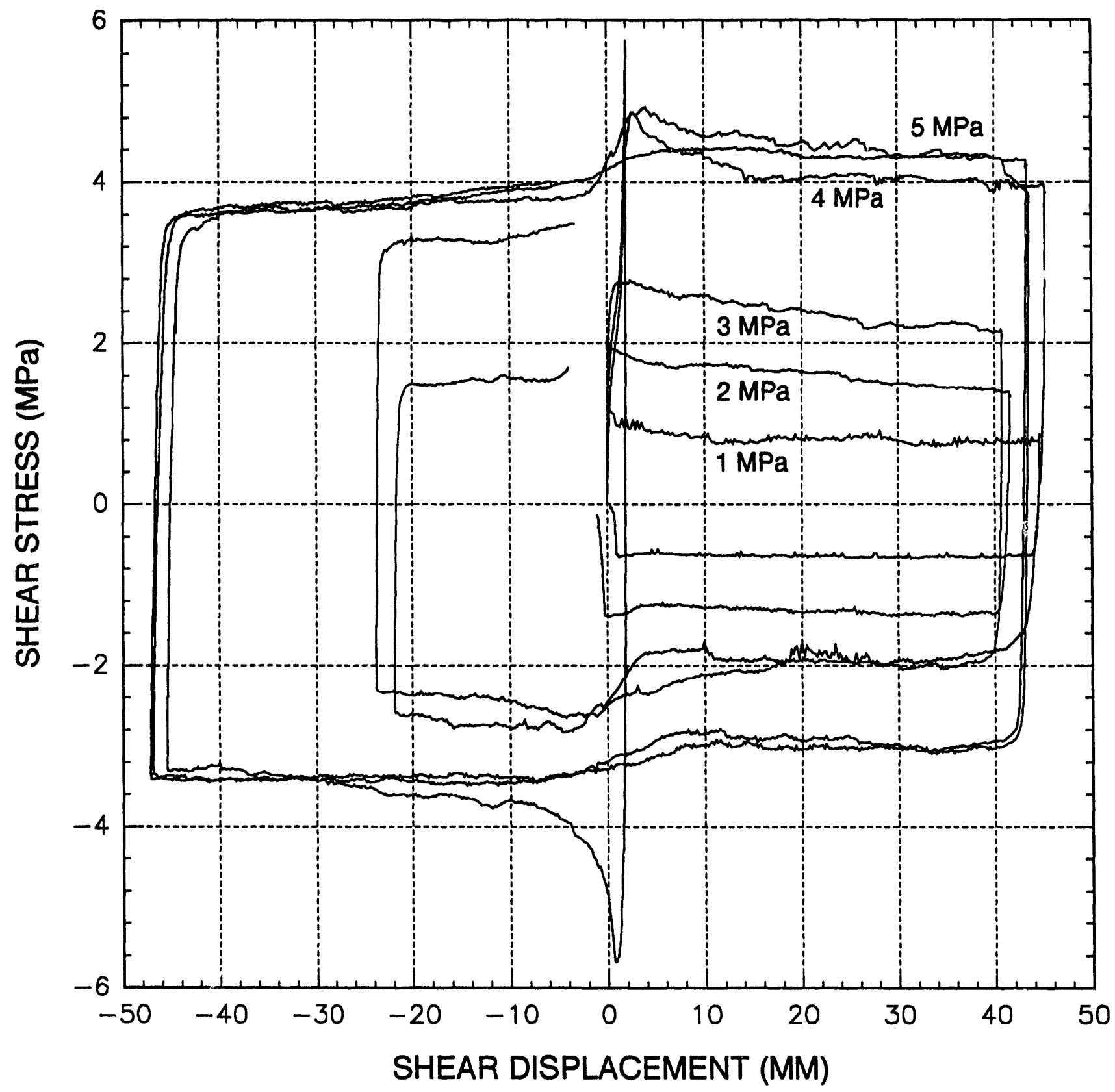

Figure A-36. Shear stress versus shear displacement response as a function of normal stress for test nos. 17 through 21 . Each curve represents the first shear cycle on one particular sample. 


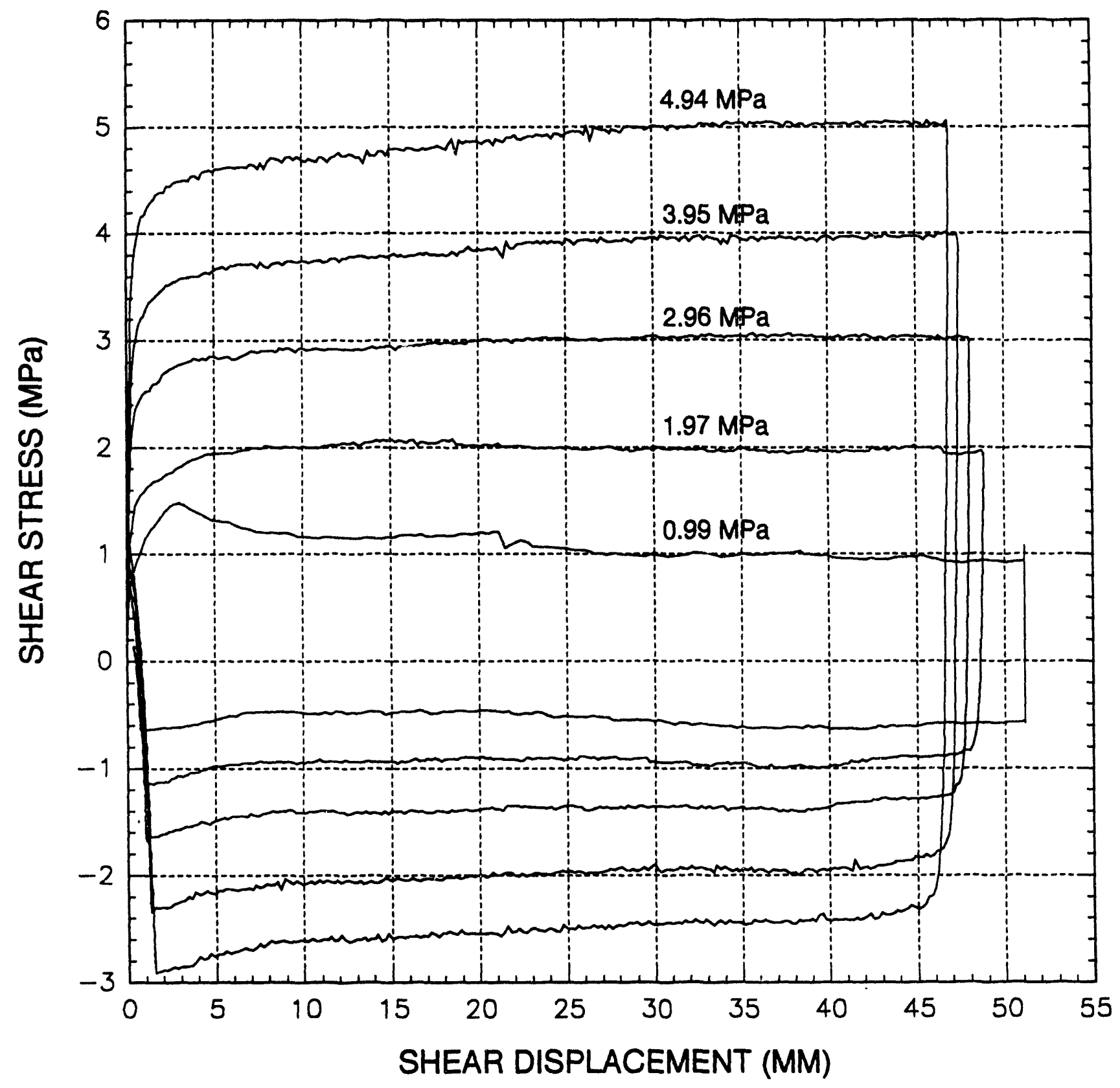

Figure A-37. Shear stress versus shear displacement response for test no. 27 under a normal stress of 5.01 MPa and saturated condition 


\section{$8 \varepsilon-\forall$}

uo!̣!puos pəłвJnjes pur вdW

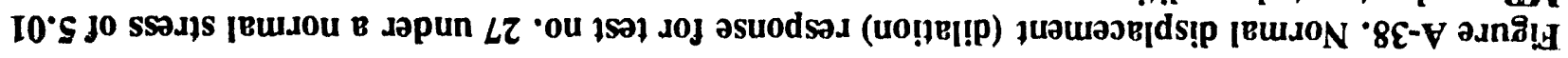

\section{(WW) $\perp N \exists W \exists O \forall 7 d S I O$ Y $\forall \exists H S$}

SG $O S \quad S D$ Ot $S E$ OE $S Z$ OZ $S L$ OL $S$ C

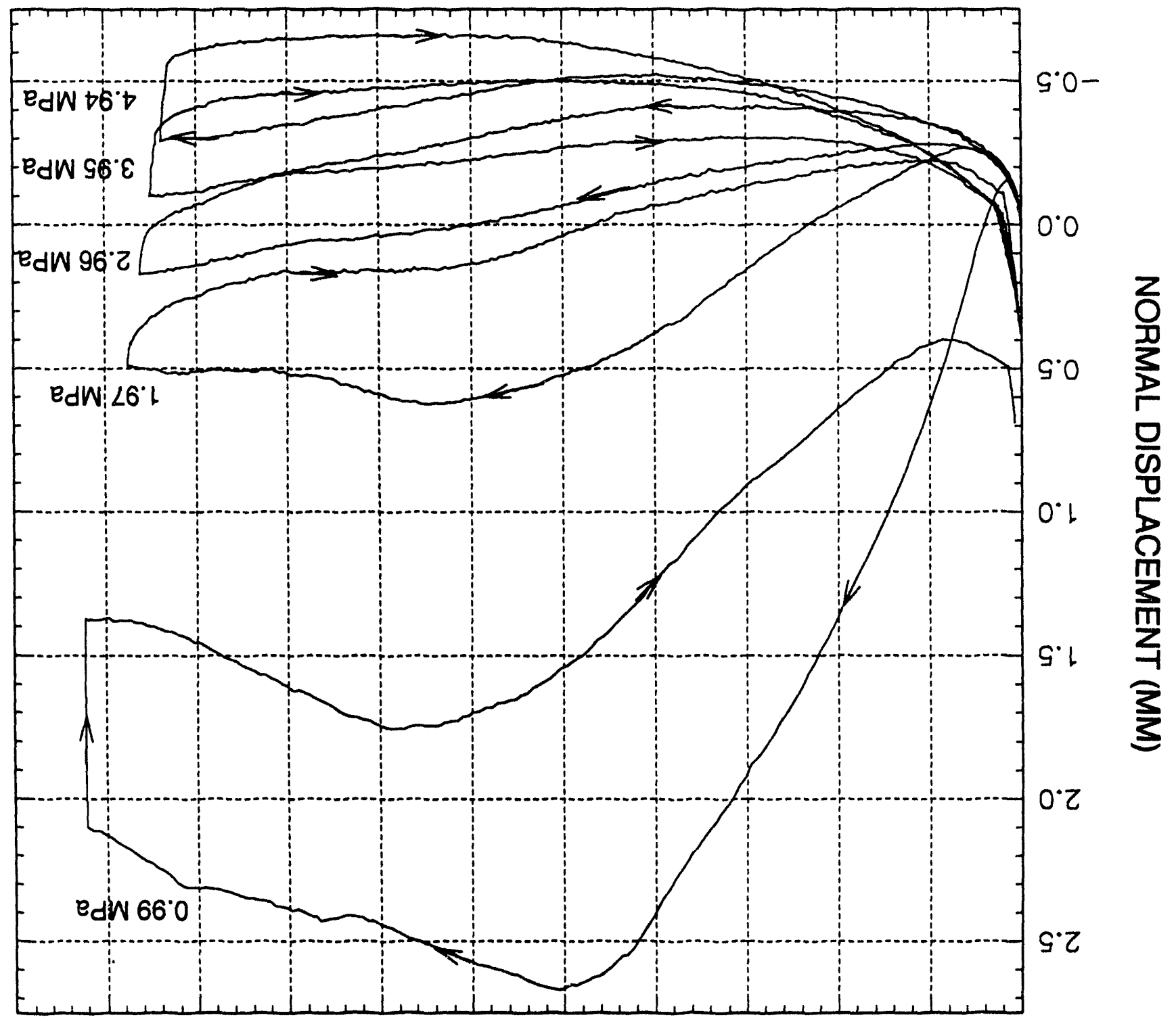




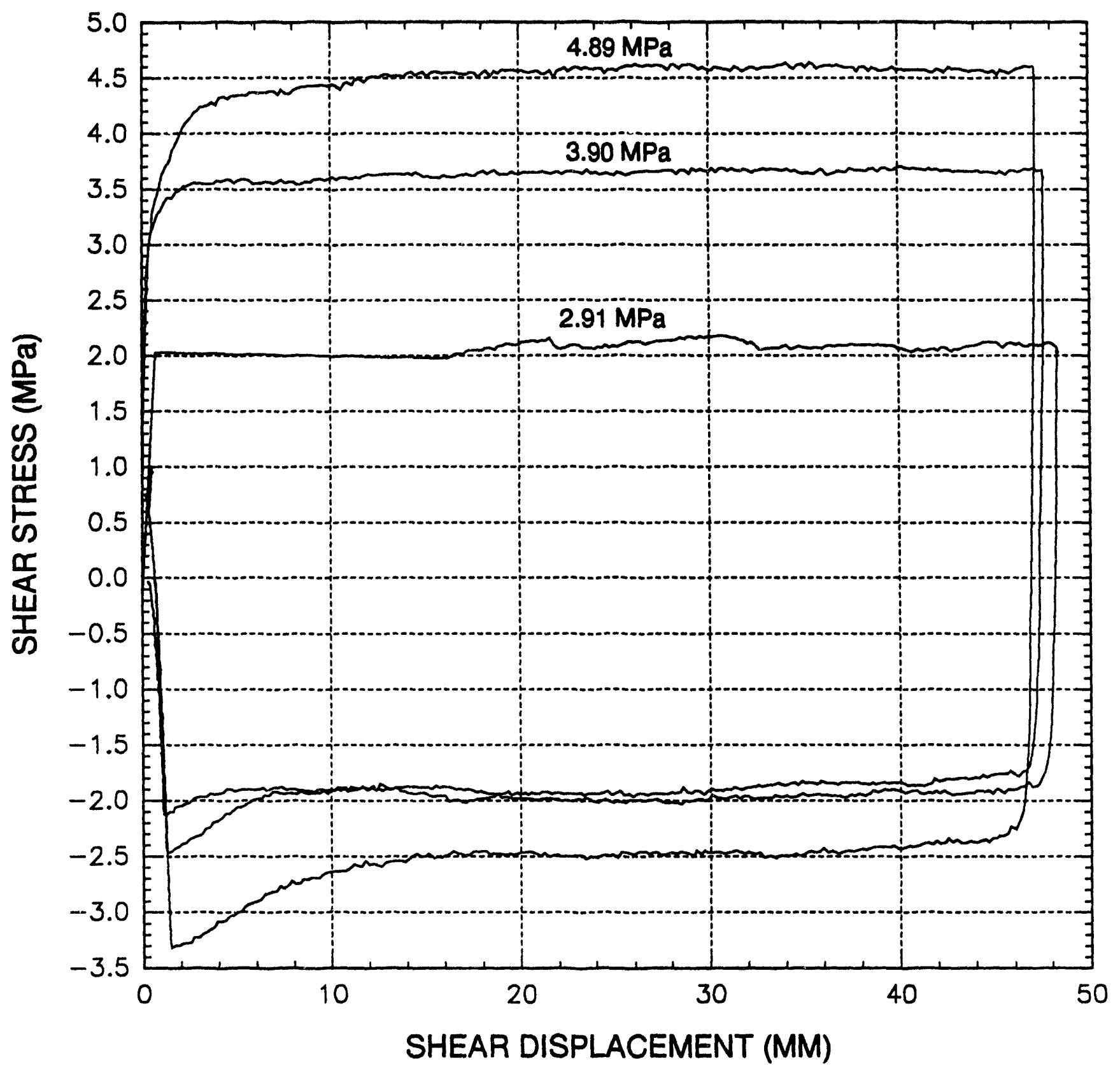

Figure A-39. Shear stress versus shear displacement response for test no. 28 as a function of normal stress under saturated condition 


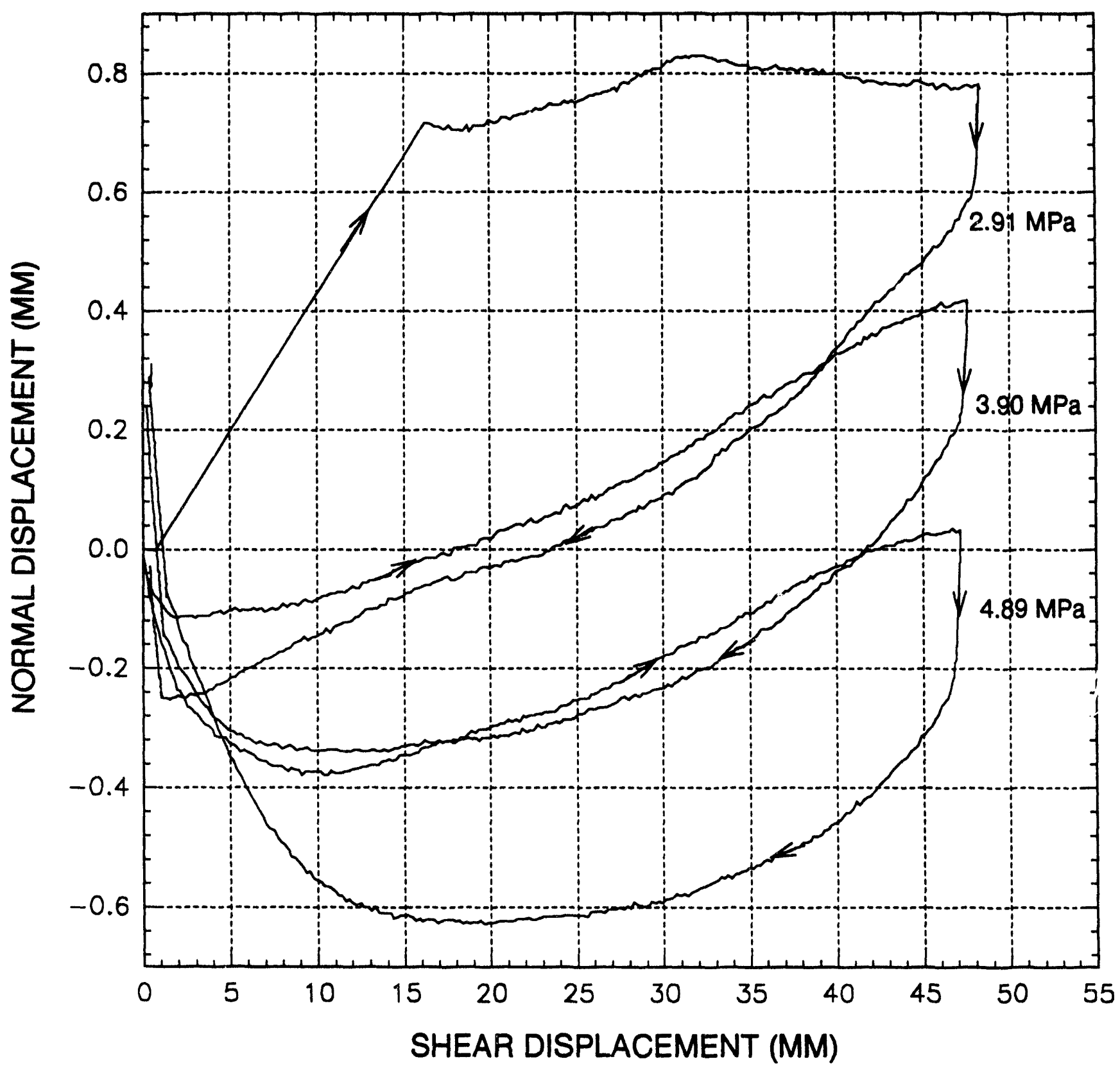

Figure A-40. Normal displacement (dilation) response for test no. 28 as a function of normal stress under saturated condition 
APPENDIX B

MEASURED AND CORRECTED REBOUND NUMBERS ON INTACT SURFACES OF TUFF ROCK 
Table B-1. Measured and corrected rebound numbers on the intact rock surfaces of the sides of specimen for test no. 5

\begin{tabular}{|c|c|c|c|c|}
\hline $\begin{array}{c}\text { No. of } \\
\text { Readings }\end{array}$ & $\begin{array}{c}\text { Measured } \\
\text { Rebound Number } \\
\text { for Top Block }\end{array}$ & $\begin{array}{c}\text { Corrected } \\
\text { Rebound Number } \\
\text { for Top Block }\end{array}$ & $\begin{array}{c}\text { Measured } \\
\text { Rebound Number } \\
\text { for Bottom Block }\end{array}$ & $\begin{array}{c}\text { Corrected } \\
\text { Rebound Number } \\
\text { for Bottom Block }\end{array}$ \\
\hline 1 & 62 & 63.70 & 64 & 65.70 \\
\hline 2 & 60 & 61.70 & 61 & 62.70 \\
\hline 3 & 60 & 61.70 & 63 & 64.70 \\
\hline 4 & 62 & 63.70 & 60 & 61.70 \\
\hline 5 & 59 & 60.75 & 61 & 62.70 \\
\hline 6 & 60 & 61.70 & 63 & 64.70 \\
\hline 7 & 56 & 57.90 & 61 & 62.70 \\
\hline 8 & 59 & 60.75 & 63 & 64.70 \\
\hline 9 & 62 & 63.70 & 63 & 64.70 \\
\hline 10 & 60 & 61.70 & 60 & 61.70 \\
\hline 11 & 59 & 60.75 & 62 & 63.70 \\
\hline 12 & 61 & 62.70 & 62 & 63.70 \\
\hline 13 & 57 & 58.85 & 60 & 61.70 \\
\hline 14 & 57 & 58.85 & 62 & 63.70 \\
\hline 15 & 61.70 & & 62.70 \\
\hline 16 & 60 & 60 & \\
\hline
\end{tabular}


Table B-2. Measured and corrected rebound numbers on the intact rock surfaces of the sides of specimen for test no. 6

\begin{tabular}{|c|c|c|c|c||}
\hline $\begin{array}{c}\text { No. of } \\
\text { Readings }\end{array}$ & $\begin{array}{c}\text { Measured } \\
\text { Rebound Number } \\
\text { for Top Block }\end{array}$ & $\begin{array}{c}\text { Corrected } \\
\text { Rebound Number } \\
\text { for Top Block }\end{array}$ & $\begin{array}{c}\text { Measured } \\
\text { Rebound Number } \\
\text { for Bottom Block }\end{array}$ & $\begin{array}{c}\text { Corrected } \\
\text { Rebound Number } \\
\text { for Bottom Block }\end{array}$ \\
\hline 1 & 60 & 61.70 & 62 & 63.70 \\
\hline 2 & 60 & 61.70 & 61 & 62.70 \\
\hline 3 & 58 & 59.80 & 61 & 62.70 \\
\hline 4 & 60 & 61.70 & 60 & 61.70 \\
\hline 5 & 61 & 62.70 & 60 & 61.70 \\
\hline 6 & 60 & 61.70 & 62 & 63.70 \\
\hline 7 & 60 & 61.70 & 62 & 63.70 \\
\hline 8 & 61 & 62.70 & 59 & 60.75 \\
\hline 9 & 61 & 62.70 & 57 & 58.85 \\
\hline 10 & 61 & 62.70 & 62 & 63.70 \\
\hline 11 & 60 & 61.70 & 63 & 64.70 \\
\hline 12 & 62 & 63.70 & 63 & 64.70 \\
\hline 13 & 61 & 62.70 & 62 & 63.70 \\
\hline 14 & 60 & 61.70 & 62 & 63.70 \\
\hline 15 & 62 & 63.70 & 61 & 62.70 \\
\hline 16 & 63 & 64.70 & 62 & 63.70 \\
\hline
\end{tabular}



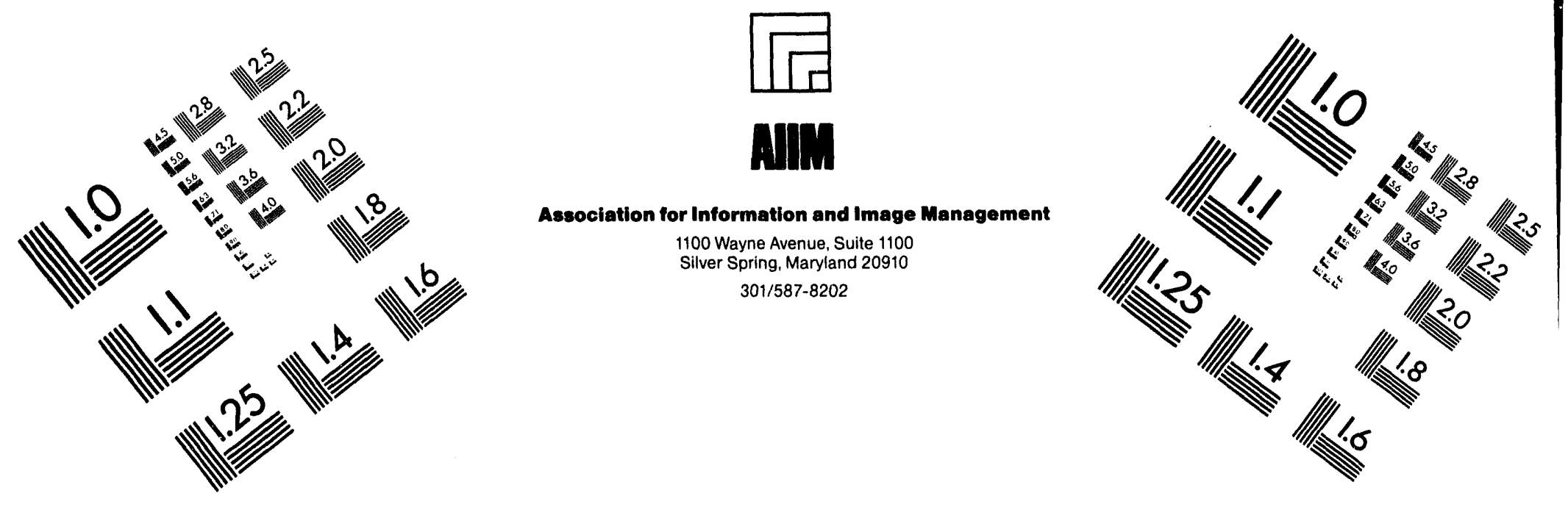

\section{Centimeter}

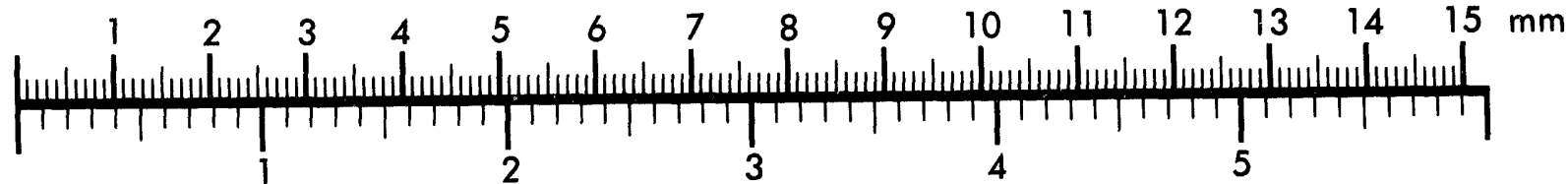

Inches
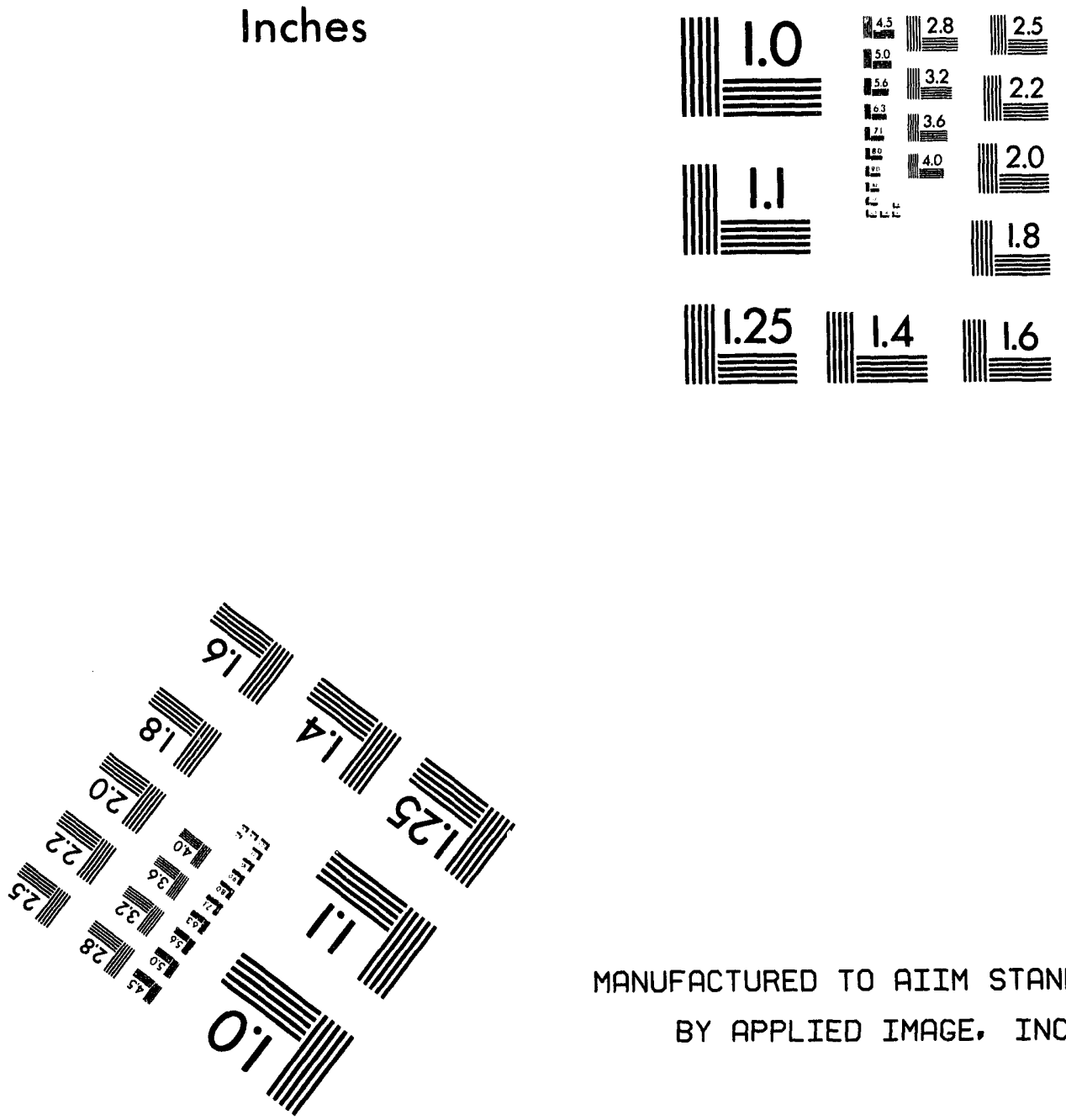

MANUFACTURED TO AIIM STANDARDS

BY APPLIED IMAGE. INC.

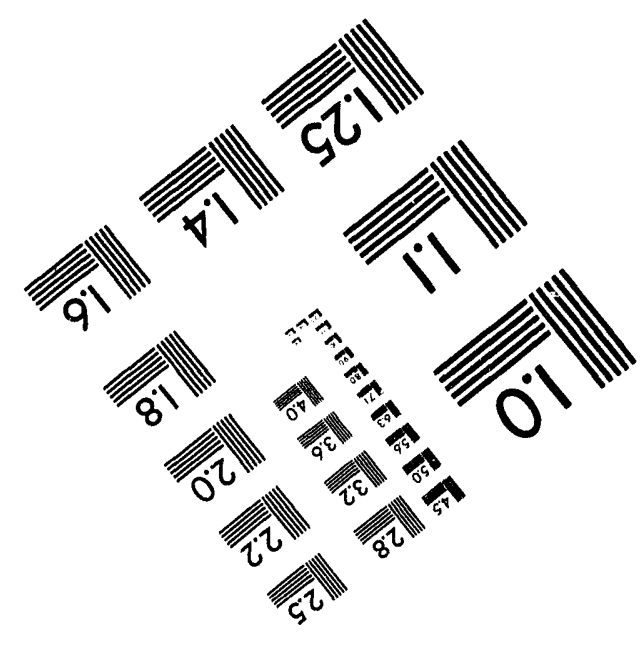



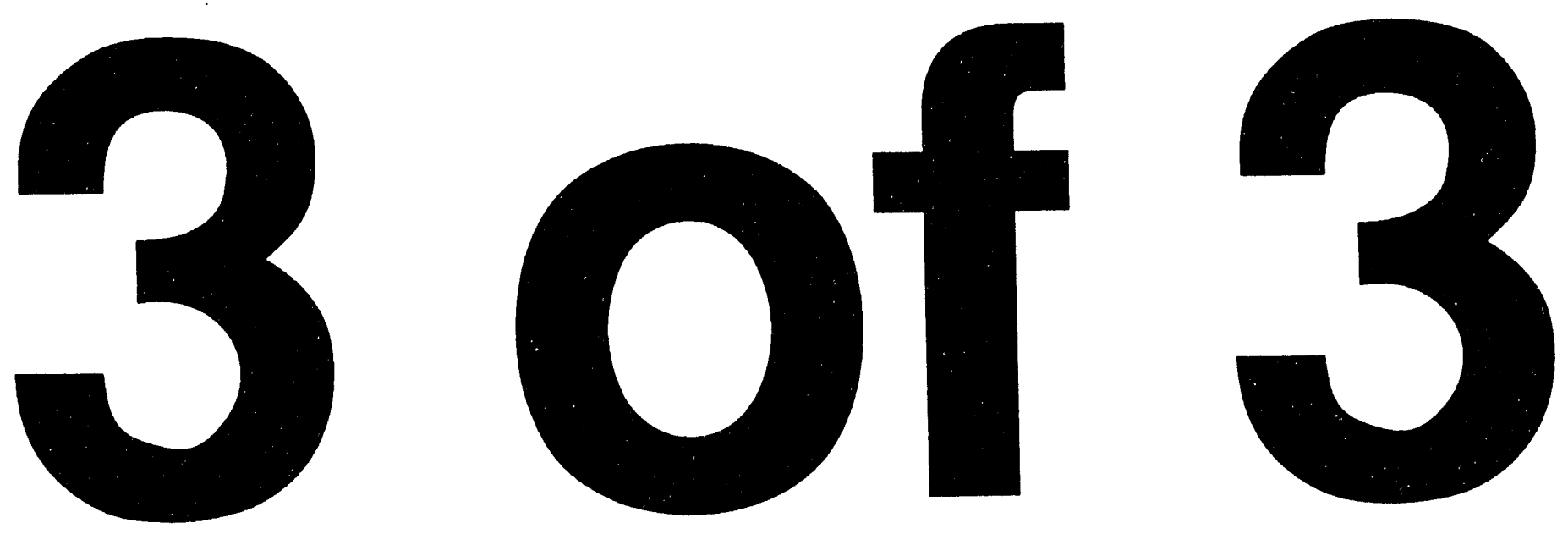
Table B-3. Measured and corrected rebound numbers on the intact rock surfaces of the sides of specimen for test no. 7

\begin{tabular}{|c|c|c|c|c|}
\hline $\begin{array}{c}\text { No. of } \\
\text { Readings }\end{array}$ & $\begin{array}{c}\text { Measured } \\
\text { Rebound Number } \\
\text { for Top Block }\end{array}$ & $\begin{array}{c}\text { Corrected } \\
\text { Rebound Number } \\
\text { for Top Block }\end{array}$ & $\begin{array}{c}\text { Measured } \\
\text { Rebound Number } \\
\text { for Bottom Block }\end{array}$ & $\begin{array}{c}\text { Corrected } \\
\text { Rebound Number } \\
\text { for Bottom Block }\end{array}$ \\
\hline \hline 1 & 60 & 61.70 & 62 & 63.70 \\
\hline 2 & 61 & 62.70 & 62 & 63.70 \\
\hline 3 & 62 & 63.70 & 62 & 63.70 \\
\hline 4 & 60 & 61.70 & 61 & 62.70 \\
\hline 5 & 62 & 63.70 & 60 & 61.70 \\
\hline 6 & 59 & 60.75 & 60 & 61.70 \\
\hline 7 & 60 & 61.70 & 58 & 59.80 \\
\hline 8 & 60 & 61.70 & 59 & 60.75 \\
\hline 9 & 64 & 65.70 & 62 & 63.70 \\
\hline 10 & 62 & 63.70 & 60 & 61.70 \\
\hline 11 & 61 & 62.70 & 60 & 61.70 \\
\hline 12 & 61 & 62.70 & 58 & 59.80 \\
\hline 13 & 60 & 61.70 & 58 & 59.80 \\
\hline 14 & 62 & 63.70 & 59 & 60.75 \\
\hline 15 & 60 & 61.70 & 58 & 59.80 \\
\hline 16 & 62 & & & 58.85 \\
\hline
\end{tabular}


Table B-4. Measured and corrected rebound numbers on the intact rock surfaces of the sides of specimen for test no. 9

\begin{tabular}{|c|c|c|c|c||}
\hline $\begin{array}{c}\text { No. of } \\
\text { Readings }\end{array}$ & $\begin{array}{c}\text { Measured } \\
\text { Rebound Number } \\
\text { for Top Block }\end{array}$ & $\begin{array}{c}\text { Corrected } \\
\text { Rebound Number } \\
\text { for Top Block }\end{array}$ & $\begin{array}{c}\text { Measured } \\
\text { Rebound Number } \\
\text { for Bottom Block }\end{array}$ & $\begin{array}{c}\text { Corrected } \\
\text { Rebound Number } \\
\text { for Bottom Block }\end{array}$ \\
\hline \hline 1 & 61 & 62.70 & 61 & 62.70 \\
\hline 2 & 60 & 61.70 & 60 & 61.70 \\
\hline 3 & 61 & 62.70 & 57 & 58.85 \\
\hline 4 & 62 & 63.70 & 62 & 63.70 \\
\hline 5 & 62 & 63.70 & 62 & 63.70 \\
\hline 6 & 61 & 62.70 & 63 & 64.70 \\
\hline 7 & 60 & 61.70 & 62 & 63.70 \\
\hline 8 & 61 & 62.70 & 61 & 62.70 \\
\hline 9 & 61 & 62.70 & 63 & 64.70 \\
\hline 10 & 61 & 62.70 & 61 & 62.70 \\
\hline 11 & 60 & 61.70 & 62 & 63.70 \\
\hline 12 & 62 & 63.70 & 63 & 64.70 \\
\hline 13 & 62 & 63.70 & 58 & 59.80 \\
\hline 14 & 60 & 61.70 & 69 & 60.75 \\
\hline 15 & 60 & 63.70 & 63.70 \\
\hline 16 & 61.70 & & 63 & \\
\hline
\end{tabular}


Table B-5. Measured and corrected rebound numbers on the intact rock surfaces of the sides of specimen for test no. 10

\begin{tabular}{|c|c|c|c|c|}
\hline $\begin{array}{c}\text { No. of } \\
\text { Readings }\end{array}$ & $\begin{array}{c}\text { Measured } \\
\text { Rebound Number } \\
\text { for Top Block }\end{array}$ & $\begin{array}{c}\text { Corrected } \\
\text { Rebound Number } \\
\text { for Top Block }\end{array}$ & $\begin{array}{c}\text { Measured } \\
\text { Rebound Number } \\
\text { for Bottom Block }\end{array}$ & $\begin{array}{c}\text { Corrected } \\
\text { Rebound Number } \\
\text { for Bottom Block }\end{array}$ \\
\hline 1 & 58 & 59.80 & 52 & 54.10 \\
\hline 2 & 60 & 61.70 & 62 & 63.70 \\
\hline 3 & 60 & 61.70 & 63 & 64.70 \\
\hline 4 & 59 & 60.75 & 60 & 61.70 \\
\hline 5 & 61 & 62.70 & 59 & 60.75 \\
\hline 6 & 61 & 62.70 & 60 & 61.70 \\
\hline 7 & 62 & 63.70 & 58 & 59.80 \\
\hline 8 & 57 & 58.85 & 62 & 63.70 \\
\hline 9 & 60 & 61.70 & 61 & 62.70 \\
\hline 10 & 59 & 60.75 & 62 & 63.70 \\
\hline 11 & 57 & 58.85 & 56 & 57.90 \\
\hline 12 & 60 & 61.70 & 59 & 60.75 \\
\hline 13 & 61 & 63.70 & 52 & 54.10 \\
\hline 14 & 60 & 62.70 & 54 & 56.00 \\
\hline 15 & 61.70 & 44 & 46.50 \\
\hline 16 & 61.70 & & 51.25 \\
\hline
\end{tabular}


Table B-6. Measured and corrected rebound numbers on the intact rock surfaces of the sides of specimen for test no. 11

\begin{tabular}{|c|c|c|c|c|}
\hline $\begin{array}{c}\text { No. of } \\
\text { Readings }\end{array}$ & $\begin{array}{c}\text { Measured } \\
\text { Rebound Number } \\
\text { for Top Block }\end{array}$ & $\begin{array}{c}\text { Corrected } \\
\text { Rebound Number } \\
\text { for Top Block }\end{array}$ & $\begin{array}{c}\text { Measured } \\
\text { Rebound Number } \\
\text { for Bottom Block }\end{array}$ & $\begin{array}{c}\text { Corrected } \\
\text { Rebound Number } \\
\text { for Bottom Block }\end{array}$ \\
\hline 1 & 60 & 61.70 & 61 & 62.70 \\
\hline 2 & 59 & 60.75 & 61 & 62.70 \\
\hline 3 & 60 & 61.70 & 62 & 63.70 \\
\hline 4 & 60 & 61.70 & 62 & 63.70 \\
\hline 5 & 61 & 62.70 & 59 & 60.75 \\
\hline 6 & 61 & 62.70 & 61 & 62.70 \\
\hline 7 & 61 & 62.70 & 61 & 62.70 \\
\hline 8 & 60 & 61.70 & 57 & 58.85 \\
\hline 9 & 63 & 64.70 & 63 & 64.70 \\
\hline 10 & 58 & 59.80 & 63 & 64.70 \\
\hline 11 & 62 & 63.70 & 62 & 63.70 \\
\hline 12 & 61 & 62.70 & 62 & 63.70 \\
\hline 13 & 61 & 62.70 & 61 & 62.70 \\
\hline 14 & 56 & 57.90 & 62.70 & 63.70 \\
\hline 15 & 61 & 67.70 & 61.70 \\
\hline 16 & 66 & & 62.70 \\
\hline
\end{tabular}


Table B-7. Measured and corrected rebound numbers on the intact rock surfaces of the sides of specimen for test no. 12

\begin{tabular}{|c|c|c|c|c|}
\hline $\begin{array}{c}\text { No. of } \\
\text { Readings }\end{array}$ & $\begin{array}{c}\text { Measured } \\
\text { Rebound Number } \\
\text { for Top Block }\end{array}$ & $\begin{array}{c}\text { Corrected } \\
\text { Rebound Number } \\
\text { for Top Block }\end{array}$ & $\begin{array}{c}\text { Measured } \\
\text { Rebound Number } \\
\text { for Bottom Block }\end{array}$ & $\begin{array}{c}\text { Corrected } \\
\text { Rebound Number } \\
\text { for Bottom Block }\end{array}$ \\
\hline \hline 1 & 58 & 59.80 & 62 & 63.70 \\
\hline 2 & 52 & 54.10 & 60 & 61.70 \\
\hline 3 & 59 & 60.75 & 62 & 63.70 \\
\hline 4 & 60 & 61.70 & 63 & 64.70 \\
\hline 5 & 51 & 53.15 & 62 & 63.70 \\
\hline 6 & 49 & 51.25 & 61 & 62.70 \\
\hline 7 & 50 & 52.20 & 62 & 63.70 \\
\hline 8 & 51 & 53.15 & 61 & 62.70 \\
\hline 9 & 56 & 57.90 & 62 & 63.70 \\
\hline 10 & 62 & 63.70 & 63 & 64.70 \\
\hline 11 & 62 & 63.70 & 63 & 64.70 \\
\hline 12 & 54 & 56.00 & 63 & 64.70 \\
\hline 13 & 61 & 62.70 & 60 & 61.70 \\
\hline 14 & 60 & 61.70 & 63 & 64.70 \\
\hline 15 & 61.70 & 63 & 63.70 \\
\hline 16 & 60 & & 63.70 \\
\hline
\end{tabular}


Table B-8. Measured and corrected rebound numbers on the intact rock surfaces of the sides of specimen for test no. 14

\begin{tabular}{|c|c|c|c|c|}
\hline $\begin{array}{l}\text { No. of } \\
\text { Readings }\end{array}$ & $\begin{array}{c}\text { Measured } \\
\text { Rebound Number } \\
\text { for Top Block }\end{array}$ & $\begin{array}{c}\text { Corrected } \\
\text { Rebound Number } \\
\text { for Top Block }\end{array}$ & $\begin{array}{l}\quad \text { Measured } \\
\text { Rebound Number } \\
\text { for Bottom Block }\end{array}$ & $\begin{array}{l}\text { Corrected } \\
\text { Rebound Number } \\
\text { for Bottom Block }\end{array}$ \\
\hline 1 & 64 & 65.70 & 60 & 61.70 \\
\hline 2 & 63 & 64.70 & 59 & 60.75 \\
\hline 3 & 62 & 63.70 & 60 & 61.70 \\
\hline 4 & 62 & 63.70 & 60 & 61.70 \\
\hline 5 & 59 & 60.75 & 60 & 61.70 \\
\hline 6 & 60 & 61.70 & 64 & 65.70 \\
\hline 7 & 60 & 61.70 & 63 & 64.70 \\
\hline 8 & 62 & 63.70 & 62 & 63.70 \\
\hline 9 & 63 & 64.70 & 62 & 63.70 \\
\hline 10 & 62 & 63.70 & 64 & 65.70 \\
\hline 11 & 60 & 61.70 & 60 & 61.70 \\
\hline 12 & 60 & 61.70 & 58 & 59.80 \\
\hline 13 & 64 & 65.70 & 62 & 63.70 \\
\hline 14 & 62 & 63.70 & 64 & 65.70 \\
\hline 15 & 60 & 61.70 & 59 & 60.75 \\
\hline 16 & 63 & 64.70 & 62 & 63.70 \\
\hline
\end{tabular}


Table B-9. Measured and corrected rebound numbers on the intact rock surfaces of the sides of specimen for test no. 15

\begin{tabular}{|c|c|c|c|c|}
\hline $\begin{array}{c}\text { No. of } \\
\text { Readings }\end{array}$ & $\begin{array}{c}\text { Measured } \\
\text { Rebound Number } \\
\text { for Top Block }\end{array}$ & $\begin{array}{c}\text { Corrected } \\
\text { Rebound Number } \\
\text { for Top Block }\end{array}$ & $\begin{array}{c}\text { Measured } \\
\text { Rebound Number } \\
\text { for Bottom Block }\end{array}$ & $\begin{array}{c}\text { Corrected } \\
\text { Rebound Number } \\
\text { for Bottom Block }\end{array}$ \\
\hline \hline 1 & 61 & 62.70 & 62 & 63.70 \\
\hline 2 & 60 & 61.70 & 60 & 61.70 \\
\hline 3 & 58 & 59.80 & 60 & 61.70 \\
\hline 4 & 60 & 61.70 & 60 & 61.70 \\
\hline 5 & 58 & 59.80 & 61 & 62.70 \\
\hline 6 & 59 & 60.75 & 60 & 61.70 \\
\hline 7 & 58 & 59.80 & 59 & 60.75 \\
\hline 8 & 60 & 61.70 & 60 & 61.70 \\
\hline 9 & 61 & 62.70 & 62 & 63.70 \\
\hline 10 & 59 & 60.75 & 59 & 60.75 \\
\hline 11 & 60 & 61.70 & 60 & 61.70 \\
\hline 12 & 60 & 61.70 & 60 & 61.70 \\
\hline 13 & 62 & 63.70 & 59 & 60.75 \\
\hline 14 & 59 & 60.75 & 60 & 61.70 \\
\hline 15 & 58 & 59.80 & 60 & 61.70 \\
\hline 16 & 58 & & 62.70 \\
\hline
\end{tabular}


Table B-10. Measured and corrected rebound numbers on the intact rock surfaces of the sides of specimen for test no. 17

\begin{tabular}{|c|c|c|c|c||}
\hline $\begin{array}{c}\text { No. of } \\
\text { Readings }\end{array}$ & $\begin{array}{c}\text { Measured } \\
\text { Rebound Number } \\
\text { for Top Block }\end{array}$ & $\begin{array}{c}\text { Corrected } \\
\text { Rebound Number } \\
\text { for Top Block }\end{array}$ & $\begin{array}{c}\text { Measured } \\
\text { Rebound Number } \\
\text { for Bottom Block }\end{array}$ & $\begin{array}{c}\text { Corrected } \\
\text { Rebound Number } \\
\text { for Bottom Block }\end{array}$ \\
\hline 1 & 56 & 57.90 & 60 & 61.70 \\
\hline 2 & 58 & 59.80 & 62 & 63.70 \\
\hline 3 & 58 & 59.80 & 61 & 62.70 \\
\hline 4 & 58 & 59.80 & 62 & 63.70 \\
\hline 5 & 59 & 60.75 & 60 & 61.70 \\
\hline 6 & 58 & 59.80 & 56 & 57.90 \\
\hline 7 & 61 & 62.70 & 61 & 62.70 \\
\hline 8 & 63 & 64.70 & 60 & 61.70 \\
\hline 9 & 60 & 61.70 & 60 & 61.70 \\
\hline 10 & 58 & 59.80 & 63 & 64.70 \\
\hline 11 & 56 & 57.90 & 62 & 63.70 \\
\hline 12 & 59 & 60.75 & 61 & 62.70 \\
\hline 13 & 60 & 61.70 & 62 & 63.70 \\
\hline 14 & 60 & 61.70 & 62 & 63.70 \\
\hline 15 & 58 & 62.70 & 61.70 \\
\hline 16 & 50 & & 62 & \\
\hline
\end{tabular}


Table B-11. Measured and corrected rebound numbers on the intact rock surfaces of the sides of specimen for test no. 18

\begin{tabular}{|c|c|c|c|c|}
\hline $\begin{array}{c}\text { No. of } \\
\text { Readings }\end{array}$ & $\begin{array}{c}\text { Measured } \\
\text { Rebound Number } \\
\text { for Top Block }\end{array}$ & $\begin{array}{c}\text { Corrected } \\
\text { Rebound Number } \\
\text { for Top Block }\end{array}$ & $\begin{array}{c}\text { Measured } \\
\text { Rebound Number } \\
\text { for Bottom Block }\end{array}$ & $\begin{array}{c}\text { Corrected } \\
\text { Rebound Number } \\
\text { for Bottom Block }\end{array}$ \\
\hline 1 & 59 & 60.75 & 61 & 62.70 \\
\hline 2 & 60 & 61.70 & 62 & 63.70 \\
\hline 3 & 60 & 61.70 & 61 & 62.70 \\
\hline 4 & 61 & 62.70 & 62 & 63.70 \\
\hline 5 & 58 & 59.80 & 62 & 63.70 \\
\hline 6 & 59 & 60.75 & 60 & 61.70 \\
\hline 7 & 59 & 60.75 & 62 & 63.70 \\
\hline 8 & 60 & 61.70 & 61 & 62.70 \\
\hline 9 & 60 & 61.70 & 60 & 61.70 \\
\hline 10 & 60 & 61.70 & 60 & 61.70 \\
\hline 11 & 60 & 61.70 & 59 & 60.75 \\
\hline 12 & 59 & 60.75 & 62 & 63.70 \\
\hline 13 & 60 & 61.70 & 60 & 61.70 \\
\hline 14 & 59 & 60.75 & 61 & 62.70 \\
\hline 15 & 59 & 60.75 & 61 & 62.70 \\
\hline 16 & 59 & 60.75 & 60 \\
\hline
\end{tabular}


Table B-12. Measured and corrected rebound numbers on the intact rock surfaces of the sides of specimen for test no. 19

\begin{tabular}{|c|c|c|c|c|}
\hline $\begin{array}{c}\text { No. of } \\
\text { Readings }\end{array}$ & $\begin{array}{c}\text { Measured } \\
\text { Rebound Number } \\
\text { for Top Block }\end{array}$ & $\begin{array}{c}\text { Corrected } \\
\text { Rebound Number } \\
\text { for Top Block }\end{array}$ & $\begin{array}{c}\text { Measured } \\
\text { Rebound Number } \\
\text { for Bottom Block }\end{array}$ & $\begin{array}{c}\text { Corrected } \\
\text { Rebound Number } \\
\text { for Bottom Block }\end{array}$ \\
\hline 1 & 60 & 61.70 & 60 & 61.70 \\
\hline 2 & 60 & 61.70 & 62 & 63.70 \\
\hline 3 & 60 & 61.70 & 62 & 63.70 \\
\hline 4 & 62 & 63.70 & 60 & 61.70 \\
\hline 5 & 62 & 63.70 & 60 & 61.70 \\
\hline 6 & 60 & 61.70 & 60 & 61.70 \\
\hline 7 & 60 & 61.70 & 58 & 59.80 \\
\hline 8 & 60 & 61.70 & 59 & 60.75 \\
\hline 9 & 60 & 61.70 & 60 & 61.70 \\
\hline 10 & 61 & 62.70 & 63 & 64.70 \\
\hline 11 & 61 & 62.70 & 60 & 61.70 \\
\hline 12 & 62 & 63.70 & 60 & 61.70 \\
\hline 13 & 60 & 61.70 & 60 & 61.70 \\
\hline 14 & 59 & 60.75 & 60 & 61.70 \\
\hline 15 & 61 & 62.70 & 69 & 62.70 \\
\hline 16 & 62 & & & 60.75 \\
\hline
\end{tabular}


Table B-13. Measured and corrected rebound numbers on the intact rock surfaces of the sides of specimen for test no. 20

\begin{tabular}{|c|c|c|c|c|}
\hline $\begin{array}{c}\text { No. of } \\
\text { Readings }\end{array}$ & $\begin{array}{c}\text { Measured } \\
\text { Rebound Number } \\
\text { for Top Block }\end{array}$ & $\begin{array}{c}\text { Corrected } \\
\text { Rebound Number } \\
\text { for Top Block }\end{array}$ & $\begin{array}{c}\text { Measured } \\
\text { Rebound Number } \\
\text { for Bottom Block }\end{array}$ & $\begin{array}{c}\text { Corrected } \\
\text { Rebound Number } \\
\text { for Bottom Block }\end{array}$ \\
\hline \hline 1 & 62 & 63.70 & 61 & 62.70 \\
\hline 2 & 62 & 63.70 & 60 & 61.70 \\
\hline 3 & 60 & 61.70 & 61 & 62.70 \\
\hline 4 & 60 & 61.70 & 58 & 59.80 \\
\hline 5 & 59 & 60.75 & 62 & 63.70 \\
\hline 6 & 58 & 59.80 & 60 & 61.70 \\
\hline 7 & 57 & 58.85 & 61 & 62.70 \\
\hline 8 & 58 & 59.80 & 63 & 64.70 \\
\hline 9 & 61 & 62.70 & 60 & 61.70 \\
\hline 10 & 60 & 61.70 & 59 & 60.75 \\
\hline 11 & 62 & 63.70 & 59 & 60.75 \\
\hline 12 & 62 & 63.70 & 60 & 61.70 \\
\hline 13 & 58 & 59.80 & 62 & 63.70 \\
\hline 14 & 58 & 59.80 & 61 & 62.70 \\
\hline 15 & 57 & 58.85 & 62 & 63.70 \\
\hline 16 & 56 & 50 & 61.70 \\
\hline
\end{tabular}


Tabie B-14. Measured and corrected rebound numbers on the intact rock surfaces of the sides of specimen for test no. 21

\begin{tabular}{|c|c|c|c|c|}
\hline $\begin{array}{c}\text { No. of } \\
\text { Readings }\end{array}$ & $\begin{array}{c}\text { Measured } \\
\text { Rebound Number } \\
\text { for Top Block }\end{array}$ & $\begin{array}{c}\text { Corrected } \\
\text { Rebound Number } \\
\text { for Top Block }\end{array}$ & $\begin{array}{c}\text { Measured } \\
\text { Rebound Number } \\
\text { for Bottom Block }\end{array}$ & $\begin{array}{c}\text { Corrected } \\
\text { Rebound Number } \\
\text { for Bottom Block }\end{array}$ \\
\hline \hline 1 & 58 & 59.80 & 58 & 59.80 \\
\hline 2 & 60 & 61.70 & 61 & 62.70 \\
\hline 3 & 61 & 62.70 & 60 & 61.70 \\
\hline 4 & 60 & 61.70 & 58 & 59.80 \\
\hline 5 & 59 & 60.75 & 59 & 60.75 \\
\hline 6 & 60 & 61.70 & 60 & 61.70 \\
\hline 7 & 59 & 60.75 & 61 & 62.70 \\
\hline 8 & 60 & 61.70 & 62 & 63.70 \\
\hline 9 & 58 & 59.80 & 61 & 62.70 \\
\hline 10 & 58 & 59.80 & 60 & 61.70 \\
\hline 11 & 60 & 61.70 & 62 & 63.70 \\
\hline 12 & 62 & 63.70 & 61 & 62.70 \\
\hline 13 & 56 & 57.90 & 58 & 59.80 \\
\hline 14 & 60 & 61.70 & 60 & 61.70 \\
\hline 15 & 60 & 61.70 & 58.85 \\
\hline 16 & 61 & & 60 & 6 \\
\hline
\end{tabular}


Table B-15. Measured and corrected rebound numbers on the intact rock surfaces of the sides of specimen for test no. 22

\begin{tabular}{|c|c|c|c|c|}
\hline $\begin{array}{c}\text { No. of } \\
\text { Readings }\end{array}$ & $\begin{array}{c}\text { Measured } \\
\text { Rebound Number } \\
\text { for Top Block }\end{array}$ & $\begin{array}{c}\text { Corrected } \\
\text { Rebound Number } \\
\text { for Top Block }\end{array}$ & $\begin{array}{c}\text { Measured } \\
\text { Rebound Number } \\
\text { for Bottom Block }\end{array}$ & $\begin{array}{c}\text { Corrected } \\
\text { Rebound Number } \\
\text { for Bottom Block }\end{array}$ \\
\hline \hline 1 & 58 & 59.80 & 60 & 61.70 \\
\hline 2 & 58 & 59.80 & 60 & 61.70 \\
\hline 3 & 61 & 62.70 & 60 & 61.70 \\
\hline 4 & 57 & 58.85 & 55 & 56.95 \\
\hline 5 & 58 & 59.80 & 58 & 59.80 \\
\hline 6 & 59 & 60.75 & 61 & 62.70 \\
\hline 7 & 60 & 61.70 & 61 & 62.70 \\
\hline 8 & 56 & 57.90 & 58 & 59.80 \\
\hline 9 & 57 & 58.85 & 57 & 58.85 \\
\hline 10 & 61 & 62.70 & 59 & 60.75 \\
\hline 11 & 59 & 60.75 & 59 & 60.75 \\
\hline 12 & 58 & 59.80 & 58 & 59.80 \\
\hline 13 & 53 & 55.05 & 60 & 61.70 \\
\hline 14 & 58 & 59.80 & 59 & 68.70 \\
\hline 15 & 59 & 60.75 & 59.75 \\
\hline 16 & 59 & & 50.75 \\
\hline
\end{tabular}


Table B-16. Measured and corrected rebound numbers on the intact rock surfaces of the sides of specimen for test no. 23

\begin{tabular}{|c|c|c|c|c|}
\hline $\begin{array}{c}\text { No. of } \\
\text { Readings }\end{array}$ & $\begin{array}{c}\text { Measured } \\
\text { Rebound Number } \\
\text { for Top Block }\end{array}$ & $\begin{array}{c}\text { Corrected } \\
\text { Rebound Number } \\
\text { for Top Block }\end{array}$ & $\begin{array}{c}\text { Measured } \\
\text { Rebound Number } \\
\text { for Bottom Block }\end{array}$ & $\begin{array}{c}\text { Corrected } \\
\text { Rebound Number } \\
\text { for Bottom Block }\end{array}$ \\
\hline 1 & 60 & 61.70 & 60 & 61.70 \\
\hline 2 & 62 & 63.70 & 59 & 60.75 \\
\hline 3 & 63 & 64.70 & 56 & 57.90 \\
\hline 4 & 59 & 60.75 & 60 & 61.70 \\
\hline 5 & 62 & 63.70 & 61 & 62.70 \\
\hline 6 & 62 & 63.70 & 65 & 66.70 \\
\hline 7 & 60 & 61.70 & 63 & 64.70 \\
\hline 8 & 58 & 59.80 & 63 & 64.70 \\
\hline 9 & 59 & 60.75 & 61 & 62.70 \\
\hline 10 & 60 & 61.70 & 61 & 62.70 \\
\hline 11 & 60 & 61.70 & 61 & 62.70 \\
\hline 12 & 62 & 63.70 & 61 & 62.70 \\
\hline 13 & 60 & 61.70 & 62 & 63.70 \\
\hline 14 & 63 & 64.70 & 62 & 63.70 \\
\hline 15 & 62.70 & 62 & 63.70 \\
\hline 16 & 61 & 63.70 \\
\hline
\end{tabular}


Table B-17. Measured and corrected rebound numbers on the intact rock surfaces of the sides of specimen for test no. 24

\begin{tabular}{|c|c|c|c|c|}
\hline $\begin{array}{c}\text { No. of } \\
\text { Readings }\end{array}$ & $\begin{array}{c}\text { Measured } \\
\text { Rebound Number } \\
\text { for Top Block }\end{array}$ & $\begin{array}{c}\text { Corrected } \\
\text { Rebound Number } \\
\text { for Top Block }\end{array}$ & $\begin{array}{c}\text { Measured } \\
\text { Rebound Number } \\
\text { for Bottom Block }\end{array}$ & $\begin{array}{c}\text { Corrected } \\
\text { Rebound Number } \\
\text { for Bottom Block }\end{array}$ \\
\hline \hline 1 & 57 & 58.85 & 60 & 61.70 \\
\hline 2 & 62 & 63.70 & 61 & 62.70 \\
\hline 3 & 61 & 62.70 & 61 & 62.70 \\
\hline 4 & 58 & 59.80 & 56 & 57.90 \\
\hline 5 & 61 & 62.70 & 52 & 54.10 \\
\hline 6 & 61 & 62.70 & 57 & 58.85 \\
\hline 7 & 61 & 62.70 & 56 & 57.90 \\
\hline 8 & 58 & 59.80 & 56 & 57.90 \\
\hline 9 & 58 & 59.80 & 56 & 57.90 \\
\hline 10 & 59 & 60.75 & 61 & 62.70 \\
\hline 11 & 61 & 62.70 & 59 & 60.75 \\
\hline 12 & 61 & 62.70 & 57 & 58.85 \\
\hline 13 & 59 & 60.75 & 58 & 59.80 \\
\hline 14 & 62 & 63.70 & 58 & 59.80 \\
\hline 15 & 59 & 60.75 & 59.80 \\
\hline 16 & & & 58 & \\
\hline
\end{tabular}


Table B-18. Measured and corrected rebound numbers on the intact rock surfaces of the sides of specimen for test no. 25

\begin{tabular}{|c|c|c|c|c||}
\hline $\begin{array}{c}\text { No. of } \\
\text { Readings }\end{array}$ & $\begin{array}{c}\text { Measured } \\
\text { Rebound Number } \\
\text { for Top Block }\end{array}$ & $\begin{array}{c}\text { Corrected } \\
\text { Rebound Number } \\
\text { for Top Block }\end{array}$ & $\begin{array}{c}\text { Measured } \\
\text { Rebound Number } \\
\text { for Bottom Block }\end{array}$ & $\begin{array}{c}\text { Corrected } \\
\text { Rebound Number } \\
\text { for Bottom Block }\end{array}$ \\
\hline 1 & 60 & 61.70 & 60 & 61.70 \\
\hline 2 & 62 & 63.70 & 64 & 65.70 \\
\hline 3 & 62 & 63.70 & 59 & 60.75 \\
\hline 4 & 56 & 57.90 & 58 & 59.80 \\
\hline 5 & 60 & 61.70 & 59 & 60.75 \\
\hline 6 & 62 & 63.70 & 61 & 62.70 \\
\hline 7 & 62 & 63.70 & 61 & 62.70 \\
\hline 8 & 57 & 58.85 & 60 & 61.70 \\
\hline 9 & 56 & 57.90 & 59 & 60.75 \\
\hline 10 & 56 & 57.90 & 59 & 60.75 \\
\hline 11 & 61 & 62.70 & 59 & 60.75 \\
\hline 12 & 60 & 61.70 & 60 & 61.70 \\
\hline 13 & 60 & 61.70 & 58 & 59.80 \\
\hline 14 & 61 & 62.70 & 58 & 59.80 \\
\hline 15 & 60 & 59.80 & 63.70 \\
\hline 16 & 60 & & 55 & 6 \\
\hline
\end{tabular}


Table B-19. Measured and corrected rebound numbers on the intact rock surfaces of the sides of specimen for test no. 26

\begin{tabular}{|c|c|c|c|c|}
\hline $\begin{array}{c}\text { No. of } \\
\text { Readings }\end{array}$ & $\begin{array}{c}\text { Measured } \\
\text { Rebound Number } \\
\text { for Top Block }\end{array}$ & $\begin{array}{c}\text { Corrected } \\
\text { Rebound Number } \\
\text { for Top Block }\end{array}$ & $\begin{array}{c}\text { Measured } \\
\text { Rebound Number } \\
\text { for Bottom Block }\end{array}$ & $\begin{array}{c}\text { Corrected } \\
\text { Rebound Number } \\
\text { for Bottom Block }\end{array}$ \\
\hline 1 & 61 & 62.70 & 54 & 56.00 \\
\hline 2 & 56 & 57.90 & 60 & 61.70 \\
\hline 3 & 60 & 61.70 & 57 & 58.85 \\
\hline 4 & 59 & 60.75 & 58 & 59.80 \\
\hline 5 & 58 & 59.80 & 55 & 56.95 \\
\hline 6 & 59 & 60.75 & 55 & 56.95 \\
\hline 7 & 57 & 58.85 & 52 & 54.10 \\
\hline 8 & 53 & 55.05 & 51 & 53.15 \\
\hline 9 & 54 & 56.00 & 54 & 56.00 \\
\hline 10 & 61 & 62.70 & 52 & 54.10 \\
\hline 11 & 61 & 62.70 & 58 & 59.80 \\
\hline 12 & 59 & 60.75 & 58 & 59.80 \\
\hline 13 & 55 & 56.95 & 56 & 57.90 \\
\hline 14 & 56 & 57.90 & 45 & 47.45 \\
\hline 15 & 57 & 58.85 & 58 & 59.80 \\
\hline 16 & 57 & 56.95 \\
\hline
\end{tabular}


Table B-20. Measured and corrected rebound numbers on the intact rock surfaces of the sides of specimen for test no. 27

\begin{tabular}{|c|c|c|c|c|}
\hline $\begin{array}{c}\text { No. of } \\
\text { Readings }\end{array}$ & $\begin{array}{c}\text { Measured } \\
\text { Rebound Number } \\
\text { for Top Block }\end{array}$ & $\begin{array}{c}\text { Corrected } \\
\text { Rebound Number } \\
\text { for Top Block }\end{array}$ & $\begin{array}{c}\text { Measured } \\
\text { Rebound Number } \\
\text { for Bottom Block }\end{array}$ & $\begin{array}{c}\text { Corrected } \\
\text { Rebound Number } \\
\text { for Bottom Block }\end{array}$ \\
\hline 1 & 56 & 57.90 & 59 & 60.75 \\
\hline 2 & 56 & 57.90 & 58 & 59.80 \\
\hline 3 & 58 & 59.80 & 58 & 59.80 \\
\hline 4 & 55 & 56.95 & 53 & 55.05 \\
\hline 5 & 56 & 57.90 & 55 & 56.95 \\
\hline 6 & 59 & 60.75 & 58 & 59.80 \\
\hline 7 & 58 & 59.80 & 58 & 59.80 \\
\hline 8 & 55 & 56.95 & 58 & 59.80 \\
\hline 9 & 56 & 57.90 & 56 & 57.90 \\
\hline 10 & 54 & 56.00 & 59 & 60.75 \\
\hline 11 & 58 & 59.80 & 59 & 60.75 \\
\hline 12 & 56 & 57.90 & 59 & 51.25 \\
\hline 13 & 56 & 57.90 & 50 & 52.20 \\
\hline 14 & 54 & 56.00 & 50 & 61.70 \\
\hline 15 & 54 & 55.05 & 59.80 \\
\hline 16 & 53 & & 5600 \\
\hline
\end{tabular}


Table B-21. Measured and corrected rebound numbers on the intact rock surfaces of the sides of specimen for test no. 28

\begin{tabular}{|c|c|c|c|c|}
\hline $\begin{array}{c}\text { No. of } \\
\text { Readings }\end{array}$ & $\begin{array}{c}\text { Measured } \\
\text { Rebound Number } \\
\text { for Top Block }\end{array}$ & $\begin{array}{c}\text { Corrected } \\
\text { Rebound Number } \\
\text { for Top Block }\end{array}$ & $\begin{array}{c}\text { Measured } \\
\text { Rebound Number } \\
\text { for Bottom Block }\end{array}$ & $\begin{array}{c}\text { Corrected } \\
\text { Rebound Number } \\
\text { for Bottom Block }\end{array}$ \\
\hline 1 & 55 & 56.95 & 55 & 56.95 \\
\hline 2 & 54 & 56.00 & 56 & 57.90 \\
\hline 3 & 56 & 57.90 & 58 & 59.80 \\
\hline 4 & 50 & 52.20 & 54 & 56.00 \\
\hline 5 & 57 & 58.85 & 58 & 59.80 \\
\hline 6 & 55 & 56.95 & 58 & 59.80 \\
\hline 7 & 55 & 56.95 & 60 & 61.70 \\
\hline 8 & 52 & 54.10 & 54 & 56.00 \\
\hline 9 & 55 & 56.95 & 57 & 58.85 \\
\hline 10 & 57 & 58.85 & 56 & 57.90 \\
\hline 11 & 57 & 58.85 & 57 & 58.85 \\
\hline 12 & 57 & 58.85 & 54 & 56.00 \\
\hline 13 & 53 & 55.05 & 57 & 58.85 \\
\hline 14 & 58 & 59.80 & 57 & 58.85 \\
\hline 15 & 58 & 59.80 & 59.80 \\
\hline 16 & 59.95 & & 57.90 \\
\hline
\end{tabular}


Table B-22. Measured and corrected rebound numbers on the intact rock surfaces of the sides of specimen for test no. 29

\begin{tabular}{|c|c|c|c|c|}
\hline $\begin{array}{c}\text { No. of } \\
\text { Readings }\end{array}$ & $\begin{array}{c}\text { Measured } \\
\text { Rebound Number } \\
\text { for Top Block }\end{array}$ & $\begin{array}{c}\text { Corrected } \\
\text { Rebound Number } \\
\text { for Top Block }\end{array}$ & $\begin{array}{c}\text { Measured } \\
\text { Rebound Number } \\
\text { for Bottom Block }\end{array}$ & $\begin{array}{c}\text { Corrected } \\
\text { Rebound Number } \\
\text { for Bottom Block }\end{array}$ \\
\hline 1 & 56 & 57.90 & 58 & 59.80 \\
\hline 2 & 57 & 58.85 & 59 & 60.75 \\
\hline 3 & 58 & 59.80 & 60 & 61.70 \\
\hline 4 & 54 & 56.00 & 58 & 59.80 \\
\hline 5 & 59 & 60.75 & 58 & 59.80 \\
\hline 6 & 57 & 58.85 & 56 & 57.90 \\
\hline 7 & 55 & 56.95 & 58 & 59.80 \\
\hline 8 & 55 & 56.95 & 57 & 58.85 \\
\hline 9 & 56 & 57.90 & 57 & 58.85 \\
\hline 10 & 57 & 58.85 & 54 & 56.00 \\
\hline 11 & 56 & 59.80 & 56 & 57.90 \\
\hline 12 & 57 & 60.75 & 51 & 53.15 \\
\hline 13 & 54 & 57.90 & 57 & 58.85 \\
\hline 14 & 55 & 58.85 & 50 & 61.70 \\
\hline 15 & 56 & 59.80 & 56 & 57.90 \\
\hline 16 & 575 & & 57 & \\
\hline
\end{tabular}


Table B-23. Measured and corrected rebound numbers on the intact rock surfaces of the sides of specimen for test no. 30

\begin{tabular}{|c|c|c|c|c|}
\hline $\begin{array}{c}\text { No. of } \\
\text { Readings }\end{array}$ & $\begin{array}{c}\text { Measured } \\
\text { Rebound Number } \\
\text { for Top Block }\end{array}$ & $\begin{array}{c}\text { Corrected } \\
\text { Rebound Number } \\
\text { for Top Block }\end{array}$ & $\begin{array}{c}\text { Mensured } \\
\text { Rebound Number } \\
\text { for Bottom Block }\end{array}$ & $\begin{array}{c}\text { Corrected } \\
\text { Rebound Number } \\
\text { for Bottom Block }\end{array}$ \\
\hline 1 & 52 & 54.10 & 53 & 55.05 \\
\hline 2 & 56 & 57.90 & 60 & 61.70 \\
\hline 3 & 55 & 56.95 & 60 & 61.70 \\
\hline 4 & 58 & 59.80 & 60 & 61.70 \\
\hline 5 & 58 & 59.80 & 61 & 62.70 \\
\hline 6 & 60 & 61.70 & 62 & 63.70 \\
\hline 7 & 61 & 62.70 & 61 & 62.70 \\
\hline 8 & 59 & 60.75 & 61 & 62.70 \\
\hline 9 & 60 & 61.70 & 57 & 58.85 \\
\hline 10 & 60 & 61.70 & 61 & 62.70 \\
\hline 11 & 60 & 61.70 & 60 & 61.70 \\
\hline 12 & 60 & 61.70 & 61 & 62.70 \\
\hline 13 & 60 & 61.70 & 61 & 62.70 \\
\hline 14 & 51 & 62.70 & 53 & 55.05 \\
\hline 15 & 59 & 60.75 & 60 & 63.70 \\
\hline 16 & 60 & & 61.70 \\
\hline
\end{tabular}




\section{APPENDIX C}

MEASURED AND CORRECTED REBOUND NUMBERS

ON TUFF JOINT SURFACES 
Table C-1. Measured and corrected rebound numbers on the two joint surfaces of specimen for test no. 5

\begin{tabular}{|c|c|c|c|c||}
\hline $\begin{array}{c}\text { No. of } \\
\text { Readings }\end{array}$ & $\begin{array}{c}\text { Measured } \\
\text { Rebound Number } \\
\text { for Joint on } \\
\text { Top Block }\end{array}$ & $\begin{array}{c}\text { Corrected } \\
\text { Rebound Number } \\
\text { for Joint on } \\
\text { Top Block }\end{array}$ & $\begin{array}{c}\text { Measured } \\
\text { Rebound Number } \\
\text { for Joint on } \\
\text { Bottom Block }\end{array}$ & $\begin{array}{c}\text { Corrected } \\
\text { Rebound Number } \\
\text { for Joint On } \\
\text { Bottom Block }\end{array}$ \\
\hline 1 & 39 & 41.74 & 56 & 57.90 \\
\hline 2 & 52 & 54.10 & 50 & 52.20 \\
\hline 3 & 52 & 54.10 & 48 & 50.30 \\
\hline 4 & 40 & 42.70 & 54 & 33.10 \\
\hline 5 & 53 & 55.05 & 46 & 56.00 \\
\hline 6 & 52 & 54.10 & 50 & 48.40 \\
\hline 7 & 48 & 50.30 & 44 & 52.20 \\
\hline 8 & 51 & 53.15 & 48 & 46.50 \\
\hline 9 & 56 & 57.90 & 52 & 50.30 \\
\hline 10 & 49 & 51.25 & 47 & 54.10 \\
\hline 11 & 47 & 49.35 & 51 & 49.35 \\
\hline 12 & 54 & 56.00 & 50 & 53.15 \\
\hline 13 & 46 & 48.40 & 52.20 \\
\hline
\end{tabular}


Table C-2. Measured and corrected rebound numbers on the two joint surfaces of specimen for test no. 6

\begin{tabular}{|c|c|c|c|c|}
\hline $\begin{array}{c}\text { No. of } \\
\text { Readings }\end{array}$ & $\begin{array}{c}\text { Measured } \\
\text { for Joint on } \\
\text { Top Block }\end{array}$ & $\begin{array}{c}\text { Corrected } \\
\text { Rebound Number } \\
\text { for Joint on } \\
\text { Top Block }\end{array}$ & $\begin{array}{c}\text { Measured } \\
\text { Rebound Number } \\
\text { for Joint on } \\
\text { Bottom Block }\end{array}$ & $\begin{array}{c}\text { Corrected } \\
\text { Rebound Number } \\
\text { for Joint On } \\
\text { Bottom Block }\end{array}$ \\
\hline 1 & 56 & 57.90 & 63 & 64.70 \\
\hline 2 & 56 & 57.90 & 60 & 61.70 \\
\hline 3 & 50 & 52.20 & 46 & 48.40 \\
\hline 4 & 49 & 51.25 & 56 & 57.90 \\
\hline 5 & 50 & 52.20 & 58 & 59.80 \\
\hline 6 & 52 & 54.10 & 57 & 58.85 \\
\hline 7 & 50 & 52.20 & 44 & 46.50 \\
\hline 8 & 52 & 54.10 & 52 & 54.10 \\
\hline 9 & 60 & 61.70 & 52 & 54.10 \\
\hline 10 & 51 & 53.15 & 48 & 50.30 \\
\hline 11 & 47 & 49.35 & 52 & 54.10 \\
\hline 12 & 46 & 48.40 & 57 & 58.85 \\
\hline 13 & 51 & 53.15 & 55 & 56.95 \\
\hline & & & & \\
\hline
\end{tabular}


Table C-3. Measured and corrected rebound numbers on the two joint surfaces of specimen for test no. 7

\begin{tabular}{|c|c|c|c|c|}
\hline $\begin{array}{c}\text { No. of } \\
\text { Readings }\end{array}$ & $\begin{array}{c}\text { Measured } \\
\text { Rebound Number } \\
\text { for Joint on } \\
\text { Top Block }\end{array}$ & $\begin{array}{c}\text { Corrected } \\
\text { Rebound Number } \\
\text { for Joint on } \\
\text { Top Block }\end{array}$ & $\begin{array}{c}\text { Measured } \\
\text { Rebound Number } \\
\text { for Joint on } \\
\text { Bottom Block }\end{array}$ & $\begin{array}{c}\text { Corrected } \\
\text { Rebound Number } \\
\text { for Joint On } \\
\text { Bottom Block }\end{array}$ \\
\hline 1 & 54 & 56.00 & 53 & 55.05 \\
\hline 2 & 49 & 51.25 & 54 & 56.00 \\
\hline 3 & 46 & 48.40 & 46 & 48.40 \\
\hline 4 & 54 & 56.00 & 48 & 50.30 \\
\hline 5 & 44 & 46.50 & 50 & 52.20 \\
\hline 6 & 52 & 54.10 & 52 & 54.10 \\
\hline 7 & 44 & 46.50 & 48 & 50.30 \\
\hline 8 & 50 & 52.20 & 46 & 48.40 \\
\hline 9 & 48 & 50.30 & 48 & 50.30 \\
\hline 10 & 48 & 50.30 & 47 & 49.35 \\
\hline 11 & 50 & 52.20 & - & - \\
\hline
\end{tabular}


Table C-4. Measured and corrected rebound numbers on the two joint surfaces of specimen for test no. 9

\begin{tabular}{|c|c|c|c|c|}
\hline $\begin{array}{c}\text { No. of } \\
\text { Readings }\end{array}$ & $\begin{array}{c}\text { Measured } \\
\text { Rebound Number } \\
\text { for Joint on } \\
\text { Top Block }\end{array}$ & $\begin{array}{c}\text { Corrected } \\
\text { Rebound Number } \\
\text { for Joint on } \\
\text { Top Block }\end{array}$ & $\begin{array}{c}\text { Measured } \\
\text { Rebound Number } \\
\text { for Joint on } \\
\text { Bottom Block }\end{array}$ & $\begin{array}{c}\text { Corrected } \\
\text { Rebound Number } \\
\text { for Joint On } \\
\text { Bottom Block }\end{array}$ \\
\hline 1 & 58 & 59.80 & 59 & 60.75 \\
\hline 2 & 57 & 58.85 & 54 & 56.00 \\
\hline 3 & 49 & 51.25 & 59 & 60.75 \\
\hline 4 & 56 & 57.90 & 55 & 56.95 \\
\hline 5 & 61 & 62.70 & 57 & 58.85 \\
\hline 6 & 63 & 64.70 & 57 & 58.85 \\
\hline 7 & 57 & 58.85 & 58 & 59.80 \\
\hline 8 & 44 & 46.50 & 51 & 53.15 \\
\hline 9 & 60 & 61.70 & 51 & 53.15 \\
\hline 10 & 57 & 58.85 & 54 & 56.00 \\
\hline 11 & 52 & 54.10 & 55 & 56.95 \\
\hline 12 & 62 & 63.70 & 52 & 54.10 \\
\hline 13 & 61 & 62.70 & 54 & 56.00 \\
\hline 14 & 56 & 58.85 & 59 & 60.75 \\
\hline 15 & 56.90 & & 61.70 \\
\hline
\end{tabular}


Table C-5. Measured and corrected rebound numbers on the two joint surfaces of specimen for test no. 10

\begin{tabular}{|c|c|c|c|c|}
\hline $\begin{array}{l}\text { No. of } \\
\text { Readings }\end{array}$ & $\begin{array}{c}\text { Measured } \\
\text { Rebound Number } \\
\text { for Joint on } \\
\text { Top Block }\end{array}$ & $\begin{array}{c}\text { Corrected } \\
\text { Rebound Number } \\
\text { for Joint on } \\
\text { Top Block }\end{array}$ & $\begin{array}{c}\text { Measured } \\
\text { Rebound Number } \\
\text { for Joint on } \\
\text { Bottom Block } \\
\end{array}$ & $\begin{array}{c}\text { Corrected } \\
\text { Rebound Number } \\
\text { for Joint On } \\
\text { Bottom Block } \\
\end{array}$ \\
\hline 1 & 54 & 56.00 & 54 & 56.00 \\
\hline 2 & 48 & 50.30 & 48 & 50.30 \\
\hline 3 & 47 & 49.35 & 31 & 34.06 \\
\hline 4 & 52 & 54.10 & 50 & 52.20 \\
\hline 5 & 44 & 46.50 & 50 & 52.20 \\
\hline 6 & 45 & 47.45 & 53 & 55.05 \\
\hline 7 & 51 & 53.15 & 53 & 55.05 \\
\hline 8 & 49 & 51.25 & 35 & 37.90 \\
\hline 9 & 56 & 57.90 & 55 & 56.95 \\
\hline 10 & 54 & 56.00 & 42 & 44.60 \\
\hline 11 & 55 & 56.95 & 33 & 35.98 \\
\hline 12 & 36 & 38.86 & 36 & 38.86 \\
\hline 13 & 46 & 48.40 & 43 & 45.55 \\
\hline 14 & 30 & 33.10 & 58 & 59.80 \\
\hline 15 & 40 & 42.70 & 40 & 42.70 \\
\hline 16 & 40 & 42.70 & 33 & 35.98 \\
\hline
\end{tabular}


Table C-6. Measured and corrected rebound numbers on the two joint surfaces of specimen for test no. 11

\begin{tabular}{|c|c|c|c|c||}
\hline $\begin{array}{c}\text { No. of } \\
\text { Readings }\end{array}$ & $\begin{array}{c}\text { Measured } \\
\text { Rebound Number } \\
\text { for Joint on } \\
\text { Top Block }\end{array}$ & $\begin{array}{c}\text { Corrected } \\
\text { Rebound Number } \\
\text { for Joint on } \\
\text { Top Block }\end{array}$ & $\begin{array}{c}\text { Measured } \\
\text { Rebound Number } \\
\text { for Joint on } \\
\text { Bottom Block }\end{array}$ & $\begin{array}{c}\text { Corrected } \\
\text { Rebound Number } \\
\text { for Joint On } \\
\text { Bottom Block }\end{array}$ \\
\hline 1 & 54 & 56.00 & 50 & 52.20 \\
\hline 2 & 51 & 53.15 & 60 & 61.70 \\
\hline 3 & 63 & 64.70 & 52 & 54.10 \\
\hline 4 & 58 & 59.80 & 55 & 56.95 \\
\hline 5 & 48 & 50.30 & 59 & 60.75 \\
\hline 6 & 52 & 54.10 & 56 & 57.90 \\
\hline 7 & 55 & 56.95 & 60 & 61.70 \\
\hline 8 & 59 & 60.75 & 54 & 56.00 \\
\hline 9 & 50 & 52.20 & 52 & 54.10 \\
\hline 10 & 54 & 56.00 & 52 & 54.10 \\
\hline 11 & 52 & 54.10 & 59 & 51.25 \\
\hline 12 & 55 & 56.95 & 55 & 56.95 \\
\hline
\end{tabular}


Table C-7. Measured and corrected rebound numbers on the two joint surfaces of specimen for test no. 12

\begin{tabular}{|c|c|c|c|c|}
\hline $\begin{array}{c}\text { No. of } \\
\text { Readings }\end{array}$ & $\begin{array}{c}\text { Measured } \\
\text { Rebound Number } \\
\text { for Joint on } \\
\text { Top Block }\end{array}$ & $\begin{array}{c}\text { Corrected } \\
\text { Rebound Number } \\
\text { for Joint on } \\
\text { Top Block }\end{array}$ & $\begin{array}{c}\text { Measured } \\
\text { Rebound Number } \\
\text { for Joint on } \\
\text { Bottom Block }\end{array}$ & $\begin{array}{c}\text { Corrected } \\
\text { Rebound Number } \\
\text { for Joint On } \\
\text { Bottom Block }\end{array}$ \\
\hline 1 & 54 & 56.00 & 52 & 54.10 \\
\hline 2 & 53 & 55.05 & 56 & 57.90 \\
\hline 3 & 53 & 55.05 & 52 & 54.10 \\
\hline 4 & 48 & 50.30 & 53 & 55.05 \\
\hline 5 & 52 & 54.10 & 52 & 54.10 \\
\hline 6 & 55 & 56.95 & 61 & 62.70 \\
\hline 7 & 51 & 53.15 & 56 & 57.90 \\
\hline 8 & 49 & 51.25 & 55 & 56.95 \\
\hline 9 & 50 & 52.20 & 55 & 56.95 \\
\hline 10 & 54 & 56.00 & 58 & 59.80 \\
\hline 11 & 54 & 56.00 & 51 & 53.15 \\
\hline 12 & 57 & 58.85 & 49 & 51.25 \\
\hline
\end{tabular}


Table C-8. Measured and corrected rebound numbers on the two joint surfaces of specimen for test no. 14

\begin{tabular}{||c|c|c|c|c||}
\hline $\begin{array}{c}\text { No. of } \\
\text { Readings }\end{array}$ & $\begin{array}{c}\text { Measured } \\
\text { Rebound Number } \\
\text { for Joint on } \\
\text { Top Block }\end{array}$ & $\begin{array}{c}\text { Corrected } \\
\text { Rebound Number } \\
\text { for Joint on } \\
\text { Top Block }\end{array}$ & $\begin{array}{c}\text { Measured } \\
\text { Rebound Number } \\
\text { for Joint on } \\
\text { Bottom Block }\end{array}$ & $\begin{array}{c}\text { Corrected } \\
\text { Rebound Number } \\
\text { for Joint On } \\
\text { Bottom Block }\end{array}$ \\
\hline 1 & 40 & 42.70 & 49 & 51.25 \\
\hline 2 & 56 & 57.90 & 50 & 52.20 \\
\hline 3 & 53 & 55.05 & 50 & 52.20 \\
\hline 4 & 44 & 46.50 & 47 & 49.35 \\
\hline 5 & 50 & 52.20 & 46 & 48.40 \\
\hline 6 & 50 & 52.20 & 48 & 50.30 \\
\hline 7 & 43 & 45.55 & 50 & 52.20 \\
\hline 8 & 50 & 52.20 & 40 & 42.70 \\
\hline 9 & 43 & 45.55 & 42 & 44.60 \\
\hline 10 & 45 & 47.45 & 44 & 46.50 \\
\hline 11 & 44 & 46.50 & 45 & 47.45 \\
\hline 12 & 46 & 48.40 & 47 & 49.35 \\
\hline
\end{tabular}


Table C-9. Measured and corrected rebound numbers on the two joint surfaces of specimen for test no. 15

\begin{tabular}{|c|c|c|c|c||}
\hline $\begin{array}{c}\text { No. of } \\
\text { Readings }\end{array}$ & $\begin{array}{c}\text { Measured } \\
\text { Rebound Number } \\
\text { for Joint on } \\
\text { Top Block }\end{array}$ & $\begin{array}{c}\text { Corrected } \\
\text { Rebound Number } \\
\text { for Joint on } \\
\text { Top Block }\end{array}$ & $\begin{array}{c}\text { Measured } \\
\text { Rebound Number } \\
\text { for Joint on } \\
\text { Bottom Block }\end{array}$ & $\begin{array}{c}\text { Corrected } \\
\text { Rebound Number } \\
\text { for Joint On } \\
\text { Bottom Block }\end{array}$ \\
\hline 1 & 54 & 56.00 & 49 & 51.25 \\
\hline 2 & 51 & 53.15 & 44 & 46.50 \\
\hline 3 & 52 & 54.10 & 49 & 51.25 \\
\hline 4 & 49 & 51.25 & 48 & 50.30 \\
\hline 5 & 55 & 56.95 & 53 & 55.05 \\
\hline 6 & 54 & 56.00 & 53 & 55.05 \\
\hline 7 & 49 & 51.25 & 46 & 48.40 \\
\hline 8 & 52 & 54.10 & 46 & 48.40 \\
\hline 9 & 53 & 55.05 & 48 & 50.30 \\
\hline 10 & 46 & 48.40 & 56 & 57.90 \\
\hline 11 & 54 & 56.00 & 55 & 56.95 \\
\hline 12 & -- & 52 & 54.10 \\
\hline
\end{tabular}


Table C-10. Measured and corrected rebound numbers on the two joint surfaces of specimen for test no. 17

\begin{tabular}{|c|c|c|c|c|}
\hline $\begin{array}{l}\text { No. of } \\
\text { Readings }\end{array}$ & $\begin{array}{l}\text { Measured } \\
\text { Rebound Number } \\
\text { for Joint on } \\
\text { Top Block }\end{array}$ & $\begin{array}{l}\text { Corrected } \\
\text { Rebound Number } \\
\text { for Joint on } \\
\text { Top Block }\end{array}$ & $\begin{array}{l}\text { Measured } \\
\text { Rebound Number } \\
\text { for Joint on } \\
\text { Bottom Block }\end{array}$ & $\begin{array}{c}\text { Corrected } \\
\text { Rebound Number } \\
\text { for Joint On } \\
\text { Bottom Block }\end{array}$ \\
\hline 1 & 52 & 54.10 & 54 & 56.00 \\
\hline 2 & 49 & 51.25 & 51 & 53.15 \\
\hline 3 & 50 & 52.20 & 36 & 38.86 \\
\hline 4 & 45 & 47.45 & 40 & 42.70 \\
\hline 5 & 49 & 51.25 & 48 & 50.30 \\
\hline 6 & 56 & 57.90 & 62 & 63.70 \\
\hline 7 & 44 & 46.50 & 42 & 44.60 \\
\hline 8 & 48 & 50.30 & 32 & 35.02 \\
\hline 9 & 47 & 49.35 & 44 & 46.50 \\
\hline 10 & 52 & 54.10 & 56 & 57.90 \\
\hline 11 & 42 & 44.60 & 50 & 52.20 \\
\hline 12 & 39 & 41.74 & 47 & 49.35 \\
\hline 13 & 51 & 53.15 & 52 & 54.10 \\
\hline 14 & 34 & 36.94 & 42 & 44.60 \\
\hline 15 & 45 & 47.45 & 39 & 41.74 \\
\hline 16 & - & -- & 39 & 41.74 \\
\hline 17 & - & - & 39 & 41.74 \\
\hline 18 & - & - & 48 & 50.30 \\
\hline 19 & - & - & 50 & 52.20 \\
\hline 20 & - & -- & 47 & 49.35 \\
\hline
\end{tabular}


Table C-11. Measured and corrected rebound numbers on the two joint surfaces of specimen for test no. 18

\begin{tabular}{|c|c|c|c|c|}
\hline $\begin{array}{c}\text { No. of } \\
\text { Readings }\end{array}$ & $\begin{array}{c}\text { Measured } \\
\text { Rebound Number } \\
\text { for Joint on } \\
\text { Top Block } \\
\end{array}$ & $\begin{array}{c}\text { Corrected } \\
\text { Rebound Number } \\
\text { for Joint on } \\
\text { Top Block } \\
\end{array}$ & $\begin{array}{c}\text { Measured } \\
\text { Rebound Number } \\
\text { for Joint on } \\
\text { Bottom Block } \\
\end{array}$ & $\begin{array}{c}\text { Corrected } \\
\text { Rebound Number } \\
\text { for Joint On } \\
\text { Bottom Block } \\
\end{array}$ \\
\hline 1 & 43 & 45.55 & 44 & 46.50 \\
\hline 2 & 54 & 56.00 & 30 & 33.10 \\
\hline 3 & 58 & 59.80 & 58 & 59.80 \\
\hline 4 & 37 & 39.82 & 23 & 26.31 \\
\hline 5 & 46 & 48.40 & 48 & 50.30 \\
\hline 6 & 42 & 44.60 & 52 & 54.10 \\
\hline 7 & 38 & 40.78 & 47 & 49.35 \\
\hline 8 & 44 & 46.50 & 58 & 59.80 \\
\hline 9 & 54 & 56.00 & 54 & 56.00 \\
\hline 10 & 42 & 44.60 & 39 & 4.1 .74 \\
\hline 11 & 46 & 48.40 & 52 & 54.10 \\
\hline 12 & 27 & 30.19 & 48 & 50.30 \\
\hline 13 & 29 & 32.13 & 49 & 51.25 \\
\hline 14 & 54 & 56.00 & 34 & 36.94 \\
\hline 15 & 54 & 56.00 & 46 & 48.40 \\
\hline 16 & 36 & 38.86 & 49 & 51.25 \\
\hline 17 & 33 & 35.98 & 50 & 52.20 \\
\hline 18 & 39 & 41.74 & 47 & 49.35 \\
\hline 19 & 59 & 60.75 & 19 & 22.02 \\
\hline 20 & 35 & 37.90 & 40 & 42.70 \\
\hline
\end{tabular}


Table C-12. Measured and corrected rebound numbers on the two joint surfaces of specimen for test no. 19

\begin{tabular}{|c|c|c|c|c|}
\hline $\begin{array}{l}\text { No. of } \\
\text { Readings }\end{array}$ & $\begin{array}{l}\text { Measured } \\
\text { Rebound Number } \\
\text { for Joint on } \\
\text { Top Block }\end{array}$ & $\begin{array}{l}\text { Corrected } \\
\text { Rebound Number } \\
\text { for Joint on } \\
\text { Top Block }\end{array}$ & $\begin{array}{c}\text { Measured } \\
\text { Rebound Number } \\
\text { for Joint on } \\
\text { Bottom Block }\end{array}$ & $\begin{array}{c}\text { Corrected } \\
\text { Rebound Number } \\
\text { for Joint On } \\
\text { Bottom Block }\end{array}$ \\
\hline 1 & 34 & 36.94 & 36 & 38.86 \\
\hline 2 & 45 & 47.45 & 39 & 41.74 \\
\hline 3 & 40 & 42.70 & 50 & 52.20 \\
\hline 4 & 17 & 20.34 & 52 & 54.10 \\
\hline 5 & 52 & 54.10 & 45 & 47.45 \\
\hline 6 & 60 & 61.70 & 49 & 51.25 \\
\hline 7 & 45 & 47.45 & 19 & 22.38 \\
\hline 8 & 26 & 29.22 & 45 & 47.45 \\
\hline 9 & 49 & 51.25 & 50 & 52.20 \\
\hline 10 & 53 & 55.05 & 42 & 44.60 \\
\hline 11 & 53 & 55.05 & 39 & 41.74 \\
\hline 12 & 53 & 55.05 & 52 & 54.10 \\
\hline 13 & 45 & 47.45 & 42 & 44.60 \\
\hline 14 & 48 & 50.30 & 52 & 54.10 \\
\hline 15 & 50 & 32.20 & 26 & 29.22 \\
\hline 16 & 45 & 47.45 & 43 & 45.55 \\
\hline 17 & 53 & 55.05 & 40 & 42.70 \\
\hline 18 & 45 & 47.45 & 50 & 52.20 \\
\hline 19 & 52 & 54.10 & 44 & 46.50 \\
\hline 20 & 38 & 40.78 & 52 & 54.10 \\
\hline
\end{tabular}


Table C-13. Measured and corrected rebound numbers on the two joint surfaces of specimen for test no. 20

\begin{tabular}{|c|c|c|c|c||}
\hline $\begin{array}{c}\text { No. of } \\
\text { Readings }\end{array}$ & $\begin{array}{c}\text { Measured } \\
\text { Rebound Number } \\
\text { for Joint on } \\
\text { Top Block }\end{array}$ & $\begin{array}{c}\text { Corrected } \\
\text { Rebound Number } \\
\text { for Joint on } \\
\text { Top Block }\end{array}$ & $\begin{array}{c}\text { Measured } \\
\text { Rebound Number } \\
\text { for Joint on } \\
\text { Bottom Block }\end{array}$ & $\begin{array}{c}\text { Corrected } \\
\text { Rebound Number } \\
\text { for Joint On } \\
\text { Bottom Block }\end{array}$ \\
\hline 1 & 34 & 36.94 & 50 & 52.20 \\
\hline 2 & 39 & 41.74 & 43 & 45.55 \\
\hline 3 & 46 & 48.40 & 43 & 45.55 \\
\hline 4 & 42 & 44.60 & 46 & 48.40 \\
\hline 5 & 42 & 44.60 & 44 & 46.50 \\
\hline 6 & 44 & 46.50 & 40 & 42.70 \\
\hline 7 & 38 & 40.78 & 40 & 42.70 \\
\hline 8 & 33 & 35.98 & 43 & 45.55 \\
\hline 9 & 48 & 50.30 & 45 & 47.55 \\
\hline 10 & 49 & 51.25 & 48 & 50.30 \\
\hline 11 & 36 & 38.86 & 44 & 46.50 \\
\hline 12 & 40 & 42.70 & 39 & 41.74 \\
\hline 13 & 32 & 35.02 & -- & - \\
\hline 14 & 42 & 43.65 & - & - \\
\hline 15 & 41 & & - & - \\
\hline
\end{tabular}


Table C-14. Measured and corrected rebound numbers on the two joint surfaces of specimen for test no. 21

\begin{tabular}{|c|c|c|c|c|}
\hline $\begin{array}{l}\text { No. of } \\
\text { Readings }\end{array}$ & $\begin{array}{c}\text { Measured } \\
\text { Rebound Number } \\
\text { for Joint on } \\
\text { Top Block } \\
\end{array}$ & $\begin{array}{l}\text { Corrected } \\
\text { Rebound Number } \\
\text { for Joint on } \\
\text { Top Block }\end{array}$ & $\begin{array}{c}\text { Measured } \\
\text { Rebound Number } \\
\text { for Joint on } \\
\text { Bottom Block } \\
\end{array}$ & $\begin{array}{c}\text { Corrected } \\
\text { Rebound Number } \\
\text { for Joint On } \\
\text { Bottom Block } \\
\end{array}$ \\
\hline 1 & 43 & 45.55 & 40 & 42.70 \\
\hline 2 & 41 & 43.65 & 46 & 48.40 \\
\hline 3 & 48 & 50.3 & 47 & 49.35 \\
\hline 4 & 46 & 48.40 & 44 & 46.50 \\
\hline 5 & 30 & 33.10 & 44 & 46.50 \\
\hline 6 & 50 & 52.20 & 42 & 44.60 \\
\hline 7 & 40 & 42.70 & 51 & 53.15 \\
\hline 8 & 36 & 38.86 & 38 & 40.78 \\
\hline 9 & 40 & 42.70 & 50 & 52.20 \\
\hline 10 & 44 & 46.50 & 50 & 52.20 \\
\hline 11 & 52 & 54.10 & 39 & 41.74 \\
\hline 12 & 44 & 46.50 & 45 & 47.45 \\
\hline 13 & 38 & 40.78 & 32 & 35.02 \\
\hline 14 & 49 & 51.25 & 49 & 51.25 \\
\hline 15 & 40 & 42.70 & 37 & 39.82 \\
\hline 16 & 30 & 33.10 & 48 & 50.30 \\
\hline 17 & 48 & 50.30 & 38 & 40.78 \\
\hline 18 & 48 & 50.30 & 48 & 50.30 \\
\hline 19 & 37 & 39.82 & 52 & 54.10 \\
\hline 20 & 41 & 43.65 & 47 & 49.35 \\
\hline 21 & 38 & 40.78 & 42 & 44.60 \\
\hline 22 & 51 & 53.15 & 33 & 35.98 \\
\hline 23 & 33 & 35.98 & 44 & 46.50 \\
\hline 24 & 36 & 38.86 & 46 & 48.40 \\
\hline 25 & 46 & 48.40 & 40 & 42.70 \\
\hline
\end{tabular}

C-14 


\begin{tabular}{|c|c|c|c|c|}
\hline $0 Z$ Z & $O S$ & $O L \$ 9$ & $\$ 9$ & $s z$ \\
\hline $08^{\circ} 65$ & 85 & $0<29$ & 19 & $b z$ \\
\hline SO'SS & ES & SS'St & $\varepsilon t$ & $\mathfrak{E Z}$ \\
\hline $09^{\circ} \downarrow t$ & $2 t$ & $06 \angle S$ & $9 S$ & $\tau z$ \\
\hline SI'ES & IS & OL'S9 & 59 & 12 \\
\hline SO'SS & ES & $S t^{\prime} L b$ & St & 02 \\
\hline SO SS & ES & 08.65 & 85 & $6 I$ \\
\hline $0 L^{\circ}+9$ & E9 & $S L 09$ & $6 S$ & $8 I$ \\
\hline $0 L^{\circ} \varepsilon 9$ & 29 & SLO09 & $6 S$ & $\angle I$ \\
\hline $58 \cdot 85$ & $\angle S$ & SLOO & $6 S$ & 91 \\
\hline SIES & Is & SSSt & $\varepsilon b$ & SI \\
\hline OL'S9 & $t 9$ & $0 L^{\prime} Z 9$ & 19 & $D I$ \\
\hline OL'S9 & $t 9$ & 00.95 & $t s$ & $\varepsilon I$ \\
\hline SO'SS & ES & SO'SS & ES & ZI \\
\hline $0 L^{\circ} \succcurlyeq 9$ & घ9 & $08^{\circ} 6 S$ & $8 S$ & II \\
\hline $08^{\circ} 65$ & $8 S$ & SLOO & $6 S$ & OI \\
\hline OL'E9 & 29 & SE'6b & $L b$ & 6 \\
\hline $06^{\circ} L S$ & $9 S$ & $06^{\circ} \mathrm{LS}$ & $9 S$ & 8 \\
\hline $0 z \cdot 2 S$ & $O S$ & ol'ts & $2 S$ & $L$ \\
\hline OL'I9 & 09 & 00.95 & $t S$ & 9 \\
\hline OI'ts & ZS & SLOS & $6 S$ & $\boldsymbol{S}$ \\
\hline SZIS & $6 t$ & $00^{\circ} 95$ & $\forall S$ & $t$ \\
\hline SI'ES & IS & $06^{\circ} L S$ & 95 & $\varepsilon$ \\
\hline $58^{\prime} 85$ & LS & SLOO & $6 S$ & 2 \\
\hline$O E^{\circ} O S$ & 86 & SI'ES & IS & I \\
\hline $\begin{array}{l}\text { Yoolg uopog } \\
\text { uo jujor doj } \\
\text { soqunn punoqəy } \\
\text { poposduos }\end{array}$ & 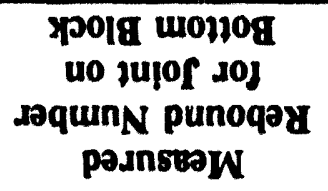 & 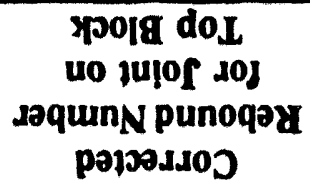 & $\begin{array}{c}\text { \$POIg doI } \\
\text { uo jujor soj } \\
\text { soqunN punoqəy } \\
\text { pasnstow }\end{array}$ & $\begin{array}{c}\text { siupeəz } \\
\text { j0 } 0 \mathrm{~N}\end{array}$ \\
\hline
\end{tabular}


Table C-16. Measured and corrected rebound numbers on the two joint surfaces of specimen for test no. 23

\begin{tabular}{|c|c|c|c|c|}
\hline $\begin{array}{l}\text { No. of } \\
\text { Readings }\end{array}$ & $\begin{array}{l}\text { Measured } \\
\text { Rebound Number } \\
\text { for Joint on } \\
\text { Top Block }\end{array}$ & $\begin{array}{l}\text { Corrected } \\
\text { Rebound Number } \\
\text { for Joint on } \\
\text { Top Block }\end{array}$ & $\begin{array}{l}\text { Measured } \\
\text { Rebound Number } \\
\text { for Joint on } \\
\text { Bottom Block }\end{array}$ & $\begin{array}{l}\text { Corrected } \\
\text { Rebound Number } \\
\text { for Joint On } \\
\text { Bottom Block }\end{array}$ \\
\hline 1 & 54 & 56.00 & 54 & 56.00 \\
\hline 2 & 47 & 49.35 & 54 & 56.00 \\
\hline 3 & 52 & 54.10 & 52 & 54.10 \\
\hline 4 & 52 & 54.10 & 52 & 54.10 \\
\hline 5 & 52 & 54.10 & 46 & 48.40 \\
\hline 6 & 45 & 47.45 & 50 & 52.20 \\
\hline 7 & 50 & 52.20 & 52 & 54.10 \\
\hline 8 & 56 & 57.90 & 62 & 63.70 \\
\hline 9 & 45 & 47.45 & 48 & 50.30 \\
\hline 10 & 50 & 52.20 & 49 & 51.25 \\
\hline 11 & 52 & 54.10 & 55 & 56.95 \\
\hline 12 & 51 & 53.15 & 56 & 57.90 \\
\hline 13 & 58 & 59.80 & 61 & 62.70 \\
\hline 14 & 52 & 54.10 & 51 & 53.15 \\
\hline 15 & 52 & 54.10 & 53 & 55.05 \\
\hline 16 & 52 & 54.10 & 53 & 55.05 \\
\hline 17 & 50 & 52.20 & 51 & 53.15 \\
\hline 18 & 52 & 54.10 & 49 & 51.25 \\
\hline 19 & 48 & 50.30 & 50 & 52.20 \\
\hline 20 & 58 & 59.80 & 56 & 57.90 \\
\hline 21 & 59 & 60.75 & 53 & 55.05 \\
\hline 22 & 56 & 57.90 & 53 & 55.05 \\
\hline 23 & 58 & 59.80 & 57 & 58.85 \\
\hline 24 & 52 & 54.10 & 55 & 56.95 \\
\hline 25 & 58 & 59.80 & 48 & 50.30 \\
\hline
\end{tabular}


Table C-17. Measured and corrected rebound numbers on the two joint surfaces of specimen for test no. 24

\begin{tabular}{|c|c|c|c|c|}
\hline $\begin{array}{l}\text { No. of } \\
\text { Readings }\end{array}$ & $\begin{array}{l}\text { Measured } \\
\text { Rebound Number } \\
\text { for Joint on } \\
\text { Top Block } \\
\end{array}$ & $\begin{array}{c}\text { Corrected } \\
\text { Rebound Number } \\
\text { for Joint on } \\
\text { Top Block } \\
\end{array}$ & $\begin{array}{c}\text { Measured } \\
\text { Rebound Number } \\
\text { for Joint on } \\
\text { Bottom Block } \\
\end{array}$ & $\begin{array}{l}\text { Corrected } \\
\text { Rebound Number } \\
\text { for Joint On } \\
\text { Bottom Block }\end{array}$ \\
\hline 1 & 51 & 53.15 & 53 & 55.05 \\
\hline 2 & 52 & 54.10 & 51 & 53.15 \\
\hline 3 & 50 & 52.20 & 42 & 44.60 \\
\hline 4 & 55 & 56.95 & 51 & 53.15 \\
\hline 5 & 55 & 56.95 & 60 & 61.70 \\
\hline 6 & 50 & 52.20 & 43 & 45.55 \\
\hline 7 & 49 & 51.25 & 38 & 40.78 \\
\hline 8 & 62 & 63.70 & 50 & 52.20 \\
\hline 9 & 52 & 54.10 & 45 & 47.45 \\
\hline 10 & 56 & 57.90 & 47 & 49.35 \\
\hline 11 & 60 & 61.70 & 46 & 48.40 \\
\hline 12 & 60 & 61.70 & 46 & 48.40 \\
\hline 13 & 53 & 55.05 & 43 & 45.55 \\
\hline 14 & 55 & 56.95 & 43 & 45.55 \\
\hline 15 & 53 & 55.05 & 45 & 47.45 \\
\hline 16 & 53 & 55.05 & 45 & 47.45 \\
\hline 17 & 51 & 53.15 & 56 & 57.90 \\
\hline 18 & 58 & 59.80 & 51 & 53.15 \\
\hline 19 & 59 & 60.75 & 46 & 48.40 \\
\hline 20 & 55 & 56.95 & 46 & 48.40 \\
\hline 21 & 51 & 53.15 & 42 & 44.60 \\
\hline 22 & 55 & 56.95 & 43 & 45.55 \\
\hline 23 & 61 & 62.70 & 47 & 49.35 \\
\hline 24 & 53 & 55.05 & 42 & 44.60 \\
\hline 25 & 52 & 54.10 & 40 & 42.70 \\
\hline
\end{tabular}


Table C-18. Measured and corrected rebound numbers on the two joint surfaces of specimen for test no. 25

\begin{tabular}{|c|c|c|c|c|}
\hline $\begin{array}{c}\text { No. of } \\
\text { Readings }\end{array}$ & $\begin{array}{l}\text { Measured } \\
\text { Rebound Number } \\
\text { for Joint on } \\
\text { Top Block } \\
\end{array}$ & $\begin{array}{c}\text { Corrected } \\
\text { Rebound Number } \\
\text { for Joint on } \\
\text { Top Block } \\
\end{array}$ & $\begin{array}{c}\text { Measured } \\
\text { Rebound Number } \\
\text { for Joint on } \\
\text { Bottom Block } \\
\end{array}$ & $\begin{array}{c}\text { Corrected } \\
\text { Rebound Number } \\
\text { for Joint On } \\
\text { Bottom Block } \\
\end{array}$ \\
\hline 1 & 48 & 50.30 & 50 & 52.20 \\
\hline 2 & 40 & 42.70 & 46 & 48.40 \\
\hline 3 & 48 & 50.30 & 48 & 50.30 \\
\hline 4 & 42 & 44.60 & 45 & 47.45 \\
\hline 5 & 47 & 49.35 & 43 & 45.55 \\
\hline 6 & 48 & 50.30 & 47 & 49.35 \\
\hline 7 & 56 & 57.90 & 49 & 51.25 \\
\hline 8 & 53 & 55.05 & 56 & 57.90 \\
\hline 9 & 52 & 54.10 & 48 & 50.30 \\
\hline 10 & 56 & 57.90 & 50 & 52.20 \\
\hline 11 & 56 & 57.90 & 46 & 48.40 \\
\hline 12 & 58 & 59.80 & 52 & 54.10 \\
\hline 13 & 55 & 56.95 & 52 & 54.10 \\
\hline 14 & 53 & 55.05 & 53 & 55.05 \\
\hline 15 & 50 & 52.20 & 53 & 55.05 \\
\hline 16 & 46 & 48.40 & 58 & 59.80 \\
\hline 17 & 60 & 61.70 & 48 & 50.30 \\
\hline 18 & 50 & 52.20 & 57 & 58.85 \\
\hline 19 & 50 & 52.20 & 50 & 52.20 \\
\hline 20 & 50 & 52.20 & 56 & 57.90 \\
\hline 21 & 56 & 57.90 & 55 & 56.95 \\
\hline 22 & 49 & 51.25 & 54 & 56.00 \\
\hline 23 & 56 & 57.90 & 59 & 60.75 \\
\hline 24 & 45 & 47.45 & 51 & 53.15 \\
\hline 25 & 56 & 57.90 & 56 & 57.90 \\
\hline
\end{tabular}

C-18 
Table C-19. Measured and corrected rebound numbers on the two joint surfaces of specimen for test no. 26

\begin{tabular}{|c|c|c|c|c|}
\hline $\begin{array}{l}\text { No. of } \\
\text { Readings }\end{array}$ & $\begin{array}{c}\text { Measured } \\
\text { Rebound Number } \\
\text { for Joint on } \\
\text { Top Block } \\
\end{array}$ & $\begin{array}{c}\text { Corrected } \\
\text { Rebound Number } \\
\text { for Joint on } \\
\text { Top Block } \\
\end{array}$ & $\begin{array}{c}\text { Measured } \\
\text { Rebound Number } \\
\text { for Joint on } \\
\text { Bottom Block } \\
\end{array}$ & $\begin{array}{c}\text { Corrected } \\
\text { Rebound Number } \\
\text { for Joint On } \\
\text { Bottom Block }\end{array}$ \\
\hline 1 & 49 & 51.25 & 44 & 46.50 \\
\hline 2 & 51 & 53.15 & 46 & 48.40 \\
\hline 3 & 58 & 59.80 & 52 & 54.10 \\
\hline 4 & 53 & 55.05 & 56 & 57.90 \\
\hline 5 & 57 & 58.85 & 50 & 52.20 \\
\hline 6 & 52 & 54.10 & 48 & 50.30 \\
\hline 7 & 50 & 52.20 & 49 & 51.25 \\
\hline 8 & 45 & 47.45 & 61 & 62.70 \\
\hline 9 & 55 & 56.95 & 55 & 56.95 \\
\hline 10 & 60 & 61.70 & 49 & 51.25 \\
\hline 11 & 60 & 61.70 & 50 & 52.20 \\
\hline 12 & 51 & 53.15 & 58 & 59.80 \\
\hline 13 & 56 & 57.90 & 60 & 61.70 \\
\hline 14 & 50 & 52.20 & 55 & 56.95 \\
\hline 15 & 57 & 58.85 & 58 & 59.80 \\
\hline 16 & 51 & 53.15 & 55 & 56.95 \\
\hline 17 & 50 & 52.20 & 50 & 52.20 \\
\hline 18 & 46 & 48.40 & 56 & 57.90 \\
\hline 19 & 58 & 59.80 & 54 & 56.00 \\
\hline 20 & 51 & 53.15 & 58 & 59.80 \\
\hline 21 & 62 & 63.70 & 50 & 52.20 \\
\hline 22 & 50 & 52.20 & 54 & 56.00 \\
\hline 23 & 56 & 57.90 & 56 & 57.90 \\
\hline 24 & 52 & 54.10 & 56 & 57.90 \\
\hline 25 & 52 & 54.10 & 52 & 54.10 \\
\hline
\end{tabular}

C-19 
Table C-20. Measured and corrected rebound numbers on the two joint surfaces of specimen for test no. 27

\begin{tabular}{|c|c|c|c|c|}
\hline $\begin{array}{c}\text { No. of } \\
\text { Readings }\end{array}$ & $\begin{array}{c}\text { Measured } \\
\text { Rebound Number } \\
\text { for Joint on } \\
\text { Top Block }\end{array}$ & $\begin{array}{c}\text { Corrected } \\
\text { Rebound Number } \\
\text { for Joint on } \\
\text { Top Block }\end{array}$ & $\begin{array}{c}\text { Measured } \\
\text { Rebound Number } \\
\text { for Joint on } \\
\text { Bottom Block }\end{array}$ & $\begin{array}{c}\text { Corrected } \\
\text { Rebound Number } \\
\text { for Joint On } \\
\text { Bottom Block }\end{array}$ \\
\hline 1 & 52 & 54.10 & 56 & 57.90 \\
\hline 2 & 52 & 54.10 & 43 & 45.55 \\
\hline 3 & 53 & 55.05 & 46 & 48.40 \\
\hline 4 & 56 & 57.90 & 42 & 44.60 \\
\hline 5 & 50 & 52.20 & 44 & 46.50 \\
\hline 6 & 51 & 53.15 & 51 & 53.15 \\
\hline 7 & 50 & 52.20 & 54 & 56.00 \\
\hline 8 & 53 & 55.05 & 56 & 57.90 \\
\hline 9 & -- & 55.05 & 53 & 55.05 \\
\hline 10 & -- & 53.15 & 47 & 49.35 \\
\hline 11 & -- & - & 56 & 48.40 \\
\hline 12 & -- & - & 56 & 48.40 \\
\hline 13 & - & - & 56 & 53.15 \\
\hline 14 & - & - & 50 & \\
\hline 15 & - & - & 56 & 50 \\
\hline
\end{tabular}


Table C-21. Measured and corrected rebound numbers on the two joint surfaces of specimen for test no. 28

\begin{tabular}{|c|c|c|c|c|}
\hline $\begin{array}{l}\text { No. of } \\
\text { Readings }\end{array}$ & $\begin{array}{l}\text { Measured } \\
\text { Rebound Number } \\
\text { for Joint on } \\
\text { Top Block }\end{array}$ & $\begin{array}{c}\text { Corrected } \\
\text { Rebound Number } \\
\text { for Joint on } \\
\text { Top Block } \\
\end{array}$ & $\begin{array}{l}\text { Mesisured } \\
\text { R2:kouro Number } \\
\text { 1or Joint un } \\
\text { Bottom Block }\end{array}$ & $\begin{array}{c}\text { Corrected } \\
\text { Rebound Number } \\
\text { for Joint On } \\
\text { Bottom Block }\end{array}$ \\
\hline 1 & 48 & 50.30 & 45 & 47.45 \\
\hline 2 & 50 & 52.20 & 50 & 52.20 \\
\hline 3 & 56 & 57.90 & 42 & 44.60 \\
\hline 4 & 51 & 53.15 & 49 & 51.25 \\
\hline 5 & 51 & 53.15 & 50 & 52.20 \\
\hline 6 & 54 & 56.00 & 53 & 55.05 \\
\hline 7 & 50 & 52.20 & 45 & 47.45 \\
\hline 8 & 54 & 56.00 & 47 & 49.35 \\
\hline 9 & 56 & 57.90 & 51 & 53.15 \\
\hline 10 & 46 & 48.40 & 40 & 42.70 \\
\hline 11 & 56 & 57.90 & 49 & 51.25 \\
\hline 12 & 48 & 50.30 & 54 & 56.00 \\
\hline 13 & 50 & 52.20 & 50 & 52.20 \\
\hline 14 & -- & - & 43 & 45.55 \\
\hline
\end{tabular}


Table C-22. Measured and corrected rebound numbers on the two joint surfaces of specimen for test no. 29

\begin{tabular}{||c|c|c|c|c||}
\hline $\begin{array}{c}\text { No. of } \\
\text { Readings }\end{array}$ & $\begin{array}{c}\text { Measured } \\
\text { Rebound Number } \\
\text { for Joint on } \\
\text { Top Block }\end{array}$ & $\begin{array}{c}\text { Corrected } \\
\text { Rebound Number } \\
\text { for Joint on } \\
\text { Top Block }\end{array}$ & $\begin{array}{c}\text { Measured } \\
\text { Rebound Number } \\
\text { for Joint on } \\
\text { Bottom Biock }\end{array}$ & $\begin{array}{c}\text { Corrected } \\
\text { Rebound Number } \\
\text { for Joint On } \\
\text { Bottom Block }\end{array}$ \\
\hline 1 & 47 & 49.35 & 47 & 49.35 \\
\hline 2 & 52 & 54.10 & 44 & 46.50 \\
\hline 3 & 52 & 54.10 & 40 & 42.70 \\
\hline 4 & 48 & 50.30 & 55 & 56.95 \\
\hline 5 & 48 & 50.30 & 55 & 56.95 \\
\hline 6 & 44 & 46.50 & 55 & 56.95 \\
\hline 7 & 43 & 45.55 & 50 & 52.20 \\
\hline 8 & 48 & 50.30 & 52 & 54.10 \\
\hline 9 & 53 & 55.05 & 54 & 56.00 \\
\hline 10 & 49 & 51.25 & 53 & 55.05 \\
\hline 11 & -- & -- & 58 & 59.80 \\
\hline 12 & -- & - & 54 & 56.00 \\
\hline 13 & - & - & 54 & 48.40 \\
\hline 14 & - & - & 56.00 \\
\hline
\end{tabular}


Table C-23. Measured and corrected rebound numbers on the two joint surfaces of specimen for test no. 30

\begin{tabular}{|c|c|c|c|c||}
\hline $\begin{array}{c}\text { No. of } \\
\text { Readings }\end{array}$ & $\begin{array}{c}\text { Measured } \\
\text { Rebound Number } \\
\text { for Joint on } \\
\text { Top Block }\end{array}$ & $\begin{array}{c}\text { Corrected } \\
\text { Rebound Number } \\
\text { for Joint on } \\
\text { Top Block }\end{array}$ & $\begin{array}{c}\text { Measured } \\
\text { Rebound Number } \\
\text { for Joint on } \\
\text { Bottom Block }\end{array}$ & $\begin{array}{c}\text { Corrected } \\
\text { Rebound Number } \\
\text { for Joint On } \\
\text { Bottom Block }\end{array}$ \\
\hline 1 & 46 & 48.40 & 56 & 57.90 \\
\hline 2 & 45 & 47.45 & 53 & 55.05 \\
\hline 3 & 49 & 51.25 & 53 & 55.05 \\
\hline 4 & 46 & 48.40 & 51 & 53.15 \\
\hline 5 & 55 & 56.95 & 58 & 59.80 \\
\hline 6 & 61 & 62.70 & 49 & 51.25 \\
\hline 7 & 47 & 49.35 & 52 & 54.10 \\
\hline 8 & 49 & 51.25 & 43 & 45.55 \\
\hline 9 & 46 & 48.40 & 50 & 52.20 \\
\hline 10 & 49 & 51.25 & 53 & 55.05 \\
\hline 11 & 54 & 56.00 & 41 & 43.65 \\
\hline 12 & 48 & 50.30 & 48 & 50.30 \\
\hline 13 & 50 & 52.20 & 53 & 55.05 \\
\hline 14 & 52 & 54.10 & 53.15 \\
\hline
\end{tabular}



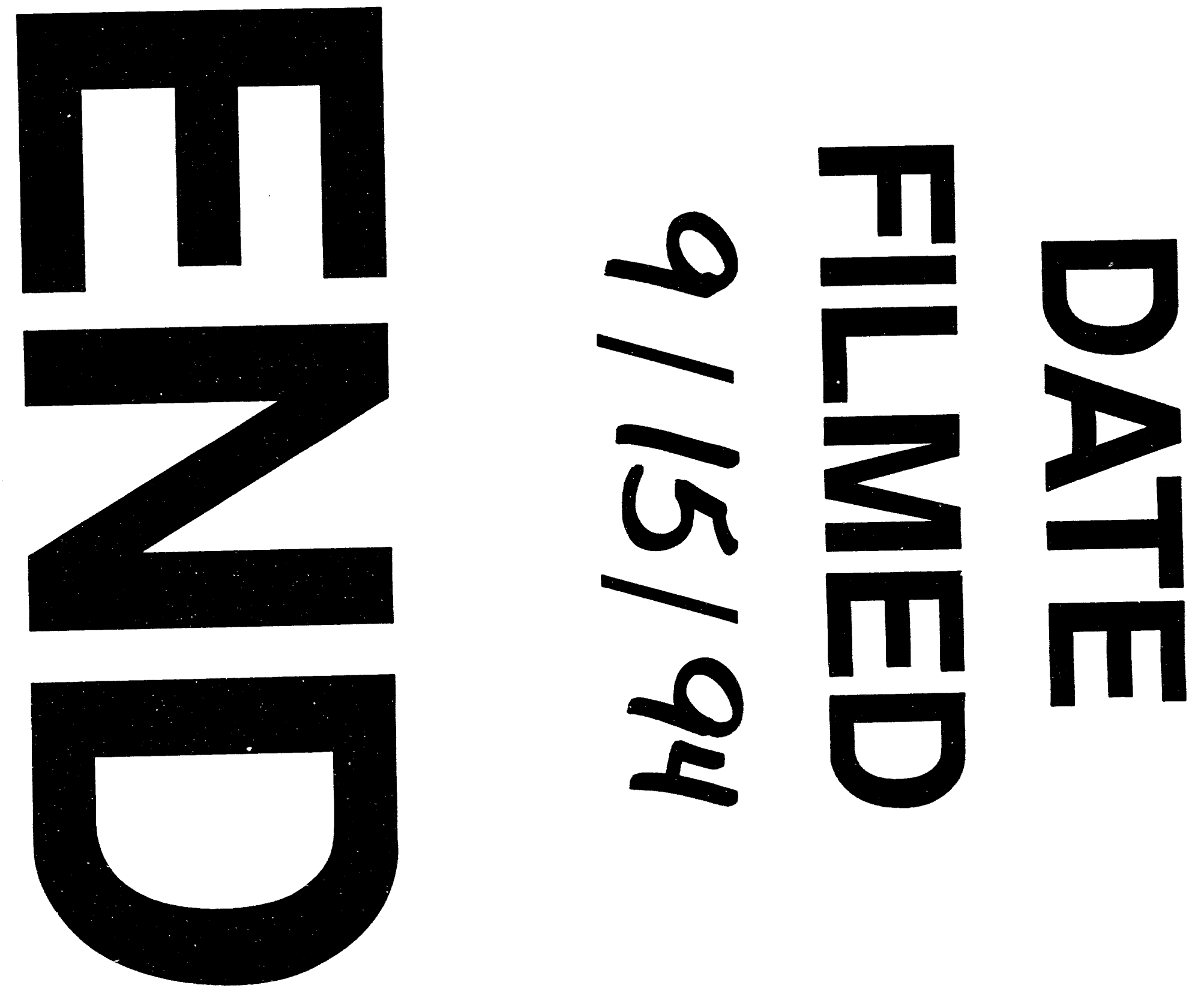
